\title{
UICN
}

État des aires protégées et de conservation d'Afrique orientale et australe

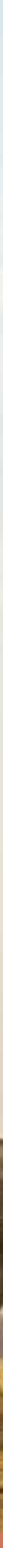

SÉRIE DE RAPPORTS SUR L'ÉTAT DES AIRES PROTÉGÉES ET DE CONSERVATION Nํ 1

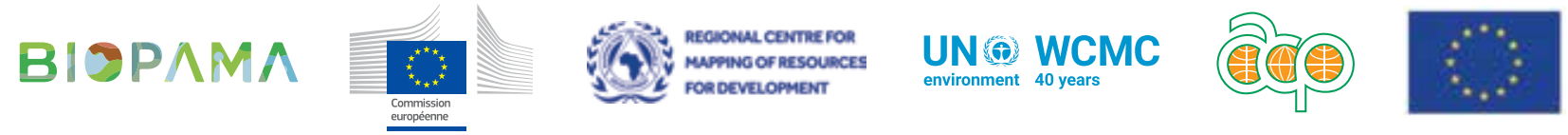





\section{État des aires protégées et de conservation d'Afrique orientale et australe}


La terminologie géographique employée dans cet ouvrage, de même que sa présentation, ne sont en aucune manière l'expression d'une opinion quelconque de la part de I'UICN ou des autres organisations concernées sur le statut juridique ou l'autorité de quelque pays, territoire ou région que ce soit, ou sur la délimitation de ses frontières.

Les opinions exprimées dans cette publication ne reflètent pas nécessairement celles de l'UICN ou des autres organisations concernées.

L'UICN remercie ses partenaires cadre pour leur précieux support et tout particulièrement : le Ministère des affaires étrangères du Danemark, le Ministère des affaires étrangères de la Finlande ; le Gouvernement Français et l'Agence Française de Développement (AFD) ; le Ministère de l'environnement de la République de Corée ; l'Agence norvégienne de développement et de coopération (Norad) ; l'Agence suédoise de coopération internationale au développement (Asdi) ; la Direction du développement et de la coopération de la Suisse (DDC) et le Département d'État des États-Unis d'Amérique.

Le contenu de cette publication relève de la seule responsabilité des auteurs et ne peut en aucun cas être considéré comme reflétant la position de l'Union européenne ou du Groupe de pays ACP.

Cette publication a été possible grâce au soutien du 11e Fonds européen de développement.

L'UICN et les autres organisations concernées rejettent toute responsabilité en cas d'erreurs ou d'omissions intervenues lors de la traduction en français de ce document dont la version originale est en anglais. En cas de divergences, veuillez vous référer à l'édition originale : The state of protected and conserved areas in Eastern and Southern Africa. State of Protected and Conserved Areas Report Series No. 1. (2020). Nairobie, Kenya : UICN ESARO. DOI: : https://doi.org/10.2305/IUCN.CH.2020.15.en

Publié par : $\quad$ UICN, Bureau régional pour l'Afrique orientale et australe, par le biais du programme BIOPAMA

Droits d'auteur : (c) 2020 UICN, Union internationale pour la conservation de la nature et de ses ressources

(C) 2021 UICN, Union internationale pour la conservation de la nature et de ses ressources, pour la traduction française La reproduction de cette publication à des fins non commerciales, notamment éducatives, est permise sans autorisation écrite préalable du (des) détenteur(s) des droits d'auteur à condition que la source soit dûment citée. La reproduction de cette publication à des fins commerciales, notamment en vue de la vente, est interdite sans autorisation écrite préalable du (des) détenteur(s) des droits d'auteur.

Citation : $\quad$ UICN ESARO (2021). État des aires protégées et de conservation d'Afrique orientale et australe. Série de rapports sur l'état des aires protégées et de conservation $n^{\circ} 1$. Nairobi, Kenya : UICN ESARO.

ISBN : $\quad$ 978-2-8317-2139-2 (PDF)

978-2-8317-2140-8 (Papier)

$\mathrm{DOI}$ :

https://doi.org/10.2305/IUCN.CH.2020.15.fr

Photo

de couverture : Éléphants, Parc national de Hwange, Zimbabwe. @ W Wilderness Safaris

Quatrième

de couverture : $\quad$ Réserve naturelle de l'île aux Aigrettes, île Maurice. @ Gina Bonne IOC

Mise en page : INTUITIV, slu - www.intuitivme.com

Traduction: $\quad$ INTUITIV, slu - www.intuitivme.com

Imprimé par : Minuteman Press

Disponible

auprès de :

\author{
UICN Afrique du Sud \\ 333 Grosvenor Street \\ Hatfield Gardens, Block A \\ Pretoria, Afrique Du Sud \\ $+27(0) 123428304 / 6$ \\ info.esaro@iucn.org \\ https://www.biopama.org/ \\ www.iucn.org/resources/publications
}

Cet ouvrage est imprimé sur du papier fabriqué à partir de fibres de bois provenant de forêts durablement gérées et certifiées conformément aux règles du Forest Stewardship Council (FSC). 


\section{(-)

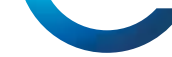

\section{$B I O P \wedge M \wedge$}

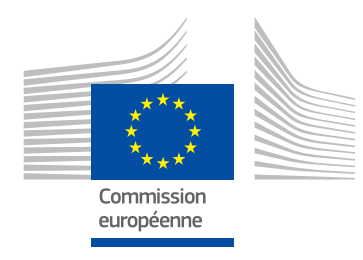
MAPPING OF RESOURCES FORDEVELOPMENT
REGIONAL CENTRE FOR

Union internationale pour la conservation de la nature (UICN)

L'UICN est une union unique de Membres composée de gouvernements et d'organisations de la société civile. Elle compte avec l'expérience, les ressources et le poids de ses plus de 1400 organisations Membres et les compétences de ses plus de 18000 experts. L'UICN est l'autorité mondiale en ce qui concerne l'état du monde naturel et les mesures nécessaires pour le protéger. www.iucn.org

\section{Programme pour la Biodiversité et la gestion des aires protégées}

Le Programme pour la biodiversité et la gestion des aires protégées (BIOPAMA) vise à améliorer la conservation à long terme et l'utilisation durable des ressources naturelles dans les pays d'Afrique, des Caraïbes et du Pacifique (ACP), dans les aires protégées et les communautés avoisinantes. II s'agit d'une initiative du Groupe des Pays ACP, financée par le 11e Fonds européen de développement (FED) de l'Union européenne, conjointement mis en œuvre par l'Union internationale pour la conservation de la nature (UICN) et le Centre commun de recherche de la Commission européenne (CCR). S'appuyant sur les cinq premières années d'activités financées par le 10e FED, la deuxième phase de BIOPAMA fournit des outils pour la gestion des données et de l'information, des services visant à améliorer les connaissances et les capacités en matière de planification et de prise de décision concernant les aires protégées, et des opportunités de financement pour des actions spécifiques sur site.

www.biopama.org

\section{Centre commun de recherche et Commission européenne}

La Commission européenne (CE) est l'organe exécutif de l'Union européenne (UE), le plus grand donateur d'aide publique au développement. En tant que service scientifique interne de la $\mathrm{CE}$, le Centre commun de recherche (CCR) fournit aux politiques de l'UE un soutien scientifique et technique indépendant et fondé sur des données probantes, y compris des politiques et des programmes au niveau mondial, et en particulier ceux axés sur le groupe des Pays d'Afrique, des Caraïbes et du Pacifique (ACP).

www.ec.europa.eu/jrc/en

\section{Centre régional de cartographie des ressources pour le développement}

Le Centre régional de cartographie des ressources pour le développement (RCMRD, selon ses sigles en anglais) est une organisation intergouvernementale composée aujourd'hui de 20 États membres d'Afrique orientale et australe. II a été créé en 1975 par l'Union africaine (UA) et la Commission économique des Nations Unies pour l'Afrique. Le RCMRD promeut un développement durable par la génération, l'application et la diffusion d'informations géographiques et de technologies connexes entre ses États membres et parties prenantes. Notre mandat est mis en œuvre dans des domaines thématiques tels que la gestion des ressources naturelles, la gestion de l'environnement, l'action climatique, la sécurité alimentaire et l'agriculture durable, la gestion des connaissances et le renforcement des capacités, la gestion des terres et le développement urbain.

www.rcmrd.org

\section{Centre mondial de surveillance de la conservation de la nature de l'ONU Environnement}

Le Centre mondial de surveillance de la conservation de la nature du Programme des Nations Unies pour l'environnement (UNEP-WCMC, selon ses sigles en anglais) est un centre mondial d'excellence en matière de biodiversité. Le Centre fonctionne comme une collaboration entre le Programme des Nations Unies pour l'environnement et le WCMC, organisme de bienfaisance enregistré au Royaume-Uni. Ensemble, nous faisons face à la crise mondiale à laquelle est confrontée la nature.

www.unep-wcmc.org

\section{Organisation des États d'Afrique, des Caraïbes et du Pacifique}

L'Organisation des États d'Afrique, des Caraïbes et du Pacifique (OEACP), anciennement connue sous le nom de Groupe des pays ACP, est une organisation créée par l'accord original de Georgetown en 1975, révisé en 2019. Les principaux objectifs de l'OEACP sont le développement durable de ses membres et leur intégration progressive dans l'économie mondiale, la coordination des activités de l'OEACP dans le cadre de la mise en œuvre de l'accord de partenariat existant avec l'Union Européenne, la consolidation de l'unité et de la solidarité entre les membres de l'OEACP, et l'installation et la consolidation de la paix, de la sécurité et de la stabilité dans un environnement de démocratie et de liberté. www.acp.int 


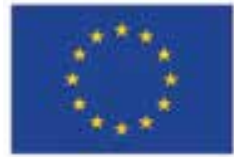

\section{Union européenne}

Les États membres de l'Union européenne ont décidé de mettre graduellement en commun leur savoirfaire, leurs ressources et leur destin. Ensemble, ils ont construit une zone de stabilité, de démocratie et de développement durable tout en préservant leur diversité culturelle, la tolérance et les libertés individuelles. L'Union européenne tient à partager ses réalisations et ses valeurs avec les pays et les peuples au-delà de ses frontières.

www.europa.eu

Cette publication a été possible grâce au soutien du 11e FED. Le contenu de cette publication relève de la seule responsabilité de ses auteurs et ne peut en aucun cas être considéré comme reflétant la position de l'Union européenne ou du Groupe de pays ACP.

\section{Communautés économiques régionales d'Afrique orientale et australe}
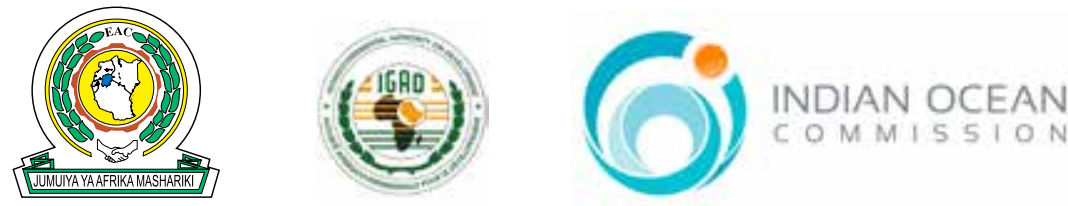

COM M IS $510 \mathrm{~N}$

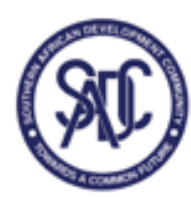

\section{Pays représentés dans le présent rapport}

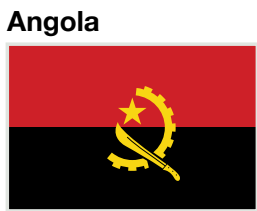

Éthiopie

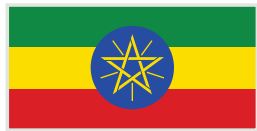

Botswana

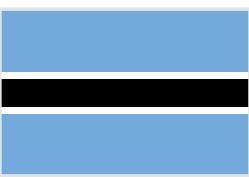

Kenya
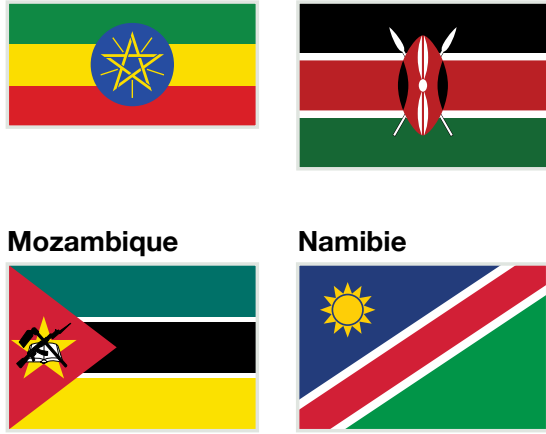

Soudan du Sud
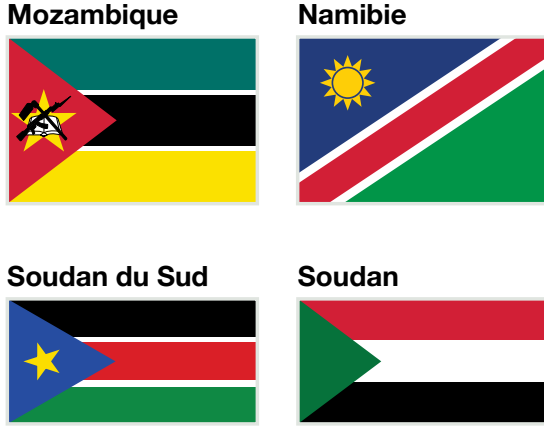

Soudan

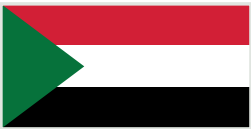

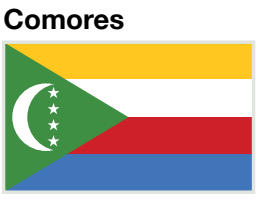

Lesotho
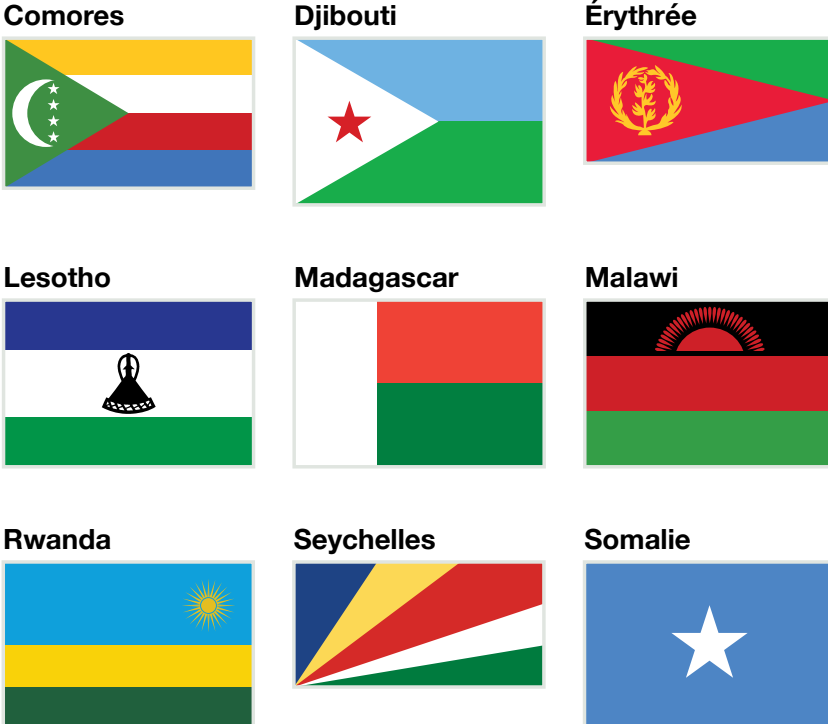

Eswatini
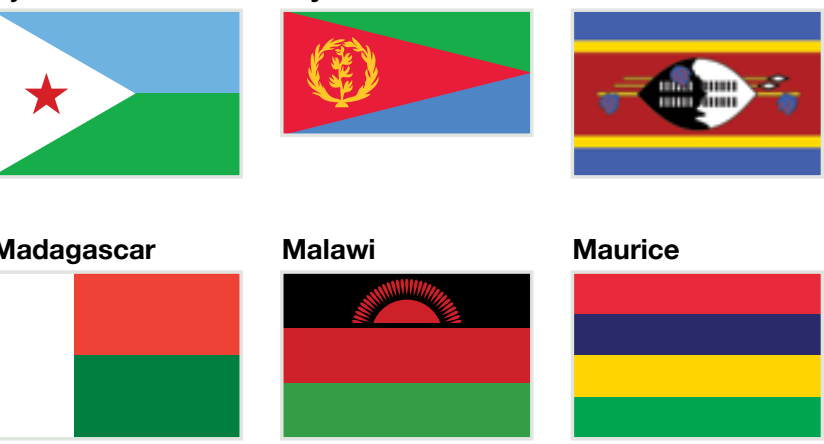

Maurice

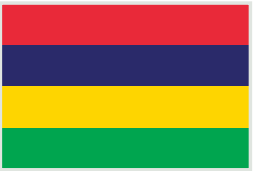

Somalie

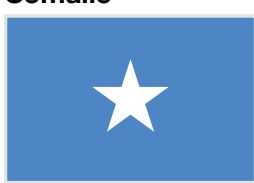

Afrique du Sud

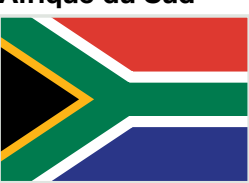

Zimbabwe

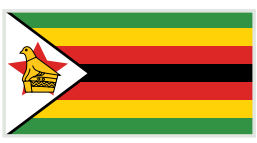

Ouganda

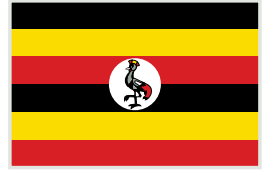

Zambie

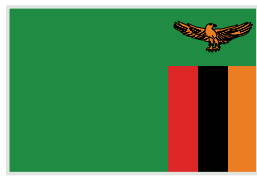




\section{Table des matières}

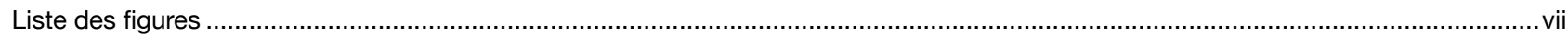

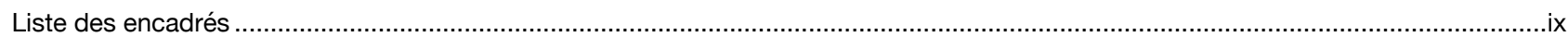

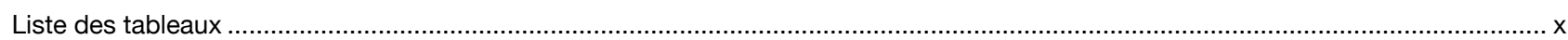

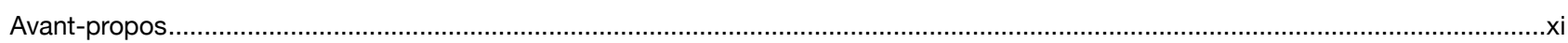

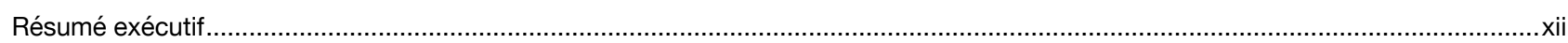

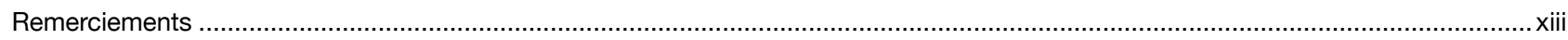

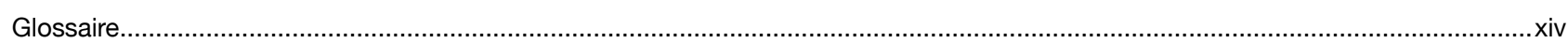

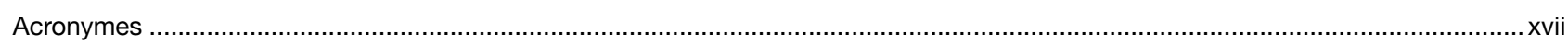

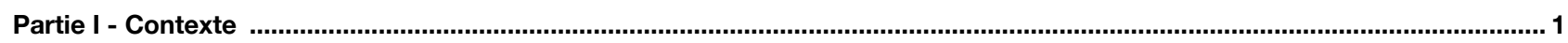

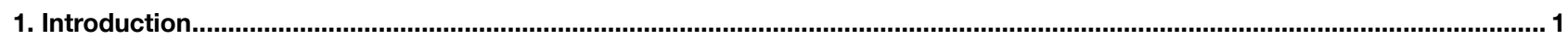

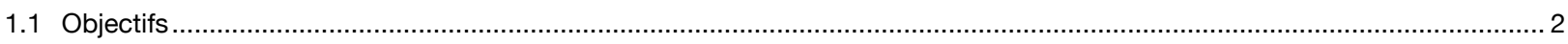

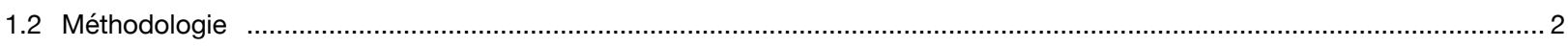

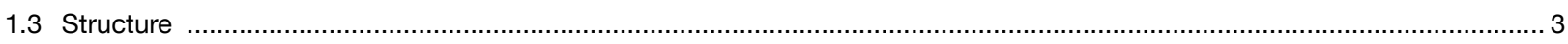

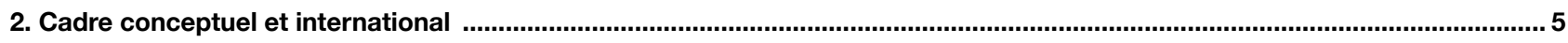

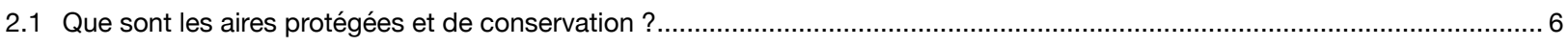

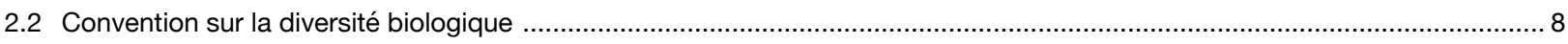

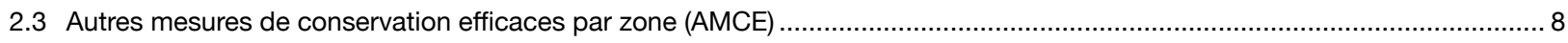

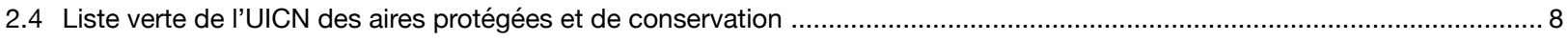

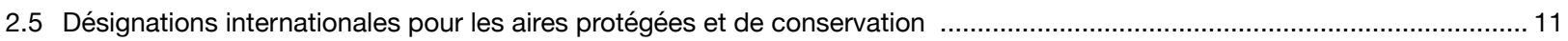

2.6 Autres domaines prioritaires pour la conservation................................................................................................ 12

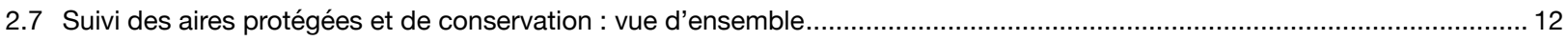

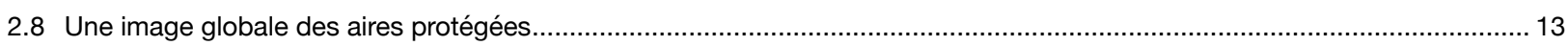

Partie II - Contexte régional, données et profils nationaux....................................................................................................... 17

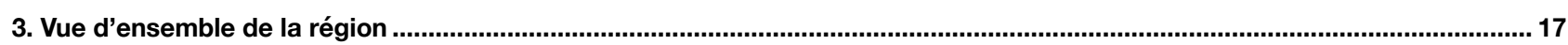

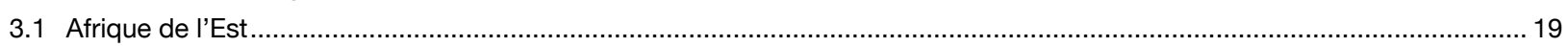

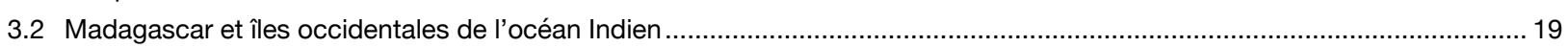

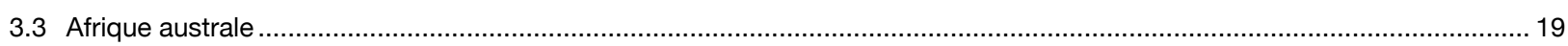

4. Aires protégées et de conservation d'Afrique orientale et australe............................................................................................... 21

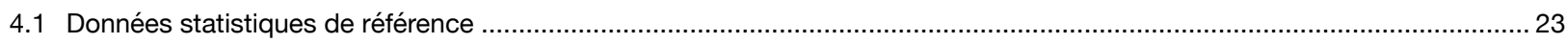

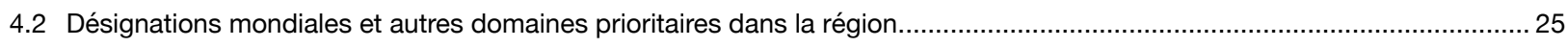

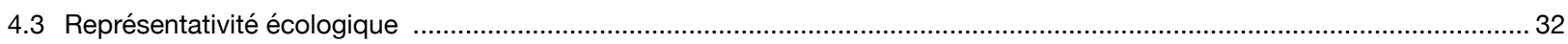

4.4 Qu'est-ce qui a changé dans la couverture des aires protégées ? .............................................................................. 33

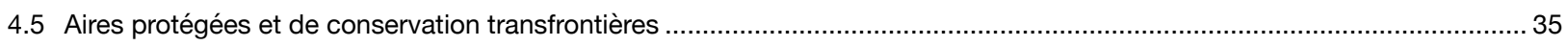

5. Services écosystémiques des aires protégées d'Afrique orientale et australe .........................................................................43

6. Politiques régionales et cadres pertinents relatifs à la conservation de la biodiversité et à la gestion des aires protégées ... 47

7. Communautés économiques régionales ............................................................................................................................. 51

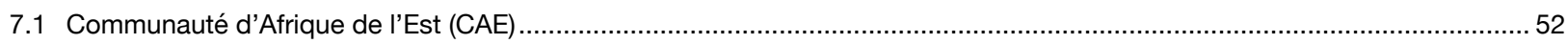

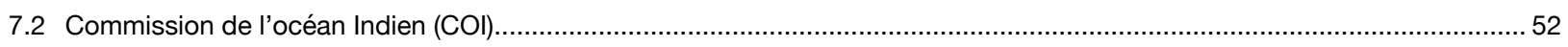

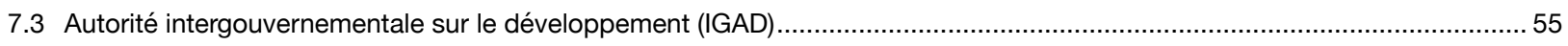

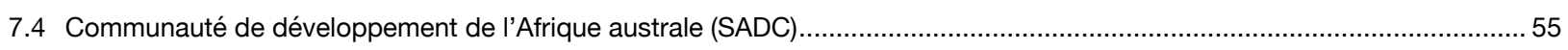

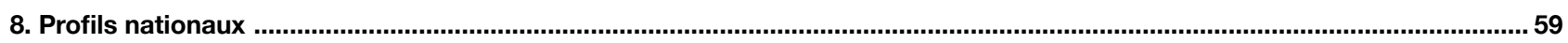

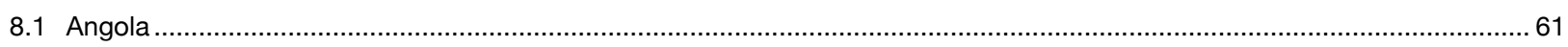

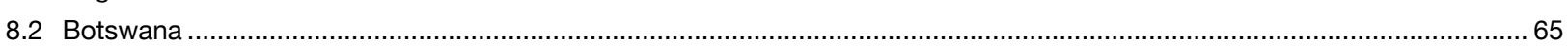

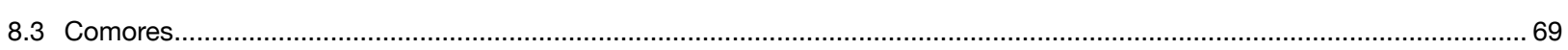

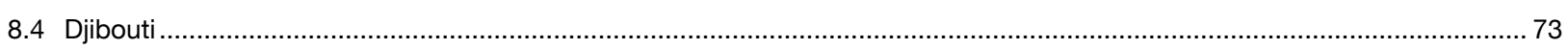

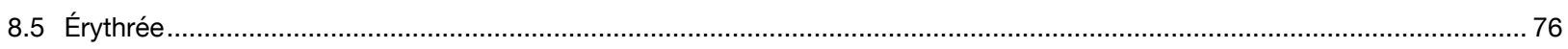

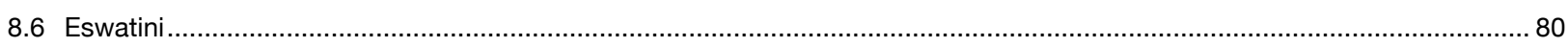

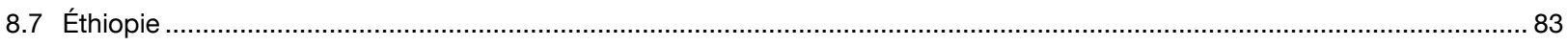

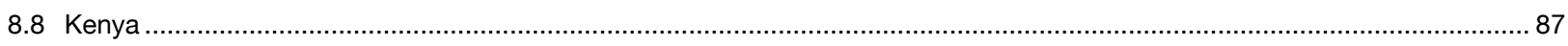

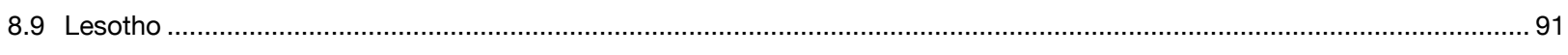

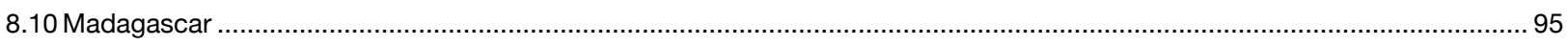




\section{Table des matières (suite)}

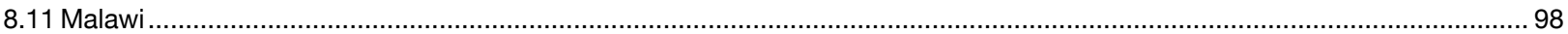

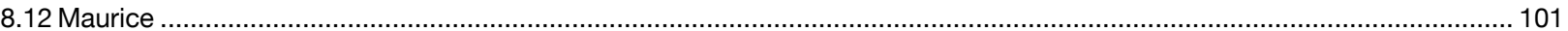

8.13 Mozambique

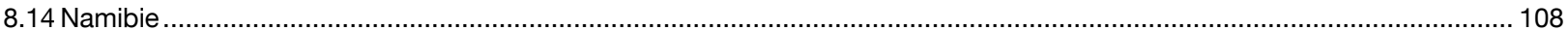

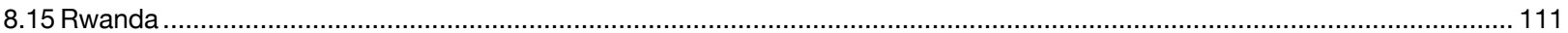

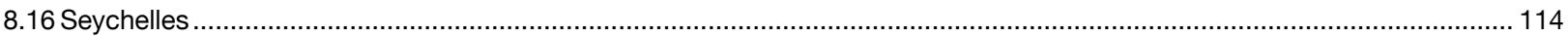

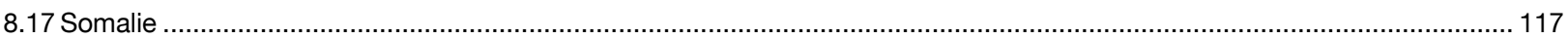

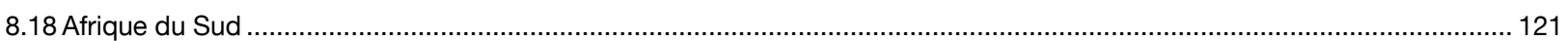

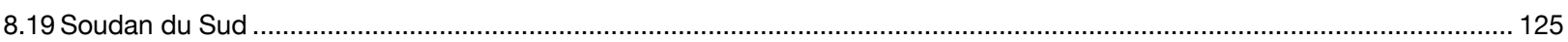

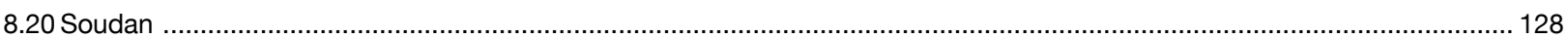

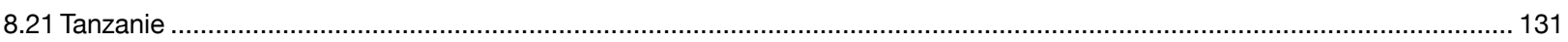

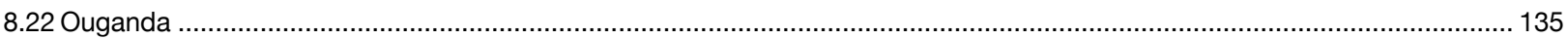

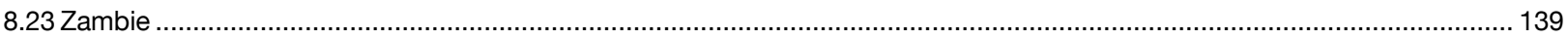

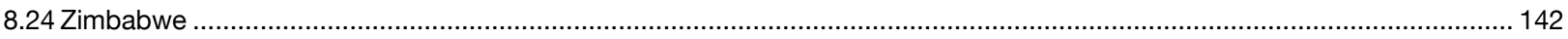

Partie III - Gouvernance et efficacité de la gestion............................................................................................................. 147

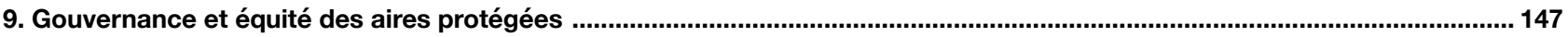

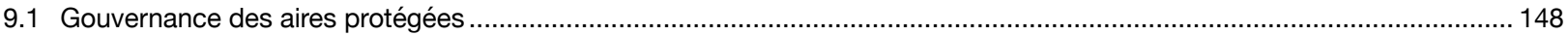

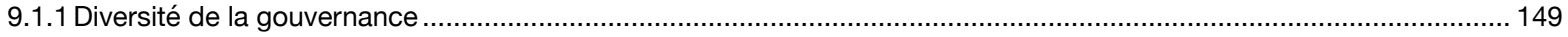

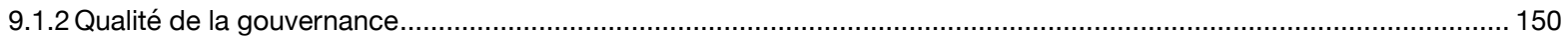

9.2 Bonne gouvernance et Liste verte de I'UICN des aires protégées et de conservation .................................................. 150

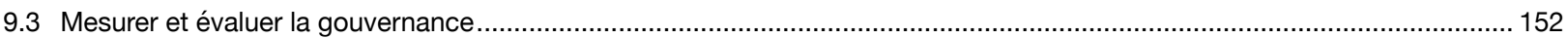

9.3.1 Lignes directrices sur les meilleures pratiques de la CMAP-UICN …................................................................. 158

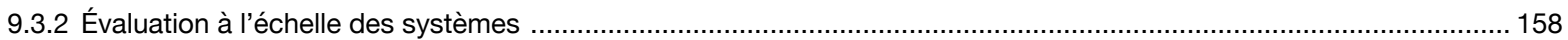

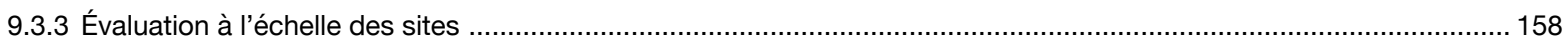

9.3.4 Évaluation de la gouvernance et de l'équité à l'échelle des sites (EGES) ................................................................. 158

9.3.5Évaluation de la gouvernance des aires protégées et de conservation (EGAP)......................................................... 159

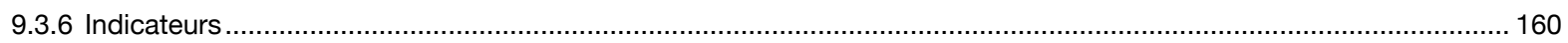

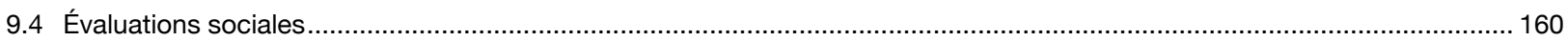

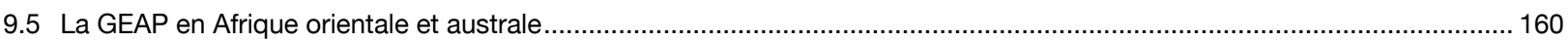

9.5.1 Évaluations de la gouvernance en Afrique orientale et australe....................................................................... 163

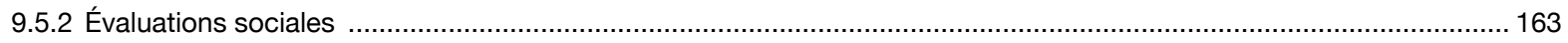

9.6 Résultats des évaluations sociales et de gouvernance en Afrique orientale et australe ................................................ 163

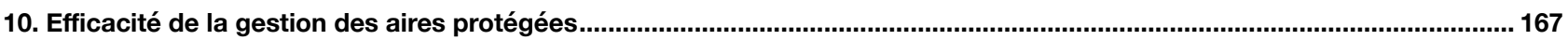

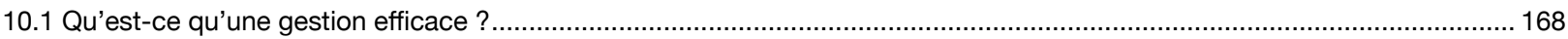

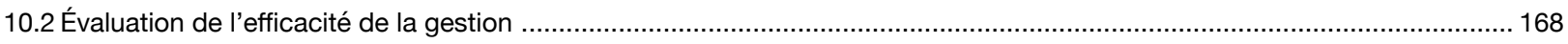

10.3 Engagements internationaux en matière d'évaluation de l'efficacité de la gestion ..........................................................169

10.4 Base de données mondiale sur l'efficacité de la gestion des aires protégées (BD-EGAP) .............................................. 169

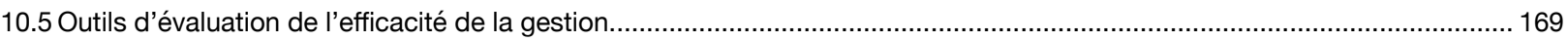

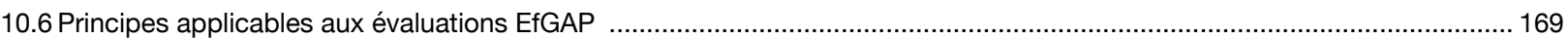

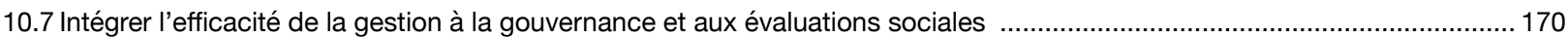

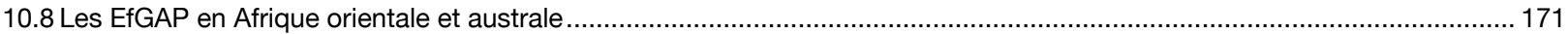

10.8.1 Inventaire des évaluations EfGAP en Afrique orientale et australe ................................................................. 171

10.8.2 Inventaire des évaluations combinées en Afrique orientale et australe ............................................................. 174

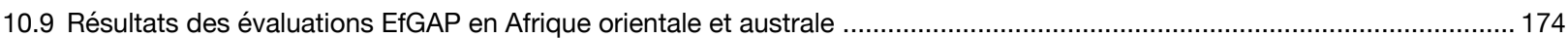

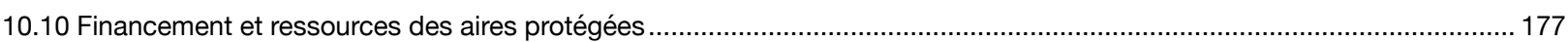

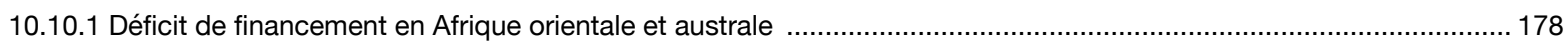

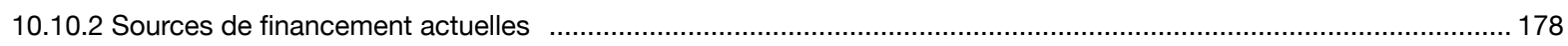

10.10.3 Sources de financement nouvelles et émergentes pour les aires protégées ........................................................ 183

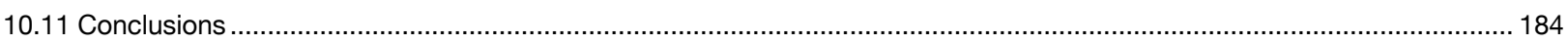

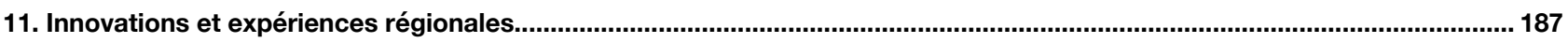




\section{Table des matières (suite)}

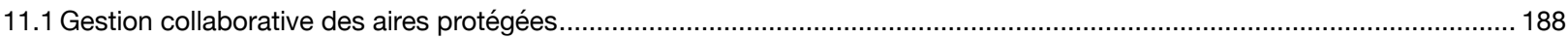

11.2 Renforcement des capacités pour les aires protégées et de conservation ................................................................ 190

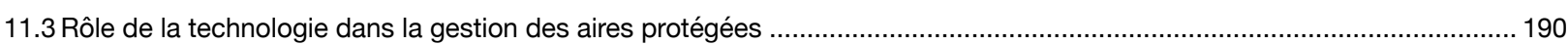

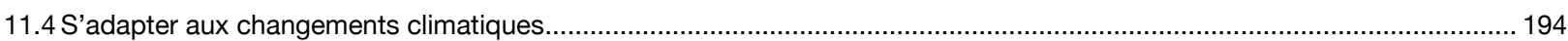

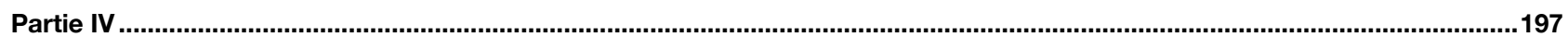

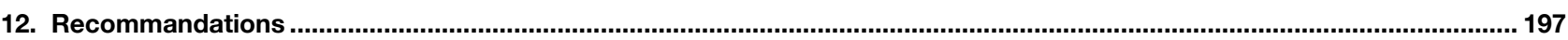

12.1 Accroître le financement durable et le soutien politique aux aires protégées et de conservation......................................... 198

12.2 Renforcer les capacités de gestion des aires protégées et de conservation ........................................................................ 198

12.3 Diversifier la gouvernance des aires protégées et reconnaître les initiatives de gouvernance

à l'échelle locale et communautaire et de cogestion................................................................................................... 198

12.4 Combler les lacunes dans la couverture des écosystèmes marins et terrestres dans les aires protégées et de conservation 198

12.5 Renforcer la collaboration transfrontalière et sectorielle pour faire face aux menaces existantes et émergentes................. 199

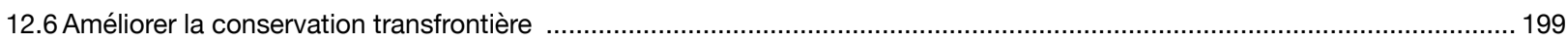

12.7 Améliorer la couverture des évaluations de l'efficacité de la gestion, de la gouvernance et de l'équité............................... 199

12.8 Améliorer la fréquence et l'exhaustivité des rapports à la Base de données mondiale des aires protégées ........................ 199

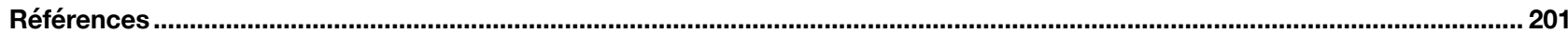

Annexes

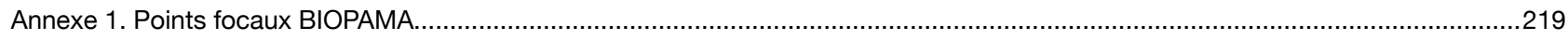

Annexe 2. Statistiques régionales sur les aires protégées et de conservation d'Afrique orientale et australe ...................................220

A2-Tableau 1. État des aires protégées et de conservation d'Afrique orientale et australe...................................................220

A2-Tableau 2. Aires côtières et marines protégées et de conservation d'Afrique orientale et australe ....................................221

A2-Tableau 3. Catégories de gestion de I'UICN des aires protégées et de conservation d'Afrique orientale et australe ............221

A2-Tableau 4. Type de gouvernance de l'UICN des aires protégées et de conservation d'Afrique orientale et australe .............222

Annexe 3. Sites d'importance mondiale en Afrique orientale et australe ....................................................................................222

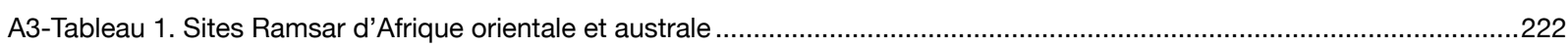

A3-Tableau 2. Réserves de biosphère d'Afrique orientale et australe ....................................................................................226

Annexe 4. Représentativité écologique en Afrique orientale et australe ...................................................................................22

A4-Tableau 1. Représentativité écologique des aires protégées d'Afrique orientale et australe ................................................227

Annexe 5. Instruments juridiques soutenant l'équité et la gouvernance non-étatique des aires protégées .......................................228

Annexe 6. Aires protégées et de conservation selon les catégories de gestion de l'UICN par pays ...................................................230

Annexe 7. Aires protégées et de conservation selon les types de gouvernance de l'UICN par pays .................................................236

\section{Liste des figures}

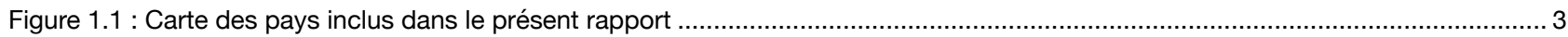

Figure 2.1: Systèmes mondiaux et régionaux de gestion des données pour les aires protégées ...................................................... 13

Figure 4.1 : Aires protégées et de conservation d'Afrique orientale et australe ............................................................................... 22

Figure 4.2 : Couverture des aires protégées terrestres en Afrique orientale et australe ................................................................ 23

Figure 4.3 : Aires côtières et marines protégées et de conservation d'Afrique orientale et australe ..................................................24

Figure 4.4 : Catégories de gestion de l'UICN des aires protégées et de conservation d'Afrique orientale et australe ...........................24

Figure 4.5: Catégories de type de gouvernance de I'UICN des aires protégées et de conservation d'Afrique orientale et australe ........24

Figure 4.6 : Degrés de protection des écorégions terrestres représentées dans la région ................................................................. 33

Figure 4.7 : Degrés de protection des écorégions marines et provinces pélagiques représentées dans la région ............................... 33

Figure 4.8: Couverture des écorégions en Afrique orientale et australe par pourcentage de protection ........................................... 34

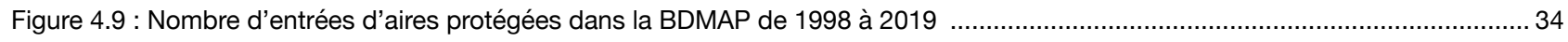

Figure 4.10 : Aires de conservation transfrontalières dans la Communauté de développement de l'Afrique australe (ACT-SADC) ..........36

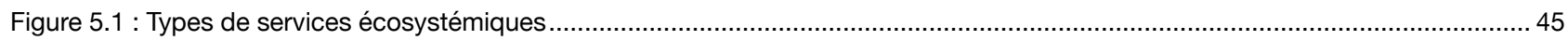

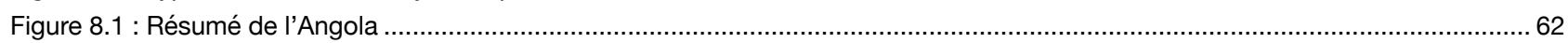

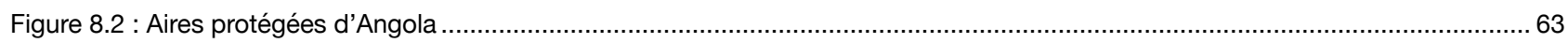

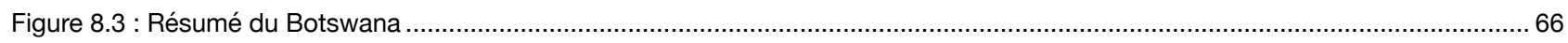




\section{Liste des figures (suite)}

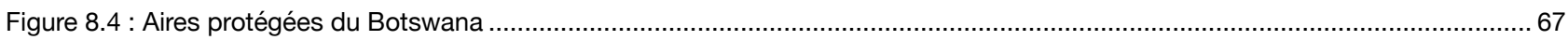

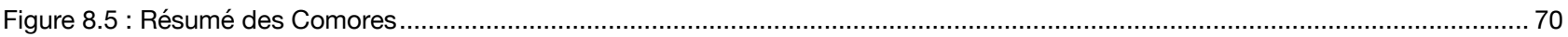

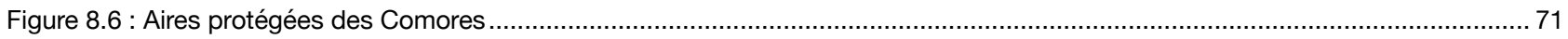

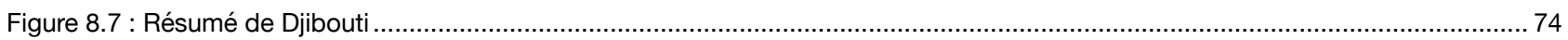

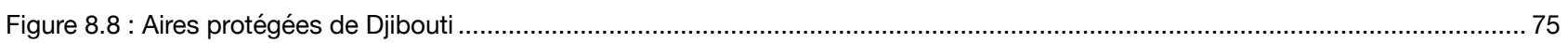

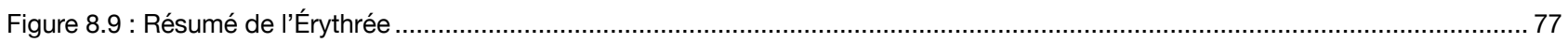

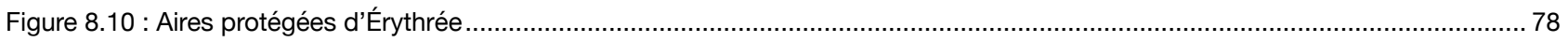

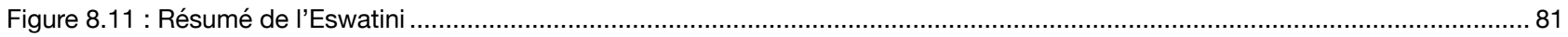

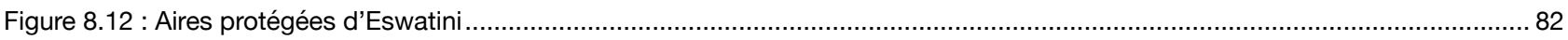

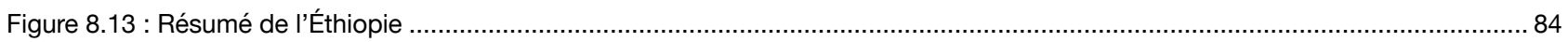

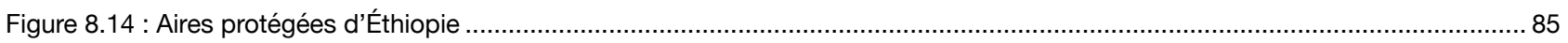

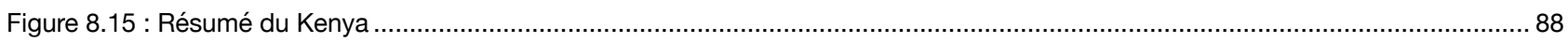

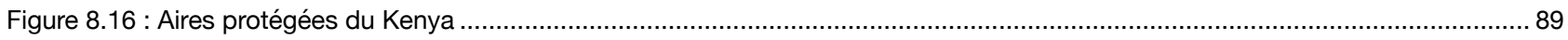

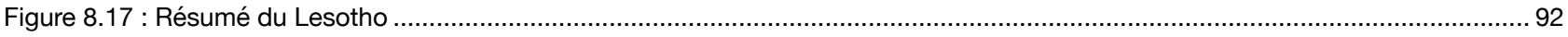

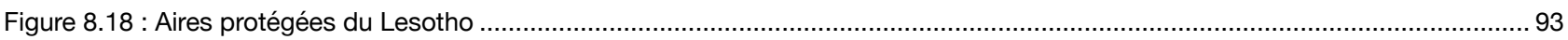

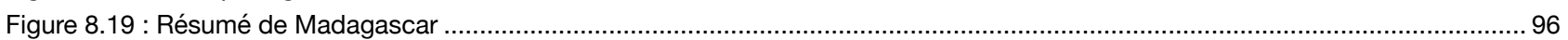

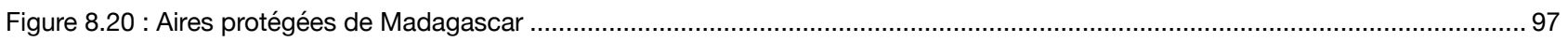

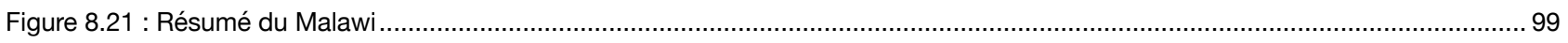

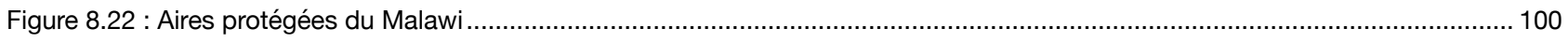

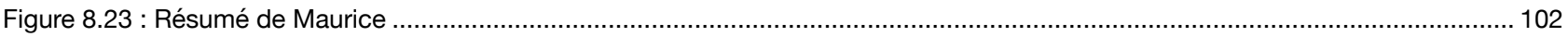

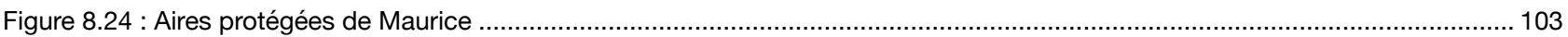

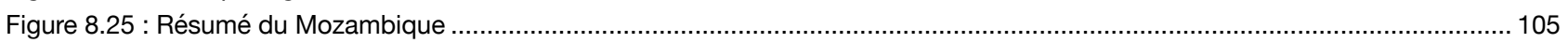

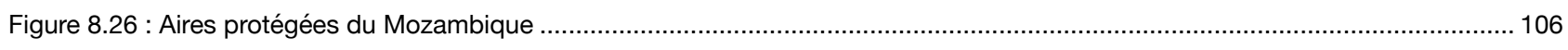

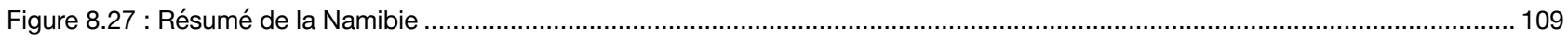

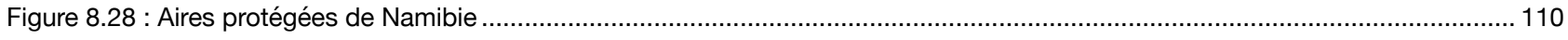

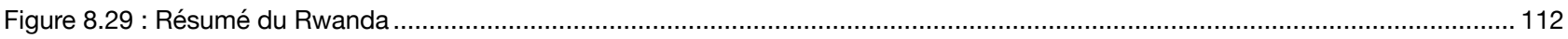

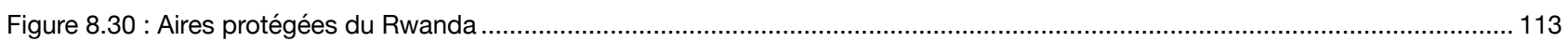

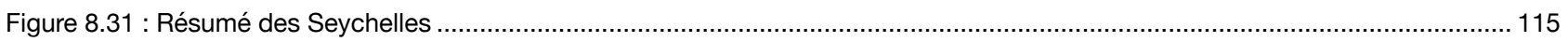

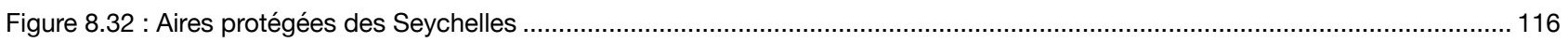

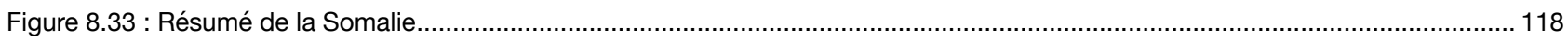

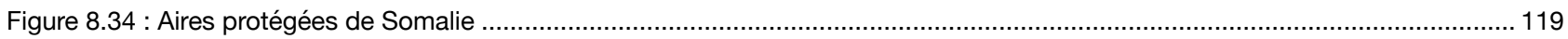

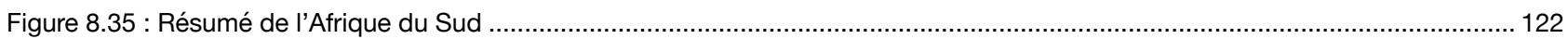

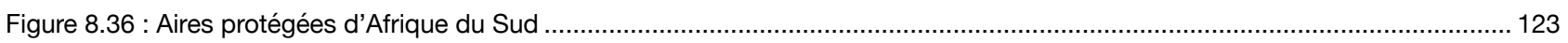

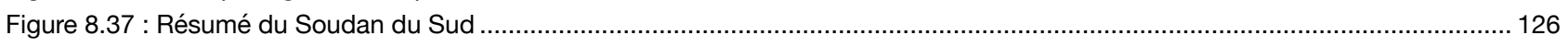

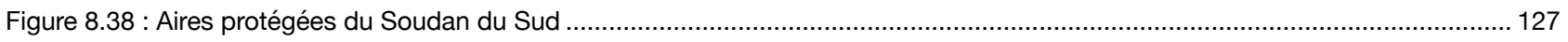

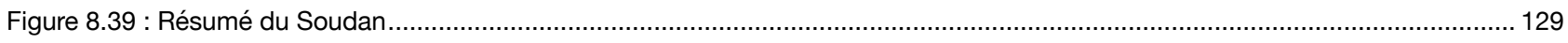

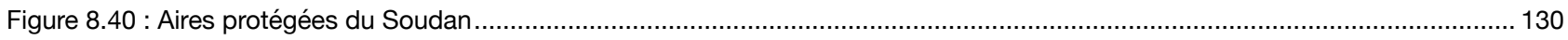

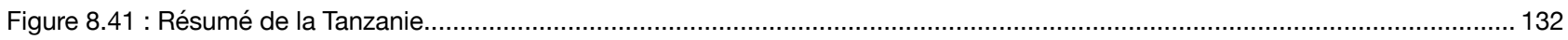

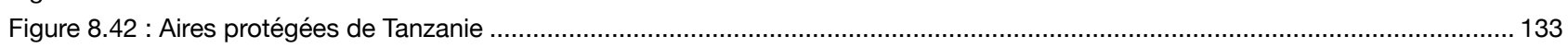

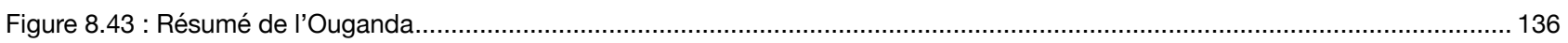

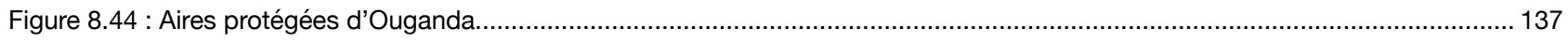

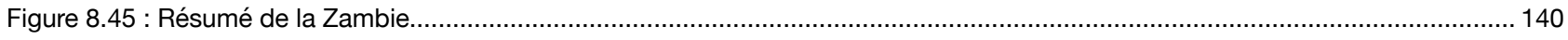

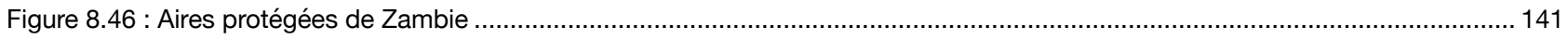

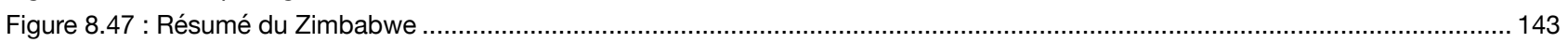

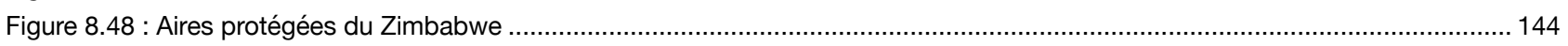

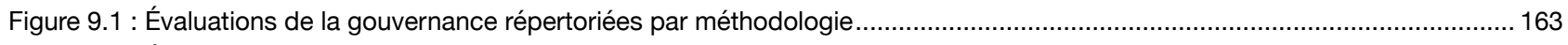

Figure 9.2 : Évaluations de la gouvernance répertoriées par pays ...................................................................................... 163

Figure 9.3 : Évaluations sociales répertoriées par méthodologie .......................................................................................... 164

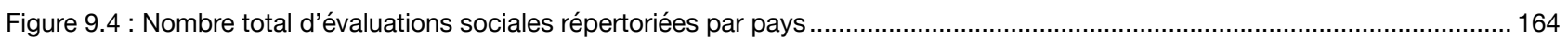

Figure 10.1 : Cycle de gestion et évaluation de la gestion des aires protégées .......................................................................... 168

Figure 10.2 : Pourcentage de couverture des évaluations de l'efficacité de la gestion par région ................................................. 172

Figure 10.3 : Nombre d'aires protégées présentant une évaluation EfGAP dans la BD-EGAP en Afrique orientale et australe ............. 173

Figure 10.4 : Pourcentage d'aires protégées possédant des évaluations EfGAP dans la BD-EGAP ............................................. 173

Figure 10.5 : Évaluations EfGAP répertoriées en Afrique orientale et australe par méthodologie / outil ........................................... 173 


\section{Liste des figures (suite)}

Figure 10.6 : Répartition des évaluations EfGAP répertoriées par pays ….......................................................................... 173

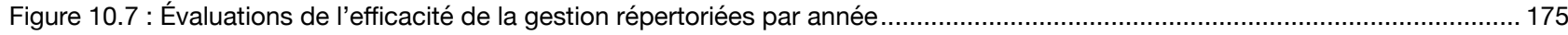

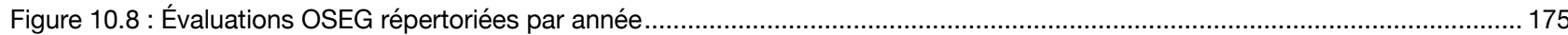

Figure 10.9 : Évaluations « combinées » répertoriées par méthodologie / outil ...................................................................... 175

Figure 10.10 : Résultats d'efficacité de la gestion des aires protégées évaluées en Afrique de l'Est ............................................... 175

Figure 10.11: Carte montrant les résultats d'efficacité de la gestion des aires protégées évaluées en Afrique de l'Est ...................... 176

Figure 10.12 : Résultats moyens pour les indicateurs principaux des évaluations les plus récentes ............................................. 177

Figure 10.13 : Déficit de financement et ressources financières disponibles dans 15 pays d'Afrique orientale et australe................... 179

Figure 10.14 : Répartition des recettes générées en interne dans sept pays (Eswatini, Éthiopie, Kenya, Namibie,

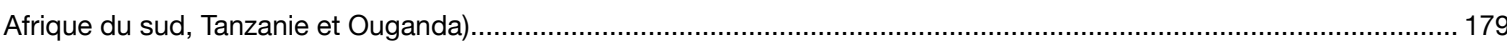

Figure 11.1 : Quadrant de l'application de la technologie dans les aires protégées d'Afrique....................................................... 191

\section{Liste des encadrés}

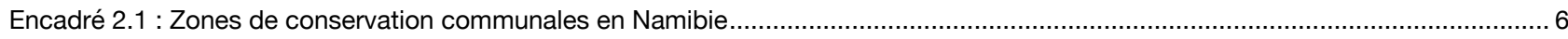

Encadré 2.2 : Autres mesures de conservation efficaces par zone (AMCE) en Afrique.................................................................... 9

Encadré 2.3 : Zones clés pour la biodiversité (KBA) en Afrique............................................................................................. 10

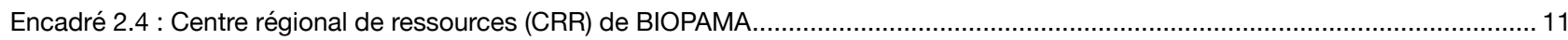

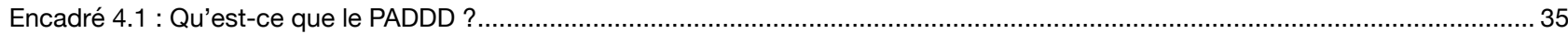

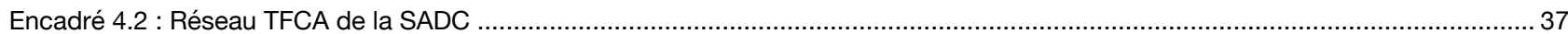

Encadré 7.3 : Conservation marine transfrontalière entre le Kenya et la Tanzanie .......................................................................54

Encadré 9.1 : Ayant-droits et parties prenantes, quelle différence ? ….................................................................................. 148

Encadré 9.2 : Relancer la conservation marine grâce à la gestion locale de la pêche ................................................................. 151

Encadré 9.3 : La diversité de la gouvernance en pratique - établir des zones marines gérées localement pour lutter contre le déclin des poissons à Kuruwitu, sur la côte nord du Kenya .................................................................. 152

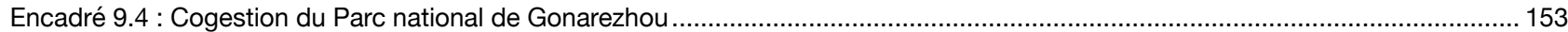

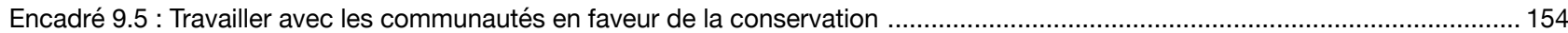

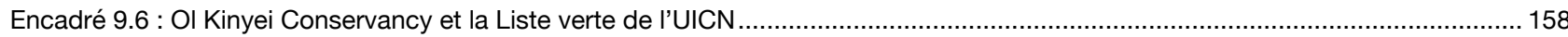

Encadré 9.7 : Évaluation de la gouvernance à l'échelle du système en Tanzanie .......................................................................... 160

Encadré 9.8 : Évaluation de la gouvernance à l'échelle des sites à Mumbwa GMA en Zambie .................................................... 161

Encadré 9.9 : État des aires de conservation autochtones et communautaires en Tanzanie ............................................................. 162

Encadré 9.10 : Évaluation sociale à OI Pejeta Conservancy, au Kenya ….................................................................................. 164

Encadré 10.1 : Pourquoi informer sur l'efficacité de la gestion des aires protégées ? ...................................................................... 169

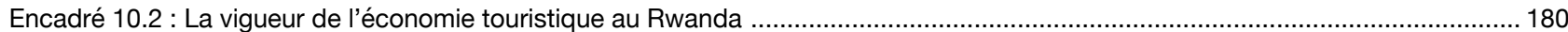

Encadré 10.3 : Première incitation fiscale efficace pour la biodiversité en Afrique du Sud ................................................................. 185

Encadré 10.4 : Impact de la pandémie de COVID-19 sur les aires protégées en Afrique orientale et australe.................................... 185

Encadré 11.1 : Renforcement des capacités de lutte contre le braconnage - le cas du Collège de la faune d'Afrique australe............ 190

Encadré 11.2 : EarthRanger - connaître de la situation pour sécuriser les aires protégées et réduire les conflits homme-faune ........... 192

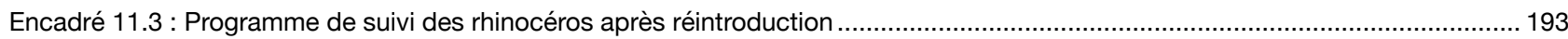

Encadré 11.4 : Piégeage photographique pour le suivi écologique et la sécurité ..........................................................................194

Encadré 11.5 : SPARC - Réduire les risques climatiques pour les réseaux de conservation......................................................... 195 


\section{Liste des tableaux}

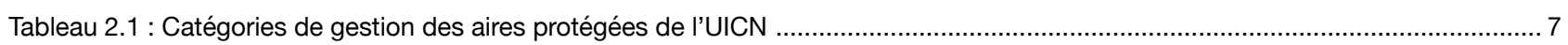

Tableau 2.2 : Norme de la Liste verte de l'UICN - composantes et critères .................................................................................... 9

Tableau 2.3 : Trois des menaces les plus fréquemment signalées dans le biome Afro-tropical ........................................................... 14

Tableau 4.1 : Sites d'importance mondiale en Afrique orientale et australe ..................................................................................... 25

Tableau 4.2 : Liste annotée des sites naturels et « mixtes » (naturels / culturels) du Patrimoine mondial en Afrique orientale et australe (en 2019), y compris les résultats de l'Évaluation des perspectives de conservation de l'UICN et les dates des missions de suivi du Centre du Patrimoine mondial / UICN.

Tableau 4.3 : Aires transfrontières de conservation d'Afrique orientale et australe ............................................................................. 38

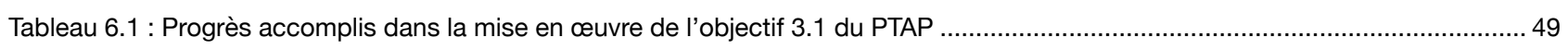

Tableau 9.1 : Types de gouvernance de I'UICN pour les aires protégées...................................................................................... 150

Tableau 9.2 : Principes de bonne gouvernance de l'UICN pour les aires protégées ....................................................................... 156

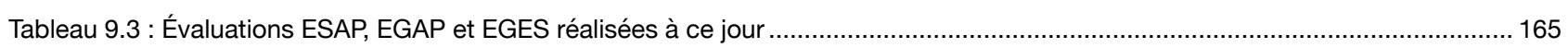

Tableau 10.1: Méthodologies EfGAP les plus couramment utilisées en Afrique orientale et australe ..............................................170

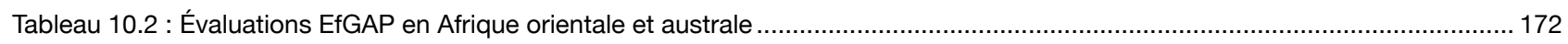

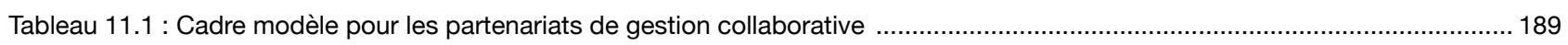

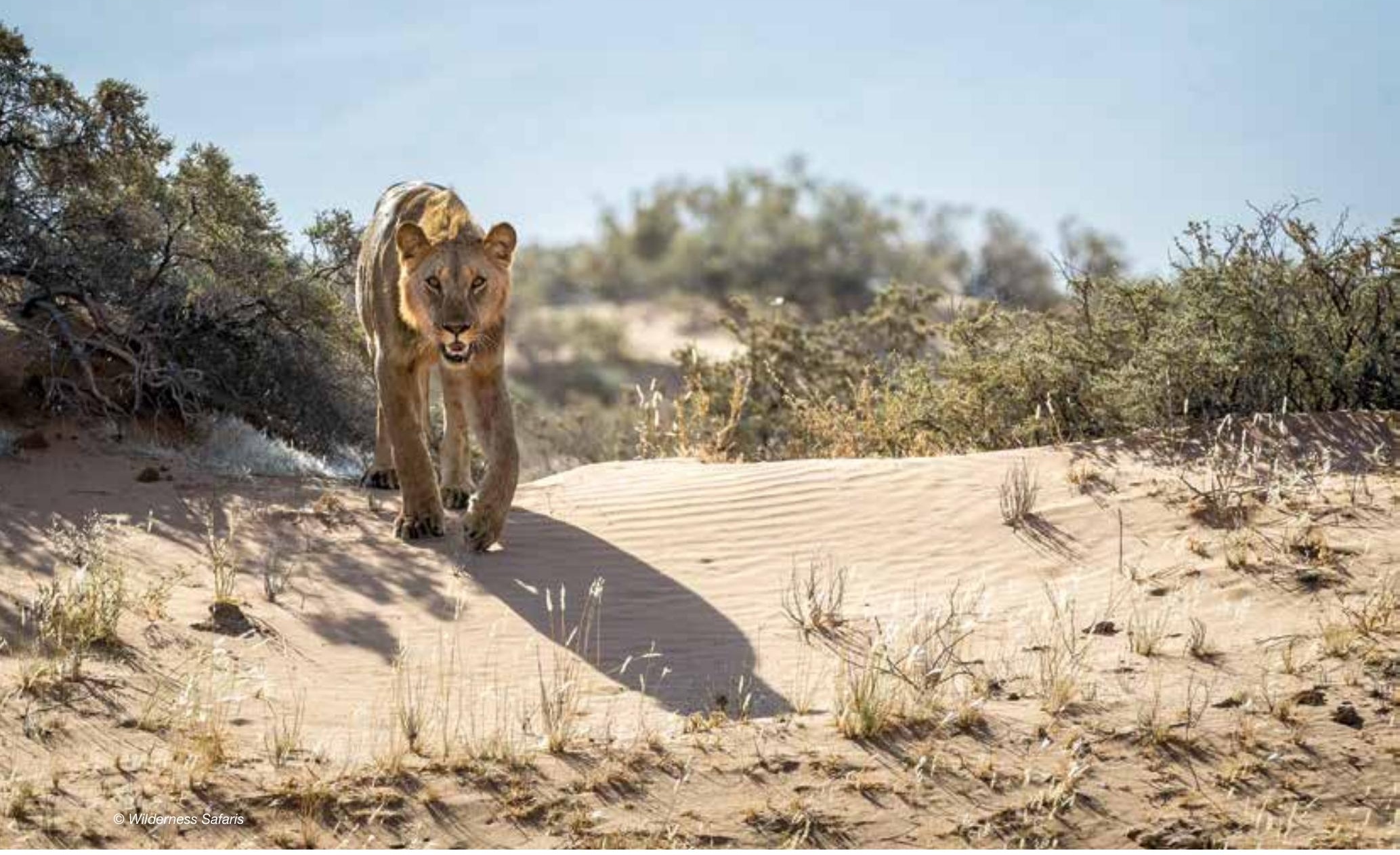




\section{Avant-propos}

L'année 2020 marque un moment charnière dans la conservation de la nature, à un moment où le monde fait le bilan des progrès accomplis en relation avec le Plan stratégique pour la biodiversité 2011-2020 et négocie le nouveau Cadre mondial pour la biodiversité pour l'après 2020. La publication de ce précieux rapport est une étape importante dans un voyage qui a débuté dans la région d'Afrique orientale et australe lors du Ve Congrès mondial des parcs de I'UICN à Durban, en 2003. Lors de cette réunion, l'audacieux Plan d'action de Durban a été élaboré, constituant la base du premier accord multilatéral complet sur les aires protégées au monde. Le Programme de travail sur les aires protégées (PTAP) a ensuite été adopté lors de la 7e Conférence des Parties à la Convention sur la diversité biologique, à Kuala Lumpur en 2004. Bon nombre des objectifs, principes, méthodes et mesures adoptés dans cette décision sont à la base du présent rapport. Par exemple, c'est à Durban que la pleine compréhension de la gouvernance, de l'équité et des droits en relation avec les aires protégées et de conservation a été documentée, comme souligné dans cette publication.

Au cours du Plan stratégique pour la biodiversité 2011-2020, les gouvernements nationaux et autres parties prenantes ont réalisé des progrès considérables sur les nombreux éléments essentiels de l'Objectif d'Aichi 11 sur les aires protégées. Un aperçu de ces réalisations a été présenté dans les rapports biennaux de Planète protégée, sur la base des informations présentes dans la Base de données mondiale des aires protégées. Ce rapport documente ces progrès et les illustre avec de nombreuses études de cas d'Afrique orientale et australe. II montre également comment les systèmes d'aires protégées et de conservation sont une stratégie de conservation essentielle pour la région, sans laquelle la perte de biodiversité aurait été beaucoup plus importante. II met également en évidence les nombreuses lacunes persistant dans la compréhension et la mise en œuvre, et nous montre à quel point il est difficile d'obtenir des résultats efficaces pour la conservation de la nature.

Le rapport souligne les raisons d'être d'une mise en œuvre de systèmes efficaces d'aires protégées et de conservation. Comme l'a déclaré Nelson Mandela lors du Congrès mondial des parcs de I'UICN à Durban, «nous savons que la clé d'un avenir durable pour les aires protégées réside dans le développement de partenariats. Ce n'est que par des alliances et des partenariats que les aires protégées pourront être adaptées aux besoins de la société ". Comprendre et documenter la pertinence des aires protégées et de conservation aux besoins de la société est l'une des principales contributions de ce rapport. La crise contemporaine liée à la pandémie de COVID-19 met brutalement cela en évidence. Les pandémies causées par le transfert d'agents pathogènes de la faune sauvage aux hôtes humains sont souvent le résultat d'une dégradation, fragmentation ou perturbation de l'intégrité des écosystèmes naturels, ainsi que d'une augmentation des mouvements et des contacts entre les humains et la faune sauvage. Maintenir l'intégrité des écosystèmes, à l'intérieur et au-delà des aires protégées, est donc essentiel, et les efforts visant à gérer efficacement les écosystèmes, ou à les restaurer, constitueront des investissements précieux pour réduire le risque de zoonoses et maintenir les moyens de subsistance des communautés.

Les aires protégées et de conservation sont une composante essentielle de la plupart des programmes de conservation de la nature, où la gouvernance et la gestion sont nécessaires pour maintenir des programmes efficaces, capables d'identifier et d'aborder les menaces conduisant à une perturbation des écosystèmes. Avec une pression démographique et une consommation de ressources naturelles croissantes, il n'y a que peu d'endroits au monde où un investissement dans une gouvernance et une gestion efficaces ne soit pas nécessaire pour faire face aux menaces et maintenir l'intégrité des écosystèmes. Outre une protection contre les pandémies, les écosystèmes naturels procurent à la société une vaste gamme d'avantages grâce à la fourniture d'eau potable et salubre, de ressources alimentaires, de stockage de carbone, de santé et de bien-être en général, et tous ont une valeur humaine et économique. Souvent, les gouvernements hésitent à investir dans le maintien des écosystèmes essentiels qui génèrent cette valeur. Ils ne pensent qu'aux coûts relativement mineurs de la gestion des aires protégées, mais mettent en péril les énormes contributions que les écosystèmes intacts et les aires protégées apportent à l'économie, y compris par le biais des moyens de subsistance qui en dépendent. Sans financement public, non seulement la gouvernance et la gestion de ces sites sont affaiblies, mais leurs fonctions et services essentiels à la société sont compromis.

Ce rapport sur l'état des aires protégées et de conservation apporte une contribution importante à l'évaluation de l'état actuel des nombreux facteurs contribuant au succès des systèmes d'aires protégées et de conservation. II analyse les progrès accomplis vers la réalisation des objectifs nationaux et mondiaux, et les mesure sur la base de normes fiables d'efficacité, telles que la Liste verte de I'UICN des aires protégées et de conservation, qui définit ce que l'on entend par des systèmes efficaces et équitables d'aires protégées et de conservation. II fournit également un diagnostic des déficits, situe les lacunes et explique comment y remédier par un développement ciblé des capacités.

Le bilan de cette situation a été possible grâce au programme BIOPAMA, un investissement de l'Union européenne et de l'Organisation des États d'Afrique, des Caraïbes et du Pacifique. Le rapport établit donc une base de référence précieuse à partir de laquelle de nouveaux progrès pourront être mesurés. II contribue aux Systèmes d'information de référence régionaux et mondiaux, ainsi qu'aux partenariats qui favoriseront une prise de décision mieux informée à l'échelle nationale et mondiale. II aidera à cibler les domaines où des interventions et des investissements sont nécessaires pour améliorer à la fois la gouvernance et la gestion, ainsi qu'à soutenir l'efficacité de ces systèmes en tant que fondement de la vie terrestre et marine, mais aussi des objectifs de développement humain, essentiels à l'avenir de notre planète.

\section{Trevor Sandwith}

Directeur

Programme mondial de I'UICN sur les aires protégées 


\section{Résumé exécutif}

La région d'Afrique orientale et australe couvre 24 pays, de l'Afrique du Sud, au sud, au Soudan, au nord, ainsi que quatre des six nations insulaires de l'océan Indien occidental. La région est culturellement diverse et extrêmement riche en biodiversité, avec une abondance de vie sauvage spectaculaire et de nombreuses espèces endémiques de flore et de faune. Des efforts considérables sont déployés pour préserver la biodiversité de la région, mais des populations humaines grandissantes, des conflits liés à l'utilisation des terres, la surexploitation des ressources, des activités récréatives non durables, la déforestation et le commerce illégal menacent les aires protégées, les espèces et les écosystèmes. S'ajoutant à ces défis, la pandémie actuelle de COVID-19 a entraîné l'arrêt de l'industrie touristique et, par conséquent, une diminution significative des financements liés à la conservation des aires protégées, dont les principaux revenus sont issus du tourisme. La pandémie aggrave le déficit de financement des aires protégées et rappelle durement la nécessité de diversifier les revenus.

L'État des aires protégées et de conservation d'Afrique orientale et australe est le premier rapport regroupant des informations sur les aires protégées et de conservation ${ }^{1}$ dans l'ensemble de la région d'Afrique de l'Est et du Sud. II constitue un rapport de référence, présentant les données et informations actuellement disponibles. Dans la mesure du possible, de nouvelles analyses ont été entreprises, et des études de cas et des encadrés ont été ajoutés pour compléter les informations de base. Un certain nombre d'autres analyses, réalisées dans le cadre du programme BIOPAMA, viennent compléter ce rapport et sont également disponibles sous forme de publications distinctes. Le rapport se compose de douze chapitres, son thème général se concentrant sur la gouvernance, l'équité et l'efficacité de la gestion des aires protégées et de conservation.

Le rapport inclut un aperçu général de la conservation et des politiques et programmes connexes, ainsi qu'une analyse régionale. En tant que région, l'Afrique orientale et australe protège 16,54\% de sa surface terrestre au sein de 4821 aires protégées, soit une superficie de $2120112 \mathrm{~km}^{2}$. Au moins sept pays de la région ont dépassé l'Objectif d'Aichi 11 concernant la couverture terrestre des aires protégées (17\%), et la région est à mi-chemin d'atteindre l'objectif de couverture côtière et marine (10\%), avec 5,60\% de sa zone marine et côtière protégée par 411 sites, couvrant une superficie de $473815 \mathrm{~km}^{2}$. Trois pays de la région ont dépassé l'Objectif d'Aichi 11 en matière de couverture des aires marines et côtières protégées.

La plupart des aires protégées de la région sont gérées par l'agence gouvernementale nationale compétente, bien que de nombreux pays incluent de plus en plus de sites gérés par les communautés et le secteur privé, y compris dans le cadre de partenariats publicprivé. Les types de gouvernance de nombreuses aires protégées n'ont pas encore été inclus dans la Base de données mondiale des aires protégées. L'Afrique orientale et australe abrite 39 Réserves de biosphère, 27 sites du Patrimoine mondial et 109 sites Ramsar (Zones humides d'importance internationale). La région abrite également 30 sites transfrontaliers de conservation, allant de modalités conceptuelles à des aires de conservation transfrontières étayées par des traités officiels. L'Afrique australe dispose d'un solide programme d'aires de conservation transfrontières, le premier de ces sites ayant été déclaré en 1990, et pourrait fournir des enseignements utiles à d'autres parties du continent.

L'objectif des Communautés économiques régionales de la région est de faciliter l'intégration économique entre les États membres des différentes régions et, plus généralement, au sein de la Communauté économique africaine. Elles jouent également un rôle important en termes de promotion de la conservation transfrontalière dans la région.

Un résumé des données disponibles pour chacun des 24 pays couverts par ce rapport recoupe les informations provenant de la Base de données mondiale des aires protégées et celles des rapports nationaux à la Convention sur la diversité biologique. Ces données constituent une référence quant aux informations disponibles. De plus amples détails et analyses à l'échelle nationale seront fournis dans de futurs rapports, au fur et à mesure de leur disponibilité.

Le rapport comprend une introduction à la gouvernance des aires protégées, passant en revue les travaux de I'UICN et autres organisations visant à fournir des outils pour aider les pays à répondre aux exigences de l'Objectif d'Aichi 11 en matière de gouvernance équitable des aires protégées. Les outils disponibles pour évaluer la diversité et la qualité de la gouvernance à l'échelle des systèmes et des sites y sont décrits, et des études de cas régionales y sont présentées. Ces outils comprennent la Liste verte de I'UICN des aires protégées et de conservation, centrée sur quatre composantes : une bonne gouvernance, une conception et une planification robustes, une gestion efficace et des résultats de conservation probants. Un rapport établi dans le cadre du programme BIOPAMA a analysé 380 évaluations de la gouvernance et 50 évaluations sociales réalisées en Afrique orientale et australe. Malgré une augmentation des évaluations sociales et de gouvernance, ce rapport a constaté que celles-ci restent limitées dans la région, et que très peu d'évaluations sont répétées dans le temps.

L'Évaluation de l'efficacité de la gestion des aires protégées (EfGAP) permet également d'obtenir des rapports sur les progrès accomplis dans la réalisation de l'Objectif d'Aichi 11, qui reprend la nécessité d'une gestion efficace. Environ 13\% des aires protégées de la région ont fait l'objet d'au moins une évaluation EfGAP, et l'analyse a répertorié 2686 évaluations de l'efficacité de la gestion, dont la plupart à partir de l'Outil de suivi de l'efficacité de la gestion (OSEG). La nouvelle Base de données mondiale du PNUE-WCMC sur l'efficacité de la gestion des aires protégées (BD-EGAP) a servi de référence pour cette analyse, malgré les lacunes importantes persistant dans les données, qui devront être comblées pour permettre une véritable réflexion sur le nombre, la localisation et le calendrier des évaluations EfGAP. De nombreux pays, comme 
Madagascar et l'Afrique du Sud, mènent des évaluations de l'efficacité de la gestion depuis un certain nombre d'années, y compris des évaluations périodiques dans de nombreuses aires protégées. Les résultats de ces évaluations sont utilisés pour améliorer la gestion de ces sites.

Il existe de nombreux défis dans la région et les menaces à la conservation augmentent, mais les engagements des pays envers les accords internationaux, des objectifs et engagements visant à assurer une gouvernance équitable et une gestion efficace des aires protégées et de conservation pourront promouvoir et assurer la conservation des espèces et des écosystèmes dans la région. Ces engagements devront être étayés par une volonté politique et les allocations de ressources nécessaires pour assurer une mise en œuvre totale au profit des aires protégées et de conservation. Des données précises, à jour et comparables, permettant de mesurer les progrès par rapport aux objectifs et aux engagements, seront essentielles pour appuyer la planification et l'affectation des ressources. Le présent rapport espère fournir une base de référence et encourager l'amélioration de la collecte et de la communication des données afin d'assurer une conservation équitable et efficace en Afrique orientale et australe.

\section{Remerciements}

Nous remercions sincèrement l'Union européenne et l'Organisation des États d'Afrique, des Caraïbes et du Pacifique pour leur soutien financier à cette publication. Nous remercions le Comité de rédaction et le Comité des Publications de l'UICN pour leur soutien et leurs conseils dans la préparation de ce document.

Tous les points focaux BIOPAMA et de l'État des aires protégées et de conservation d'Afrique orientale et australe (SoPACA, selon ses sigles en anglais) dans les 24 pays présentés dans ce rapport ont apporté une contribution inestimable, tout comme les points focaux des Communautés économiques régionales.

L'équipe principale impliquée dans l'élaboration de ce rapport comprenait : Sue Snyman, Beryl Nyamgeroh, Christine Mentzel et Leo Niskanen (UICN ESARO), Jessica Stewart (UNEP-WCMC), Bastian Bertzky et Lucy Bastin (CCR), Patrick Kabatha et Ngugi Kimani (RCMRD) et Diane Skinner et Eleanor Shadwell.

Les contributions importantes des personnes suivantes à différents chapitres ont été très appréciées : Jennifer Kelleher (Programme mondial de l'UICN sur les aires protégées), Phil Franks (International Institute of Environment and Development), Daniel Marnewick (BirdLife - Afrique du Sud), Rachel Golden Kroner (Conservation International), Lily Arison Réné de Roland (Fonds Peregrine), Ashwell Glasson (Collège de la faune d'Afrique australe), Drew
Bantlin (Parcs africains), Candice Stevens (Fondation Wilderness, Afrique du Sud), Claudia Capitani, Jan Philipp Schägner et Andrew Cottam (CCR), Francois Barnard et Kathleen Fitzgerald (Conservation Capital), Caitlin Kelly (Projet «Planification spatiale pour une conservation par zone en réponse aux changements climatiques »), Ted Schmitt (Vulcan), Lisa Blanken (Deutsche Gesellschaft für Internationale Zusammenarbeit), Elsabé van der Westhuizen (Société zoologique de Frankfurt), Stephen Nindi (Commission nationale d'aménagement du territoire de Tanzanie), Arthur Tuda (Service de la faune du Kenya), Jessica Campese, Emmanuel Sulle et Yemeserach Tessema, Beatrice Chataigner (UICN), Des Bowden (Association de conservation et de bien-être de Kuruwitu) et Rupert Quinan (Blue ventures).

Nous remercions I'UICN, le RCMRD, I'UNEP-WCMC, le CCR, la Fondation Peace Parks et Birdlife International pour avoir fourni les données à la base de ce rapport.

Trois évaluateurs externes, Peter Lindsey, Evans Mwangi et Andrew Parker, ont consacré beaucoup de temps et d'efforts à l'analyse du rapport, le rendant beaucoup plus robuste. Enfin, nous remercions les correcteurs Marc Hockings et Fiona Leverington, la relectrice Diwata Hunziker et la graphiste Mary-Anne van der Byl pour leur travail complet et détaillé qui a permis de garantir que la version en anglais de ce rapport soit à la fois précise et visuellement attrayante.

Nous remercions également toutes les personnes et organisations ayant aimablement fourni des photos pour le rapport. 


\section{Glossaire}

\begin{tabular}{|c|c|}
\hline Terme & Signification \\
\hline $\begin{array}{l}\text { Aire de conservation } \\
\text { communautaire }\end{array}$ & $\begin{array}{l}\text { Écosystèmes naturels et modifiés, y compris la biodiversité importante, les services écologiques et } \\
\text { les valeurs culturelles volontairement conservés par les peuples autochtones et les communautés } \\
\text { locales et mobiles grâce à un droit coutumier ou autres moyens efficaces. }\end{array}$ \\
\hline Aire protégée & $\begin{array}{l}\text { La CDB définit une aire protégée comme " une zone géographiquement définie, désignée ou } \\
\text { réglementée et gérée pour atteindre des objectifs de conservation spécifiques " (article } 2 \text { de la CDB). } \\
\text { L'UICN fournit une définition plus précise: « un espace géographique clairement défini, reconnu, } \\
\text { consacré et géré, par des moyens juridiques et autres moyens efficaces, pour parvenir à la } \\
\text { conservation à long terme de la nature et des services écosystémiques et valeurs culturelles qui lui } \\
\text { sont associés " (Dudley 2008). La CDB et l'UICN reconnaissent que les deux définitions sont } \\
\text { équivalentes dans la pratique, car dans les deux cas, ces sites sont destinées à assurer la } \\
\text { conservation in situ. }\end{array}$ \\
\hline Aires de conservation & $\begin{array}{l}\text { Les aires de conservation sont définies comme des sites maintenant l'intégrité écologique et / ou } \\
\text { une conservation in situ efficace de la biodiversité. }\end{array}$ \\
\hline $\begin{array}{l}\text { Aires marines gérées } \\
\text { localement }\end{array}$ & $\begin{array}{l}\text { Une zone d'eaux côtières et ses ressources marines et côtières associées, en grande partie ou } \\
\text { entièrement gérées à l'échelle locale par les communautés côtières, des groupes de propriétaires } \\
\text { fonciers, des organisations partenaires et / ou des représentants collaboratifs du gouvernement } \\
\text { résidant ou basés dans la zone même. }\end{array}$ \\
\hline Autorité de gouvernance & $\begin{array}{l}\text { Institution, individu, peuple autochtone ou groupe communautaire ou tout autre organisme reconnu } \\
\text { comme dépositaire de l'autorité et de la responsabilité de la prise de décision et de la gestion d'une } \\
\text { région. }\end{array}$ \\
\hline Ayant-droits & $\begin{array}{l}\text { Personnes socialement dotées de droits légaux ou coutumiers concernant les terres, l'eau et les } \\
\text { ressources naturelles }\end{array}$ \\
\hline
\end{tabular}

Base de référence

Informations recueillies à propos d'une cible spécifique (p. ex. état d'une ressource, connaissances, population d'une espèce particulière, etc.) aux étapes initiales d'un projet, fournissant ainsi une base pour mesurer des progrès ou une évolution au fil du temps.

Biodiversité

La variabilité des organismes vivants de toutes origines, y compris terrestres, marins et autres écosystèmes aquatiques et les complexes écologiques dont ils font partie, incluant la diversité intraspécifique, entre les espèces et entre les écosystèmes.

\section{Biome}

Une grande partie de l'environnement de vie d'une région particulière, caractérisée par sa végétation distinctive et maintenue en grande partie par les conditions climatiques locales.

Catégories d'aires protégées

Ensemble de six classes, conçu par l'UICN, dans lequel une aire protégée peut être classée en fonction de ses principaux objectifs de gestion globale. Certaines aires protégées, cependant, sont divisées en zones, chacune pouvant avoir un objectif de gestion différent contribuant à l'objectif principal global.

Communauté

Groupe social de toute taille dont les membres résident dans une localité spécifique, partagent un gouvernement et peuvent avoir un patrimoine culturel et historique commun. II peut également s'agir d'un groupe d'individus interagissant dans leur environnement immédiat, présentant une cohésion et une continuité à travers le temps, et montrant des caractéristiques telles que l'interaction sociale, l'intimité, les engagements moraux, les relations multiples et la réciprocité.

\section{Connectivité (biologique)}

Mesure dans laquelle la production locale entraîne le recrutement d'autres populations. Pour toute population locale, la connectivité peut être caractérisée par : (1) la proportion de recrutement dans la population locale autosuffisante, (2) les contributions proportionnelles d'autres populations au recrutement dans la population locale, d'une manière spatialement explicite, et (3) la répartition spatiale et la représentation proportionnelle des contributions de la production locale au recrutement externe d'autres populations.

\section{Conservation}

Maintien ou utilisation durable des ressources de la Terre afin de préserver la diversité des écosystèmes, des espèces et génétique, ainsi que les processus évolutifs et autres qui les façonnent. 


\begin{tabular}{|c|c|}
\hline Terme & Signification \\
\hline Conservation de la nature & $\begin{array}{l}\text { Dans le présent contexte, la nature fait toujours référence à la biodiversité, au niveau génétique, des } \\
\text { espèces et des écosystèmes, et fait souvent également référence à la géodiversité, au relief et aux } \\
\text { valeurs naturelles plus générales. Dans le contexte des aires protégées, la conservation se réfère au } \\
\text { maintien in situ des écosystèmes et des habitats naturels et semi-naturels et de populations viables } \\
\text { d'espèces dans leur environnement naturel ainsi que, dans le cas des espèces domestiquées ou } \\
\text { cultivées, dans l'environnement où elles ont développé leurs propriétés distinctives. }\end{array}$ \\
\hline Corridor & $\begin{array}{l}\text { Moyen de maintenir une connectivité écologique ou environnementale vitale en maintenant des liens } \\
\text { physiques entre les zones centrales. }\end{array}$ \\
\hline Développement durable & $\begin{array}{l}\text { Un développement répondant aux besoins du présent sans compromettre la capacité des } \\
\text { générations futures à satisfaire leurs propres besoins }\end{array}$ \\
\hline Durabilité & $\begin{array}{l}\text { Dans le cas des aires protégées, état de persistance sur une longue période, avec des valeurs } \\
\text { naturelles et culturelles de base intactes mais pas nécessairement inchangées. }\end{array}$ \\
\hline Écosystème & $\begin{array}{l}\text { Complexe dynamique de communautés végétales, animales et micro-organismes, ainsi que leur } \\
\text { environnement non vivant, interagissant en tant qu'unité fonctionnelle. }\end{array}$ \\
\hline Écotourisme & $\begin{array}{l}\text { Voyage responsable dans des zones naturelles, qui préserve l'environnement, soutient le bien-être } \\
\text { des populations locales et implique une interprétation et l'éducation. }\end{array}$ \\
\hline Efficacité de la gestion & $\begin{array}{l}\text { La façon dont une aire protégée est gérée. Principalement la mesure dans laquelle elle protège ses } \\
\text { valeurs et atteint ses buts et objectifs. }\end{array}$ \\
\hline Équité & $\begin{array}{l}\text { Vise l'accès des personnes à l'égalité des chances et au développement des capacités de base. } \\
\text { Cela signifie que les obstacles entravant les opportunités économiques et politiques et l'accès à } \\
\text { l'éducation et aux services de base devraient être éliminés, afin que les personnes (femmes et } \\
\text { hommes de tous âges, conditions et professions) puissent profiter de ces opportunités et en } \\
\text { bénéficier. Cela implique un sens de justice, c'est-à-dire donner à chaque personne ou groupe ce } \\
\text { qui lui revient de droit, en reconnaissant les conditions ou caractéristiques spécifiques de chaque } \\
\text { personne ou groupe humain (sexe, genre, classe, religion, âge). Il s'agit de la reconnaissance de la } \\
\text { diversité, sans aucun motif de discrimination. }\end{array}$ \\
\hline Espèce & $\begin{array}{l}\text { Groupe d'organismes différant des autres groupes d'organismes et capable de se reproduire et de } \\
\text { générer une progéniture fertile. }\end{array}$ \\
\hline Espèces envahissantes & $\begin{array}{l}\text { Organisme introduit (plante, animal, champignon ou bactérie) qui entre en concurrence avec les } \\
\text { espèces autochtones pour l'espace et les ressources, causant des dommages écologiques et / ou } \\
\text { économiques. Toutes les espèces introduites ne sont pas envahissantes et, lorsqu'elle est utilisée de } \\
\text { façon plus générale, la définition peut inclure les espèces autochtones colonisant et dégradant } \\
\text { fortement un habitat particulier. }\end{array}$ \\
\hline Évaluation & $\begin{array}{l}\text { Jugement des conditions ou de la performance d'un aspect de la gestion par rapport à des critères } \\
\text { prédéterminés (généralement un ensemble de normes ou d'objectifs), y compris, dans le cas } \\
\text { présent, les objectifs pour lesquels les aires protégées ont été établies. }\end{array}$ \\
\hline Évaluation de la gestion & Mesure ou estimation d'un aspect de la gestion. \\
\hline Gestion adaptative & $\begin{array}{l}\text { Le processus cyclique consistant à tester systématiquement des hypothèses, à générer des leçons } \\
\text { d'apprentissage par l'évaluation des résultats de ces tests et à réviser et améliorer continuellement } \\
\text { les pratiques de gestion. L'objectif de la gestion adaptative dans un contexte d'aire protégée est } \\
\text { d'améliorer l'efficacité et de progresser vers la réalisation de buts et d'objectifs. }\end{array}$ \\
\hline Gestion des données & $\begin{array}{l}\text { L'acte, le processus ou les moyens par lesquels des données sont gérées. Cela peut inclure la } \\
\text { compilation, le stockage, la sauvegarde, la saisie, l'organisation, l'extraction, la récupération, la } \\
\text { manipulation et la diffusion des données. }\end{array}$ \\
\hline Gestionnaire d'aire protégée & $\begin{array}{l}\text { Professionnel ou autre intervenant travaillant dans une aire protégée. Le terme inclut les } \\
\text { administrateurs, les gestionnaires et les planificateurs susceptibles de travailler pour et avec des } \\
\text { organisations gouvernementales, non gouvernementales, des groupes communautaires locaux, des } \\
\text { propriétaires fonciers privés ou autres entités. }\end{array}$ \\
\hline
\end{tabular}

2 https://www.cbd.int/doc/meetings/tk/aheg-lcr-01/official/aheg-Icr-01-02-en.pdf 


\begin{tabular}{l|l}
\hline Terme & Signification \\
\hline Gouvernance & $\begin{array}{l}\text { Dans le contexte des aires protégées, la gouvernance a été définie comme les interactions entre les } \\
\text { structures, les processus et les traditions qui déterminent comment le pouvoir est exercé, comment } \\
\text { les décisions sont prises sur des questions d'intérêt public et comment les citoyens ou autres parties } \\
\text { prenantes y participent. Les mécanismes de gouvernance sont exprimés par des cadres juridiques } \\
\text { et politiques, des stratégies et des plans de gestion. Ils comprennent les modalités organisationnelles } \\
\text { de suivi des politiques, des plans et du rendement. La gouvernance couvre les règles de prise de } \\
\text { décision, y compris qui a accès à l'information et participe au processus décisionnel, ainsi que les } \\
\text { décisions elles-mêmes. }\end{array}$ \\
\hline
\end{tabular}

\begin{tabular}{l|l}
\hline Habitat & $\begin{array}{l}\text { Le lieu où le type de site où un organisme ou une population se développe naturellement. (CDB, } \\
\text { Article 2). }\end{array}$ \\
\hline Parties prenantes & $\begin{array}{l}\text { Personnes ou organisations possédant des intérêts et des préoccupations directs ou indirects } \\
\text { concernant les terres, l'eau et les ressources naturelles, mais ne jouissant pas nécessairement d'un } \\
\text { droit légalement ou socialement reconnu sur celles-ci. }\end{array}$ \\
\hline $\begin{array}{l}\text { Peuples autochtones et } \\
\text { communautés locales }\end{array}$ & $\begin{array}{l}\text { Le présent rapport utilise la définition de la Convention sur la diversité biologique des termes } \\
\text { Q peuples autochtones "t « communautés locales ».2 }\end{array}$ \\
\hline $\begin{array}{l}\text { La façon dont une aire protégée est gouvernée. La mesure dans laquelle celle-ci répond aux } \\
\text { principes et critères de " bonne gouvernance " identifiés et choisis par les personnes, les } \\
\text { communautés et les gouvernements concernés (et faisant partie de leur sens de la moralité, de leur } \\
\text { identité culturelle et de leur fierté) et s'aligne généralement sur les principes adoptés par les } \\
\text { organisations et conventions internationales. }\end{array}$ \\
\hline
\end{tabular}

Réserve de biosphère $\quad$ Site formant un réseau international d'écosystèmes reconnus par l'UNESCO, qui favorisent la biodiversité, la conservation et l'utilisation durable, ainsi que des approches interdisciplinaires permettant de comprendre et de gérer les changements et interactions entre les systèmes sociaux et écologiques.

\begin{tabular}{ll}
\hline Richesse spécifique & Nombre d'espèces différentes présentes dans une zone ou une communauté donnée. \\
\hline Services écosystémiques & $\begin{array}{l}\text { Avantages que les personnes tirent des écosystèmes. II s'agit notamment de services } \\
\text { d'approvisionnement tels que la nourriture et l'eau, de services de régulation tels que la régulation } \\
\text { des inondations, des sécheresses, de la dégradation des terres et des maladies, de services de } \\
\text { soutien tels que la formation des sols et le cycle des nutriments, et de services culturels tels que les } \\
\text { avantages récréatifs, spirituels, religieux et autres avantages non-matériels. }\end{array}$ \\
\hline Sites du Patrimoine mondial & $\begin{array}{l}\text { Système international d'aires protégées, créé en vertu de la Convention du patrimoine mondial, qui } \\
\text { vise à inclure les exemples les plus remarquables du patrimoine naturel et culturel au monde. }\end{array}$ \\
\hline Sites Ramsar & $\begin{array}{l}\text { Système international de zones humides protégées, reconnues comme d'importance mondiale en } \\
\text { vertu de la Convention de Ramsar (Ramsar étant le nom de la ville d'Iran où la convention a été } \\
\text { adoptée). }\end{array}$ \\
\hline
\end{tabular}
nationaux pour la biodiversité

Territoires et aires conservés par les peuples autochtones et les communautés (APAC)
Stratégies et plans d'action

Principaux instruments de mise en œuvre de la CDB à l'échelle nationale, les SPANB décrivent l'engagement de chaque Partie contractante à la conservation et à l'utilisation durable de la diversité biologique, ainsi qu'à l'intégration de cet engagement dans tous les secteurs de l'économie nationale et du cadre décisionnel.

Recueillir des informations sur des indicateurs à plusieurs reprises au fil du temps, afin d'identifier les tendances dans les conditions de l'aire protégée et les activités et processus de gestion.

Les territoires et aires conservés par les peuples autochtones et les communautés sont des écosystèmes naturels et / ou modifiés abritant des valeurs importantes de biodiversité, des services écologiques et des valeurs culturelles, volontairement conservés par les peuples autochtones et les communautés locales, sédentaires et mobiles, par le biais d'un droit coutumier ou autres moyens efficaces.

Les aires conservées par les peuples autochtones et les communautés locales peuvent être reconnues comme aires protégées ou de conservation, sous réserve de « consentement préalable » ou « consentement préalable, libre et informé » ou « approbation et participation » ou demande, selon les circonstances nationales.

Tourisme

Activités de personnes voyageant et séjournant dans des lieux autres que leur environnement habituel au plus pendant une année consécutive, à des fins de loisirs, d'affaires et autres. 


\begin{tabular}{l|l}
\hline Terme & Signification \\
\hline Tourisme axé sur la nature & $\begin{array}{l}\text { Formes de tourisme utilisant les ressources naturelles sous une forme sauvage ou non développée. } \\
\text { Le tourisme axé sur la nature est un voyage dans le but de profiter d'aires naturelles non développées } \\
\text { ou de la faune et la flore sauvages. }\end{array}$ \\
\hline Types de gouvernance & $\begin{array}{l}\text { Les quatre principaux types de gouvernance des aires protégées sont (i) la gouvernance par un } \\
\text { gouvernement, (ii) la gouvernance partagée, (iii) la gouvernance par le secteur privé (y compris les } \\
\text { ONG) et (iv) les aires et territoires gouvernés par les peuples autochtones et communautés locales. } \\
\text { Pour chaque type, il est possible que la responsabilité du tourisme ou de tout autre aspect de la } \\
\text { gestion soit délégué à une autre autorité dirigeante ou confié à des opérateurs privés. }\end{array}$ \\
\hline Utilisation durable & $\begin{array}{l}\text { Utilisation des composantes de la diversité biologique d'une manière et à un rythme qui n'entraîne } \\
\text { pas son déclin à long terme, maintenant ainsi son potentiel pour répondre aux besoins et aux } \\
\text { aspirations des générations présentes et futures. }\end{array}$ \\
\hline
\end{tabular}

\section{Acronymes}

\begin{tabular}{|c|c|}
\hline ACT & Aire de conservation transfrontalière \\
\hline AMCE & $\begin{array}{l}\text { Autres mesures de conservation efficaces } \\
\text { par zone }\end{array}$ \\
\hline AGG & Aire de gestion du gibier \\
\hline AMP & Aire marine protégée \\
\hline APAC & $\begin{array}{l}\text { Aires de conservation autochtones et } \\
\text { communautaires }\end{array}$ \\
\hline AZE & Alliance pour une extinction zéro \\
\hline BD-AMCE & $\begin{array}{l}\text { Base de données mondiale sur les autres mesures } \\
\text { efficaces de conservation par zone }\end{array}$ \\
\hline BD-EGAP & $\begin{array}{l}\text { Base de données mondiale sur l'efficacité de la } \\
\text { gestion des aires protégées }\end{array}$ \\
\hline BDMAP & Base de données mondiale des aires protégées \\
\hline BIOFIN & Initiative de financement de la biodiversité du PNUD \\
\hline BIOPAMA & $\begin{array}{l}\text { Programme pour la biodiversité et la gestion des } \\
\text { des aires protégées }\end{array}$ \\
\hline CCR & $\begin{array}{l}\text { Centre commun de recherche de la Commission } \\
\text { européenne }\end{array}$ \\
\hline CDB & Convention sur la diversité biologique \\
\hline CE & Commission européenne \\
\hline CER & Communauté économique régionale \\
\hline CMAP & $\begin{array}{l}\text { Commission mondiale de I'UICN des aires } \\
\text { protégées }\end{array}$ \\
\hline $\mathrm{COI}$ & Commission de l'océan Indien \\
\hline CRR & Centre régional de ressources \\
\hline EAC & Communauté d'Afrique de l'Est \\
\hline EGAP & $\begin{array}{l}\text { Évaluation de la gouvernance des aires } \\
\text { protégées et de conservation }\end{array}$ \\
\hline EfGAP & Efficacité de la gestion des aires protégées \\
\hline EGES & $\begin{array}{l}\text { Évaluation de la gouvernance et de l'équité à } \\
\text { l'échelle des sites }\end{array}$ \\
\hline ESAP & $\begin{array}{l}\text { Évaluation sociale des aires protégées et de } \\
\text { conservation }\end{array}$ \\
\hline ESARO & Bureau régional pour l'Afrique orientale et australe \\
\hline GEAP & Gouvernance et équité des aires protégées \\
\hline IBA & Zone importante pour les oiseaux et la biodiversité \\
\hline IGAD & $\begin{array}{l}\text { Autorité intergouvernementale pour le } \\
\text { développement }\end{array}$ \\
\hline
\end{tabular}

IIED

KBA

OCDE

ODD

OIEG

ONAP

OSEG

PADDD

PIB

PNUD

PTAP

RAPPAM

RCMRD

SADC

SMART

SoPACA

SPANB

SRIR

TWIX

UICN Union internationale pour la conservation de la nature

UNEP-WCMC Centre mondial de surveillance de la conservation de la nature du Programme des Nations Unies pour l'environnement

UNESCO Organisation des Nations Unies pour l'éducation, la science et la culture

WCMC Centre mondial de surveillance de la conservation de la nature 


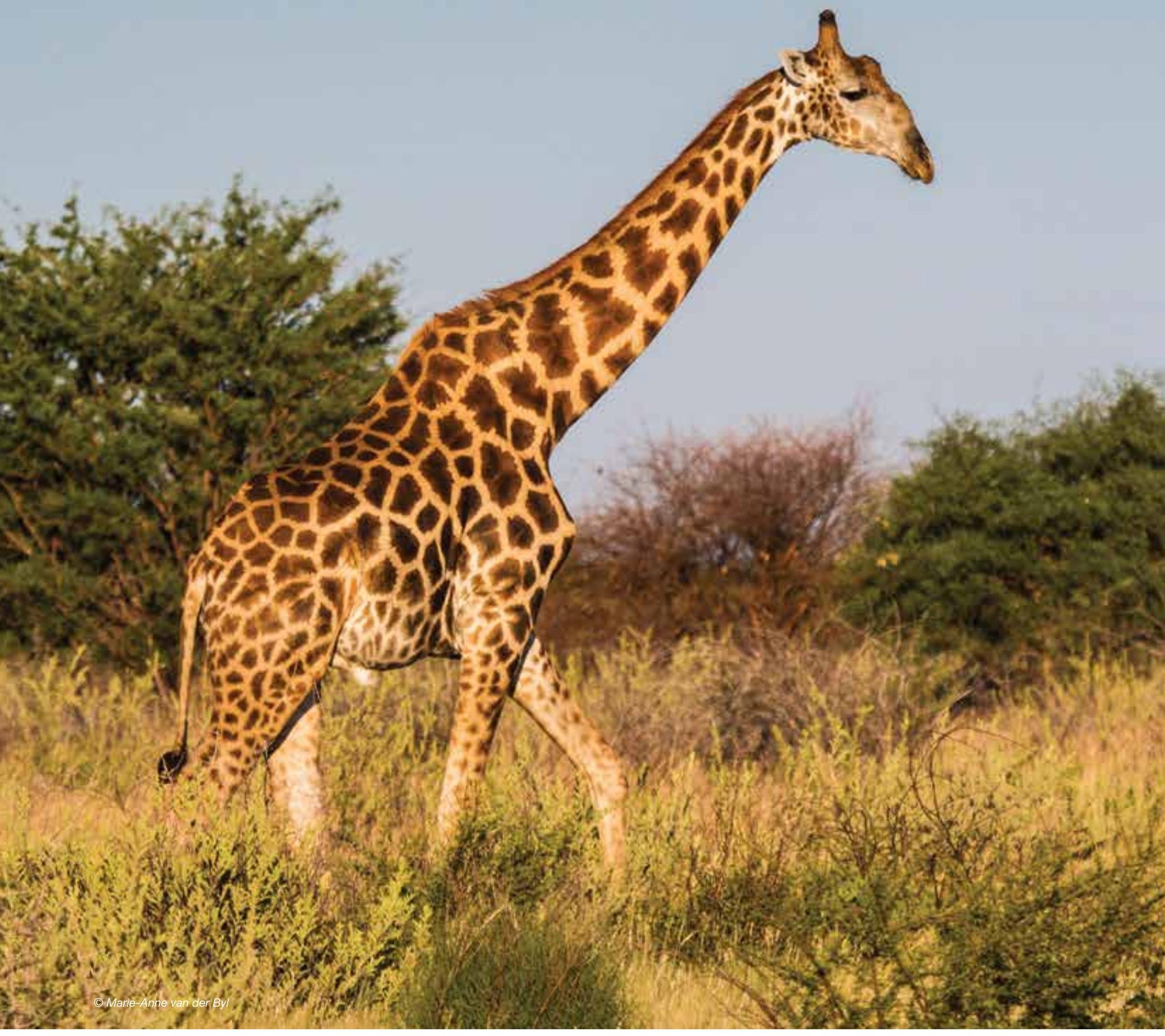


Partie I - Contexte

\section{Introduction}


La région de l'Afrique orientale et australe est l'une des zones les plus riches en biodiversité du monde, abritant un certain nombre d'aires protégées et de conservation gérées par un large éventail de parties prenantes, gouvernements, organisations nongouvernementales (ONG), communautés locales, secteur privé et autres partenariats entre ces différentes entités. La région connaît des niveaux élevés de pauvreté et de chômage et, pour cette raison, les gouvernements ont tendance à se concentrer sur le développement socioéconomique, l'emploi et la réduction de la pauvreté. En particulier, l'accent mis sur le secteur agricole et minier, ainsi que les grands développements infrastructurels, peuvent entraîner des conflits d'utilisation des terres et de faibles investissements et financements dans les aires protégées et de conservation.

Cependant, des écosystèmes sains peuvent réduire la vulnérabilité socioéconomique en favorisant le bien-être, et les connaissances environnementales détenues par les populations autochtones peuvent conduire à la découverte de nouvelles espèces et populations et peuvent améliorer notre compréhension de l'état et des tendances concernant les espèces et les écosystèmes, en particulier ceux contribuant aux moyens de subsistance et au bienêtre des populations humaines. L'efficacité des aires protégées est faible dans de nombreuses parties de la région en raison d'une combinaison de facteurs, tels que les changements climatiques, la surexploitation (braconnage de viande de brousse, exploitation forestière, élevage), les conflits civils, l'empiétement des populations locales pour maintenir leurs moyens de subsistance, et l'insuffisance de la conception, du financement et de l'administration des parcs (EC, 2015).

La biodiversité d'eau douce en Afrique est soumise à de fortes pressions, la majorité des espèces menacées se trouvant dans des zones à fort développement et à forte demande en ressources en eau, telles que le sud et l'est de l'Afrique du Sud et les grands lacs d'Afrique de l'Est. Une grande partie de la biodiversité marine et côtière africaine est également menacée. Le large plateau continental situé le long de la côte nord-ouest de l'Afrique, les forêts de mangroves d'Afrique de l'ouest et de l'est, ainsi que les îles adjacentes, fournissent des habitats diversifiés qui abritent des niveaux élevés de biodiversité d'espèces de poissons et d'invertébrés. La biodiversité terrestre est également menacée par l'exploitation minière, le braconnage, le commerce illégal d'espèces sauvages, la perte d'habitats, la végétation exotique et l'augmentation des populations humaines et des conflits relatifs à l'utilisation des terres qui en résultent, entre autres (EC, 2015).

Dans cette perspective, il est important de comprendre l'état des aires protégées et de conservation dans la région, afin de disposer d'une base de référence sur laquelle les progrès vers les objectifs de conservation auxquels les gouvernements se sont engagés pourront être mesurés.

Ce rapport couvre les pays d'Afrique orientale et australe suivants : Afrique du Sud, Angola, Botswana, Comores, Djibouti, Érythrée, Eswatini, Éthiopie, Kenya, Lesotho, Madagascar, Malawi, Maurice, Mozambique, Namibie, Ouganda, Rwanda, Seychelles, Somalie, Soudan du Sud, Soudan, Tanzanie, Zambie et Zimbabwe (voir la Figure 1.1).

\subsection{Objectifs}

En tant que première évaluation régionale complète des aires protégées et de conservation d'Afrique orientale et australe, ce rapport sur l'État des aires protégées et de conservation d'Afrique orientale et australe (SoPACA) vise à :

- fournir un aperçu de l'état des aires protégées et de conservation dans la région de l'Afrique orientale et australe, en incluant une référence particulière à la Gouvernance et à l'équité des aires protégées (GEAP) et à l'Efficacité de la gestion des aires protégées (EfGAP), ainsi qu'aux outils d'évaluation connexes ;

- utiliser les données disponibles pour donner un aperçu des progrès de la région concernant l'Objectif d'Aichi 11 de la Convention sur la diversité biologique (CDB), ainsi que d'autres objectifs mondiaux et régionaux pertinents ;

- analyser et souligner les questions relatives aux aires protégées et de conservation présentant un intérêt particulier pour la région à l'aide d'études de cas ;

- articuler et approfondir la compréhension des réussites et des principaux défis auxquels la région est confrontée en matière d'aires protégées et de conservation ;

- fournir les faits et chiffres requis par les gouvernements pour prendre des décisions éclairées, suivre les progrès et fournir des conseils pour la mise en œuvre de l'Objectif d'Aichi 11 et autres objectifs mondiaux et régionaux

- valoriser les systèmes régionaux de gestion des données, y compris le Centre régional de ressources soutenu par BIOPAMA ;

- promouvoir l'apprentissage des enseignements entre les pays et les régions d'Afrique orientale et australe ;

- explorer les questions liées au financement des aires protégées et de conservation, et comment celles-ci affectent la GEAP et l'EfGAP ; et

- fournir des recommandations clés pour les politiques et la pratique.

De nombreuses institutions et personnes sont susceptibles d'utiliser ce rapport, notamment les gouvernements de toute l'Afrique orientale et australe, ainsi que les gouvernements partenaires et donateurs, les organisations et associations communautaires, les Communautés économiques régionales, les entreprises privées, les organisations de soutien, les institutions universitaires et les chercheurs.

Le rapport présente un certain nombre d'utilisations possibles :

- fournir une base de référence permettant de suivre les progrès concernant les objectifs nationaux, régionaux et internationaux ;

- fournir des données pour des décisions mieux informées ;

- mettre en évidence les innovations et voies potentielles vers une gestion durable des aires protégées dans la région ;

- souligner les lacunes dans les connaissances et l'information, ainsi que les besoins et opportunités de recherche ;

- identifier les priorités d'actions plus poussées et futures ;

- influencer les politiques au moyen d'une approche fondée sur le savoir ; et

- fournir des informations détaillées pour de meilleures décisions des donateurs grâce à un résumé des principales priorités régionales. 
Figure 1.1 : Carte des pays inclus dans le présent rapport

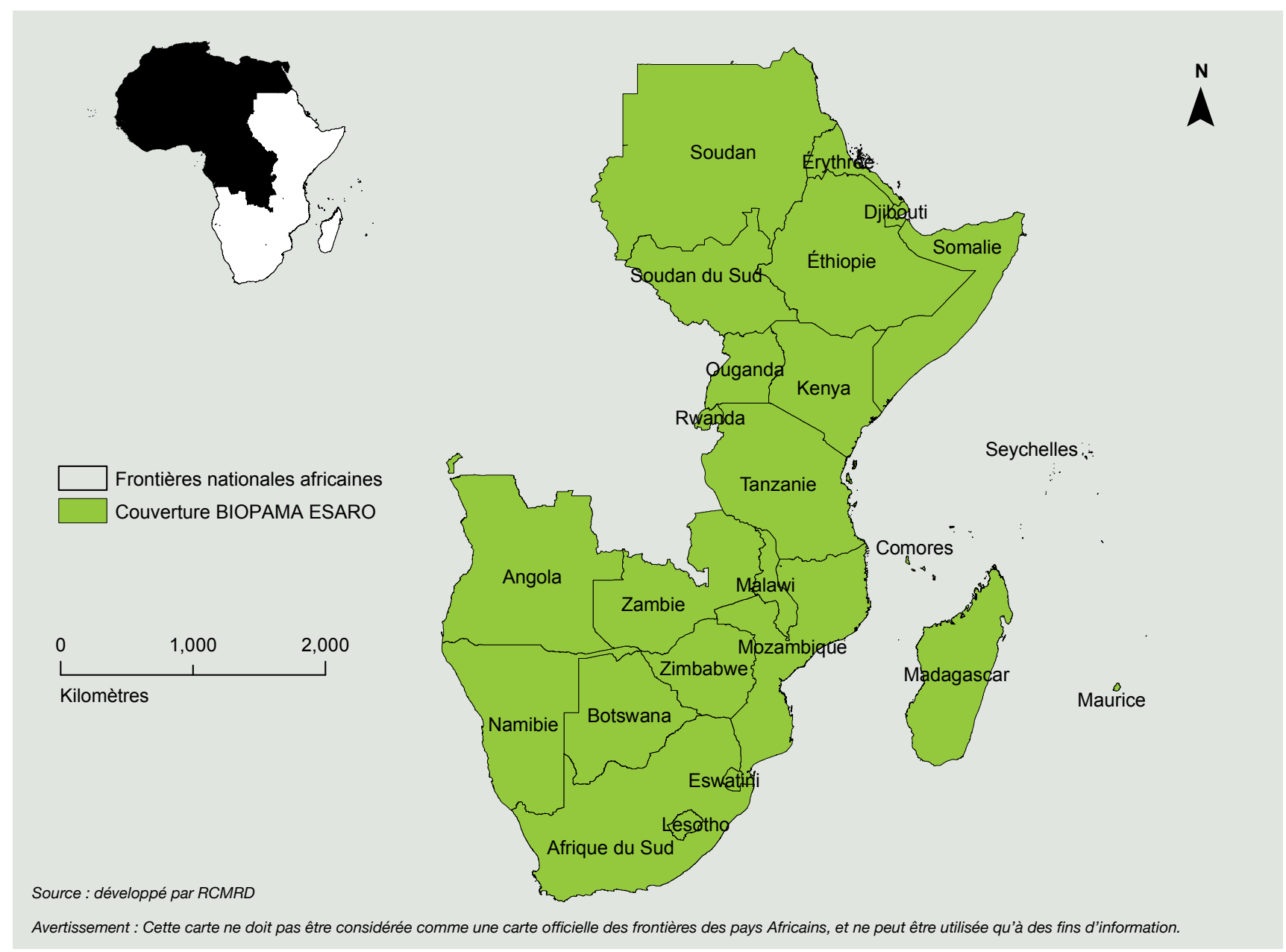

\subsection{Méthodologie}

Ce rapport a été élaboré en partenariat avec les gouvernements des pays, par l'intermédiaire de leurs points focaux BIOPAMA désignés (voir Annexe 1). Des ateliers de planification pour le rapport ont été organisés avec les points focaux nationaux BIOPAMA et autres organisations concernées à Nairobi (13-14 février 2019) et Johannesburg (26-27 février 2019).

Tout au long de l'élaboration de ce rapport, l'équipe a fait son possible pour prendre en compte les rapports nationaux et régionaux existants, y compris les Stratégies et plans d'action nationaux pour la biodiversité (SPANB) et les rapports nationaux à la CDB. Les points focaux nationaux BIOPAMA et autres experts nationaux, régionaux et mondiaux pertinents ont été contactés tout au long du processus de développement, afin d'analyser les données, les informations et les récits, et s'assurer que les informations les plus récentes et les plus précises étaient inclues dans le rapport.

\subsection{Structure}

Le rapport et les études de cas se concentreront sur les principaux thèmes affectant la gestion et la gouvernance des aires protégées et de conservation dans la région de l'Afrique orientale et australe.
La deuxième partie décrit le contexte régional, les données et les profils nationaux, le Chapitre 3 fournissant un contexte et détaillant les politiques et statistiques régionales, tandis que le Chapitre 4 se concentre sur un aperçu régional des aires protégées et le Chapitre 5 sur les services écosystémiques. Les Chapitres 6 (politiques régionales) et 7 (communautés économiques régionales) fournissent un contexte régional aux statistiques et informations nationales des 24 pays couverts par le présent rapport, telles que décrites au Chapitre 8.

La troisième partie aborde la gouvernance, l'efficacité de la gestion et l'innovation. Le Chapitre 9 traite spécifiquement de la gouvernance et de l'équité, et comprend des informations sur la gouvernance à l'échelle des systèmes et des sites, l'engagement des parties prenantes et les outils d'évaluation connexes, tandis que le Chapitre 10 se concentre sur l'efficacité de la gestion et les outils d'évaluation correspondants. Le Chapitre 11, quant à lui, donne un aperçu des innovations et expériences régionales, du financement des aires protégées, de l'utilisation de la technologie dans la gestion de la conservation et de la conservation transfrontalière.

La quatrième partie présente des recommandations politiques et pratiques fondées sur les conclusions du rapport.

La première partie présente le contexte et décrit le cadre conceptuel et international. 


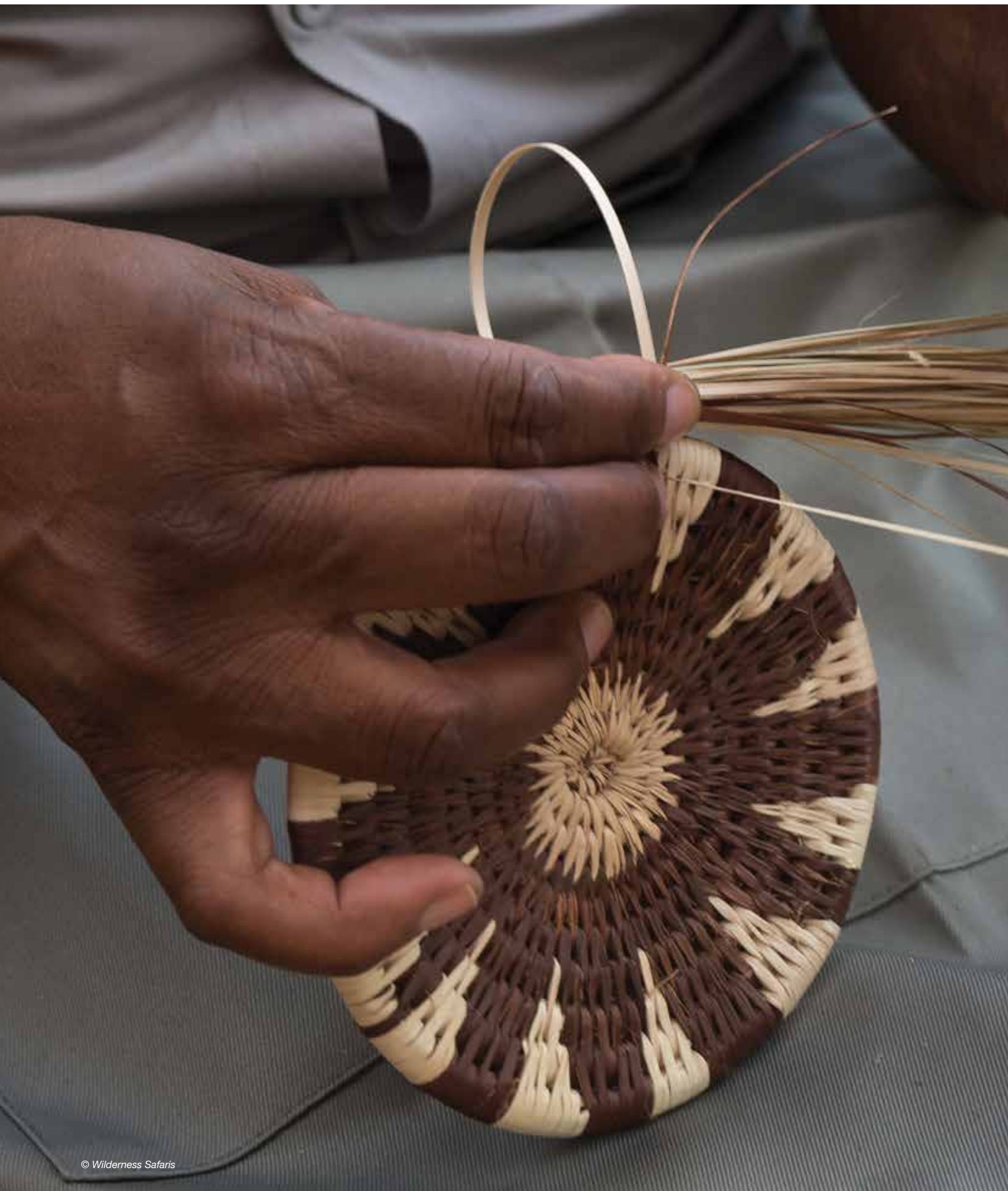




\section{Cadre conceptuel et international}




\subsection{Que sont les aires protégées et de conservation?}

Les aires protégées sont essentielles à la conservation de la biodiversité et sous-tendent la plupart des stratégies nationales et régionales de conservation. Outre leur rôle dans le maintien des écosystèmes naturels et la conservation des espèces, beaucoup abritent des caractéristiques majeures de l'histoire et des processus de la Terre, tandis que d'autres préservent l'interaction entre l'activité humaine et la nature dans des paysages d'utilisation durable. Des aires protégées plus grandes et plus naturelles offrent également un espace pour l'évolution, l'adaptation et la restauration écologiques futures, toutes deux de plus en plus importantes dans un contexte de changements climatiques rapides (UNEP-WCMC et al., 2018).

Les aires protégées sont vitales pour les cultures et les moyens de subsistance des peuples autochtones et des communautés locales, préservant les lieux de valeur culturelle et sacrée. Elles fournissent des opportunités de loisirs et de resourcement, de l'air et de l'eau propres et apportent des avantages à des millions de personnes grâce au tourisme (UNEP-WCMC et IUCN, 2016).

La définition communément admise d'une aire protégée, utilisée dans le présent rapport, est celle d'« un espace géographique clairement défini, reconnu, consacré et géré, par tout moyen efficace, juridique ou autre, pour assurer à long terme la conservation de la nature ainsi que les services écosystémiques et les valeurs culturelles qui lui sont associés 》 (Dudley, 2008, p. 8).

L'UICN a développé un ensemble de catégories de gestion des aires protégées, généralisé pour aider au développement et à la compréhension des systèmes d'aires protégées dans différents contextes nationaux et systèmes juridiques (Dudley, 2008). Chaque pays de la région possède sa propre gamme de types d'aires protégées, définis dans la législation et les politiques, tels que les parcs nationaux, réserves nationales et réserves forestières. Ces définitions varient d'un pays à l'autre. Cependant, elles peuvent généralement être reliées aux catégories de l'UICN, bien qu'il n'existe pas toujours de correspondance « exacte " et que, souvent, toutes les catégories ne soient pas représentées dans un pays ou une région en particulier. La gamme complète des catégories I à VI (voir Tableau 2.1) permet aux systèmes d'aires protégées d'inclure les sites où les activités humaines sont strictement limitées, ainsi que ceux où des activités durables sont autorisées.

Les différentes catégories de gestion des aires protégées de l'UICN et des exemples dans la région sont décrits dans le Tableau 2.1. En Afrique orientale et australe, un changement s'est opéré au fil du temps, d'un accent mis sur la Catégorie II (parcs nationaux) vers une utilisation plus large de tout l'éventail des catégories, bien qu'il n'existe encore qu'un nombre limité d'aires protégées de Catégorie la et lb. II est donc important de noter que deux ou plusieurs catégories peuvent se chevaucher.

Les catégories de gestion des aires protégées sont fréquemment utilisées à des fins allant bien au-delà de leurs intentions initiales. On peut citer, par exemple, la planification des aires protégées et des systèmes d'aires protégées, l'amélioration de la gestion de l'information sur les aires protégées, la réglementation des activités dans les aires protégées, la fourniture d'une base pour la législation, ou leur utilisation comme outil de plaidoyer. Les principales utilisations se sont développées de telle sorte que I'UICN en soutient et encourage certaines, tout en s'opposant à d'autres (Dudley, 2008, p. 5-6).

Toute catégorie d'aires protégées peut être gouvernée et gérée par des communautés, des gouvernements, des entités privées ou des partenariats entre ces acteurs. Traditionnellement, les aires protégées de la région ont été créées par les gouvernements, mais au cours des 40 à 50 dernières années, de nombreuses aires protégées et de conservation ont été créées par des communautés locales, des peuples autochtones, des organisations caritatives environnementales, des particuliers, des entreprises et autres. La conservation communautaire est désormais plus courante et dans

\section{Encadré 2.1 : Zones de conservation communales en Namibie}

En Namibie, la gestion communautaire des ressources naturelles (GCRN) permet aux communautés d'intégrer de nouvelles options d'utilisation des terres aux stratégies de subsistance existantes (par exemple, l'élevage), afin de contribuer à la conservation de la faune sauvage et à l'amélioration du bien-être des ménages ruraux (Long, 2002). II existe actuellement 86 zones de conservation communales, couvrant une superficie totale de $166045 \mathrm{~km}^{2}$ (environ 20,2\% du pays), et regroupant environ 227941 personnes (NACSO, s.d.). Le succès relatif de la GCRN en Namibie est en grande partie dû à un environnement politique et législatif favorable, qui transfère l'autorité directement au niveau communautaire. Cela contraste avec le programme Zimbabwéen de gestion des zones communales pour les ressources autochtones (CAMPFIRE, selon ses sigles en anglais), qui transfère l'autorité aux conseils de district déjà établis et non directement au niveau communautaire. Cette approche a été couronnée de succès dans les années 1990 au Zimbabwe, principalement grâce au soutien substantiel des donateurs, mais a ensuite disparu en raison de la situation politique et économique du pays (Snyman, 2012).

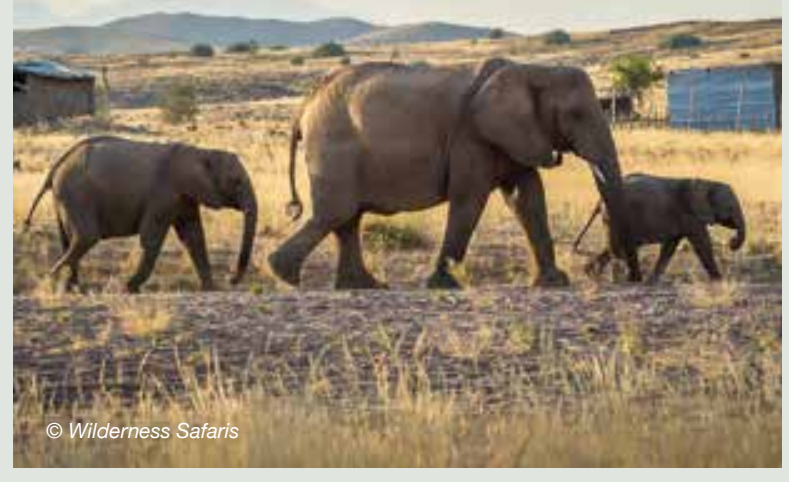


Tableau 2.1 : Catégories de gestion des aires protégées de l'UICN

\begin{tabular}{|c|c|c|}
\hline Catégorie & Définition & Exemples \\
\hline $\begin{array}{l}\text { la - Réserve } \\
\text { naturelle intégrale }\end{array}$ & $\begin{array}{l}\text { Aires strictement protégées mises en réserve pour protéger } \\
\text { la biodiversité ainsi qu'éventuellement, des caractéristiques } \\
\text { géologiques / géomorphologiques, où les visites, } \\
\text { l'utilisation et les impacts humains sont strictement } \\
\text { contrôlés et limités pour garantir la protection des valeurs } \\
\text { de conservation. II n'existe que peu d'exemples de cette } \\
\text { catégorie dans la région, bien que certains parcs nationaux } \\
\text { renferment certaines zones d'accès limité, plutôt que } \\
\text { d'être entièrement classés dans la catégorie la. }\end{array}$ & $\begin{array}{l}\text { Tsingy de Bermaraha, Tsaratanana et Betampona } \\
\text { (Madagascar) } \\
\text { Atoll d'Aldabra, Cousin, La Digue et Aride } \\
\text { (Seychelles) }\end{array}$ \\
\hline $\begin{array}{l}\text { Ib - Zone de } \\
\text { nature sauvage }\end{array}$ & $\begin{array}{l}\text { Aires protégées généralement vastes et intactes ou } \\
\text { légèrement modifiées, qui ont conservé leur caractère et } \\
\text { leur influence naturels, sans habitations humaines } \\
\text { permanentes ou significatives, et protégées et gérées aux } \\
\text { fins de préserver leur état naturel. }\end{array}$ & $\begin{array}{l}\text { Réserves de faune de Moremi, Khutse et Kalahari } \\
\text { Central (Botswana) } \\
\text { Réserves forestières de Koko Hill, Mamboya et } \\
\text { lkwamba (Tanzanie) }\end{array}$ \\
\hline II - Parc national & $\begin{array}{l}\text { Vastes aires naturelles ou quasi naturelles mises en réserve } \\
\text { pour protéger des processus écologiques à grande échelle, } \\
\text { ainsi que les espèces et caractéristiques des écosystèmes } \\
\text { de la région. Elles fournissent aussi une base pour des } \\
\text { opportunités de visites de nature spirituelle, scientifique, } \\
\text { éducative et récréative, dans le respect de l'environnement } \\
\text { et de la culture des communautés locales. II s'agit de la } \\
\text { catégorie de gestion la plus courante dans la région. }\end{array}$ & $\begin{array}{l}\text { Parc marin de Mohéli (Comores) } \\
\text { Amboseli et Masai Mara (Réserve nationale) } \\
\text { (Kenya) } \\
\text { Niassa (Réserve nationale) (Mozambique) } \\
\text { Parc des Volcans (Rwanda) } \\
\text { Kruger (Afrique du Sud) } \\
\text { Serengeti (Tanzanie) } \\
\text { Bwindi Impenetrable (Ouganda) } \\
\text { Kafue (Zambie) }\end{array}$ \\
\hline $\begin{array}{l}\text { III - Monument ou } \\
\text { élément naturel }\end{array}$ & $\begin{array}{l}\text { Zone mise en réserve pour protéger un monument naturel } \\
\text { spécifique, qui peut être un élément topographique, une } \\
\text { montagne ou une caverne sous-marine, une caractéristique } \\
\text { géologique telle qu'une grotte ou même un élément vivant } \\
\text { comme un îlot boisé ancien. }\end{array}$ & $\begin{array}{l}\text { Parc national des chutes Victoria (Zimbabwe) } \\
\text { Réserves de gibier de Popa et Gross barmen Hot } \\
\text { Springs (Namibie) } \\
\text { Toro-Semliki, Karuma, Bugungu et un certain } \\
\text { nombre d'autres réserves de faune (Ouganda) }\end{array}$ \\
\hline $\begin{array}{l}\text { IV - Aire de } \\
\text { gestion des } \\
\text { habitats ou des } \\
\text { espèces }\end{array}$ & $\begin{array}{l}\text { Visent à protéger des espèces ou des habitats particuliers, } \\
\text { et leur gestion reflète cette priorité. }\end{array}$ & $\begin{array}{l}\text { Réserve partielle du Namib (Angola) } \\
\text { Sanctuaire de faune de Maun (Botswana) } \\
\text { Réserve de faune de Gash-Setit (Érythrée) } \\
\text { Réserves de faune d'Alledeghi et de Bale (Éthiopie) } \\
\text { Parc national de Sehlabathebe (Lesotho) } \\
\text { Réserves de faune de Majete et de Nkhotakota } \\
\text { (Malawi) } \\
\text { Réserves de pêche Poudre d'or et Trou d'eau } \\
\text { douce (Maurice) } \\
\text { Réserve de chasse de Sabaloka (Soudan) }\end{array}$ \\
\hline $\begin{array}{l}\text { V - Paysage } \\
\text { terrestre ou marin } \\
\text { protégé }\end{array}$ & $\begin{array}{l}\text { Site où l'interaction des hommes et de la nature a produit, } \\
\text { au fil du temps, une aire qui possède un caractère distinct, } \\
\text { avec des valeurs écologiques, biologiques, culturelles et } \\
\text { panoramiques considérables, et où la sauvegarde de } \\
\text { l'intégrité de cette interaction est vitale pour protéger et } \\
\text { maintenir l'aire, la conservation de la nature associée ainsi } \\
\text { que d'autres valeurs. }\end{array}$ & $\begin{array}{l}\text { Îles Musha et Maskhali (Djibouti) } \\
\text { Réserve naturelle de Libhetse (Eswatini) } \\
\text { De nombreuses aires de Madagascar } \\
\text { Réserve forestière d'Imatong (Soudan Du Sud) }\end{array}$ \\
\hline $\begin{array}{l}\text { VI - Aire protégée } \\
\text { avec utilisation } \\
\text { durable des } \\
\text { ressources } \\
\text { naturelles }\end{array}$ & $\begin{array}{l}\text { Sites qui préservent des écosystèmes et des habitats, ainsi } \\
\text { que les valeurs culturelles et systèmes de gestion des } \\
\text { ressources naturelles traditionnelles qui y sont associés. lls } \\
\text { sont généralement vastes, et la plus grande partie de leur } \\
\text { superficie présente des conditions naturelles, une certaine } \\
\text { proportion y est soumise à une gestion durable des } \\
\text { ressources naturelles et une utilisation modérée des } \\
\text { ressources naturelles, non industrielle et compatible avec } \\
\text { la conservation de la nature, y est considérée comme l'un } \\
\text { des objectifs principaux de l'aire. }\end{array}$ & $\begin{array}{l}\text { Vallée de Dabus, Jikao, Tedo, Ouest Omo et de } \\
\text { nombreuses autres aires de chasse contrôlée } \\
\text { (Éthiopie) } \\
\text { Réserves naturelles de Beacon, Booby Island, } \\
\text { Étoile et Mamelles (Seychelles) } \\
\text { Aires de safari de Matetsi, Sapi et Hurungwe } \\
\text { (Zimbabwe) }\end{array}$ \\
\hline
\end{tabular}


certains pays, comme la Namibie et le Kenya, la législation accorde aux communautés le droit de gérer et de profiter directement des bénéfices de ces sites de conservation (voir Encadré 2.1). Dotée de nombreux parcs nationaux et réserves emblématiques (tels que le Masai Mara, le Serengeti, le Kruger et les Volcans), la région dispose d'atouts majeurs pour le tourisme animalier, générant d'importants revenus pour les gouvernements nationaux et infranationaux. Alors qu'en Afrique du Sud et en Namibie, les aires de conservation privées constituent une proportion importante du réseau d'aires protégées, dans d'autres pays de la région, la propriété privée des terres de conservation n'est pas légiférée et l'ensemble de la faune sauvage appartient à l'État. Certaines questions, telles que le financement des activités de gestion des aires protégées, ont conduit à des approches novatrices, certains gouvernements confiant la gestion à des ONG. Les partenariats public-privé, en particulier dans le domaine du tourisme animalier, sont de plus en plus fréquents dans de nombreux pays.

\subsection{Convention sur la diversité biologique}

Le Plan stratégique pour la biodiversité 2011-2020 a été adopté par la Conférence des Parties à la CDB lors de sa 10 e réunion à Nagoya, au Japon (CDB, 2010A). Le plan décrit une approche stratégique globale pour la mise en œuvre de la CDB, et comprend une vision et une mission, ainsi que des buts et des objectifs stratégiques, connus sous le nom d'Objectifs d'Aichi pour la biodiversité. Les cinq buts stratégiques ( $\mathrm{A}$ à $\mathrm{E}$ ) sont étayés par 20 objectifs. Tous les pays de la région sont signataires de la CDB et, par conséquent, sont tenus de rendre compte à la $\mathrm{CDB}$ des progrès accomplis dans la réalisation de ces objectifs.

BIOPAMA se concentre sur l'Objectif d'Aichi 11, dans le cadre du But stratégique $\mathrm{C}$, qui appelle les Parties à atteindre :

- d'ici à 2020 , au moins $17 \%$ des zones terrestres et d'eaux intérieures et $10 \%$ des zones marines et côtières, y compris les zones particulièrement importantes pour la diversité biologique et les services fournis par les écosystèmes, conservées au moyen de réseaux écologiquement représentatifs et bien reliés d'aires protégées gérées efficacement et équitablement et autres mesures de conservation efficaces par zone, et intégrées dans l'ensemble du paysage terrestre et marin (CBD 2011).

\subsection{Autres mesures de conservation efficaces par zone (AMCE)}

Bien que les AMCE soient inclues dans l'Objectif d'Aichi 11 depuis 2011, le terme n'a été correctement clarifié qu'en 2018, lorsque la CDB a défini les AMCE comme :

[ ... ] une zone géographiquement délimitée, autre qu'une aire protégée, qui est réglementée et gérée de façon à obtenir des résultats positifs et durables à long terme pour la conservation in situ de la biodiversité ${ }^{3}$ y compris des fonctions et services écosystémiques connexes et, le cas échéant, des valeurs culturelles, spirituelles, socioéconomiques et autres valeurs pertinentes à l'échelle locale (CDB, 2018, p. 1).
Pour être considéré comme AMCE, un site doit présenter des résultats positifs en matière de biodiversité, quels que soient ses principaux objectifs de gestion, et doit pouvoir démontrer des actions de gestion liées à la conservation de la biodiversité (Groupe de travail sur les autres mesures de conservation efficaces par zone de la CMAP-UICN, 2020). Cela contraste avec une aire protégée, où l'objectif principal doit être la conservation. Dans le cadre de l'initiative Planète protégée, I'UNEP-WCMC gère désormais la Base de données mondiale sur les autres mesures efficaces de conservation par zone (BD-AMCE) (UNEP-WCMC, 2019a). La BD-AMCE peut être combinée avec la Base de données mondiale des aires protégées (BDMAP) afin de fournir une image plus complète du réseau mondial de conservation.

II est probable que les AMCE renforcent considérablement le patrimoine de conservation reconnu de nombreux pays (Donald et al., 2019), y compris en Afrique, où un certain nombre d'aires de conservation ne relèvent pas des définitions traditionnelles des catégories, comme les bases militaires ou les aires de conservation communautaires utilisées principalement pour l'élevage. Très peu de pays ont entamé le processus d'évaluation de leurs AMCE potentielles. En réponse, le Groupe de travail de la Commission mondiale des aires protégées (CMAP) de I'UICN sur les AMCE a rédigé un Rapport technique pour la reconnaissance et la notification des AMCE (Groupe de travail sur les autres mesures de conservation efficaces par zone de la CMAP-UICN, 2020). Le cadre d'évaluation des AMCE en Afrique, par exemple, a été développé par Candice Stevens et Daniel Marnewick en Afrique du Sud (voir Encadré 2.2).

\subsection{Liste verte de l'UICN des aires protégées et de conservation}

La norme de la Liste verte de l'UICN des aires protégées et de conservation (norme de la Liste verte de l'UICN) est une nouvelle norme internationale de durabilité servant de référence pour des aires protégées et de conservation à la fois efficaces et équitables. Officiellement approuvée par le Conseil de l'UICN à la fin de 2017, elle a été recommandée pour mise en œuvre ultérieure par les Membres de I'UICN dans le monde entier (Hockings et al., 2019; IUCN et WCPA, 2017).

La norme de la Liste verte de I'UICN décrit un ensemble de dixsept critères applicables à l'échelle mondiale, classés en quatre composantes et accompagnés de 50 indicateurs, pour une conservation réussie à l'échelle des sites, dans les aires protégées et de conservation. Les sites adhèrent volontairement à la Liste verte de I'UICN en s'engageant à respecter cette norme, et sont certifiés une fois la conformité à la norme démontrée. La norme de la Liste verte de I'UICN aborde quatre composantes: une bonne gouvernance, une conception et une planification robustes, une gestion efficace et des résultats positifs en matière de conservation (voir la Tableau 2.2) (IUCN et WCPA, 2017).

La norme de la Liste verte de l'UICN est conçue pour être à la fois cohérente au niveau mondial et pertinente à l'échelle locale, exigences qui décrivent collectivement les efforts nécessaires pour atteindre pleinement la norme. Un site de la Liste verte est un site actuellement évalué comme répondant à tous les critères, dans les quatre composantes. La norme est adaptée à chaque pays ou

"Tel que défini à l'Article 2 de la Convention sur la diversité biologique et conformément aux dispositions de la Convention" (CDB, 2018, p. 1). 


\section{Encadré 2.2: Autres mesures de conservation efficaces par zone (AMCE) en Afrique}

Bien que l'identification des AMCE n'ait commencé à prendre de l'ampleur que vers la fin de la stratégie 2011-2020 de la CDB, il a été suggéré que les AMCE contribueront de manière significative à l'Objectif 11 actuel, à son successeur, ainsi qu'à l'ODD 15, et qu'elles constitueront un cadre important pour la conservation des zones situées en dehors des aires protégées formelles. Cela aidera les pays africains à sauvegarder et à tirer profit de la biodiversité de ces sites.

Les AMCE fourniront une base pour l'engagement et le renforcement d'un large éventail de parties prenantes de la conservation par zone, y compris le secteur agricole, les entreprises, les communautés locales et les peuples autochtones, qui contribuent à la conservation par zones en dehors du domaine officiel des aires protégées. Cela est particulièrement vrai pour l'Afrique, où la plupart des zones naturelles appartiennent à des propriétaires fonciers communaux ou à des ayant-droits. De plus, les AMCE constituent une plateforme idéale pour inclure et développer des activités économiques plus diversifiées et pour le financement de la biodiversité, en particulier autour de l'économie de la faune sauvage.

Le Groupe de travail de la Commission mondiale des aires protégées (CMAP) de I'UICN sur les AMCE a rédigé un Rapport technique pour la reconnaissance et le signalement des AMCE (Groupe de travail sur les autres mesures de conservation efficaces par zone de la CMAP-UICN, 2020). Une ébauche d'Outil d'évaluation des AMCE et une ébauche de méthodologie d'identification et d'évaluation des AMCE à l'échelle nationale sont en cours d'élaboration, en complément du Rapport technique, afin d'aider à l'identification des AMCE.

Daniel Marnewick et Candice Stevens ont développé et testé la méthodologie d'évaluation nationale sud-africaine, en partenariat avec le Groupe de travail de I'UICN sur les AMCE et divers acteurs gouvernementaux et non-gouvernementaux. Les résultats de l'Étude de cas sur les AMCE dans la région de la Réserve de biosphère de Kruger à Canyons, en Afrique du Sud, indiquent un certain nombre d'opportunités pour fusionner les AMCE et le cadre de gestion de la biodiversité existant, d'identifier des opportunités de renforcer d'autres cadres nationaux et de créer des synergies avec l'économie de la faune sauvage pour renforcer les cadres de gouvernance et de gestion associés, ainsi que les résultats de conservation de la biodiversité (Jonas et Sandwith, 2019). En utilisant la méthodologie d'évaluation des AMCE en Afrique du Sud, Daniel et Candice ont aidé le Groupe de travail de I'UICN sur les AMCE à élaborer un projet de méthodologie mondiale d'évaluation des AMCE.

Les AMCE fourniront un cadre pour soutenir et développer des opportunités économiques légitimes, diversifiées et durables, ainsi qu'un financement de la biodiversité qui s'intègre aux économies rurales, tout en produisant des résultats de conservation de la biodiversité in situ, en particulier autour de l'économie de la faune sauvage.

Contribution de Daniel Marnewick, Président de la communauté $K B A$ et représentant de l'Afrique au sein de la communauté $K B A$, et Point focal régional KBA pour l'Afrique.

\section{Tableau 2.2 : Norme de la Liste verte de I'UICN - composantes et critères}

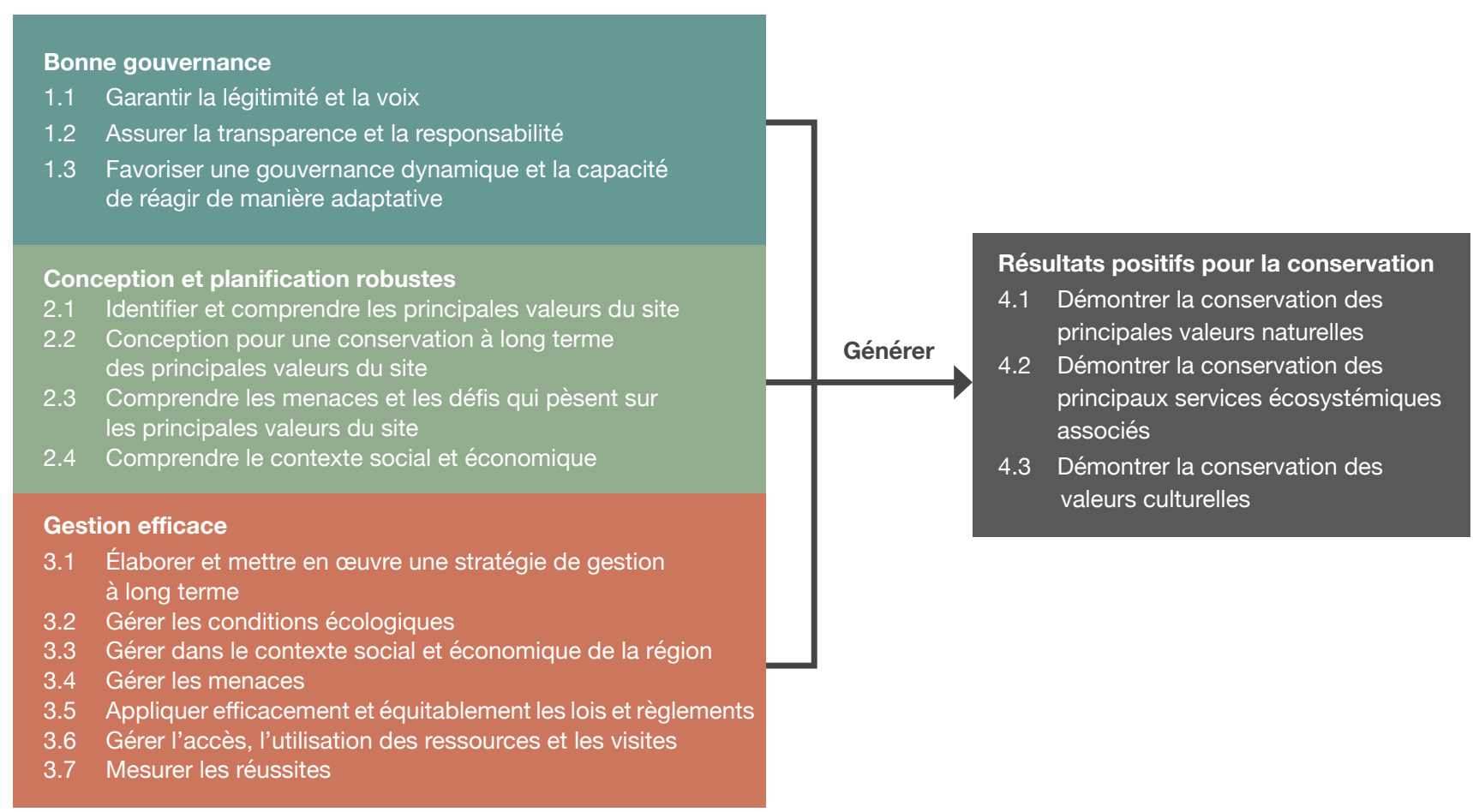




\section{Encadré 2.3 : Zones clés pour la biodiversité (KBA) en Afrique}

À ce jour, six pays d'Afrique ont établis des Groupes nationaux de coordination KBA, dont cinq ont terminé ou sont en train d'identifier les KBA. Onze autres pays souhaitent lancer le processus. Dans de nombreux pays africains, les KBA constitueront la seule cartographie spatiale permettant de guider l'établissement de priorités en matière de biodiversité, il est donc impératif de continuer à identifier les KBA en Afrique.

L'identification des KBA et leur reconnaissance dans les politiques nationales est importante pour la planification nationale de la conservation et du développement. Tout d'abord, les pays peuvent mieux cibler leurs investissements en matière de conservation, par exemple pour l'expansion des aires protégées et de conservation. Ensuite, la planification du développement peut permettre de prévenir les impacts négatifs sur les sites d'importance mondiale de la région. Et finalement, une telle carte aidera les entreprises à éviter des coûts élevés de planification de développements dans des zones biologiquement sensibles, ainsi que les conflits avec les intérêts de conservation qui en découlent.

Des directives globales détaillées sont à disposition des pays pour identifier les KBA. Celles-ci incluent notamment la Norme mondiale pour l'identification des Zones clés pour la biodiversité (UICN, 2016a), les Lignes directrices pour l'utilisation d'une norme mondiale pour l'identification des Zones clés pour la biodiversité (KBA Standards and Appeals Committee, 2019) et le Processus de proposition des Zones clés pour la biodiversité : conseils pour la proposition, l'évaluation, la nomination et la confirmation des sites (KBA Secretariat, 2019).

Contribution de Daniel Marnewick (Président de la communauté $K B A$ et représentant de l'Afrique au sein de la communauté $K B A$, et Point focal régional KBA pour l'Afrique).

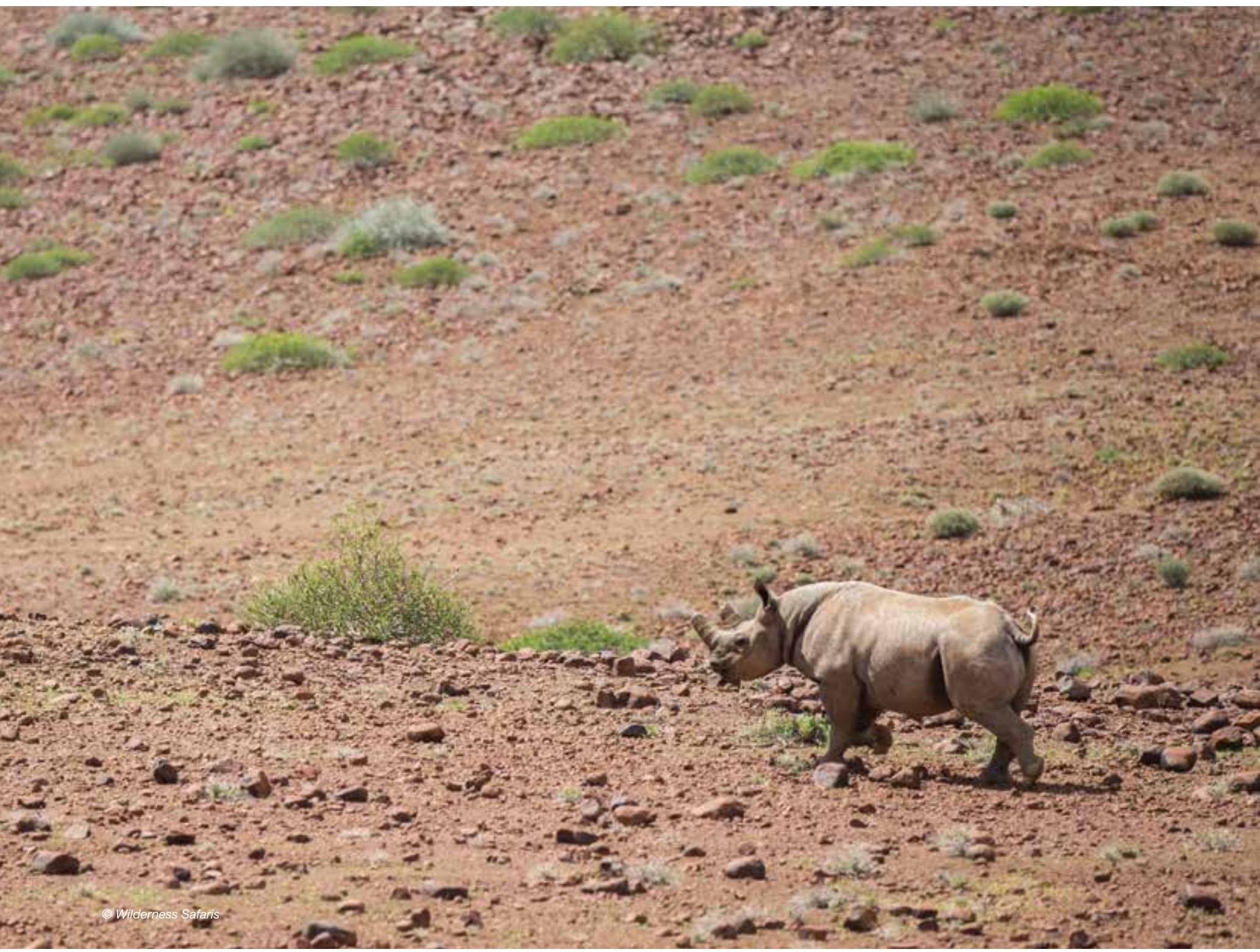


région dans lequel elle est adoptée. Pour chaque critère de la norme, un ensemble d'indicateurs génériques et les moyens de vérification associés sont fournis par I'UICN. Ces indicateurs génériques peuvent être adaptés au contexte de chaque juridiction participante afin de refléter les caractéristiques et les circonstances régionales et locales dans lesquelles les aires protégées et de conservation opèrent.

\subsection{Désignations internationales pour les aires protégées et de conservation}

Des politiques nationales et régionales et des conventions internationales ont été mises en œuvre pour promouvoir l'expansion du réseau mondial d'aires protégées, conduisant à une diversification des stratégies, des types et des désignations d'aires protégées. En conséquence, de nombreux sites sont protégés par plus d'une convention, instrument juridique, ou autres moyens efficaces. Ce chevauchement peut être bénéfique si la structure juridique signifie qu'une protection supplémentaire est conférée par chaque désignation, mais peut également entraîner un manque de clarté quant aux régimes de gouvernance et de gestion de certains sites (Deguignet et al., 2017). Les désignations mondiales confirment non seulement l'importance de ces sites à l'échelle mondiale, mais soutiennent également leur protection, gestion, promotion et utilisation durable, par exemple en attirant des ressources touristiques, financières et techniques supplémentaires, ainsi qu'un soutien politique et public. Certains de ces sites désignés au niveau mondial sont également des sites

\section{Encadré 2.4 : Centre régional de ressources (CRR) de BIOPAMA}

Le CRR est l'observatoire régional du programme BIOPAMA pour l'Afrique orientale et australe. II s'agit d'une plateforme unique pour faciliter l'échange de données / informations entre décideurs et gestionnaires d'aires protégées et de conservation dans la région.

La vision du CRR est d'être un centre de ressources de premier plan qui soutient une prise de décision et une gouvernance (à échelle locale, nationale et régionale) efficaces des aires protégées et de la biodiversité, ainsi que de leur lien avec les objectifs de développement durable.

Le CRR est au cœur des travaux de BIOPAMA et soutiendra la collecte et l'analyse de données, ainsi que le suivi et l'établissement de rapports, en développant les capacités du personnel et des organisations à gérer les données et à fournir des directrices politiques pour une meilleure prise de décision en matière de conservation de la biodiversité. Les produits en cours d'élaboration par le CRR incluent des récits, des cartes, des infographies, des profils nationaux et régionaux, des rapports, des lignes directrices, des outils, des informations et des événements, des exemples de réussite et des données résumées à partir d'ensembles mondiaux de données.

Le Système régional d'information de référence $(S R I R)^{\star}$, qui regroupe science et connaissances, facilitant ainsi l'accès régional, national et local à celles-ci, constitue un élément important du Centre régional de ressources. Le SRIR soutient l'élaboration de politiques sur les thèmes interdépendants de biodiversité, conservation et développement à travers les outils suivants :

1. Outil de suivi - suivi d'indicateurs relatifs aux politiques et aux objectifs et de conservation.

2. Outils analytiques - y compris l'outil web MARXAN ${ }^{4}$ et des données d'observation de la Terre.

3. Module sur la gouvernance et l'équité des aires protégées - en lien avec divers outils d'évaluation sociale, de la gouvernance et de l'équité.

4. Module sur l'efficacité de la gestion des aires protégées regroupe les outils et types d'évaluations, ainsi que des liens vers l'Outil d'efficacité de la gestion intégrée, BDEGAP.

5. Tableau de bord des aires protégées - regroupe les informations de base sur les aires protégées et la biodiversité.

L'objectif du SRIR est de créer un système de gestion de contenu basé sur une communauté d'utilisateurs, qui soit pertinent pour les politiques et soutienne la prise de décision. Axé sur les aires protégées et de conservation, le SRIR intégrera les informations provenant de différents fournisseurs de données, tout en fournissant des liens entre les ensembles mondiaux de données (tels que la BDMAP, I'ONAP et la BDEGAP) et les ensembles de données régionaux et nationaux. La Figure 2.1 montre le flux de données à travers ces différents canaux. Le SRIR et le Centre régional de ressources permettront aux parties prenantes de la région d'accéder aux données de conservation pertinentes à l'échelle nationale et régionale.

En résumé, le $C R R$ :

- fonctionne comme une plateforme pour faciliter l'échange de données / informations entre décideurs et gestionnaires d'aires protégées et soutient les priorités régionales dans les produits d'aide à la décision ;

- constitue un référentiel / centre de données et d'analyses pour soutenir l'élaboration de rapports, le suivi et la prise de décision, de manière spécifique à la région ;

- fournit des outils analytiques, des produits et autres services à la région ;

- favorise la mise en réseau d'experts et les liens avec des partenaires clés travaillant sur des questions pertinentes ;

- fournit des informations sur les opportunités de formation et de financement et identifie les priorités d'action pour le financement.

* Pour de plus amples informations, veuillez consulter : http://biopama-rris.rcmrd.org/ https://esahub.rcmrd.org/

4 Marxan est un logiciel de planification de la conservation en libre accès. II fournit un soutien décisionnel pour toute une gamme de problèmes de planification de la conservation, y compris la conception de nouveaux systèmes de réserves, la production de rapports sur le rendement des systèmes de réserves existants et l'élaboration de plans de zonage à usages multiples pour la gestion des ressources naturelles. 
transfrontaliers, partagés par deux pays ou plus (voir la Section 4.5). Les trois désignations mondiales pour de tels sites sont les Réserves de biosphère et les sites du Patrimoine mondial de I'UNESCO, ainsi que les sites Ramsar (zones humides d'importance internationale) (UNESCO, 1971; 1972; 2019a; 2019b). Chacune définit des critères clairs pour la désignation des sites.

\subsection{Autres domaines prioritaires pour la conservation}

Outre les sites désignés à l'échelle mondiale, un certain nombre d'autres classifications de zones prioritaires pour la conservation ont été identifiées sous l'égide des Zones clés pour la biodiversité (KBA, selon leurs sigles en anglais) (voir également l'Encadré 2.3). Ces sites contribuent de manière significative à la persistance mondiale de la biodiversité et sont identifiés à l'aide d'un ensemble standard de critères applicables aux plantes, aux animaux et aux écosystèmes des milieux terrestres, d'eaux intérieures et marins (UICN, 2016a). Les classifications ci-dessous sont tous des sousensembles de KBA (Stattersfieldet al., 1998).

- Sites de l'Alliance pour une extinction zéro (AZE, selon leurs sigles en anglais) : programme lancé à l'échelle mondiale en 2005, l'AZE a été créée pour identifier, conserver et sauvegarder efficacement les sites les plus importants pour prévenir les extinctions mondiales d'espèces (AZE Secretariat, 2019).

- Zones d'oiseaux endémiques (EBA, selon leurs sigles en anglais): zones englobant la superposition des aires de reproduction d'espèces à distribution restreinte, de sorte que les aires de répartition complètes de deux ou plusieurs espèces à distribution restreinte soient entièrement inclues dans les limites d'une EBA (BirdLife International, 2019a).

- Zones importantes pour les oiseaux et la biodiversité (IBA, selon leurs sigles en anglais) : KBA identifiées pour les oiseaux en utilisant des critères internationalement convenus appliqués localement par les partenaires et experts de BirdLife (UICN 2016a).

\subsection{Suivi des aires protégées et de conservation : vue d'ensemble}

La base de données mondiale des aires protégées (BDMAP) est un produit conjoint du Programme des Nations Unies pour l'environnement et de l'UICN, et est gérée par l'UNEP-WCMC dans le cadre de l'initiative Planète protégée. Les données de cette initiative sont compilées et gérées en collaboration avec les gouvernements, des organisations non gouvernementales, des acteurs communautaires et privés, des universités et autres parties prenantes du secteur industriel. La BDMAP et la BD-AMCE sont mises à jour de façon mensuelle et disponibles en ligne sur le site web Protected Planet, où les données sont à la fois consultables et téléchargeables. Un rapport semestriel Protected Planet est également publié, désormais sous la forme d'un rapport numérique Protected Planet actualisé en temps réel ${ }^{5}$.

Les données de l'initiative Protected Planet sont utilisées dans les rapports à la $\mathrm{CDB}$ sur les progrès accomplis dans la réalisation des
Objectifs d'Aichi pour la biodiversité (en particulier l'Objectif 11) et aux Nations Unies (ONU) pour suivre les progrès vers les Objectifs de développement durable à l'horizon 2030, certains indicateurs de la Plateforme intergouvernementale scientifique et politique sur la biodiversité et les services écosystémiques (IPBES) ainsi que d'autres évaluations et rapports internationaux.

L'initiative Protected Planet repose sur des mises à jour régulières des informations provenant de fournisseurs de données. Les sites désignés comme aires protégées doivent être conformes à la définition de l'UICN (voir la Section 2.1). Chaque aire protégée doit être entrée dans la base de données sous un format SIG, par exemple au moyen d'un fichier de formes (points ou polygone). Celui-ci doit inclure une série d'attributs descriptifs associés, tels que la désignation, la catégorie de gestion de l'UICN et le type de gouvernance de I'UICN. Les normes relatives aux données de Protected Planet sont expliquées en détail dans la section 3 du manuel de l'utilisateur (UNEP-WCMC et IUCN, 2019a).

La $\mathrm{BD}-\mathrm{AMCE}^{6}$ présente une structure similaire à la BDMAP, et ces deux bases de données sont entièrement interopérables. Pour de plus amples conseils sur la façon de soumettre des données à la BD-AMCE, voir la section 2 du manuel de l'utilisateur (UNEPWCMC et IUCN, 2019a).

La base de données mondiale sur l'efficacité de la gestion des aires protégées (BD-EGAP) relève également de l'initiative Protected Planet. II s'agit de la base de données mondiale la plus complète sur les évaluations de l'efficacité de la gestion des aires protégées, et elle est liée à la BDMAP. La BD-EGAP est une base de données consultable comprenant des données sur les évaluations EfGAP soumises par un large éventail d'organisations gouvernementales et non-gouvernementales à I'UNEP-WCMC, et est mise à jour de façon mensuelle. En 2019, la base de données comprenait plus de 28000 évaluations de 169 pays utilisant 69 méthodologies différentes. II existe cependant très peu de liens avec les évaluations réelles ou les rapports connexes. Les avantages pour les pays de soumettre leurs informations d'évaluation EfGAP à la base de données incluent :

1. rassembler les données nationales en un seul endroit ;

2. informer les pratiques de gestion adaptative ;

3. prioriser l'allocation des ressources ; et

4. établir des rapports en relation avec les objectifs de conservation.

L'Observatoire numérique des aires protégées (ONAP) est géré par le Centre commun de recherche de la Commission européenne (CCR). II s'agit d'un ensemble de services et d'applications web pouvant être utilisés principalement pour évaluer, réaliser un suivi, établir des rapports et éventuellement prévoir l'état des aires protégées et les pressions exercées sur celles-ci à plusieurs échelles. Les données, indicateurs, cartes et outils fournis par I'ONAP sont pertinents pour les utilisateurs finaux, y compris les décideurs, les agences de financement, les agences et gestionnaires d'aires protégées, les chercheurs et la CDB. Les informations peuvent être utilisées, par exemple, pour soutenir la 


\section{Figure 2.1 : Systèmes mondiaux et régionaux de gestion de données pour les aires protégées}

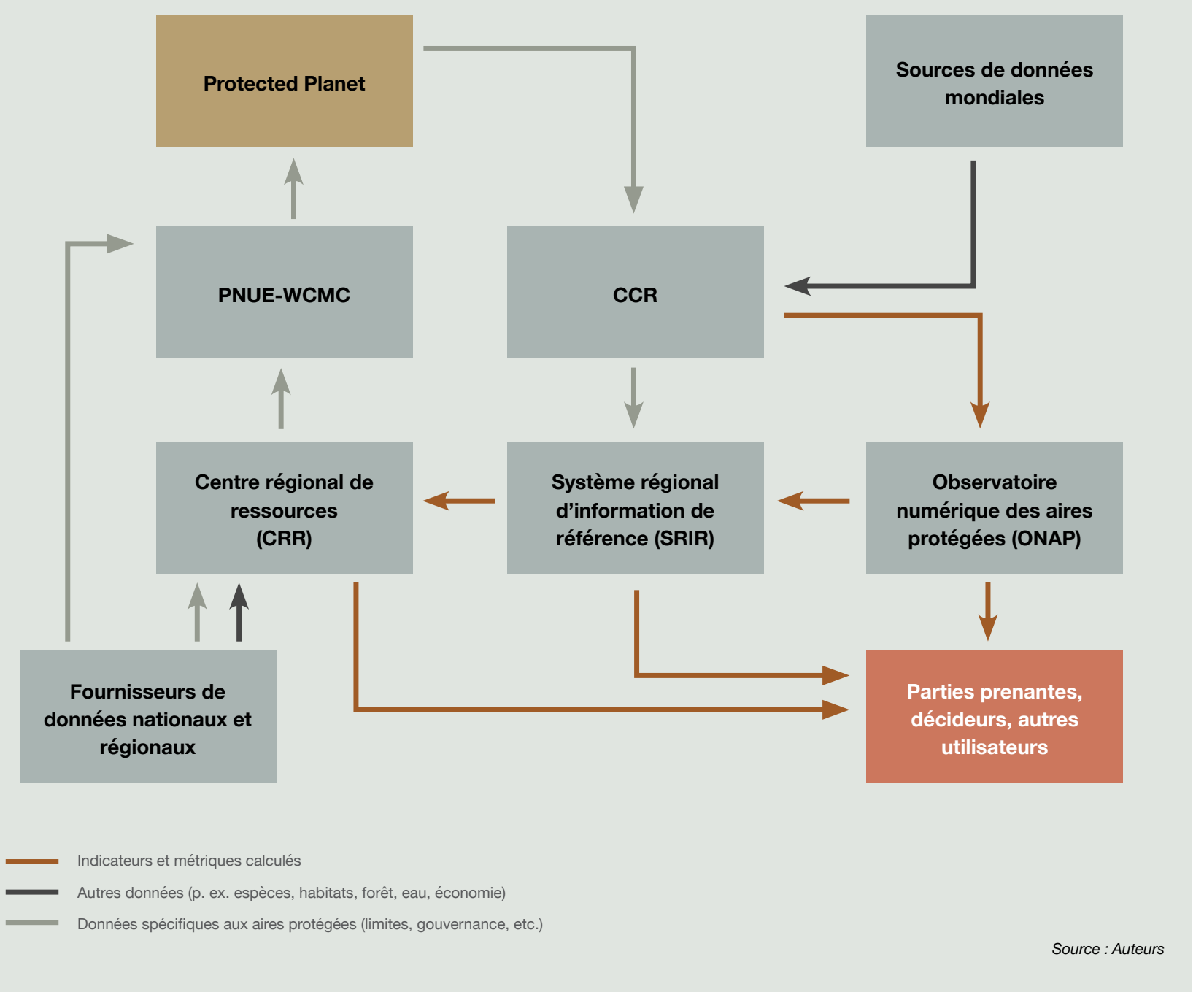

planification spatiale, l'allocation de ressources, le développement et la gestion des aires protégées, ainsi que dans les rapports nationaux et internationaux. À partir d'ensembles mondiaux de données de référence, l'ONAP soutient les évaluations mondiales et fournit un large éventail d'indicateurs cohérents et comparables à l'échelle des pays, des écorégions et des aires protégées (Bastin et al., 2017; Dubois et al., 2016; EC JRC/DOPA, 2019a).

Les Observatoires régionaux des aires protégées et de la biodiversité ont été créés dans le cadre du programme BIOPAMA. Ils soutiennent la collecte, l'analyse, le suivi et l'établissement de rapports de données, renforcent les capacités du personnel et des organisations à gérer les données et fournissent des orientations politiques pour une meilleure prise de décisions en matière de conservation de la biodiversité. L'un des principaux outils fournis dans le cadre du système d'Observatoires régionaux est le Système régional d'information de référence (SRIR) ou Centre régional de ressources (CRR) qui, pour l'Afrique orientale et australe, est hébergé par le Centre Régional de cartographie des ressources pour le développement (RCMRD) au Kenya (voir Encadré 2.4 et Figure 2.1).

\subsection{Une image globale des aires protégées}

Partout dans le monde, des signes de stress croissant sur l'environnement se font sentir, dont les principales causes sont la croissance démographique et l'industrialisation, contribuant toutes deux aux changements climatiques. L'un des principaux objectifs des aires protégées est de conserver la nature en éliminant, minimisant ou réduisant les pressions et les menaces humaines opérant à l'intérieur de leurs limites.

Un certain nombre d'initiatives ou de mécanismes mesurent et évaluent les pressions et les menaces à l'échelle mondiale et régionale. La télédétection peut être utilisée pour mesurer certaines menaces, tandis que d'autres nécessiteront des études in situ afin d'obtenir une compréhension globale des facteurs affectant les aires protégées et de conservation.

L'UICN et le Partenariat pour les mesures de Conservation (CMP, selon ses sigles en anglais) ont produit un ensemble de classifications types des menaces directes que les défenseurs de l'environnement 
rencontrent dans le monde entier, ainsi que des mesures de conservation à leur disposition pour affronter ces menaces (TNC, s.d.). La Liste rouge de I'UICN des espèces menacées ${ }^{\mathrm{TM}}$ utilise ce système de classification pour assurer une comparabilité entre espèces et habitats. La Liste rouge de l'UICN fournit des informations sur l'aire de répartition, la taille des populations, l'habitat et l'écologie, I'utilisation et / ou le commerce, les menaces et les mesures de conservation qui aideront à guider les décisions de conservation nécessaires.

En outre, de nombreuses évaluations EfGAP (voir le Chapitre 5) comprennent également une évaluation systématique et comparable des menaces pesant sur les valeurs et / ou les principaux taxons présents dans les aires protégées, dans de nombreux cas, à partir du système de classification type. Cela fournit une base pour des efforts plus coordonnés et des investissements plus ciblés visant à réduire les menaces et à améliorer les résultats de conservation dans les aires protégées. L'Outil intégré sur l'efficacité de la gestion (OIEG), développé par BIOPAMA, analyse également le contexte de l'aire protégée et de conservation afin de déterminer les menaces potentielles futures (BIOPAMA et IUCN, 2016).

Une étude visant à obtenir une vue d'ensemble globale des menaces auxquelles sont confrontées les aires protégées terrestres à l'échelle mondiale et par biome a analysé les données collectées dans le cadre d'évaluations EfGAP dans 1961 aires protégées de 149 pays, à partir de trois méthodologies différentes: l'Outil de suivi de l'efficacité de la gestion (OSEG), l'évaluation des Perspectives du Patrimoine mondial et le protocole de suivi des IBA de BirdLife International (Schulze et al., 2018). L'étude a révélé que la chasse non durable était la menace la plus souvent signalée et se produisait dans $61 \%$ de toutes les aires protégées, suivie par les perturbations causées par les activités récréatives dans $55 \%$ des cas, et les modifications du système naturel causées par le feu ou sa suppression dans $49 \%$ des cas. Le nombre de menaces signalées était plus faible dans les aires protégées présentant un plus grand isolement, un meilleur contrôle de la corruption et des scores de développement humain inférieurs (Schulze et al., 2018). Dans les pays en développement, les principales menaces signalées étaient liées à la surexploitation résultant de l'extraction des ressources, tandis que les effets négatifs des activités récréatives non durables dominaient dans les pays développés (Schulze et al., 2018). Les résultats ont montré que bon nombre des menaces les plus graves pour les aires protégées sont difficiles à suivre par télédétection, et soulignent l'importance de données in situ sur les menaces pour guider la mise en œuvre d'une conservation plus efficace de la biodiversité dans les aires protégées mondiales (Schulze et al., 2018). II convient de noter que cette analyse comprenait des données jusqu'en 2014, après quoi le braconnage à grande échelle pour le commerce illégal mondial d'espèces sauvages est apparu comme une menace majeure pour la biodiversité en Afrique. Le Tableau 2.3 résume les résultats pour le biome Afro-tropical, qui comprend la majeure partie de l'Afrique subsaharienne.

Dans une autre étude, une analyse de la performance des aires protégées africaines mettant l'accent sur les lions et leurs proies a montré que le braconnage de viande de brousse constituait la menace la plus importante pour les lions et la faune en général (Lindsey et al., 2017).

Outre le braconnage de viande de brousse, on considère également que les principales menaces directes à la conservation en Afrique incluaient la perte et la fragmentation des habitats, la surpêche, le trafic illégal d'espèces sauvages et les espèces exotiques envahissantes. Une analyse de la Commission européenne (EC, 2015) a révélé que les principaux moteurs de ces menaces dans la région étaient :

- la croissance démographique et la pauvreté ;

- une mauvaise gouvernance ;

- des régimes fonciers et droits sur les ressources locales inadéquats ;

- les conflits nationaux et régionaux;

- I'indifférence politique et le manque de sensibilisation ;

- les changements climatiques ;

- les maladies endémiques et émergentes ; et

- les conflits homme-faune.

Tableau 2.3: Trois des menaces les plus fréquemment signalées dans le biome Afro-tropical

\begin{tabular}{l|l|r|l|l|l}
\hline Biome & Groupe de biome & Sites $\mathbf{( N )}$ & $\begin{array}{l}\text { Menace } \\
\text { la plus fréquemment } \\
\text { documentée }\end{array}$ & $\begin{array}{l}\text { Deuxième menace } \\
\text { la plus fréquemment } \\
\text { documentée }\end{array}$ & $\begin{array}{l}\text { Troisième menace la } \\
\text { plus fréquemment } \\
\text { documentée }\end{array}$ \\
\hline Afro-tropical & Forêts tropicales & 150 & $\begin{array}{l}\text { Chasse et collecte } \\
\text { d'animaux terrestres }\end{array}$ & $\begin{array}{l}\text { Récolte de plantes } \\
\text { terrestres }\end{array}$ & $\begin{array}{l}\text { Exploitation forestière et } \\
\text { récolte de bois }\end{array}$ \\
\hline Afro-tropical & $\begin{array}{l}\text { Savanes, arbustes et } \\
\text { prairies }\end{array}$ & 22 & $\begin{array}{l}\text { Espèces / maladies } \\
\text { exotiques / non } \\
\text { autochtones } \\
\text { envahissantes }\end{array}$ & $\begin{array}{l}\text { Incendies et } \\
\text { suppression des } \\
\text { incendies }\end{array}$ & Activités de loisirs \\
\hline Afro-tropical & Mangroves & 7 & Pêche et récolte & Chasse et collecte & $\begin{array}{l}\text { Collecte de plantes } \\
\text { terrestres }\end{array}$ \\
\hline
\end{tabular}

Source : (Schulze et al., 2018, Tableau 1, p. 7/10). 


$$
\text { मींखि }
$$




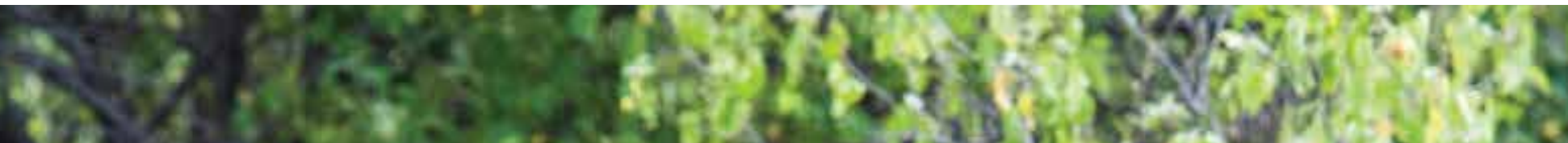

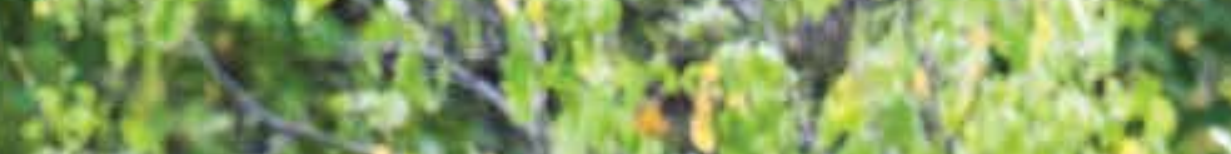

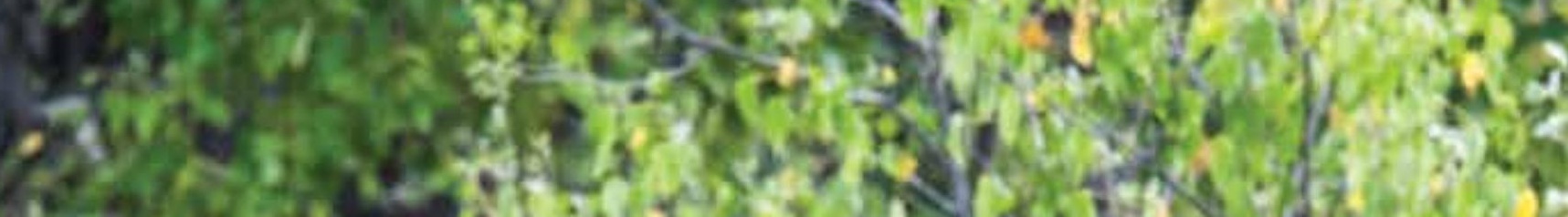

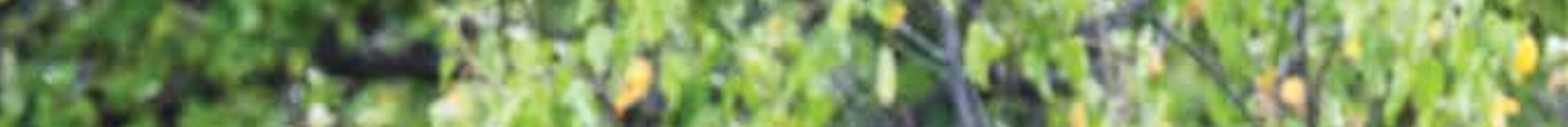

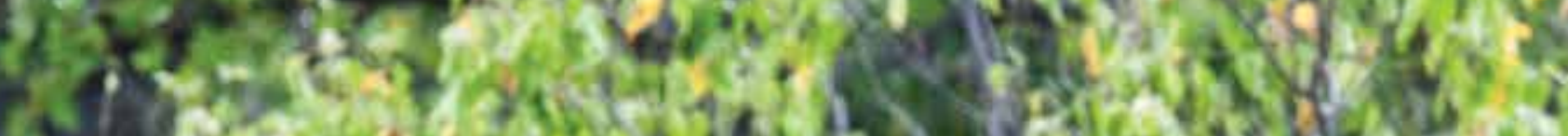
4 .

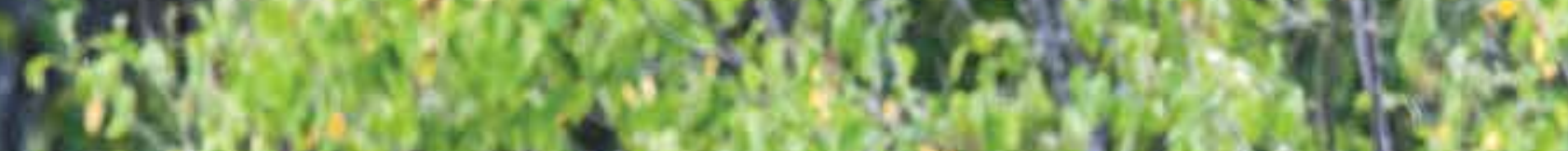

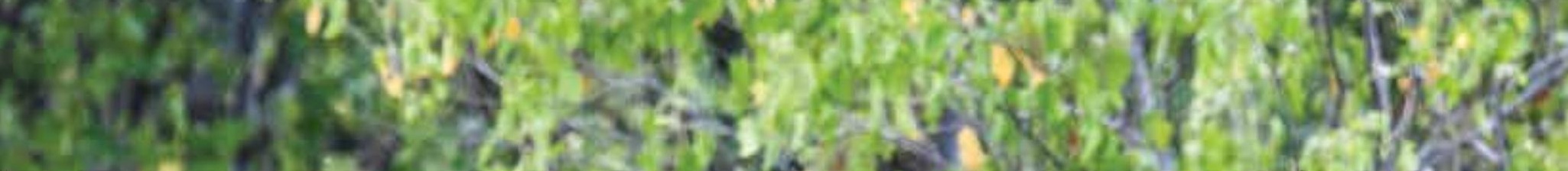

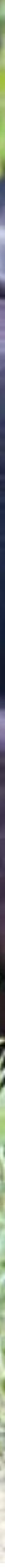


Partie II - Contexte régional, données et profils nationaux

\section{Vue d'ensemble de la région ${ }^{7}$}




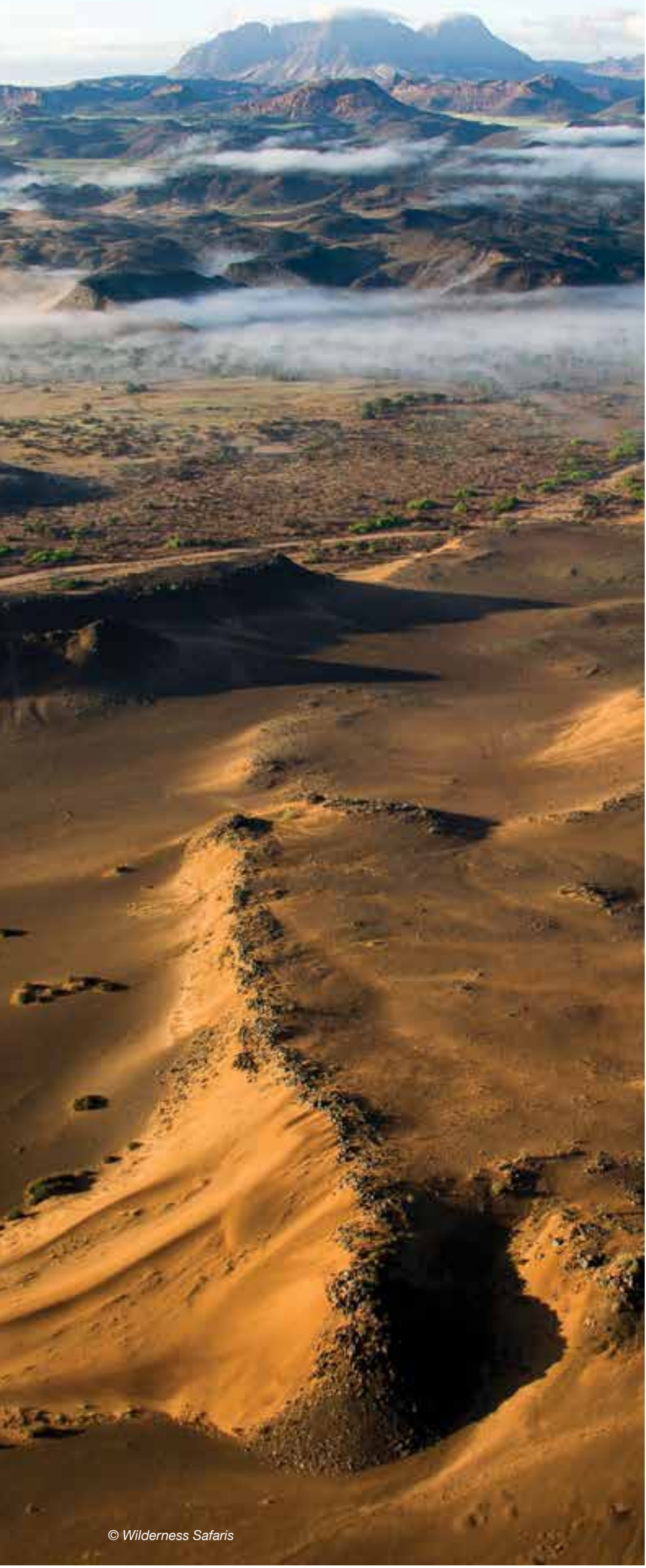

Cette section fournit le contexte de ce rapport et un aperçu de l'état des aires protégées et de conservation dans la région de l'Afrique orientale et australe dans son ensemble. Lorsque des données étaient disponibles, des analyses complètes ont été entreprises. La section présente des informations concernant les institutions créées pour répondre aux besoins et priorités spécifiques des sous-régions, y compris les politiques régionales et instruments juridiques. Les approches novatrices guidant et démontrant des résultats positifs sont mises en évidence et recommandées.

La région de l'Afrique orientale et australe couvre 24 pays, y compris les îles de l'océan Indien occidental. Elle abrite quatre communautés économiques régionales: la Communauté de l'Afrique de l'Est (EAC, selon ses sigles en anglais), la Commission de l'océan Indien (COI), l'Autorité intergouvernementale pour le développement (IGAD, selon ses sigles en anglais) et la Communauté de développement de l'Afrique australe (SADC, selon ses sigles en anglais). La région de l'Afrique orientale et australe est vaste, couvrant environ 16 millions de $\mathrm{km}^{2}$, soit environ la moitié du continent Africain. C'est une région géographiquement diverse, qui s'étend de la mer Rouge, au nord, jusqu'au Cap de Bonne-Espérance, au sud, et inclut les îles de l'océan Indien occidental. La région comprend de nombreux biomes différents, y compris des savanes, des prairies, des zones arides et désertiques, des forêts tropicales et subtropicales sèches et humides, des zones humides et le biome unique des fynbos d'Afrique du Sud.

Les différences sous-régionales ont des implications sur la gestion et la gouvernance des aires protégées et de conservation. II existe une diversité de besoins et de priorités de développement entre les pays, y compris pour une conservation durable, comme la révision de la législation et des politiques pour permettre une conservation plus inclusive. Dans les zones encore en conflit, comme au Soudan du Sud et en Somalie, il sera peut-être nécessaire de mettre l'accent sur l'application de la loi, ce qui aura une incidence sur les priorités et les budgets de gestion. Les pays se trouvent également à des stades très différents en matière de conservation durable, l'Afrique du Sud, le Botswana, le Kenya, la Namibie, le Rwanda, la Tanzanie et l'Ouganda disposant de politiques et processus plus avancés en matière de gestion et de gouvernance, tandis que l'Érythrée, la Somalie, le Soudan du Sud et le Soudan n'en sont encore qu'aux premiers stades d'élaboration des politiques, de création de zones de conservation et de politiques de gouvernance. Les îles de l'océan Indien occidental présentent des opportunités et des défis uniques.

En 2019, la population de l'Afrique a atteint 1,32 milliard (Worldometer, s.d.), soit $16,7 \%$ de la population mondiale, avec une densité de population de 44 personnes par $\mathrm{km}^{2}$ à l'échelle du continent. La même année, la population de l'Afrique orientale et australe était de 512 millions d'habitants, soit $6,6 \%$ de la population mondiale, avec une densité de population de 32 personnes par $\mathrm{km}^{2}$. Ce chiffre varie considérablement d'une région à l'autre, la Namibie ayant l'une des densités de population les plus faibles (trois personnes par $\mathrm{km}^{2}$ ) et le Rwanda l'une des plus élevées (512 personnes par $\left.\mathrm{km}^{2}\right)$. Les estimations démographiques suggèrent que la croissance restera forte dans les décennies à venir, de sorte qu'en 2050, une personne sur quatre dans le monde sera Africaine. Une forte croissance démographique présente des défis devant 
être gérés efficacement (IPBES, 2018), en plus de niveaux élevés de pauvreté et de chômage. Un certain nombre de menaces régionales pour la conservation sont directement liées à la croissance démographique et à la concurrence pour les terres (EC, 2015; IPBES, 2018).

\subsection{Afrique de l'Est}

La région de l'Afrique de l'Est abrite les points les plus élevés et les plus bas du continent et comprend une gamme d'habitats allant de forêts tropicales et de récifs côtiers aux déserts. Ses caractéristiques uniques incluent la faune et la flore montagnardes des hauts plateaux éthiopiens, dont le loup d'Abyssinie endémique et menacé (Canis simensis), les montagnes tropicales enneigées du Rwenzori et du Kilimandjaro, les escarpements boisés de la vallée du Rift Albertine, les grands lacs d'Afrique, la singulière Corne de l'Afrique, les plus grandes migrations de faune des savanes et les importantes forêts reliques des côtes est-africaines. La région abrite également certaines des aires protégées les plus célèbres du continent, notamment la Réserve nationale du Masai Mara et le Parc national du Serengeti. Elle abrite les chimpanzés (Pan troglodytes) et la plus grande population de lions (Panthera leo) au monde (en Tanzanie).

Le lac Tanganyika est le plus long lac d'eau douce du monde et abrite 250 espèces différentes de poissons cichlidés, dont $98 \%$ sont endémiques. Le lac Victoria présente moins d'endémisme, mais constitue un réservoir de pêche important pour les populations locales de trois pays. ${ }^{8}$

Comme dans d'autres régions tropicales, l'étendue des forêts tropicales de plaine et de montagne et des forêts sèches a diminué en Afrique de l'Est. Dans les forêts côtières de la région, cette perte est principalement due à la conversion des forêts en terres agricoles, principalement par la culture itinérante. En Tanzanie, par exemple, le couvert forestier côtier a diminué de plus d'un tiers, passant de 420765 hectares en 1990 à 358333 hectares en 2000 et à 273709 hectares en 2007. Cepenant, le taux de déforestation a été plus faible dans les réserves tanzaniennes : $0,2 \%$ et $0,4 \%$ par an entre 1990 et 2000 etentre 2000 et 2007 respectivement, contre $1,3 \%$ et $0,6 \%$ par an en dehors des réserves au cours des mêmes périodes (Burguess et al., 2017; Godoy et al., 2012).

\subsection{Madagascar et îles occidentales de l'océan Indien}

L'île de Madagascar possède une grande richesse d'espèces et des niveaux extraordinaires d'endémisme, particulièrement chez les lémuriens, les tenrecs et les caméléons. Il existe plus d'espèces végétales à Madagascar que dans tout le bassin du Congo. Les forêts du nord et de l'est sont humides, celles de l'ouest et du sud se faisant progressivement plus arides. L'île constitue une région d'une importance disproportionnée pour la conservation, avec des niveaux élevés d'endémisme et une forte proportion d'espèces menacées. Les petites îles des Comores, de Maurice et des Seychelles sont également d'une importance exceptionnelle pour la conservation. Elles font partie du hotspot de biodiversité des îles de Madagascar et de l'océan Indien, et abritent de nombreuses espèces et écosystèmes endémiques et menacés, tels que le zostérops des Seychelles (Zosterops modestus).

Les forêts tropicales de l'est malgache ont diminué de 1,69\% par an de 1990 à 2000 et de $1,08 \%$ de 2000 à 2010 (Mayaux et al., 2013), et on estime que $97 \%$ des forêts occidentales sèches malgaches ont été détruites depuis l'arrivée de l'homme sur l'île (WWF, 2017), avec un taux de déforestation annuel de $0,75 \%$ de 1990 à 2000 (Gorenflo et al., 2011).

\subsection{Afrique australe}

Les 10 pays d'Afrique australe constituent la sous-région la plus riche et la plus développée de l'Afrique subsaharienne, bien que de façon inégale. Ils présentent également une grande diversité d'espèces et d'habitats.

Les merveilles naturelles de l'Afrique australe comprennent les grands marais salants d'Etosha, les chutes Victoria et le fleuve Zambèze, ainsi que l'unique delta intérieur de l'Okavango. Les déserts du Kalahari et du Namib sont tous deux de grands déserts, le Namib étant considéré comme le plus ancien désert du monde. Le désert du Karoo, en Afrique du Sud, présente la flore la plus riche du monde en ce qui concerne les plantes succulentes, et les arbustes de Fynbos représente un élément majeur de la région floristique du Cap, en Afrique du Sud, qui constitue l'un des six règnes floraux reconnus du monde, avec plus de 9000 espèces de plantes vasculaires dont $69 \%$ sont endémiques. La côte orientale de l'Afrique australe, sous le Grand Escarpement, est un autre centre important d'endémisme végétal.

Le lac Malawi / Niassa / Nyasa, long de 570 km, est le lac le plus au sud de la vallée du Rift, et contient plus d'espèces de poissons que tout autre lac sur Terre, dont plus de 1000 espèces endémiques de poissons cichlidés et de nombreux mollusques endémiques.

L'Afrique australe abrite plus d'éléphants et de rhinocéros que le reste du continent, ainsi que certaines des plus anciennes et des plus grandes réserves et parcs d'Afrique. Les pays d'Afrique australe possèdent une longue histoire de conservation de la faune et de gestion du gibier, et ont été pionniers en matière d'utilisation communautaire des ressources naturelles, de conservation transfrontalière et autres approches de conservation innovantes. Le premier Parc de la paix a vu le jour en Afrique australe en 1990, et l'Aire de conservation transfrontalière de Lubombo, créée en 2000, a été la première aire de conservation transfrontalière (ACT) marine en Afrique (voir la Section 4.5 pour plus d'informations sur les $A C T)$. 
(4) F.t.

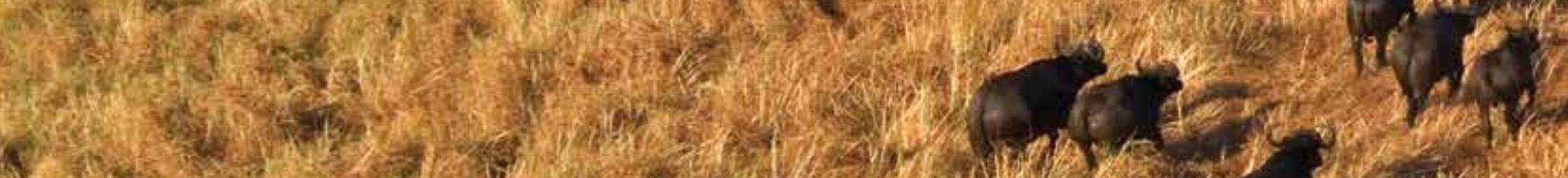
1.5.

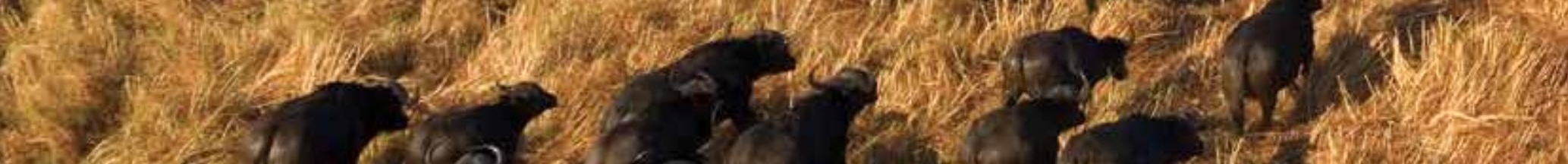

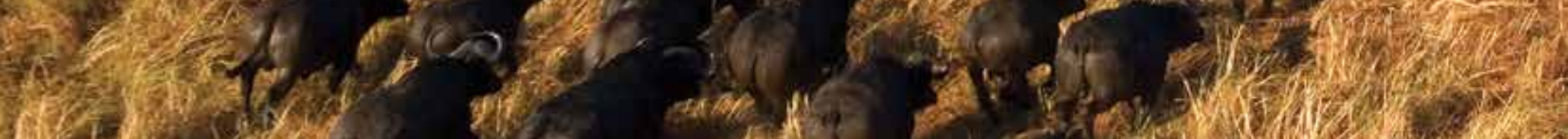

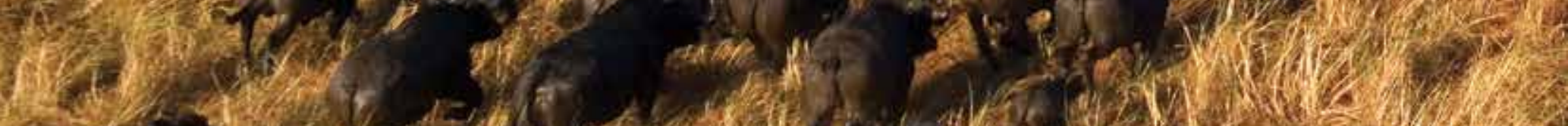

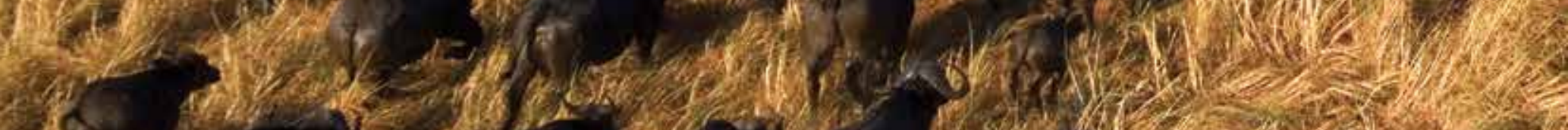
Lic. 20.

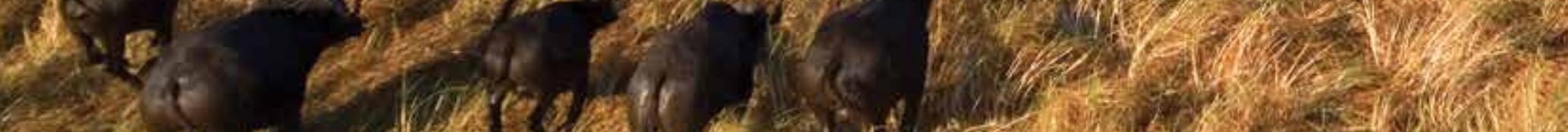

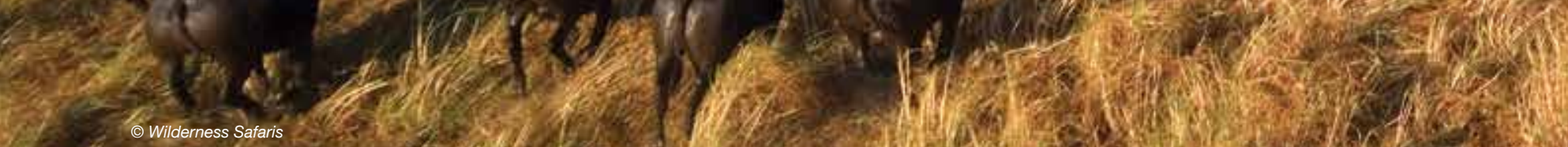
(3) 


\section{4 État des aires protégées et de conservation \\ d'Afrique orientale et australe}


Figure 4.1 : Aires protégées et de conservation d'Afrique orientale et australe

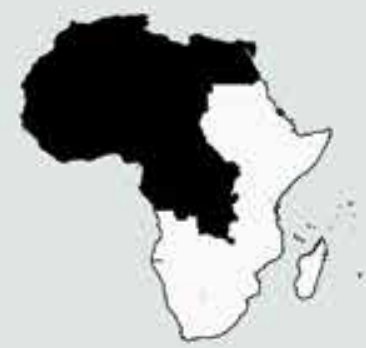

AIRES PROTÉGÉES

AFRIQUE ORIENTALE ET AUSTRALE BIOPAMA

Aires protégées

Frontières nationales africaines

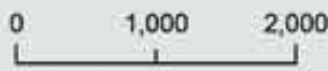

Kilomètres

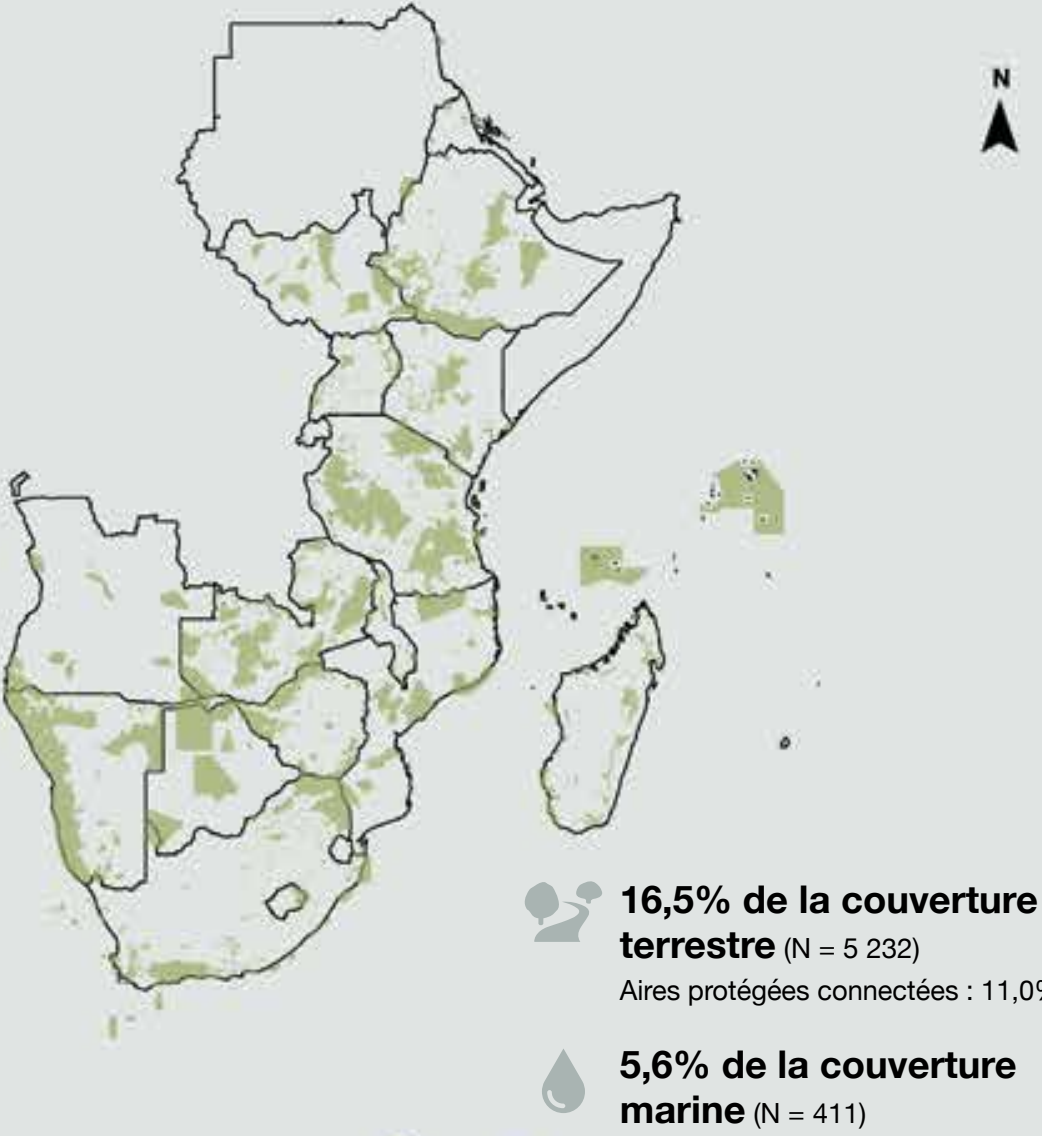

\section{Espèces endémiques de la région}

522 amphibiens dont

247 sont menacés $(47,3 \%)$

365 mammifères dont

178 sont menacés $(48,8 \%)$

306 oiseaux dont

104 sont menacés $(34,0 \%)$

24 requins et raies dont

6 sont menacés (25\%)
Statistiques régionales de couverture du sol

$88,1 \%$ de terres naturelles ${ }^{*}$ dont

$22,1 \%$ sont protégés

$32,0 \%$ de couverture forestière dont

$27,6 \%$ sont protégés

$1,8 \%$ d'eaux intérieures dont

$11,3 \%$ sont protégés

53,1 Pg de stock total de carbone dont $21,9 \%$ sont protégés

$5,3 \%$ de couverture urbaine et agricole dans les aires protégées

Données

- Couches d'unités administratives globales (GAUL). Révision de 2015. Disponible à : http://www.fao.org/geonetwork/srv/en/metadata.show?id=12691

- Zones économiques exclusives (ZEE) v9 (2016-10-21). Disponible à : http://www. marineregions.org/downloads.php

- UNEP-WCMC et IUCN (2019). Protected Planet: The World Database on Protected Areas (WDPA). [En ligne]. Données de mai 2019 utilisées pour la connectivité des AP et les statistiques régionales de couverture terrestre,

- JRC-VITO-IIASA (2019). Carte de couverture du sol Copernic Global 100m pour l'année 2015. Disponible à : https://land.copernicus.eu/global/products/lc

- IUCN (2019). Liste rouge de I'UICN des espèces menacées. Tiré du Tableau 8a. Version 2019.1. Disponible à : https://www.iucnredlist.org/resources/summary-statistics Avitabile, V., Garcia Bendito, E., Delli, G., Mandrici, A., Battistella, L., Dubois, G. (2019). Carte globale du stock total de carbone. [En ligne]. Disponible à : https://dopa.jrc. ec.europa.eu/sites/default/files/dopa_explorer_4-total_carbon.zip [10/2019]. Ispra, Italie.

* La catégorie " Terres naturelles » inclut toutes les classes sauf les terres cultivées (classe 40) et urbaines (classe 50)

Source : EC JRC/DOPA, 2019a. 


\subsection{Données statistiques de référence}

Les données de ce rapport ont été tirées de la BDMAP, ainsi que des informations disponibles dans les rapports de chaque pays à la $C D B$, et en particulier les cinquième et sixième rapports nationaux rédigés entre 2014 et 2019 . Certains rapports nationaux contiennent des informations sur les aires de conservation et protégées.

L'Afrique orientale et australe compte 5232 aires protégées couvrant $2120112 \mathrm{~km}^{2}$ de surface terrestre et $473815 \mathrm{~km}^{2}$ de zones océaniques (UNEP-WCMC et IUCN, 2019b). La Figure 4.1 présente la carte de ces sites ainsi qu'un aperçu des espèces menacées et de la représentation de la couverture terrestre dans ces aires protégées. Les données ont été calculées en utilisant l'information spatiale disponible dans la BDMAP, en combinaison avec une série d'autres ensembles de données fiables. Cependant, dans certains cas, les limites des aires protégées ne sont pas à jour ou complètes dans la BDMAP, ce qui peut affecter l'exactitude des statistiques à l'échelle des pays. Par exemple, dans le cas de la Somalie, 21 aires protégées ont été signalées à la BDMAP, mais aucune ne dispose de limites polygonales, ce qui empêche la production d'une carte ou l'application de techniques d'analyse spatiale.

À l'échelle régionale, l'Afrique orientale et australe est sur le point d'atteindre l'objectif de couverture de l'Objectif d'Aichi 11, avec $16,54 \%$ de sa superficie terrestre protégée dans 5232 aires protégées, soit plus de 2,1 millions de $\mathrm{km}^{2}$ (UNEP-WCMC et IUCN, 2019b). Comme le montre la Figure 4.2, au moins neuf pays de la région ont dépassé les objectifs de couverture d'Aichi en matière de protection terrestre, selon leurs rapports nationaux. Néanmoins, il existe une grande variabilité au sein de la région, $42 \%$ des pays restant en dessous de $10 \%$ de couverture terrestre selon la BDMAP, alors que ce chiffre peut aller jusqu'à $33 \%$ sur la base des statistiques nationales.

La valeur de connectivité présentée à la Figure 4.2 (barres bleues) tient compte de la disposition spatiale, de la taille et de la couverture des aires protégées et se base sur la superficie terrestre pouvant être atteinte au sein du réseau d'aires protégées par des organismes présentant une distance médiane de dispersion de $10 \mathrm{~km}$ (comme c'est le cas pour de nombreux vertébrés terrestres) $)^{9}$. De manière similaire, la connectivité varie considérablement d'une région à l'autre, de moins de $1 \%$ au Lesotho à plus de $36 \%$ aux Seychelles.

L'Afrique orientale et australe est à mi-chemin d'atteindre l'élément de couverture des aires marines protégées de l'Objectif d'Aichi 11, avec $5,60 \%$ de l'espace marin protégé dans 411 aires côtières et marines protégées, soit $473815 \mathrm{~km}^{2}$ (UNEP-WCMC et IUCN, 2019b). Comme le montre la Figure 4.2, l'Afrique du Sud, les Seychelles et le Soudan ont dépassé les objectifs d'Aichi en matière de protection marine et côtière, selon la BDMAP.

Les catégories de gestion de I'UICN pour la plupart des aires protégées en Afrique orientale et australe n'ont pas été déclarées à la BDMAP (Figure 4.4), bien que, sur la base des données disponibles, les catégories II, IV et VI soient les plus couramment utilisées. Cet écart est en partie dû à un manque de rapports, ainsi qu'à la façon dont les autres catégories sont comprises en Afrique, où le concept historique de "forteresses de conservation ", axé sur la protection formelle des ressources naturelles grâce à des parcs nationaux, a constitué un paradigme dominant. II est probable qu'on assiste à une augmentation des autres catégories à mesure que les politiques et les lois permettant de gérer ces approches de conservation seront élaborées et mises en œuvre dans toute la région. Certains pays, comme l'Afrique du Sud qui compte plus de 1500 aires protégées, ne les ont pas spécifiquement classées selon les catégories de gestion de I'UICN.

\section{Figure 4.2: Couverture des aires protégées terrestres en Afrique orientale et australe}

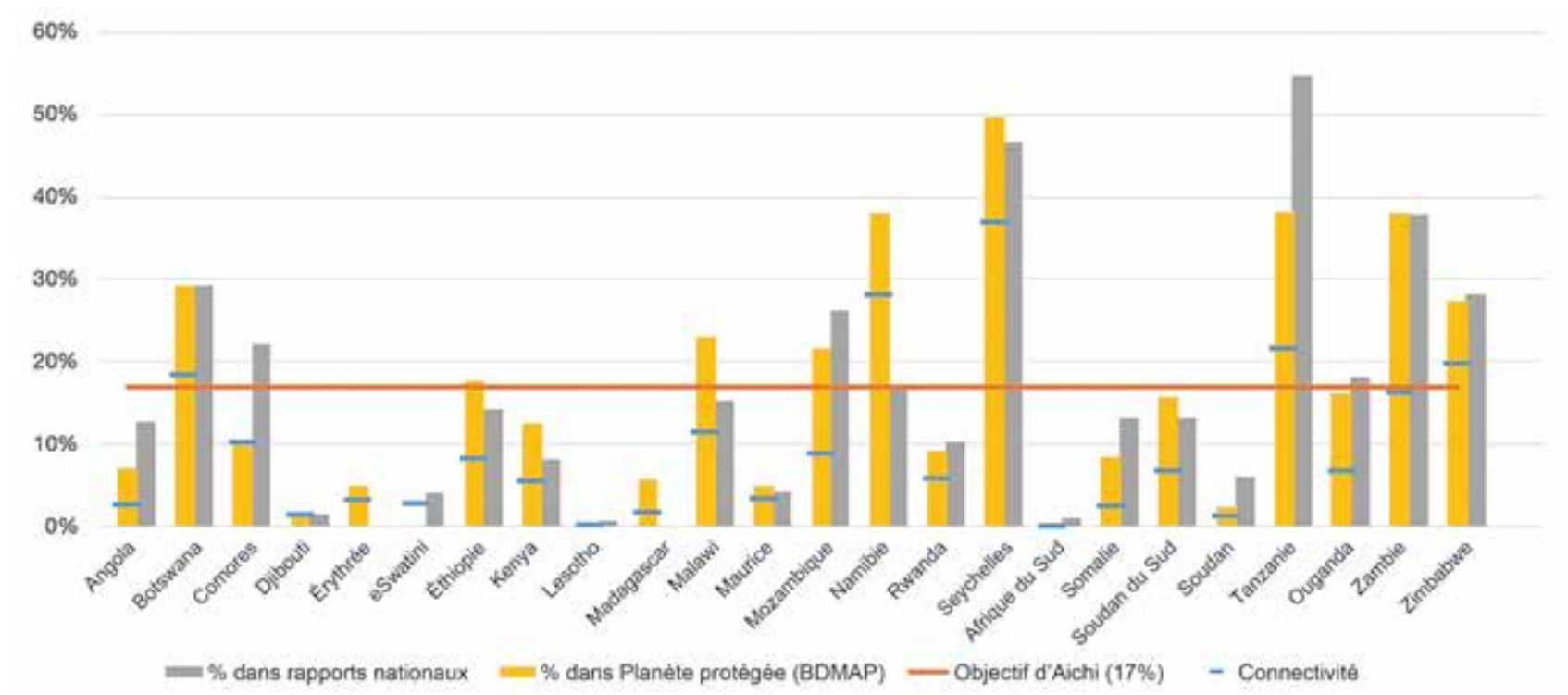

Note : Voir l'Annexe 2 pour la source de ces chiffres, et le Chapitre 8 pour des informations détaillées sur les rapports nationaux.

Sources : Base de données mondiale des aires protégées (UNEP-WCMC et IUCN, 2019b), EC JRC/DOPA (2019a) et Rapports nationaux à la Convention sur la diversité biologique.

9 L'indicateur est calculé par analyse de réseau (EC JRC/DOPA, 2019b; Saura et al., 2017, 2018 et 2019). 
Figure 4.3: Aires côtières et marines protégées et de conservation d'Afrique orientale et australe

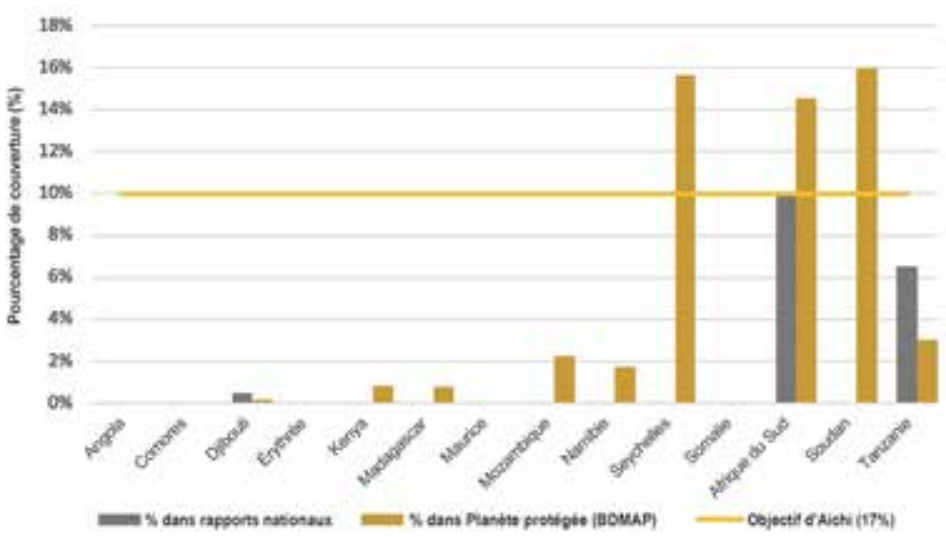

Note : voir l'Annexe 2 pour la source de ces chiffres, et le Chapitre 3 pour des informations détaillées sur

les rapports nationaux. nationaux à la Convention sur la diversité biologique.

Figure 4.4: Catégories de gestion de I'UICN des aires protégées et de conservation d'Afrique orientale et australe

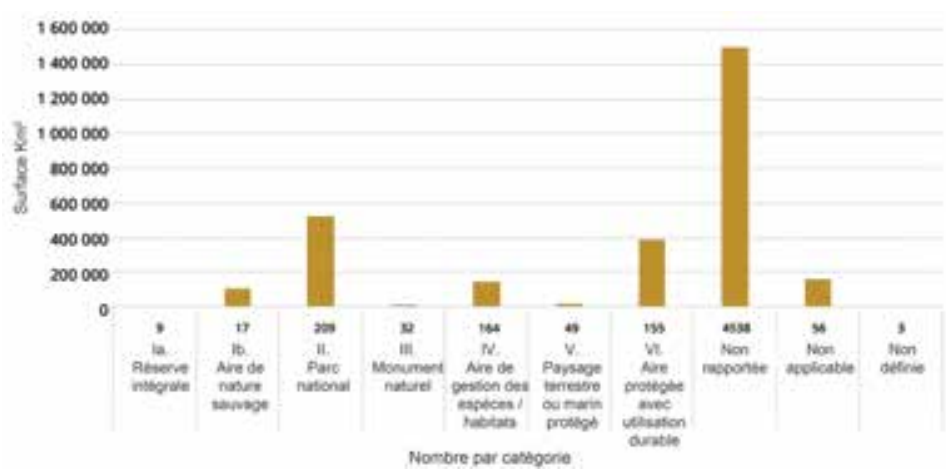

Note : Voir l'Annexe 2 pour la source des données de cette figure.

Source : Base de données mondiale des aires protégées (UNEP-WCMC et IUCN, 2019a).

Figure 4.5: Types de gouvernance de I'UICN parmi les aires protégées et de conservation d'Afrique orientale et australe

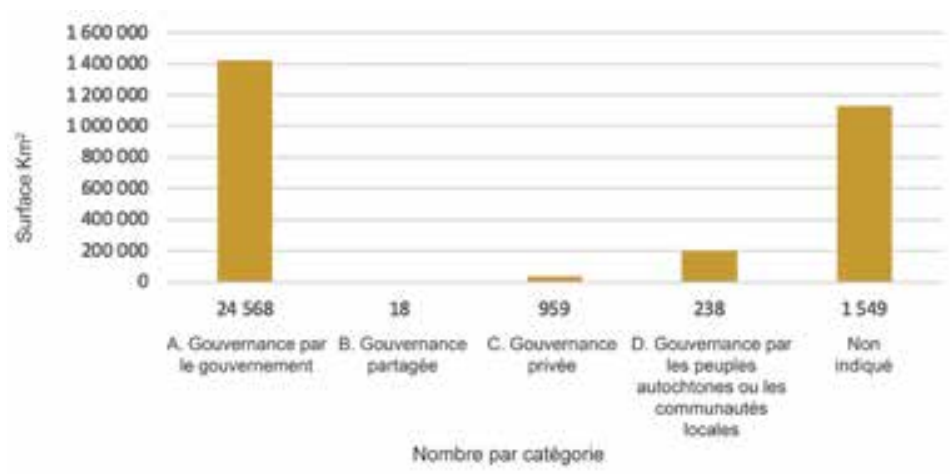

Note : voir l'Annexe 2 pour la source des données de cette figure.

Source : Base de données mondiale des aires protégées (UNEP-WCMC et IUCN, 2019a). 
Bien que le type de gouvernance de nombreuses aires protégées de la région n'ait pas été signalé dans la BDMAP, la plupart sont régies par l'État ou des organismes gouvernementaux (Type de gouvernance A; voir la Figure 4.5). La domination de la gouvernance par l'État résulte, en grande partie, de processus historiques liés à la création d'aires protégées selon le concept de « forteresses de conservation ». Ceci a évolué au fil du temps, avec une plus grande inclusion des communautés dans la gouvernance de la conservation et des aires protégées. Par exemple, sur les 238 aires protégées sous gouvernance de peuples autochtones et communautés locales, $47 \%$ se trouvent en Namibie sous gouvernance de communautés locales et le reste au Kenya, à Madagascar et en Tanzanie, avec un site au Botswana. La gouvernance privée est encore largement limitée à l'Afrique australe, dans des pays tels que la Namibie et l'Afrique du Sud (98\% des 959 sites privés se trouvent en Afrique du Sud), et largement liée au tourisme animalier, à l'élevage et à la chasse aux trophées.

\subsection{Désignations mondiales et autres domaines prioritaires dans la région}

En Afrique orientale et australe, 175 sites ont été désignés comme d'importance internationale (Tableau 4.1). En tête de liste figurent les sites Ramsar, qui soulignent l'importance de la conservation des zones humides dans la région.

Le Tableau 4.2 fournit une liste annotée des sites africains naturels et «mixtes» (naturels/culturels) du Patrimoine mondial (en 2019), comprenant les résultats des évaluations des Perspectives de conservation de l'UICN ${ }^{10}$ et les dates des missions de suivi entreprises par le Centre du Patrimoine mondial et I'UICN (Howard et Bertzky, 2020).
De nombreux « sites revêtant une importance particulière pour la biodiversité » (comme indiqué dans l'Objectif d'Aichi 11) ont été reconnus comme des KBA. Certains sous-ensembles spécifiques de KBA incluent les sites de l'Alliance pour une extinction zéro (AZE), qui représentent les derniers refuges d'une ou plusieurs espèces menacées ou en danger critique d'extinction, et les IBA, importantes pour la conservation mondiale des oiseaux (voir la Section 2.6). À l'heure actuelle, 735 KBA ont été identifiées dans la région, dont 107 AZE et 692 IBA (AZE Secretariat, 2019; BirdLife International, 2019b et 2019c). Étant donné que les AZE, les IBA et les KBA sont des sites prioritaires reconnus pour la conservation de la biodiversité, beaucoup sont déjà couverts par des aires protégées et de conservation, y compris les différentes désignations mondiales mentionnées précédemment. Les AZE, IBA et KBA non protégées devraient être considérées comme des priorités pour l'expansion des aires protégées.

\section{Tableau 4.1 : Sites d'importance mondiale en Afrique orientale et australe}

\begin{tabular}{l|r}
\hline Désignation mondiale & Nombre de sites \\
\hline $\begin{array}{l}\text { Sites Ramsar (Zones humides } \\
\text { d'importance internationale) }\end{array}$ & 109 \\
\hline Réserves de biosphère de l'UNESCO & 39 \\
\hline $\begin{array}{l}\text { Sites du Patrimoine mondial de l'UNESCO } \\
\text { (naturels ou mixtes) }\end{array}$ & 27 \\
\hline
\end{tabular}

Source: Ramsar Convention on Wetlands (2019); UNESCO (2019a; 2019b). Des informations détaillées sur les sites Ramsar et les Réserves de biosphère sont disponibles à l'Annexe 3.

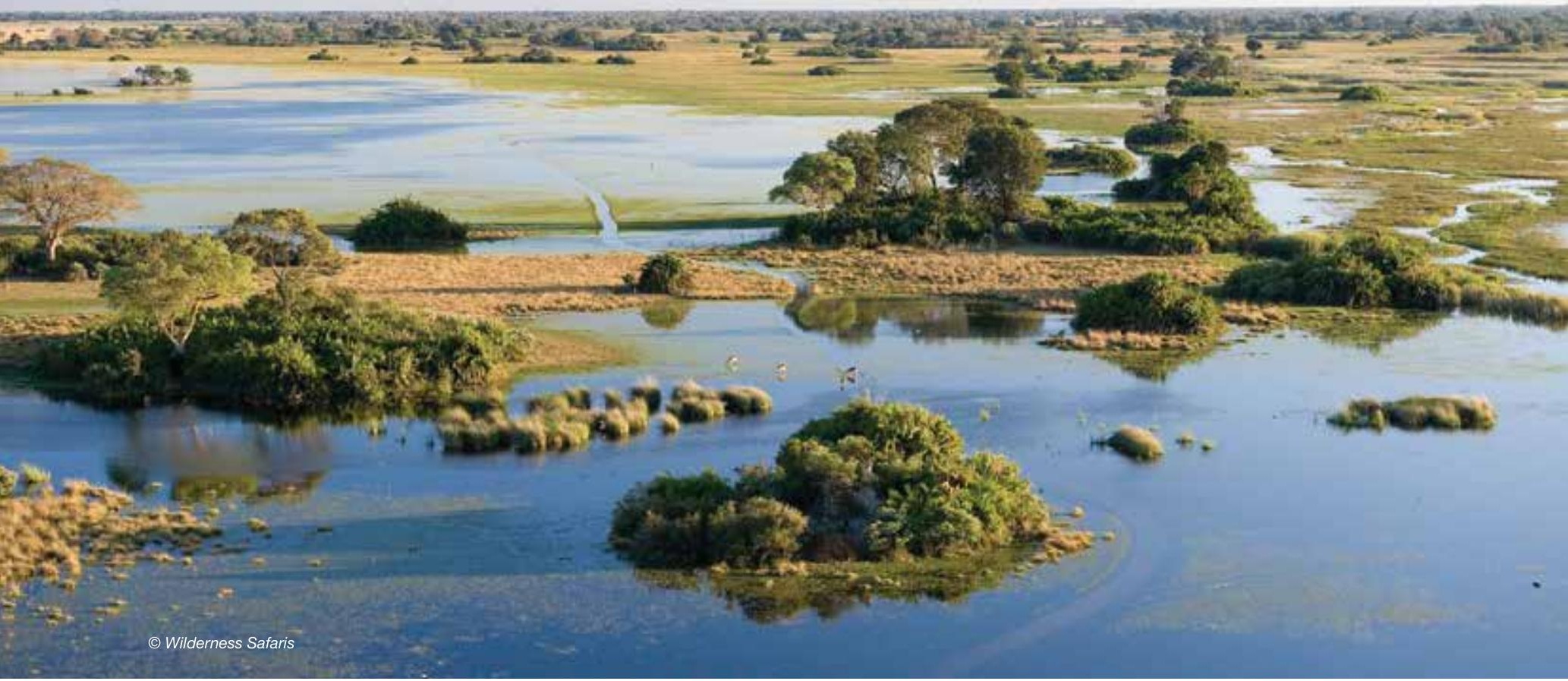

10 Pour plus d'informations, veuillez consulter : https://www.iucn.org/resources/conservation-tools/iucn-world-heritage-outlook 
Tableau 4.2 : Liste annotée des sites naturels et « mixtes " (naturels / culturels) du Patrimoine mondial en Afrique orientale et australe (en 2019), comprenant les résultats des évaluations des Perspectives de conservation de l'UICN et les dates des missions de suivi entreprises par le Centre du Patrimoine mondial et I'UICN

\begin{tabular}{|c|c|c|c|c|c|c|c|c|c|c|c|c|}
\hline$\frac{\varepsilon}{\text { E }}$ & 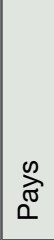 & 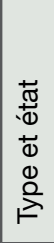 & 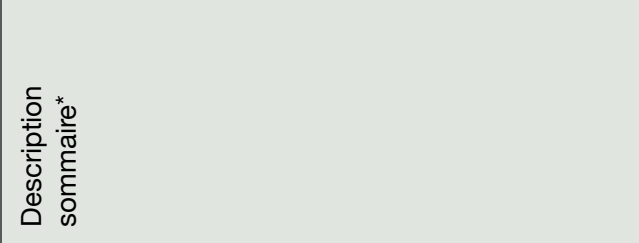 & 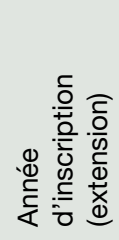 & 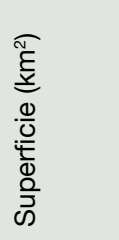 & 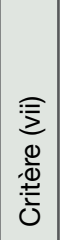 & 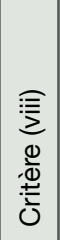 & 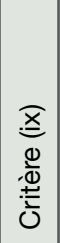 & 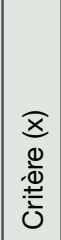 & 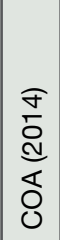 & $\begin{array}{l}\text { T } \\
\text { D } \\
\text { v } \\
\text { o } \\
0\end{array}$ & $\begin{array}{l}3 \\
30 \\
0 \\
0 \\
0 \\
0 \\
0 \\
\frac{0}{00} \\
.0 \\
.0 \\
\sum\end{array}$ \\
\hline $\begin{array}{l}\frac{\pi}{0} \\
\frac{0}{\pi} \\
\frac{\pi}{0} \\
\frac{1}{0} \\
\overline{\overline{0}} \\
+\frac{1}{4}\end{array}$ & $\begin{array}{l}0 \\
\frac{0}{0} \\
\overline{0} \\
\frac{1}{0} \\
0 \\
0 \\
\infty\end{array}$ & 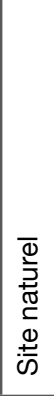 & $\begin{array}{l}\text { L'atoll est composé de quatre grandes îles } \\
\text { coralliennes entourant un lagon peu profond. Le } \\
\text { groupe d'îles est lui-même entouré d'un récif } \\
\text { corallien. En raison des difficultés d'accès et de } \\
\text { l'isolement de l'atoll, Aldabra a été protégé de } \\
\text { l'influence humaine et conserve ainsi quelque } \\
152000 \text { tortues géantes, la plus grande } \\
\text { population mondiale de ce reptile. Pour plus de } \\
\text { détails, voir: http://whc.unesco.org/en/list/185 } \\
\text { http://whc.de l'unesco.org/fr/list/185 }\end{array}$ & 1982 & 350 & & & & & & & - \\
\hline 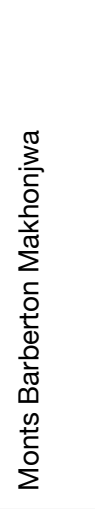 & 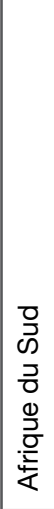 & 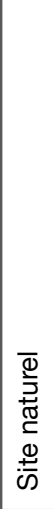 & $\begin{array}{l}\text { Situés au nord-est de l'Afrique du Sud, les monts } \\
\text { Barberton Makhonjwa comprennent } 40 \% \text { de la } \\
\text { ceinture de roches vertes de Barberton, l'une des } \\
\text { plus anciennes structures géologiques du monde. } \\
\text { Le site représente la succession la mieux } \\
\text { conservée de roches volcaniques et sédimentaires } \\
\text { datant de } 3,6 \text { à } 3,25 \text { milliards d'années, et } \\
\text { constitue une réserve diversifiée d'informations } \\
\text { sur les conditions de surface, les impacts de } \\
\text { météorites, le volcanisme, les processus de } \\
\text { construction continentale et l'environnement de la } \\
\text { vie précoce. Pour plus de détails voir: } \\
\text { http://whc.unesco.org/fr/list/1575 }\end{array}$ & 2018 & 1131 & & & & & & & - \\
\hline 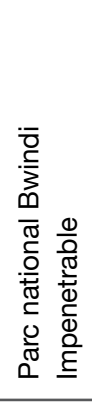 & $\begin{array}{l}\frac{\pi}{0} \\
\stackrel{0}{\tilde{\pi}} \\
\stackrel{0}{3} \\
0\end{array}$ & 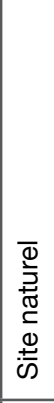 & $\begin{array}{l}\text { Situé dans le sud-ouest de l'Ouganda, Bwindi } \\
\text { couvre } 32000 \text { ha de forêt montagnarde et est } \\
\text { connu pour sa biodiversité exceptionnelle, avec } \\
\text { plus de } 160 \text { espèces d'arbres et plus de } 100 \\
\text { espèces de fougères. De nombreux types } \\
\text { d'oiseaux et de papillons peuvent y être observés, } \\
\text { ainsi que de nombreuses espèces menacées, y } \\
\text { compris le gorille de montagne, en danger } \\
\text { d'extinction. Pour plus de détails voir: } \\
\text { http://whc.unesco.org/fr/list/682 }\end{array}$ & 1994 & 321 & & & & & & & - \\
\hline 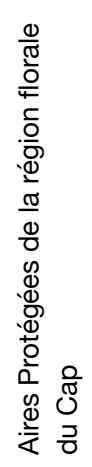 & 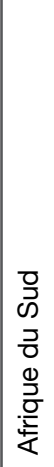 & 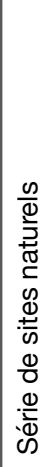 & $\begin{array}{l}\text { La région est l'un des grands centres mondiaux } \\
\text { de biodiversité terrestre. Cette vaste étendue } \\
\text { comprend des parcs nationaux, des réserves } \\
\text { naturelles, des aires de nature sauvage, des forêts } \\
\text { domaniales et des bassins versants de montagne. } \\
\text { Elle abrite un nombre important d'espèces } \\
\text { endémiques associées à la végétation des } \\
\text { Fynbos, des arbustes sclérophylles à feuilles fines } \\
\text { adaptés à la fois à un climat méditerranéen et à } \\
\text { des incendies périodiques, uniques à la Région } \\
\text { florale du Cap. Pour plus de détails voir: } \\
\text { http://whc.unesco.org/fr/list/1007 }\end{array}$ & $\begin{array}{r}2004 \\
(2015)\end{array}$ & 10947 & & & & & & & - \\
\hline
\end{tabular}




\begin{tabular}{|c|c|c|c|c|c|c|c|c|c|c|c|c|}
\hline$\frac{\varepsilon}{\mathcal{E}}$ & $\stackrel{\infty}{\sigma}_{0}^{\infty}$ & 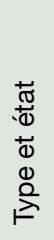 & 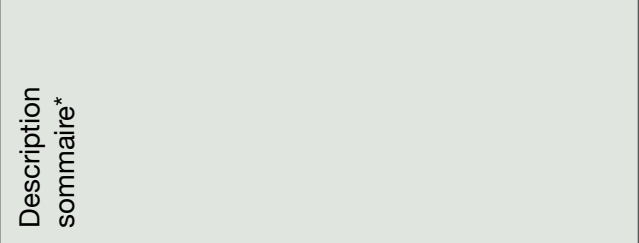 & 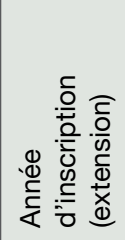 & 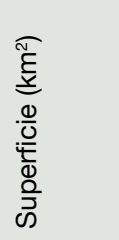 & 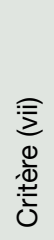 & 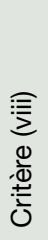 & 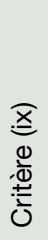 & 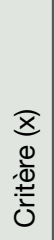 & 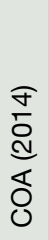 & $\begin{array}{l}\text { T } \\
\text { ¿ } \\
\text { d } \\
0\end{array}$ & 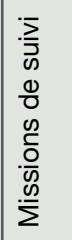 \\
\hline 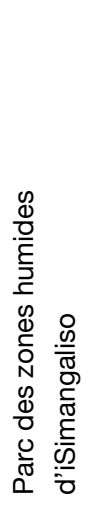 & 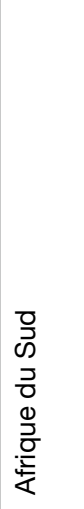 & 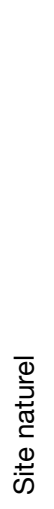 & $\begin{array}{l}\text { L'action des processus fluviaux, marins et éoliens } \\
\text { sur ce site ont produit une variété de formes de } \\
\text { relief, y compris des récifs coralliens, de longues } \\
\text { plages de sable, des dunes côtières, des } \\
\text { systèmes lacustres, des marécages et de vastes } \\
\text { zones humides de roseaux et de papyrus. La } \\
\text { mosaïque de formes de relief et de types } \\
\text { d'habitats crée des panoramas à couper le } \\
\text { souffle. Le site abrite des habitats critiques pour } \\
\text { toute une gamme d'espèces des milieux marins, } \\
\text { humides et de savane d'Afrique. Pour plus de } \\
\text { détails, voir: http://whc.unesco.org/fr/list/914 }\end{array}$ & 1999 & 2396 & & & & & & & - \\
\hline 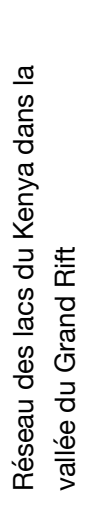 & $\begin{array}{l}\stackrel{\sigma}{\widehat{D}} \\
\stackrel{\Phi}{\mathscr{Q}}\end{array}$ & 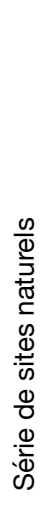 & $\begin{array}{l}\text { Le site comprend trois lacs interconnectés et peu } \\
\text { profonds: le lac Bogoria, le lac Nakuru et le lac } \\
\text { Elementaita, dans la vallée du Rift. II abrite } 13 \\
\text { espèces d'oiseaux menacées à l'échelle mondiale } \\
\text { et sa diversité en oiseaux et l'une des plus } \\
\text { diversifiées au monde. C'est le plus important site } \\
\text { de nourrissage de la planète pour les flamants } \\
\text { nains. La région abrite d'importantes populations } \\
\text { de mammifères, notamment de rhinocéros noir, } \\
\text { de girafe de Rothschild, de grand koudou, de lion, } \\
\text { de guépard et de lycaons. Pour plus de détails } \\
\text { voir : http://whc.unesco.org/fr/list/1060 }\end{array}$ & 2011 & 320 & & & & & & & - \\
\hline 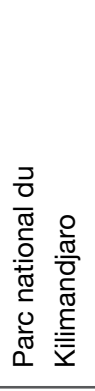 & 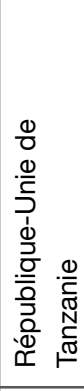 & 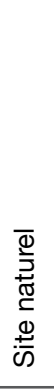 & $\begin{array}{l}\text { Avec ses } 5895 \text { m, le Kilimandjaro est le point } \\
\text { culminant de l'Afrique. Ce massif volcanique se } \\
\text { dresse dans un splendide isolement au-dessus } \\
\text { des plaines environnantes, son sommet enneigé } \\
\text { surplombant la savane. Il est entourée d'une forêt } \\
\text { de montagne, et abrite de nombreux mammifères, } \\
\text { dont beaucoup d'espèces en voie de disparition. } \\
\text { Pour plus de détails voir: } \\
\text { http://whc.unesco.org/fr/list/403 }\end{array}$ & 1987 & 756 & & & & & & & - \\
\hline 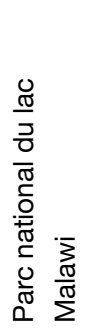 & $\frac{\sqrt{\frac{\pi}{0}}}{\sum^{\frac{\pi}{2}}}$ & 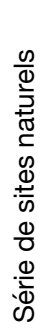 & $\begin{array}{l}\text { Situé à l'extrême sud de la grande étendue du Lac } \\
\text { Malawi / Nyasa / Niassa, avec ses eaux profondes } \\
\text { et claires sur fond de montagnes, le parc national } \\
\text { abrite plusieurs centaines d'espèces de poissons, } \\
\text { presque toutes endémiques. Son importance } \\
\text { pour l'étude de l'évolution est comparable à celle } \\
\text { des Îles Galapagos. Pour plus de détails voir: } \\
\text { http://whc.unesco.org/fr/list/289 }\end{array}$ & 1984 & 94 & & & & & & & $\begin{array}{l}1995 \\
2014\end{array}$ \\
\hline
\end{tabular}




\begin{tabular}{|c|c|c|c|c|c|c|c|c|c|c|c|c|}
\hline$\frac{\varepsilon}{\mathrm{o}}$ & 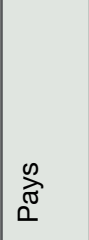 & 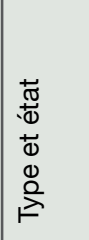 & 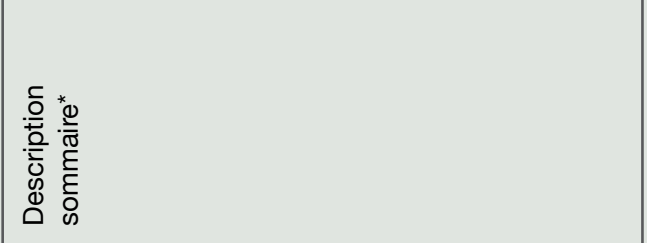 & 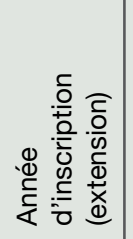 & 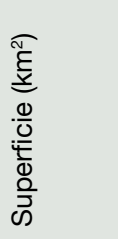 & 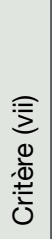 & 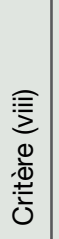 & 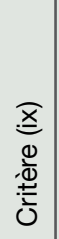 & $\begin{array}{l}\bar{x} \\
\frac{w}{w} \\
\frac{w}{v} \\
\overline{0}\end{array}$ & \begin{tabular}{l}
\multirow{\sigma}{\sigma}{} \\
$\stackrel{0}{\hat{d}}$ \\
$\delta$ \\
0
\end{tabular} & 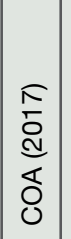 & $\begin{array}{l}: \bar{z} \\
0 \\
0 \\
0 \\
0 \\
0 \\
.0 \\
0 \\
.0\end{array}$ \\
\hline 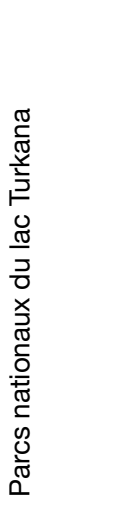 & 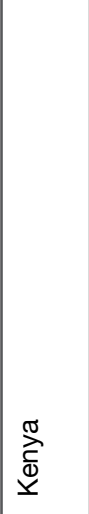 & 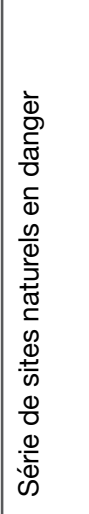 & $\begin{array}{l}\text { Le plus salé des grands lacs d'Afrique, le Turkana } \\
\text { est un laboratoire exceptionnel pour l'étude des } \\
\text { communautés végétales et animales. Les trois } \\
\text { parcs nationaux sont une étape importante pour } \\
\text { les oiseaux d'eau migrateurs et un lieu de } \\
\text { reproduction majeur pour le crocodile du Nil et } \\
\text { autres espèces. Les gisements fossilifères de } \\
\text { Koobi Fora, où l'on trouve de nombreux restes de } \\
\text { mammifères, de mollusques et autres espèces, } \\
\text { ont davantage contribué à la compréhension des } \\
\text { paléo-environnements que tout autre site sur le } \\
\text { continent. Pour plus de détails voir: } \\
\text { http://whc.unesco.org/fr/list/801 }\end{array}$ & 2001 & 1615 & & & & & & & $\begin{array}{l}2012 \\
2015\end{array}$ \\
\hline 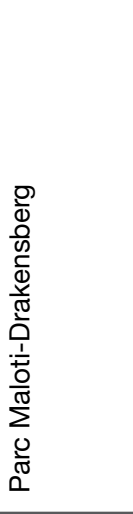 & 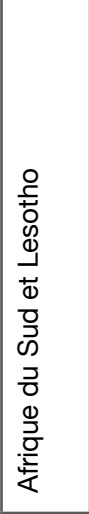 & 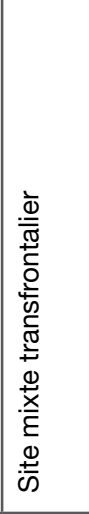 & $\begin{array}{l}\text { Le site présente une beauté naturelle } \\
\text { exceptionnelle grâce à ses contreforts basaltiques } \\
\text { vertigineux, ses arrière-plans incisifs et } \\
\text { spectaculaires et ses remparts de grès doré, } \\
\text { tandis que la diversité des habitats protège un } \\
\text { niveau élevé de plantes endémiques et } \\
\text { d'importance mondiale, ainsi que plusieurs } \\
\text { espèces animales en voie de disparition. Ce site } \\
\text { naturel spectaculaire contient de nombreuses } \\
\text { grottes et abris sous roche, dont le groupe le plus } \\
\text { grand et le plus dense de peintures rupestres } \\
\text { d'Afrique, au sud du Sahara. Pour plus de détails } \\
\text { voir : http://whc.unesco.org/fr/list/985 }\end{array}$ & $\begin{array}{r}2000 \\
(2013)\end{array}$ & 2493 & & & & & & & - \\
\hline 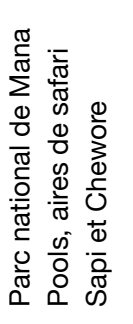 & 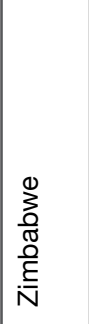 & 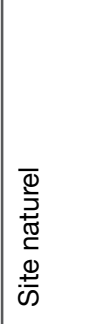 & 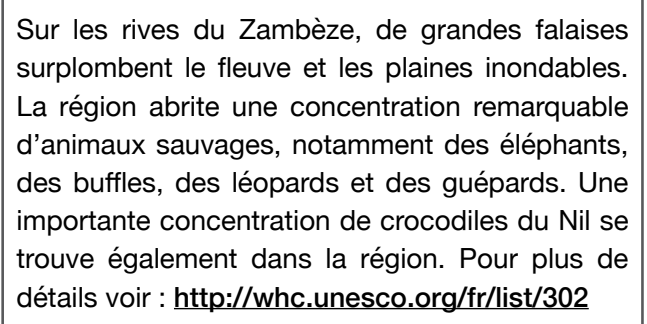 & 1984 & 6766 & & & & & & & 2011 \\
\hline 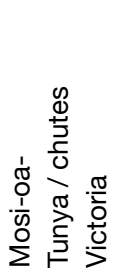 & 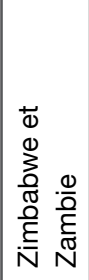 & 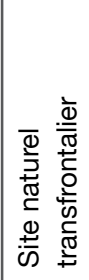 & $\begin{array}{l}\text { Elles figurent parmi les chutes d'eau les plus } \\
\text { spectaculaires du monde. Le Zambèze, large de } \\
\text { plus de } 2 \mathrm{~km} \text { à cet endroit, s'engouffre } \\
\text { bruyamment dans une série de gorges de basalte, } \\
\text { provoquant une brume irisée visible à plus de } 20 \\
\mathrm{~km} \text { de distance. Pour plus de détails voir: } \\
\text { http://whc.unesco.org/fr/list/509 }\end{array}$ & 1989 & 69 & & & & & & & $\begin{array}{l}2000 \\
2006\end{array}$ \\
\hline
\end{tabular}




\begin{tabular}{|c|c|c|c|c|c|c|c|c|c|c|c|c|}
\hline$\frac{\varepsilon}{\text { g }}$ & $\begin{array}{l}\infty \\
\widehat{\sigma} \\
0\end{array}$ & 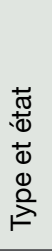 & 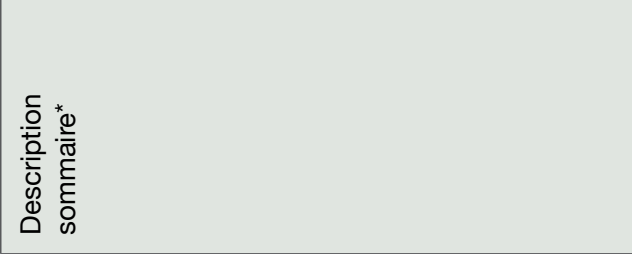 & 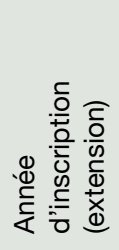 & 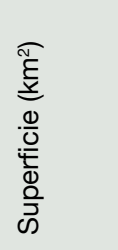 & 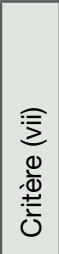 & 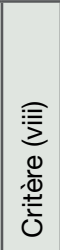 & 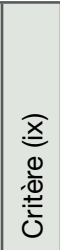 & 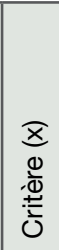 & $\begin{array}{l}\widehat{\sigma} \\
\stackrel{d}{\grave{d}} \\
\delta \\
\delta\end{array}$ & $\mid \begin{array}{l}\mathbb{T} \\
\hat{2} \\
\mathfrak{d} \\
\mathbb{\sigma} \\
0 \\
0\end{array}$ & 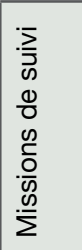 \\
\hline 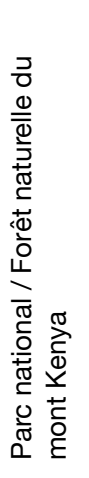 & 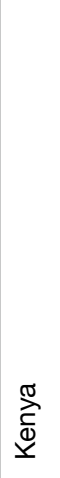 & 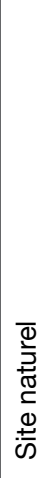 & $\begin{array}{l}\text { Ancien volcan éteint, le mont Kenya est le } \\
\text { deuxième plus haut sommet d'Afrique. II reste } \\
\text { une douzaine de glaciers sur la montagne, tous } \\
\text { en retrait rapide, et l'on trouve quatre sommets } \\
\text { secondaires situés à la tête de vallées glaciaires } \\
\text { en forme de U. Avec ses sommets escarpés } \\
\text { recouverts de glaciers et ses pentes moyennes } \\
\text { boisées, le mont Kenya est l'un des paysages les } \\
\text { plus impressionnants d'Afrique de l'Est. } \\
\text { L'évolution et l'écologie de sa flore afro-alpine } \\
\text { constituent un exemple remarquable de } \\
\text { processus écologiques et biologiques. Pour plus } \\
\text { de détails, voir : http://who.unesco.org/fr/list/800 }\end{array}$ & $\begin{array}{r}1997 \\
(2013)\end{array}$ & 2023 & & & & & & & 2008 \\
\hline 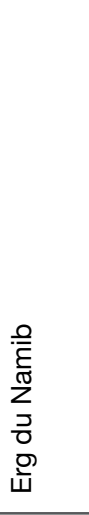 & 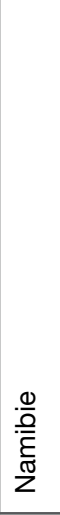 & 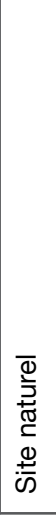 & $\begin{array}{l}\text { L'erg du Namib est le seul désert côtier abritant } \\
\text { de vastes champs de dunes de sable sous } \\
\text { influence du brouillard. Le site comprend des } \\
\text { plaines de gravier, des plaines côtières, des } \\
\text { collines rocheuses, des inselbergs à l'intérieur de } \\
\text { l'erg, un lagon côtier et des cours d'eau } \\
\text { éphémères, le tout formant un paysage d'une } \\
\text { exceptionnelle beauté. Le brouillard est ici la } \\
\text { principale source d'eau, contribuant à un } \\
\text { environnement unique où invertébrés, reptiles et } \\
\text { mammifères endémiques s'adaptent à une } \\
\text { grande variété de micro-habitats et de niches } \\
\text { écologiques en constante évolution. Pour plus de } \\
\text { détails, voir: http://whc.unesco.org/fr/list/1430 }\end{array}$ & 2013 & 30777 & & & & & & & - \\
\hline 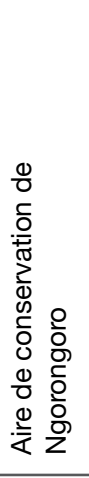 & 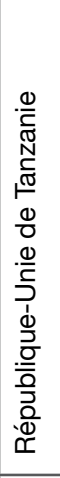 & 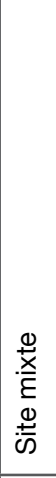 & $\begin{array}{l}\text { Cette zone d'utilisation multiple des terres, où la } \\
\text { faune sauvage coexiste avec les bergers Massaï } \\
\text { semi-nomades pratiquant l'élevage traditionnel } \\
\text { du bétail, comprend le spectaculaire cratère du } \\
\text { Ngorongoro, la plus grande caldeira du monde. } \\
\text { Le site jouxte le Parc national du Serengeti et } \\
\text { accueille la migration annuelle des gnous, zèbres } \\
\text { et gazelles dans ses plaines du nord, pendant une } \\
\text { partie de l'année. Le site fournit des preuves de } \\
\text { l'évolution humaine, y compris les premières } \\
\text { empreintes d'hominidés datant de } 3,6 \text { millions } \\
\text { d'années. Pour plus de détails, voir: } \\
\text { http://whc.unesco.org/fr/list/39 }\end{array}$ & $\begin{array}{r}1979 \\
(2010)\end{array}$ & 8094 & & & & & & & $\begin{array}{l}1986 \\
2007 \\
2012 \\
2017 \\
2019\end{array}$ \\
\hline 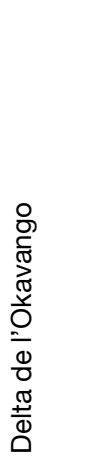 & 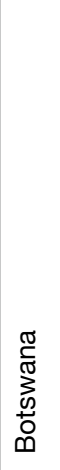 & 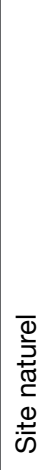 & $\begin{array}{l}\text { Ce delta comprend des marécages permanents } \\
\text { et des prairies saisonnièrement inondées. Il s'agit } \\
\text { d'un des très rares grands systèmes de deltas } \\
\text { intérieurs n'ayant pas de débouché dans la mer } \\
\text { ou l'océan, et d'un système de zones humides } \\
\text { quasi intact. C'est un exemple exceptionnel de } \\
\text { l'interaction des processus climatiques, } \\
\text { hydrologiques et biologiques. Le delta de } \\
\text { l'Okavango abrite certaines des espèces de } \\
\text { grands mammifères les plus menacées aumonde, } \\
\text { telles que le guépard, le rhinocéros blanc, le } \\
\text { rhinocéros noir, le lycaon et le lion. Pour plus de } \\
\text { détails voir : http:///whc.unesco.org/fr/list/1432 }\end{array}$ & 2014 & 20236 & & & & & & & - \\
\hline
\end{tabular}




\begin{tabular}{|c|c|c|c|c|c|c|c|c|c|c|c|c|}
\hline$\frac{\varepsilon}{\text { E }}$ & $\stackrel{\infty}{\underset{\varpi}{0}}$ & 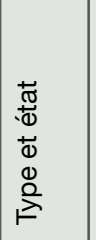 & 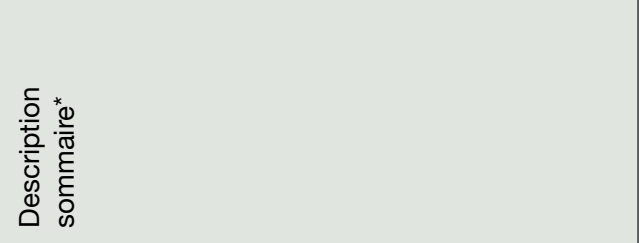 & 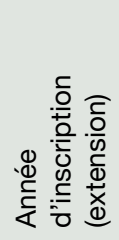 & 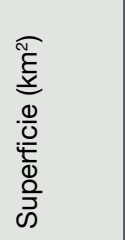 & 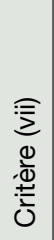 & 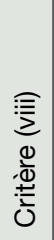 & 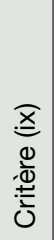 & 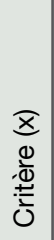 & $\begin{array}{l}\frac{\sigma}{\sigma} \\
\stackrel{d}{\sigma} \\
\delta \\
0\end{array}$ & $\begin{array}{l}\text { T } \\
\stackrel{0}{\hat{d}} \\
\delta \\
\delta \\
0\end{array}$ & 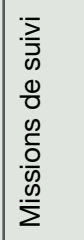 \\
\hline 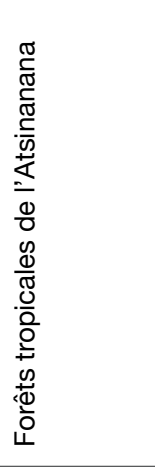 & 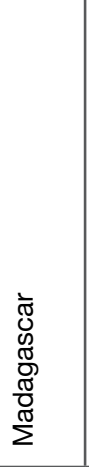 & 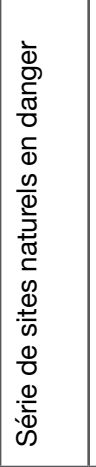 & $\begin{array}{l}\text { Le site comprend six parcs nationaux protégeant } \\
\text { des forêts anciennes d'une importance cruciale } \\
\text { pour le maintien des processus écologiques } \\
\text { nécessaires à la survie de la biodiversité unique } \\
\text { de Madagascar. La vie végétale et animale de } \\
\text { Madagascar a évolué de manière isolée, et de } \\
\text { nombreuses espèces sont rares et menacées à } \\
\text { l'échelle mondiale, en particulier les } \\
\text { emblématiques lémuriens. Les forêts tropicales } \\
\text { sont importantes pour les processus écologiques } \\
\text { et biologiques ainsi que pour leur biodiversité et } \\
\text { les espèces menacées qu'elles abritent. Pour plus } \\
\text { de détails voir: http://whc.unesco.org/fr/list/1257 }\end{array}$ & 2007 & 4797 & & & & & & & $\begin{array}{l}2011 \\
2015\end{array}$ \\
\hline 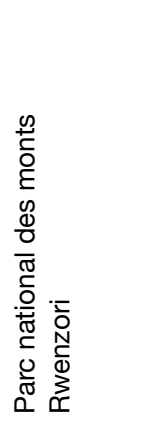 & $\begin{array}{l}\frac{\pi}{0} \\
\frac{0}{\pi} \\
\frac{0}{3} \\
0\end{array}$ & 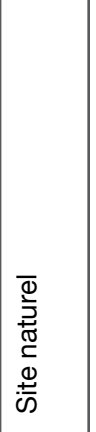 & $\begin{array}{l}\text { Le Parc national des monts Rwenzori couvre près } \\
\text { de } 100000 \text { ha dans l'ouest de l'Ouganda et } \\
\text { comprend la majeure partie de la chaîne des } \\
\text { Rwenzori, dont le troisième plus haut sommet } \\
\text { d'Afrique (le mont Margherita: } 5109 \mathrm{~m} \text { ). Ses } \\
\text { glaciers, ses cascades et ses lacs en font l'une } \\
\text { des plus belles régions alpines d'Afrique. Le parc } \\
\text { possède de nombreux habitats naturels } \\
\text { d'espèces menacées et une flore riche et } \\
\text { inhabituelle comprenant, entre autres, les } \\
\text { bruyères géantes. Pour plus de détails voir: } \\
\text { http://whc.unesco.org/fr/list/684 }\end{array}$ & 1994 & 996 & & & & & & & - \\
\hline 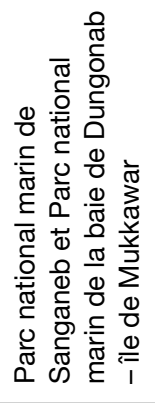 & $\begin{array}{l}\frac{5}{\pi} \\
\frac{\pi}{0} \\
\text { œ }\end{array}$ & 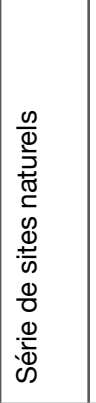 & $\begin{array}{l}\text { Le site se compose de deux zones distinctes: } \\
\text { Sanganeb est un atoll corallien isolé dans la mer } \\
\text { Rouge centrale, et la composante de la baie de } \\
\text { Dungonab et de l'île de Mukkawar comprend un } \\
\text { système diversifié de récifs coralliens, de } \\
\text { mangroves, d'herbiers marins, de plages et } \\
\text { d'îlots. Le site abrite une importante population } \\
\text { de dugongs, ainsi que des oiseaux de mer, des } \\
\text { mammifères marins, des poissons, des requins, } \\
\text { des tortues et des raies manta. Pour plus de } \\
\text { détails voir : http://whc.unesco.org/fr/list/262 }\end{array}$ & 2016 & 2607 & & & & & & & - \\
\hline 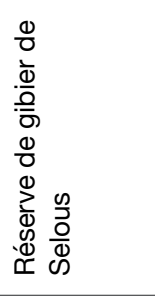 & 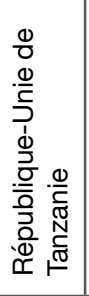 & 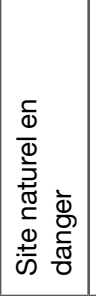 & $\begin{array}{l}\text { Un grand nombre d'éléphants, de rhinocéros } \\
\text { noirs, de guépards, de girafes, d'hippopotames et } \\
\text { de crocodiles vivent dans cet immense sanctuaire } \\
\text { couvrant } 50000 \mathrm{~km}^{2} \text { et relativement peu perturbé } \\
\text { par l'homme. Le parc présente toute une variété } \\
\text { de zones de végétation, allant des fourrés denses } \\
\text { à des prairies boisées ouvertes. Pour plus de } \\
\text { détails, voir : http://whc.unesco.org/fr/list/199 }\end{array}$ & 1982 & 51200 & & & & & & & $\begin{array}{l}2007 \\
2008 \\
2013 \\
2017\end{array}$ \\
\hline 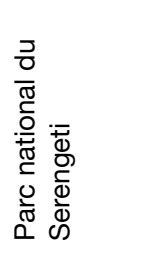 & 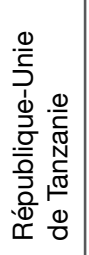 & 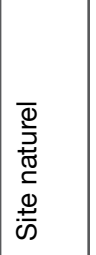 & $\begin{array}{l}\text { Les vastes plaines du Serengeti couvrent } 1,5 \\
\text { million d'ha de savane. La migration annuelle vers } \\
\text { des trous d'eau permanents de vastes troupeaux } \\
\text { d'herbivores (gnous, gazelles et zèbres), suivis de } \\
\text { leurs prédateurs, est l'un des événements naturels } \\
\text { les plus impressionnants au monde. Pour plus de } \\
\text { détails voir : http://whc.unesco.org/fr/list/156 }\end{array}$ & 1981 & 14763 & & & & & & & - \\
\hline
\end{tabular}




\begin{tabular}{|c|c|c|c|c|c|c|c|c|c|c|c|c|}
\hline$\frac{\varepsilon}{\text { E }}$ & $\underset{\widetilde{\sigma}}{\stackrel{\infty}{\sigma}}$ & 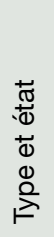 & 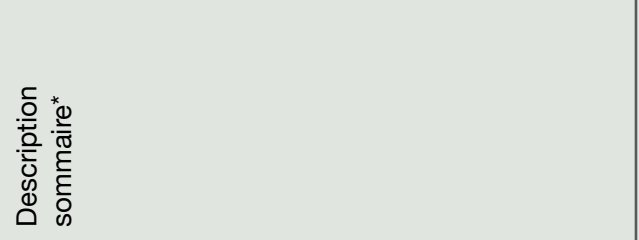 & 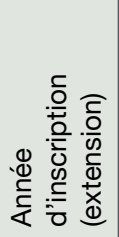 & 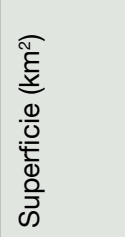 & 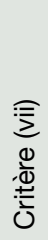 & 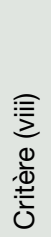 & 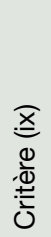 & 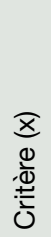 & 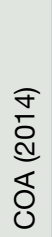 & 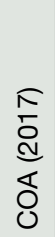 & 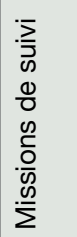 \\
\hline 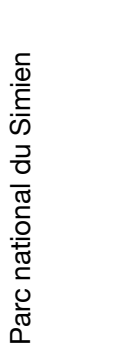 & 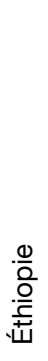 & 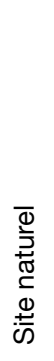 & $\begin{array}{l}\text { Une érosion massive du plateau Éthiopien au } \\
\text { cours de millions d'années a créé l'un des } \\
\text { paysages les plus spectaculaires du monde, avec } \\
\text { des pics déchiquetés, des vallées profondes et } \\
\text { des précipices atteignant jusqu'à } 1500 \mathrm{~m} \text { de } \\
\text { profondeur. Le parc abrite des animaux } \\
\text { extrêmement rares tels que le babouin Gelada, le } \\
\text { loup d'Abyssinie ou le Walia ibex, sorte de chèvre } \\
\text { qu'on ne trouve nulle part ailleurs. Pour plus de } \\
\text { détails, voir : http://whc.unesco.org/fr/list/9 }\end{array}$ & 1978 & 136 & & & & & & & $\begin{array}{l}1981 \\
1996 \\
1997 \\
2017\end{array}$ \\
\hline 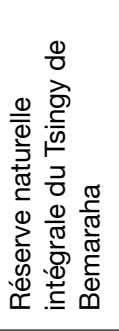 & 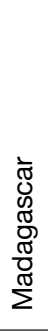 & 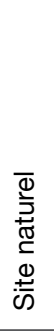 & $\begin{array}{l}\text { Ce site comprend des paysages karstiques et des } \\
\text { hauts plateaux calcaires découpés en } \\
\text { impressionnants «tsingy », ou «forêt » d'aiguilles } \\
\text { calcaires, le spectaculaire canyon de la rivière } \\
\text { Manambolo, des collines et des hauts sommets. } \\
\text { Les forêts intactes, les lacs et les mangroves sont } \\
\text { l'habitat de lémuriens et d'oiseaux rares et } \\
\text { menacés. Pour plus de détails voir: } \\
\text { http://whc.unesco.org/fr/list/494 }\end{array}$ & 1990 & 1520 & & & & & & & - \\
\hline 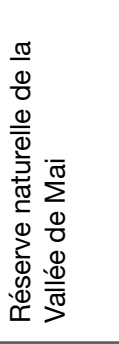 & 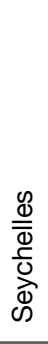 & 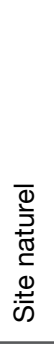 & $\begin{array}{l}\text { Au cœur de la petite île de Praslin, la réserve } \\
\text { abrite les vestiges d'une unique palmeraie } \\
\text { naturelle pratiquement préservée dans son état } \\
\text { d'origine. Le célèbre " coco de mer ", fruit d'un } \\
\text { palmier dont on pensait autrefois qu'il poussait au } \\
\text { fond des mers, est la plus grosse graine du règne } \\
\text { végétal. Pour plus de détails, voir : } \\
\text { http://whc.unesco.org/fr/list/261 }\end{array}$ & 1982 & 0,2 & & & & & & & - \\
\hline 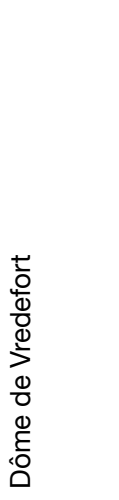 & 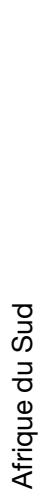 & 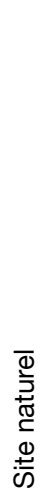 & $\begin{array}{l}\text { Le Dôme de Vredefort est une partie représentative } \\
\text { de la structure d'impact d'une météorite, ou } \\
\text { astroblème. II fournit la preuve de la plus grande } \\
\text { libération d'énergie jamais connue sur la planète, } \\
\text { avec des effets dévastateurs à l'échelle mondiale, } \\
\text { y compris, selon certains scientifiques, des } \\
\text { changements évolutifs terrestres majeurs. Datant } \\
\text { de } 2023 \text { millions d'années, c'est le plus ancien } \\
\text { astroblème découvert à ce jour et, avec un rayon } \\
\text { de } 190 \mathrm{~km} \text {, c'est aussi le plus grand et le plus } \\
\text { profondément érodé. Pour plus de détails voir: } \\
\text { http://whc.unesco.org/fr/list/1162 }\end{array}$ & 2005 & 300 & & & & & & & - \\
\hline
\end{tabular}

Source : Howard et Bomhard (2019). 


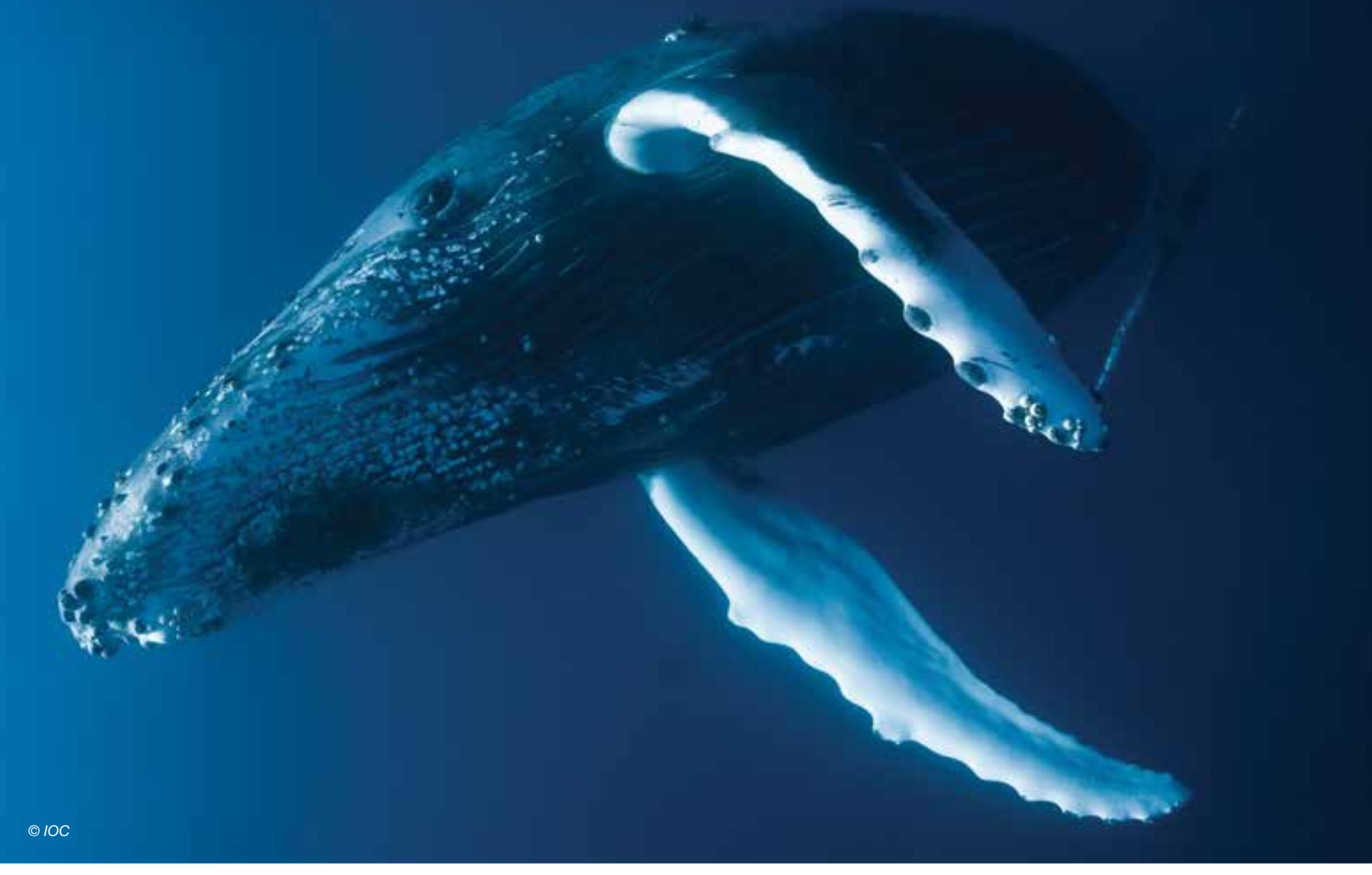

\subsection{Représentativité écologique}

L'un des principaux engagements de la CDB est le principe selon lequel des échantillons représentatifs de toutes les espèces et de tous les écosystèmes sont conservés au sein du réseau d'aires protégées, à une échelle suffisante pour assurer leur persistance à long terme. Les lacunes de représentation font référence aux espèces, aux écosystèmes et aux processus écologiques non inclus, ou insuffisamment inclus, dans le système d'aires protégées. Cette section fournit une analyse initiale des lacunes écologiques, en évaluant la mesure dans laquelle les écorégions sont représentées dans les aires protégées de la région de l'Afrique orientale et australe.

Il est tout aussi important de veiller à ce que les aires protégées soient gérées de manière équitable et efficace (voir les Chapitres 9 et 10). Les espèces et écosystèmes du réseau d'aires protégées ne seront conservés que si les aires protégées sont bien gérées.

Un résumé régional complet de représentativité concernant les écorégions marines et terrestres et les provinces pélagiques est disponible à l'Annexe 4. Ces statistiques ont été compilées en superposant le réseau d'aires protégées à une couche de données combinée représentant les écorégions marines et terrestres et provinces pélagiques du monde, préparée par le CCR/ONAP de la CE sur la base des données définies par Olson et al. (2001) et Spalding et al. (2007 et 2012). Les écorégions marines ont été délimitées au niveau du littoral des écorégions terrestres et à une limite extérieure correspondant à l'isobathe de 200 mètres (Spalding et al., 2007), tel que décrit sur le site web de l'ONAP.11

Quatre-vingt-six des écorégions terrestres du monde sont présentes en Afrique orientale et australe, telle que définie dans le présent rapport. Soixante-trois de ces écorégions terrestres comptent plus de $97 \%$ de leur superficie dans la région, et parmi elles, 32 (environ 50\%) atteignent des superficies de protection supérieures à 17\% (Spalding et al., 2007; 2012).

Certaines écorégions endémiques, telles que la mosaïque forêtprairies montagnardes angolaises, le désert côtier érythréen, les prairies et zones arbustives Hobyo et les forêts xériques montagnardes somaliennes, ne sont couvertes que par moins de $1 \%$ des aires protégées et de conservation officiellement délimitées dans la BDMAP. 
Figure 4.6 : Degrés de protection des écorégions terrestres représentées dans la région
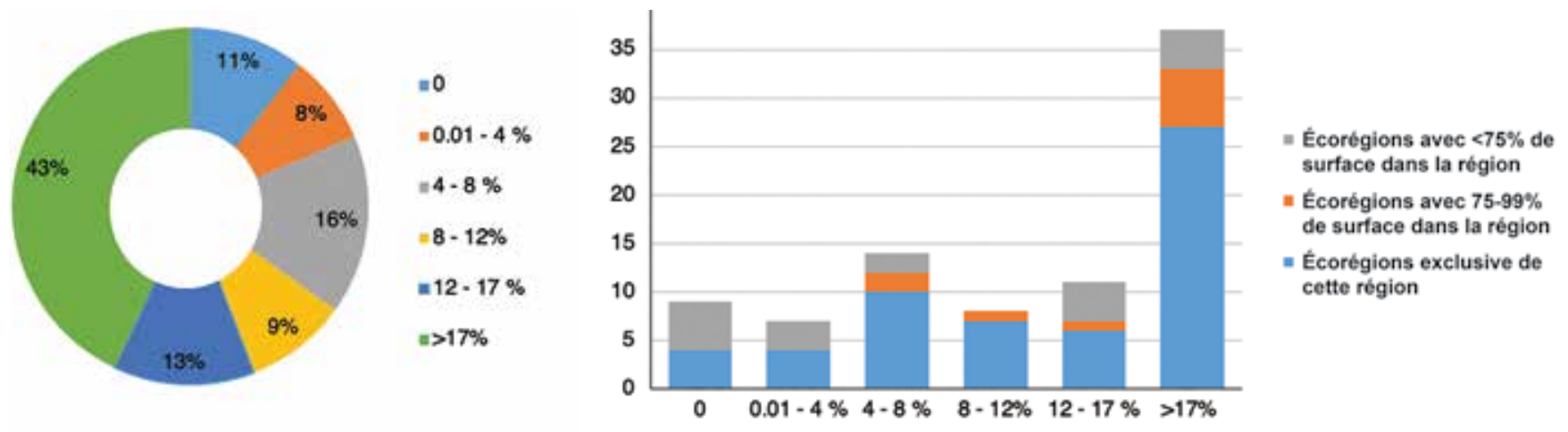

Source : EC JRC/DOPA (2019a).

Figure 4.7 : Degrés de protection des écorégions marines et provinces pélagiques représentées dans la région
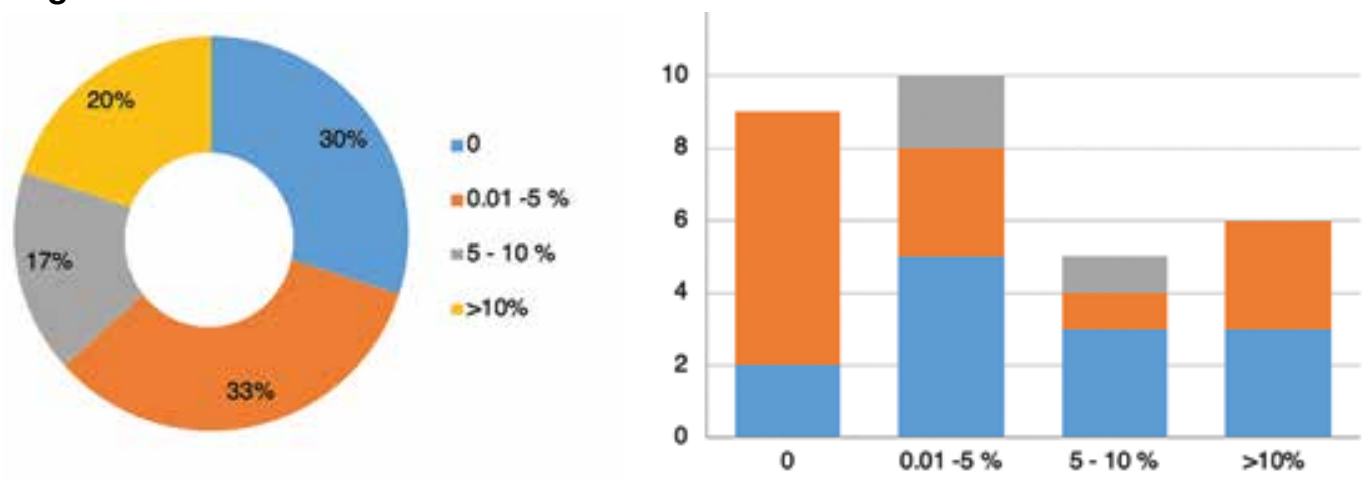
= Écorégions avec $<75 \%$ de surface dans la région
= Écorégions avec 75-99\% de surface dans la région " Écorégions exclusive de cette région

Source : EC JRC/DOPA (2019a).

Parmi les écorégions marines ou provinces pélagiques du monde, 30 se trouvent dans la région (Figure 4.7), dont 13 à hauteur de plus de $95 \%$ de leur superficie. Trois sont protégées à plus de $10 \%$ de leur superficie régionale : la Baie de Sofala au Mozambique, la côte de Corail est-africaine et les îles du Prince-Édouard. L'écorégion des îles du Prince-Édouard (appartenant à l'Afrique du Sud) est $100 \%$ endémique et $100 \%$ protégée, mais les prélèvements ne sont interdits que sur une partie de sa superficie (le plus haut niveau de protection, qui interdit le prélèvement de tout poisson ou autre organisme), comme pour de nombreuses autres aires marines protégées. Un résumé régional complet de la représentativité concernant les écorégions terrestres telles que définies par le WWF est disponible en Annexe 4.

Les systèmes de classification biogéographique peuvent aider les planificateurs à inclure toute la gamme des écosystèmes dans les stratégies mondiales et régionales de conservation et de développement. La meilleure cartographie disponible pour la représentativité écologique est celle des "écorégions terrestres " (voir les résultats de la Figure 4.8). Cependant, conformément à la pratique actuelle, les Réserves de biosphère de l'UNESCO ne sont pas inclues dans les calculs, car bon nombre de leurs zones tampons ne répondent pas à la définition des aires protégées de I'UICN (UNEP-WCMC et IUCN, 2016).
Les écorégions fournissent un indicateur général de la représentativité écologique, et ont été choisies en raison de la disponibilité de données cohérentes pour des analyses à grande échelle. À un niveau plus fin, les pays entreprennent des analyses beaucoup plus détaillées afin d'assurer la protection des écosystèmes, des paysages et des espèces végétales et animales.

\subsection{Qu'est-ce qui a changé dans la couverture des aires protégées?}

L'Objectif d'Aichi 11 a encouragé les pays à protéger $10 \%$ de leur espace marin et $17 \%$ de leur surface terrestre, et des progrès significatifs ont été réalisés en ce sens. II est parfois difficile, cependant, de comprendre la nature dynamique du domaine des aires protégées. Beaucoup de changements ont lieu, y compris la création de nouveaux sites par déclaration officielle, la suppression de sites par déclassement et l'expansion ou la réduction de sites existants (Golden Kroner et al., 2019; Lewis et al., 2017). Les restrictions et réglementations relatives aux aires protégées peuvent également changer, améliorant ou dégradant les protections existantes (Golden Kroner et al., 2019). Parfois, un changement de désignation ou de nom pour un site, ou la combinaison de deux aires protégées pour en former une plus 
grande, peut apparaître simultanément comme un déclassement et une nouvelle déclaration, peut-être sous un nom différent, rendant les changements réels dans l'étendue et la protection des sites difficiles à interpréter. Un exemple en est le Parc national Julius Nyerere, en Tanzanie, auparavant intégré à la réserve de gibier de Selous et aujourd'hui le plus grand parc national d'Afrique.

Un suivi précis de la couverture des aires protégées au fil du temps est difficile, car il existe des limites à toute approche (Lewis et al., 2017). II est tout particulièrement difficile en Afrique orientale et australe en raison de la qualité variable des données dans les versions précédentes de la BDMAP, et notamment le grand nombre de données ponctuelles. Lorsque seules des données ponctuelles sont disponibles, il est nécessaire de se fier à la taille déclarée des aires protégées, qui peut souvent être manquante ou inexacte, par opposition aux superficies réelles de polygones. II en résulte des inexactitudes dans les mesures des aires protégées (Visconti et al., 2013). Pourtant, omettre complètement les données ponctuelles conduirait à une sous-évaluation dramatique de la couverture des aires protégées. Pour cette raison, nous avons choisi d'utiliser les changements concernant le nombre d'aires protégées dans la région plutôt que les données concernant les limites des sites. Dans ce contexte et dans cette région, cette approche a été considérée comme plus précise et a abouti aux données présentées à la Figure 4.9.

Les politiques et pratiques de conservation supposent généralement que les aires protégées constituent des installations permanentes dans le paysage, selon l'intention même de leur définition. Les données indiquent cependant que la diminution de la catégorisation ou de la superficie et le déclassement des aires protégées (PADDD, selon les sigles en anglais) est un phénomène répandu, mais largement négligé (Mascia et Pailler, 2011 - voir l'Encadré 4.1). Selon l'analyse mondiale la plus récente, au moins 3700 événements de PADDD ont été réalisés dans 73 pays entre 1892 et 2018, affectant une superficie d'environ 2 millions de km² (Golden Kroner et al., 2019), et plus de 800 événements proposés ont été enregistrés dans les 24 pays d'Afrique orientale et australe au cours de la même période.

\section{Encadré 4.1 : Qu'est-ce que le PADDD?}

PADDD signifie diminution de la catégorisation, de la superficie et déclassement des aires protégées (Protected Area Downgrading, Downsizing and Degazettement en anglais)

- La diminution de la catégorisation est l'autorisation légale d'une augmentation du nombre, de l'ampleur ou de l'étendue des activités humaines dans une aire protégée.

- La réduction de la superficie est la diminution de la taille d'une aire protégée suite à l'excision d'une zone terrestre ou maritime par un changement de limite légale.

- Le déclassement est la perte de protection juridique pour l'ensemble d'une aire protégée

Les cas de PADDD sont compilés par Conservation International et le Fonds mondial pour la nature. Les données sont disponibles sur : https://www.padddtracker.org/. Source : $\mathrm{Cl}$ et WWF (s.d.).
À l'échelle mondiale, bien qu'il n'existe aucune exigence quant au suivi ou à la déclaration des PADDD (Qin et al., 2019), des analyses ont montré que ceux-ci sont un phénomène ponctuel et épisodique, largement associé aux activités suivantes: extraction des ressources naturelles et développements à l'échelle industrielle $(62 \%)$, pressions foncières locales et revendications territoriales (28\%) et planification de la conservation $(1,7 \%)$ (Mascia et al., 2014). Les grandes aires protégées situées à proximité des centres urbains sont plus susceptibles d'être réduites ou déclassées (Symes et al., 2016).

À l'échelle régionale, en Afrique, le suivi des événements de PADDD a été effectué sur une base ad hoc, et aucun des pays d'Afrique orientale et australe n'a encore fait l'objet d'une analyse détaillée. Jusqu'en 2019, les événements disponibles dans la base de données des PADDD montraient 296 événements réalisés et huit proposés, dans 13 pays d'Afrique orientale et australe ( $\mathrm{Cl}$ et WWF, s.d.). La base de données indique les causes immédiates de diminution de la catégorisation ou de la superficie ou de déclassement qui, dans le contexte régional, incluent: la planification de la conservation $(21)^{13}$, la pêche (1), l'exploitation forestière (9), l'agriculture industrielle (16), l'industrialisation (5), les infrastructures (5), les revendications territoriales (20), l'exploitation minière (24), le pétrole et le gaz (3), l'hébergement de réfugiés (2), les établissements humains ruraux (18) et la subsistance (4).

\subsection{Aires protégées et de conservation transfrontières}

L'importance de la coopération transfrontalière en matière de conservation est de plus en plus reconnue dans toute l'Afrique orientale et australe, où les écosystèmes et les populations animales ne connaissent pas les frontières nationales. Les aires de conservation transfrontalières vont de parcs transfrontaliers, comprenant deux ou plusieurs aires protégées adjacentes, à des aires de conservation incluant une multitude d'utilisations des terres, comme des terres communautaires, des terres privées et des aires protégées officielles. Ces aires de conservation transfrontalières jouent un rôle essentiel dans la sauvegarde d'importantes ressources régionales s'étendant au-delà des frontières, telles que les forêts et autres écosystèmes clés, les bassins versants, les habitats et refuges fauniques continus et les corridors de connectivité permettant les mouvements de la faune. Les aires de conservation transfrontières sont importantes pour le développement national et régional, car elles constituent une base pour le développement d'un tourisme axé sur la nature. Les approches transfrontalières joueront probablement un rôle encore plus important dans l'adaptation aux changements climatiques, car elles permettront des changements dans l'habitat ainsi que le mouvement des espèces, en raison de leur grande taille et de leur approche paysagère de la gestion de l'utilisation des terres. En outre, les financements ont tendance à être plus élevés dans les aires protégées faisant partie d'aires de conservation transfrontalières (Lindsey et al., 2018).

En Afrique australe, la SADC a adopté un programme sur les Aires de conservation transfrontières (ACT), dont la mission est de:

13 Fait généralement référence aux changements juridiques conçus pour améliore l'efficacité et l'efficience de la conservation d'une classe, d'un groupe ou d'un ensemble géographiquement distinct d'aires protégées. 


\section{Figure 4.10: Aires de conservation transfrontalières dans la Communauté de développement de l'Afrique australe (ACT-SADC)}

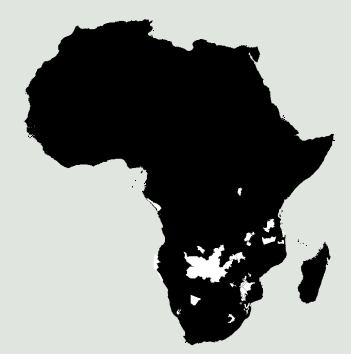

Couverture BIOPAMA ESARO

ACT SADC
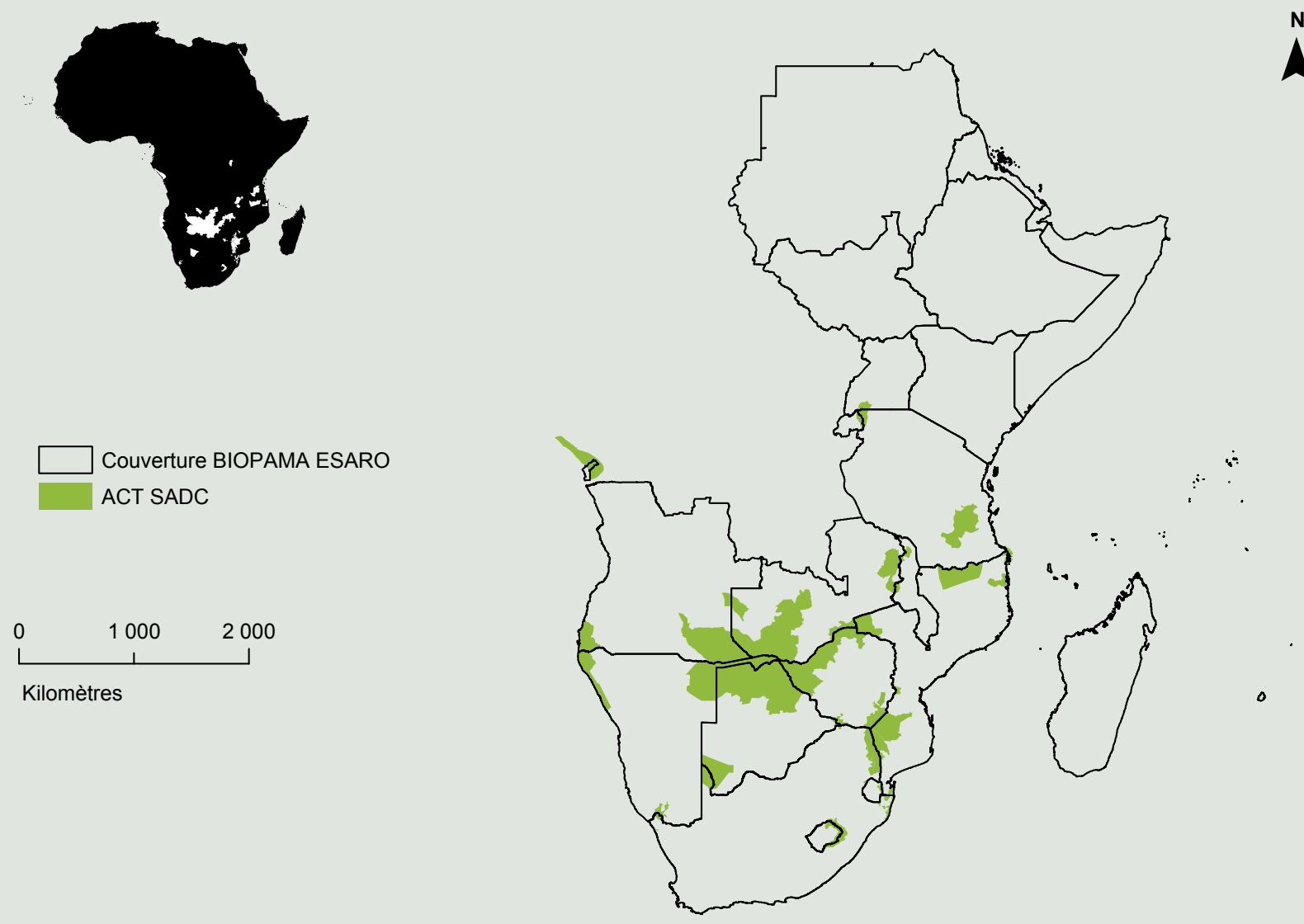

Source : élaboré par le RCMRD à partir des données des Parcs de la paix et de la SADC

développer la SADC en un réseau fonctionnel et intégré d'Aires de conservation transfrontières, dans lequel les ressources naturelles partagées sont cogérées et conservées de manière durable, afin de favoriser le développement socioéconomique et l'intégration régionale au profit des personnes vivant dans et autour des aires de conservation transfrontières, de la région de la SADC et du monde (SADC Secretariat, 2013, p. 4).

Afin de soutenir la mise en œuvre du programme, un réseau d'ACT de la SADC est en place pour rassembler les professionnels de toute la région (voir l'Encadré 4.2). Ce réseau a élaboré un certain nombre de documents utiles à l'appui de la conservation transfrontière, dont les :

- Lignes directrices pour l'engagement communautaire dans les ACT-SADC (SADC Secretariat, 2018) ;

- Lignes directrices de la SADC concernant les produits touristiques transfrontaliers (Spenceley, 2018) ; et

- Lignes directrices pour l'établissement et le développement d'initiatives ACT entre les États membres de la SADC (Zunckel, 2014).

Les deux premières lignes directrices sont en attente d'approbation ministérielle, tandis que les lignes directrices sur l'établissement ont déjà été approuvées.
En Afrique de l'Est, il existe diverses initiatives visant à améliorer la gestion transfrontalière d'écosystèmes clés, mais celles-ci semblent davantage motivées par des sites et organisations individuels, plutôt que par une approche cohérente soutenue par les agences nationales (BIOPAMA, non publié). En 2010, l'EAC a déposé un projet de loi sur la gestion des écosystèmes transfrontaliers, fournissant un cadre et un outil susceptibles de faciliter une approche plus coordonnée de la conservation transfrontalière dans la région (EAC, 2010). À ce jour, cependant, ce projet de loi doit encore être ratifié par les États partenaires de l'EAC.

Bien que bon nombre des aires de conservation transfrontalières de la région aient été officiellement adoptées par les gouvernements participants au moyen d'un traité signé par les chefs d'État, d'autres sont gérées en vertu d'un protocole d'entente entre divers ministères ou organismes gouvernementaux, ou demeurent conceptuelles (voir le Tableau 4.3). La Figure 4.10 montre les ACT établies dans la région. 


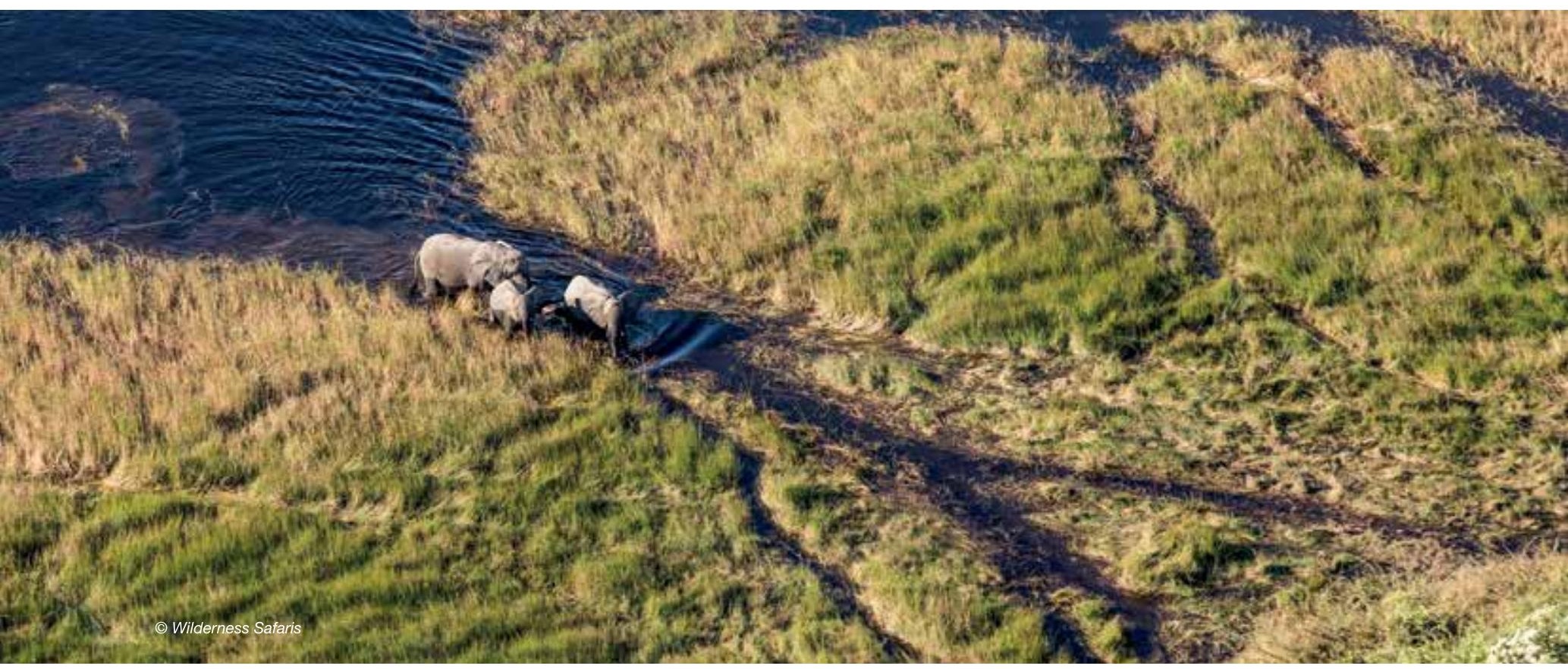

\section{Encadré 4.2 : Réseau d'ACT de la SADC}

Depuis la création, en 1990, du parc transfrontalier de Kgalagadi, premier parc transfrontalier d'Afrique australe entre le Botswana et l'Afrique du Sud, la SADC est restée à l'avantgarde de la conservation transfrontalière. Afin de promouvoir la mise en place et le développement d'ACT en tant que modèle de conservation et de développement dans toute la région, un Programme ACT-SADC a été approuvé en octobre 2013. ॥ existe actuellement $18 \mathrm{ACT}$ terrestres et marines existantes ou en projet dans la région de la SADC, couvrant plus d'un million de kilomètres carrés, soit plus de la moitié de la superficie des aires protégées d'Afrique australe.

Le réseau ACT-SADC a été créé la même année que le Programme ACT, dans le but d'accélérer la mise en œuvre du programme et de renforcer l'apprentissage et la coopération régionale entre les gouvernements, les responsables de la mise en œuvre, la communauté internationale des donateurs, les représentants des communautés, le secteur privé et les spécialistes de la conservation transfrontalière. Plus précisément, ceux-ci ont convenu de partager des informations entre les professionnels et le public, apprendre les uns des autres et créer et élargir les connaissances sur les ACT, favoriser l'innovation sur le terrain ainsi qu'au niveau politique, mobiliser des ressources et contribuer à l'autonomisation des intendants ultimes des ressources naturelles, les communautés.

À ce jour, le réseau comprend plus de 350 membres issus de tous les groupes de parties prenantes concernés, qui communiquent et partagent des informations via un portail web ACT-SADC: www.tfcaportal.org. Son réseau est intégré aux structures de gouvernance de la SADC et guidé par un Comité directeur composé du Secrétariat et des points focaux ACT des États membres. Ainsi, le Comité directeur et le réseau ACT-SADC ont facilité et accéléré les processus décisionnels de la SADC, par exemple par le développement et la promotion de produits touristiques transfrontaliers et des lignes directrices citées précédemment, ainsi que par l'adoption, en 2019, du Programme touristique ACT-SADC, toutes deux pilotées par le réseau.

\section{Leurs réalisations incluent :}

1. participation de plus de 350 adhérents actifs, aux niveaux régional et mondial, démontrant le succès des accords de partenariat de la SADC ;

2. convocation de réunions annuelles du réseau ACT-SADC et participation à des événements mondiaux, tels que le Congrès mondial des parcs de l'UICN en 2014, la CDP17 de la CITES en 2016 et la CDP14 de la CDB en 2018 ;

3. organisation de réunions communautaires transfrontalières, telles que le Forum d'échange intercommunautaire transfrontalier ;

4. appui à la création d'un mécanisme régional de financement des ACT-SADC ;

5. documentation des leçons apprises du soutien à l'élaboration de lignes directrices régionales de l'ACTSADC sur le développement d'ACT, les concessions touristiques, les productions touristiques transfrontalières et l'engagement communautaire ; et

6. création de cinq communautés de pratique destinées à aider à informer les structures statutaires de la SADC grâce à des experts dans les domaines suivants :

- gestion, suivi et évaluation des données ;

- renforcement des capacités et formation ;

- tourisme ;

- engagement communautaire ; et

- application de la loi et lutte contre le braconnage.

Contribution de Lisa Blanken, Deutsche Gesellschaft für Internationale Zusammenarbeit. 
Tableau 4.3 : Aires transfrontières de conservation d'Afrique orientale et australe

\begin{tabular}{|c|c|c|c|c|c|c|}
\hline Nom & Pays inclus & $\begin{array}{l}\text { Superficie } \\
\left(\mathbf{k m}^{2}\right)\end{array}$ & Statut & $\begin{array}{l}\text { Écotype / } \\
\text { biome }\end{array}$ & Aires protégées & $\begin{array}{l}\text { Particularités / } \\
\text { importance }\end{array}$ \\
\hline $\begin{array}{l}\text { ACT de } \\
\text { /Ai-/Ais- } \\
\text { Richtersveld }\end{array}$ & $\begin{array}{l}\text { Namibie, } \\
\text { Afrique du } \\
\text { Sud }\end{array}$ & 5920 & Traité signé & $\begin{array}{l}\text { Désertique ; } \\
\text { Fluvial }\end{array}$ & $\begin{array}{l}\text { Namibie: } \\
\text { Réserve de gibier de Ais-Ais } \\
\text { Hot Spring } \\
\text { Afrique du Sud : } \\
\text { Parc national de Richtersveld }\end{array}$ & Fish River Canyon \\
\hline $\begin{array}{l}\text { Amboseli- } \\
\text { Kilimandjaro- } \\
\text { Longido }\end{array}$ & $\begin{array}{l}\text { Kenya, } \\
\text { Tanzanie }\end{array}$ & $\mathrm{n} / \mathrm{a}$ & Conceptuel & $\begin{array}{l}\text { Montagne ; } \\
\text { Forêt ; } \\
\text { Savane }\end{array}$ & $\mathrm{n} / \mathrm{a}$ & $\begin{array}{l}\text { Endémiques } \\
\text { montagnardes ; } \\
\text { carnivores ; zone de très } \\
\text { grande importance pour } \\
\text { les éléphants }\end{array}$ \\
\hline $\begin{array}{l}\text { Paysage de } \\
\text { Boma- } \\
\text { Gambella }\end{array}$ & $\begin{array}{l}\text { Sud-Soudan, } \\
\text { Éthiopie }\end{array}$ & $\mathrm{n} / \mathrm{a}$ & Conceptuel & $\begin{array}{l}\text { Savane; } \\
\text { Zones } \\
\text { humides }\end{array}$ & $\mathrm{n} / \mathrm{a}$ & $\begin{array}{l}\text { Migration majeure de } \\
\text { gibier des plaines }\end{array}$ \\
\hline $\begin{array}{l}\text { ACT de } \\
\text { Chimanimani }\end{array}$ & $\begin{array}{l}\text { Mozambique, } \\
\text { Zimbabwe }\end{array}$ & 4091 & Traité signé & $\begin{array}{l}\text { Montagnes } \\
\text { et forêts de } \\
\text { miombo }\end{array}$ & $\begin{array}{l}\text { Zimbabwe : } \\
\text { Parc national de Chimanimani } \\
\text { Mozambique: } \\
\text { Réserve naturelle de } \\
\text { Chimanimani }\end{array}$ & $\begin{array}{l}\text { Forêt, paysages, faune } \\
\text { sauvage et culture }\end{array}$ \\
\hline $\begin{array}{l}\text { Parc } \\
\text { transfrontalier } \\
\text { et aire de } \\
\text { conservation } \\
\text { du Grand } \\
\text { Limpopo }\end{array}$ & $\begin{array}{l}\text { Afrique du } \\
\text { Sud, } \\
\text { Mozambique, } \\
\text { Zimbabwe }\end{array}$ & 37572 & Traité signé & $\begin{array}{l}\text { Forêts de } \\
\text { miombo }\end{array}$ & $\begin{array}{l}\text { Mozambique : } \\
\text { Parc national du Limpopo } 0 \\
\text { Afrique du Sud : } \\
\text { Parc national de Kruger } 0 \\
\text { Zimbabwe: } \\
\text { Parc national de Gonarezhou } 0\end{array}$ & $\begin{array}{l}\text { Ripisylves ; endémisme } \\
\text { régional ; zones } \\
\text { importantes de } \\
\text { dispersion des } \\
\text { éléphants }\end{array}$ \\
\hline $\begin{array}{l}\text { ACT du Grand } \\
\text { Mapungubwe }\end{array}$ & $\begin{array}{l}\text { Botswana, } \\
\text { Afrique du } \\
\text { Sud, } \\
\text { Zimbabwe }\end{array}$ & 5909 & $\begin{array}{l}\text { Protocole } \\
\text { d'accord } \\
\text { signé }\end{array}$ & Savane & $\begin{array}{l}\text { Botswana: } \\
\text { Réserve de gibier de Tuli du } \\
\text { Nord 0 } \\
\text { Zimbabwe: } \\
\text { Zone de safari du Cercle de Tuli } 0 \\
\text { Afrique du Sud: } \\
\text { Parc national de Mapungubwe } \\
\text { et paysage culturel de } \\
\text { Mapungubwe, site du } \\
\text { Patrimoine mondial } 0\end{array}$ & $\begin{array}{l}\text { Artefacts culturels ; } \\
\text { géologie unique ; faune } \\
\text { et flore distinctives }\end{array}$ \\
\hline $\begin{array}{l}\text { Grand } \\
\text { paysage des } \\
\text { Virunga }\end{array}$ & $\begin{array}{l}\text { Rwanda, } \\
\text { Ouganda, } \\
\text { RDC }\end{array}$ & 15000 & $\begin{array}{l}\text { Traité signé } \\
\text { (en attente } \\
\text { de } \\
\text { ratification) }\end{array}$ & $\begin{array}{l}\text { Forêt de } \\
\text { moyenne } \\
\text { altitude et de } \\
\text { montagne } \\
\text { du Rift } \\
\text { Albertine; } \\
\text { savane } \\
\text { est- } \\
\text { soudanaise; } \\
\text { zones } \\
\text { humides }\end{array}$ & $\begin{array}{l}\text { RDC : } \\
\text { Site du Patrimoine } \\
\text { mondial / Parc national des } \\
\text { Virunga } \\
\text { Rwanda : } \\
\text { Parc national des Volcans } \\
\text { Ouganda: } \\
\text { Parc national de Mgahinga } \\
\text { Parc national Queen Elizabeth } \\
\text { Site du Patrimoine } \\
\text { mondial / Parc national de } \\
\text { Bwindi } \\
\text { Parc national de Semuliki } \\
\text { Site du Patrimoine } \\
\text { mondial / Parc national de } \\
\text { Ruwenzori } \\
\text { Parc national de Kibale } \\
\text { Réserve forestière de Kasyoha- } \\
\text { Kitomi } \\
\text { Réserve forestière de Kalinzu- } \\
\text { Maramgambo } \\
\text { Réserve des zones humides de } \\
\text { Kayumbura }\end{array}$ & $\begin{array}{l}\text { Écorégion du Rift } \\
\text { Albertine ; } 3 \text { sites du } \\
\text { Patrimoine mondial ; } \\
\text { intégralité de la } \\
\text { population de gorilles } \\
\text { de montagne et } \\
\text { importantes populations } \\
\text { de chimpanzés; } \\
\text { majorité des espèces } \\
\text { endémiques Albertines ; } \\
\text { potentiel touristique } \\
\text { exceptionnel ; } \\
\text { protection de stocks } \\
\text { vitaux de poissons } \\
\text { d'eau douce; protection } \\
\text { des bassins versants }\end{array}$ \\
\hline $\begin{array}{l}\text { ACT de lona } \\
\text { - Côte des } \\
\text { squelettes }\end{array}$ & $\begin{array}{l}\text { Angola, } \\
\text { Namibie }\end{array}$ & 47698 & $\begin{array}{l}\text { Protocole } \\
\text { d'accord } \\
\text { signé }\end{array}$ & Désert & $\begin{array}{l}\text { Angola : } \\
\text { Parc national de lona } \\
\text { Namibie: } \\
\text { Parc national la côte des } \\
\text { Squelettes }\end{array}$ & $\begin{array}{l}\text { Rivière et écosystème } \\
\text { Kunene } \\
\text { Sources naturelles } \\
\text { Espèces végétales } \\
\text { endémiques }\end{array}$ \\
\hline
\end{tabular}




\begin{tabular}{|c|c|c|c|c|c|c|}
\hline Nom & Pays inclus & $\begin{array}{l}\text { Superficie } \\
\left(\mathbf{k m}^{2}\right)\end{array}$ & Statut & $\begin{array}{l}\text { Écotype / } \\
\text { biome }\end{array}$ & Aires protégées & $\begin{array}{l}\text { Particularités / } \\
\text { importance }\end{array}$ \\
\hline $\begin{array}{l}\text { ACT de } \\
\text { Kagera }\end{array}$ & $\begin{array}{l}\text { Reste à } \\
\text { finaliser, mais } \\
\text { inclut le } \\
\text { Rwanda, la } \\
\text { Tanzanie et } \\
\text { l'Ouganda }\end{array}$ & 2500 & $\begin{array}{l}\text { Protocole } \\
\text { d'accord } \\
\text { signé }\end{array}$ & $\begin{array}{l}\text { Savane; } \\
\text { Prairies ; } \\
\text { Forêts } \\
\text { humides ; } \\
\text { Zones } \\
\text { humides ; } \\
\text { Forêt } \\
\text { afro-monta- } \\
\text { gnarde; } \\
\text { forêt } \\
\text { tropicale } \\
\text { humide }\end{array}$ & $\begin{array}{l}\text { Rwanda : } \\
\text { Parc national de l'Akagera } \\
\text { Tanzanie: } \\
\text { Parcs nationaux d'lbanda et de } \\
\text { Rumanyika }\end{array}$ & $\begin{array}{l}\text { Rivière Kagera ; plus } \\
\text { grande zone humide } \\
\text { protégée d'Afrique de } \\
\text { l'Est ; cascades de } \\
\text { forêts sacrées, } \\
\text { systèmes de grottes et } \\
\text { peintures rupestres ; } \\
\text { biodiversité } \\
\text { exceptionnelle }\end{array}$ \\
\hline $\begin{array}{l}\text { ACT de } \\
\text { Kavango- } \\
\text { Zambèze }\end{array}$ & $\begin{array}{l}\text { Angola, } \\
\text { Botswana, } \\
\text { Namibie, } \\
\text { Zambie et } \\
\text { Zimbabwe }\end{array}$ & 520000 & Traité signé & $\begin{array}{l}\text { Forêt de } \\
\text { miombo ; } \\
\text { Prairies } \\
\text { inondées } \\
\text { zambé- } \\
\text { ziennes ; } \\
\text { savane }\end{array}$ & $\begin{array}{l}\text { Angola: } \\
\text { Parc national de Luengue- } \\
\text { Luiana } \\
\text { Parc national de Mavinga } \\
\text { Botswana: } \\
\text { Parc national de Chobe } \\
\text { Parc national de Makgadikgadi } \\
\text { Parc national de Nxai Pan } \\
\text { Réserve de gibier de Moremi } \\
\text { Namibie: } \\
\text { Parc national de Mamili } \\
\text { Parc national de Mudumu } \\
\text { Parc national de Bwabwata } \\
\text { Zambie: } \\
\text { Parc national de Kafue } \\
\text { Parc national de Mosi-oa-Tunya } \\
\text { Parc national de Sioma Ngwezi } \\
\text { Zimbabwe: } \\
\text { Parc national de Hwange } \\
\text { Parc national de Kazuma Pan } \\
\text { Parc national de Matusadona } \\
\text { Parc national du Zambèze } \\
\text { Parc national des chutes } \\
\text { Victoria }\end{array}$ & $\begin{array}{l}\text { Zones humides uniques } \\
\text { du Delta de } \\
\text { l'Okavango ; migrations } \\
\text { de la faune; } \\
\text { grande population } \\
\text { d'éléphants ; } \\
\text { autres grands } \\
\text { mammifères ; Parc de la } \\
\text { paix ; potentiel } \\
\text { touristique exceptionnel }\end{array}$ \\
\hline $\begin{array}{l}\text { Paysage de } \\
\text { Kidepo }\end{array}$ & $\begin{array}{l}\text { Ouganda, } \\
\text { Soudan du } \\
\text { Sud }\end{array}$ & $\mathrm{n} / \mathrm{a}$ & $\begin{array}{l}\text { Protocole } \\
\text { d'accord } \\
\text { partiel } \\
\text { (pour } \\
\text { certaines } \\
\text { réserves } \\
\text { forestières) }\end{array}$ & Savane & $\mathrm{n} / \mathrm{a}$ & $\begin{array}{l}\text { Guépard, lycaon, petit } \\
\text { koudou, Karamoja } \\
\text { Apalis }\end{array}$ \\
\hline $\begin{array}{l}\text { Parc } \\
\text { transfrontalier } \\
\text { de Kgalagadi }\end{array}$ & $\begin{array}{l}\text { Botswana, } \\
\text { Afrique du } \\
\text { Sud }\end{array}$ & 35551 & Traité signé & Désert & $\begin{array}{l}\text { Botswana : } \\
\text { Parc national de Gemsbok } \\
\text { Afrique du Sud: } \\
\text { Parc national du Kalahari } \\
\text { Gemsbok }\end{array}$ & $\begin{array}{l}\text { Écosystème unique du } \\
\text { Kalahari ; lions à crinière } \\
\text { noire ; Gemsbok,etc. }\end{array}$ \\
\hline $\begin{array}{l}\text { ACT des } \\
\text { Plaines de } \\
\text { Liuwa- } \\
\text { Mussuma }\end{array}$ & $\begin{array}{l}\text { Angola, } \\
\text { Zambie }\end{array}$ & 14464 & $\begin{array}{l}\text { ACT } \\
\text { conceptuel }\end{array}$ & $\begin{array}{l}\text { Écorégion } \\
\text { des prairies } \\
\text { inondées } \\
\text { du } \\
\text { Zambèze, } \\
\text { écorégion } \\
\text { des forêts } \\
\text { de miombo } \\
\text { et écoré- } \\
\text { gion des } \\
\text { forêts } \\
\text { sèches de } \\
\text { Cryptose- } \\
\text { palum du } \\
\text { Zambèze }\end{array}$ & $\begin{array}{l}\text { Zambie: } \\
\text { Parc national des Plaines de } \\
\text { Liuwa } \\
\text { Angola: } \\
\text { Parc national de Massuma }\end{array}$ & $\begin{array}{l}\text { Deuxième plus grande } \\
\text { migration de gnous en } \\
\text { Afrique, une partie } \\
\text { importante du bassin } \\
\text { versant du fleuve } \\
\text { Zambèze, le quatrième } \\
\text { plus grand système } \\
\text { fluvial d'Afrique }\end{array}$ \\
\hline $\begin{array}{l}\text { Paysage du } \\
\text { Bas Awash } \\
\text { - lac Abbé }\end{array}$ & $\begin{array}{l}\text { Djibouti, } \\
\text { Éthiopie }\end{array}$ & $\mathrm{n} / \mathrm{a}$ & Conceptuel & $\begin{array}{l}\text { Terres } \\
\text { arides }\end{array}$ & $\mathrm{n} / \mathrm{a}$ & $\mathrm{n} / \mathrm{a}$ \\
\hline
\end{tabular}




\begin{tabular}{|c|c|c|c|c|c|c|}
\hline Nom & Pays inclus & $\begin{array}{l}\text { Superficie } \\
\left(\mathrm{km}^{2}\right)\end{array}$ & Statut & $\begin{array}{l}\text { Écotype / } \\
\text { biome }\end{array}$ & Aires protégées & $\begin{array}{l}\text { Particularités / } \\
\text { importance }\end{array}$ \\
\hline $\begin{array}{l}\text { ACT du Bas } \\
\text { Zambèze } \\
\text { - Mana Pools }\end{array}$ & $\begin{array}{l}\text { Zambie, } \\
\text { Zimbabwe }\end{array}$ & 17745 & $\begin{array}{l}\text { ACT } \\
\text { conceptuel }\end{array}$ & $\begin{array}{l}\text { Forêts de } \\
\text { miombo }\end{array}$ & $\begin{array}{l}\text { Zimbabwe : } \\
\text { Parc national / Site du } \\
\text { Patrimoine mondial de Mana } \\
\text { Pools } \\
\text { Zones de safari de Sapi et } \\
\text { Chewore } \\
\text { Parc national du Bas Zambèze } \\
+6 \text { réserves supplémentaires }\end{array}$ & $\begin{array}{l}\text { Fleuve Zambèze ; plaine } \\
\text { inondable ; } \\
\text { escarpement ; } \\
\text { populations de grands } \\
\text { mammifères }\end{array}$ \\
\hline $\begin{array}{l}\text { ACT de } \\
\text { Lubombo }\end{array}$ & $\begin{array}{l}\text { Eswatini, } \\
\text { Mozambique, } \\
\text { Afrique du } \\
\text { Sud }\end{array}$ & 10029 & Traité signé & $\begin{array}{l}\text { Plaine } \\
\text { côtière }\end{array}$ & $\begin{array}{l}\text { Regroupe } 5 \text { projets d'ACT } \\
\text { Eswatini : } \\
\text { Parc national royal de Hlana } \\
\text { Afrique du Sud : } \\
\text { Parc des éléphants de Tembe } \\
\text { Mozambique: } \\
\text { Réserve spéciale de Maputo } \\
\text { + } 12 \text { aires protégées par l'État } \\
\text { et autres réserves, ainsi que } \\
\text { des terres privées }\end{array}$ & $\begin{array}{l}\text { Haute biodiversité ; } 5 \\
\text { sites Ramsar ; zones } \\
\text { humides ; zones } \\
\text { boisées }\end{array}$ \\
\hline $\begin{array}{l}\text { ACT Malawi- } \\
\text { Zambie }\end{array}$ & $\begin{array}{l}\text { Malawi, } \\
\text { Zambie }\end{array}$ & 32278 & Traité signé & $\begin{array}{l}\text { Montagne ; } \\
\text { Prairie ; } \\
\text { Zones } \\
\text { humides ; }\end{array}$ & $\begin{array}{l}3 \text { aires protégées, dont le Parc } \\
\text { national de Nyika et la Réserve } \\
\text { de faune du Marais de Vwaza }\end{array}$ & $\begin{array}{l}\text { Prairies et flore } \\
\text { montagnardes ; zones } \\
\text { humides ; programme } \\
\text { de repeuplement }\end{array}$ \\
\hline $\begin{array}{l}\text { ACT de Maloti } \\
\text { Drakensberg } \\
\text { (également un } \\
\text { site } \\
\text { transfrontalier } \\
\text { du Patrimoine } \\
\text { mondial) }\end{array}$ & $\begin{array}{l}\text { Lesotho, } \\
\text { Afrique du } \\
\text { Sud }\end{array}$ & 14740 & $\begin{array}{l}\text { Protocole } \\
\text { d'accord } \\
\text { signé }\end{array}$ & Montagnes & $\begin{array}{l}\text { Lesotho : } \\
\text { Site transfrontalier du } \\
\text { Patrimoine mondial de Maloti } \\
\text { Drakensberg, dont le Parc } \\
\text { national de Sehlabathebe et } \\
\text { Afrique du Sud : } \\
\text { le Parc uKhahlamba } \\
\text { Drakensberg }\end{array}$ & $\begin{array}{l}\text { Montagnes du Sud ; } \\
\text { escarpements ; riche } \\
\text { flore endémique ; zones } \\
\text { humides ; culture San }\end{array}$ \\
\hline $\begin{array}{l}\text { Aire protégée } \\
\text { transfronta- } \\
\text { lière de la forêt } \\
\text { de Mayombe }\end{array}$ & $\begin{array}{l}\text { Angola, } \\
\text { République } \\
\text { Démocratique } \\
\text { du Congo, } \\
\text { Gabon, } \\
\text { République } \\
\text { du Congo }\end{array}$ & 36000 & $\begin{array}{l}\text { Protocole } \\
\text { d'accord } \\
\text { signé }\end{array}$ & $\begin{array}{l}\text { Forêt } \\
\text { tropicale } \\
\text { humide }\end{array}$ & $\begin{array}{l}\text { Angola: } \\
\text { Parc national du Mayombe } \\
\text { RDC : } \\
\text { Parc national de Luki } \\
\text { République du Congo : } \\
\text { Réserve de biosphère de } \\
\text { Dimonika, Parc national de } \\
\text { Conkouati-Douli et Réserve } \\
\text { nationale de Tchimpounga }\end{array}$ & $\begin{array}{l}\text { Bassin forestier tropical } \\
\text { humide; chimpanzés et } \\
\text { gorilles des plaines }\end{array}$ \\
\hline $\begin{array}{l}\text { ACT de la } \\
\text { Baie de } \\
\text { Mnazi- } \\
\text { Quirimbas }\end{array}$ & $\begin{array}{l}\text { Mozambique, } \\
\text { Tanzanie }\end{array}$ & 8150 & $\begin{array}{l}\text { ACT } \\
\text { conceptuel }\end{array}$ & $\begin{array}{l}\text { Biome des } \\
\text { forêts } \\
\text { côtières et } \\
\text { broussailles } \\
\text { d'Afrique } \\
\text { de l'Est }\end{array}$ & $\begin{array}{l}\text { Mozambique : } \\
\text { Parc national de Quirimbas } \\
\text { Tanzanie: } \\
\text { Parc marin de la Baie de Mnazi } \\
\text { et estuaire du Ruvuma }\end{array}$ & $\begin{array}{l}\text { Refuge important pour } \\
\text { la diversité des récifs } \\
\text { dans les zones en aval } \\
\text { du nord et du sud sur } \\
\text { les zones côtières } \\
\text { continentales }\end{array}$ \\
\hline $\begin{array}{l}\text { Site } \\
\text { transfrontalier } \\
\text { du Patrimoine } \\
\text { mondial de } \\
\text { Mosi-oa- } \\
\text { Tunya / chutes } \\
\text { Victoria }\end{array}$ & $\begin{array}{l}\text { Zambie, } \\
\text { Zimbabwe }\end{array}$ & 69 & Traité signé & Fluvial & $\begin{array}{l}\text { Zambie: } \\
\text { Parc national de Mosi-oa-Tunya } \\
\text { Zimbabwe: } \\
\text { Parc national des chutes } \\
\text { Victoria }\end{array}$ & $\begin{array}{l}\text { Chutes Victoria; } \\
\text { site du Patrimoine } \\
\text { mondial ; } \\
\text { caractéristiques } \\
\text { géologiques et } \\
\text { géomorphologiques } \\
\text { exceptionnelles }\end{array}$ \\
\hline Mont Elgon & $\begin{array}{l}\text { Ouganda, } \\
\text { Kenya }\end{array}$ & $\mathrm{n} / \mathrm{a}$ & $\begin{array}{l}\text { Protocole } \\
\text { d'accord } \\
\text { rédigé }\end{array}$ & Montagnes & $\begin{array}{l}\text { Ouganda : } \\
\text { Parc national du Mont Elgon } \\
\text { Kenya: } \\
\text { Parc national du Mont Elgon } \\
\text { Réserves forestières du Mont } \\
\text { Elgon et de Trans-Nzoia } \\
\text { Réserve nationale de } \\
\text { Chepkitale }\end{array}$ & Volcan bouclier éteint \\
\hline
\end{tabular}




\begin{tabular}{|c|c|c|c|c|c|c|}
\hline Nom & Pays inclus & $\begin{array}{l}\text { Superficie } \\
\left(\mathbf{k m}^{2}\right)\end{array}$ & Statut & $\begin{array}{l}\text { Écotype / } \\
\text { biome }\end{array}$ & Aires protégées & $\begin{array}{l}\text { Particularités / } \\
\text { importance }\end{array}$ \\
\hline $\begin{array}{l}\text { ACT de } \\
\text { Niassa-Selous }\end{array}$ & $\begin{array}{l}\text { Mozambique, } \\
\text { Tanzanie }\end{array}$ & 154000 & $\begin{array}{l}\text { Protocole } \\
\text { d'accord } \\
\text { signé }\end{array}$ & $\begin{array}{l}\text { Forêt de } \\
\text { miombo ; } \\
\text { Zones } \\
\text { humides ; } \\
\text { Savane }\end{array}$ & $\begin{array}{l}\text { Mozambique : Réserve } \\
\text { nationale de Niassa } \\
\text { Tanzanie: } \\
\text { Site du Patrimoine } \\
\text { mondial / Réserve de gibier de } \\
\text { Selous } \\
\text { Parc national de Mikumi } \\
\text { Parc national d'Udzungwa } \\
\text { Aire de conservation du gibier } \\
\text { de Kilombero } \\
\text { + zones de gestion de la faune, } \\
\text { zones de conservation et blocs } \\
\text { de chasse }\end{array}$ & $\begin{array}{l}\text { Couloir de migration ; } \\
\text { zone de très grande } \\
\text { importance pour les } \\
\text { éléphants ; buffles, } \\
\text { hippopotames }\end{array}$ \\
\hline $\begin{array}{l}\text { Nyungwe- } \\
\text { Kibira }\end{array}$ & $\begin{array}{l}\text { Burundi, } \\
\text { Rwanda }\end{array}$ & 1171 & $\begin{array}{l}\text { Protocole } \\
\text { d'accord } \\
\text { signé }\end{array}$ & $\begin{array}{l}\text { Forêt } \\
\text { monta- } \\
\text { gnarde de } \\
\text { moyenne } \\
\text { altitude }\end{array}$ & $\begin{array}{l}\text { Rwanda: } \\
\text { Parc national de Nyungwe } \\
\text { Burundi : } \\
\text { Kibira }\end{array}$ & $\begin{array}{l}\text { Forêt et espèces } \\
\text { endémiques }\end{array}$ \\
\hline $\begin{array}{l}\text { Baie de Sango } \\
\text { - Minziro }\end{array}$ & $\begin{array}{l}\text { Tanzanie, } \\
\text { Ouganda }\end{array}$ & 861 & Conceptuel & $\begin{array}{l}\text { Zones } \\
\text { humides et } \\
\text { forêts } \\
\text { maréca- } \\
\text { geuses }\end{array}$ & $\begin{array}{l}\text { Tanzanie : } \\
\text { Réserve naturelle de la Forêt de } \\
\text { Minziro } \\
\text { Ouganda : } \\
\text { Baie de Sango - Île Musambwa } \\
\text { - Système de zones humides } \\
\text { de Kagera }\end{array}$ & $\begin{array}{l}\text { Forêts de Baikiaea- } \\
\text { Podocarpus, espèces } \\
\text { endémiques de papyrus }\end{array}$ \\
\hline $\begin{array}{l}\text { Serengeti- } \\
\text { Mara }\end{array}$ & $\begin{array}{l}\text { Tanzanie, } \\
\text { Kenya }\end{array}$ & 25000 & Conceptuel & Savane & $\begin{array}{l}\text { Parc national du Serengeti } \\
\text { Réserve nationale du Masai } \\
\text { Mara }\end{array}$ & $\begin{array}{l}\text { Migration annuelle de } \\
\text { près de } 2 \text { millions } \\
\text { d'herbivores }\end{array}$ \\
\hline $\begin{array}{l}\text { Paysage } \\
\text { terrestre et } \\
\text { marin de } \\
\text { Tana-Kipini- } \\
\text { Laga Badana } \\
\text { Bushbush }\end{array}$ & $\begin{array}{l}\text { Kenya, } \\
\text { Somalie }\end{array}$ & $\mathrm{n} / \mathrm{a}$ & Conceptuel & $\mathrm{n} / \mathrm{a}$ & $n / a$ & $n / a$ \\
\hline $\begin{array}{l}\text { Système des } \\
\text { réserves } \\
\text { marines de } \\
\text { Tanga et Parc } \\
\text { marin de } \\
\text { Tanga } \\
\text { Coelacanth } \\
\text { (TZ) et (KE) } \\
\text { AMP de Diani } \\
\text { Chale et AMP } \\
\text { de Kisite- } \\
\text { Mpunguti }\end{array}$ & $\begin{array}{l}\text { Tanzanie, } \\
\text { Kenya }\end{array}$ & $\mathrm{n} / \mathrm{a}$ & Conceptuel & & $n / a$ & $n / a$ \\
\hline $\begin{array}{l}\text { Parc marin } \\
\text { transfrontalier } \\
\text { de l'océan } \\
\text { Indien } \\
\text { occidental }\end{array}$ & $\begin{array}{l}\text { Reste à } \\
\text { finaliser, mais } \\
\text { inclut } \\
\text { Madagascar, } \\
\text { Maurice, } \\
\text { Mozambique, } \\
\text { Seychelles, } \\
\text { Tanzanie }\end{array}$ & $\mathrm{n} / \mathrm{a}$ & Conceptuel & $\begin{array}{l}\text { Zones } \\
\text { marines }\end{array}$ & $n / a$ & $\begin{array}{l}\text { Troisième plus grand } \\
\text { récif corallien de la } \\
\text { planète ; abrite cinq des } \\
\text { sept espèces de tortues } \\
\text { marines ; dugong }\end{array}$ \\
\hline $\begin{array}{l}\text { ACT de } \\
\text { ZIMOZA }\end{array}$ & $\begin{array}{l}\text { Mozambique, } \\
\text { Zambie, } \\
\text { Zimbabwe }\end{array}$ & 29859 & Conceptuel & $\begin{array}{l}\text { Prairies, } \\
\text { ripisylves et } \\
\text { forêts } \\
\text { sèches }\end{array}$ & $\begin{array}{l}\text { Aucune aire officiellement } \\
\text { protégée au Mozambique } \\
\text { Zambie: } \\
\text { Parc national du Bas Zambèze } \\
\text { et toute la zone de gestion du } \\
\text { gibier de Rufunsa } \\
\text { Zimbabwe: } \\
\text { Aire de safari de Chewore et } \\
\text { Dande }\end{array}$ & $\begin{array}{l}\text { Nombreux corridors } \\
\text { fauniques; variété } \\
\text { d'espèces, y compris } \\
\text { éléphants, } \\
\text { hippopotames, buffles, } \\
\text { lions, léopards, zibelines } \\
\text { et roans }\end{array}$ \\
\hline
\end{tabular}

Note : La superficie de certaines ACT ne peut pas être déterminée avec précision car celles-ci sont principalement conceptuelles, comme dans le cas de Kagera, Plaines de Liuwa, Bas Zambèze-Mana Pools, Baie de Mnazi-Quirimbas et ZIMOZA. Par conséquent, leurs limites ne sont définies dans aucun document officiel. De même, il est totalement impossible de déterminer la superficie du parc marin transfrontalier de l'océan Indien occidental avant qu'un accord soit trouvé, d'où l'indication « n/a ».

Sources : BIOPAMA (2017); EC (2015); SADC TFCA Portal (s.d.). 

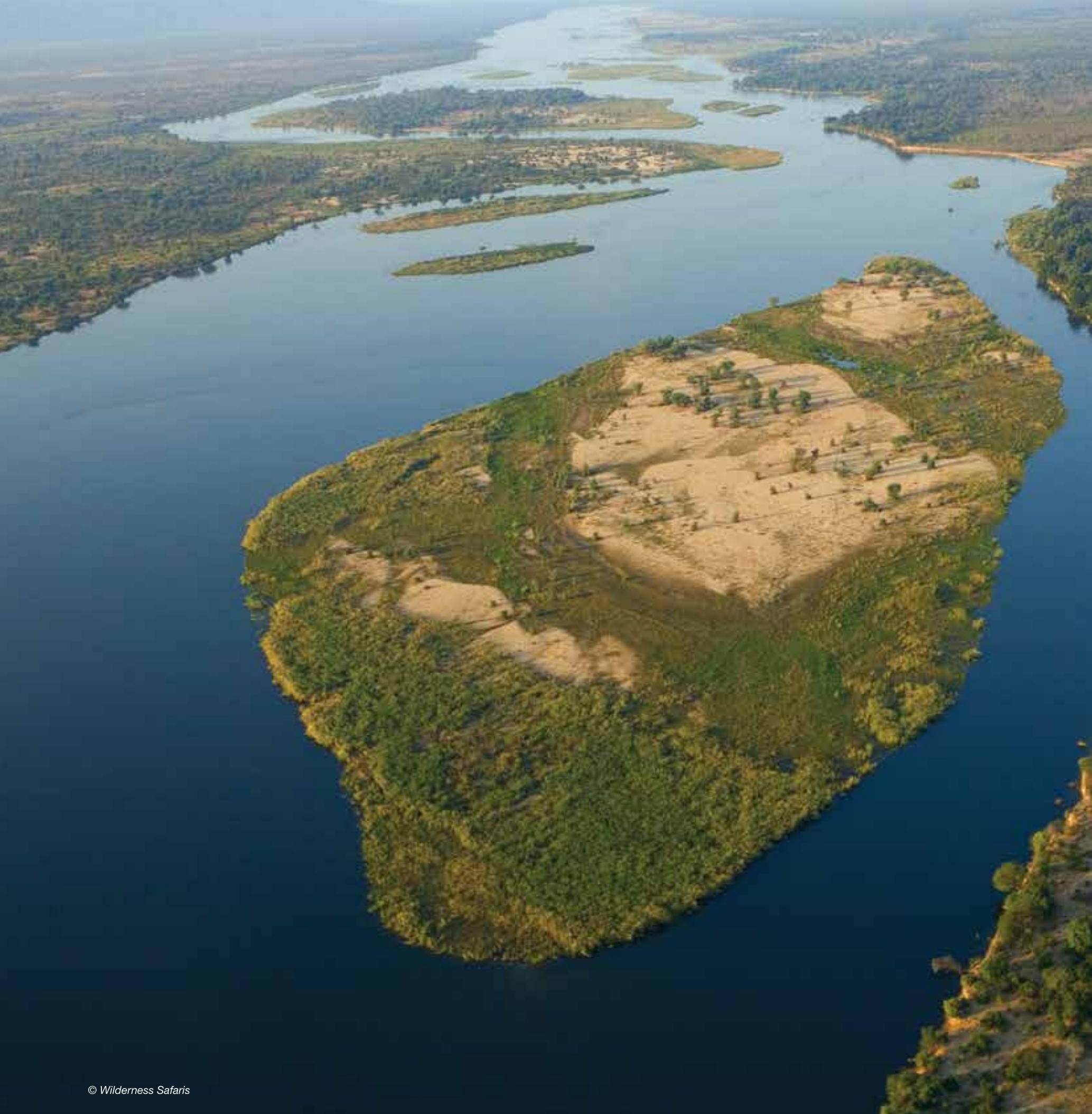


\section{Services}

écosystémiques des aires protégées d'Afrique orientale et australe 


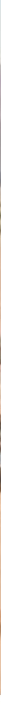

Les services écosystémiques (SE) décrivent les avantages ou contributions de la nature aux personnes. La nature fournit aux humains non seulement de l'oxygène, de l'eau, de la nourriture et des matières premières pour répondre à leurs besoins de base, mais également d'innombrables autres services contribuant à leur bien-être, tels que des possibilités de loisirs, la régulation du climat et des inondations, ou des valeurs spirituelles (voir la Figure 5.1)

Les SE sont apparus dans les années 1980 pour évaluer et communiquer les avantages et contributions de la nature aux personnes au moyen d'un cadre complet et cohérent. L'objectif de ce dernier est de reconnaitre les multiples services fournis par la nature afin d'améliorer la gestion des écosystèmes et des ressources naturelles dans divers domaines politiques, tels que l'aménagement du territoire, les pratiques agricoles, la conservation de la nature ou la gestion des aires protégées. L'Évaluation des écosystèmes pour le Millénaire (MEA, selon ses sigles en anglais) est largement connue pour analyser les liens entre écosystèmes et bien-être humain (MEA, 2005).

Le concept est de plus en plus appliqué à l'élaboration de politiques de conservation de la nature pour un large éventail d'activités. Par exemple, dans le domaine du plaidoyer pour la conservation de la nature, le concept facilite la communication des avantages fournis par les aires protégées de façon suffisamment visuelle et compréhensibles pour renforcer les engagements politiques et financiers. La mise en évidence des avantages et des valeurs des aires protégées contribue à accroître l'acceptation des politiques de conservation de la nature par les politiciens et le grand public, et à stimuler leur financement.

Dans le domaine des aires protégées, le concept de services écosystémiques a été introduit dans les stratégies de gestion et la planification de la conservation spatiale (Hummel et al., 2019). Il est également largement observé dans d'autres secteurs, tels que le tourisme dans les aires protégées, l'agriculture durable et la production hydroélectrique. Bien que son application augmente la complexité et l'information requise, le concept offre de grandes possibilités pour améliorer le zonage, la planification et la gestion des aires protégées, tout en améliorant les connaissances permettant de répondre aux intérêts et aux besoins des différents groupes de parties prenantes, à l'intérieur et autour des aires protégées. Le concept peut aider à faciliter les négociations et les processus décisionnels liés aux aires protégées.

Selon la catégorie de celles-ci, ce changement se reflète également dans les objectifs politiques récents des stratégies de gestion des aires protégées. Par exemple, dans le Parc national Kruger, en Afrique du Sud, les membres des communautés locales sont autorisés à collecter des vers mopane sur une base annuelle pour générer un revenu et comme source de nourriture.

Les loisirs liés au tourisme animalier, qui génèrent des revenus importants pour de nombreux pays de la région, sont un service écosystémique important en Afrique orientale et australe. Les services d'approvisionnement alimentaire et les médicaments traditionnels sont également essentiels, et la dépendance de nombreuses communautés à l'égard des ressources naturelles pour leur survie est grande. Dans une étude menée dans une zone adjacente au Parc national Mosi-oa-Tunya en Zambie en 2017, il a été constaté que $79 \%$ des 136 ménages communautaires interrogés collectaient des ressources naturelles autour du village, $5 \%$ déclarant qu'ils le faisaient à l'intérieur de la réserve forestière et $2 \%$ à l'intérieur du parc national (Snyman, 2012). Cette activité est illégale dans l'un ou l'autre de ces endroits. Afin de déterminer la valeur approximative des ressources naturelles pour les ménages ruraux, il était demandé aux répondants de donner une valeur approximative aux ressources collectées (c'est-à-dire, quelle serait la valeur approximative des ressources s'ils devaient les acheter ?). Les résultats révèlent que la valeur moyenne était d'environ 340 USD par ménage et par mois. Compte tenu du revenu total moyen des ménages, il s'agit là d'une contribution substantielle à leur bien-être global, représentant près de $30 \%$ de revenus supplémentaires mensuels pour les ménages et mettant en évidence la dépendance des communautés à l'égard des ressources naturelles en ce qui concerne le bien-être global des ménages et les services d'approvisionnement alimentaire. 


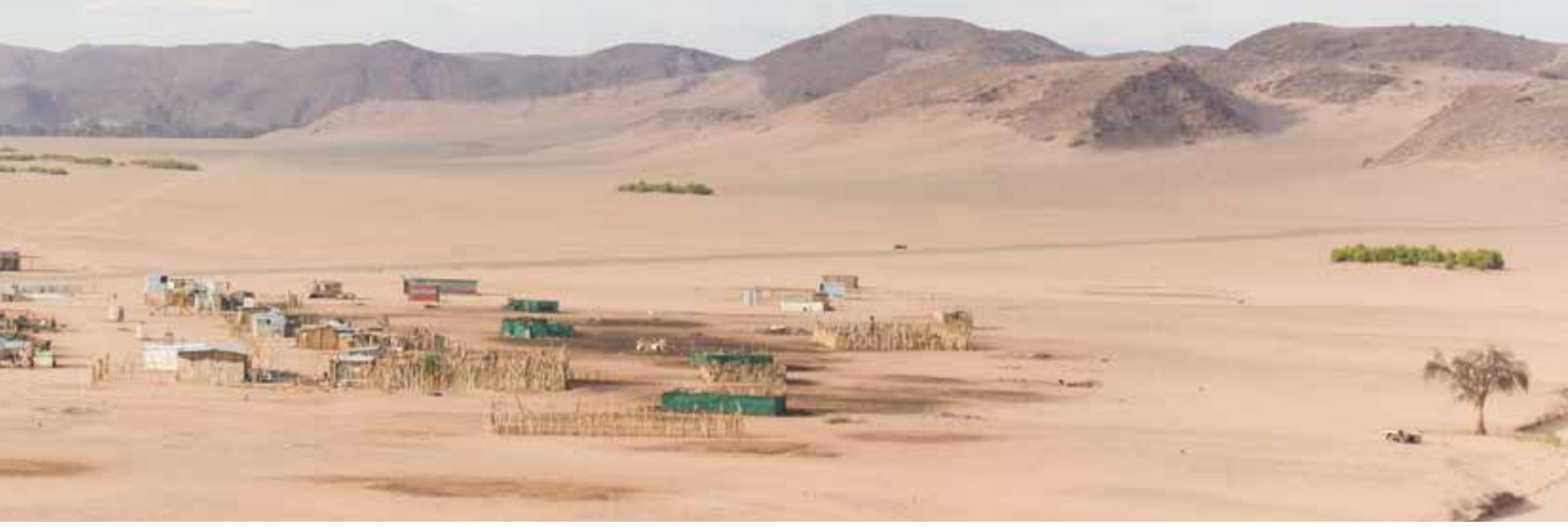

Les services écosystémiques essentiels fournis par les aires protégées et de conservation de la région comprennent la séquestration du carbone et l'approvisionnement en eau. Les services de soutien (habitat, production primaire, biomasse, pollinisation, formation des sols, traitement des déchets, cycle des nutriments et lutte contre l'érosion) sont également d'une importance capitale dans la région.

\section{Figure 5.1 : Types de services écosystémiques}

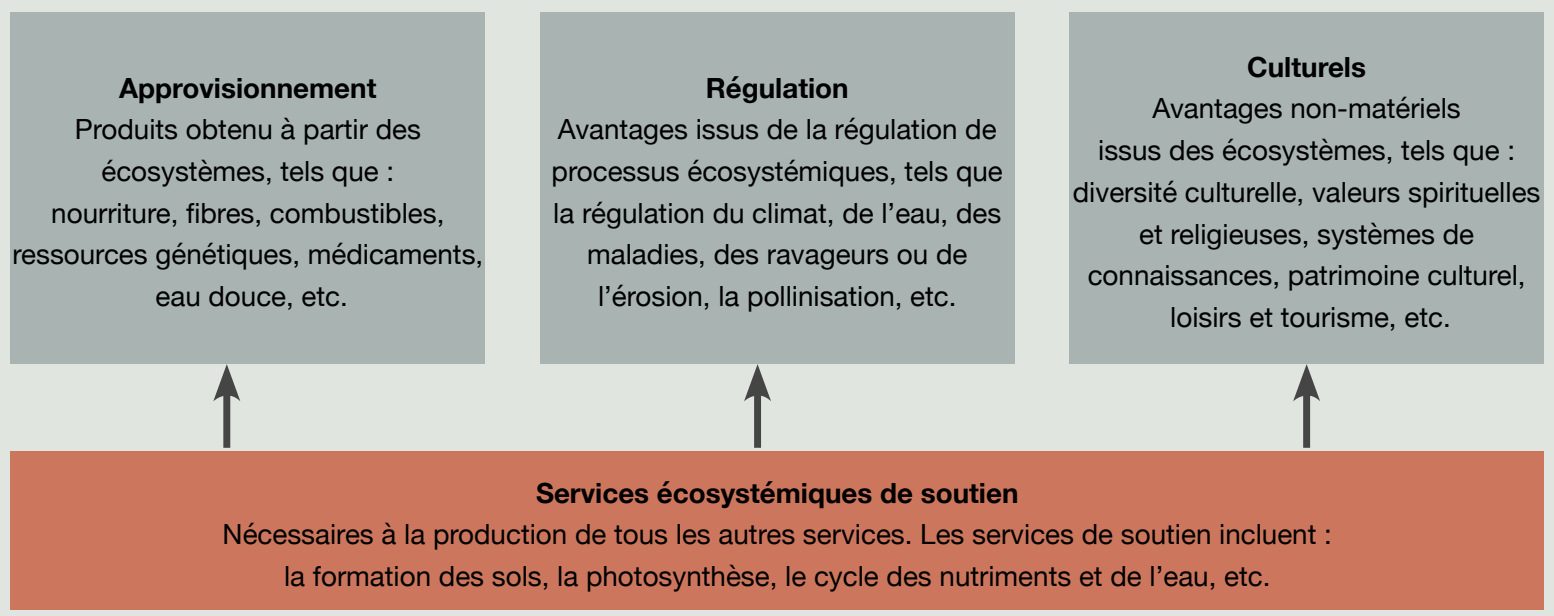

Source : UNGC et UICN (2012, p, 69). 


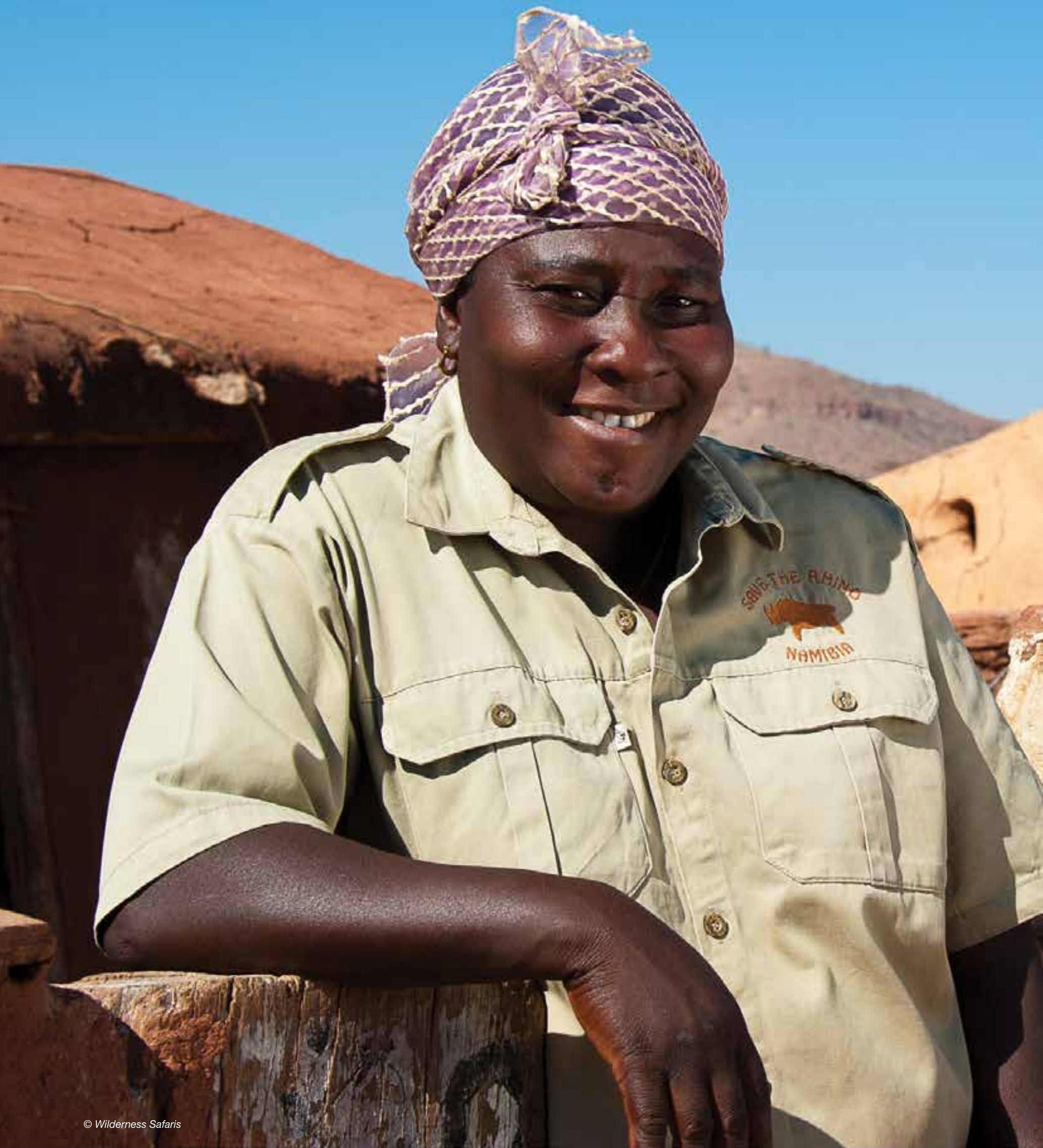




\section{Politiques}

régionales et cadres pertinents relatifs à la conservation de la biodiversité et à la gestion des aires protégées 
L'Agenda $2063^{14}$ est le cadre stratégique de l'Afrique visant à atteindre son objectif de promouvoir un développement inclusif et durable, en complément des SPANB en tant qu'instruments nationaux pour intégrer la stratégie de biodiversité dans la planification du développement. Certains pays, comme le Botswana et la Tanzanie, sont allés encore plus loin en intégrant la biodiversité et les services écosystémiques dans leurs stratégies de réduction de la pauvreté, tandis que des pays comme le Malawi et les Seychelles ont intégré la conservation de la biodiversité dans des plans de développement concernant l'agriculture et la foresterie (IPBES, 2018). Un certain nombre de pays, dont l'Éthiopie, le Kenya et Maurice, ont également intégré des évaluations environnementales stratégiques dans leurs cadres juridiques (UNEP-WCMC et IUCN, 2016), bien que dans plusieurs autres, elles soient moins explicites (IPBES, 2018). Idéalement, la conservation et les aires protégées devraient être intégrées dans les politiques nationales et régionales, afin d'assurer leur inclusion dans la prise de décisions, en particulier en ce qui concerne l'aménagement du territoire.

Une analyse des politiques et de la législation relatives à la gestion, la gouvernance et l'équité des aires protégées dans la région de l'Afrique orientale et australe a été effectué dans le cadre du programme BIOPAMA (Tessema, 2019). L'analyse révèle que, bien que plusieurs pays aient fait de grands progrès dans l'élaboration de cadres juridiques solides visant à renforcer la gestion, la gouvernance et l'équité des aires protégées et de conservation, des différences substantielles subsistent en matière de portefeuilles législatifs entre les pays, ainsi qu'entre pays de l'EAC, de l'IGAD et de la SADC. Cependant, l'analyse révèle que même si la gouvernance par l'État reste le modèle dominant, il existe une tendance encourageante de politiques et de législation promouvant divers types de gouvernance non étatiques, impliquant les communautés, les particuliers et les accords de collaboration.

Ces changements soutiennent également l'expansion des aires protégées et de conservation, et aspirent à une plus grande équité dans la gestion des aires protégées ainsi qu'au partage des avantages. Une autre constatation importante concerne la gestion conjointe des aires de conservation transfrontières, et la façon dont les politiques et la législation font largement défaut dans toutes les régions, à l'exception de la SADC (Tessema, 2019) (voir la Section 4.5).

Les principales conclusions de l'analyse BIOPAMA des politiques et de la législation de l'Afrique orientale et australe indiquent que :

- les pays relativement nouveaux, tels que le Soudan du Sud et le Soudan, ont besoin de soutien pour élaborer leur cadre juridique relatif aux aires protégées et de conservation ;

- certaines des lois régissant les aires protégées au Botswana, en Eswatini, à Djibouti, en Érythrée, aux Comores, au Lesotho, aux Seychelles, en Somalie, au Soudan et au Zimbabwe ont été élaborées il y a un certain temps et pourraient être révisées pour intégrer la pensée et la pratique actuelles en matière de gestion des aires protégées ;
- plusieurs pays, tels que la Namibie, l'Afrique du Sud et le Rwanda, disposent de cadres juridiques solides pour la gestion des aires protégées. Il convient donc d'encourager les échanges d'expériences et de compétences entre pays ;

- les similitudes entre les pays des organisations régionales de I'EAC, de I'IGAD et de la SADC pourraient être explorées en tant que plateformes pour un renforcement ciblé des capacités régionales ;

- les cadres juridiques reconnaissant et soutenant la tendance croissante vers des types de gouvernance diversifiés et collaboratifs doivent être renforcés ;

- un manque de synergie et des lois contradictoires sont signalés dans de nombreux pays de l'EAC, en particulier entre les lois régissant les ressources naturelles et celles de l'industrie extractive ; et

- les principes de coopération transfrontalière sont bien avancés au sein de la SADC et pourraient guider ceux de l'EAC et de I'IGAD.

Dans l'ensemble, les pays de la région de l'Afrique orientale et australe ont progressé dans l'élaboration de politiques et de législations relatives aux aires protégées et de conservation au cours de la dernière décennie. Tessema (2019) a constaté que 14 des 24 pays d'Afrique orientale et australe ont soumis des Plans d'action au Programme de travail sur les aires protégées (PTAP) de la CDB (CDB, 2004) au cours de la période 2010-2014. Au titre de l'Élément de Programme 3 (activités habilitantes) et de l'Objectif 3.1 du PTAP de « créer un environnement politique, institutionnel et socioéconomique favorable pour les aires protégées 》 (CDB, 2004, p. 15), les pays ont autoévalué leurs progrès de mise en œuvre sur une échelle de 1 à 4 ( 1 pour tout juste initié, progrès limités et 4 pour activité terminée). La note globale des progrès de mise en œuvre dans la région est de 2 (Activité pleinement en cours), et 11 des 14 pays ont indiqué se situer au niveau ou au-dessus de la note globale des progrès de mise en œuvre pour atteindre l'Objectif 3.1 (voir le Tableau 4.4).

II convient de noter qu'un certain nombre de pays ont élaboré des instruments juridiques spécifiquement destinés à soutenir l'équité et les types de gouvernance non étatiques, à savoir l'Afrique du Sud, le Kenya, le Mozambique, la Namibie, l'Ouganda et le Zimbabwe. Toutefois, le nombre de cadres juridiques ne reflète pas nécessairement un progrès dans la mise en œuvre. De même, le nombre de lois par pays indiqué au Tableau 4.4 n'est pas un indicateur de l'efficacité de la législation, étant donné qu'une seule loi bien appliquée peut s'avérer plus efficace que 20 lois non conformes ou fragmentées. À cet égard, de nouvelles études sur la mise en œuvre de la législation et son efficacité seraient utiles pour fournir une analyse plus détaillée des politiques et de la législation dans la région. 
Tableau 6.1 : Progrès accomplis dans la mise en œuvre de l'objectif 3.1 du PTAP

\begin{tabular}{|c|c|c|}
\hline Pays & $\begin{array}{r}\text { Progrès dans la } \\
\text { mise en œuvre de } \\
\text { l'Objectif } 3.1^{15} \\
\text { (échelle de } 1 \text { à } 4 \text { ) }\end{array}$ & $\begin{array}{r}\text { Nombre } \\
\text { d'instruments } \\
\text { juridiques } \\
\text { développés depuis } \\
2010^{16}\end{array}$ \\
\hline Angola & 3 & 28 \\
\hline Botswana & - & 8 \\
\hline Comores & - & 5 \\
\hline Djibouti & - & 2 \\
\hline Érythrée & - & 3 \\
\hline Eswatini & 1 & 1 \\
\hline Éthiopie & 3 & 10 \\
\hline Kenya & 3 & 24 \\
\hline Lesotho & - & 3 \\
\hline Madagascar & 1 & 23 \\
\hline Malawi & - & 6 \\
\hline Maurice & - & 10 \\
\hline Mozambique & 4 & 30 \\
\hline Namibie & - & 11 \\
\hline Rwanda & 2 & 36 \\
\hline Seychelles & - & 4 \\
\hline Somalie & - & 4 \\
\hline Afrique du Sud & 4 & 58 \\
\hline Soudan du Sud & - & 2 \\
\hline Soudan & 2 & 3 \\
\hline Tanzanie & - & 11 \\
\hline Ouganda & 4 & 16 \\
\hline Zambie & 2 & 16 \\
\hline Zimbabwe & - & 8 \\
\hline
\end{tabular}

Source : Tessema (2019). 


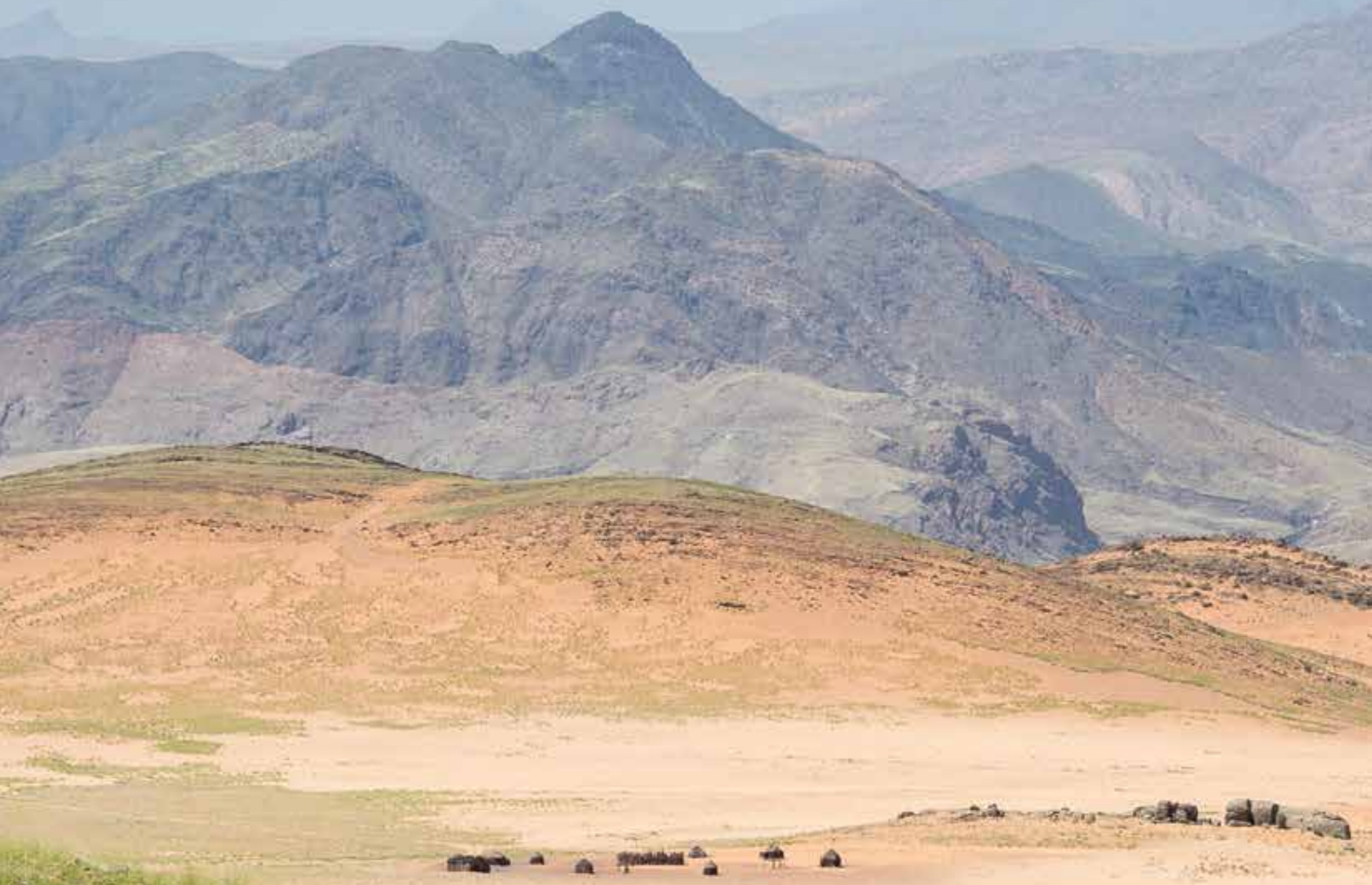

Cot

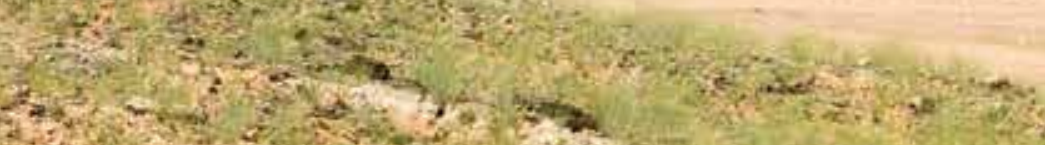

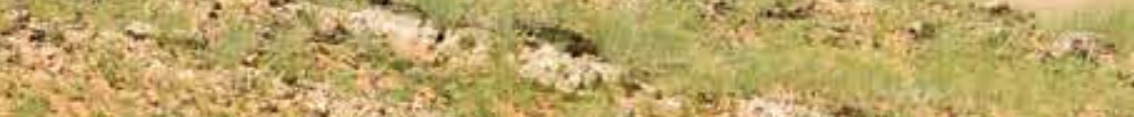

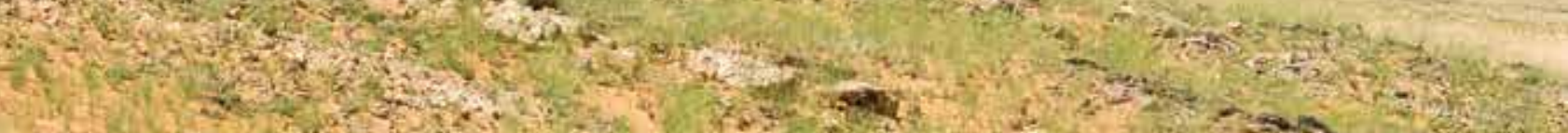

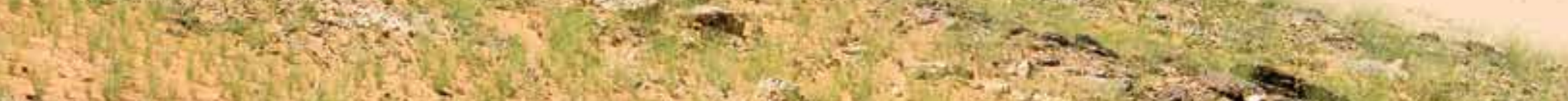

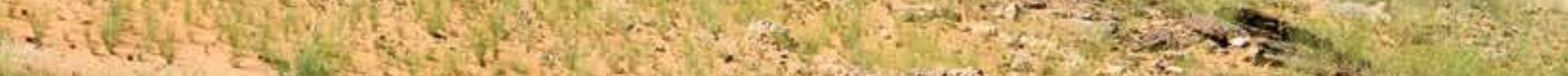

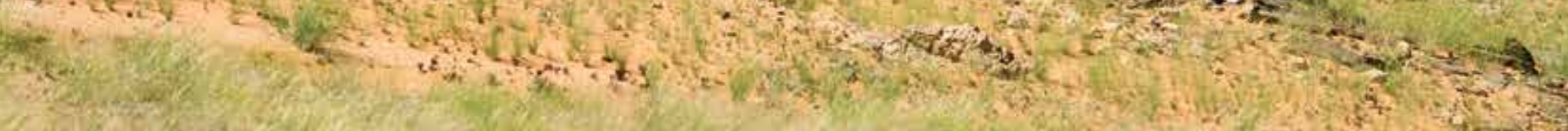 (2)

a (1) 


\section{Communautés économiques régionales}


Les communautés économiques régionales (CER) sont des regroupements régionaux d'États africains dont le but est de faciliter l'intégration économique régionale entre les membres des différentes régions et à travers la Communauté économique africaine au sens large. Elles jouent également un rôle important en termes de promotion de la conservation transfrontalière dans la région. En Afrique orientale et australe, le programme BIOPAMA collabore avec l'EAC, l'IGAD, la SADC et la COI. Celles-ci constituent des partenaires importants du programme BIOPAMA et de la région dans son ensemble, car elles coordonnent les activités régionales avec les États membres, notamment en répondant aux priorités et besoins régionaux spécifiques.

Les CER aident à l'élaboration de priorités pour des besoins régionaux spécifiques. En outre, elles collaborent à la définition d'outils et de produits analytiques et décisionnels utiles pour leur région, ainsi qu'à la préparation de notes d'orientation et autres documents. Les CER contribuent également à la communication des questions relatives aux aires protégées aux décideurs de niveau supérieur, garantissant ainsi que la recherche et les informations produites par ou à partir du programme jouent un rôle important dans l'élaboration des politiques.

Les pays relevant des organisations régionales ${ }^{17}$ de l'AEC, de l'IGAD et de la SADC constituent des groupements idéals pour les comparaisons actuelles et futures des cadres juridiques relatifs aux aires protégées, susceptibles de fournir et promouvoir une plateforme d'échange de connaissances entre les régions.

\subsection{Communauté d'Afrique de l'Est (EAC)}

L'EAC est une organisation intergouvernementale régionale de six États partenaires, comprenant le Burundi, le Kenya, le Rwanda, le Soudan du Sud, la Tanzanie ${ }^{18}$ et l'Ouganda, dont le siège est situé à Arusha, en Tanzanie. Considérant que les ressources naturelles sont le moteur du développement économique national et régional, l'objectif du secteur de l'environnement et de la gestion des ressources naturelles au sein de l'EAC est de promouvoir l'utilisation et la gestion durables des ressources naturelles ainsi que l'adaptation aux changements climatiques.

Le Traité de l'EAC, établi en juillet 2000, prévoit une coopération dans le domaine de l'environnement et des ressources naturelles, et les États partenaires de l'EAC ont convenu d'efforts conjoints pour coopérer à la gestion efficace de ces ressources. L'EAC est axée sur le renforcement de la résilience et la gestion durable des écosystèmes d'eau douce transfrontaliers importants d'un point de vue biologique (EAC, 2010), ainsi que sur le soutien aux capacités d'adaptation et de résilience aux impacts négatifs des changements climatiques.

L'Assemblée législative d'Afrique de l'Est (EALA, selon ses sigles en anglais), une branche de l'EAC, a adopté le projet de loi sur les écosystèmes transfrontaliers d'Afrique de l'Est en janvier 2012 Celui-ci n'a pas encore été ratifié par les États partenaires de l'EAC et, par conséquent, la Commission correspondante n'a pas encore été créée et les EIE sont entreprises en vertu des lois des États partenaires de l'EAC. La Commission du bassin du lac Victoria et
I'Initiative du bassin du Nil ont, par ailleurs, fourni une plateforme de collaboration pour la gestion des ressources en eau et en terres partagées pendant un certain nombre d'années. Cependant, un plan à l'échelle de l'EAC visant à harmoniser les politiques et les lois afin de mieux gérer les ressources naturelles transfrontières est toujours en cours d'élaboration (Tessema, 2019).

Une stratégie 2017-2022 de lutte contre le braconnage, le commerce illégal et le trafic d'espèces sauvages et de produits issus d'espèces sauvages (CAE, 2018) compte parmi les autres instruments développés par l'EAC pour améliorer la conservation dans la région. II s'agit là d'une coopération transfrontalière importante en matière de conservation des ressources partagées. Elle appuiera la mise en œuvre d'activités, notamment l'élaboration d'une politique régionale de conservation des espèces sauvages, leur évaluation économique et non économique, le renforcement de la participation communautaire à la gestion des ressources fauniques transfrontalières et la mise en place d'un Système d'échange d'informations sur le commerce des espèces sauvages (TWIX, selon ses sigles en anglais).

Le protocole de I'EAC sur l'environnement et la gestion des ressources naturelles de 2006 (qui doit encore être ratifié par la Tanzanie) régit la coopération des États partenaires en matière de gestion de l'environnement et des ressources naturelles dans les zones relevant de leur juridiction, y compris l'environnement et les ressources naturelles transfrontalières.

\subsection{Commission de l'océan Indien (COI)}

La COI est une organisation intergouvernementale créée en 1984 dans le cadre d'un accord général de coopération connu sous le nom d'accord de Victoria. ${ }^{19}$ Les membres de la COI sont les Comores, Madagascar, Maurice, les Seychelles et l'île de la Réunion (département d'outre-mer français).

Ces îles partagent des points communs en termes de ressources naturelles riches en biodiversité, ainsi que des caractéristiques environnementales ayant une influence significative sur leur développement national. Leurs économies sont fortement dépendantes des ressources côtières et marines naturelles, et le tourisme basé sur leur dotation en ressources naturelles. Une bonne qualité environnementale est essentielle pour l'écotourisme à forte valeur ajoutée recherché par ces pays. L'environnement et la gestion des ressources naturelles ont été l'un des principaux domaines de coopération entre les États membres, avec plus de 205 millions d'euros investis dans le secteur, soit près de 20 projets mis en œuvre par la COI depuis 1999.

Avec le développement des activités de pêche industrielle au thon dans l'océan Indien, la COI a mis en œuvre son premier projet régional de pêche au thon, dans lequel l'accent a été mis sur la gestion des stocks et l'aide aux pays pour développer leurs capacités de gestion des pêches. Au début de l'an 2000, la COI, en collaboration avec la Commission des thons de l'océan Indien, a mis en œuvre le premier projet régional d'étiquetage du thon, et a 
aidé les autorités nationales des pêches à renforcer les capacités de suivi, de contrôle et de surveillance des pêches.

Les activités de la COI dans le milieu marin et côtier continuent de se développer, avec un accent sur la gestion des aires marines protégées, le suivi et la surveillance des récifs coralliens et écosystèmes associés, la pollution marine résultant de marées noires, la gestion intégrée des zones côtières et les espèces marines envahissantes. Les capacités ont été développées aux niveaux institutionnel et communautaire, et des outils ont été mis au point pour soutenir la gestion des habitats côtiers et la conservation des ressources marines et côtières, notamment :

- Participation aux outils régionaux relatifs au milieu marin

La Commission de l'océan Indien a contribué directement et indirectement à la mise en place d'instruments régionaux et au développement d'outils en milieu marin. D'importants cadres d'action stratégiques, plateformes et réseaux régionaux ont été mis en place et soutenus, tels que le réseau des récifs coralliens et le réseau des aires marines protégées, pour n'en citer que quelques-uns. Compte tenu de l'importance de l'environnement côtier et marin pour les États membres de la COI, une stratégie d'économie bleue est en cours d'élaboration et a été adoptée par le Conseil des ministres de la COI en mars 2020.

- Élaboration d'une Stratégie et d'un plan d'action régionaux pour la conservation des écosystèmes marins et de la pêche dans l'écorégion marine des îles de l'océan Indien occidental Le cadre stratégique de la $\mathrm{COI}$ inclut les domaines

d'intervention suivants :

1. organiser l'acquisition de données sur les écosystèmes marins, les ressources marines et leurs usages, en les partageant et en les valorisant durablement au moyen d'un observatoire régional ;

2. partager les connaissances avec toutes les communautés de parties prenantes, fournir et promouvoir des outils d'aide à la prise de décisions ;

3. former toutes les parties prenantes, capitaliser et échanger les bonnes pratiques en matière de développement marin durable ;

4. soutenir la mise en œuvre de la stratégie de gestion de pêches afin de promouvoir une pêche et une aquaculture coordonnées, responsables et durables ;

5. renforcer la gestion durable des aires marines protégées et leur mise en réseau ;

6. mettre en œuvre des mesures de conservation des espèces migratrices et / ou à grande portée, conformément à leurs conventions correspondantes ;

7. soutenir la mise en œuvre de la Stratégie régionale d'adaptation aux changements climatiques afin de contribuer à une meilleure résilience et à réduire la vulnérabilité des écosystèmes marins ; et

8. développer une approche responsable et concertée de l'exploitation des ressources non-renouvelables (gaz, pétrole, énergies renouvelables, minéraux, biomolécules, etc.).

- Protocole de mise en œuvre d'une Gestion intégrée des zones côtières (GIZC)

L'approche de la gestion intégrée des zones côtières au sein des États membres de la $\mathrm{COI}$ a été développée dans le cadre de son programme régional pour l'environnement, mis en œuvre à la fin des années 1990. La principale ligne d'action était de sensibiliser à une approche intégrée et concertée de la gestion des côtes. S'appuyant sur les résultats du programme environnemental régional «PRE-COI », de 1996 à 2011, la COI a mis en œuvre le Programme régional de gestion durable des zones côtières. Celui-ci a permis aux pays de mettre en place et / ou de renforcer leur Comité national de gestion intégrée des zones côtières. La $\mathrm{COI}$, en collaboration avec ses partenaires régionaux, a appuyé l'élaboration du Protocole GIZC qui sera établi dans le cadre de la Convention de Nairobi (voir la section suivante). Le projet de protocole a maintenant été approuvé et devrait être soumis pour approbation à la prochaine Conférence des parties à la Convention de Nairobi.

- Adoption de la Convention de Nairobi pour la protection, la gestion et la mise en valeur du milieu côtier et marin de l'océan Indien occidental (1985) ${ }^{20}$

Les États membres de la $\mathrm{COI}$ sont tous Parties à la Convention de Nairobi, et les programmes environnementaux de la $\mathrm{COI}$ tiennent compte des dispositions de celle-ci. La COI et le Secrétariat de la Convention de Nairobi collaborent aux différents programmes régionaux. En 2012, le PNUE, au nom du Secrétariat de la Convention de Nairobi et de la COI, a officialisé sa collaboration et signé un mémorandum d'accord visant à renforcer la collaboration dans des domaines d'intérêt commun pour inclure les aires marines protégées. La COI dispose d'un statut d'observateur à la CDP de la Convention de Nairobi et participe à divers groupes de travail et programmes de la Convention. À cet effet, la COI a aligné tous ses programmes et activités relatifs aux écosystèmes côtiers et marins sur les dispositions de la Convention et ses protocoles pertinents. Beaucoup a été accompli grâce à cette collaboration, notamment : l'élaboration du Protocole GIZC, le renforcement du Forum science-politiques, la création d'une Aire de conservation transfrontalière entre le Kenya et la Tanzanie (Encadré 7.3), le renforcement du suivi des récifs coralliens, le renforcement des capacités pour la gestion des aires marines protégées et le renforcement des capacités pour la prévention et la gestion de la pollution marine provenant des marées noires, entre autres.

- Création du Consortium pour les cétacés de l'océan Indien Les actions de la $\mathrm{COI}$ en matière de conservation des espèces migratrices et des grands mammifères ont commencé en 2005. La COI a été chargée par ses États membres de sensibiliser à la nécessité de protéger les espèces migratrices marines. En 2008, la $\mathrm{COI}$ a lancé une initiative régionale pour la conservation des cétacés et des espèces de dugongs. L'objectif était d'améliorer les connaissances scientifiques sur les cétacés, d'étudier les mouvements des populations, de créer un réseau d'acteurs impliqués dans la protection des cétacés et de réduire l'impact des activités humaines sur les cétacés, telles que la pêche, l'observation des baleines et les impacts acoustiques. La COI a collaboré avec l'Agence française pour les aires marines protégées à la réalisation de la Campagne de l'océan Indien pour l'étude de la migration des cétacés. Elle a également soutenu la création du Réseau de l'océan Indien pour la recherche et la conservation des cétacés (IndoCet), regroupant les ONG de la région de l'océan Indien occidental œuvrant à la protection des cétacés, principalement des baleines et des dauphins. Le réseau a créé un site web et développé un outil pour aider à l'identification des cétacés. ${ }^{21}$ 


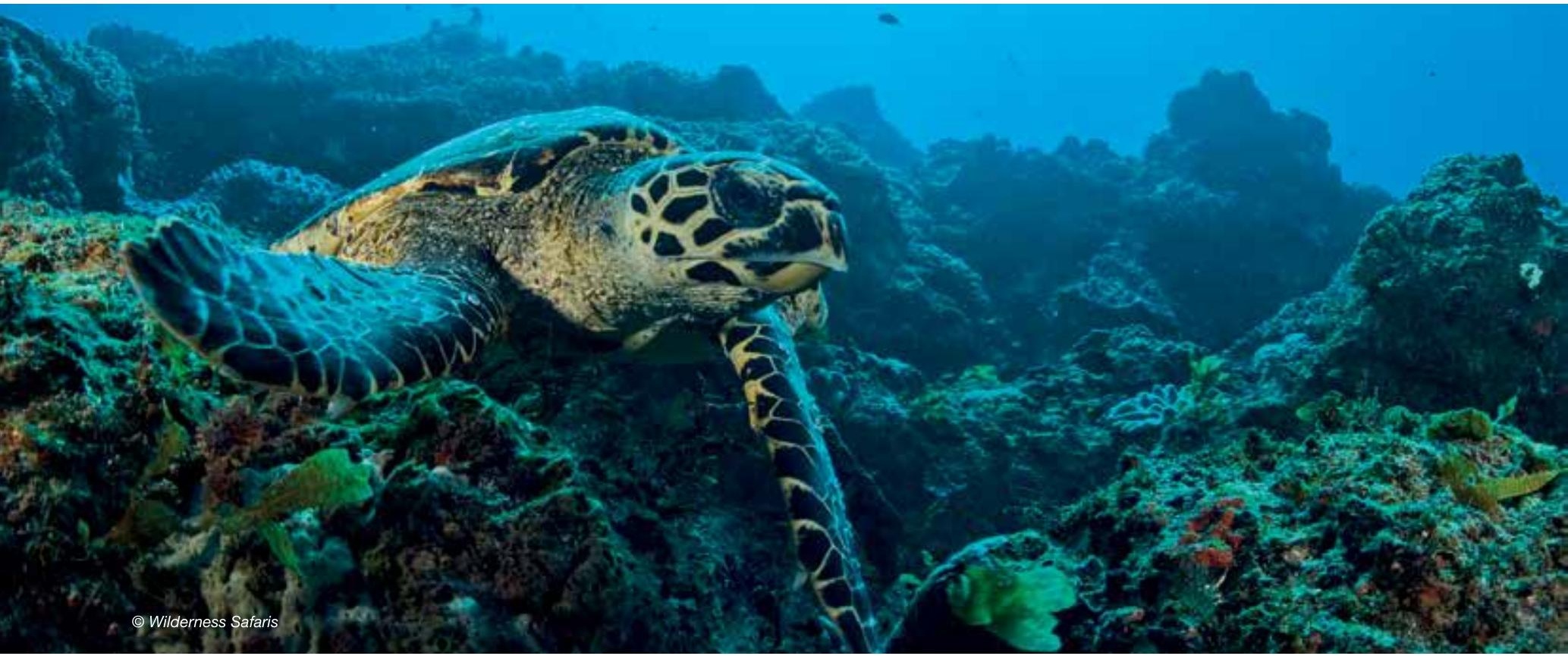

\section{Encadré 7.3 : Conservation marine transfrontalière entre le Kenya et la Tanzanie}

Le littoral d'Afrique de l'Est, que se partagent le Kenya et la Tanzanie, est riche en ressources marines naturelles, avec des plages immaculées de corail, des estuaires, des mangroves, des lagunes et plusieurs belles îles riches en biodiversité. Ces environnements soutiennent une vie marine diversifiée et sont essentiels à la subsistance des communautés côtières. Cependant, cet environnement côtier est menacé par les changements climatiques, la pollution, la destruction des habitats et la pression croissante des populations côtières, du tourisme et de l'urbanisation. Les récifs coralliens du Kenya et de Tanzanie ont été largement blanchis pendant le phénomène El Niño de 1997-1998, avec une réduction de la couverture corallienne de plus de $80 \%$ dans la plupart des zones. La récupération après blanchiment a été très lente dans de nombreux systèmes de récifs coralliens, en raison des pressions croissantes des activités humaines. L'augmentation de la population côtière au Kenya et en Tanzanie exerce également une pression sur les ressources marines et côtières, avec une demande croissante de nourriture et de matériaux. En raison des lignes côtières contiguës des deux pays, il est possible que la perte et la dégradation des habitats côtiers dans l'un aient des impacts sur l'autre, en raison des perturbations et de la fragmentation.

Pour inverser la perte de biodiversité marine, le Kenya et la Tanzanie se sont efforcés d'améliorer la gestion des ressources marines grâce à des cadres politiques et juridiques. Un certain nombre d'aires marines protégées (AMP) ont été établies dans les deux pays pour protéger les habitats et les espèces critiques. Récemment, le Kenya et la Tanzanie ont commencé à étudier la possibilité d'une coopération transfrontalière en matière de conservation marine, en créant une aire de conservation transfrontière (ACT) marine. Le PNUE, par l'intermédiaire du Secrétariat de la Convention de Nairobi, a engagé une série de discussions entre les organismes de gestion des aires protégées des deux pays pour faire avancer ce processus.
L'objectif de l'ACT marine du Kenya et de Tanzanie est d'intégrer les objectifs et les priorités de gestion des écosystèmes dans les pratiques et politiques du secteur productif. Le concept vise à renforcer les capacités de restauration de la santé des écosystèmes et de conservation de la biodiversité aux niveaux local, national et transfrontalier, dans les deux pays. L'initiative vise à tester des approches axées sur les écosystèmes en matière d'aménagement du territoire, de gestion de l'eau, d'agriculture, de forêts, de pêche et de gestion des aires protégées. Le site proposé s'étend de la limite nord de la Réserve nationale marine de Diani-Chale, au Kenya, à la limite sud du District de Mkinga, en Tanzanie, au nord du parc marin de Tanga Coelacanth. La zone d'intérêt abrite une biodiversité marine et côtière très importante. En raison de sa riche biodiversité et de sa contribution à la vie socioéconomique des communautés côtières, la zone a été reconnue par plusieurs organismes internationaux comme un site d'importance, méritant une attention particulière pour la conservation.

L'ACT proposée est complémentaire aux efforts déployés par les deux pays pour gérer et conserver durablement les ressources côtières et marines, contribuer à la réduction de la pauvreté des communautés côtières et promouvoir la mise en œuvre d'instruments régionaux et internationaux clés pour la conservation des ressources marines et côtières et de la biodiversité. En outre, la protection de l'ACT complète les efforts déployés par la Tanzanie pour protéger toutes les réserves marines des petites îles situées au sud de sa frontière, à savoir les réserves marines d'Ulenge, Kwale, Kirui et Mwewe. Elle augmentera également la superficie que le Kenya et la Tanzanie consacrent à la conservation marine, ce qui contribuera à la réalisation de l'Objectif d'Aichi 11 et de l'ODD 14 de la CDB.

Contribution d'Arthur Tuda (Service de la faune du Kenya). 
- Collaboration internationale dans le cadre de l'Accord de Cotonou (2000)

Conformément à l'Accord de Cotonou'22, la $\mathrm{COI}$ a bénéficié de plusieurs programmes de développement régional dans les domaines de l'agriculture, de la pêche, de l'environnement et de la sécurité maritime, pour un montant de plus de 156 millions d'euros. Ces programmes ont contribué à renforcer la collaboration et la coopération entre les pays de la région de l'est, du sud et de l'océan Indien en matière de pêche durable, de gestion des ressources naturelles, de protection, de gestion intégrée des zones côtières, d'éducation à l'environnement, de conservation et d'utilisation de la biodiversité, de changements climatiques et d'amélioration de la sécurité maritime dans la région. En particulier, ils ont également ouvert des possibilités de coopération interrégionale entre la $\mathrm{COI}$, les Caraïbes et le Pacifique sur des questions touchant les petits États insulaires, telles que les changements climatiques, les catastrophes naturelles et l'océan. Grâce à l'aide globale européenne au développement, facilitée par l'accord aux régions Afrique, Caraïbes et Pacifique, la $\mathrm{COI}$, ainsi que I'Union africaine et d'autres communautés régionales africaines, ont pu bénéficier d'un accès facilité aux données d'observation terrestre de l'Agence spatiale européenne pour la gestion des ressources naturelles et le suivi de la dégradation côtière.

Dans le cadre de l'Accord de Cotonou, la COI collabore avec le Secrétariat ACP sur des programmes de sensibilisation des petits États insulaires d'Afrique aux changements climatiques et à la biodiversité côtière et marine.

\subsection{Autorité intergouvernementale pour le développement (IGAD)}

Composée de huit pays d'Afrique orientale et australe (Djibouti, Érythrée, Éthiopie, Kenya, Somalie, Soudan du Sud, Soudan et Ouganda), I'IGAD a pour objectif principal de parvenir à la paix et au développement durable dans la région. Riches en biodiversité, les principaux facteurs de croissance des membres de I'IGAD sont leurs ressources naturelles, et plus précisément les écosystèmes d'eau douce, marins et côtiers, les forêts et la faune sauvage, les zones humides, les pâturages, les terres arables et les montagnes, ainsi que les ressources minérales et énergétiques.

Deux des priorités de I'IGAD pour les environnements côtiers et marins incluent un soutien à la mise en œuvre des Conventions d'Abidjan et de Nairobi, et le Processus africain pour la gestion des ressources côtières et marines de l'Afrique. Concrètement, ceux-ci impliquent la lutte contre la pollution et l'érosion côtière, la promotion de l'utilisation durable des ressources biologiques, la gestion durable des principaux habitats et écosystèmes et un développement économique durable.

Les instruments développés par l'IGAD pour la conservation de l'environnement comprennent :

- Stratégie 2007 de I'IGAD sur les ressources naturelles et l'environnement, visant à soutenir l'harmonisation des politiques relatives aux ressources naturelles et à l'environnement, ainsi qu'à promouvoir une gestion transfrontalière des ressources.
- Stratégie de l'IGAD pour la protection des ressources naturelles et de l'environnement 2016-2020 (intégrée à la stratégie régionale quinquennale de I'IGAD), élaborée à partir d'études approfondies visant à identifier les problèmes et défis clés dans chaque pays, y compris la dégradation des terres, des zones humides et des forêts, les changements climatiques, la croissance démographique, la gouvernance des ressources, le manque d'investissements dans les marchés de développement et le changement de valeurs, ainsi que la question de la marginalisation continue des écosystèmes arides et semiarides.

- Politique régionale de biodiversité, visant à aider à conserver et à gérer durablement les ressources de la biodiversité, et à favoriser le développement socioéconomique pour (i) des moyens d'existence durables, (ii) la subsistance environnementale, (iii) la coexistence pacifique et sûre et (iv) l'intégration régionale grâce à une gestion durable des ressources de la biodiversité dans la région.

- Protocole régional sur la biodiversité, élaboré et approuvé au niveau ministériel en juillet 2017 pour mettre en œuvre la Politique régionale de biodiversité, et fournissant un guide sur la manière de favoriser la coopération dans la mise en œuvre de la Politique régionale et la question du développement durable des écosystèmes dans la région.

- Stratégie pour le partage des avantages de la biodiversité, élaborée et approuvée au niveau ministériel, et encourageant le partage équitable des avantages de la biodiversité entre les États membres de I'IGAD, tout en respectant la situation des pays les moins dotés, afin de contribuer au développement de l'unité et de la paix dans la région.

- Stratégie de contrôle et de gestion des espèces envahissantes, élaborée et approuvée au niveau ministériel, et abordant la question de l'introduction d'espèces exotiques envahissantes par le contrôle de l'expansion, la gestion, l'utilisation ou, si possible, l'éradication, en particulier dans les secteurs agricole et forestier de la région.

- Stratégie de l'IGAD pour la gestion de la faune sauvage, élaborée et approuvée au niveau ministériel, et fournissant une stratégie commune sur la façon de gérer les ressources fauniques de la région.

- Réseau spécialisé de l'IGAD, créé dans le cadre de l'IGAD pour le suivi et la coordination des activités d'application de la législation relative à la faune sauvage dans la région.

- Plan de gestion du paysage marin de Djibouti, élaboré dans le cadre du programme de gestion de la biodiversité, à partir duquel des aires marines de conservation communautaires locales ont été identifiées et établies. ${ }^{23}$

- Plan de mise en œuvre de la stratégie régionale de l'IGAD (20162020), visant à promouvoir activement la coopération et l'intégration économiques dans la région de I'IGAD par le renforcement des capacités régionales, y compris, mais sans s'y limiter, la gestion des ressources naturelles et la protection de l'environnement, en promouvant une gestion durable de l'environnement et des ressources naturelles. 


\subsection{Communauté de développement de l'Afrique australe (SADC)}

La SADC est une organisation intergouvernementale régionale dont le siège est situé à Gaborone, au Botswana, et qui comprend 16 États partenaires (Afrique du Sud, Angola, Botswana, Comores, République Démocratique du Congo, Eswatini, Lesotho, Madagascar, Malawi, Maurice, Mozambique, Namibie, Seychelles, République-Unie de Tanzanie, Zambie et Zimbabwe) ${ }^{24}$. Les ressources naturelles sont d'une importance vitale pour l'économie de la région et sa croissance. La SADC et ses États Membres reconnaissent qu'il importe d'améliorer l'utilisation et la gestion des ressources naturelles pour assurer un développement et une croissance durables à l'avenir. Les ressources naturelles importantes comprennent les forêts, l'eau, la faune sauvage (espèces aquatiques, terrestres et marines) et les minéraux. Afin d'aider à protéger ces ressources et favoriser la coopération régionale, des protocoles et initiatives, tels que le développement d'accords multilatéraux sur l'environnement, ont été développés par la SADC.

En vertu du Protocole sur la conservation de la faune sauvage et l'application de la loi, le Programme 2013 de la SADC pour les aires de conservation transfrontières définit sa mission comme le développement de la SADC en un réseau fonctionnel et intégré d'aires de conservation transfrontières, où les ressources naturelles partagées sont cogérées et conservées de manière durable afin de favoriser le développement socioéconomique et l'intégration régionale au profit des personnes vivant dans et autour des ACT.

L'harmonisation des politiques et de la législation pour une gestion efficace de ces aires de conservation transfrontières est un élément reconnu du Programme ACT de la SADC. Parmi les politiques et instruments juridiques régionaux de la SADC, on peut citer :

- Protocole sur le développement du tourisme (1998). ${ }^{25}$

Le protocole énonce l'objectif de la SADC de tirer parti du potentiel de la région en tant que destination touristique. La SADC entend assurer une répartition uniforme du développement touristique dans toute la région et créer un environnement favorable au tourisme, utilisant ainsi celui-ci comme vecteur de développement socioéconomique.

- Protocole sur la conservation de la faune sauvage et de l'application de la loi (1999). ${ }^{26}$

Entré en vigueur en 2003, il est juridiquement contraignant pour les pays l'ayant signé et ratifié. Les objectifs du protocole comprennent l'harmonisation des instruments juridiques relatifs à la faune sauvage, l'échange d'informations pertinentes pour la conservation de la faune sauvage, le renforcement des capacités nationales et régionales pour la conservation, la création d'aires de conservation transfrontières et la promotion d'une gestion communautaire des ressources. II fournit les mécanismes pour la conservation et la gestion des ressources partagées, tout en reconnaissant les droits des États individuels à gérer leurs ressources fauniques respectives.

- Protocole révisé sur les cours d'eau partagés (2000). ${ }^{27}$ De nombreux cours d'eau de la région sont partagés entre plusieurs États membres, une situation qui exige leur développement de manière écologiquement rationnelle. Le protocole vise à favoriser une coopération plus étroite entre les États membres pour la protection, la gestion et l'utilisation des cours d'eau partagés dans la région. Les États membres conviennent de coopérer sur des projets et d'échanger des informations sur les cours d'eau partagés, de se consulter et de collaborer à des initiatives équilibrant la mise en valeur des cours d'eau et la conservation de l'environnement.

\section{- Protocole forestier (2002). ${ }^{2}$}

Le protocole vise à promouvoir le développement, la conservation, la gestion et l'utilisation durables de tous les types de forêts et d'arbres, le commerce des produits forestiers et la protection efficace de l'environnement. II fournit des directives sur la réalisation d'évaluations forestières ainsi que de politiques, programmes et lois forestières nationales. Les politiques et mécanismes adoptés par les États membres devraient permettre aux populations locales, y compris aux femmes, de participer efficacement aux activités de gestion des forêts, tout en respectant les connaissances traditionnelles relatives aux forêts.

\section{- Politique régionale sur l'eau (2005).29}

La région de la SADC regroupe 15 grands bassins fluviaux transfrontaliers. La politique fournit le contexte et l'intention de la gestion des ressources en eau à l'échelle régionale de la SADC, en représentant les aspirations et les intérêts des États membres. Le Protocole sur les cours d'eau partagés constitue l'instrument juridique pour la mise en œuvre de cette politique, en vertu duquel des accords bilatéraux et multilatéraux peuvent être élaborés entre les États partageant un cours d'eau.

\section{- Stratégie régionale pour l'eau de la SADC (2006). ${ }^{30}$}

La stratégie vise à fournir un cadre pour la mise en valeur l'utilisation, la protection et le contrôle durables, intégrés et coordonnés des ressources en eau nationales et transfrontalières. Il décrit les plans de mise en œuvre de la stratégie, y compris les objectifs associés du Plan d'action stratégique indicatif régional et du Programme de mise en œuvre stratégique piloté par les Plans d'action stratégiques régionaux (PASR) pour le secteur de l'eau de la SADC. Le document se termine par une discussion sur les indicateurs de suivi et d'évaluation qui seront utilisés pour assurer la supervision du cadre de mise en œuvre.

\section{- Protocole de la SADC sur la pêche (2006). ${ }^{3}$}

Le protocole vise à promouvoir une utilisation responsable et durable des ressources vivantes et des écosystèmes aquatiques présentant un intérêt pour les États Parties, afin de : i) promouvoir et améliorer la sécurité alimentaire et la santé humaine, ii) préserver les moyens de subsistance des communautés de pêcheurs, iii) créer des opportunités économiques pour les ressortissants de la région, iv) s'assurer que les générations futures pourront bénéficier de ces ressources renouvelables, et v) atténuer la pauvreté avec l'objectif ultime de l'éliminer.

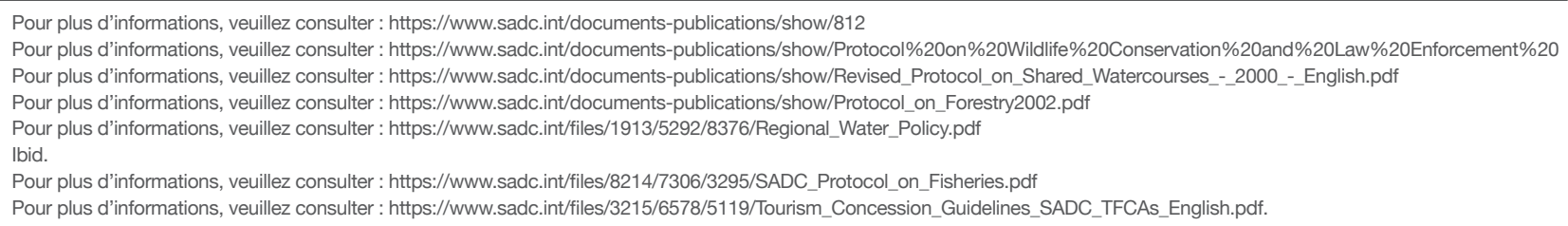


- Lignes directrices sur les concessions touristiques pour les ACT au sein de la SADC (2015). ${ }^{32}$

L'objectif des lignes directrices est de fournir une orientation pour la gestion des concessions touristiques dans les ACT au sein de la SADC, tout en veillant à ce que les objectifs de conservation et de développement des ACT régionales soient atteints, y compris le développement rural et la participation communautaire. Le principal avantage des lignes directrices est l'acquisition d'informations de base sur la manière d'encourager, de développer et d'exploiter des concessions touristiques dans les ACT au sein de la SADC.
II serait utile de partager les connaissances au niveau régional, notamment en ce qui concerne la conservation transfrontalière et l'expérience de 20 ans de la SADC dans ce domaine. Les efforts de lutte contre le braconnage et d'application de la loi bénéficieraient également d'un échange croisé régional d'informations relatives aux politiques, à la législation et au partage d'informations via les réseaux TWIX.

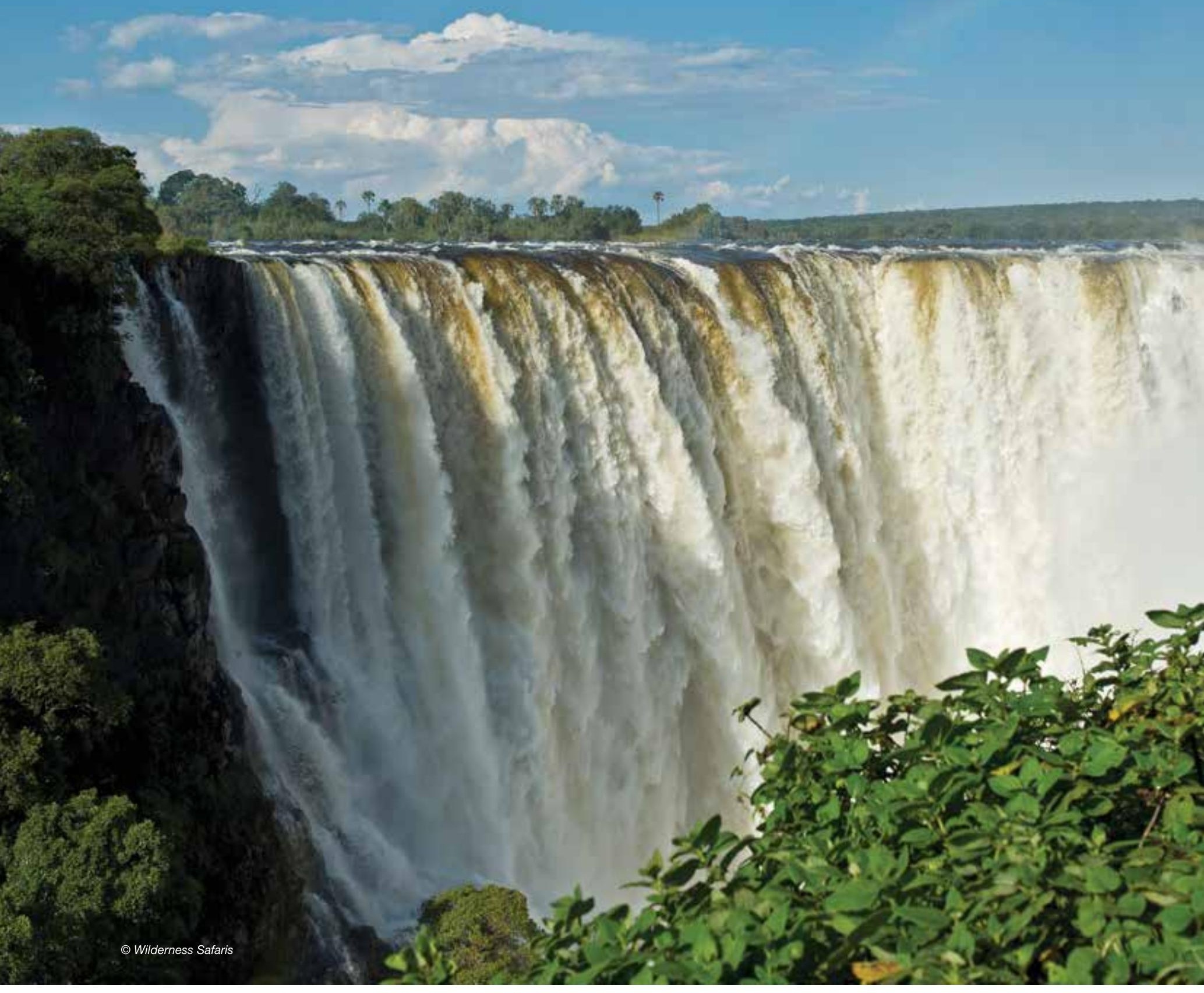




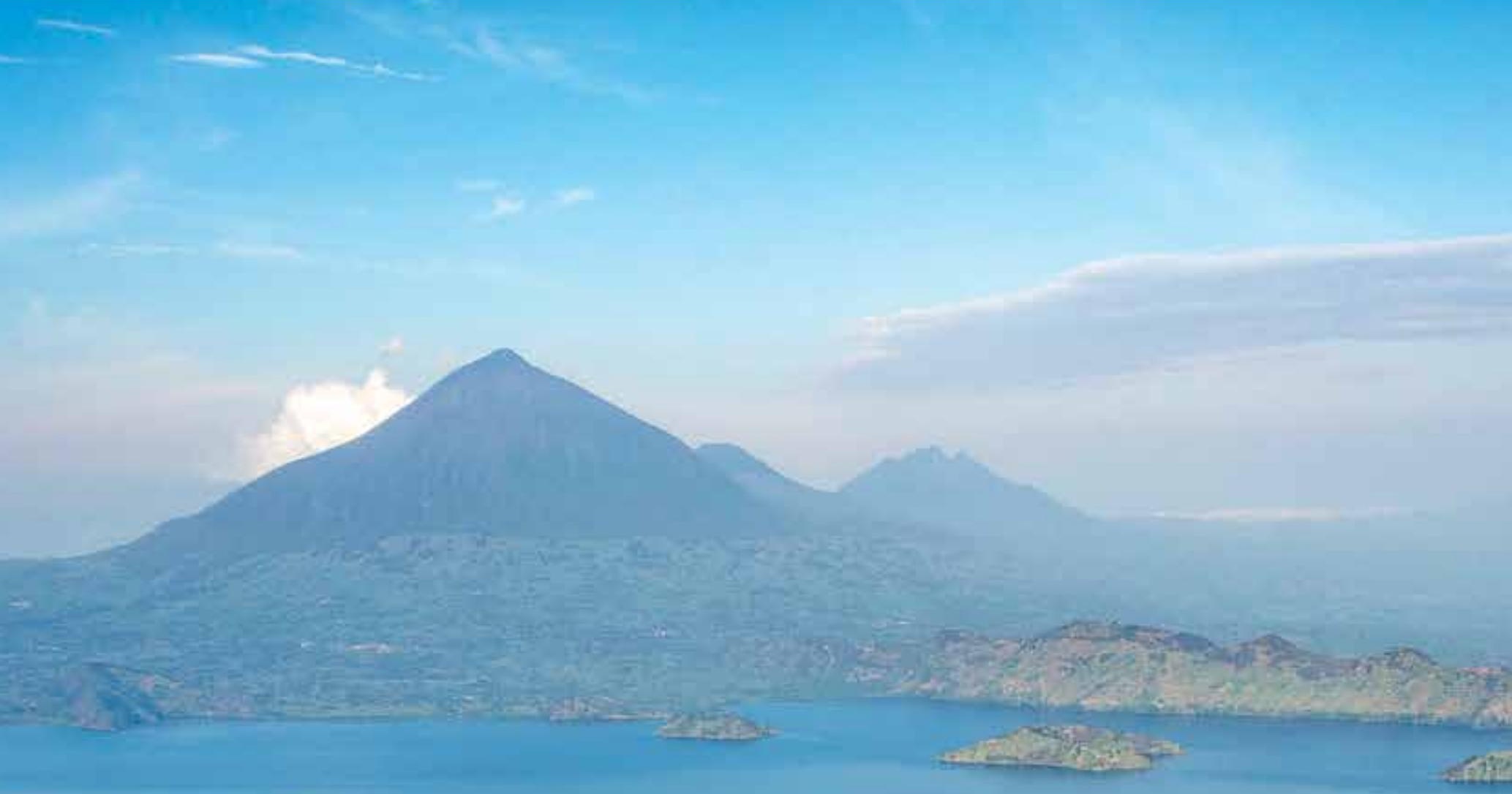

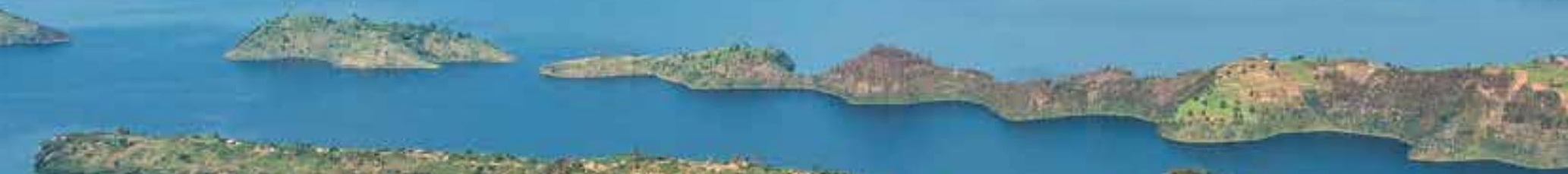

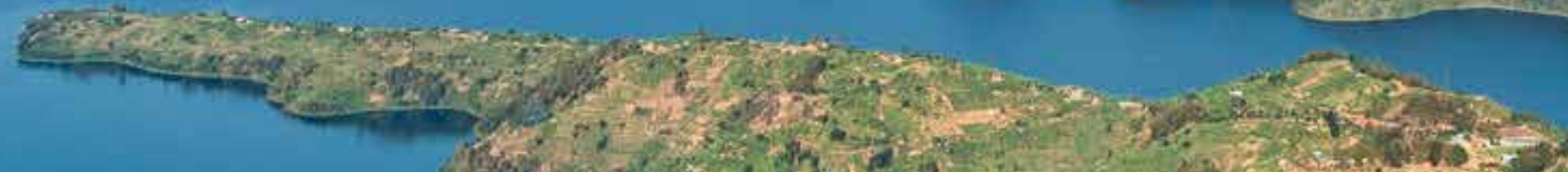
23 th

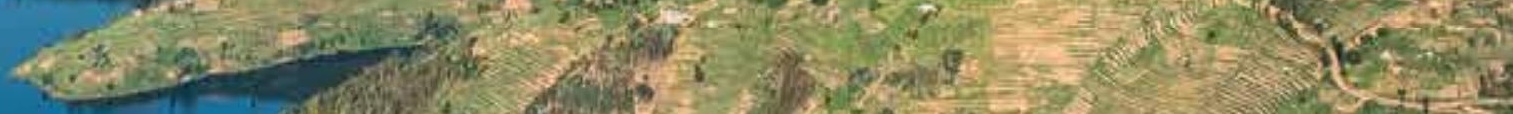

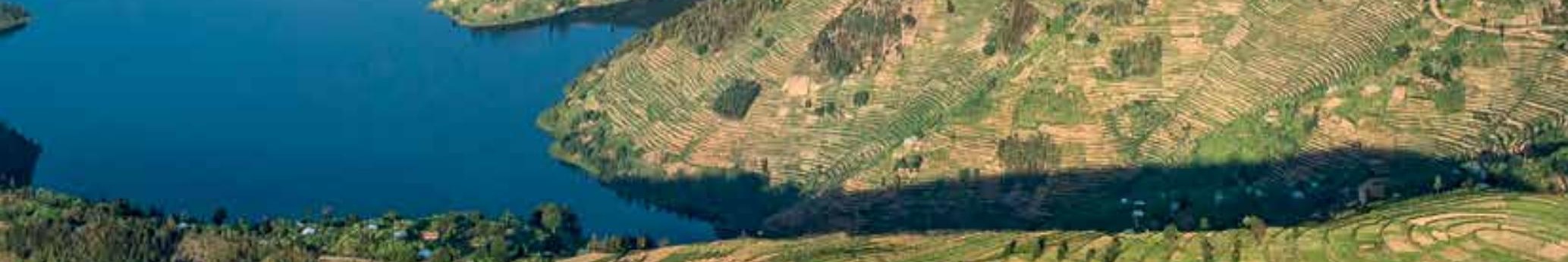

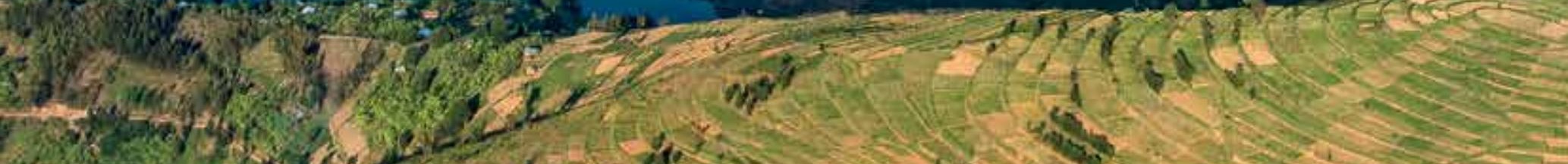

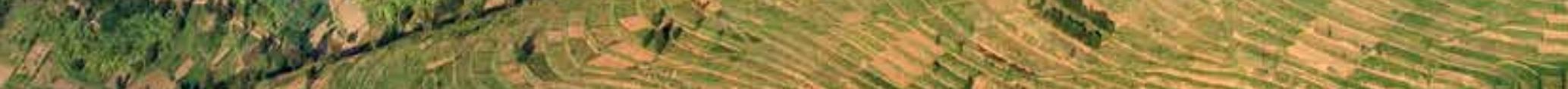

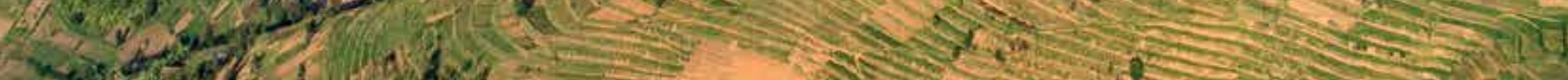

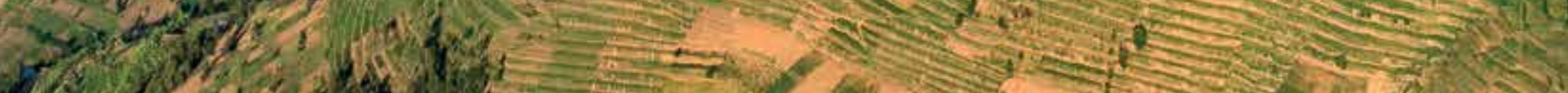

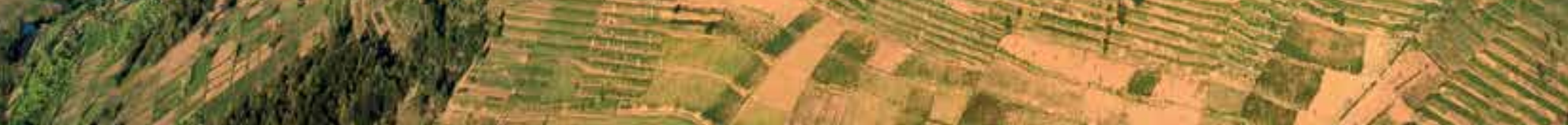
(2) 


\section{Profils nationaux}

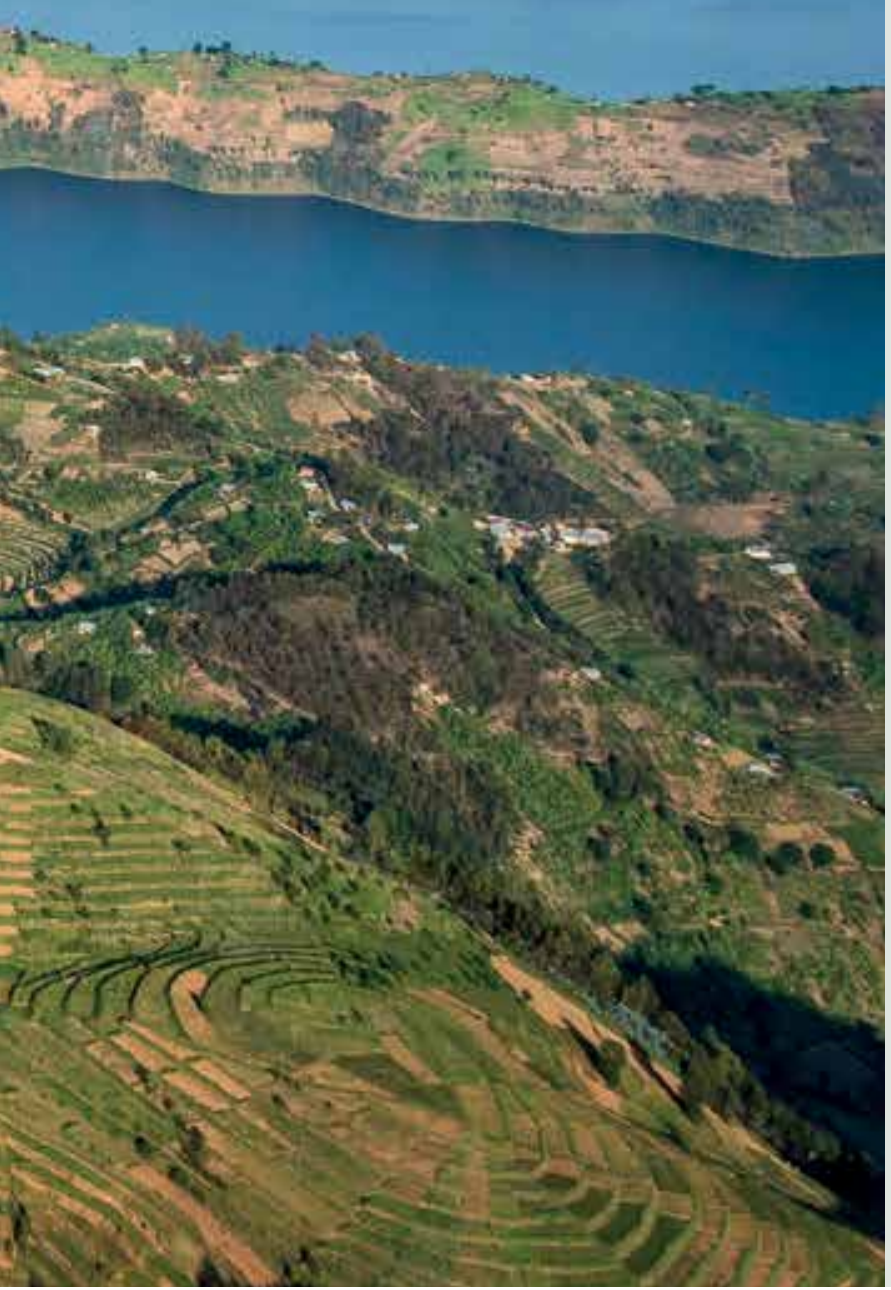




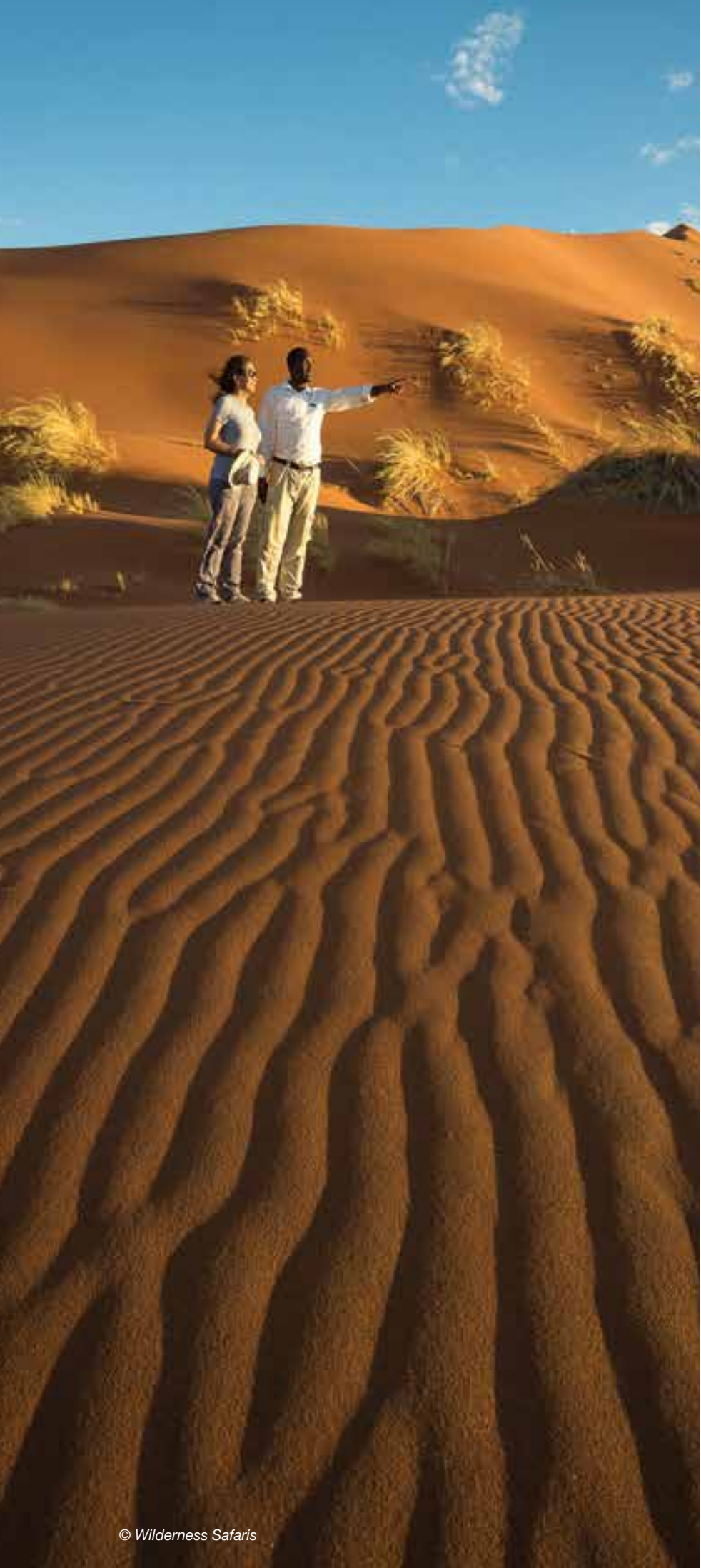

Cette section présente un profil des aires protégées et de conservation dans chacun des 24 pays de la région de l'Afrique orientale et australe. Chaque profil comprend les données suivantes :

- une brève description des aires protégées et de conservation, ainsi que de leur couverture :

- des données sur le nombre d'aires protégées et de conservation selon les types de gouvernance et les catégories de gestion de I'UICN ;

- des données sur le nombre et la superficie des aires protégées et de conservation désignées dans le pays ;

- les sites prioritaires selon trois désignations : Alliance pour une extinction zéro, Zones importantes pour les oiseaux et la biodiversité (IBA) de BirdLife International et Zones clés pour la biodiversité (KBA) de l'UICN ; et

- autres données : aires de conservation transfrontalières, contexte politique, espèces, pressions et menaces principales.

Les Annexes 6 et 7 fournissent respectivement des informations détaillées (statistiques) sur les catégories de gestion et les types de gouvernance de I'UICN par pays. Chaque profil national dans cette section comporte un lien hypertexte vers la page pertinente de l'Annexe, afin de faciliter la lecture.

Afin de permettre une comparabilité à l'échelle régionale, les mêmes analyses et ensembles de données ont été utilisés pour les 24 pays. La BDMAP, source mondiale faisant autorité en matière de données sur les aires protégées, a été utilisée pour les statistiques concernant les aires protégées, et en particulier sa mise à jour de septembre 2019. Certains pays, cependant, n'ont pas encore été mis à jour dans la BDMAP. Les statistiques nationales différentes de la BDMAP sont indiquées en conséquence.

Les statistiques nationales ont été extraites des rapports nationaux à la CDB et des Stratégies et plans d'action nationaux pour la biodiversité (SPANB). Dans la plupart des cas, les données ont été tirées du cinquième rapport national de chaque pays et, dans certains cas, du sixième rapport national, lorsque celui-ci était disponible au moment de la rédaction (septembre 2019).

\section{Méthodologie utilisée pour générer les statistiques de la BDMAP}

Toutes les statistiques de comptage, telles que le nombre d'aires protégées dans un pays où le nombre d'aires protégées dans une catégorie de gestion donnée de l'UICN, sont dérivées de la version non modifiée de septembre 2019 de la BDMAP pour les 24 pays. Les statistiques de couverture, telles que la superficie couverte par les aires protégées dans un pays, ou la superficie couverte par une catégorie de gestion donnée de l'UICN, sont également dérivées d'un sous-ensemble de la version de septembre 2019 de la BDMAP. Dans ce sous-ensemble, certains sites ont été supprimés, conformément à la méthodologie standard de calcul de couverture à l'aide de la BDMAP. ${ }^{33}$ Les sites présentant les caractéristiques suivantes ont été retirés du sous-ensemble de la BDMAP :

- site correspondant à un statut « proposé » ou «non déclaré »;

- points ne correspondant à aucun site déclaré ;

- Réserves de biosphère de l'UNESCO. Ces sites sont exclus parce qu'ils ont été déclarés selon un zonage comprenant des zones tampons et de transition, quand ces zones ne répondent souvent pas à la définition d'une aire protégée.

\section{Avertissement}

Les données de couverture $\left(\mathrm{km}^{2}\right)$ peuvent présenter un chevauchement entre les catégories, mais pas à l'intérieur de celles-ci. Ceci est négligeable. Cependant, en cas de chevauchement, les totaux combinés résulteront en un chiffre supérieur à $100 \%$ des aires protégées du pays. La BDMAP est une agrégation de données nationales. La qualité des limites dépend donc de la qualité des données disponibles dans le pays. Le PNUE-WCMC ne modifie pas les limites ou les emplacements des sites, mais travaille avec les fournisseurs de données pour essayer d'assurer l'exactitude des données.

33 Pour plus d'informations, veuillez consulter

https://www.protectedplanet.net/c/calculating-protected-area-coverage 
Figure 8.1 : Résumé pour l'Angola

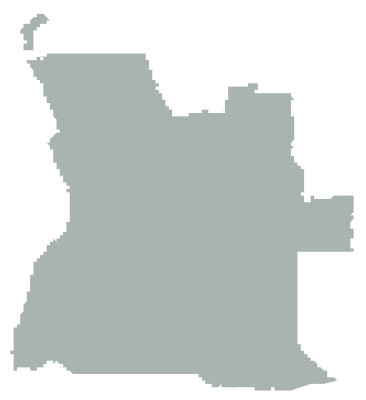

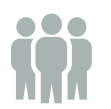

Population totale (en millions) 30,81

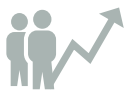

Démographie (\% annuel)

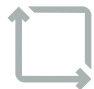

Superficie (en milliers de $\mathrm{km}^{2}$ )

1246,70

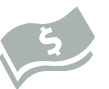

PIB (en milliards de USD actuels) 105,75
Croissance du PIB (\% annuel)

Source : The World Bank Group, 2018

Aires protégées :

14 aires protégées

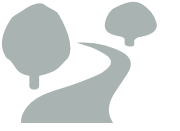

couverture terrestre couverture marine 87531 km$^{2} \quad 24$ km$^{2}$
Aires protégées et de conservation de l'Angola par catégorie de gestion de l'UICN

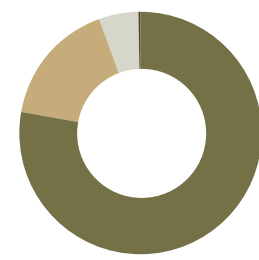

II. Parc national (8)

IV. Aire de gestion habitats / espèces (4)

V. Paysage terrestre / marin protégé (1)

Non rapportée (1)

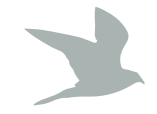

25 espèces d'oiseaux endémiques

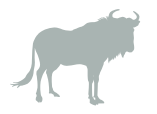

291 espèces animales autochtones

\section{Importante biodiversité marine et d'eau douce}

Couverture des aires protégées en Angola

\begin{tabular}{l|r|r}
\hline Type d'aire protégée & $\begin{array}{r}\text { Aire protégée } \\
\text { ou conservée* }\end{array}$ & $\begin{array}{r}\text { Aire protégée } \\
\text { ou conservée** }\end{array}$ \\
\hline $\begin{array}{l}\text { Terrestres et eaux } \\
\text { intérieures }\end{array}$ & $6,97 \%$ & $12,50 \%$ \\
\hline Marines et côtières & $0,00 \%$ & $\begin{array}{r}\text { Aucune } \\
\text { correspondance }\end{array}$ \\
\hline
\end{tabular}

* Ensemble de données de la BDMAP $\quad$ ** Rapport national sur la biodiversité

Aires protégées et de conservation en Angola par type de gouvernance de I'UICN

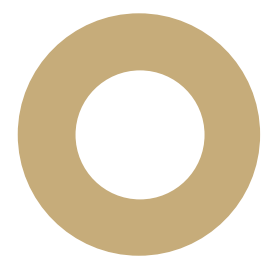

Non rapporté (14) Source : Republic of Angola (2014); UNEP-WCMC et IUCN (2019c).

\section{Aires prioritaires pour la conservation}

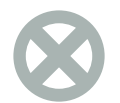

\section{1 site}

Sites de l'Alliance pour une extinction zéro

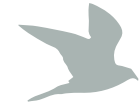

23 sites

Zones importantes pour les oiseaux et la biodiversité

Source : AZE Secretariat (2019) ; BirdLife International (2019b, 2019c).

\section{2 sites}

Zones clés pour la biodiversité

SOURCE : UNEP-WCMC et IUCN (2019C). 


\section{Figure 8.2 : Aires protégées de l'Angola}

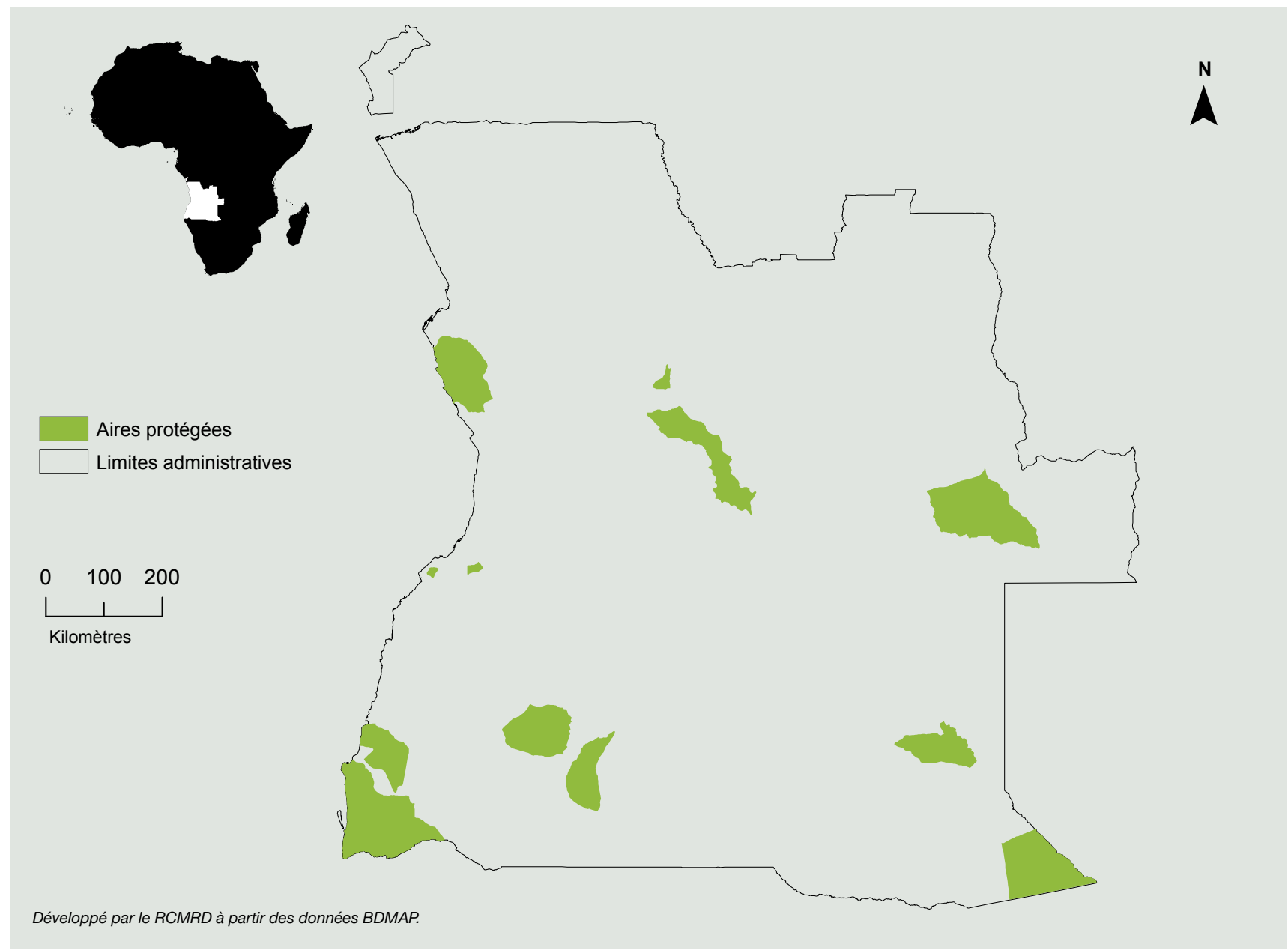

\section{Espèces clées ${ }^{35}$}

L'Angola abrite une incroyable diversité d'habitats, et donc une grande variété d'espèces, avec jusqu'à 291 espèces autochtones, dont la plupart appartiennent aux ordres Rodentia (85), Chiroptera (73), Carnivora (39) et Cetartiodactyla (33). Un grand nombre d'espèces, la plupart des rongeurs ou des chauves-souris, sont endémiques ou quasi endémiques.

Selon le cinquième Rapport national de l'Angola à la CDB (2014), les mammifères d'intérêt particulier incluent l'hippotrague noir (Hippotragus niger variani), endémique, le gorille de plaine occidental (Gorilla gorilla ssp. gorilla), le lamantin d'Afrique (Trichechus senegalensis) et le zèbre de montagne (Equus zebra). L'état de conservation de bon nombre de ces espèces est mal connu. Les populations d'éléphants d'Afrique (Loxodonta africana), d'hippopotames (Hippopotamus amphibius) et d'otarie à fourrure d'Afrique du Sud (Arctocephalus pusillus) sont considérées comme stables.

L'Angola abrite 25 espèces d'oiseaux endémiques. On ne sait que peu de choses sur la diversité de la microfaune et de la flore de l'Angola, mais on sait que de nombreuses espèces souffrent des niveaux élevés de récolte de bois, de charbon de bois et de nourriture, ainsi que du commerce local et international.

Le pays présente également une grande biodiversité marine et d'eau douce, y compris cinq espèces de tortues de mer, et de nombreuses espèces de cétacés. La pêche artisanale de poissons et crustacés est un élément essentiel de la subsistance des communautés côtières rurales. Le maquereau a été gravement surexploité, entrainant l'imposition d'une interdiction annuelle de quatre mois. L'introduction d'espèces exotiques de tilapia est probablement due à la prévalence de projets de pisciculture.

\section{Pressions et menaces ${ }^{36}$}

La biodiversité angolaise est soumise à de nombreuses menaces et pressions. Les principales concernent les habitats, en raison de l'agriculture de subsistance, de l'exploitation minière, des infrastructures, de la déforestation pour le charbon de bois et le bois, et d'une très forte incidence d'incendies. Le braconnage, y compris pour le commerce de viande de brousse, constitue également une menace majeure. La surpêche, en particulier du maquereau, a entrainé une interdiction annuelle de quatre mois. L'Angola est en train de réviser sa législation, mais des efforts de mise en œuvre et d'application sont nécessaires. 


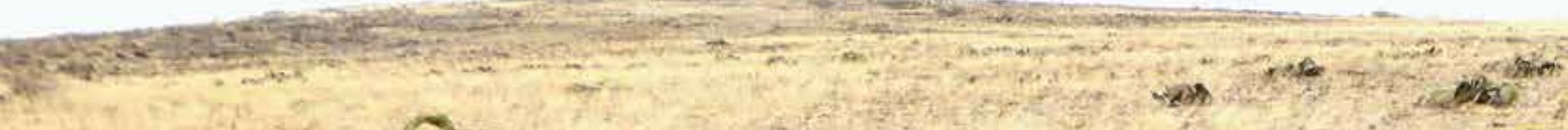

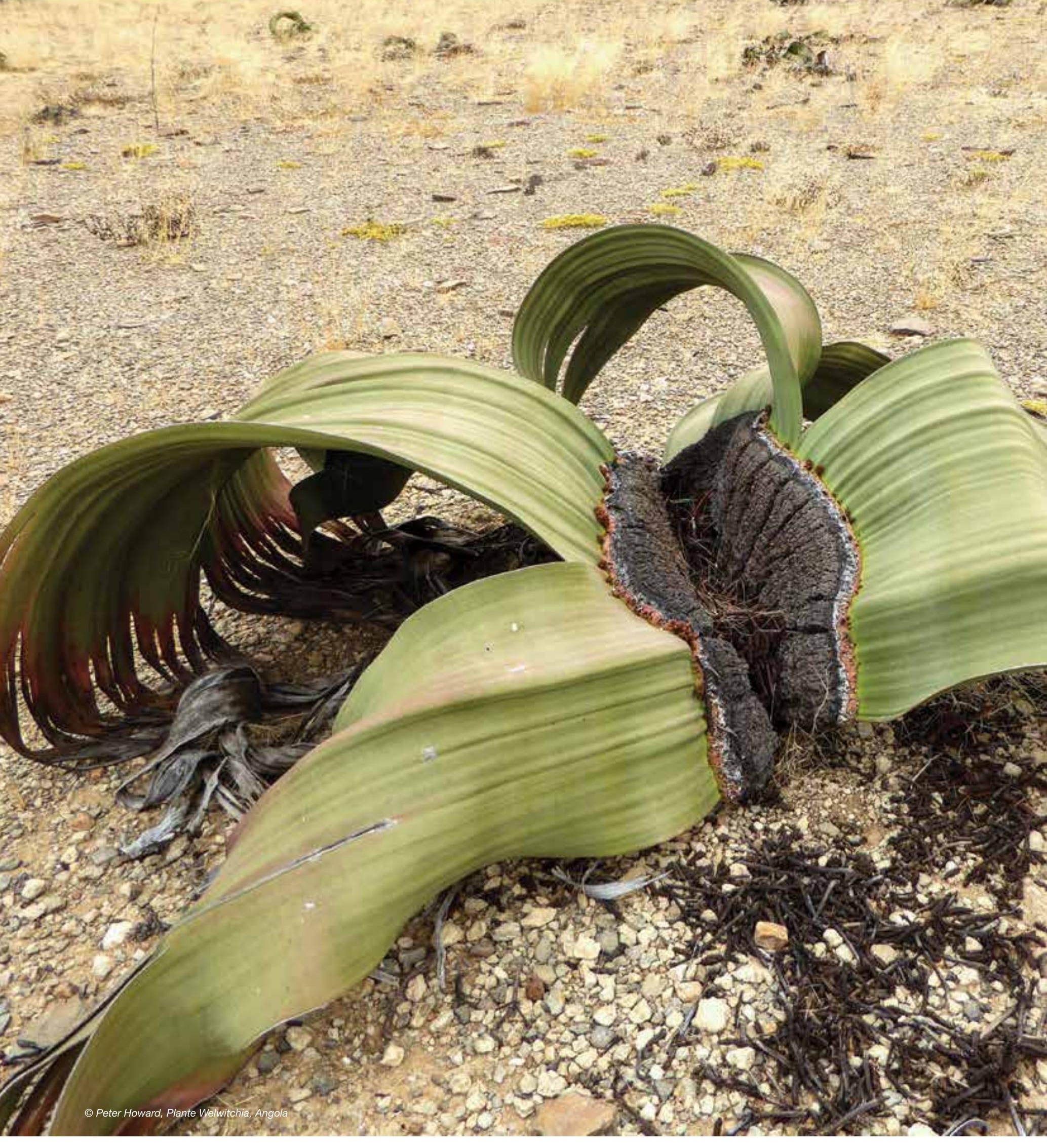




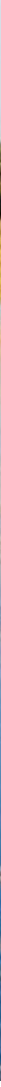

\subsection{Botswana}

\section{Aires protégées et de conservation du Botswana ${ }^{37}$}

Le Botswana compte 22 aires protégées couvrant 169370 km² d'écosystèmes terrestres (UNEP-WCMC et IUCN, 2019d).

Au Botswana, l'utilisation des terres est divisée en aires protégées, aires de gestion de la faune sauvage (AGF), zones résidentielles pastorales, fermes et concessions minières. Le Botswana étant un grand pays avec une faible population, il a été possible d'y créer de vastes aires protégées, avec plus de $45 \%$ du pays sous une forme ou une autre de gestion environnementale. La majorité des écosystèmes du pays sont modérément ou bien représentés (c'est à dire qu'ils se situent soit à un niveau de représentation de moins de $50 \%$, soit à plus de $100 \%$ des $17 \%$ de l'Objectif d'Aichi). Une grande partie des écosystèmes se trouve entièrement dans des aires protégées.

Depuis 2009, la couverture des aires protégées officielles a changé. Bien que les aires protégées aient globalement augmenté, la probabilité d'obtenir un statut de protection a diminué dans certaines zones. II s'agit notamment de plusieurs zones inscrites comme aires proposées de gestion de la faune sauvage (AGF) il y a plus de 15 ans, mais qui n'ont jamais été officiellement déclarées. Le Botswana fait partie de grandes aires de conservation transfrontières (ACT), ce qui favorise les liens entre les objectifs de conservation du pays et ceux de la région.

\section{Aires protégées et de conservation transfrontières}

Le Botswana comprend une partie de trois aires de conservation transfrontières, à savoir l'ACT du Grand Mapungubwe, l'ACT du Kavango-Zambèze et l'ACT de Kgalagadi.

\section{Contexte politique}

Un rapport complet sur la législation et les politiques relatives à la gestion, à la gouvernance et à l'équité des aires protégées a été réalisé par le programme BIOPAMA. Il a identifié 49 lois et politiques pertinentes au Botswana (Tessema, 2019).

\section{Espèces clées ${ }^{38}$}

Le Botswana possède une grande biodiversité, en particulier dans et autour du delta de l'Okavango, avec un indice de richesse spécifique compris entre 9,3 et 15 . Les espèces végétales sont estimées entre 2150 et 3000 , dont 15 sont endémiques et 43 figurent sur la Liste rouge de l'UICN.

La faune est également riche et variée, avec 157 espèces de mammifères, dont trois sont endémiques et 112 figurent sur la Liste rouge. Le Botswana abrite l'une des plus grandes populations restantes de lycaons (Lycaon pictus) et la plus grande population restante d'éléphants d'Afrique (Loxodonta africana). Les plaines inondables saisonnières autour de l'Okavango et du Zambèze et de vastes zones sauvages accueillent quelques-unes des principales routes de migration de la faune en Afrique australe, faisant du Botswana l'un des derniers refuges pour les espèces nécessitant une aire de répartition ouverte. 
Figure 8.3 : Résumé du Botswana
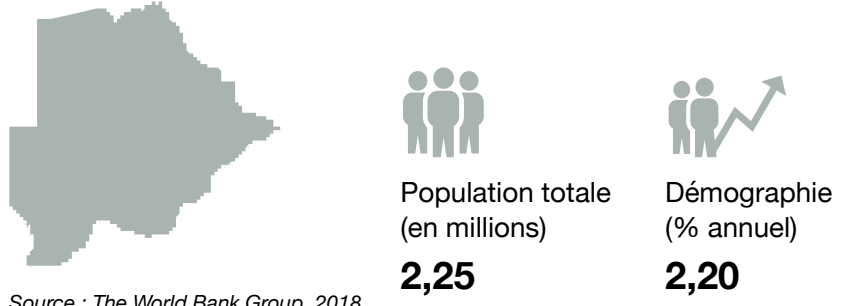

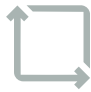

Superficie (en milliers de $\mathrm{km}^{2}$ ) 581,70

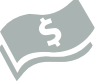

PIB (en milliards de USD actuels)

18,62
Croissance du PIB (\% annuel)

4,50

Source : The World Bank Group, 2018

2,20

couverture terrestre

169370 km² $^{2}$

\section{2 aires protégées}

Source : UNEP-WCMC et IUCN, 2019d

\section{Aires prioritaires pour la conservation}

\section{2 sites}

Source : AZE Secretariat (2019) ; BirdLife International (2019b, 2019c).
Aires protégées et de conservation du Botswana selon les catégories de gestion de l'UICN

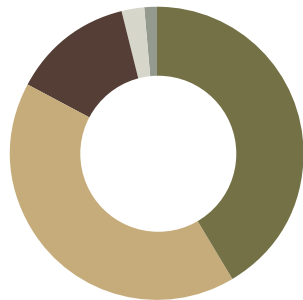

Ib. Aire de nature sauvage (7)

Non rapportée (1)

Ne s'applique pas (1)

II. Parc national (6)

IV. Aire de gestion habitats / espèces (7)

Source : UNEP-WCMC et IUCN (2019c).

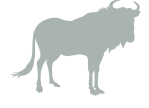

157 espèces de mammifères

112 sur la Liste rouge

\section{3 sur la Liste rouge}

15 endémiques

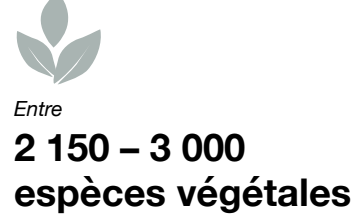

\section{1 espèces} de reptiles

\section{7 espèces d'oiseaux \\ 25 menacées à l'échelle mondiale \\ 44 espèces d'amphibiens}

99 espèces

de poissons d'eau douce

2 menacées à

l'échelle mondiale

\section{Couverture des aires protégées au Botswana}

\begin{tabular}{l|r|r}
\hline Type d'aire protégée & $\begin{array}{r}\text { Aire protégée } \\
\text { ou conservée }\end{array}$ & $\begin{array}{r}\text { Aire protégée } \\
\text { ou conservée* }^{\star *}\end{array}$ \\
\hline $\begin{array}{l}\text { Terrestres et eaux } \\
\text { intérieures }\end{array}$ & $29,14 \%$ & $29,10 \%$ \\
\hline
\end{tabular}

*Ensemble de données de la BDMAP ${ }^{* *}$ Rapport national sur la biodiversité

Source : Republic of Botswana (2019) ; UNEP-WCMC et IUCN (2019d).

Aires protégées et de conservation du Botswana par type de gouvernance de l'UICN

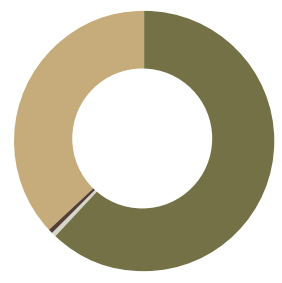

Non rapporté (2)

D. Gouvernance par les peuples

autochtones ou communautés locales (1)

C. Gouvernance privée (1)

A. Gouvernance par le gouvernement (18)
Désignations nationales des aires protégées et de conservation au Botswana

\begin{tabular}{l|r|r}
\hline Désignation nationale & $\mathbf{N}^{\circ}$ & $\begin{array}{r}\text { Superficie } \\
\left(\mathbf{k m}^{2}\right)\end{array}$ \\
\hline Parc national & 4 & 43926 \\
\hline Réserve de gibier & 6 & 60352 \\
\hline Sanctuaire de gibier & 1 & 89 \\
\hline Réserve forestière & 6 & 4057 \\
\hline Sanctuaire pour les oiseaux & 3 & 974 \\
\hline Source : UNEP-WCMC et IUCN (2019c). & \multicolumn{2}{|l}{}
\end{tabular}

Aires protégées et de conservation désignées comme sites d'importance mondiale au Botswana

\begin{tabular}{l|l}
\hline Désignation mondiale & $\begin{array}{l}\text { Nombre de } \\
\text { sites }\end{array}$ \\
\hline $\begin{array}{l}\text { Sites du Patrimoine mondial de l'UNESCO } \\
\text { (naturels ou mixtes) }\end{array}$ & 1 \\
\hline $\begin{array}{l}\text { Zones humides d'importance internationale } \\
\text { (sites Ramsar) }\end{array}$ & \\
\hline
\end{tabular}

Source : Ramsar (2019) ; UNESCO (2019a, 2019b). 
Le Botswana abrite 587 espèces d'oiseaux, dont 25 espèces menacées à l'échelle mondiale, et huit autres espèces considérées comme menacées à l'échelle nationale, ainsi que deux espèces quasi endémiques.

Sur les 99 espèces de poissons d'eau douce recensées au Botswana, deux sont menacées à l'échelle mondiale. En outre, 131 espèces de reptiles et 44 espèces d'amphibiens ont été recensées. II n'existe que peu d'informations disponibles sur les invertébrés, bien que les papillons et les libellules aient été inventoriés de façon plus précise que d'autres taxons.

Le Botswana abrite 13 espèces endémiques de plantes, ainsi que 10 autres potentiellement endémiques et sept quasi endémiques.

\section{Pressions et menaces ${ }^{39}$}

La principale menace pour la biodiversité au Botswana est la perte et la dégradation des habitats. Les causes indirectes de ces menaces comprennent: le surpâturage, du fait de la nonréglementation du pâturage du bétail, la dégradation des pâturages, les incendies, l'exploitation minière, l'érosion éolienne, l'extraction accrue d'eau pour l'irrigation entraînant une augmentation de la salinité, le manque de protection des sites de reproduction aviaire, le tourisme incontrôlé et la perturbation des routes de migration par des clôtures. Le braconnage de produits de la faune sauvage et de viande de brousse constitue une autre menace sérieuse pour la biodiversité du pays. Les conflits homme-faune sont un problème critique et permanent dans le pays.

Le cinquième Rapport national du Botswana à la CDB a montré les principales menaces pour la biodiversité dans le pays, reliant les menaces directes aux causes sous-jacentes, aux principaux impacts et aux principales implications (Republic of Botswana, 2015). Le rapport identifie la destruction des habitats, les obstacles aux mouvements de la faune sauvage, le braconnage, la perturbation des régimes de feux et la surexploitation comme les principales menaces internes, ainsi que les changements climatiques et hydrologiques comme les principales menaces externes.

Les menaces secondaires incluent les espèces envahissantes dans les écosystèmes terrestres et d'eau douce. Les changements climatiques apparaissent comme une menace majeure pour l'écosystème du delta de l'Okavango et le bassin du Kalahari.

\section{Figure 8.4 : Aires protégées du Botswana}

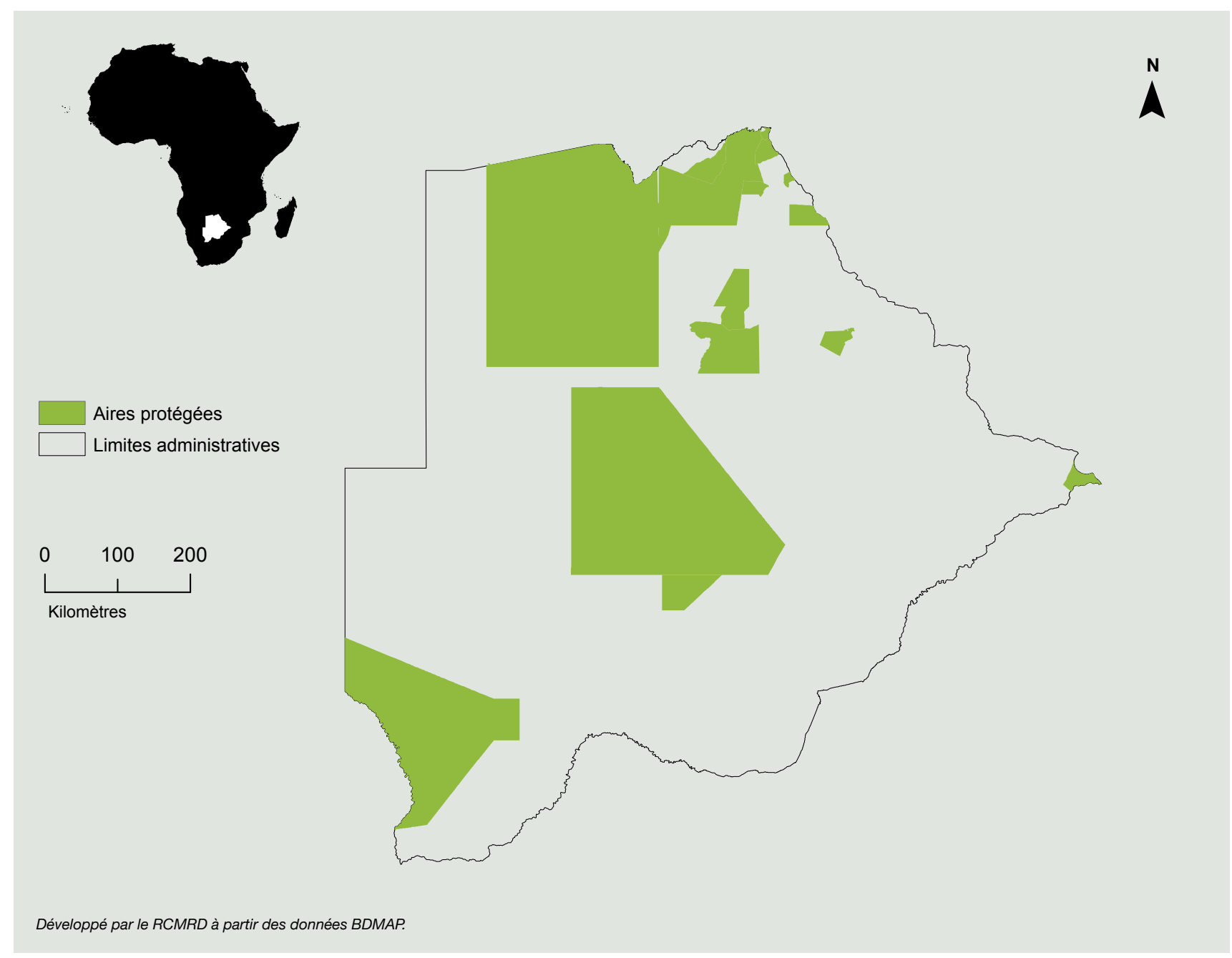

39 Cette section s'appuie sur les informations contenues dans le sixième Rapport national du Botswana à la CDB, ainsi que dans son troisième SPANB (Republic of Botswana, 2016, 2019). 

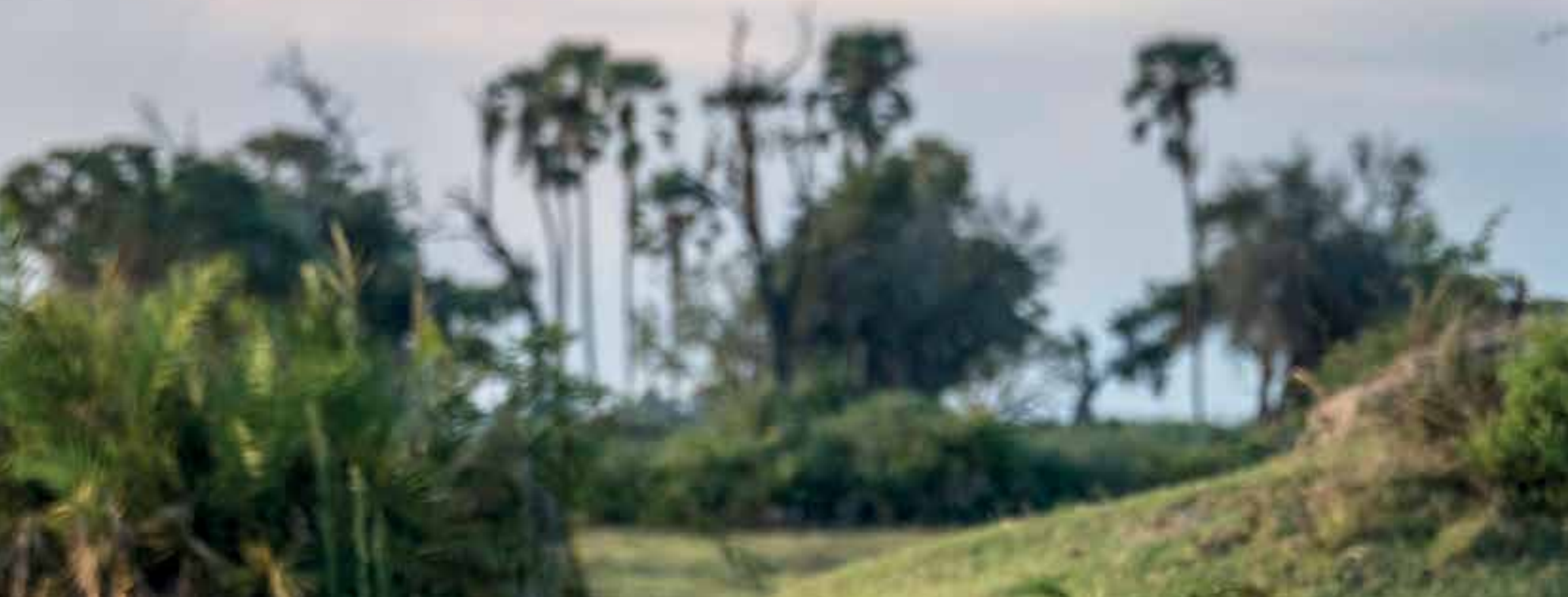

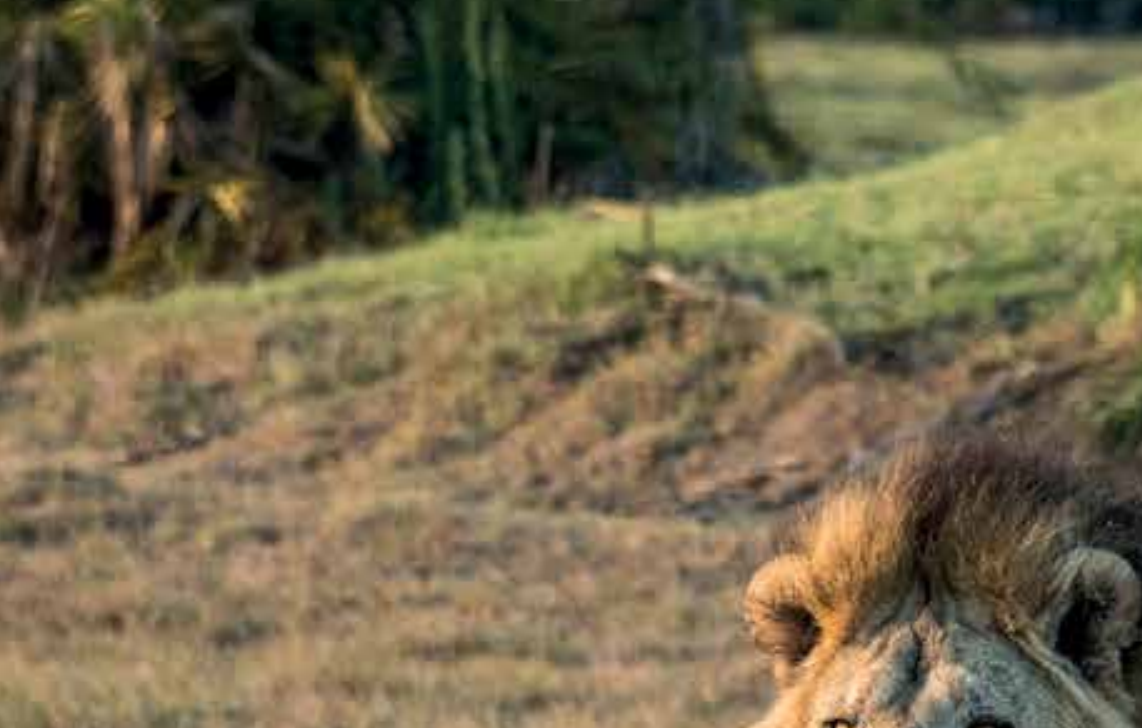

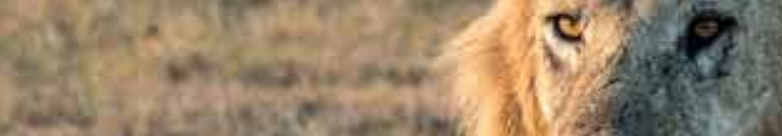

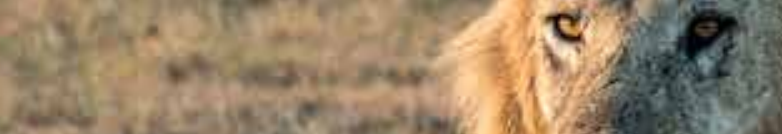

$x+2$

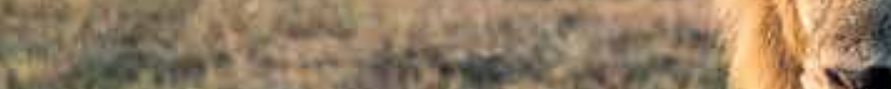
tions 6.

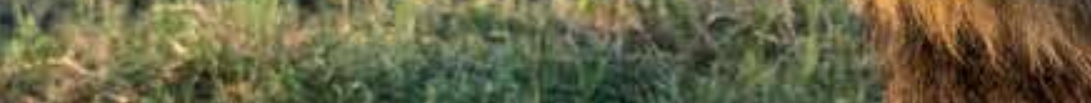

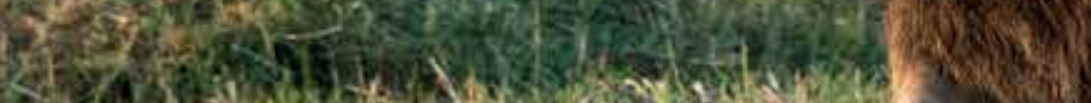

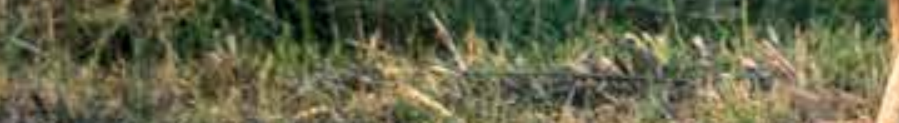
Q6. Q

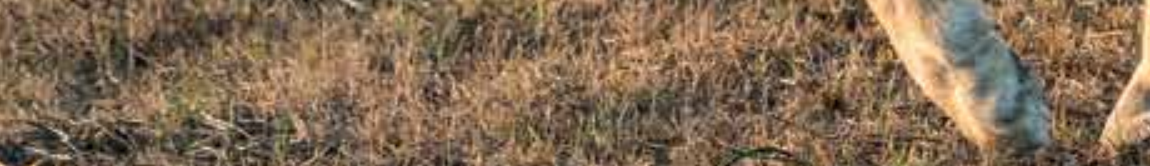

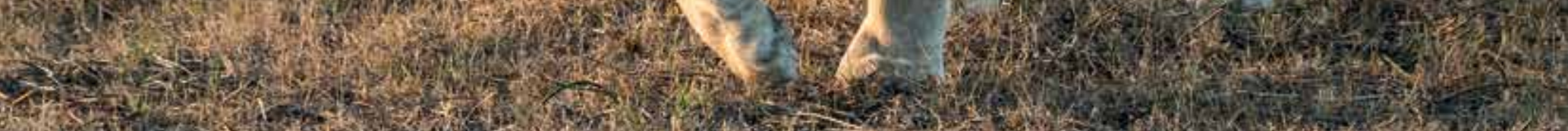

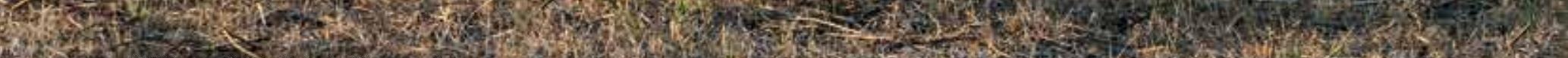

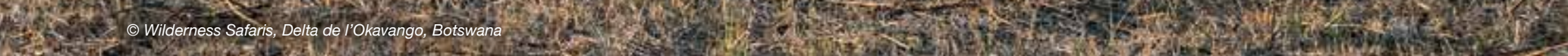




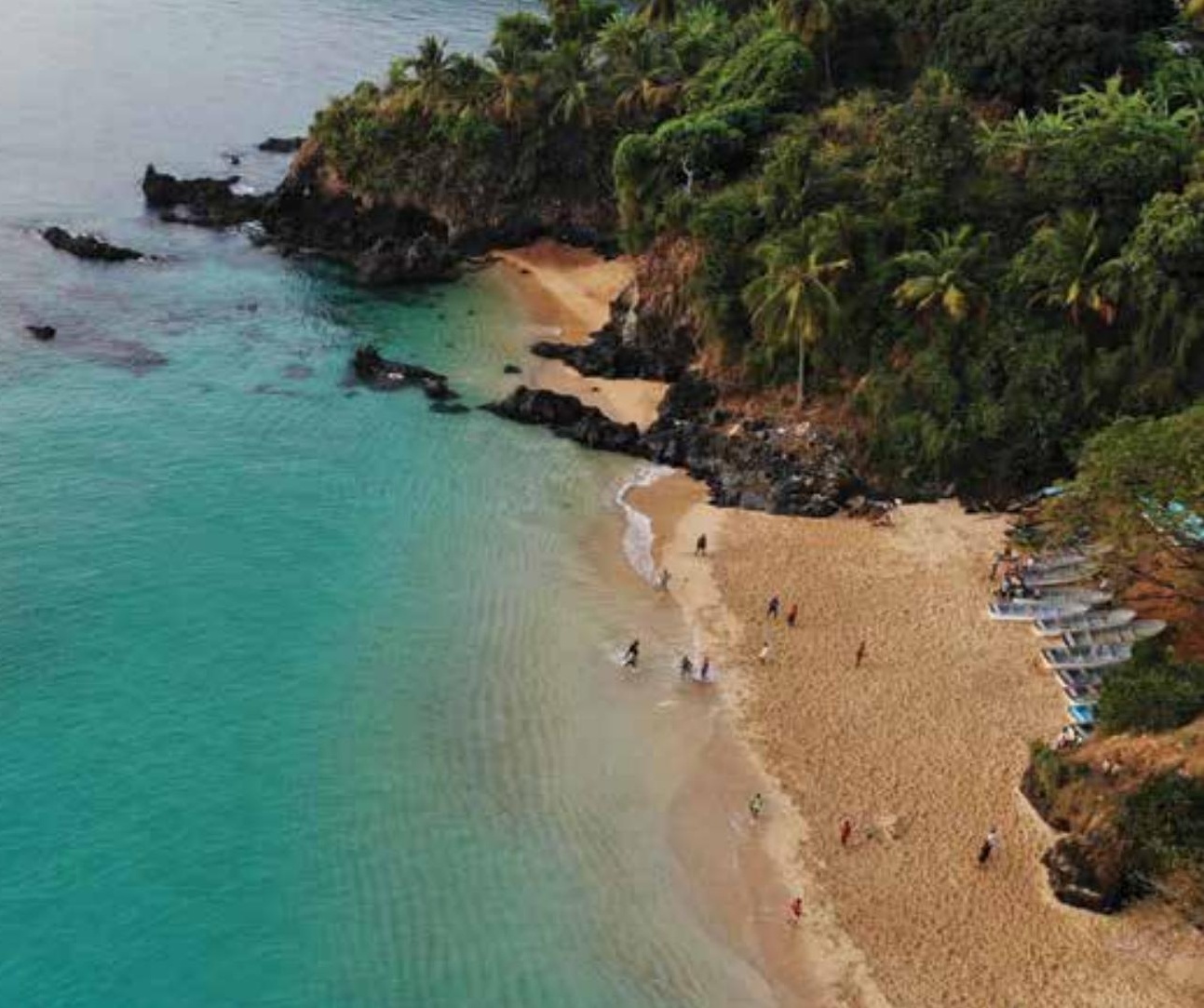

\subsection{Comores}

\section{Aires protégées et de conservation des Comores ${ }^{40}$}

Les Comores comptent huit aires protégées couvrant $173 \mathrm{~km}^{2}$ d'écosystèmes terrestres et $37 \mathrm{~km}^{2}$ d'écosystèmes marins (UNEPWCMC et IUCN, 2019d).

Les sites terrestres et d'eaux intérieures dans les aires protégées restent limités et ne sont pas connectés au sein de réseaux d'aires protégées écologiquement représentatifs. II sera nécessaire d'augmenter leur couverture pour atteindre l'Objectif d'Aichi 11, et pour cela, de créer de nouvelles aires protégées dans des écosystèmes fragiles présentant une biodiversité élevée et sensible, et d'intensifier les actions de conservation et de gestion de la biodiversité des ONG et des particuliers. Cependant, il est important de noter que depuis 2014, I'Union des Comores a augmenté son parc d'aires protégées de un à cinq sites. Cette augmentation de la couverture s'accompagne également d'une plus grande implication des communautés locales dans le processus de développement et de gestion des aires protégées. La création de nouvelles aires protégées, en plus du Parc national existant de Mohéli, s'inscrit dans l'engagement du gouvernement d'atteindre l'Objectif d'Aichi 11.

\section{Aires protégées et de conservation transfrontières}

Les Comores ne font partie d'aucune aire de conservation transfrontière.

\section{Contexte politique}

Un rapport complet sur la législation et les politiques relatives à la gestion, à la gouvernance et à l'équité des aires protégées a été réalisé par le programme BIOPAMA. II a identifié 15 lois et politiques pertinentes aux Comores (Tessema, 2019).

\section{Espèces clées ${ }^{41}$}

Quatre-vingt-seize espèces d'oiseaux ont été recensées aux Comores, dont 33 sont menacées. L'Union des Comores abrite un certain nombre de mammifères menacés, dont la petite roussette des Comores (Rousettus obliviosus), endémique, le lémur mongos (Eulemur mongoz), la roussette de Livingstone (Pteropus livingstonii), endémique, le dugong (Dugong dugon), la baleine à bosse (Megaptera novaeangliae) et le tenrec acaude (Tenrec ecaudatus)

Plus de 1200 espèces d'insectes ont été recensées aux Comores, et au moins 16 espèces végétales sont menacées d'extinction.

Deux espèces d'amphibiens et 29 reptiles ont également été recensées, les deux espèces d'amphibiens et 14 des 29 reptiles terrestres étant endémiques. Un certain nombre de reptiles sont menacés d'extinction. Un certain nombre d'espèces de tortues marines nichent également aux Comores, et leur état de conservation s'améliore.

Le pays abrite également le cœlacanthe (Latimeria chalumnae), classé en danger critique d'extinction. Un certain nombre

40 Cette section s'appuie sur les informations contenues dans le sixième rapport national des Comores à la CDB (Union des Comores, 2019).

41 Cette section s'appuie sur les informations contenues dans le cinquième Rapport national des Comores à la CDB, dans leur deuxième Stratégie et plan d'action nationaux pour la biodiversité (SPANB) (Union des Comores, 2014; 2016), ainsi que dans leur Stratégie 2017-2021 d'extension du système national d'aires protégées (Union des Comores, 2017). 
Figure 8.5 : Résumé des Comores

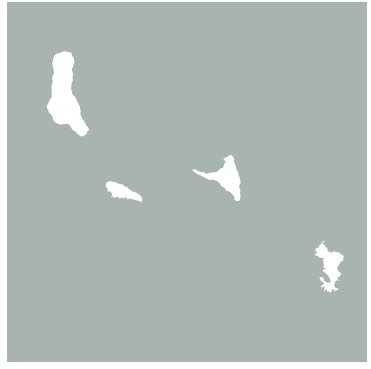

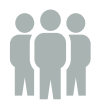

Population totale (en millions)

0,83

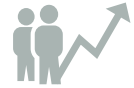

Démographie

(\% annuel)

Source : The World Bank Group, 2018.

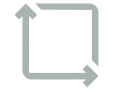

Superficie

(en milliers de $\mathrm{km}^{2}$ )

1,90

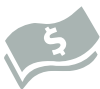

PIB (en milliards de USD actuels)

1,20
Croissance du

PIB (\% annuel)

2,80
Aires protégées :

8 aires protégées

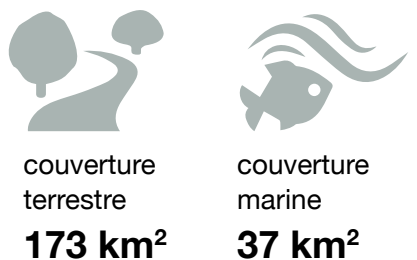

Source : UNEP-WCMC et IUCN, 2019d
Aires protégées et de conservation des Comores par catégorie de gestion de l'UICN

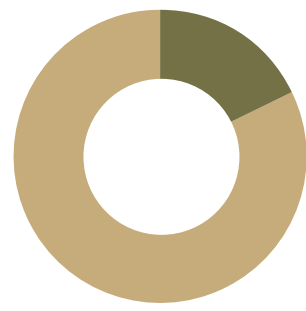

Source : UNEP-WCMC et IUCN (2019d).
Non rapportée (7)

II. Parc national (1)

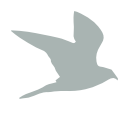

96 espèces d'oiseaux

33 menacées
16 espèces végétales menacées

\section{2 espèces \\ d'amphibiens endémiques}

14 reptiles endémiques

\section{Couverture des aires protégées aux Comores}

\begin{tabular}{l|r|r}
\hline Type d'aire protégée & $\begin{array}{r}\text { Aire protégée } \\
\text { ou conservée* }\end{array}$ & $\begin{array}{r}\text { Aire protégée ou } \\
\text { conservée }^{\star *}\end{array}$ \\
\hline $\begin{array}{l}\text { Terrestres et eaux } \\
\text { intérieures }\end{array}$ & $10,15 \%$ & $22,00 \%$ \\
\hline Marines et côtières & $0,02 \%$ & $\begin{array}{r}\text { Aucune } \\
\text { correspondance }\end{array}$ \\
\hline
\end{tabular}

*Ensemble de données de la BDMAP ** Rapport national sur la biodiversité Source : UNEP-WCMC et IUCN (2019d); Union des Comores (2014).

Aires protégées et de conservation des Comores par type de gouvernance de I'UICN

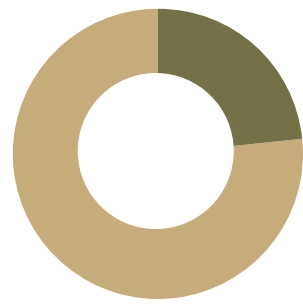

Non rapporté (2)

B. Gouvernance partagée (6)
Source : UNEP-WCMC et IUCN (2019d).
Désignations nationales des aires protégées et de conservation aux Comores

\begin{tabular}{l|r|r}
\hline Désignation nationale & $\mathbf{N}$ & $\begin{array}{r}\text { Superficie } \\
\left(\mathbf{k m}^{2}\right)\end{array}$ \\
\hline Parc national & 1 & 37 \\
\hline Aire protégée nationale & 4 & 573 \\
\hline Source : UNEP-WCMC et IUCN (2019d).
\end{tabular}

Aires protégées et de conservation désignées comme sites d'importance mondiale aux Comores

\begin{tabular}{l|r}
\hline Désignation mondiale & $\begin{array}{r}\text { Nombre de } \\
\text { sites }\end{array}$ \\
\hline $\begin{array}{l}\text { Zones humides d'importance internationale } \\
\text { (sites Ramsar) }\end{array}$ & 3 \\
\hline
\end{tabular}

Source : Ramsar (2019); UNESCO (2019a, 2019b).

\section{Aires prioritaires pour la conservation}
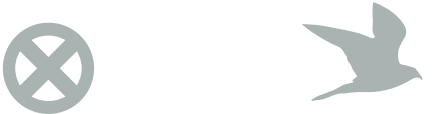

$\begin{array}{ll}\mathbf{3} \text { sites } & \mathbf{4} \text { sites } \\ \text { Sites de l'Alliance } & \text { Zones importantes } \\ \text { pour une extinction } & \begin{array}{l}\text { pour les oiseaux } \\ \text { et la biodiversité }\end{array}\end{array}$




\section{Figure 8.6 : Aires protégées des Comores}

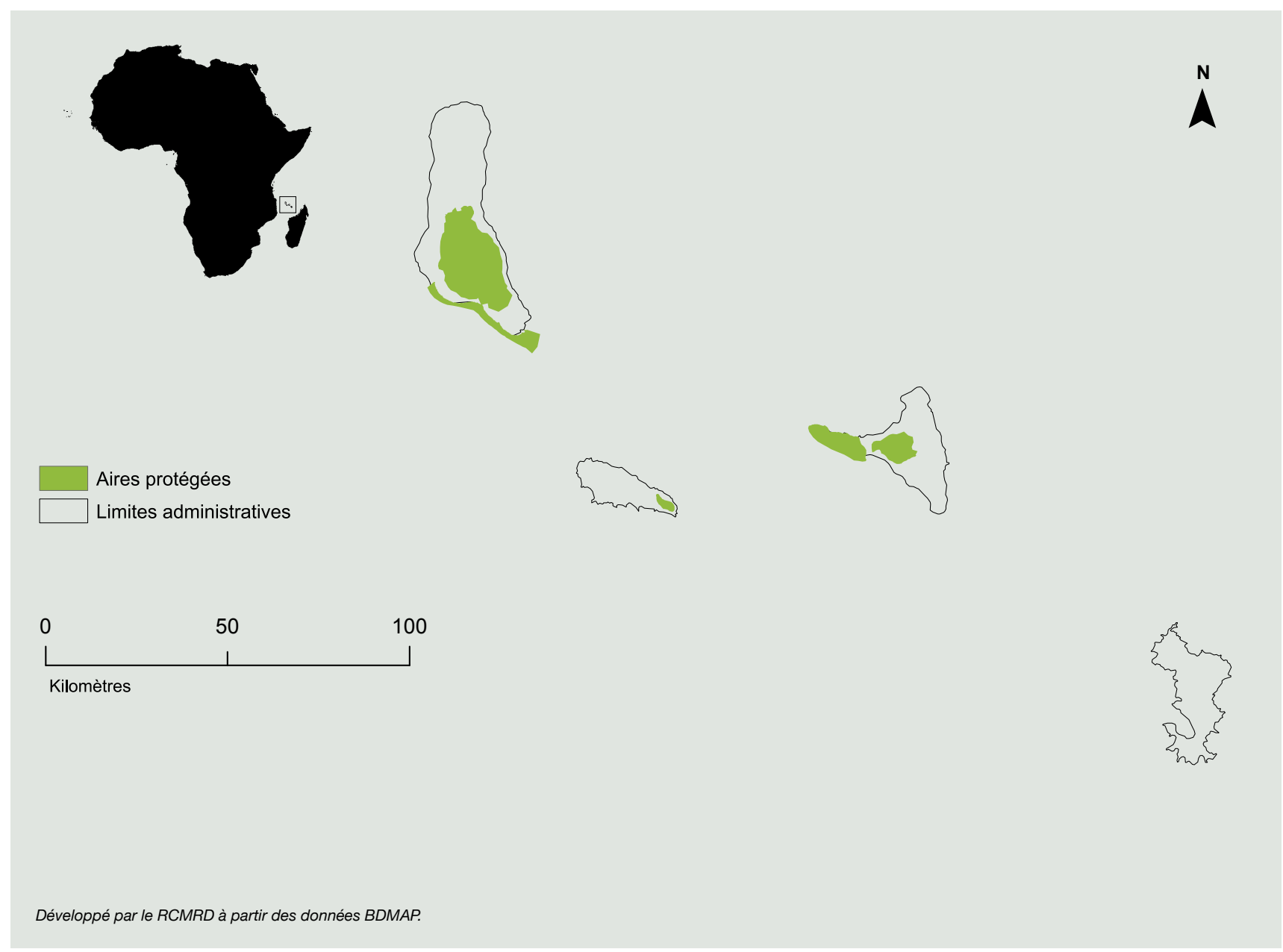

d'espèces de cétacés protégées par la CITES, telles que la baleine à bosse (Megaptera novaeangliae), la baleine franche australe (Eubalaena australis), la baleine de Bryde (Balaenoptera edeni) et le cachalot (Physeter macrocephaleus), fréquentent les eaux marines comoriennes.

Certaines espèces de coraux, comme le corail noir (Antipathes dichotoma), sont inscrites aux annexes de la CITES en raison d'une forte demande pour la bijouterie. Au moins 16 espèces végétales sont menacées d'extinction.

\section{Pressions et menaces ${ }^{42}$}

Les principales pressions directes sur la biodiversité des Comores sont la perte et la dégradation des habitats du fait de l'agriculture sur brûlis, les espèces exotiques envahissantes, le besoin croissant de bois de chauffage pour la distillation de I'ylang-ylang, la surexploitation du corail et du sable pour la construction et la pollution. La surexploitation de certaines espèces, y compris les reptiles et un certain nombre d'espèces marines, constitue une menace majeure. Un certain nombre d'espèces de mollusques ont disparu en raison de la surexploitation.
Les principales causes indirectes de ces menaces incluent la fragilité naturelle de l'écosystème, avec une population humaine croissante et des niveaux de pauvreté très élevés. Le cadre institutionnel présente certaines faiblesses, notamment des capacités humaines faibles, une insécurité foncière, un cadre réglementaire inadéquat et non appliqué et des politiques publiques inefficaces.

Les changements climatiques représentent une menace majeure à court et à long terme pour la biodiversité des Comores. Dans certains endroits, les récifs coralliens ont subi un blanchiment de plus de $60 \%$ en raison de la hausse des températures de l'eau de mer, tandis que les prairies côtières ont reculé de 30 à 40 mètres en raison de la hausse du niveau de la mer.

42 Cette section s'appuie sur les informations contenues dans le cinquième Rapport national des Comores à la CDB, leur deuxième SPANB (Union des Comores, 2014, 2016), ainsi que dans le Système national détaillant la stratégie des aires protégées 2017-2021 (DGEF, 2017). 


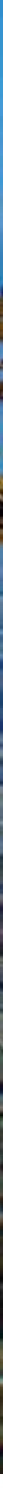




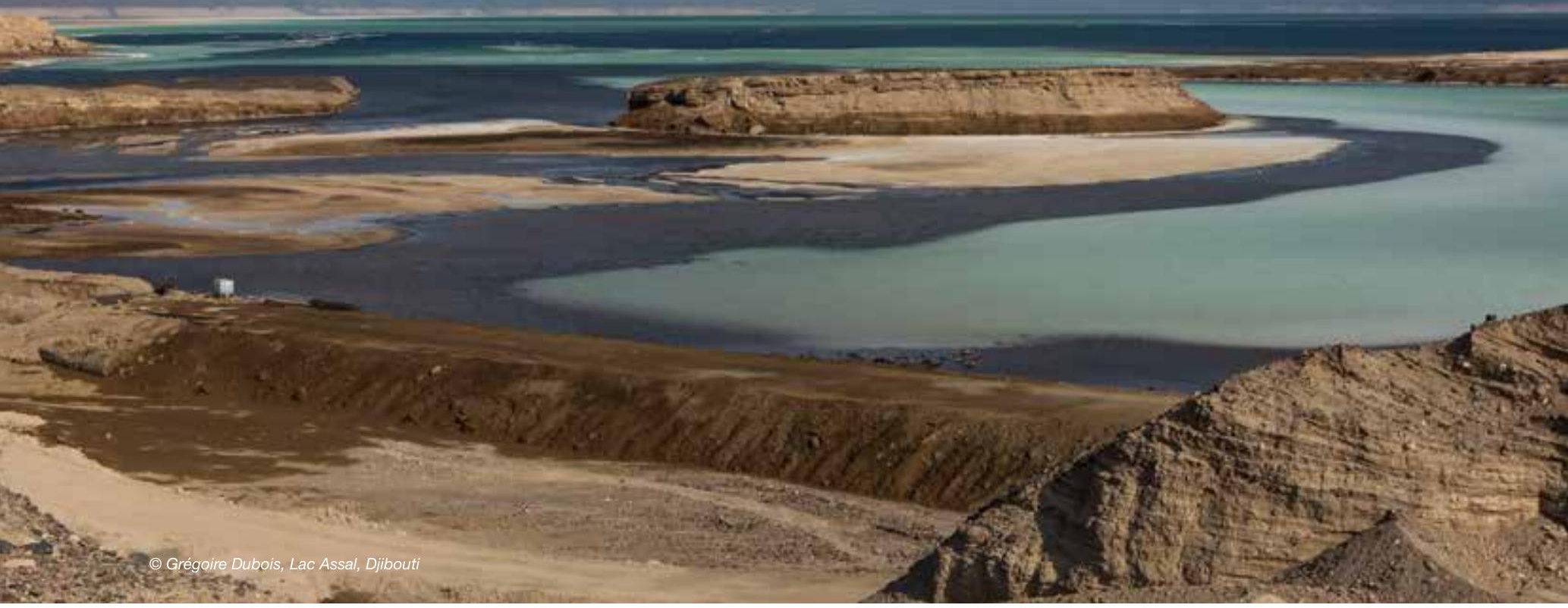

\subsection{Djibouti}

\section{Aires protégées et de conservation de Djibouti ${ }^{43}$}

Djibouti compte sept aires protégées couvrant $344 \mathrm{~km}^{2}$ d'écosystèmes terrestres et 12 km² d'écosystèmes marins (UNEPWCMC et IUCN (2019e).

En 2015, il a été proposé d'étendre le réseau des AMP au secteur maritime et côtier, dans l'optique de former une grande unité de gestion étendant la couverture des AMP à une superficie totale de 56500 ha de paysages marins. De plus, en 2019, plusieurs sites terrestres ont été identifiés comme candidats à une protection.

À Djibouti, les aires protégées terrestres et marines ne sont pas des zones fermées. Les activités traditionnelles d'agriculture et de pêche, ainsi que l'écotourisme, sont autorisées, mais réglementées et contrôlées en vue de préserver la biodiversité. Cependant, des restrictions telles que l'abattage ou l'élagage des arbres et la cueillette ou l'arrachage des plantes sont réglementées et contrôlées dans les aires protégées terrestres.

\section{Aires protégées et de conservation transfrontières}

Djibouti comprend une partie de l'aire de conservation transfrontière du paysage du Bas Awash-Lac Abbé.

\section{Contexte politique}

Un rapport complet sur la législation et les politiques relatives à la gestion, à la gouvernance et à l'équité des aires protégées a été réalisé par le programme BIOPAMA. II a identifié 21 lois et politiques pertinentes à Djibouti (Tessema, 2019).

\section{Espèces clées $^{44}$}

Ces rapports ne fournissent pas un résumé global des espèces présentes dans le pays, mais prennent note des écosystèmes clés, y compris les forêts et les mangroves. Une attention particulière est accordée à la forêt de Day et au massif de Goda, qui abritent une variété de plantes, d'animaux et d'oiseaux, dont le francolin somal (Francolinus ochropectus), endémique et en danger critique d'extinction.

\section{Pressions et menaces ${ }^{45}$}

La biodiversité de Djibouti fait face à des menaces majeures. Les rares ressources en eau douce du pays sont menacées par la salinisation, la détérioration des infrastructures, la pollution et la dégradation des principaux bassins versants par la déforestation pour le bois de chauffage et le charbon de bois. Djibouti souffre également d'une importante invasion de Prosopis, ou mesquite, qui dégrade les pâturages. Les milieux marins sont également touchés par la pollution, y compris par le stockage de produits pétroliers. La pêche illégale et non réglementée entraine une surexploitation de certaines espèces.

Les pressions indirectes incluent la sécheresse, la croissance urbaine, l'augmentation de la population, la pression des populations réfugiées de pays voisins, et la pauvreté et l'insécurité alimentaire rurales persistantes.

43 Cette section s'appuie sur les informations contenues dans le sixième Rapport national de Djibouti à la CDB (République de Djibouti, 2019), ainsi que dans son deuxième SPANB (République de Djibouti, 2017).

44 Cette section s'appuie sur les informations contenues dans le cinquième Rapport national de Djibouti à la CDB, ainsi que dans son deuxième SPANB (République de Djibouti, $2014 ; 2017)$.

45 lbid. 
Figure 8.7 : Résumé de Djibouti

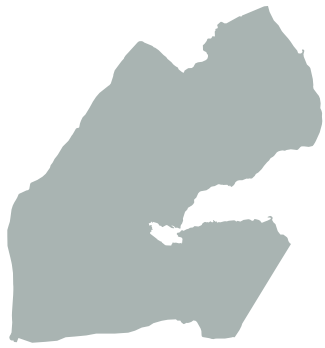

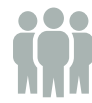

Population totale (en millions) 0,96

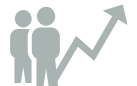

Démographie (\% annuel) 1,60

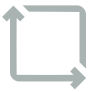

Superficie (en milliers de $\mathrm{km}^{2}$ )

23,2

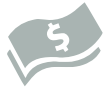

PIB (en milliards de USD actuels)

1,97
Croissance du PIB (\% annuel) 6,00
Aires protégées :

7 aires protégées

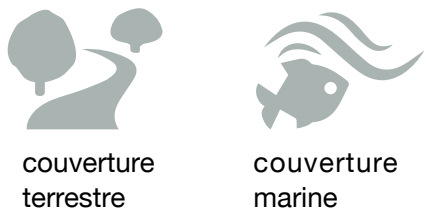

$344 \mathrm{~km}^{2} \quad 12 \mathrm{~km}^{2}$

Source : UNEP-WCMC et IUCN, 2019e

\section{Les écosystèmes clés incluent :} les forêts et les mangroves
Aires protégées et de conservation de Djibouti par catégorie de gestion de l'UICN

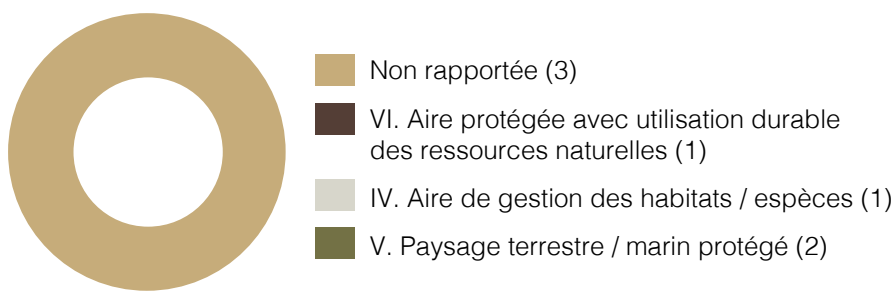

Source : UNEP-WCMC et IUCN (2019e).
Couverture des aires protégées à Djibouti

\begin{tabular}{l|r|r}
\hline Type d'aire protégée & $\begin{array}{r}\text { Aire protégée } \\
\text { ou conservée* }\end{array}$ & $\begin{array}{r}\text { Aire protégée } \\
\text { ou conservée** }\end{array}$ \\
\hline $\begin{array}{l}\text { Terrestres et eaux } \\
\text { intérieures }\end{array}$ & $1,57 \%$ & $1,34 \%$ \\
\hline Marines et côtières & $0,17 \%$ & \multicolumn{2}{|c}{$0,46 \%$} \\
\hline $\begin{array}{l}\text { *Ensemble de données de la BDMAP } \\
\text { Source : République de Djibouti (2014) ; UNEP-WCMC et IUCN (2019e). }\end{array}$
\end{tabular}

Aires protégées et de conservation de Djibouti par type de gouvernance de l'UICN

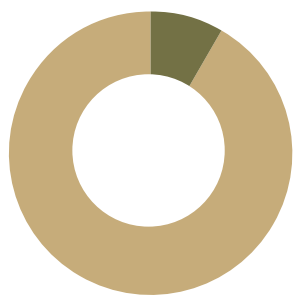

A. Gouvernance par le gouvernement (3) Non rapporté (1)
Désignations nationales des aires protégées et de conservation à Djibouti

\begin{tabular}{l|r|r}
\hline Désignation nationale & Nombre & $\begin{array}{r}\text { Superficie } \\
\left(\mathbf{k m}^{2}\right)\end{array}$ \\
\hline Aire protégée terrestre & 2 & 323 \\
\hline Paysage marin protégé & 3 & 514 \\
\hline $\begin{array}{l}\text { Aire protégée pour les } \\
\text { habitats et les espèces }\end{array}$ & 1 & 26 \\
\hline Source : UNEP-WCMC et IUCN (2019e). & & \\
\end{tabular}

Aires protégées et de conservation désignées comme sites d'importance mondiale à Djibouti

\begin{tabular}{l|r}
\hline Désignation mondiale & $\begin{array}{r}\text { Nombre de } \\
\text { sites }\end{array}$ \\
\hline $\begin{array}{l}\text { Zones humides d'importance internationale } \\
\text { (sites Ramsar) }\end{array}$ & 1 \\
\hline Source : Ramsar (2019) ; UNESCO (2019a, 2019b).
\end{tabular}

\section{Aires prioritaires pour la conservation}

\section{7 sites}

Zones importantes pour les oiseaux et la biodiversité

Source : BirdLife International (2019c). 


\section{Figure 8.8 : Aires protégées de Djibouti}
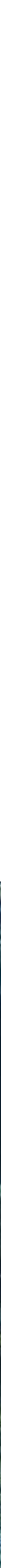
Figure 8.9 : Résumé de l'Érythrée

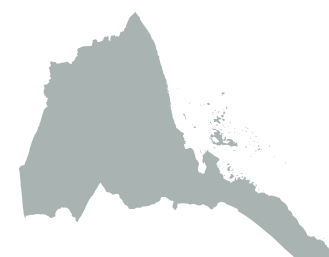

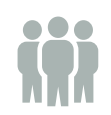

Population totale (en millions)

3,17

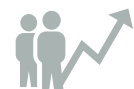

Démographie (\% annuel) 1,60

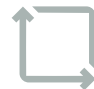

Superficie

(en milliers de $\mathrm{km}^{2}$ )

117,6

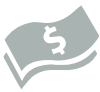

PIB (en milliards de USD actuels)

2,12

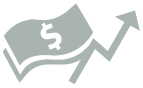

Croissance du PIB (\% annuel)

2,20
Aires protégées :

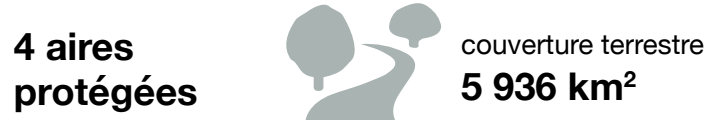

Source : UNEP-WCMC et IUCN, $2019 f$
Aires protégées et de conservation de l'Érythrée par catégorie de gestion de I'UICN

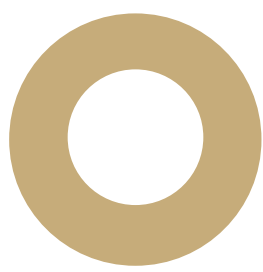

Non rapportée (1)

IV. Aire de gestion des habitats / espèces (3)

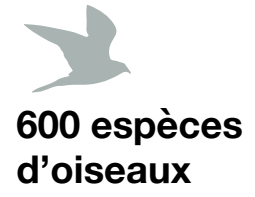

\section{d'oiseaux}

\section{0 espèces de reptiles}

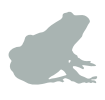

19 espèces

d'amphibiens

\section{0 espèces de coraux}

\section{Couverture des aires protégées en Érythrée}

\begin{tabular}{l|r|r}
\hline Type d'aire protégée & $\begin{array}{r}\text { Aire protégée } \\
\text { ou conservée* }\end{array}$ & $\begin{array}{r}\text { Aire protégée } \\
\text { ou conservée** }\end{array}$ \\
\hline $\begin{array}{l}\text { Terrestres et eaux } \\
\text { intérieures }\end{array}$ & $4,87 \%$ & $\begin{array}{r}\text { Aucune } \\
\text { correspondance }\end{array}$ \\
\hline Marines et côtières & $0,00 \%$ & $\begin{array}{r}\text { Aucune } \\
\text { correspondance }\end{array}$ \\
\hline
\end{tabular}

*Ensemble de données de la BDMAP ${ }^{* *}$ Rapport national sur la biodiversité Source : UNEP-WCMC et IUCN (2019f).

Aires protégées et de conservation de l'Érythrée par type de gouvernance de l'UICN

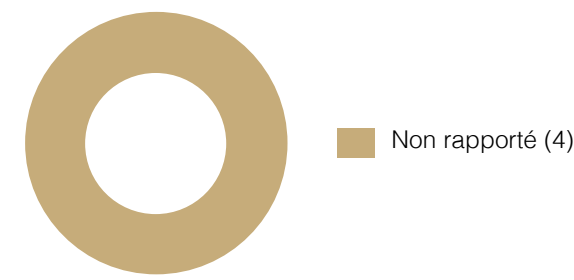

Source : UNEP-WCMC et IUCN (2019f).
Désignations nationales des aires protégées et de conservation en Érythrée

\begin{tabular}{l|r|r}
\hline Désignation nationale & $\mathbf{N}^{\circ}$ & $\begin{array}{r}\text { Superficie } \\
\left(\mathbf{k m}^{2}\right)\end{array}$ \\
\hline Réserve de faune sauvage & 3 & 5903 \\
\hline Parc national marin & 1 & 652 \\
\hline Source : UNEP-WCMC et IUCN (2019f).
\end{tabular}

Aires prioritaires pour la conservation

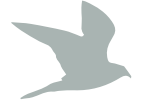

\section{4 sites}

Zones importantes pour les oiseaux et la biodiversité

Source : BirdLife International (2019b, 2019c).

\section{9 sites}

Zones clés pour la biodiversité 


\section{Pressions et menaces ${ }^{48}$}

La transformation des habitats, du fait de l'expansion de l'agriculture et de la pollution des écosystèmes d'eau douce et marins, ainsi que pour le développement urbain et industriel, constitue l'une des menaces directes les plus importantes pour la biodiversité en Érythrée. Les herbiers marins et les algues sont touchés par une sédimentation croissante. Les espèces exotiques envahissantes représentent une menace majeure. La déforestation et l'étêtage excessif ont un impact sur les ressources forestières. La chasse illégale de la faune sauvage pour le commerce de viande de brousse est un problème, en particulier dans les écosystèmes de prairies.

La surexploitation des coraux, des poissons et autres espèces marines constitue une grave pression sur ces espèces. Les espèces envahissantes, y compris les mammifères prédateurs s'attaquant aux oiseaux nicheurs des îles, constituent une menace pour de nombreuses espèces et écosystèmes. Les tortues de mer sont menacées par la perturbation des sites de nidification, le braconnage des œufs et la chasse illégale des animaux matures, ainsi que par les prises accessoires dans les chalutiers.

\section{Figure 8.10 : Aires protégées de l'Érythrée}

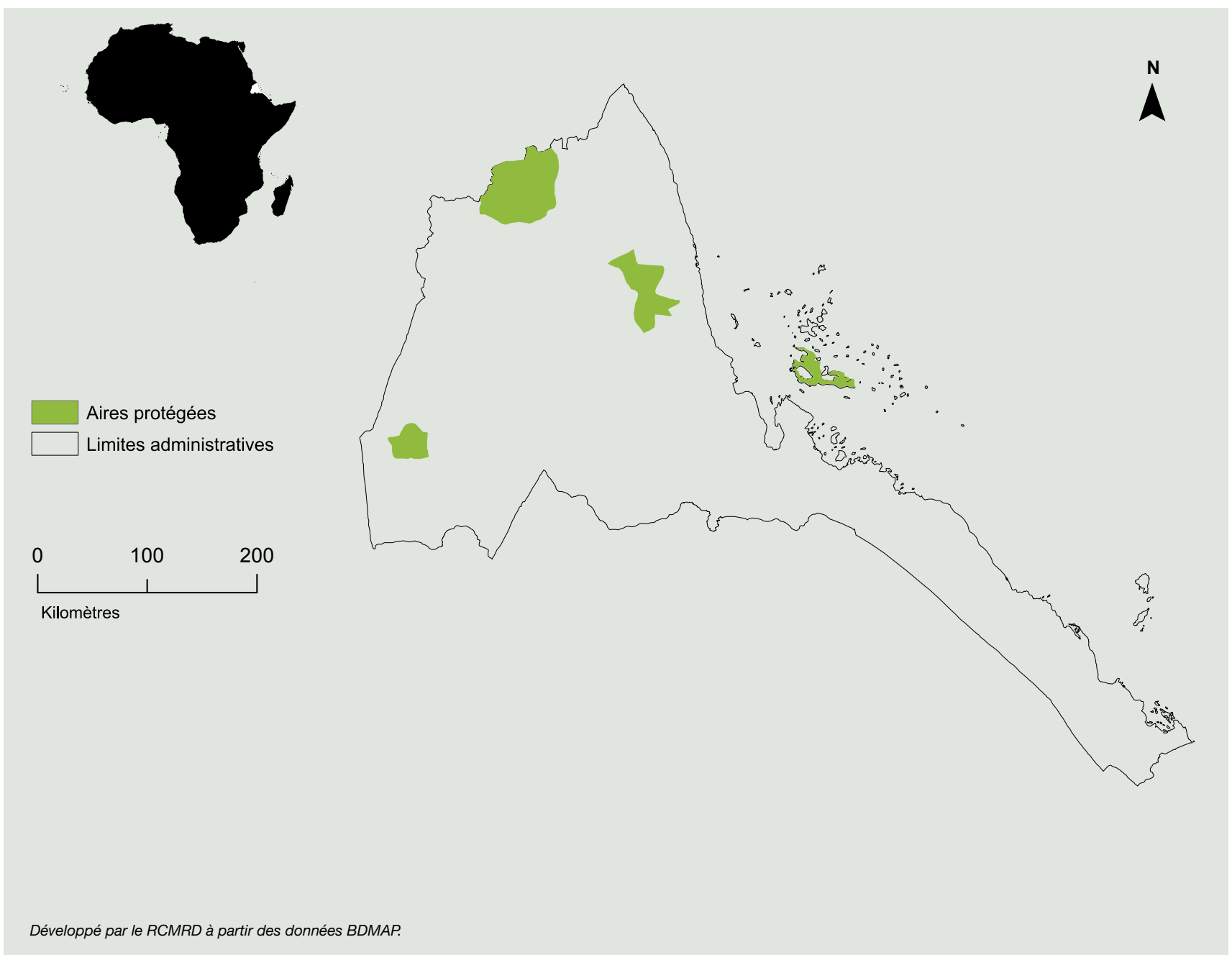




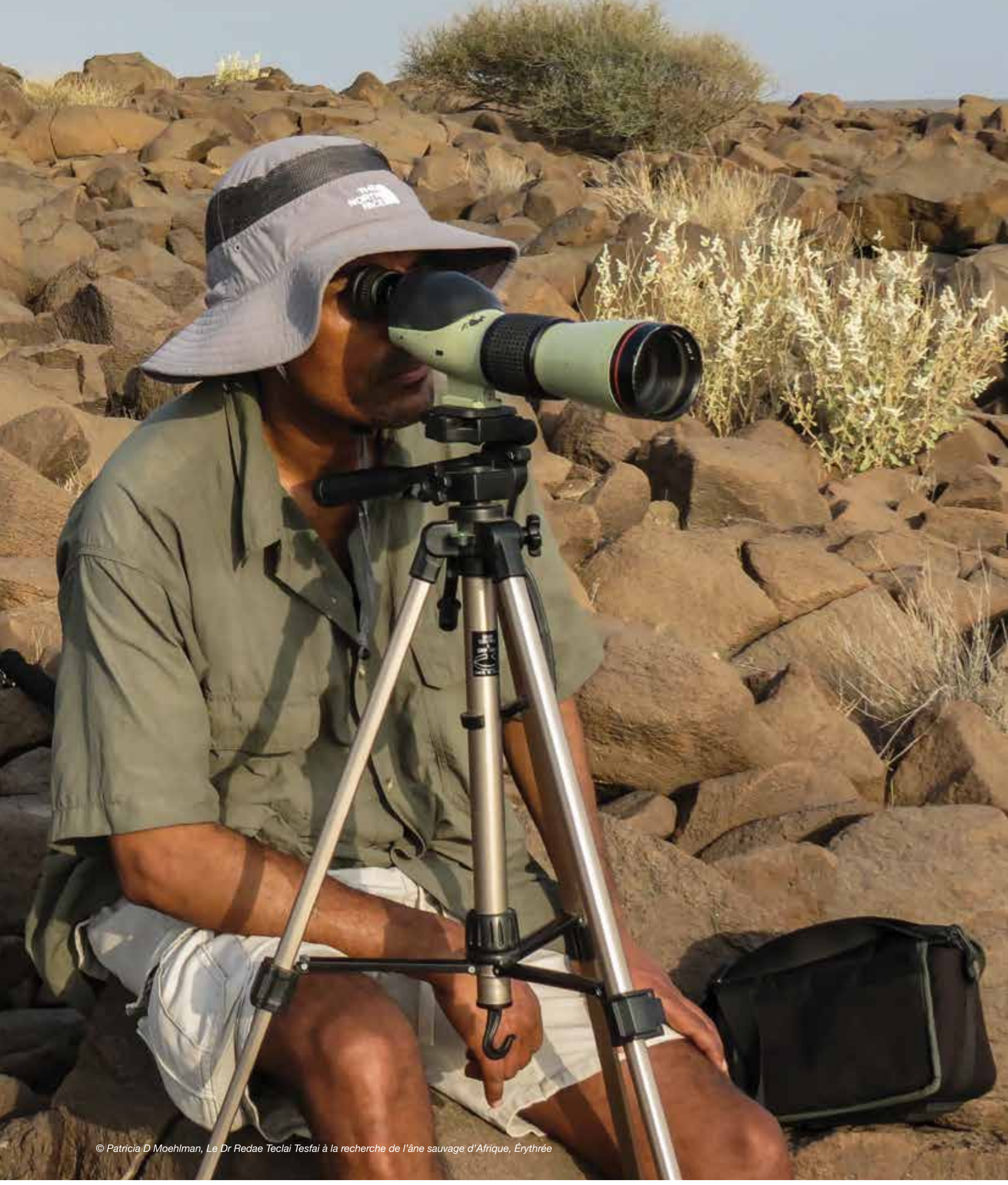




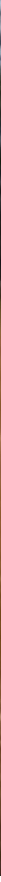

\subsection{Eswatini}

\section{Aires protégées et de conservation de l'Eswatini ${ }^{49}$}

L'Eswatini compte 14 aires protégées couvrant $738 \mathrm{~km}^{2}$ d'écosystèmes terrestres (UNEP-WCMC et IUCN, 2019g).

Le nombre d'aires protégées du pays a augmenté en un an, passant de 3,9\% en 2017 à 4,26\% en 2018. Les aires protégées d'Eswatini sont composées de très petites aires protégées vulnérables, mal réparties entre les écosystèmes. II est donc nécessaire d'étendre ses aires protégées, tout en renforçant les compétences en matière de gestion. Cela nécessitera, à son tour, la participation d'un large éventail de parties prenantes, y compris les propriétaires fonciers privés, les communautés locales et l'industrie du tourisme.

\section{Aires protégées et de conservation transfrontières}

L'Eswatini accueille une partie de l'aire de conservation transfrontalière de Lubombo.

\section{Contexte politique}

Un rapport complet sur la législation et les politiques relatives à la gestion, à la gouvernance et à l'équité des aires protégées a été réalisé par le programme BIOPAMA. II a identifié 10 lois et politiques pertinentes en Eswatini (Tessema, 2019).

\section{Espèces clées $^{50}$}

Pour un petit pays, l'Eswatini possède une riche diversité florale et faunique. Sur les plus de 3500 espèces végétales recensées, 12 sont endémiques, 89 espèces de vertébrés et 305 espèces de plantes sont inscrites sur les Listes rouges nationales, et 813 espèces de vertébrés ont été recensées, dont une seule endémique, le grand gecko rupicole (Afroedura major).

\section{Pressions et menaces ${ }^{51}$}

Les principales pressions à l'origine de l'évolution de la biodiversité du pays incluent la perte et le changement des habitats du fait de l'agriculture croissante et pour l'urbanisation et les installations humaines, ainsi que les incendies de forêt et les espèces envahissantes, $80 \%$ de l'Eswatini étant infestés par au moins une espèce végétale envahissante. La récolte non durable d'espèces végétales et animales à des fins médicinales constitue une menace majeure pour de nombreuses espèces. De même, la récolte non durable d'arbres pour la production de charbon de bois a eu un impact majeur sur l'habitat de nombreuses espèces d'oiseaux et de mammifères.

Les changements climatiques constituent une pression émergente en Eswatini, susceptible de perturber les écosystèmes naturels dans tout le pays. Les menaces indirectes incluent les pressions économiques, démographiques, sociopolitiques et culturelles. Avec plus de $40 \%$ de la population âgée de moins de 25 ans, il est prévu que la population de l'Eswatini doublera dans un avenir proche.

49 Cette section s'appuie sur les informations contenues dans le sixième Rapport national de l'Eswatini à la CDB (Kingdom of Eswatini, 2019).

50 Cette section s'appuie sur les informations contenues dans le cinquième Rapport national de l'Eswatini à la CDB, ainsi que dans son deuxième SPANB (Eswatini Environment Authority, $2014 ;$ 2016)

51 Cette section s'appuie sur les informations contenues dans le cinquième Rapport national de l'Eswatini à la CDB (Eswatini Environment Authority, 2014). 
Figure 8.11 : Résumé de l'Eswatini

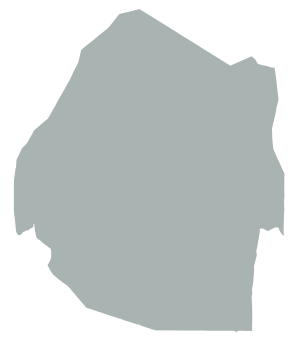

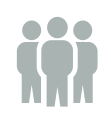

Population totale (en millions)

1,14

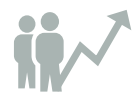

Démographie (\% annuel)

1,00

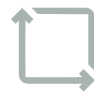

Superficie (en milliers de $\mathrm{km}^{2}$ )

17,40

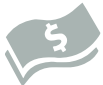

PIB (en milliards de USD actuels)

\section{4,70}

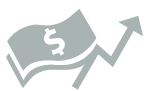

Croissance du PIB (\% annuel) 0,60

Source : The World Bank Group, 2018

\section{Aires protégées :}

14 aires protégées couverture

terrestre

$738 \mathrm{~km}^{2}$
Aires protégées et de conservation de l'Eswatini par catégorie de gestion de l'UICN

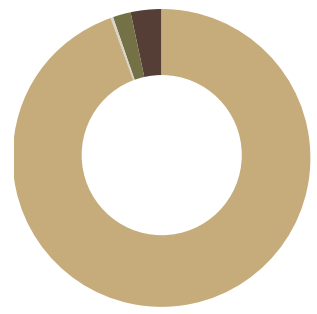

Non rapportée

V. Paysage terrestre / marin protégé (1)

IV. Aire de gestion habitats / espèces (2)

II. Parc national (6)

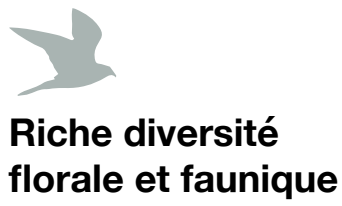

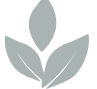

3500 espèces végétales

12 endémiques

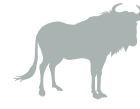

813 espèces de vertébrés

\section{Couverture des aires protégées en Eswatini}

\begin{tabular}{l|r|r}
\hline Type d'aire protégée & $\begin{array}{r}\text { Aire protégée } \\
\text { ou conservée* }\end{array}$ & $\begin{array}{r}\text { Aire protégée } \\
\text { ou conservée }\end{array}$ \\
\hline $\begin{array}{l}\text { Terrestres et eaux } \\
\text { intérieures }\end{array}$ & $4,26 \%$ & $3,90 \%$ \\
\hline
\end{tabular}

"Ensemble de données de la BDMAP ${ }^{* *}$ Rapport national sur la biodiversité Source : Eswatini Environment Authority (2014) ; UNEP-WCMC et IUCN (2019g).

Aires protégées et de conservation de l'Eswatini par type de gouvernance de l'UICN

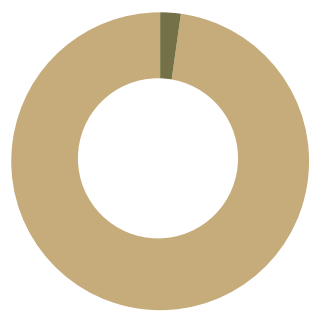

Non rapporté (11)

B. Privée (3)
Désignations nationales des aires protégées et de conservation en Eswatini

\begin{tabular}{l|r|r}
\hline Désignation nationale & $\mathbf{N}^{\circ}$ & $\begin{array}{r}\text { Superficie } \\
\left.\mathbf{( k m}^{2}\right)\end{array}$ \\
\hline Parc national & 1 & 217 \\
\hline Réserve naturelle & 10 & 520 \\
\hline
\end{tabular}

Source : UNEP-WCMC et IUCN (2019g).

Aires protégées et de conservation désignées comme sites d'importance mondiale en Eswatini

\begin{tabular}{l|r}
\hline Désignation mondiale & $\begin{array}{r}\text { Nombre de } \\
\text { sites }\end{array}$ \\
\hline $\begin{array}{l}\text { Zones humides d'importance internationale } \\
\text { (sites Ramsar) }\end{array}$ & 3 \\
\hline Source : Ramsar (2019) ; UNESCO (2019a, 2019b)
\end{tabular}

\section{Aires prioritaires pour la conservation}

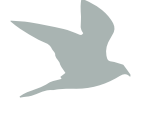

\section{3 sites}

Zones importantes pour les oiseaux et la biodiversité

Zones clés pour la biodiversité

Source : BirdLife International (2019b, 2019c). 


\section{Figure 8.12: Aires protégées de l'Eswatini}

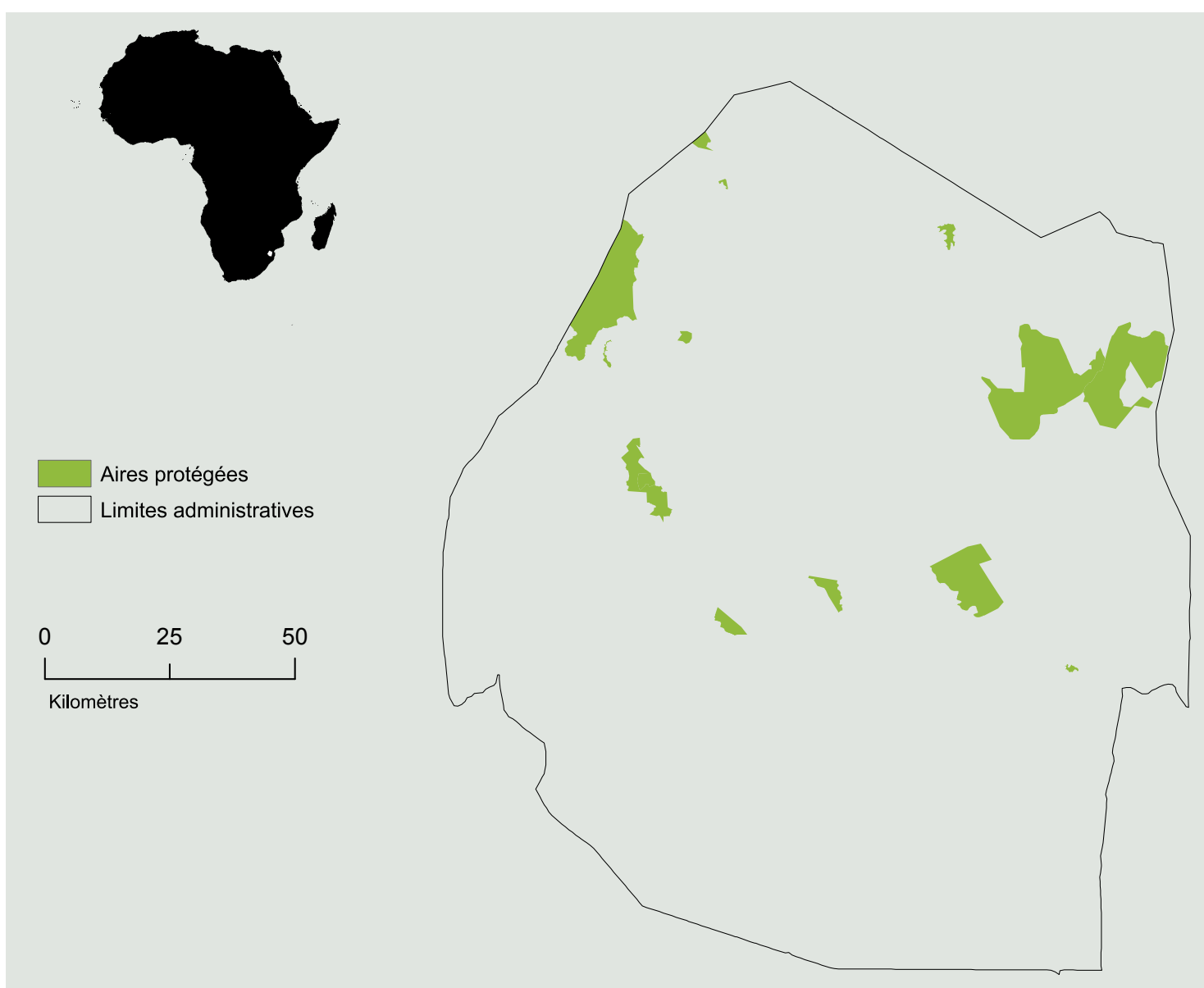

$\stackrel{N}{\Lambda}$

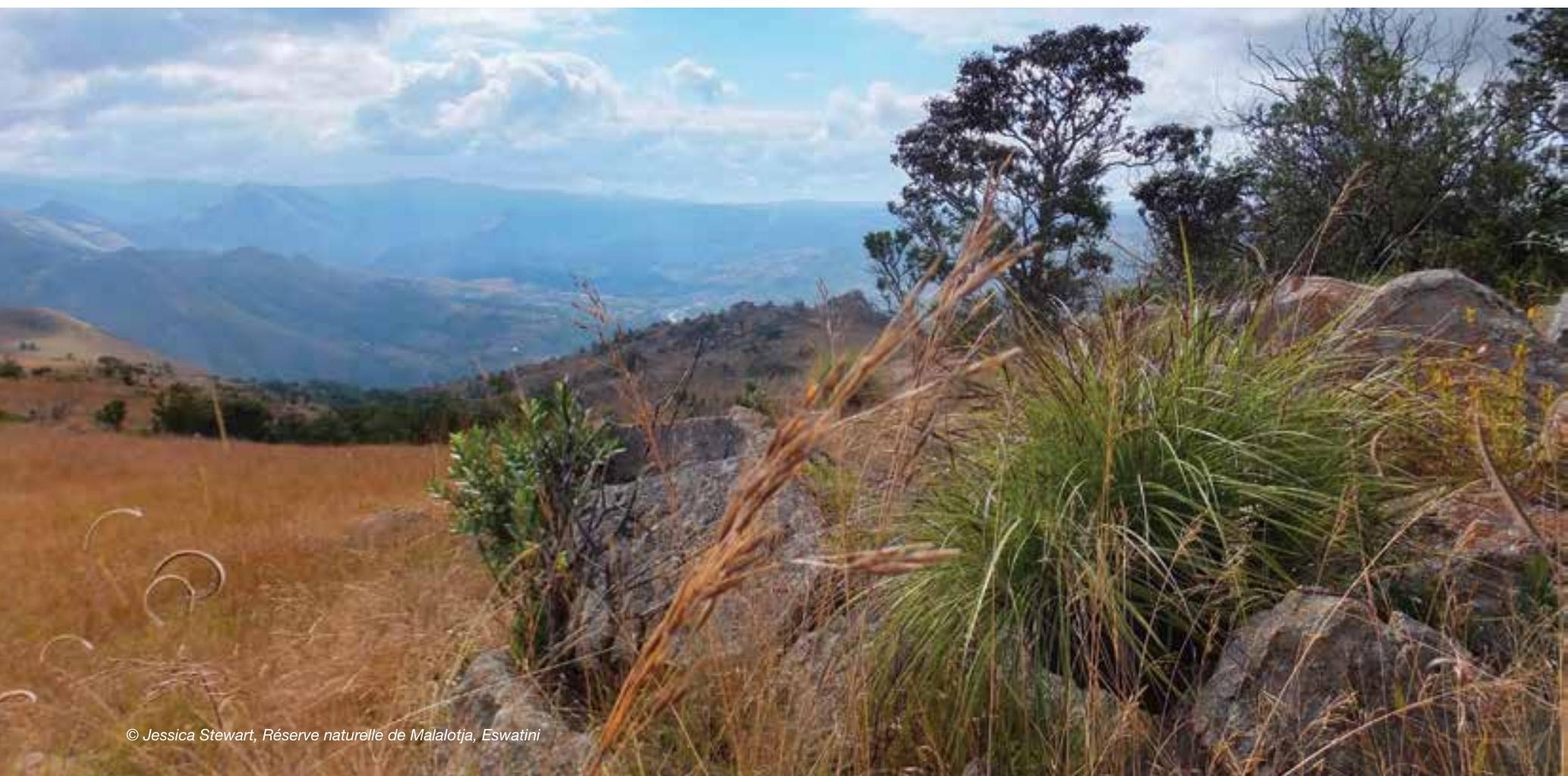




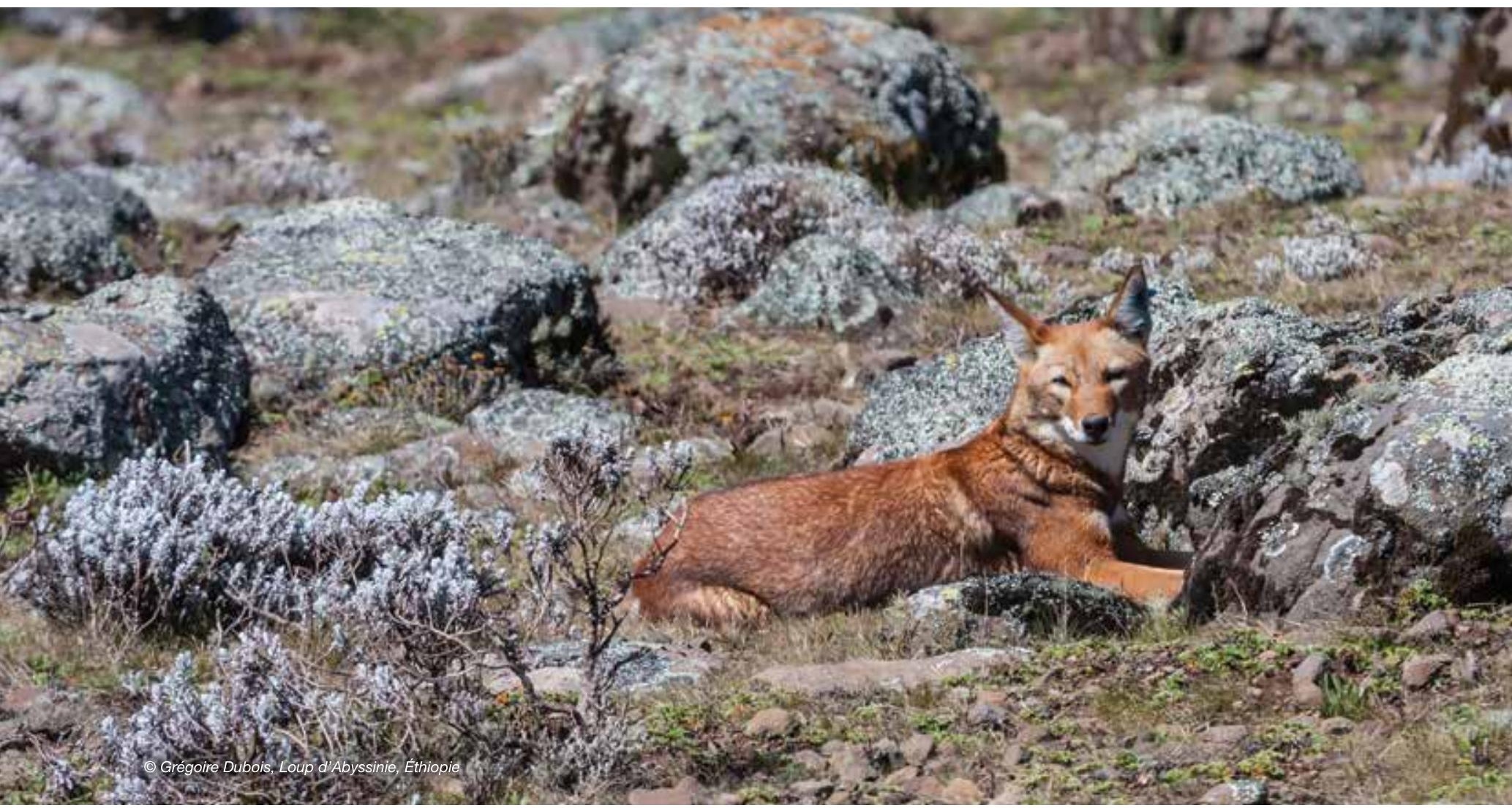

\section{7 Éthiopie}

\section{Aires protégées et de conservation de l'Éthiopie ${ }^{52}$}

L'Éthiopie compte 104 aires protégées couvrant 200074 km² d'écosystèmes terrestres (UNEP-WCMC et IUCN, 2019h).

Située dans la Corne de l'Afrique, l'Éthiopie est un pays enclavé relativement grand, présentant une grande diversité de topographie, de substrats et de climats. Cette diversité topographique, s'étendant sur une plage altitudinale de 4620 mètres, a favorisé de grandes variations de précipitations, d'humidité, de température et de sols, faisant que le pays abrite six des principaux biomes terrestres du monde (alpin, forêts de conifères, forêts de feuillus, forêts tropicales humides, savanes et déserts) et neuf types d'écosystèmes distincts.

Des financements internationaux sous différentes formes de mécanismes commerciaux internationaux pour l'atténuation des changements climatiques, comme le Mécanisme pour un développement propre (MDP) et REDD+, aident à financer la protection des quatre parcs nationaux Éthiopiens, de l'un des sanctuaires de faune sauvage et de trois des aires de conservation communautaires.

L'absence de statut juridique de la plupart des aires protégées constitue un défi majeur en Éthiopie. L'Autorité éthiopienne de conservation de la faune, créée en 2008, ne gère que 13 parcs nationaux, réserves et sanctuaires de faune. Les autres sont gérés par des autorités régionales, des communautés rurales et le secteur privé, et sont insuffisamment protégés, en particulier dans le cas des écosystèmes de zones humides et d'eau douce. II est nécessaire d'accroître la couverture des aires officiellement protégées, en tenant dûment compte de leur représentation écosystémique ainsi que de leur efficacité en termes de gestion.

\section{Aires protégées et de conservation transfrontières}

L'Éthiopie comprend une partie du paysage de Boma-Gambella et des aires de conservation transfrontières du paysage du Bas Awash-Lac Abbé.

\section{Contexte politique}

Un rapport complet sur la législation et les politiques relatives à la gestion, à la gouvernance et à l'équité des aires protégées a été réalisé par le programme BIOPAMA. II a identifié 29 lois et politiques pertinentes en Éthiopie (Tessema, 2019).

\section{Espèces clées $^{53}$}

L'Éthiopie abrite environ 6000 espèces de plantes supérieures dont $10 \%$ sont endémiques. Le pays compte 284 espèces de mammifères sauvages et 861 espèces d'oiseaux.

\footnotetext{
52 Cette section s'appuie sur les informations contenues dans le sixième Rapport national de l'Éthiopie à la CDB (Republic of Ethiopia et Ethiopian Biodiversity Institute, 2014), ains que dans son deuxième SPANB (Republic of Ethiopia, 2019).

53 Cette section s'appuie sur les informations contenues dans les cinquième et sixième Rapports nationaux de l'Éthiopie à la CDB, ainsi que dans son deuxième SPANB (Government of the Federal Democratic Republic of Ethiopia et Ethiopian Biodiversity Institute, 2014; 2015 ; Republic of Ethiopia, 2019).
} 
Figure 8.13 : Résumé de l'Éthiopie

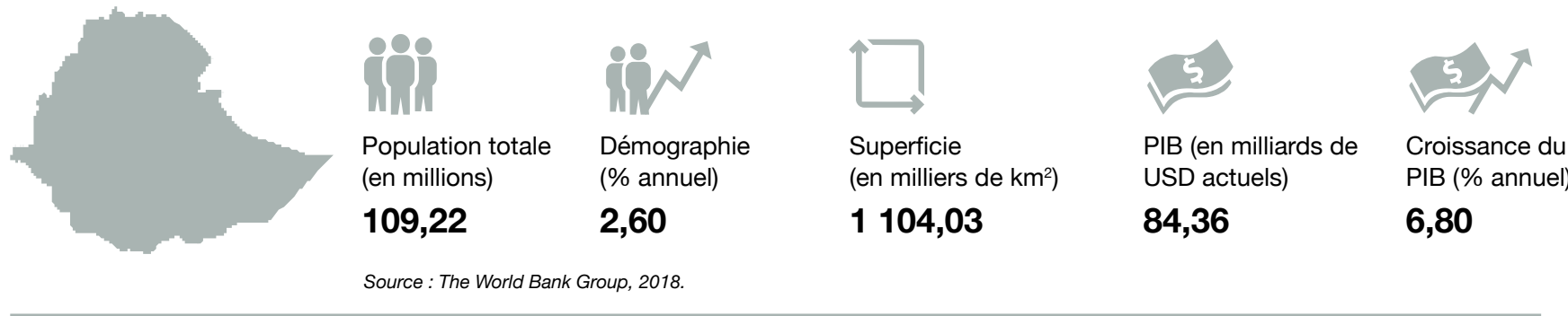

\section{Aires protégées :}

104 aires protégées

couverture terrestre 200074 km² $^{2}$
Aires protégées et de conservation de l'Éthiopie par catégorie de gestion de I'UICN

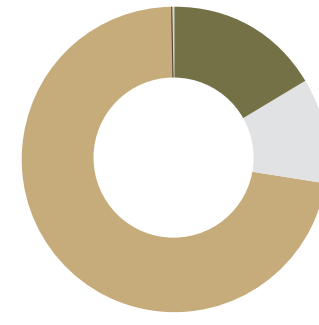

Ne s'applique pas (3)

Non rapportée (58)

VI. Aire protégée avec utilisation durable des ressources naturelles (18)

IV. Aire de gestion habitats / espèces (8)

II. Parc national (17)

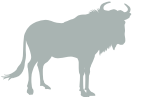

6000 espèces végétales $10 \%$ endémiques
284 espèces de mammifères 29 endémiques

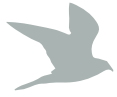

861 espèces d'oiseaux 18 endémiques

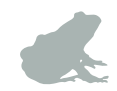

63 amphibiens
200 espèces de poissons
Couverture des aires protégées en Éthiopie

\begin{tabular}{l|r|r}
\hline Type d'aire protégée & $\begin{array}{r}\text { Aire protégée } \\
\text { ou conservée* }\end{array}$ & $\begin{array}{r}\text { Aire protégée } \\
\text { ou conservée** }\end{array}$ \\
\hline $\begin{array}{l}\text { Terrestres et eaux } \\
\text { intérieures }\end{array}$ & $17,62 \%$ & $14,00 \%$ \\
\hline *Ensemble de données de la BDMAP & ** Rapport national sur la biodiversité \\
Source : Republic of Ethiopia (2019); UNEP-WCMC et IUCN (2019h).
\end{tabular}

Aires protégées et de conservation désignées comme sites d'importance mondiale en Éthiopie

\begin{tabular}{l|r}
\hline Désignation mondiale & $\begin{array}{r}\text { Nombre de } \\
\text { sites }\end{array}$ \\
\hline Réserves de biosphère de l'UNESCO & 5 \\
\hline $\begin{array}{l}\text { Sites du Patrimoine mondial de l'UNESCO } \\
\text { (naturels ou mixtes) }\end{array}$ & 1 \\
\hline
\end{tabular}

Source : Ramsar (2019) ; UNESCO (2019a, 2019b).

\section{Aires protégées et de conservation de l'Éthiopie par} type de gouvernance de l'UICN

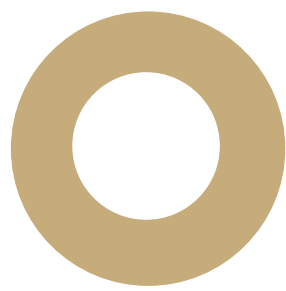

Non rapporté (105)
Désignations nationales des aires protégées et de conservation en Éthiopie

\begin{tabular}{l|r|r}
\hline Désignation nationale & No & $\begin{array}{r}\text { Superficie } \\
\left(\mathbf{k m}^{2}\right)\end{array}$ \\
\hline Sanctuaire & 4 & 11037 \\
\hline Parc national & 13 & 23672 \\
\hline Réserve de faune sauvage & 8 & 23392 \\
\hline $\begin{array}{l}\text { Aire forestière nationale } \\
\text { prioritaire }\end{array}$ & 58 & 44132 \\
\hline Zone de chasse régulée & 18 & 151577 \\
\hline Source : UNEP-WCMC et IUCN (2019h). & & \\
\end{tabular}

\section{Aires prioritaires pour la conservation}

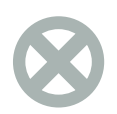

\section{3 sites}

Sites de l'Alliance pour une extinction zéro

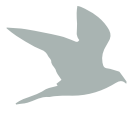

\section{7 sites}

Zones importantes pour les oiseaux et la biodiversité

\section{9 sites}

Zones clés pour la biodiversité

Source : AZE Secretariat (2019) ; BirdLife International (2019b, 2019c). 


\section{Figure 8.14 : Aires protégées de l'Éthiopie}

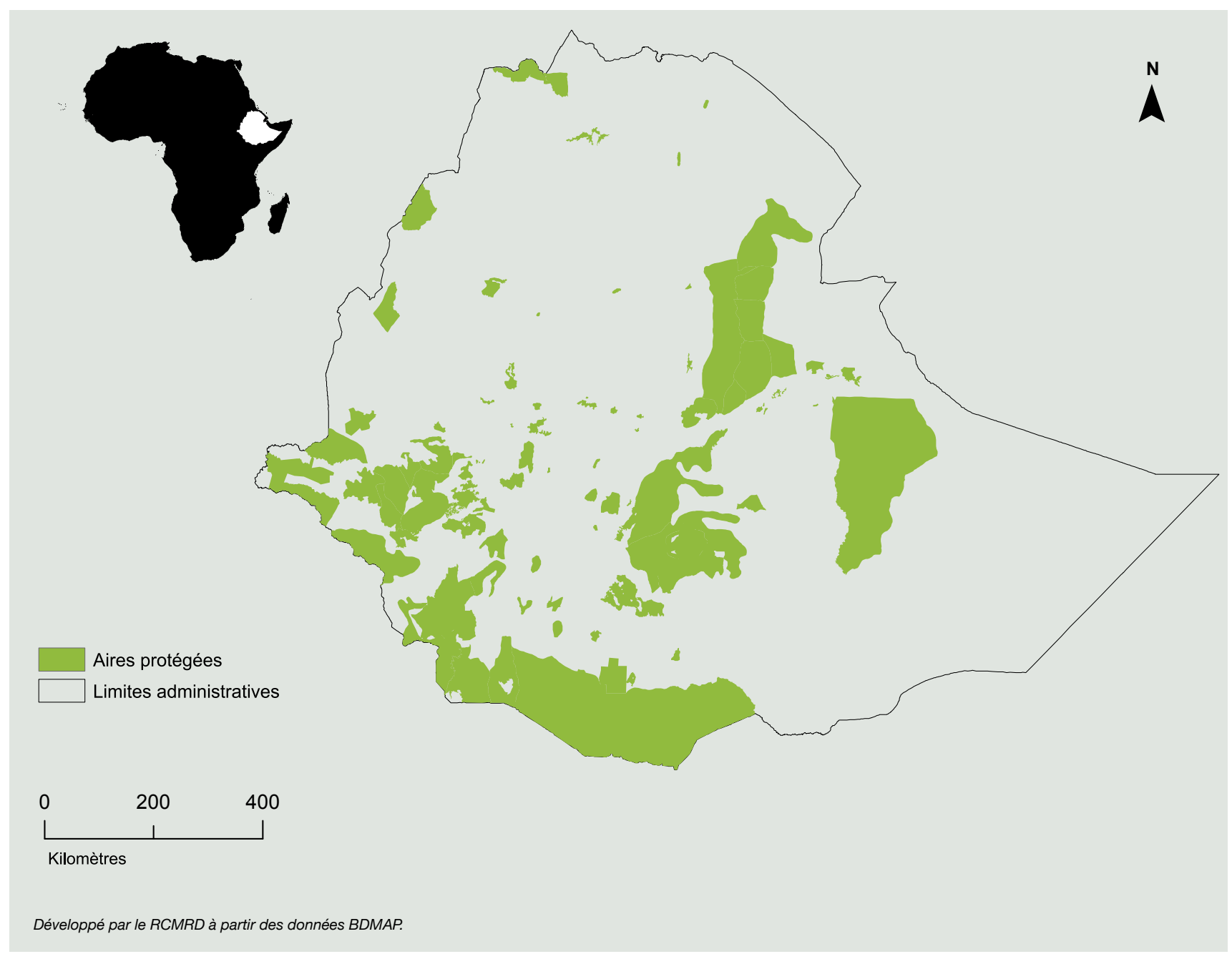

Les données concernant les autres animaux sauvages font défaut et, jusqu'à présent, 201 reptiles, 200 poissons, 63 amphibiens et 1225 arthropodes ont été identifiés. Parmi ces ressources fauniques, 29 mammifères sauvages, 18 oiseaux, 10 reptiles, 40 poissons, 25 amphibiens et sept espèces d'arthropodes sont endémiques d'Éthiopie, comme le loup d'Abyssinie (Canis simensis). L'Éthiopie possède également une grande diversité microbienne, à peine explorée.

\section{Pressions et menaces ${ }^{54}$}

Les principales menaces directes pour la biodiversité éthiopienne incluent la perte et la dégradation des habitats dues à l'expansion de l'agriculture et des établissements humains, ainsi qu'à l'empiétement des espèces envahissantes, l'utilisation non durable de la biodiversité due au surpâturage, à la surexploitation et à la chasse non réglementée, la prolifération des espèces envahissantes et la pollution.
Les causes indirectes de perte de biodiversité dans le pays sont les changements démographiques, la pauvreté et le manque de sensibilisation et de coordination. À long terme, les changements climatiques présenteront un certain nombre de défis, en particulier en décalant les saisons de croissance.

54 Cette section s'appuie sur les informations contenues dans les cinquième et sixième Rapports nationaux de l'Éthiopie à la CDB, ainsi que dans son deuxième SPANB (Government of the Federal Democratic Republic of Ethiopia et Ethiopian Biodiversity Institute, 2014 et 2015 ; Republic of Ethiopia, 2019). 


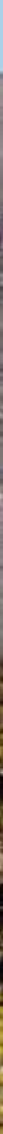

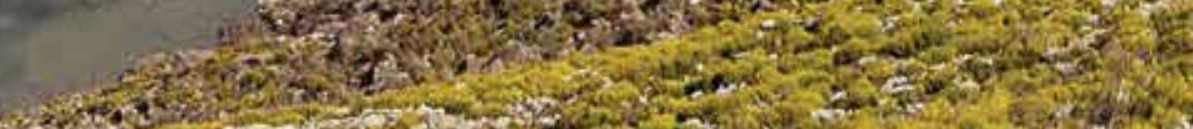

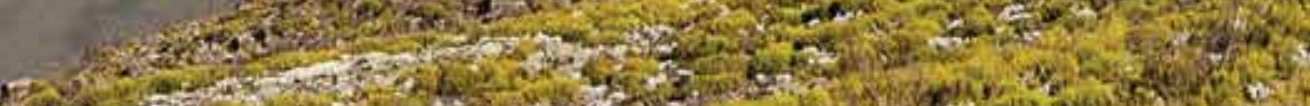

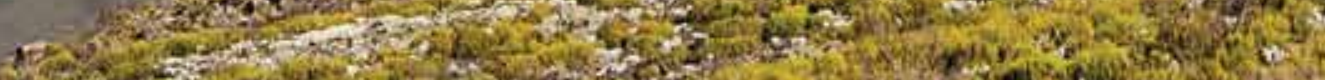

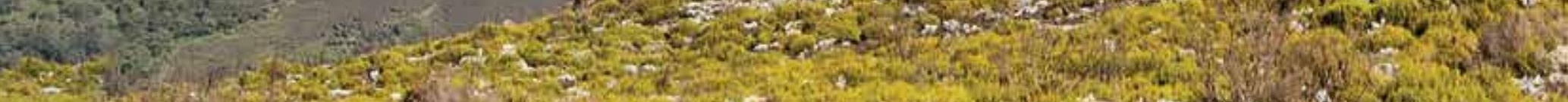

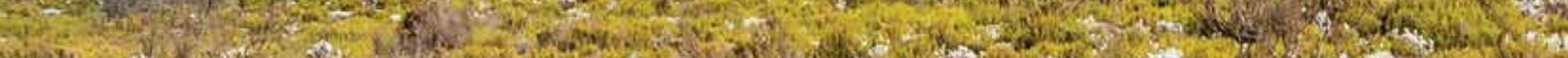
6. ${ }^{2}$.

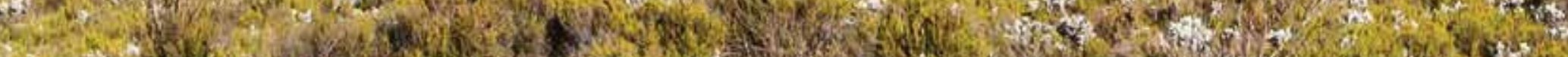

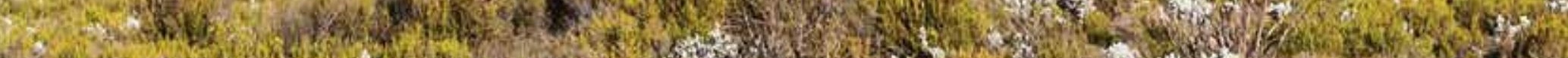
2.x.

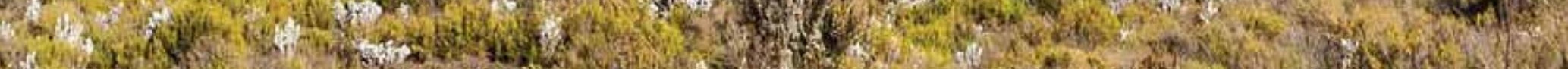
Q6. V.7.

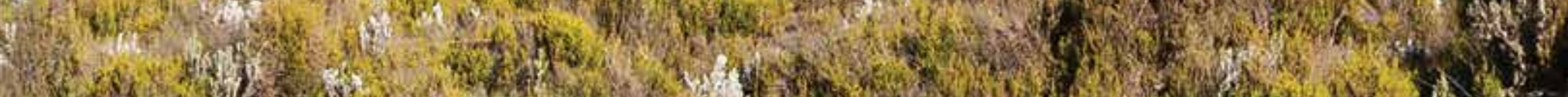
3.5e Wiver

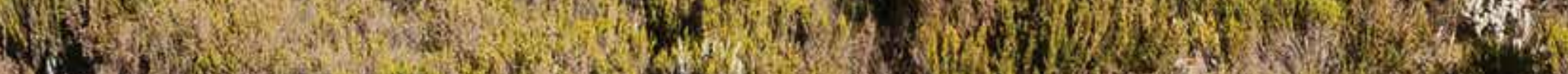

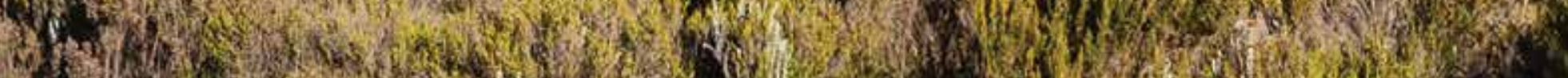

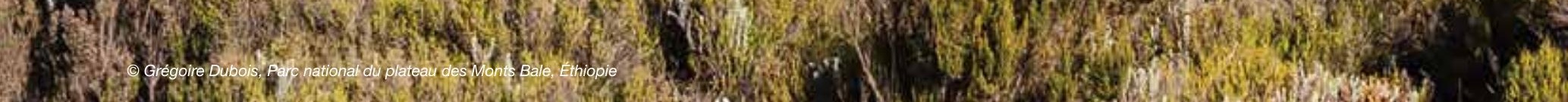




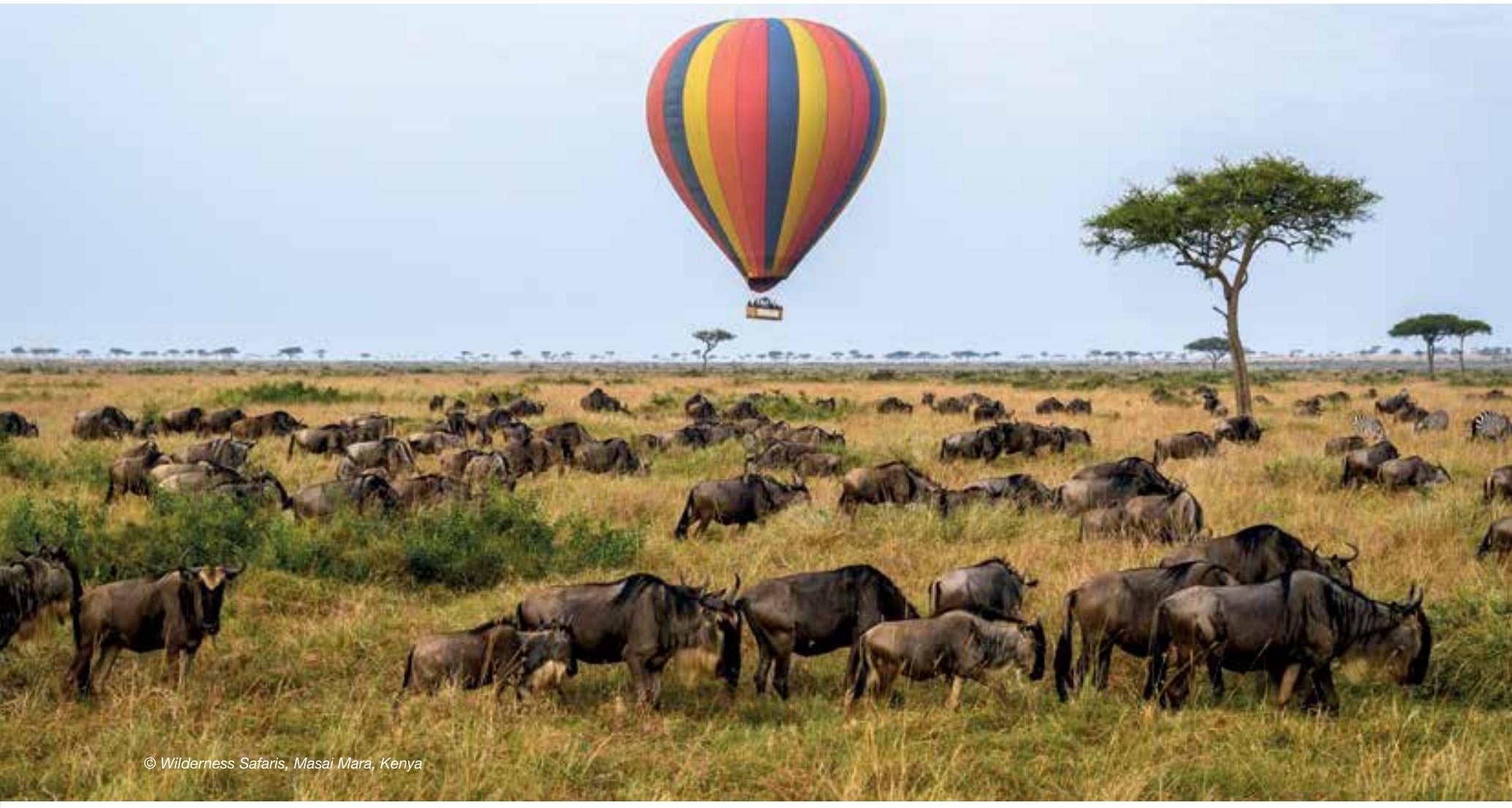

\subsection{Kenya}

\section{Aires protégées et de conservation du Kenya ${ }^{55}$}

Le Kenya compte 411 aires protégées couvrant 72545 km² $^{2}$ d'écosystèmes terrestres et $904 \mathrm{~km}^{2}$ d'écosystèmes marins (UNEP-WCMC et IUCN, 2019i).

Le gouvernement postindépendance a hérité de quatre parcs nationaux et six réserves de gibier, dont la déclaration officielle a fait l'objet d'un processus parlementaire. En outre, un certain nombre de réserves de gibier sont sous la gestion d'autorités locales. II existe également un grand nombre de zones de conservation de la faune sauvage propriétés d'entreprises privées et / ou communautaires. Le nombre de parcs et réserves a donc considérablement augmenté.

Sur les $12 \%$ de terres désignées comme aires protégées, y compris les forêts, $50 \%$ se trouvent sur des terres arides et semi-arides. La tendance actuelle montre une forte diminution de la diversité des espèces animales et de l'abondance des populations dans ces écosystèmes. Devant le fait que ces aires protégées étaient incapables d'atteindre de manière adéquate les objectifs de conservation de la biodiversité et de soutenir les moyens de subsistance, l'idée d'établir des sanctuaires privés et des zones de conservations communautaires a pris de l'ampleur au cours des dernières décennies au Kenya. Celles-ci constituent la pierre angulaire du système actuel d'aires protégées, plus de $70 \%$ de toutes les grandes espèces sauvages vivant de façon permanente ou saisonnière à l'extérieur des aires protégées gérées par des organismes gouvernementaux.

\section{Aires protégées et de conservation transfrontières}

Le Kenya accueille une partie de cinq aires de conservation transfrontières, à savoir: I) Amboseli-Kilimandjaro-Longido, ii) Mont Elgon, iii) Serengeti-Mara, iv) Paysage terrestre et marin de Tana-Kipini-Laga Badana Bushbush, et v) Système de réserves marines de Tanga et parc marin de Tanga Coelacanth, Diani Chale et Kisitee-Mpunguti.

\section{Contexte politique}

Un rapport complet sur la législation et les politiques relatives à la gestion, à la gouvernance et à l'équité des aires protégées a été réalisé par le programme BIOPAMA. II a identifié 41 lois et politiques pertinentes au Kenya (Tessema, 2019).

\section{Espèces clées $^{56}$}

Le Kenya possède des écosystèmes et des habitats diversifiés, abritant une flore et une faune uniques et diverses. Plus de 7000 espèces végétales ont été recensées au Kenya, dont plus de 1000 endémiques ou quasi endémiques. Quelque 356 espèces végétales ont été évaluées comme menacées dans le cadre du processus de Liste rouge de l'UICN, dont un tiers sont endémiques au Kenya. On estime que plus de 5000 espèces de champignons sont présentes dans le pays, bien que seulement 2000 aient été documentées.

Les 1100 espèces d'oiseaux du Kenya comprennent huit espèces endémiques. Plus de 200 reptiles (cinq tortues marines, cinq tortues terrestres, 100 serpents, 100 lézards, un crocodile et cinq espèces de tortues d'eau douce) et 110 espèces d'amphibiens

55 Cette section s'appuie sur les informations contenues dans le cinquième Rapport national du Kenya à la CDB (Republic of Kenya, 2015). 56 Ibid. 
Figure 8.15 : Résumé du Kenya

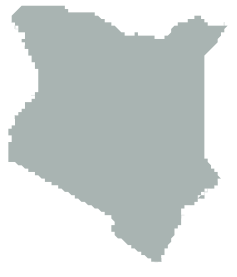

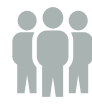

Population totale (en millions)

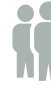

Démographie (\% annuel)

$51,39 \quad 2,30$

Source : The World Bank Group, 2018.

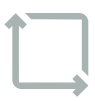

Superficie (en milliers de $\mathrm{km}^{2}$ )

580,40

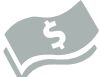

PIB (en milliards de USD actuels)

87,91
Croissance du PIB (\% annuel)
Aires protégées :

411 aires protégées

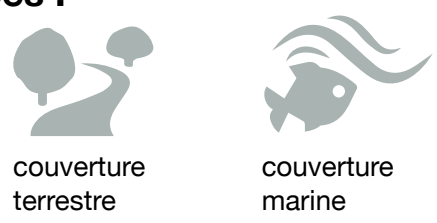

72545 km $^{2} \quad 904$ km$^{2}$

Source : UNEP-WCMC et IUCN, 2019i

$\begin{array}{lll}315 & 1100 & 200 \\ \text { mammifères } & \text { oiseaux } & \text { reptiles }\end{array}$

Aires protégées et de conservation du Kenya par catégorie de gestion de I'UICN

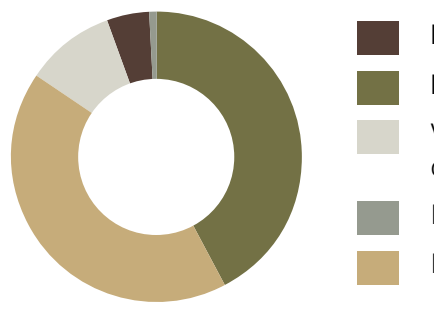

Ne s'applique pas (9)

Non rapportée (345)

VI. Aire protégée avec utilisation durable des ressources naturelles (16)

IV. Aire de gestion habitats / espèces (5)

II. Parc national (36)

\section{Couverture des aires protégées au Kenya}

\begin{tabular}{l|r|r}
\hline Type d'aire protégée & $\begin{array}{r}\text { Aire protégée } \\
\text { ou conservée* }\end{array}$ & $\begin{array}{r}\text { Aire protégée } \\
\text { ou conservée** }\end{array}$ \\
\hline $\begin{array}{l}\text { Terrestres et eaux } \\
\text { intérieures }\end{array}$ & $12,36 \%$ & $8,00 \%$ \\
\hline Marines et côtières & $0,80 \%$ & $\begin{array}{r}\text { Aucune } \\
\text { correspondance }\end{array}$ \\
\hline
\end{tabular}

* Ensemble de données de la BDMAP ${ }^{* *}$ Rapport national sur la biodiversité

Source : Republic of Kenya (2015); UNEP-WCMC et IUCN (2019i).

\section{Aires protégées et de conservation du Kenya par} type de gouvernance de l'UICN

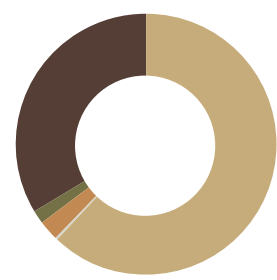

Non rapporté (267)

D. Gouvernance par les peuples

autochtones ou communautés locales (51)

C. Gouvernance privée (16)

B. Gouvernance partagée (1)

A. Gouvernance par le gouvernment (76)

Source : UNEP-WCMC et IUCN (2019i).

\section{Aires prioritaires pour la conservation}

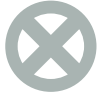

\section{6 sites}

Sites de l'Alliance pour une extinction zéro

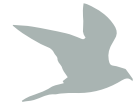

\section{8 sites}

Zones importantes pour les oiseaux et la biodiversité

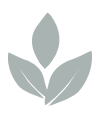

72 sites

Zones clés pour la biodiversité

Source : AZE Secretariat (2019) ; BirdLife International (2019b, 2019c).

Aires protégées et de conservation désignées comme sites d'importance mondiale au Kenya

\begin{tabular}{l|r}
\hline Désignation mondiale & $\begin{array}{r}\text { Nombre } \\
\text { de sites }\end{array}$ \\
\hline Réserves de biosphère de l'UNESCO & 6 \\
\hline $\begin{array}{l}\text { Sites du Patrimoine mondial de I'UNESCO } \\
\text { (naturels ou mixtes) }\end{array}$ & 3 \\
\hline $\begin{array}{l}\text { Zones humides d'importance internationale } \\
\text { (sites Ramsar) }\end{array}$ & 6 \\
\hline
\end{tabular}

Source : Ramsar (2019) ; UNESCO (2019a, 2019b).

Désignations nationales des aires protégées et de conservation au Kenya

\begin{tabular}{l|r|r}
\hline Désignation nationale & $\mathbf{N}^{\mathbf{2}}$ & $\begin{array}{r}\text { Superficie } \\
\left(\mathbf{k m} \mathbf{2}^{\mathbf{2}}\right.\end{array}$ \\
\hline Réserve communautaire de faune sauvage & 1 & 223 \\
\hline Parc national & 23 & 28844 \\
\hline Réserve nationale & 31 & 17941 \\
\hline Ranch collectif & 1 & 66 \\
\hline Réserve naturelle privée & 1 & 197 \\
\hline Sanctuaire de gibier & 1 & 0 \\
\hline Aire protégée privée & 2 & 522 \\
\hline Sanctuaire national & 6 & 36 \\
\hline Ranch privé & 4 & 645 \\
\hline Réserve marine nationale & 5 & 510 \\
\hline Parc national marin & 4 & 61 \\
\hline Réserve naturelle & 2 & 17941 \\
\hline Non rapporté & 5 & 8 \\
\hline Réserve forestière & 234 & 18776 \\
\hline Parc national (proposé) & 1 & 145 \\
\hline Zone de conservation communautaire & 21 & 2719 \\
\hline Réserve naturelle communautaire & 28 & 30016 \\
\hline Réserve privée & 16 & 8121 \\
\hline Sanctuaire de faune sauvage & 1 & 109 \\
\hline Aire marine gérée localement & 9 & 37 \\
\hline Source : UNEP-WCMC et IUCN (2019i). & &
\end{tabular}


sont présentes sur l'ensemble du pays, à l'exception des hauts sommets tels que le mont Kenya. Le Kenya abrite également 315 espèces de mammifères, y compris un certain nombre d'espèces endémiques et quasi endémiques, dont le zèbre de Grévy (Equus grevyi) et le hirola (Beatragus hunteri). Le déclin de nombreuses espèces de mammifères, à l'exception de l'éléphant d'Afrique (Loxodonta africana), a été attribué aux changements dans l'utilisation des terres, à la sécheresse, au braconnage, aux maladies et à la compétition pour les ressources.

Les écosystèmes d'eau douce et marins du Kenya abritent des populations de poissons à la fois biologiquement diverses et commercialement importantes. Plus de 60 de ces espèces sont menacées, selon la Liste rouge de I'UICN. Plus de 35000 taxons d'invertébrés ont été identifiés et décrits, et plusieurs milliers d'autres restent à décrire.

\section{Pressions et menaces ${ }^{57}$}

Les principales menaces auxquelles est confrontée la biodiversité du Kenya sont la dégradation, la fragmentation et la perte des habitats, telles que les changements d'utilisation des terres, la modification physique ou les prélèvements excessifs dans les cours d'eau, la perte des récifs coralliens et les dommages infligés aux fonds marins par le chalutage. Les principaux moteurs en sont la croissance démographique, exerçant une pression sur les habitats de la biodiversité et les ressources foncières, ainsi que la pauvreté, conduisant à une utilisation non durable des ressources foncières et de la biodiversité et à des ressources financières limitées pour soutenir la conservation de la biodiversité.

D'autres menaces critiques incluent les changements climatiques, les espèces exotiques envahissantes, la surexploitation et la pollution. Certains taxons, comme les amphibiens et les reptiles, sont particulièrement touchés par la surexploitation pour le commerce local et international. Le commerce international illégal d'ivoire et de corne de rhinocéros constitue également une menace pour les populations d'éléphants et de rhinocéros dans le pays, tandis que le bois de santal africain (Osyris lanceolata), moins connu, est également gravement menacé par la surexploitation illégale. Le commerce illégal de viande de brousse a gravement affecté de nombreuses espèces d'antilopes.

\section{Figure 8.16 : Aires protégées du Kenya}

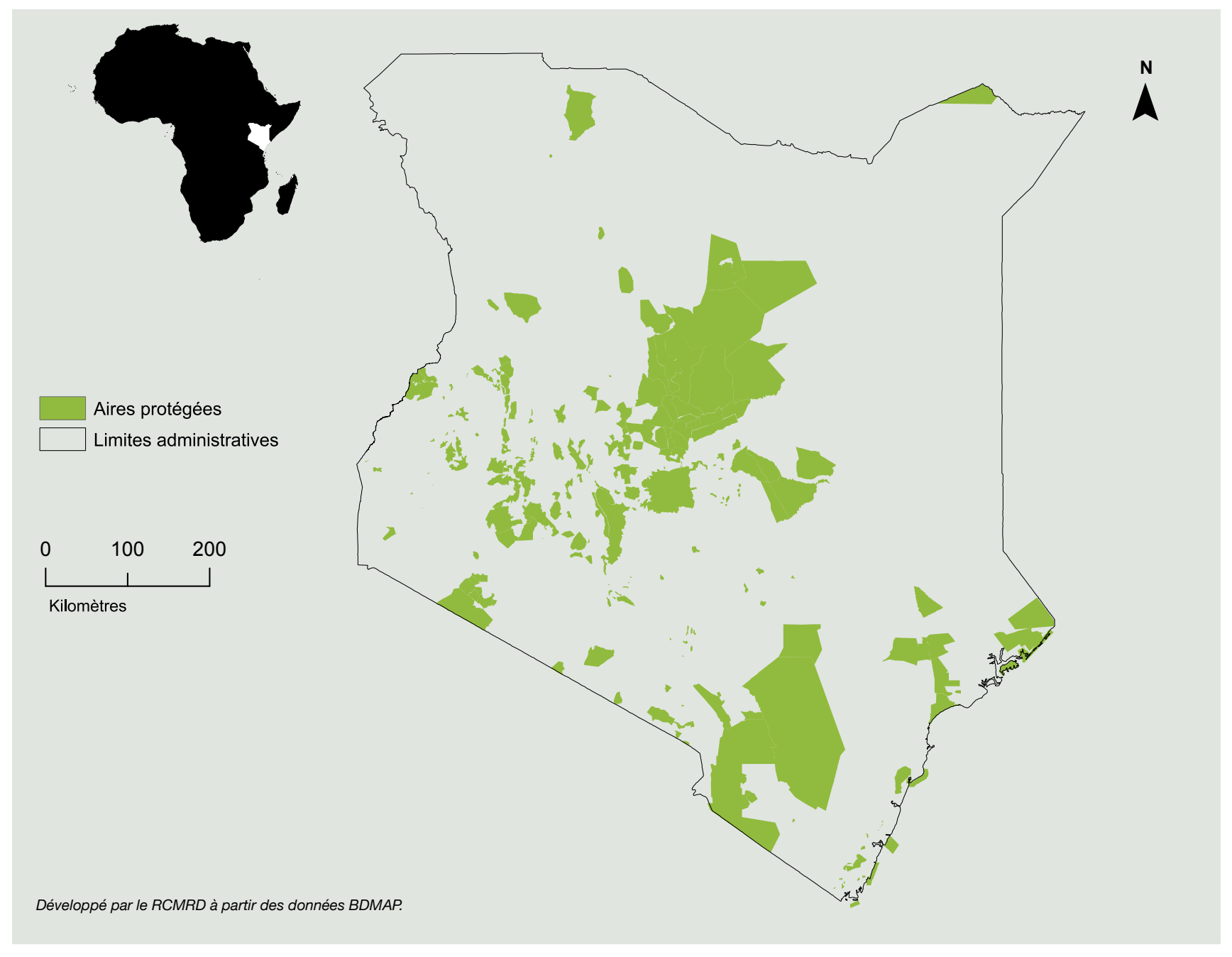



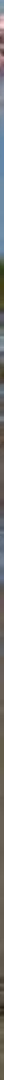

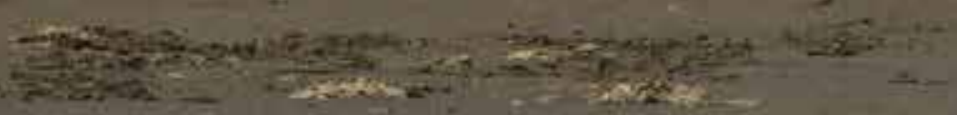

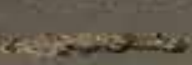

axiscistes

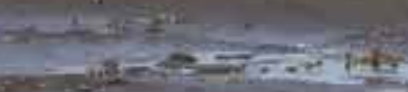

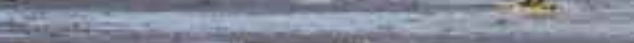

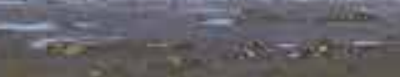

(c) Grégoire Dubois, Flamants roses et buffles, Parc national du lac Nakurü, Kenya 


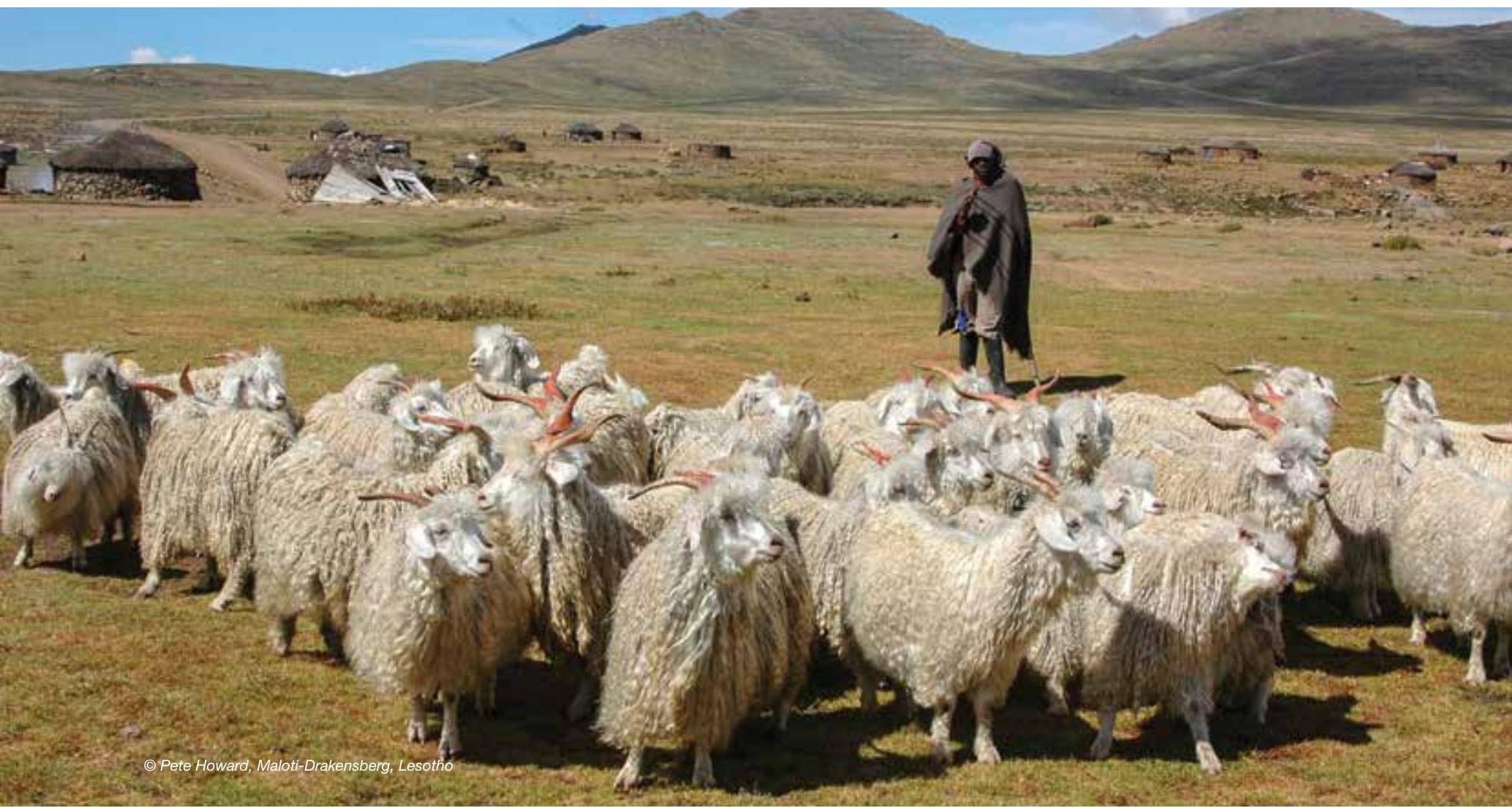

\subsection{Lesotho}

\section{Aires protégées et de conservation du Lesotho ${ }^{58}$}

Le Lesotho compte quatre aires protégées couvrant $80 \mathrm{~km}^{2}$ d'écosystèmes terrestres (UNEP-WCMC et IUCN, 2019j).

L'un des parcs du Lesotho, le Parc national de Sehlabathebe est un site mixte naturel / culturel du Patrimoine mondial et, avec le Parc national de Khahlamba Drakensberg, en Afrique du Sud, il forme une aire protégée transfrontalière connue sous le nom de Parc Maloti Drakensberg, un refuge pour de nombreuses espèces menacées et endémiques.

En plus des aires protégées officiellement désignées, il existe plusieurs sites désignés de façon informelle ou proposés à des fins de protection dans diverses régions du pays. II est prévu de déclarer la Réserve naturelle de Letsa-la-Letsie et Tsatsane en tant qu'aire protégée. Afin d'atteindre tous les objectifs en matière de biodiversité, $49 \%$ des hauts plateaux du Lesotho devraient faire l'objet d'une forme de gestion de la conservation, éventuellement au moyen d'une mosaïque de zones de gestion des ressources et d'aires protégées plus petites. Le projet transfrontalier MalotiDrakensberg a identifié huit domaines d'action prioritaires.

\section{Aires protégées et de conservation transfrontières}

Le Lesotho comprend une partie du site du Patrimoine mondial du Parc Maloti Drakensberg, inclus dans l'ACT Maloti Drakensberg.

\section{Contexte politique}

Un rapport complet sur la législation et les politiques relatives à la gestion, à la gouvernance et à l'équité des aires protégées a été réalisé par le programme BIOPAMA. II a identifié 17 lois et politiques pertinentes au Lesotho (Tessema, 2019).

\section{Espèces clées $^{59}$}

Malgré sa petite taille, le Lesotho possède des niveaux très élevés d'endémisme végétal, avec au moins 54 espèces endémiques. Le Lesotho abrite également 340 espèces d'oiseaux et un certain nombre d'espèces de mammifères, dont le rat de glace (Otomys sloggetti), endémique, et la souris à queue blanche (Mystromys albicaudatus). Le babouin chacma (Papio ursinus), autrefois abondant, a connu un déclin précipité.

Le Lesotho présente également des niveaux élevés d'endémisme dans les groupes des reptiles et des amphibiens. Les 14 espèces de poissons recensées incluent une espèce endémique.

\section{Pressions et menaces ${ }^{60}$}

L'une des principales menaces pour la biodiversité au Lesotho est la perte et la dégradation des habitats, en particulier des zones humides et des pâturages. Les mauvaises pratiques de gestion des pâturages ont entraîné une perte du couvert végétal et de la terre végétale. Les incendies incontrôlés sont également une 
Figure 8.17 : Résumé du Lesotho

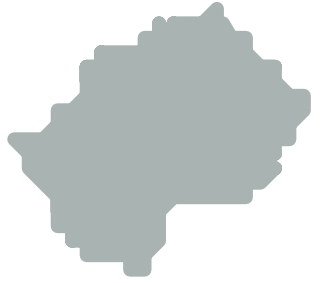

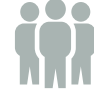

Population totale (en millions)

2,11

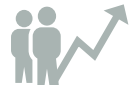

Démographie (\% annuel)

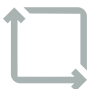

Superficie (en milliers de $\mathrm{km}^{2}$ )

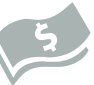

PIB (en milliards de USD actuels)

2,79
Croissance du PIB (\% annuel) 1,50

Source : The World Bank Group, 2018.

Aires protégées :

\section{4 aires} protégées

Source : UNEP-WCMC et IUCN, (2019j)

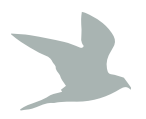

\section{0 espèces} d'oiseaux couverture terrestre $80 \mathrm{~km}^{2}$
Couverture des aires protégées au Lesotho

\begin{tabular}{l|r|r}
\hline Type d'aire protégée & $\begin{array}{r}\text { Aire protégée } \\
\text { ou conservée* }\end{array}$ & $\begin{array}{r}\text { Aire protégée } \\
\text { ou conservée** }\end{array}$ \\
\hline $\begin{array}{l}\text { Terrestres et eaux } \\
\text { intérieures }\end{array}$ & $0,26 \%$ & $0,50 \%$ \\
\hline \\
$\begin{array}{l}\text { *Ensemble de données de la BDMAP } \\
\text { Source : Kingdom of Lesotho (2019); UNEP-WCMC et IUCN (2019j). }\end{array}$
\end{tabular}

Désignations nationales des aires protégées et de conservation du Lesotho

\begin{tabular}{l|r|r}
\hline Désignation nationale & $\mathbf{N}^{\circ}$ & $\begin{array}{r}\text { Superficie } \\
\left(\mathbf{k m}^{2}\right)\end{array}$ \\
\hline Parc national & 2 & 6394 \\
\hline
\end{tabular}

Source : UNEP-WCMC et IUCN (2019j).

Aires protégées et de conservation du Lesotho par type de gouvernance de I'UICN

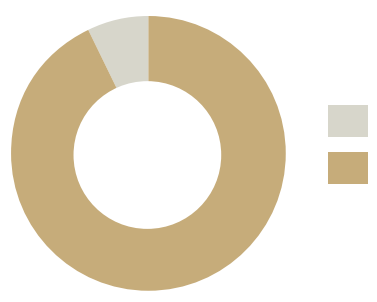

Non rapporté (1)

A. Gouvernance par le gouvernement (3)
Aires protégées et de conservation du Lesotho par catégorie de gestion de I'UICN

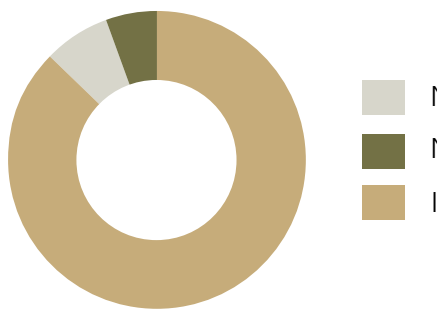

Ne s'applique pas (1)

Non rapportée (2)

IV. Aire de gestion habitats / espèces (1)

Source : UNEP-WCMC et IUCN (2019j).

Aires protégées et de conservation désignées comme sites d'importance mondiale au Lesotho

\begin{tabular}{l|r}
\hline Désignation mondiale & $\begin{array}{r}\text { Nombre de } \\
\text { sites }\end{array}$ \\
\hline $\begin{array}{l}\text { Patrimoine Mondial de l'UNESCO } \\
\text { (naturel ou mixte) }\end{array}$ & 1 \\
\hline $\begin{array}{l}\text { Zones humides d'importance internationale } \\
\text { (sites Ramsar) }\end{array}$ & 1 \\
\hline
\end{tabular}

Source : Ramsar (2019) ; UNESCO (2019a, 2019b)

\section{Aires prioritaires pour la conservation}

\section{6 sites}

Zones importantes pour les oiseaux et la biodiversité

Source : BirdLife International (2019c). 
menace pour les pâturages. Les initiatives de développement économique, telles que l'exploitation minière, peuvent également représenter des menaces pour les habitats du Lesotho. Avec l'incertitude climatique croissante, l'agriculture de subsistance empiète de plus en plus sur les habitats restants.
Les espèces envahissantes représentent une menace majeure dans les écosystèmes terrestres et aquatiques. En outre, les changements climatiques augmentent l'incertitude climatique.

\section{Figure 8.18: Aires protégées du Lesotho}

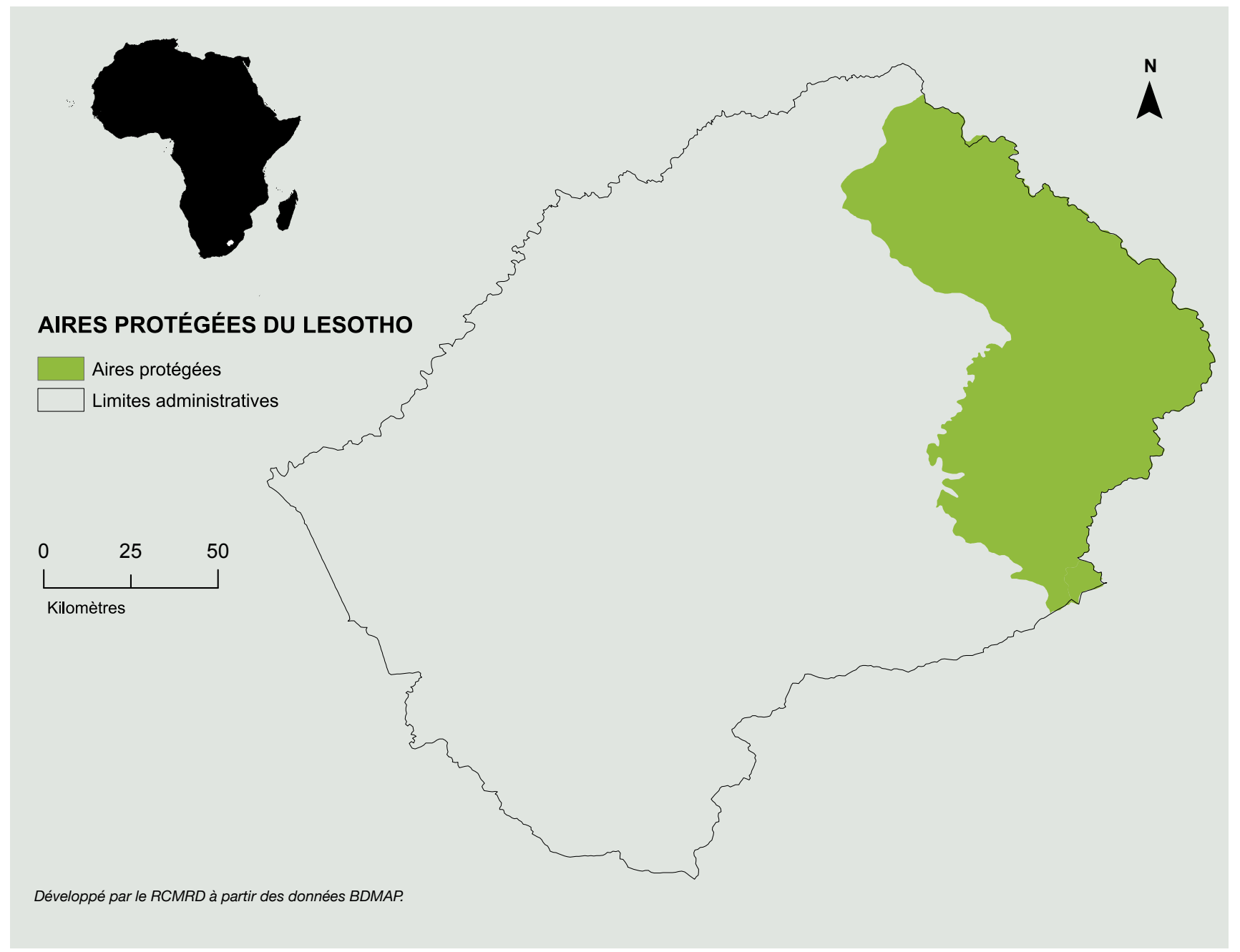



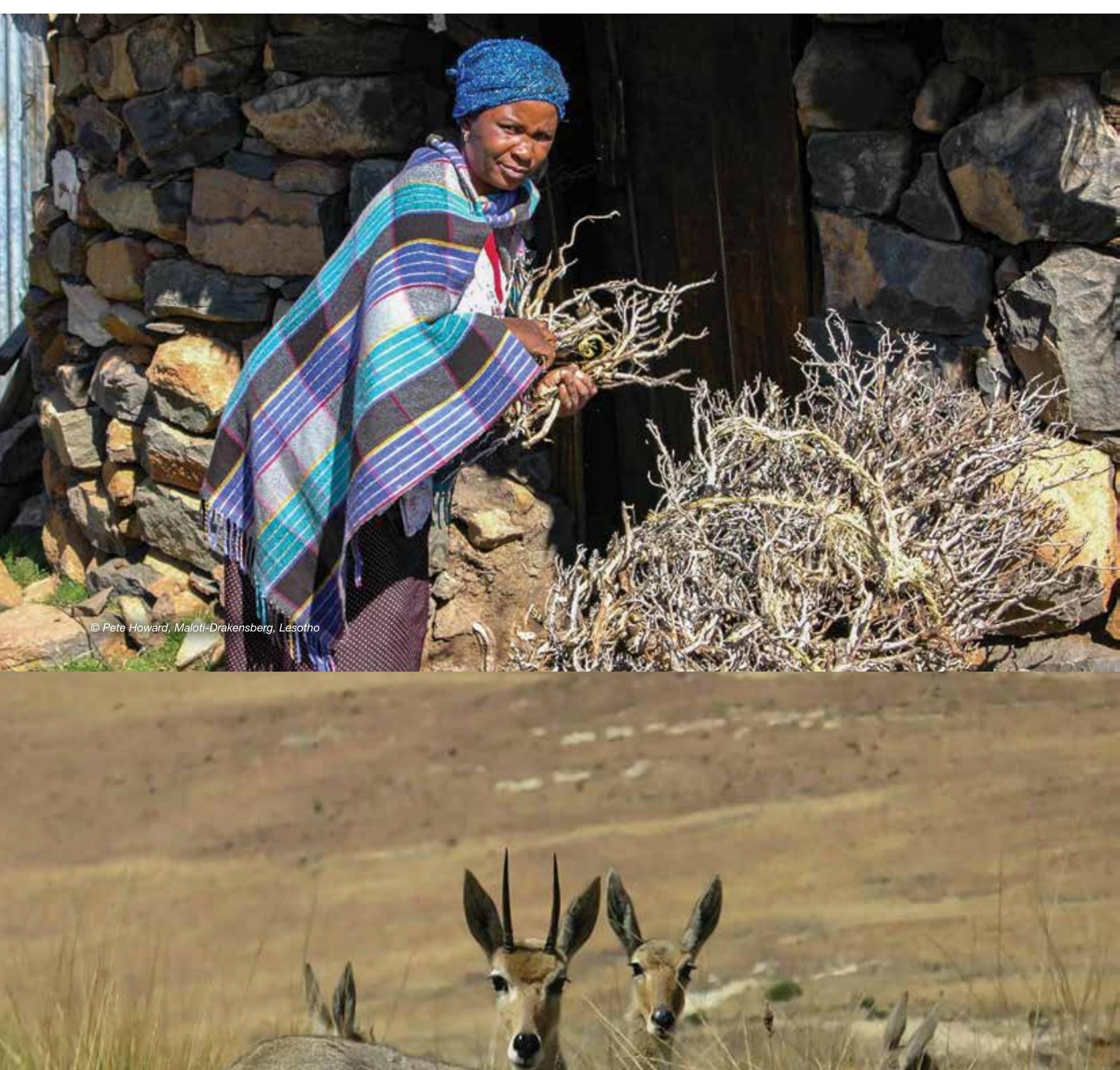
9.

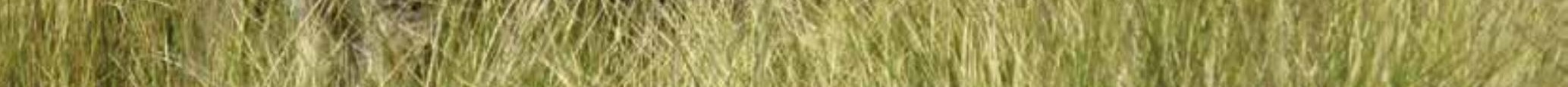
Hes. 


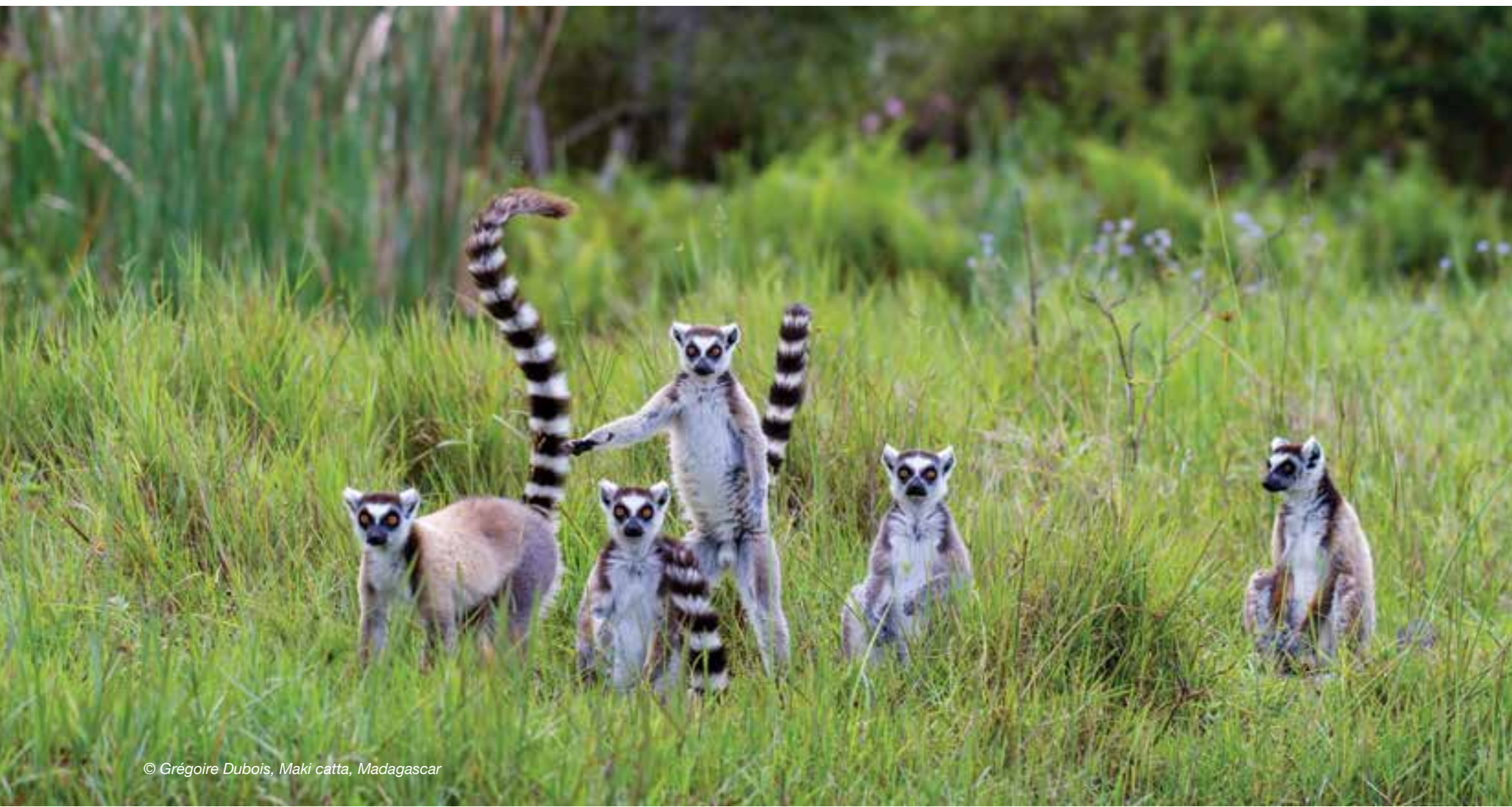

\subsection{Madagascar}

\section{Aires protégées et de conservation de Madagascar ${ }^{61}$}

Madagascar compte 157 aires protégées couvrant $33242 \mathrm{~km}^{2}$ d'écosystèmes terrestres et $8998 \mathrm{~km}^{2}$ d'écosystèmes marins (UNEP-WCMC et IUCN, 2019k).

Madagascar a relevé le défi du Congrès mondial des parcs de Sydney de tripler la superficie des aires marines protégées, un objectif largement atteint. Certains sites sont encore en cours de désignation, alors que d'autres sont en cours d'extension. L'un des objectifs de ce travail est d'assurer la participation des communautés locales. La gestion efficace et le financement durable de ces aires protégées constitue actuellement le défi principal. En outre, des corridors d'aires protégées ont été établis sur une longueur totale d'environ $1200 \mathrm{~km}$, reliant six aires protégées faisant partie de sites du Patrimoine mondial.

\section{Aires protégées et de conservation transfrontières}

Madagascar accueille une partie du Parc marin transfrontalier de l'océan Indien occidental.

\section{Contexte politique}

Un rapport complet sur la législation et les politiques relatives à la gestion, à la gouvernance et à l'équité des aires protégées a été réalisé par le programme BIOPAMA. II a identifié 75 lois et politiques pertinentes à Madagascar (Tessema, 2019).

\section{Espèces clées $^{62}$}

On estime que Madagascar compte entre 13000 et 14000 espèces végétales, dont $80 \%$ sont endémiques. L'endémisme est particulièrement élevé chez les palmiers, les orchidées et les baobabs, Madagascar abritant six des huit espèces mondiales de baobabs. De même, les mammifères présentent également un haut niveau d'endémisme, en particulier chez les lémuriens et autres primates. Madagascar abrite de nombreuses espèces d'oiseaux.

Les connaissances sur les invertébrés de Madagascar sont incomplètes, mais des niveaux élevés d'endémisme ont été révélés chez les fourmis, les crevettes et les crabes d'eau douce, ainsi que chez les écrevisses. De même, les poissons d'eau douce et marins, les amphibiens et les reptiles affichent tous des niveaux élevés d'endémisme, certains proches de 100\%. 23 des 37 espèces de mammifères marins de la région l'océan Indien occidental ont été observées dans les zones côtières de Madagascar.

\section{Pressions et menaces ${ }^{63}$}

Les principales menaces pour la biodiversité de Madagascar incluent la déforestation et la dégradation des forêts, l'exploitation illégale des ressources naturelles, y compris le bois et de nombreuses espèces terrestres et marines, l'impact des espèces et maladies exotiques envahissantes et les impacts environnementaux des industries extractives telles que l'exploitation minière. Les changements climatiques restent une menace à court et à long terme pour les écosystèmes de Madagascar, et en particulier pour les écosystèmes marins.

61 Cette section s'appuie sur les informations contenues dans le sixième Rapport national de Madagascar à la CDB (Republic of Madagascar, 2019).

62 Cette section s'appuie sur les informations contenues dans le cinquième Rapport national de Madagascar à la CDB (Republic of Madagascar. 2014).

63 Cette section s'appuie sur les informations contenues dans le cinquième Rapport national de Madagascar à la CDB, ainsi que dans son deuxième SPANB (Republic of Madagascar, 2014; 2016). 
Figure 8.19 : Résumé de Madagascar
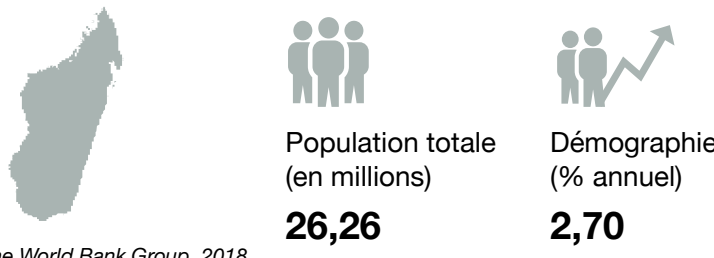

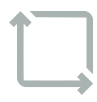

Superficie

(en milliers de $\mathrm{km}^{2}$ )

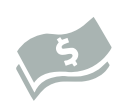

PIB (en milliards de USD actuels)

12,10
Croissance du PIB (\% annuel)

5,20

\section{7 aires protégées}

Aires protégées :

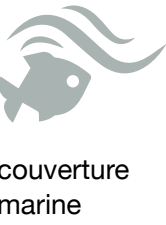

8998 km² $^{2}$
Aires protégées et de conservation de Madagascar par catégorie de gestion de l'UICN

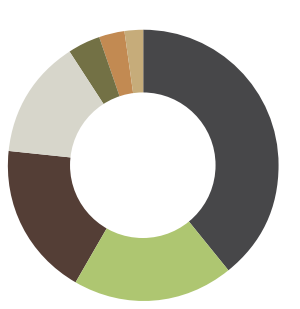

Source : UNEP-WCMC et IUCN, (2019k)

Source : UNEP-WCMC et IUCN (2019k)

Couverture des aires protégées à Madagascar

\begin{tabular}{l|r|r}
\hline Type d'aire protégée & $\begin{array}{r}\text { Aire protégée } \\
\text { ou conservée* }\end{array}$ & $\begin{array}{r}\text { Aire protégée } \\
\text { ou conservée }^{\star \star}\end{array}$ \\
\hline $\begin{array}{l}\text { Terrestres et eaux } \\
\text { intérieures }\end{array}$ & $5,59 \%$ & $\begin{array}{r}\text { Aucune } \\
\text { correspondance }\end{array}$ \\
\hline Marines et côtières & $0,75 \%$ & $\begin{array}{r}\text { Aucune } \\
\text { correspondance }\end{array}$ \\
\hline
\end{tabular}

* Ensemble de données de la BDMAP ** Rapport national sur la biodiversité

Source : UNEP-WCMC et IUCN (2019k).

Aires protégées et de conservation désignées comme sites d'importance mondiale à Madagascar

\begin{tabular}{l|r}
\hline Désignation mondiale & $\begin{array}{r}\text { Nombre de } \\
\text { sites }\end{array}$ \\
\hline Réserves de biosphère de l'UNESCO & 3 \\
\hline $\begin{array}{l}\text { Sites du Patrimoine mondial de I'UNESCO } \\
\text { (naturels ou mixtes) }\end{array}$ & 2 \\
\hline $\begin{array}{l}\text { Zones humides d'importance internationale } \\
\text { (sites Ramsar) }\end{array}$ & 20 \\
\hline
\end{tabular}

Source : Ramsar (2019) ; UNESCO (2019a, 2019b).

\section{Aires protégées et de conservation de} Madagascar par type de gouvernance de I'UICN

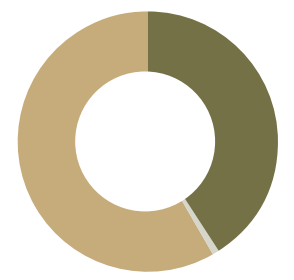

C. Gouvernance privée (2)

B. Gouvernance partagée (2)

A.Gouvernance par le gouvernement (8)
Désignations nationales des aires protégées et de conservation à Madagascar

\begin{tabular}{|c|c|c|}
\hline Désignation nationale & $\mathbf{N}^{\circ}$ & $\begin{array}{r}\text { Superficie } \\
\left(\mathbf{k m}^{2}\right)\end{array}$ \\
\hline Réserve de chasse & 2 & 150 \\
\hline Paysage harmonieux protégé & 1 & 139 \\
\hline Parc naturel & 1 & 3649 \\
\hline Paysage harmonieux protégé & 20 & 14015 \\
\hline Parc national & 26 & 19136 \\
\hline Réserve de ressources naturelles & 1 & 443 \\
\hline Projet d'aire protégée & 14 & 5215 \\
\hline Parc marin & 4 & 119 \\
\hline Parc national marin & 1 & $0^{*}$ \\
\hline $\begin{array}{l}\text { Zone de gestion collaborative de la } \\
\text { pêche }\end{array}$ & 1 & 2865 \\
\hline Réserve naturelle intégrale & 3 & 1356 \\
\hline Réserve de ressources naturelles & 1 & 443 \\
\hline Projet de parc marin & 1 & 1564 \\
\hline Non rapporté & 1 & 469 \\
\hline Forêt classée & 1 & 400 \\
\hline Nouvelle aire protégée & 5 & 3701 \\
\hline Réserve spéciale & 22 & 3550 \\
\hline Aire marine gérée localement & 26 & 2173 \\
\hline Aire marine protégée & 1 & 451 \\
\hline
\end{tabular}

\section{Aires prioritaires pour la conservation}

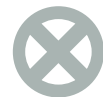

\section{0 sites}

Sites de l'Alliance pour une extinction zéro

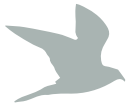

74 sites

Zones importantes pour les oiseaux et la biodiversité

\section{7 sites}

Zones clés pour la biodiversité 
Figure 8.20 : Aires protégées de Madagascar
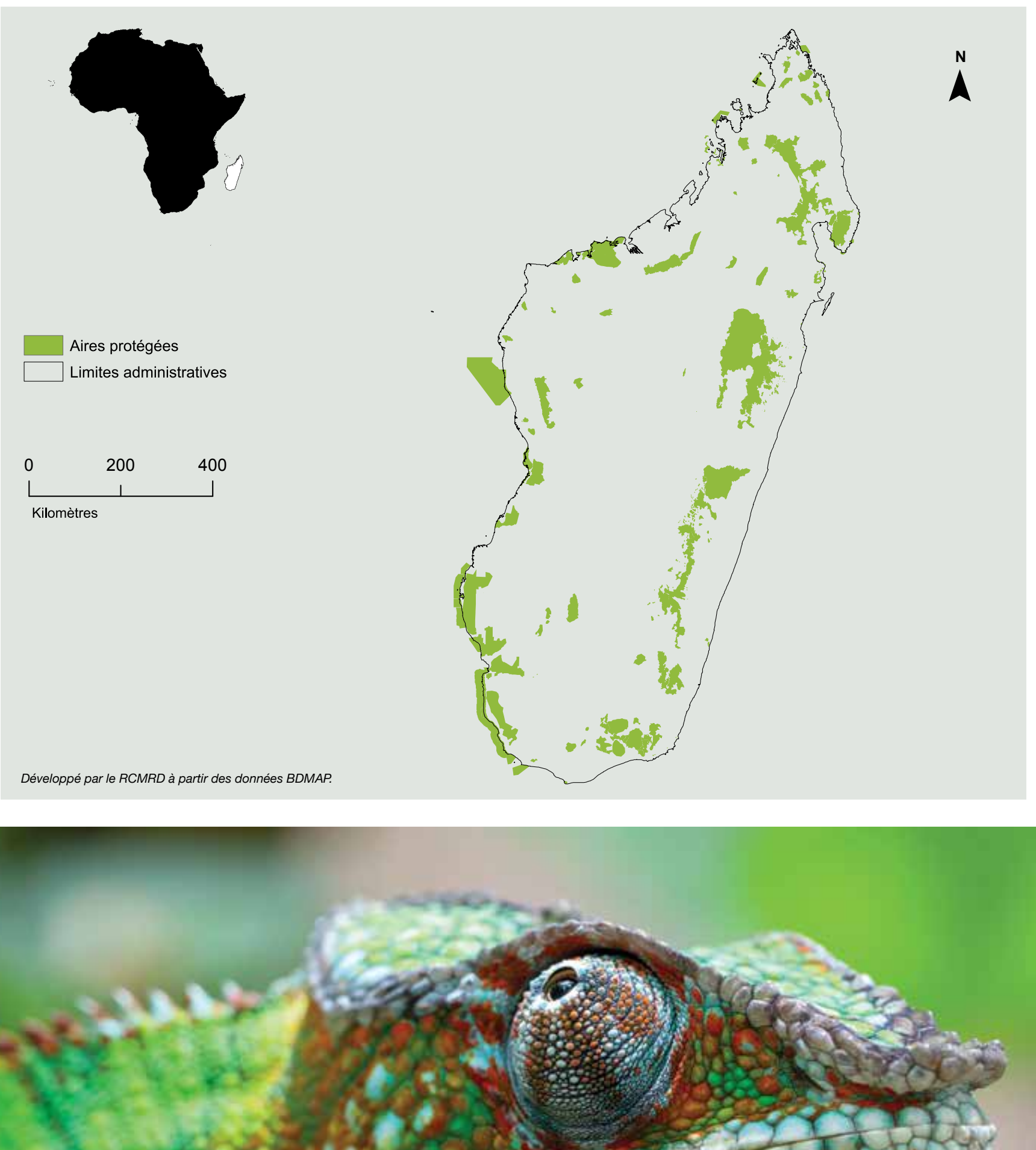


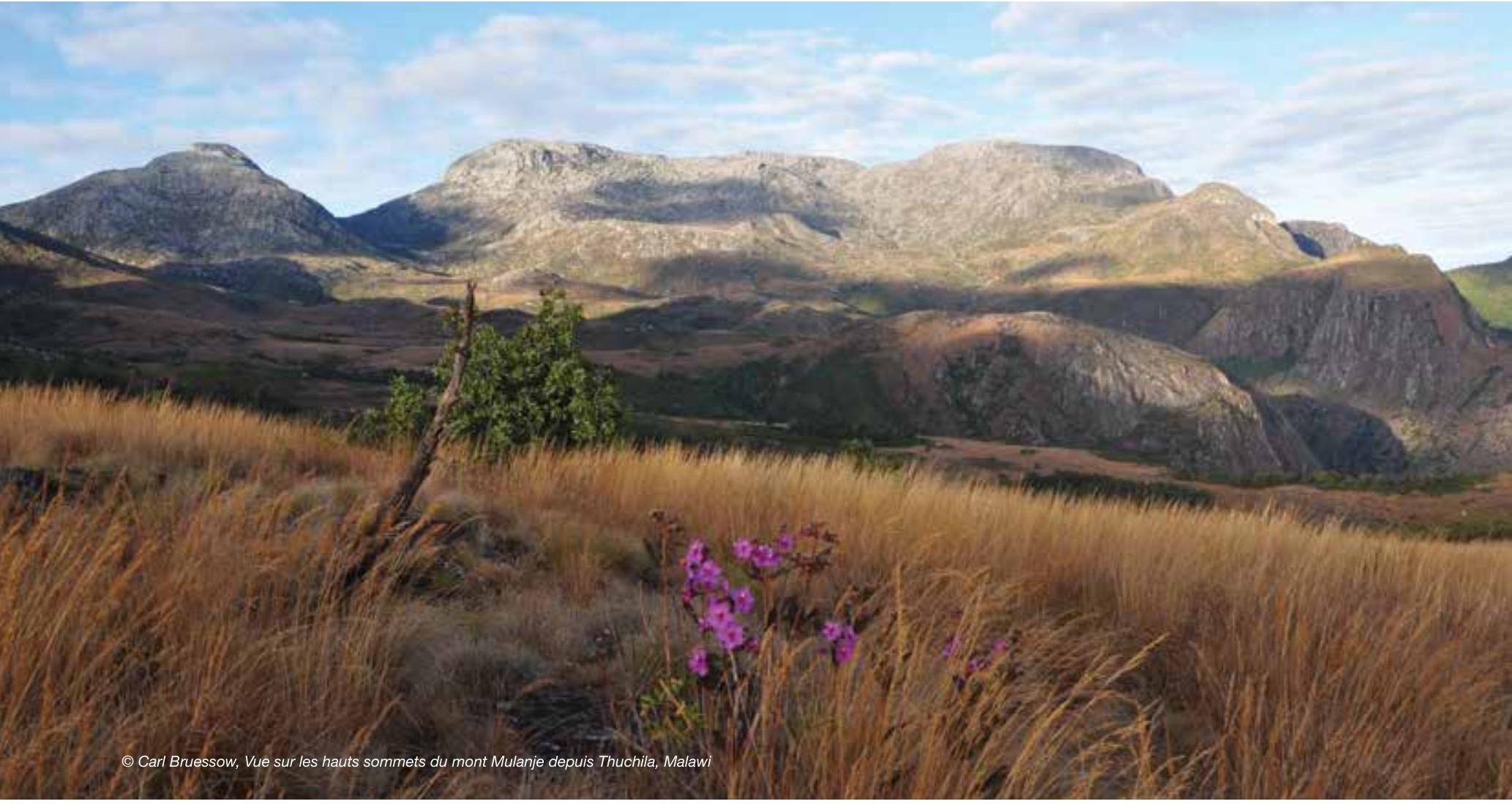

\subsection{Malawi}

\section{Aires protégées et de conservation du Malawi ${ }^{64}$}

Le Malawi compte 133 aires protégées couvrant 27190 km² d'écosystèmes terrestres (UNEP-WCMC et IUCN, 2019I).

Le Malawi présente une forte densité de population, ce qui rend la délimitation des aires protégées difficile et fait que la plupart des écosystèmes à l'intérieur des aires protégées soient vulnérables. Le gouvernement du Malawi a conclu un accord avec le secteur privé, selon lequel la réseau Parcs Africains étend sa gestion des aires protégées de deux à cinq sites, pour inclure la Réserve de gibier de Nkhotakota, le Parc national de Liwonde et la Réserve forestière de Mangochi, afin de les restaurer et de les protéger à des fins de durabilité.

\section{Aires protégées et de conservation transfrontières}

Le Malawi possède une aire protégée inclue dans l'aire de conservation transfrontière Malawi-Zambie.

\section{Contexte politique}

Un rapport complet sur la législation et les politiques relatives à la gestion, à la gouvernance et à l'équité des aires protégées a été réalisé par le programme BIOPAMA. II a identifié 25 lois et politiques pertinentes au Malawi (Tessema, 2019).

\section{Espèces clées $^{65}$}

Le Malawi possède une riche diversité végétale, avec plus de 6000 espèces de plantes à fleurs, dont 122 sont endémiques. Sur les 192 espèces de mammifères du Malawi, huit sont considérées comme menacées par la Liste rouge de I'UICN. 83 espèces d'amphibiens ont été décrites au Malawi, dont six endémiques, ainsi que huit des 145 espèces de reptiles. Le Malawi compte plus de 630 espèces d'oiseaux, dont une endémique. D'autre part, sur plus de 850 espèces de poissons d'eau douce, 99\% sont endémiques du Malawi. Le pays abrite également une grande variété d'invertébrés et de microorganismes.

\section{Pressions et menaces ${ }^{66}$}

Les menaces à la biodiversité du Malawi sont principalement d'origine humaine et comprennent la perte et la fragmentation des habitats, la surexploitation des ressources biologiques, l'introduction d'espèces exotiques et les changements climatiques. La croissance démographique et le développement économique ont entrainé un changement majeur d'affectation des terres au Malawi, créant une demande de terres pour l'agriculture et les établissements humains. Des niveaux élevés de pauvreté ont accru la dépendance à l'égard des ressources naturelles, et en particulier des forêts, qui fournissent des combustibles de cuisson à la grande majorité de la population du Malawi. 
Figure 8.21 : Résumé du Malawi

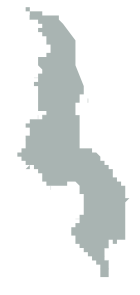

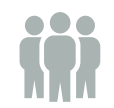

Population totale (en millions)

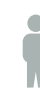

Démographie (\% annuel)

2,60

Source : The World Bank Group, 2018

Aires protégées :

133 aires
protégées

couverture terrestre

27190 km $^{2}$
Aires protégées et de conservation du Malawi par catégorie de gestion de l'UICN

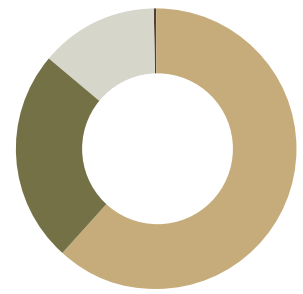

Ne s'applique pas (3)

Non rapportée (121)

IV. Aire de gestion habitats / espèces (4)

II. Parc national (5)

Source : UNEP-WCMC et IUCN (2019l).

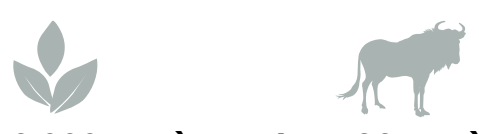

\section{0 espèces de} plantes à fleurs

\section{2 espèces de} mammifères

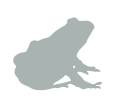

83 espèces d'amphibiens

\section{5 espèces} de reptiles

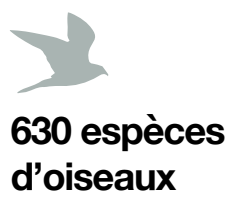

PIB (en milliards de USD actuels)
Croissance du PIB (\% annuel) 122 endémiques

850 espèces de poissons $99 \%$ endémiques

\section{Couverture des aires protégées au Malawi}

\begin{tabular}{l|r|r}
\hline Type d'aire protégée & $\begin{array}{r}\text { Aire protégée } \\
\text { ou conservée* }\end{array}$ & $\begin{array}{r}\text { Aire protégée } \\
\text { ou conservée }\end{array}$ \\
\hline $\begin{array}{l}\text { Terrestres et eaux } \\
\text { intérieures }\end{array}$ & $22,88 \%$ & $15,12 \%$ \\
\hline${ }^{*}$ Ensemble de données de la BDMAP & $*$ Rapport national sur la biodiversité \\
\hline
\end{tabular}

*Ensemble de données de la BDMAP $\quad$ ** Rapport national sur la biodiversité Source : Government of Malawi (2015); UNEP-WCMC et IUCN (2019l).

Désignations nationales des aires protégées et de conservation au Malawi

\begin{tabular}{l|r|r}
\hline Désignation nationale & Nombre & $\begin{array}{r}\text { Superficie } \\
\left(\mathbf{k m}^{2}\right)\end{array}$ \\
\hline Aire de conservation & 1 & 6493 \\
\hline Parc national & 5 & 6961 \\
\hline Réserve de faune sauvage & 4 & 3816 \\
\hline Réserve forestière & 118 & 1485 \\
\hline
\end{tabular}

Source : UNEP-WCMC et IUCN (2019I).

Aires protégées et de conservation du Malawi par type de gouvernance de l'UICN

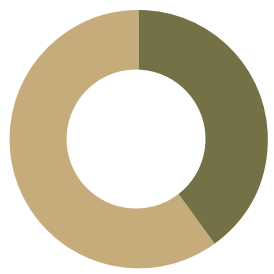

Non rapporté (123)

A. Gouvernance par le gouvernement (10)

Aires protégées et de conservation désignées comme sites d'importance mondiale au Malawi

\begin{tabular}{l|r}
\hline Désignation mondiale & $\begin{array}{r}\text { Nombre de } \\
\text { sites }\end{array}$ \\
\hline Réserves de biosphère de l'UNESCO & 2 \\
\hline $\begin{array}{l}\text { Patrimoine Mondial de I'UNESCO } \\
\text { (naturel ou mixte) }\end{array}$ & 1 \\
\hline $\begin{array}{l}\text { Zones humides d'importance internationale } \\
\text { (sites Ramsar) }\end{array}$ & 2 \\
\hline
\end{tabular}

Source : Ramsar (2019) ; UNESCO (2019a, 2019b).

\section{Aires prioritaires pour la conservation}
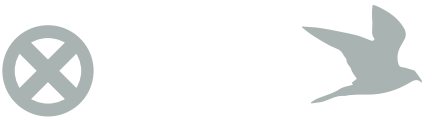

\section{3 sites \\ 21 sites \\ Sites de l'Alliance pour une extinction \\ Zones importantes pour les oiseaux et \\ 11 sites \\ Zones clés pour la biodiversité} zéro la biodiversité

Source : AZE Secretariat (2019); BirdLife International (2019b, 2019c). 
Figure 8.22 : Aires protégées du Malawi
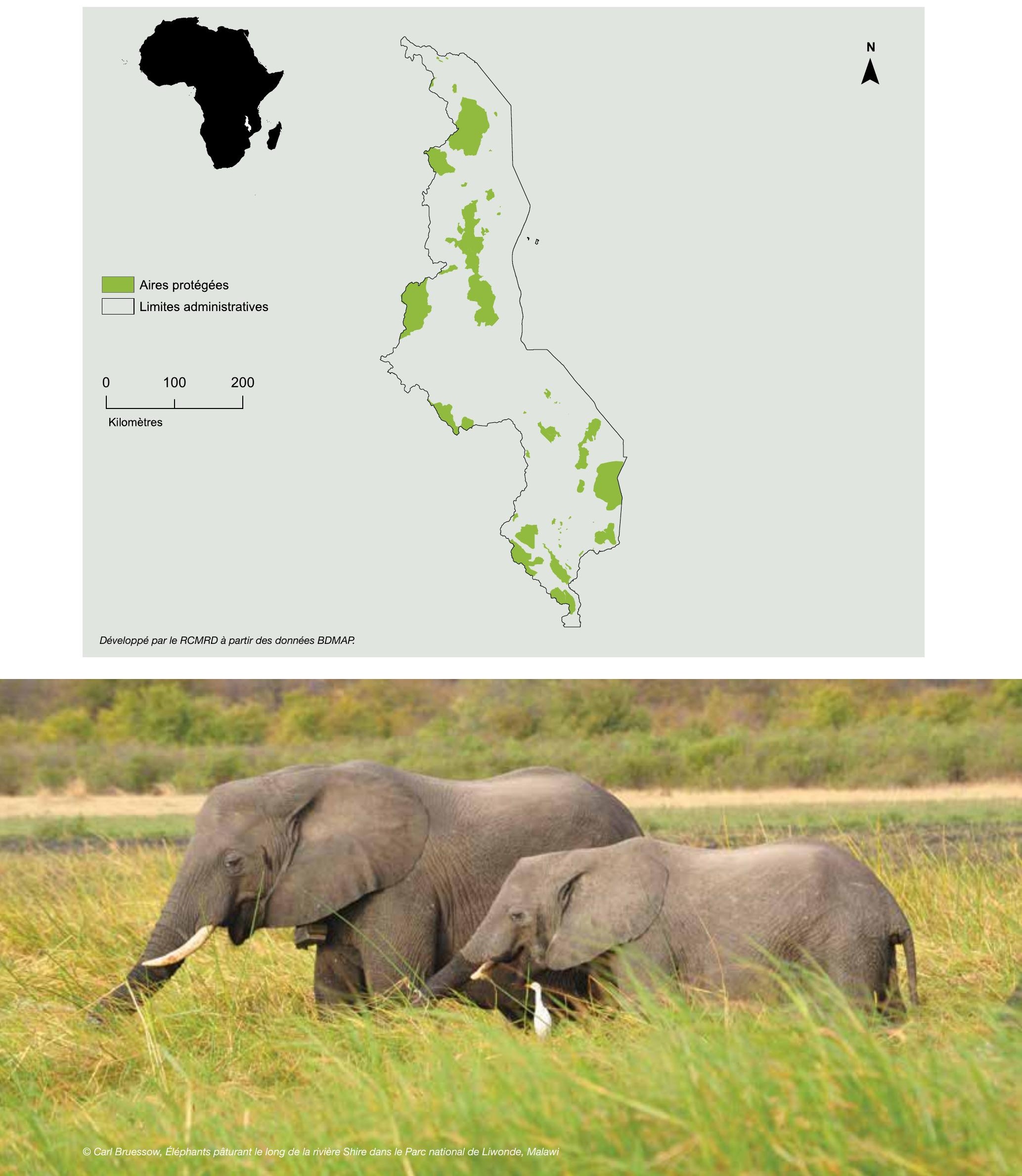


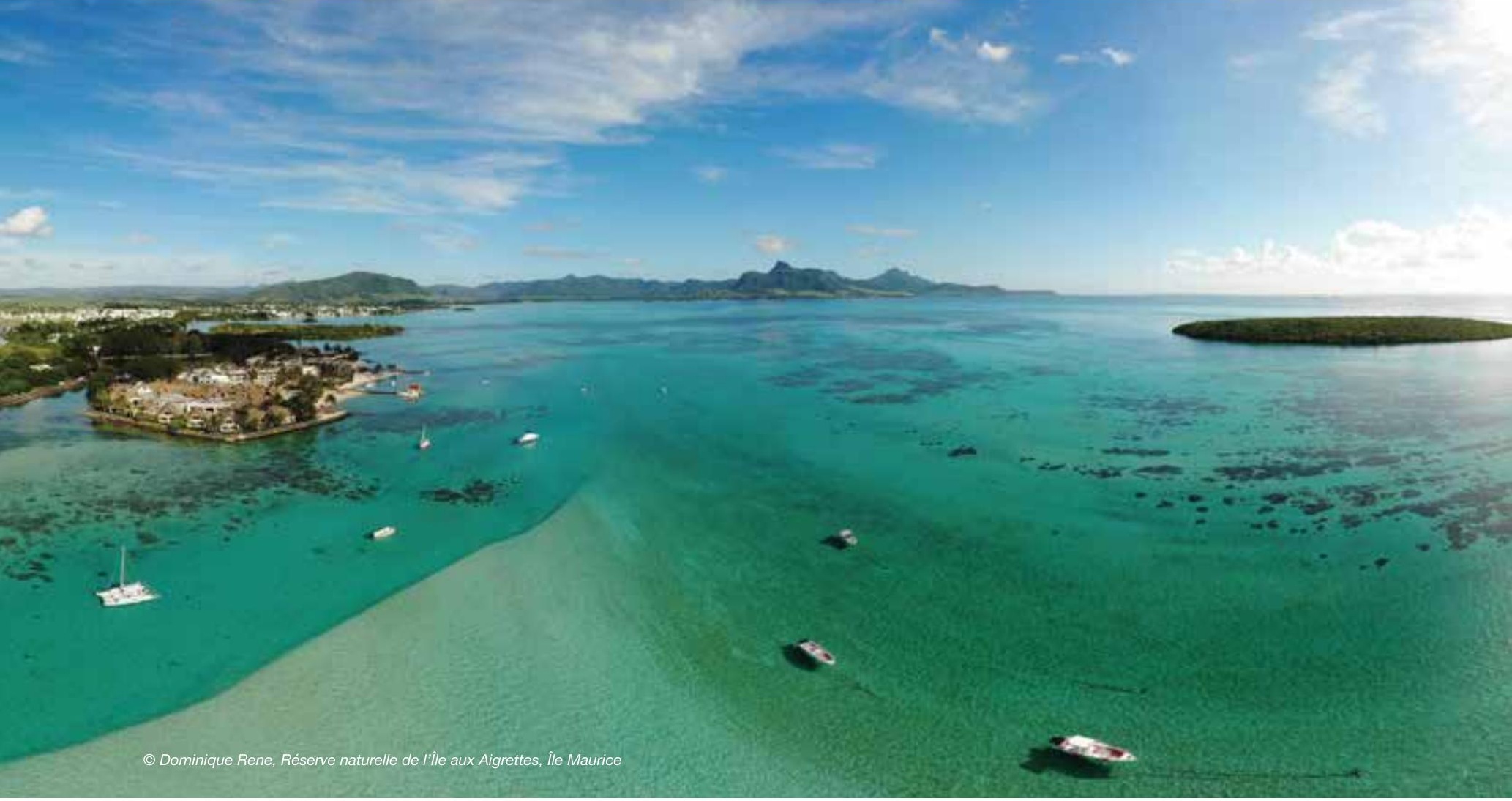

\subsection{Maurice}

\section{Aires protégées et de conservation de Maurice ${ }^{67}$}

Maurice compte 44 aires protégées couvrant $97 \mathrm{~km}^{2}$ d'écosystèmes terrestres et $50 \mathrm{~km}^{2}$ d'écosystèmes marins (UNEP-WCMC et IUCN, 2019m).

Bien que la couverture des aires protégées terrestres reste inchangée depuis 2010, l'accent a été mis sur la restauration des forêts autochtones, et un vaste système d'aires marines protégées comprenant des réserves de pêche, des parcs marins et des réserves marines a été mis en place dans les eaux entourant les îles Maurice et Rodrigues. Maurice a également établi un nouveau paradigme en matière d'aires protégées, encourageant la participation du secteur privé à la propriété et à la gestion des aires protégées.

\section{Aires protégées et de conservation transfrontières}

Maurice comprend une partie du parc marin transfrontalier de l'océan Indien occidental.

\section{Contexte politique}

Un rapport complet sur la législation et les politiques relatives à la gestion, à la gouvernance et à l'équité des aires protégées a été réalisé par le programme BIOPAMA. II a identifié 41 lois et politiques pertinentes à Maurice (Tessema, 2019).

\section{Espèces clées $^{68}$}

Les îles Maurice et Rodrigues abritent des niveaux élevés d'endémisme parmi les plantes, les reptiles, les invertébrés et les oiseaux, malgré plusieurs extinctions dues à des espèces envahissantes. Il existe 691 espèces de plantes à fleurs autochtones, dont 273 endémiques de l'île Maurice (150 endémiques de l'archipel des Mascareignes), et 150 espèces de plantes à fleurs autochtones, dont 47 endémiques de l'île Rodrigues (72 endémiques de l'archipel des Mascareignes). Les seuls mammifères autochtones sont des chauves-souris (chauves-souris frugivores et tombales) et à ce jour, neuf espèces endémiques d'oiseaux terrestres et onze espèces de reptiles ont été recensées sur l'île. Deux espèces de chauve-souris frugivores sont présentes actuellement en République de Maurice: Pteropus niger sur l'île Maurice et Pteropus rodricensis sur l'île Rodrigues. On ne compte plus que 12 des 17 espèces de reptiles autrefois présentes à Maurice, dont 11 sont endémiques, et 7 d'entre elles sont limitées à des îlots marins, où elles ont échappé à l'extinction provoquée par les rats. De plus, cinq de ces espèces sont limitées à l'île Ronde.

\section{Pressions et menaces ${ }^{69}$}

La destruction des habitats et les espèces exotiques envahissantes constituent à ce jour les menaces les plus importantes pour la biodiversité de Maurice. Les changements climatiques et la pollution sont également responsables de pressions sur les écosystèmes de l'île. Les facteurs indirects de perte de biodiversité incluent les changements démographiques et des facteurs sociopolitiques, en particulier les financements et les capacités pour la conservation de la biodiversité.

67 Cette section s'appuie sur les informations contenues dans le cinquième Rapport national de Maurice à la CDB, ainsi que dans son deuxième SPANB (Republic of Mauritius, 2015; 2017).

68 Ibid.

69 Ibid. 
Figure 8.23 : Résumé de Maurice

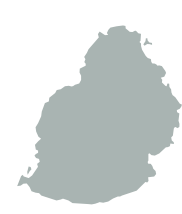

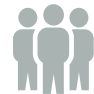

Population totale (en millions)

1,27

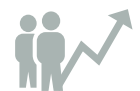

Démographique (\% annuel)

0,10

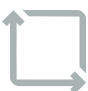

Superficie (en milliers de $\mathrm{km}^{2}$ )

2,00

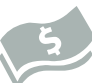

PIB (en milliards de USD actuels)

14,22
Croissance du PIB (\% annuel) 3,80
Aires protégées :

44 aires protégées

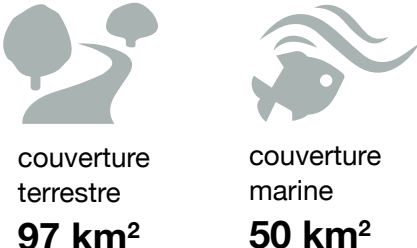

Source : UNEP-WCMC et IUCN, 2019m
Aires protégées et de conservation de Maurice par catégorie de gestion de I'UICN

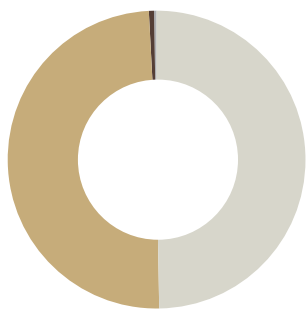

Non définie (1)

Non rapportée (10)

IV. Aire de gestion habitats / espèces (21)

II. Parc national (10)

la. Réserve naturelle intégrale (1)

Source : UNEP-WCMC et IUCN (2019m)

\section{1 espèces de plantes à fleurs autochtones}

Les seuls mammifères autochtones sont des chauves-souris

\section{2 espèces de reptiles}

\section{Couverture des aires protégées à Maurice}

\begin{tabular}{l|r|r}
\hline Type d'aire protégée & $\begin{array}{r}\text { Aire protégée } \\
\text { ou conservée }\end{array}$ & $\begin{array}{r}\text { Aire protégée } \\
\text { ou conservée }^{\star *}\end{array}$ \\
\hline $\begin{array}{l}\text { Terrestres et eaux } \\
\text { intérieures }\end{array}$ & $4,73 \%$ & $4,00 \%$ \\
\hline Marines et côtières & $0,00 \%$ & $0,01 \%$ \\
\hline
\end{tabular}

*Ensemble de données de la BDMAP ${ }^{* *}$ Rapport national sur la biodiversité

Source : Republic of Mauritius (2017); UNEP-WCMC et IUCN (2019m).

\section{Aires protégées et de conservation désignées} comme sites d'importance mondiale à Maurice

\begin{tabular}{l|r}
\hline Désignation mondiale & $\begin{array}{r}\text { Nombre de } \\
\text { sites }\end{array}$ \\
\hline Réserves de biosphère de l'UNESCO & 1 \\
\hline $\begin{array}{l}\text { Zones humides d'importance internationale } \\
\text { (sites Ramsar) }\end{array}$ & 3 \\
\hline
\end{tabular}

Source : Ramsar (2019) ; UNESCO (2019a, 2019b).

\section{Aires protégées et de conservation de Maurice par} type de gouvernance de l'UICN

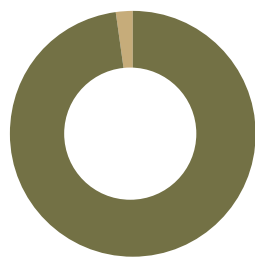

C. Gouvernance privée (2)

A. Gouvernance par le gouvernement (42)
Désignations nationales des aires protégées et de conservation à Maurice

\begin{tabular}{l|r|r}
\hline Désignation nationale & $\mathbf{N}^{\circ}$ & $\begin{array}{r}\text { Superficie } \\
\left(\mathbf{k m}^{2}\right)\end{array}$ \\
\hline Parc national & 2 & 61 \\
\hline Parc marin & 2 & 6 \\
\hline Réserve naturelle & 18 & 9 \\
\hline Réserve de tortues & 2 & 0 \\
\hline Réserve de pêche & 6 & 68 \\
\hline Îlot parc national & 8 & 2 \\
\hline Jardin endémique & 1 & 3 \\
\hline Monument ancien & 1 & 0 \\
\hline Source : UNEP-WCMC et IUCN (2019m) & &
\end{tabular}

\section{Aires prioritaires pour la conservation}

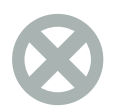

\section{2 sites}

Sites de l'Alliance pour une extinction zéro

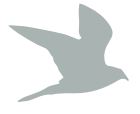

\section{6 sites}

Zones importantes pour les oiseaux et la biodiversité

\section{8 sites}

Zones clés pour la biodiversité 
Figure 8.24 : Aires protégées de Maurice
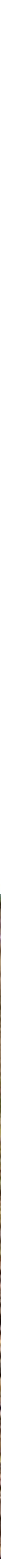


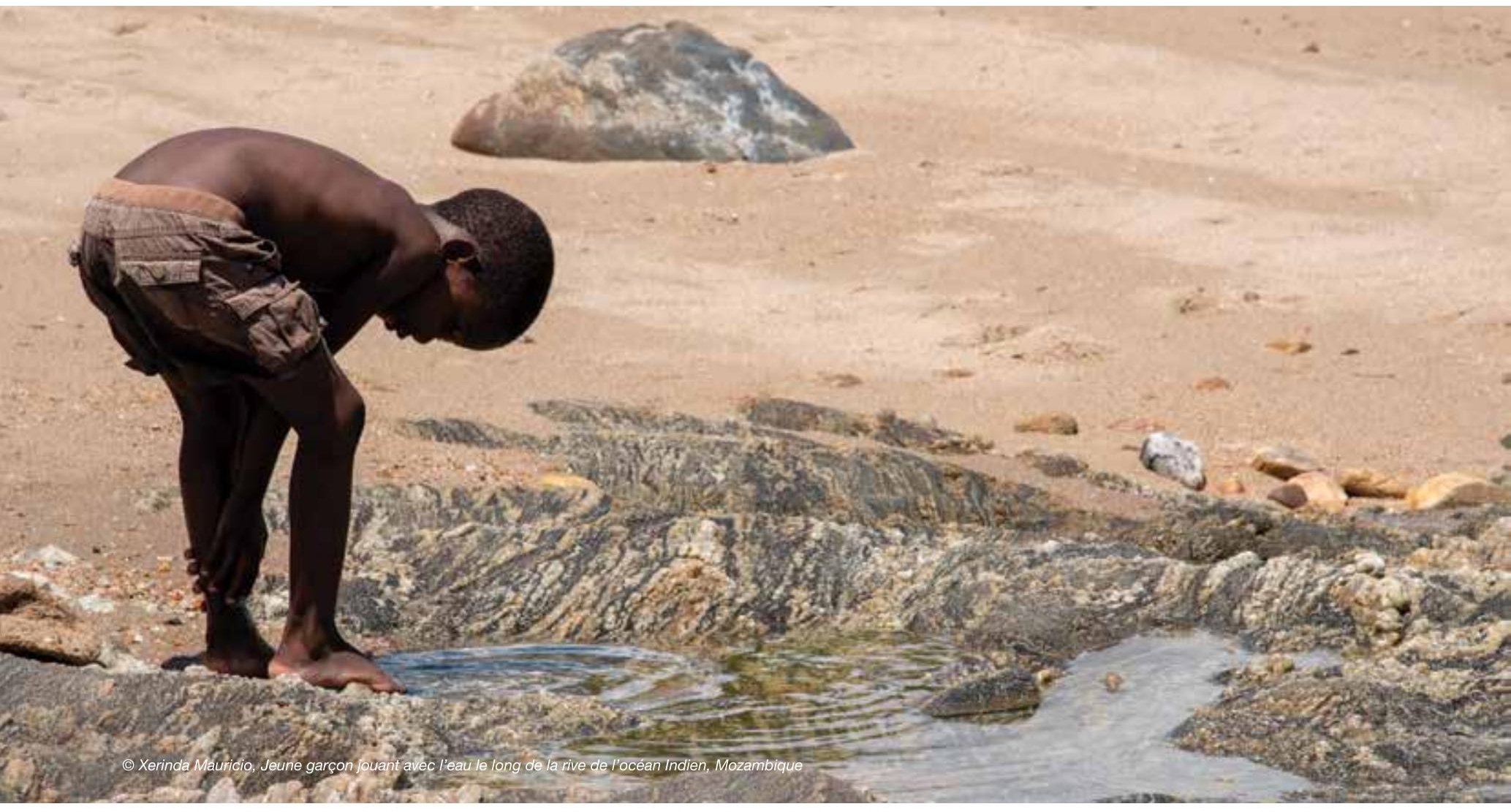

\subsection{Mozambique}

\section{Aires protégées et de conservation du Mozambique $^{70}$}

Le Mozambique compte 44 aires protégées couvrant 170662 km² d'écosystèmes terrestres et $12821 \mathrm{~km}^{2}$ d'écosystèmes marins (UNEP-WCMC et IUCN, 2019n). La couverture terrestre des aires protégées dans le pays a augmenté au cours des 10 dernières années. Reconnaissant la valeur nationale et mondiale de la biodiversité, le gouvernement du Mozambique s'est attaché à assurer l'inclusion d'écosystèmes auparavant non-représentés, tels que le seul écosystème d'eau douce protégé du pays, la Réserve partielle du lac Niassa.

Les aires marines protégées ont également été étendues avec la création de l'Aire de protection de l'environnement des îles Primeiras et Segundas et de la Réserve marine partielle MaputoPonta do Ouro. Certains sanctuaires marins ont également été déclarés.

Le gouvernement mozambicain a entrepris une analyse des différents modèles de cogestion et adopté des partenariats publicprivé pour améliorer la gestion de ses aires protégées. Ceux-ci incluent la Fondation Carr pour le Parc national de Gorongosa, et Parcs Africains pour le Parc national de l'archipel de Bazaruto, entre autres.

\section{Aires protégées et de conservation transfrontières}

Le Mozambique fait partie de sept aires de conservation transfrontières, à savoir l'ACT de Chimanimani, l'ACT du Parc transfrontalier et aire de conservation du Grand Limpopo (GLTP), l'ACT de Lubombo, l'ACT de l'Aire de conservation de Mnazi BayQuirimbas, I'ACT de Niassa-Selous, l'ACT de la Réserve marine Ponta de Ouro-Cosibay, I'ACT REM-Tembe_Ndumo et I'ACT ZIMOZA.

\section{Contexte politique}

Un rapport complet sur la législation et les politiques relatives à la gestion, à la gouvernance et à l'équité des aires protégées a été réalisé par le programme BIOPAMA. II a identifié 80 lois et politiques pertinentes au Mozambique (Tessema, 2019).

\section{Espèces clées $^{71}$}

La connaissance de la biodiversité du Mozambique reste faible, mais s'améliore. 4271 espèces animales terrestres ont été recensées, dont $72 \%$ d'insectes, $17 \%$ d'oiseaux, $5 \%$ seulement de mammifères et $2 \%$ d'amphibiens. L'évaluation la plus récente indique la présence de près de 6000 espèces de plantes. Les études sur les espèces autochtones sont rares, bien qu'il existe deux centres d'endémisme végétal : la région du Maputaland et le Chimanimani.

Parmi les espèces végétales recensées au Mozambique, environ 800 espèces sont endémiques et presque endémiques. Les régions montagneuses du Mozambique sont relativement riches en espèces endémiques, avec au moins 45 espèces de plantes présentes uniquement à Chimanimani.

De nouvelles espèces ont été découvertes au Mozambique, suite à

70 Cette section s'appuie sur les informations contenues dans le cinquième Rapport national du Mozambique à la CDB, ainsi que dans la Stratégie et Plan d'action nationaux pour la diversité biologique du Mozambique (2015-2035) (Republic of Mozambique, 2014; 2015).

71 Cette section s'appuie sur les informations contenues dans le cinquième Rapport national du Mozambique à la CDB (Republic of Mozambique, 2014). 
Figure 8.25 : Résumé du Mozambique

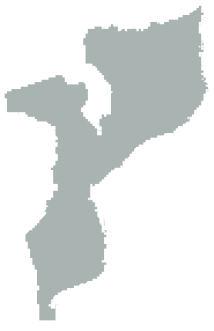

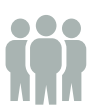

Population totale (en millions)

29,50

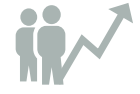

Démographie (\% annuel)

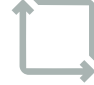

Superficie (en milliers de $\mathrm{km}^{2}$ )

786,40

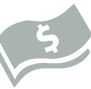

PIB (en milliards de USD actuels)

14,46
Croissance du PIB (\% annuel)

3,30

Source : The World Bank Group, 2018

\section{Aires protégées :}

44 aires protégées

couverture terrestre couverture marine 170662 km² 12821 km²

Source : UNEP-WCMC et IUCN, 2019n

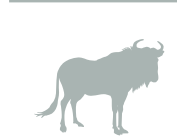

\section{1 espèces $\quad 6000$ espèces animales terrestres végétales}

Aires protégées et de conservation du Mozambique par catégorie de gestion de I'UICN

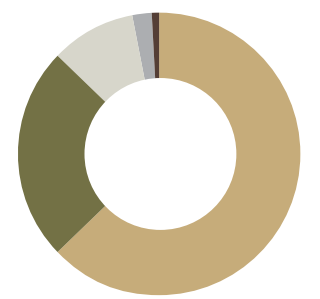

Non définie (2)

Non rapportée (29)

VI. Aire protégée avec utilisation durable des ressources naturelles (3)

IV. Aire de gestion habitats / espèces (4)

II. Parc national (6)

Source: UNEP-WCMC et IUCN (2019n)

\section{Couverture des aires protégées au Mozambique}

\begin{tabular}{l|r|r}
\hline Type d'aire protégée & $\begin{array}{r}\text { Aire protégée } \\
\text { ou conservée* }\end{array}$ & $\begin{array}{r}\text { Aire protégée } \\
\text { ou conservée** }\end{array}$ \\
\hline $\begin{array}{l}\text { Terrestres et eaux } \\
\text { intérieures }\end{array}$ & $21,57 \%$ & $26,00 \%$ \\
\hline Marines et côtières & $2,23 \%$ & $\begin{array}{r}\text { Aucune } \\
\text { correspondance }\end{array}$ \\
\hline
\end{tabular}

*Ensemble de données de la BDMAP ${ }^{* *}$ Rapport national sur la biodiversité Source : Ministry for the Coordination of Environmental Affairs, Republic of Mozambique (2014); UNEP-WCMC et IUCN (2019n)

Aires protégées et de conservation désignées comme sites d'importance mondiale au Mozambique

\begin{tabular}{l|r}
\hline Désignation mondiale & $\begin{array}{r}\text { Nombre de } \\
\text { sites }\end{array}$ \\
\hline $\begin{array}{l}\text { Zones humides d'importance internationale } \\
\text { (sites Ramsar) }\end{array}$ & 2 \\
\hline
\end{tabular}

Source : Ramsar (2019) ; UNESCO (2019a, 2019b)

Aires protégées et de conservation du Mozambique par type de gouvernance de I'UICN

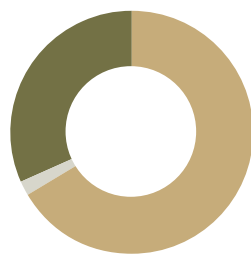

Non rapporté (14)

D. Gouvernance par les peuples

autochtones et communautés locales (1)

B. Gouvernance partagée (1)

A. Gouvernance par le gouvernement (28)
Désignations nationales des aires protégées et de conservation au Mozambique

\begin{tabular}{l|r|r}
\hline Désignation nationale & $\mathbf{N}^{\circ}$ & $\begin{array}{r}\text { Superficie } \\
\left(\mathbf{k m} \mathbf{2}^{\mathbf{}}\right.\end{array}$ \\
\hline Parc national & 6 & 33569 \\
\hline Réserve de gibier & 2 & 1683 \\
\hline Réserve nationale & 2 & 44981 \\
\hline Réserve spéciale & 1 & 1040 \\
\hline Réserve de chasse & 14 & 38887 \\
\hline Réserve naturelle & 1 & 1 \\
\hline Réserve de faune & 1 & 20 \\
\hline Réserve forestière & 13 & 5286 \\
\hline Aire de protection de & 1 & 24589 \\
\hline 'environnement & 1 & 1148 \\
\hline Non rapporté & &
\end{tabular}

Source: UNEP-WCMC et IUCN (2019n).

\section{Aires prioritaires pour la conservation}

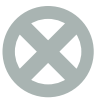

\section{4 sites}

Sites de l'Alliance pour une extinction zéro

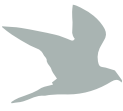

16 sites

Zones importantes pour les oiseaux et la biodiversité
11 sites

Zones clés pour la biodiversité

Source: UNEP-WCMC et IUCN (2019n). 
de nouvelles études scientifiques et expéditions dans des endroits auparavant inaccessibles. Par exemple, certaines espèces ont été identifiées à Monte Inago, dont le caméléon pygmée (Rhampholeon sp.), un papillon (Cymothoe sp.), le carrangueijo d'eau douce (Potamonautes sp.), ainsi qu'une possible nouvelle espèce (Encephalartos sp.).

Le nombre d'espèces menacées a tendance à augmenter au Mozambique. Plus de 300 espèces de plantes figurent sur la Liste rouge de I'UICN, dont $22 \%$ sont confirmées comme étant endémiques. Certaines espèces d'Encefalartos méritent une attention particulière, comme le cycas de Munch (Encephalartos munchii) et Encephalartos pterogonus. D'autre part, le cycas de Jozini (E. senticosus) est considéré comme en danger critique d'extinction, et le cycas de Lebombo (E. lebomboensis), le cycas d'Umbeluzi ( $E$. umbeluziensis) et le cycas de Chimanimani ( $E$. chimanimaniensis) comme menacés.

Les mammifères les plus menacés au Mozambique sont le rhinocéros blanc (Ceratotherium simum), le sassabi (Damaliscus lunatus), le sitatunga (Tragelaphus spekei), le rhinocéros noir (Diceros bicornis), la girafe (Giraffa camelopardalis), le cobe de montagne (Redunca fulvorufula) et le guépard (Acinomyx jutabus). Le rhinocéros blanc, la girafe et le palapala gris ont été réintroduits dans le Parc national du Limpopo, et des girafes ont été réintroduites dans la Réserve nationale de Maputo.

Le Mozambique abrite également de nombreuses espèces d'oiseaux en voie de disparition, ainsi que des tortues de mer et des dugongs. Le magazine Nature Science mène actuellement des recherches sur les écosystèmes marins dans les provinces d'Inhambane, Zambèze et Nampula, qui aideront l'ANAC à établir une base de données sur la présence d'espèces marines au Mozambique.

\section{Pressions et menaces ${ }^{72}$}

Les principales menaces directes pour la biodiversité incluent les changements d'utilisation des terres, la perte et la fragmentation des écosystèmes naturels, des habitats et des espèces par des facteurs anthropiques, la surexploitation de certaines espèces, les invasions par des espèces non-autochtones au détriment des écosystèmes et espèces autochtones, la pollution ou la contamination des habitats ou des espèces par des produits chimiques dans les écosystèmes naturels, les feux de forêt incontrôlés et les changements climatiques affectant les habitats naturels ou les espèces, le développement et les catastrophes naturelles.

\section{Figure 8.26 : Aires protégées du Mozambique}
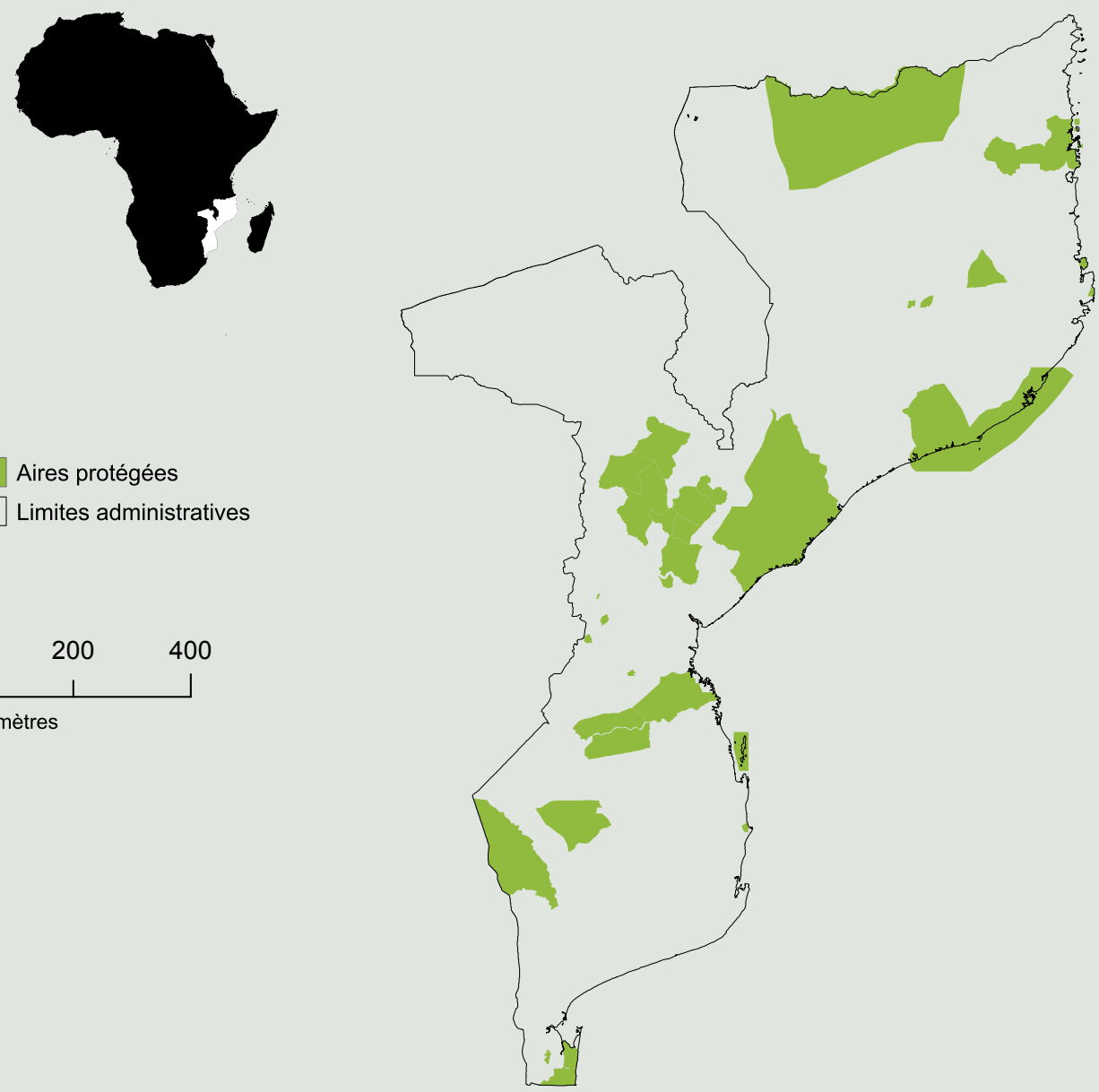

Aires protégées

Limites administratives

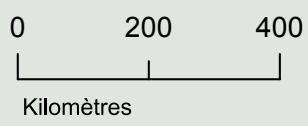




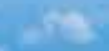

is
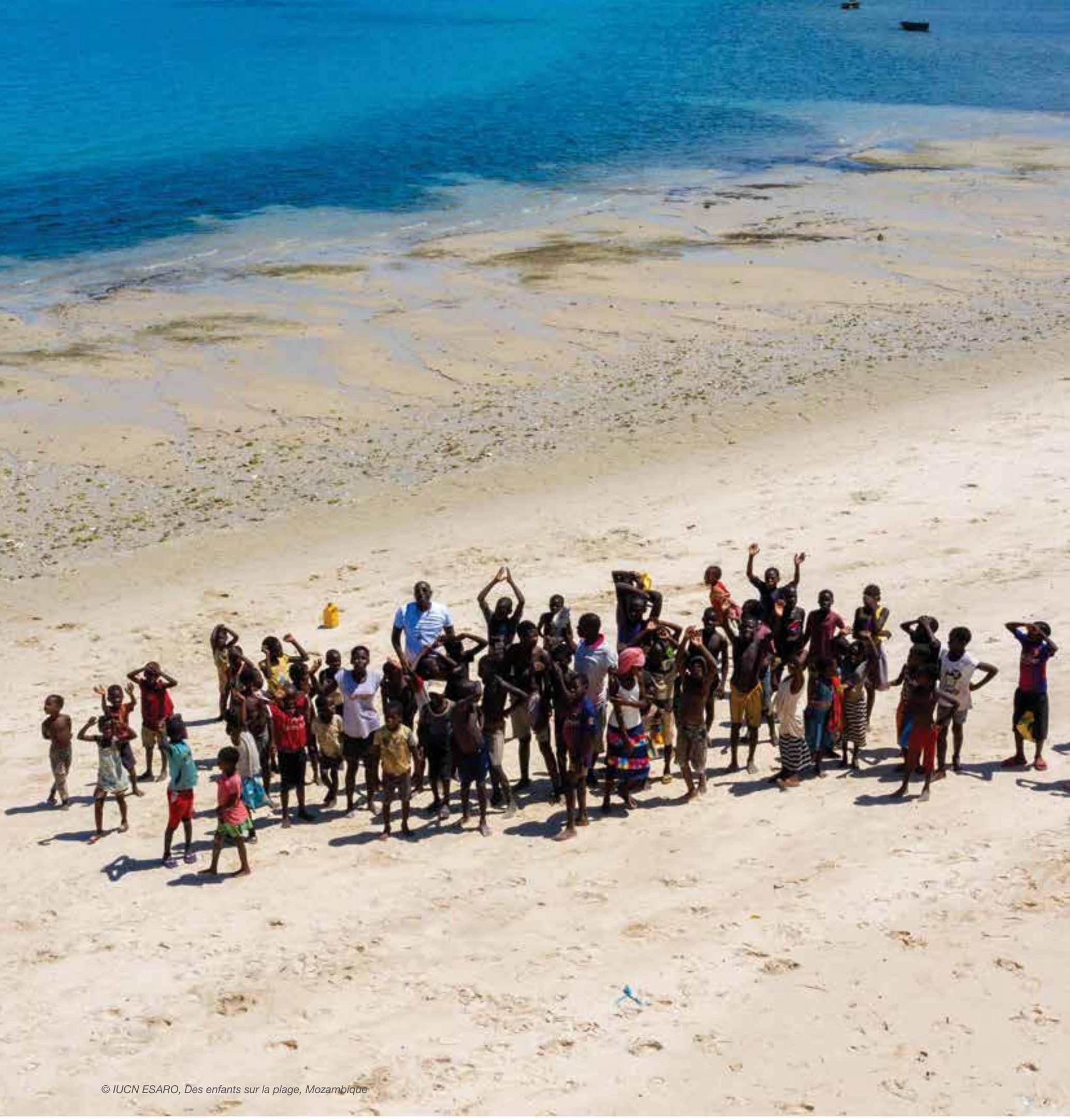


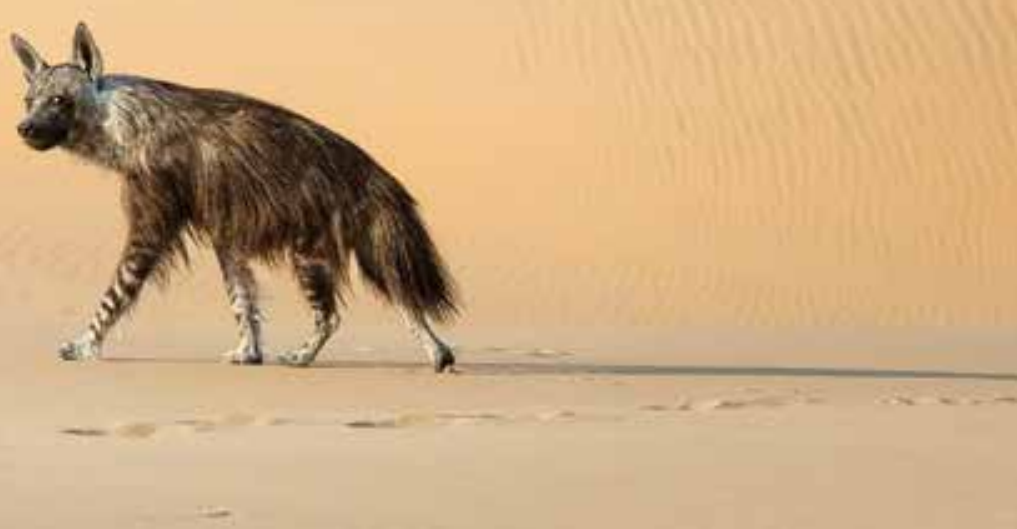

\subsection{Namibie}

\section{Aires protégées et de conservation de Namibie ${ }^{73}$}

La Namibie compte 148 aires protégées couvrant 313534 km² d'écosystèmes terrestres et $9646 \mathrm{~km}^{2}$ d'écosystèmes marins (UNEP-WCMC et IUCN, 2019o).

Afin de protéger sa riche biodiversité, la Namibie a mis en place un système de 21 aires protégées gérées par l'État, dans le but de protéger et de conserver la diversité biologique, mais également de générer des revenus indispensables grâce au tourisme. Ces aires protégées sont complétées par une forte gestion communautaire des ressources naturelles par le biais d'aires de conservation communales. De façon remarquable, l'ensemble du littoral namibien est protégé. Grâce au système d'upwelling de Benguela, qui fait remonter les eaux riches en nutriments situées autour 200$300 \mathrm{~m}$ de profondeur et permet des taux élevés de croissance du phytoplancton, la Namibie possède un écosystème marin riche, considéré comme l'un des plus productifs au monde.

\section{Aires protégées et de conservation transfrontières}

La Namibie comprend une partie de trois aires de conservation transfrontières, à savoir l'ACT /Ai/Ais-Richtersveld, l'ACT de lona Côte des Squelettes et l'ACT du Kavango Zambèze.

\section{Contexte politique}

Un rapport complet sur la législation et les politiques relatives à la gestion, à la gouvernance et à l'équité des aires protégées a été réalisé par le programme BIOPAMA. II a identifié 31 lois et politiques pertinentes en Namibie (Tessema, 2019).

\section{Espèces clées $^{74}$}

Bien que la Namibie présente généralement un nombre relativement inférieur d'espèces par rapport à des pays au climat plus humide, elle abrite un niveau élevé d'endémisme, en particulier chez les plantes, les invertébrés, les reptiles et les grenouilles. La Namibie compte 50 espèces d'amphibiens (12 endémiques), 618 espèces d'arachnides (11 endémiques), 592 espèces d'oiseaux (2 endémiques), 114 espèces de poissons ( 8 endémiques), plus de 6400 espèces d'insectes (24 endémiques), 229 espèces de mammifères ( 7 endémiques), plus de 4000 espèces de plantes (14 endémiques) et 254 espèces de reptiles (28 endémiques).

\section{Pressions et menaces ${ }^{75}$}

Les principales menaces pesant sur la biodiversité de la Namibie sont l'utilisation non durable de l'eau (irrigation à grande échelle, pollution, barrages et captage excessif des eaux souterraines), les effets des changements climatiques (sécheresse et inondations accrues, changements dans la répartition des espèces et impacts sur les écosystèmes vulnérables), les industries extractives (expansion de l'exploitation et de la prospection minières dans des sites écologiquement sensibles), la gestion non durable des terres (érosion des sols, dégradation des terres, déboisement et empiètements excessifs sur la brousse), les espèces exotiques envahissantes, le prélèvement et le commerce illégaux des ressources fauniques et végétales, les conflits homme-faune et les feux de brousse incontrôlés.

Nombre de ces menaces sont dues à l'expansion des zones urbaines, ainsi qu'à l'industrialisation croissante, entraînant une demande chaque fois plus importante de ressources et de services et une augmentation des types et des volumes de déchets et de pollution. 
Figure 8.27 : Résumé de la Namibie

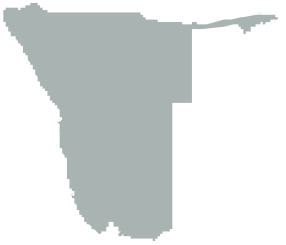

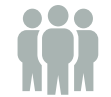

Population totale (en millions)

2,45

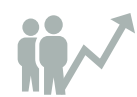

Démographie (\% annuel)

1,90
Superficie (en milliers de $\mathrm{km}^{2}$ )

824,30
PIB (en milliards de USD actuels)

14,52
Croissance du PIB (\% annuel) $-0,10$

Source : The World Bank Group, 2018.

Aires protégées :

\section{8 aires} protégées

couverture terrestre couverture marine $313534 \mathrm{~km}^{2} \quad 9646$ km$^{2}$

Source : UNEP-WCMC et IUCN, 2019o

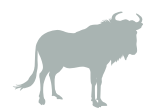

229 mammifères

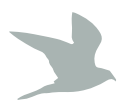

592

oiseaux
254

reptiles
Aires protégées et de conservation de Namibie par catégorie de gestion de l'UICN

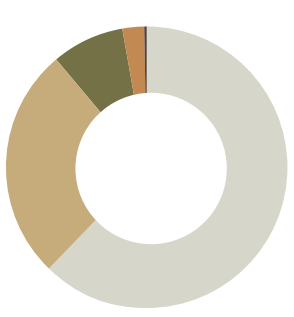

Ne s'applique pas (1)

Non rapportée (131)

VI. Aire protégée avec utilisation durable des ressources naturelles (1)

V. Paysage terrestre / marin protégé (3)

IV. Aire de gestion habitats / espèces (1)

III. Monument naturel (2)

II. Parc national (9)

\section{Couverture des aires protégées en Namibie}

\begin{tabular}{l|r|r}
\hline Type d'aire protégée & $\begin{array}{r}\text { Aire protégée } \\
\text { ou conservée }\end{array}$ & $\begin{array}{r}\text { Aire protégée } \\
\text { ou conservée** }\end{array}$ \\
\hline $\begin{array}{l}\text { Terrestres et eaux } \\
\text { intérieures }\end{array}$ & $37,89 \%$ & $17,00 \%$ \\
\hline Marines et côtières & $1,71 \%$ & - \\
\hline
\end{tabular}

*Ensemble de données de la BDMAP ${ }^{* *}$ Rapport national de 2014 sur la biodiversité Source : Ministry of Environment \& Tourism, Republic of Namibia (2014); UNEP-WCMC et IUCN (2019o).

Aires protégées et de conservation désignées comme sites d'importance mondiale en Namibie

\begin{tabular}{l|r}
\hline Désignation mondiale & $\begin{array}{r}\text { Nombre de } \\
\text { sites }\end{array}$ \\
\hline $\begin{array}{l}\text { Patrimoine Mondial de l'UNESCO } \\
\text { (naturel ou mixte) }\end{array}$ & 1 \\
\hline $\begin{array}{l}\text { Zones humides d'importance internationale } \\
\text { (sites Ramsar) }\end{array}$ & 5 \\
\hline
\end{tabular}

Source : Ramsar (2019) ; UNESCO (2019a, 2019b).

Aires protégées et de conservation de Namibie par type de gouvernance de I'UICN

Source : UNEP-WCMC et IUCN (2019o).

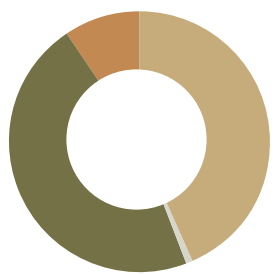

Non rapporté (3)

D. Gouvernance par les peuples

autochtones ou communautés locales (112)

C. Gouvernance privée (2)

A. Gouvernance par le gouvernement (31)
Désignations nationales des aires protégées et de conservation en Namibie

\begin{tabular}{l|r|r}
\hline Désignation nationale & No & $\begin{array}{r}\text { Superficie } \\
\left(\mathbf{k m}^{\mathbf{2}}\right)\end{array}$ \\
\hline Réserve privée & 2 & 2887 \\
\hline Forêt communautaire & 33 & 31998 \\
\hline Parc national & 19 & 137446 \\
\hline Aire marine protégée & 1 & 9492 \\
\hline $\begin{array}{l}\text { Zone de conservation } \\
\text { communautaire }\end{array}$ & 79 & 160425 \\
\hline Concession & 7 & 14535 \\
\hline Réserve forestière & 1 & 1485 \\
\hline
\end{tabular}

Source : UNEP-WCMC et IUCN (20190).

\section{Aires prioritaires pour la conservation}

\section{9 sites}

Zones importantes pour les oiseaux et la biodiversité

Source : BirdLife International (2019c). 
Figure 8.28 : Aires protégées de Namibie

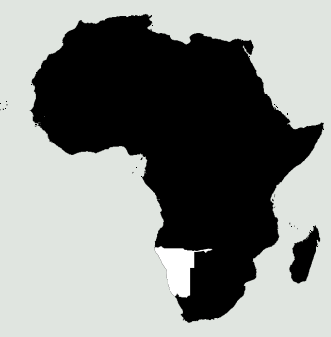

Aires protégées

Limites administratives
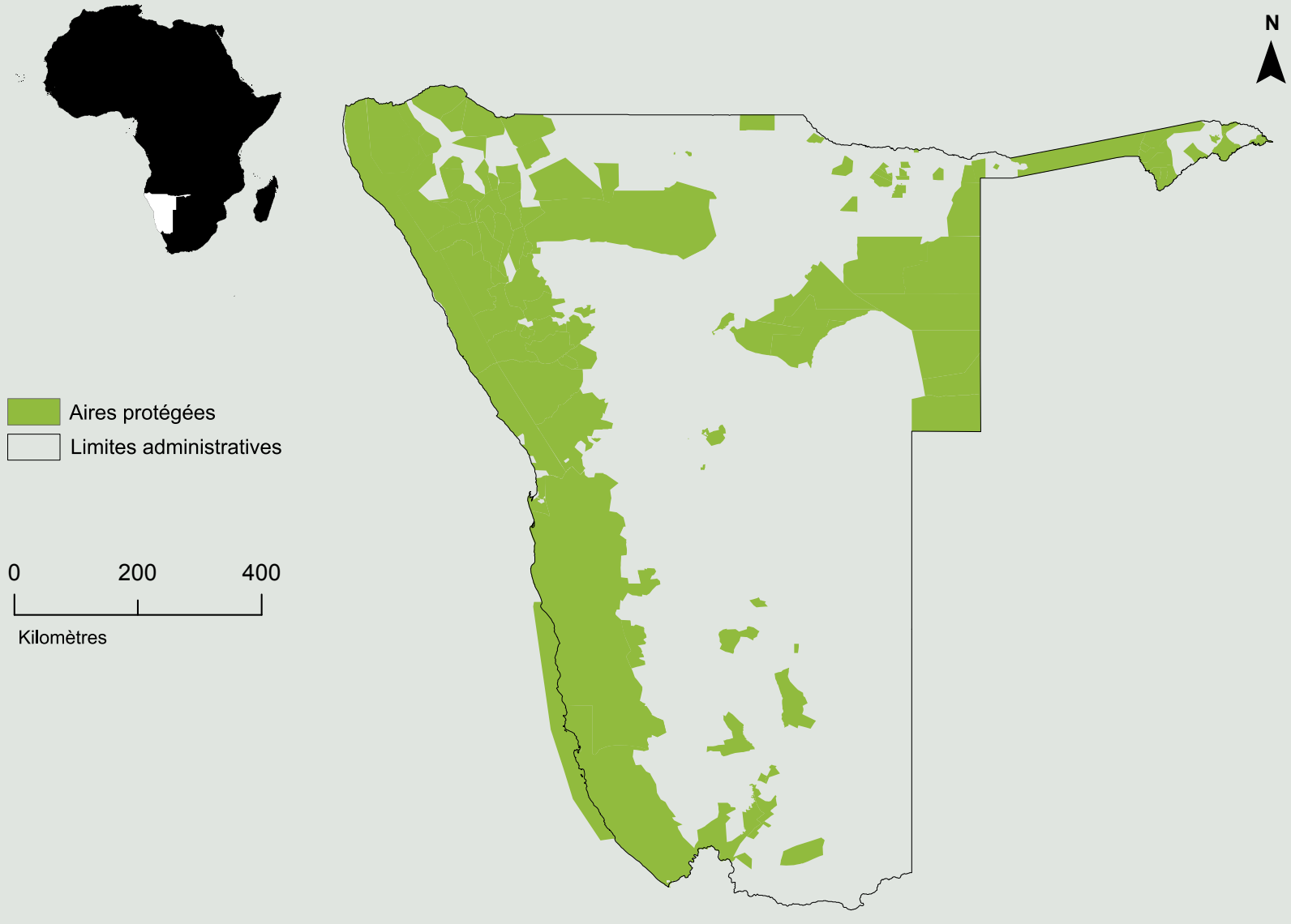

Développé par le RCMRD à partir des données BDMAP.

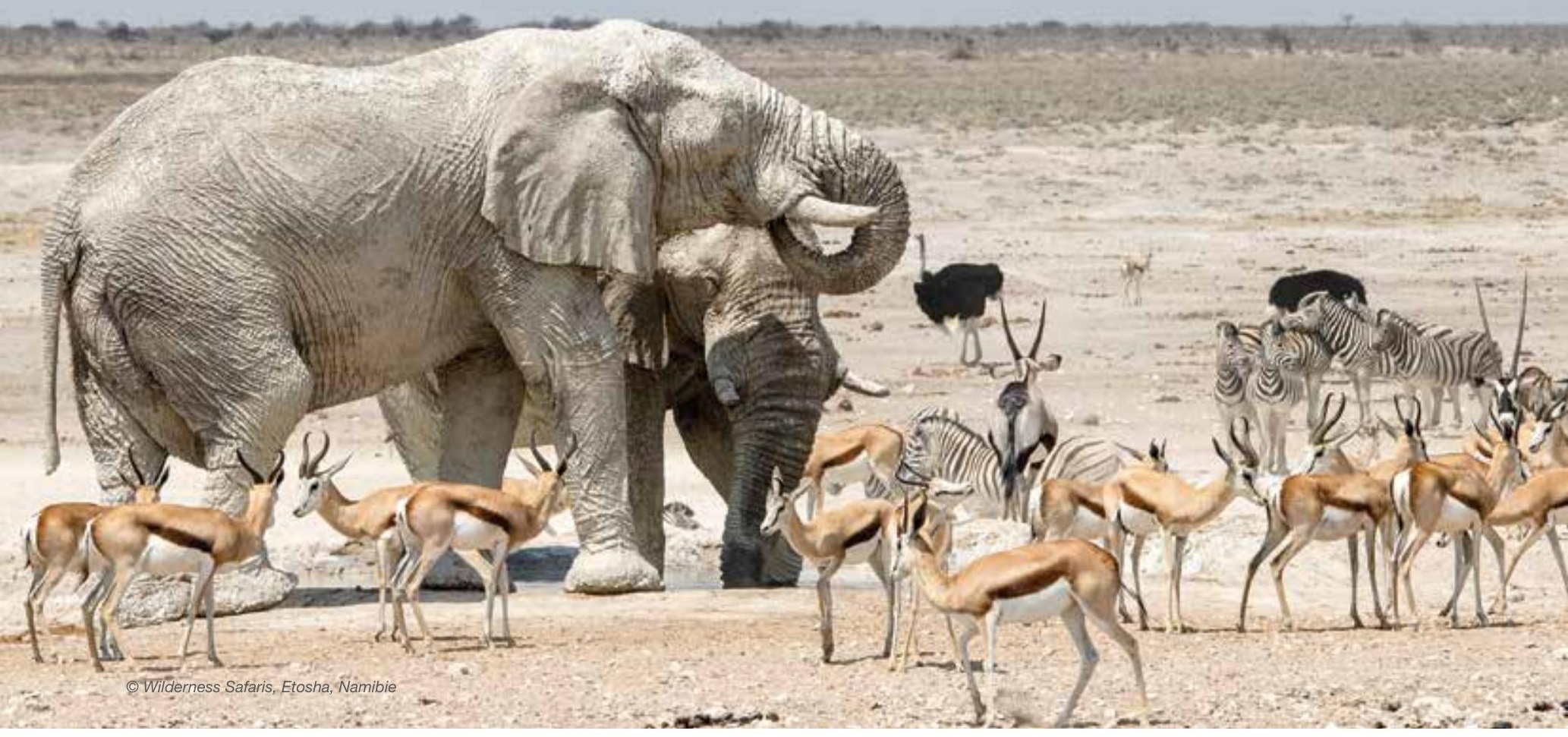




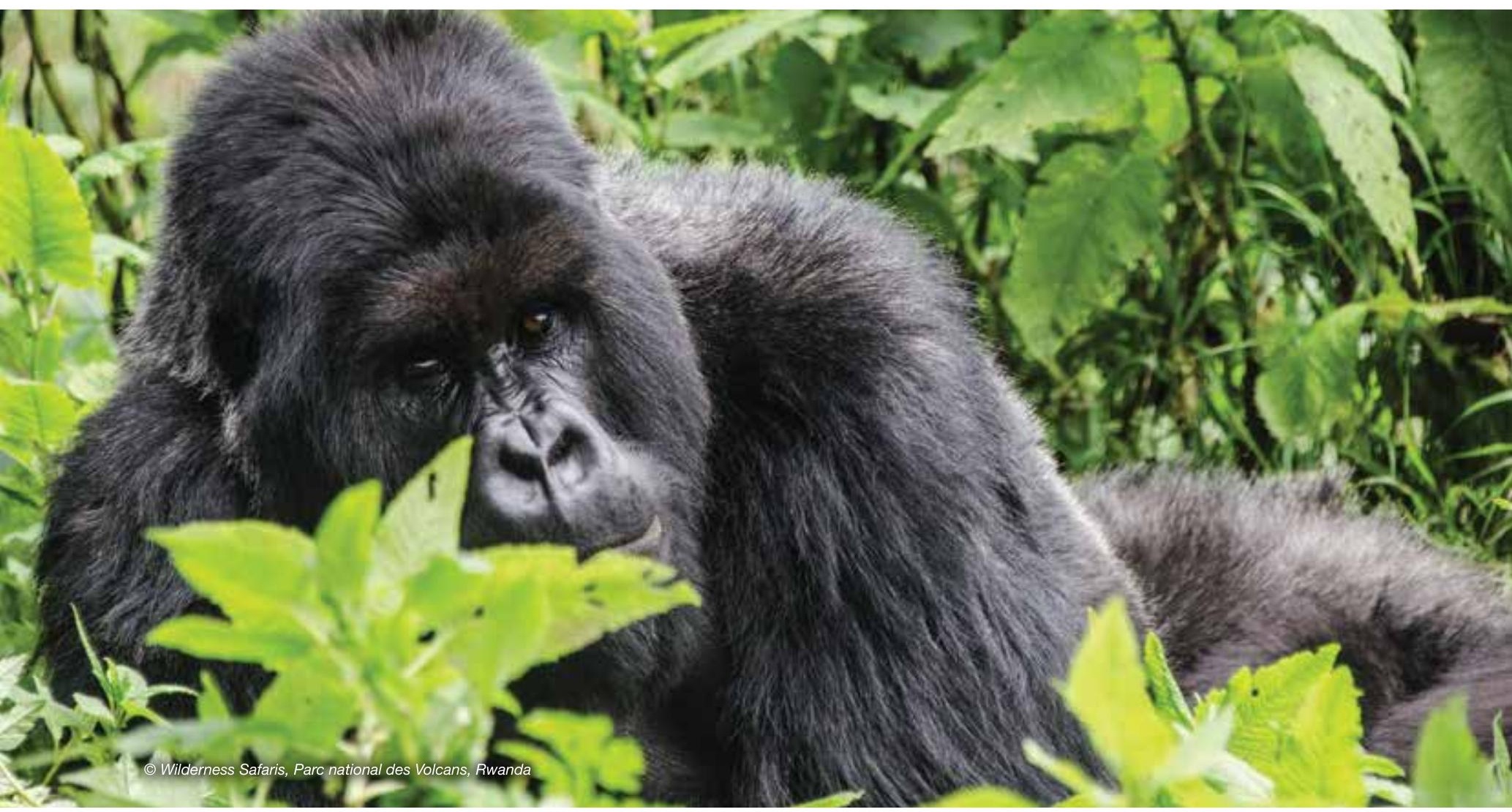

\subsection{Rwanda}

\section{Aires protégées et de conservation du Rwanda ${ }^{76}$}

Le Rwanda compte 10 aires protégées couvrant $2320 \mathrm{~km}^{2}$ d'écosystèmes terrestres (UNEP-WCMC et IUCN, 2019p).

La majorité des écorégions du pays sont sous protection, en particulier les zones humides, reconnues comme des sanctuaires d'une riche diversité biologique. Une analyse des lacunes écologiques au Rwanda a permis d'identifier de nouveaux sites à désigner comme aires protégées. Le Parc national d'Akagera est géré par un partenariat public-privé avec Parcs Africa.

\section{Aires protégées et de conservation transfrontières}

Le Rwanda comprend une partie de trois aires de conservation transfrontières, à savoir l'ACT du Grand paysage des Virunga, I'ACT de Kagera et le site de Nyungwe-Kibira.

\section{Contexte politique}

Un rapport complet sur la législation et les politiques relatives à la gestion, à la gouvernance et à l'équité des aires protégées a été réalisé par le programme BIOPAMA. II a identifié 47 lois et politiques pertinentes au Rwanda (Tessema, 2019).

\section{Espèces clées ${ }^{77}$}

La biodiversité du Rwanda est fortement menacée en raison de populations humaines élevées et des pressions qui en découlent sur les ressources naturelles. Dans les aires protégées, y compris les parcs nationaux et les forêts, la biodiversité est bien protégée et représente un ensemble diversifié d'écosystèmes. Le Rwanda abrite le gorille de montagne (Gorilla beringei beringei), dont la population, partagée avec la République Démocratique du Congo et l'Ouganda, montre une augmentation significative. Le Parc national d'Akagera a fait l'objet d'un effort de restauration intensif. La diversité des oiseaux du Rwanda est très riche, d'autant plus que le pays offre de nombreux habitats diversifiés. Les systèmes d'eau douce abritent également une diversité d'espèces de poissons, y compris certaines espèces endémiques.

\section{Pressions et menaces ${ }^{78}$}

Les menaces qui pèsent sur la biodiversité au Rwanda incluent le braconnage et autres activités illégales, les incendies, les espèces exotiques envahissantes, la déforestation, l'exploitation minière, le pâturage illégal, les barrages, la baisse des niveaux d'eau, la pêche non durable, le manque de connectivité, une utilisation non durable du tourisme et le développement d'infrastructures, ainsi que les empiétement excessifs sur les zones humides et la pollution. Le Rwanda présente une très forte densité humaine, exerçant une pression croissante sur les ressources naturelles disponibles. 
Figure 8.29 : Résumé du Rwanda

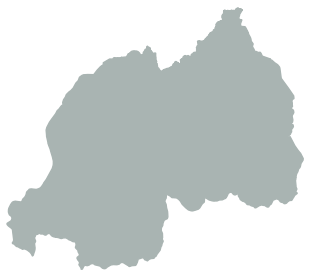

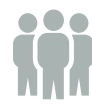

Population totale (en millions) 12,30

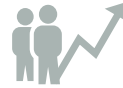

Démographie (\% annuel) 2,60

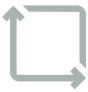

Superficie (en milliers de $\mathrm{km}^{2}$ )

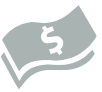

PIB (en milliards de USD actuels)

\section{$\mathbf{9 , 5 1}$}

Croissance du PIB (\% annuel)

$\mathbf{8 , 7 0}$

Source : The World Bank Group, 2018.

\section{Aires protégées :}

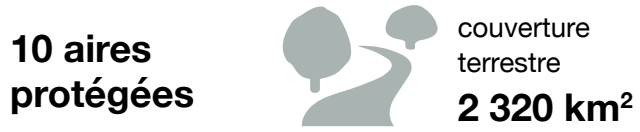

Source: UNEP-WCMC et IUCN, (2019p)
Aires protégées et de conservation du Rwanda par catégorie de gestion de I'UICN

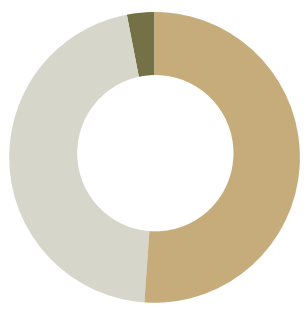

Non rapportée (2)

IV. Aire de gestion habitats / espèces (3)

II. Parc national (4)

Source : UNEP-WCMC et IUCN (2019p).

\section{Couverture des aires protégées au Rwanda}

\begin{tabular}{l|r|r}
\hline Type d'aire protégée & $\begin{array}{r}\text { Aire protégée } \\
\text { ou conservée }\end{array}$ & $\begin{array}{r}\text { Aire protégée } \\
\text { ou conservée** }\end{array}$ \\
\hline $\begin{array}{l}\text { Terrestres et eaux } \\
\text { intérieures }\end{array}$ & $9,11 \%$ & $10,10 \%$ \\
\hline${ }^{*}$ Ensemble de données de la BDMAP & ${ }^{* *}$ Rapport national sur la biodiversité
\end{tabular}

Source : Republic of Rwanda (2014); UNEP-WCMC et IUCN (2019p).

\section{Désignations nationales des aires protégées et de} conservation au Rwanda

\begin{tabular}{l|r|r}
\hline Désignation nationale & No & \multicolumn{2}{|l}{$\begin{array}{l}\text { Superficie } \\
\left(\mathbf{( k m}^{2}\right)\end{array}$} \\
\hline Autre désignation & 3 & 308 \\
\hline Parc national & 3 & 2201 \\
\hline Réserve forestière & 2 & 34 \\
\hline
\end{tabular}

Source : UNEP-WCMC et IUCN (2019p).

\section{Aires protégées et de conservation du Rwanda par} type de gouvernance de I'UICN

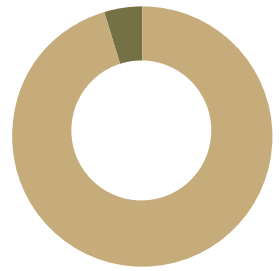

Non rapporté (7)

A.Gouvernance par le gouvernement (3)
Aires protégées et de conservation désignées comme sites d'importance mondiale au Rwanda

\begin{tabular}{l|r}
\hline Désignation mondiale & $\begin{array}{r}\text { Nombre de } \\
\text { sites }\end{array}$ \\
\hline Réserves de biosphère de l'UNESCO & 1 \\
\hline $\begin{array}{l}\text { Zones humides d'importance internationale } \\
\text { (sites Ramsar) }\end{array}$ & 1 \\
\hline
\end{tabular}

Source : Ramsar (2019); UNESCO (2019a, 2019b).

\section{Aires prioritaires pour la conservation}

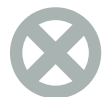

\section{2 sites}

Sites de l'Alliance pour une extinction zéro

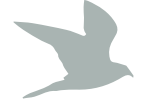

\section{7 sites}

Zones importantes pour les oiseaux et la biodiversité
14 sites

Zones clés pour la biodiversité 
Figure 8.30 : Aires protégées du Rwanda

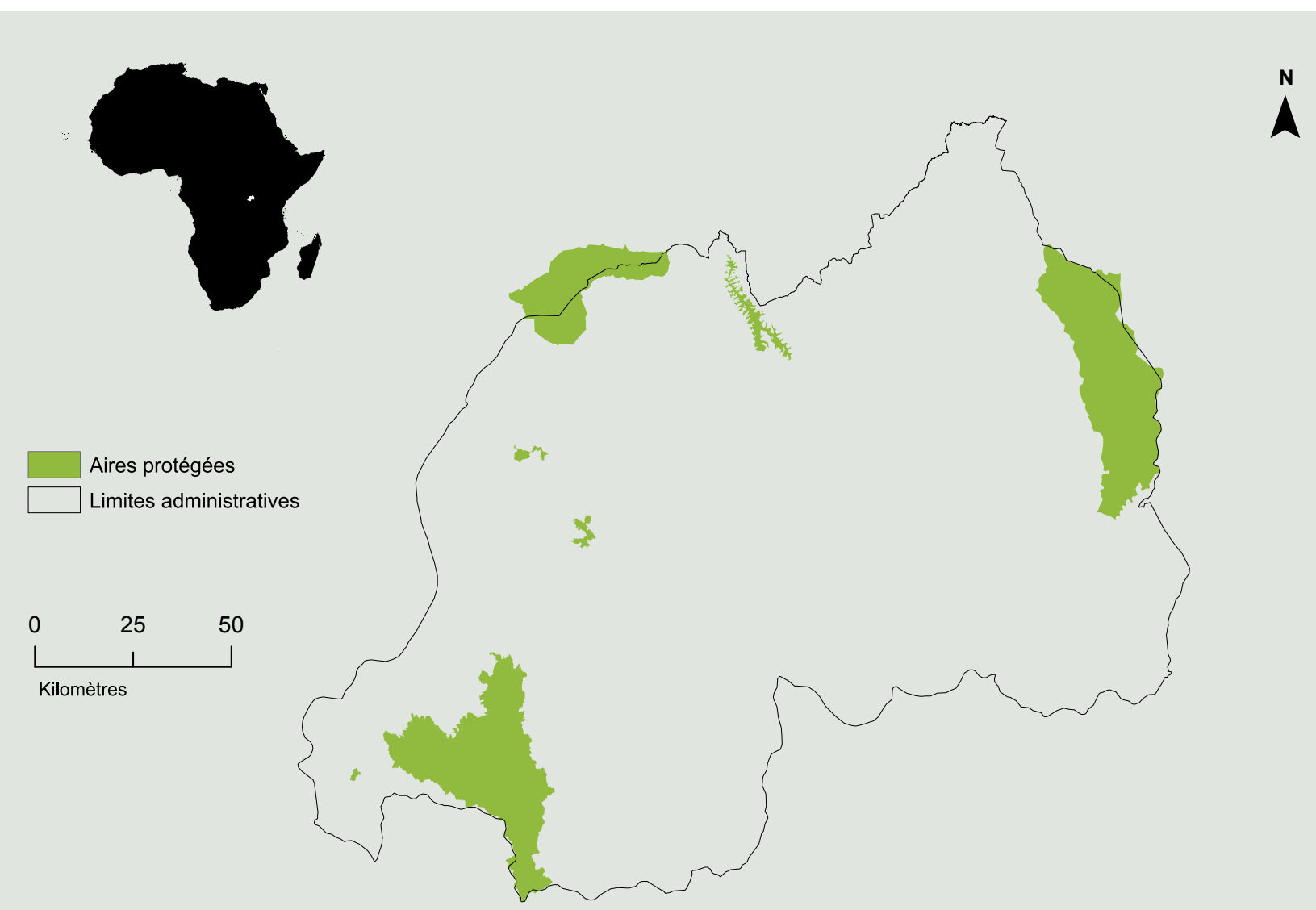

Développé par le RCMRD à partir des données BDMAP. 


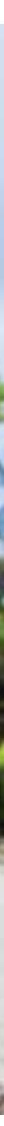

\subsection{Seychelles}

\section{Aires protégées et de conservation des Seychelles ${ }^{79}$}

Les Seychelles comptent 40 aires protégées couvrant $242 \mathrm{~km}^{2}$

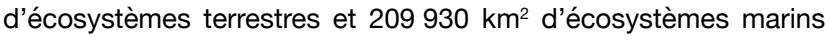
(UNEP-WCMC et IUCN, 2019q).

Une grande partie du territoire terrestre des Seychelles est protégée. Les Seychelles possèdent l'un des réseaux d'aires marines protégées les plus anciens d'Afrique de l'Est, mais jusqu'à récemment, celui-ci ne couvrait que $0,03 \%$ des écosystèmes côtiers et marins du pays. Ce retard a été pris en compte par le gouvernement des Seychelles, qui a annoncé son intention de protéger $30 \%$ de ses eaux territoriales, dont la moitié (soit 15\%) par une zone d'interdiction stricte de la pêche. Les Seychelles se sont engagées dans un mécanisme d'échange de dette afin de mener à bien cette désignation.

\section{Aires protégées et de conservation transfrontières}

Les Seychelles comprennent une partie du Parc marin transfrontalier de l'océan Indien occidental.

\section{Contexte politique}

Un rapport complet sur la législation et les politiques relatives à la gestion, à la gouvernance et à l'équité des aires protégées a été réalisé par le programme BIOPAMA. II a identifié 28 lois et politiques pertinentes aux Seychelles (Tessema, 2019).

\section{Espèces clées $^{80}$}

Les espèces marines et côtières sont économiquement importantes pour les Seychelles, et la diversité et l'abondance de ces espèces ont été influencées par les modes de récolte, au cours des deux derniers siècles. Le rapport national du pays fournit des données très détaillées sur les espèces marines et côtières, y compris les tendances actuelles et les efforts de conservation. Les Seychelles abritent un certain nombre de cétacés, ainsi que cinq espèces de tortues marines.

En termes de biodiversité terrestre et d'eau douce, la diversité fongique est mal connue, mais le pays montre des niveaux élevés de diversité chez les invertébrés, ainsi que chez les plantes. Les niveaux d'endémisme sont élevés dans la plupart des groupes. Les 11 espèces d'amphibiens et les deux serpents recensés sont tous endémiques. La tortue géante d'Aldabra (Aldabrachelys gigantea) est endémique du pays. Les Seychelles abritent au moins 65 espèces d'oiseaux, dont 13 sont endémiques. Les mammifères autochtones des Seychelles sont tous des chauves-souris, dont il existe six espèces (quatre endémiques).

\section{Pressions et menaces ${ }^{81}$}

Les incursions incessantes d'espèces exotiques envahissantes constituent la principale menace pour les écosystèmes terrestres. Avec des niveaux élevés d'endémisme, les îles sont particulièrement vulnérables aux impacts des espèces envahissantes. Les changement d'utilisation des terres et la perte d'habitats constituent la deuxième menace, les pressions liées au développement menaçant de nombreux habitats. La principale menace dans les écosystèmes marins est la surpêche, avec des impacts au-delà des espèces exploitées. Les changements climatiques représentent une menace majeure pour les écosystèmes terrestres et marins.

79 Cette section s'appuie sur les informations contenues dans le cinquième Rapport national des Seychelles à la CDB, ainsi que dans leur SPANB (Government of Seychelles, 2014b; 2014a)

80 Cette section s'appuie sur les informations contenues dans le cinquième Rapport national des Seychelles à la CDB (Government of Seychelles, 2014a)

81 Cette section s'appuie sur les informations contenues dans le deuxième SPANB des Seychelles (Government of Seychelles, 2014b) 
Figure 8.31 : Résumé des Seychelles

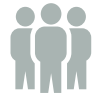

Population totale (en millions)

0,10

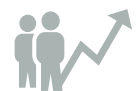

Démographie (\% annuel)

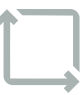

Superficie (en milliers de $\mathrm{km}^{2}$ ) 0,50

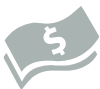

PIB (en milliards de USD actuels)

1,59

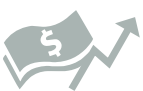

Croissance du PIB (\% annuel)

3,60

Source : The World Bank Group, 2018

\section{Aires protégées :}

\section{0 aires} protégées

\section{couverture} terrestre

\section{2 km$^{2}$}

Source: UNEP-WCMC et IUCN, $2019 q$

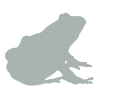

11 amphibiens

\section{5} oiseaux

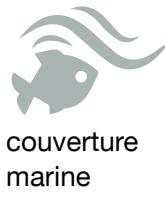

209930 km² $^{2}$
Couverture des aires protégées aux Seychelles

\begin{tabular}{l|r|r}
\hline Type d'aire protégée & $\begin{array}{r}\text { Aire protégée } \\
\text { ou conservée* }\end{array}$ & $\begin{array}{r}\text { Aire protégée } \\
\text { ou conservée }\end{array}$ \\
\hline $\begin{array}{l}\text { Terrestres et eaux } \\
\text { intérieures }\end{array}$ & $49,64 \%$ & $46,60 \%$ \\
\hline Marines et côtières & $15,66 \%$ & $0,03 \%$ \\
\hline
\end{tabular}

*Ensemble de données de la BDMAP ${ }^{* *}$ Rapport national sur la biodiversite Source : Government of Seychelles (2014a); UNEP-WCMC et IUCN (2019q).

Aires protégées et de conservation désignées comme sites d'importance mondiale aux Seychelles

\begin{tabular}{l|r}
\hline Désignation mondiale & $\begin{array}{r}\text { Nombre de } \\
\text { sites }\end{array}$ \\
\hline $\begin{array}{l}\text { Sites du Patrimoine mondial de l'UNESCO } \\
\text { (naturels ou mixtes) }\end{array}$ & 2 \\
\hline $\begin{array}{l}\text { Zones humides d'importance internationale } \\
\text { (sites Ramsar) }\end{array}$ & 4 \\
\hline
\end{tabular}

Source : Ramsar (2019) ; UNESCO (2019a, 2019b).

Aires protégées et de conservation des Seychelles par type de gouvernance de l'UICN

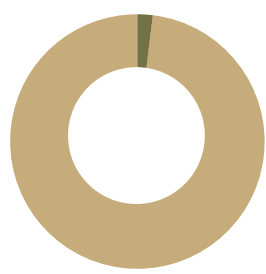

Non rapporté (20)

A.Gouvernance par le gouvernement (20)
Aires protégées et de conservation des Seychelles par catégorie de gestion de l'UICN

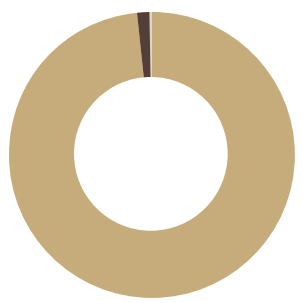

Ne s'applique pas (2)

Non rapportée (18)

VI. Aire protégée avec utilisation durable des ressources naturelles (6)

II. Parc national (8)

lb. Aire de nature sauvage (1)

la. Réserve naturelle intégrale (5)

Source : UNEP-WCMC et IUCN (2019q).

Désignations nationales des aires protégées et de conservation aux Seychelles

\begin{tabular}{l|r|r}
\hline Désignation nationale & Nombre & $\begin{array}{r}\text { Superficie } \\
\left(\mathbf{k m} \mathbf{2}^{\mathbf{2}}\right.\end{array}$ \\
\hline Parc national & 4 & 55 \\
\hline Réserve spéciale & 8 & 2436 \\
\hline Parc national marin & 6 & 48 \\
\hline Réserve naturelle & 9 & 0 \\
\hline $\begin{array}{l}\text { Zone marine de protection } \\
\text { spéciale 2 }\end{array}$ & 1 & 136717 \\
\hline $\begin{array}{l}\text { Zone marine de protection } \\
\text { spéciale 1 }\end{array}$ & 1 & 69524 \\
\hline Réserve de coquillages & 4 & 8 \\
\hline Aire protégée & 1 & 8 \\
\hline Source : UNEP-WCMC et IUCN (2019q). & &
\end{tabular}

\section{Aires prioritaires pour la conservation}
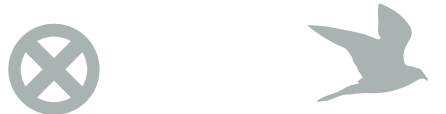

\section{2 sites}

Sites de l'Alliance pour une extinction zéro
20 sites

Zones importantes pour les oiseaux et la biodiversité

\section{9 sites}

Zones clés pour la biodiversité

Source : UNEP-WCMC et IUCN (2019q). 


\section{Figure 8.32 : Aires protégées des Seychelles}

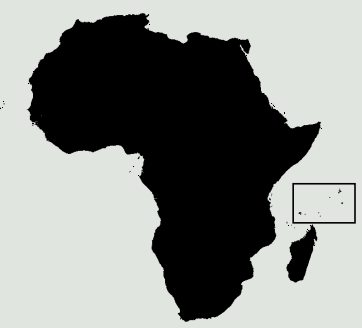

\section{Aires protégées}

Limites administratives
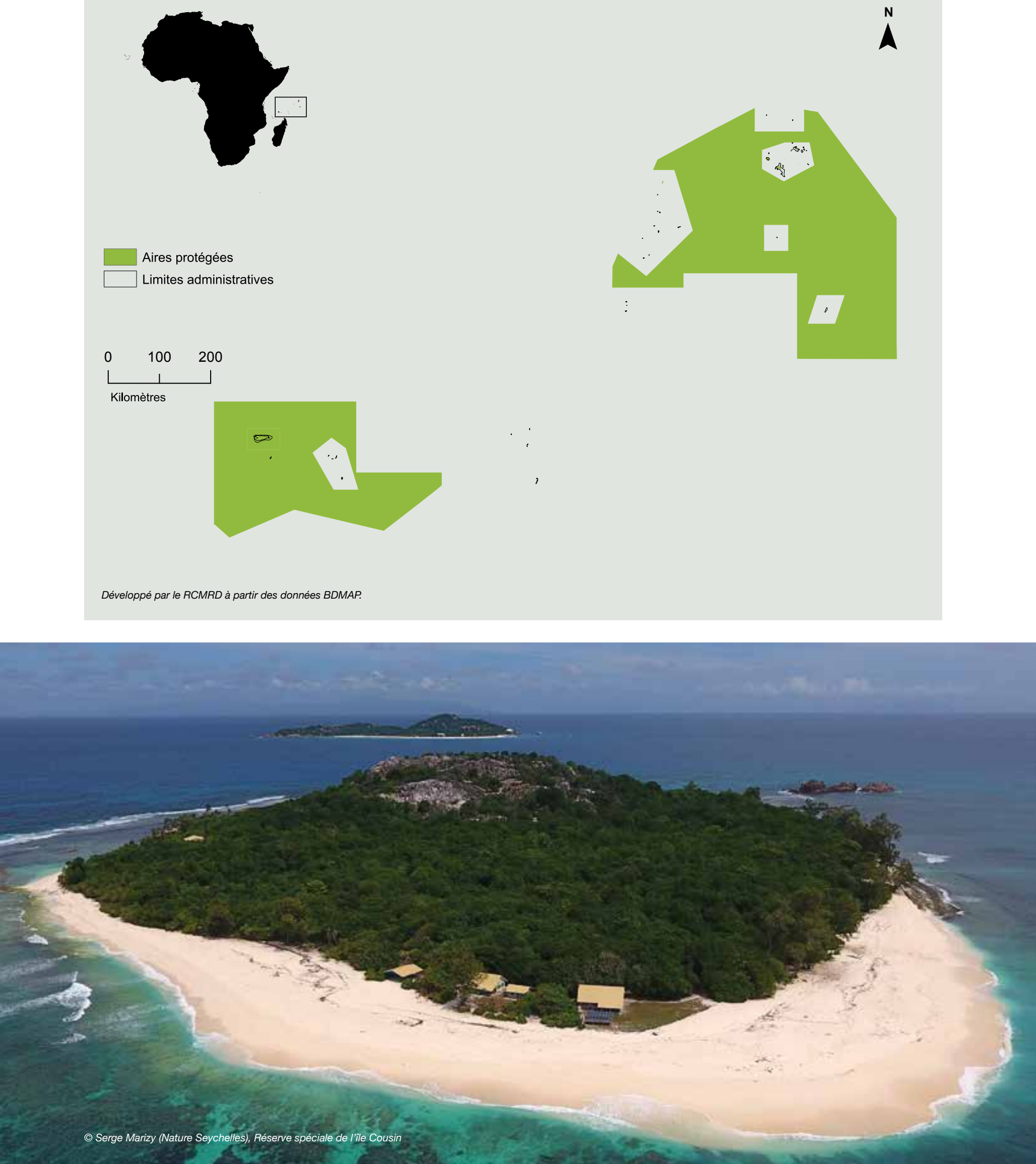


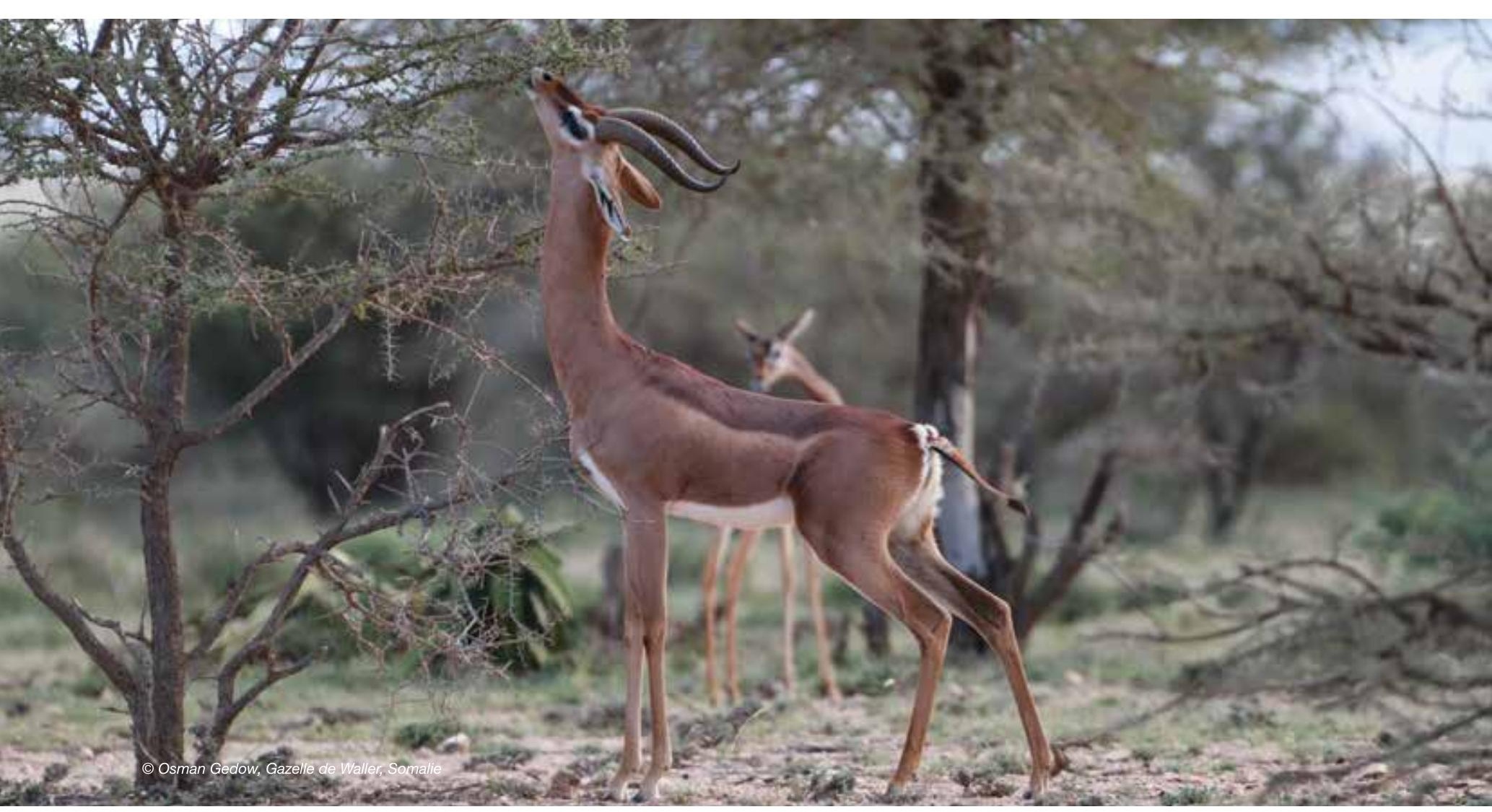

\subsection{Somalie}

\section{Aires protégées et de conservation de Somalie ${ }^{82}$}

La Somalie compte 21 aires protégées. Celles-ci ont été rapportées sous forme de points, sans aucune superficie. II n'est donc pas possible de déterminer la couverture de ces aires protégées (UNEP-WCMC et IUCN, 2019r). Aucune gestion efficace des ressources de biodiversité et aucune protection formelle des aires protégées a eu lieu depuis l'effondrement du gouvernement central en 1991. La préoccupation la plus grave est l'absence de législation efficace concernant la gestion des aires protégées et l'absence d'une infrastructure de conservation fonctionnelle. Onze réserves fauniques ont été déclarées depuis les années 1970, mais seulement deux sont considérées comme fonctionnelles. Dans la pratique, aucun de ces sites n'est officiellement protégé depuis le début des années 1990.

Dans le milieu marin, quatre aires marines protégées ont été proposées: l'île de Saad-ad-din et Aibat, dans l'ouest du Somaliland, près de Zeila, une ville historique, l'île de Maydh, dans le Puntland, et la forêt voisine de Daalo sur le continent, et le site de Gara'ad sur la côte de l'océan Indien, dans le Puntland. Cette dernière a été déclarée AMP en 2005 par l'association locale des pêcheurs GARFISH. Les îles Saad-ad-Din et Maydh sont d'importantes sites de reproduction pour les oiseaux de mer. Les récifs coralliens de l'île de Saad-ad-Din représentent les récifs les plus divers et les mieux formés de la côte du golfe d'Aden.

\section{Aires protégées et de conservation transfrontières}

La Somalie comprend une partie de l'aire de conservation transfrontière du Paysage terrestre et marin de Tana-Kipini-Laga Badana Bushbush.

\section{Contexte politique}

Un rapport complet sur la législation et les politiques relatives à la gestion, à la gouvernance et à l'équité des aires protégées a été réalisé par le programme BIOPAMA. II a identifié 10 lois et politiques pertinentes en Somalie (Tessema, 2019).

\section{Espèces clées $^{83}$}

Les niveaux d'endémisme sont élevés dans la Corne de l'Afrique, dont la Somalie fait partie. II n'existe que peu d'études sur la diversité d'espèces en Somalie, mais on pense que le pays abrite plus de 175 espèces de mammifères et 671 espèces d'oiseaux. Plus de 3000 espèces végétales ont été recensées, dont 836 seraient endémiques du pays. La Somalie abrite 230 espèces de reptiles, dont $80 \%$ sont endémiques, ainsi que 29 espèces d'amphibiens. De nombreuses autres espèces du Somaliland n'ont pas encore été rapportées.

La connaissance des espèces marines et côtières est faible, bien que celles-ci sous-tendent de nombreuses activités économiques le long du littoral.

2 Cette section s'appuie sur les informations contenues dans le sixième Rapport national de la Somalie à la CDB (The Somali Republic, 2019).

83 Cette section s'appuie sur les informations contenues dans le cinquième Rapport national de la Somalie à la CDB (Federal Republic of Somalia, 2014). 
Figure 8.33 : Résumé de la Somalie

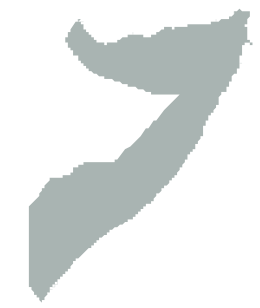

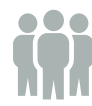

Population totale (en millions)

15,01

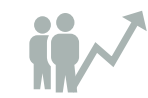

Démographie (\% annuel) 2,80

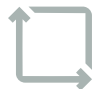

Superficie (en milliers de $\mathrm{km}^{2}$ ) 637,70

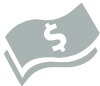

PIB (en milliards de USD actuels)

4,72
Croissance du PIB (\% annuel)

Source : The World Bank Group, 2018.

Aires protégées :

Source : UNEP-WCMC et IUCN, 2019r
21 aires protégées
Aires protégées et de conservation de Somalie par catégorie de gestion de l'UICN

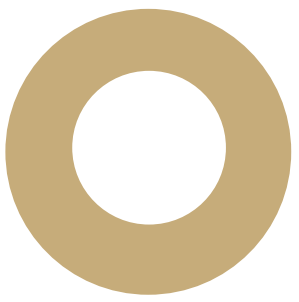

Non rapportée (21)

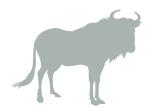

175 espèces de mammifères

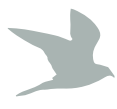

671 espèces d'oiseaux
29 espèces d'amphibiens végétales

\section{Couverture des aires protégées en Somalie}

\begin{tabular}{l|r|r}
\hline Type d'aire protégée & $\begin{array}{r}\text { Aire protégée } \\
\text { ou conservée* }\end{array}$ & $\begin{array}{r}\text { Aire protégée } \\
\text { ou conservée }\end{array}$ \\
\hline $\begin{array}{l}\text { Terrestres et eaux } \\
\text { intérieures }\end{array}$ & $0,00 \%$ & $0,80 \%$ \\
\hline Marines et côtières & $0,00 \%$ & $\begin{array}{r}\text { Aucune } \\
\text { correspondance }\end{array}$ \\
\hline
\end{tabular}

"Ensemble de données de la BDMAP ** Rapport national sur la biodiversité Source : Federal Republic of Somalia (2014); UNEP-WCMC et IUCN (2019r).

Aires protégées et de conservation de Somalie par type de gouvernance de I'UICN

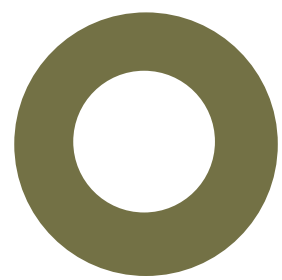

Gouvernance par le gouvernement (21)

Source : UNEP-WCMC et IUCN (2019r).
Désignations nationales des aires protégées et de conservation en Somalie

\begin{tabular}{l|r}
\hline Désignation nationale & Nombre \\
\hline Parc national & 12 \\
\hline Réserve de faune sauvage & 9 \\
\hline Source : UNEP-WCMC et IUCN (2019r).
\end{tabular}

\section{Aires prioritaires pour la conservation}

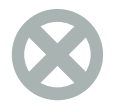

\section{2 sites}

Sites de l'Alliance pour une extinction zéro

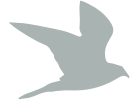

\section{2 sites}

Zones importantes pour les oiseaux et la biodiversité

\section{2 sites}

Zones clés pour la biodiversité

Source : AZE Secretariat (2019) ; BirdLife International (2019b, 2019c). 


\section{Figure 8.34 : Aires protégées de Somalie}

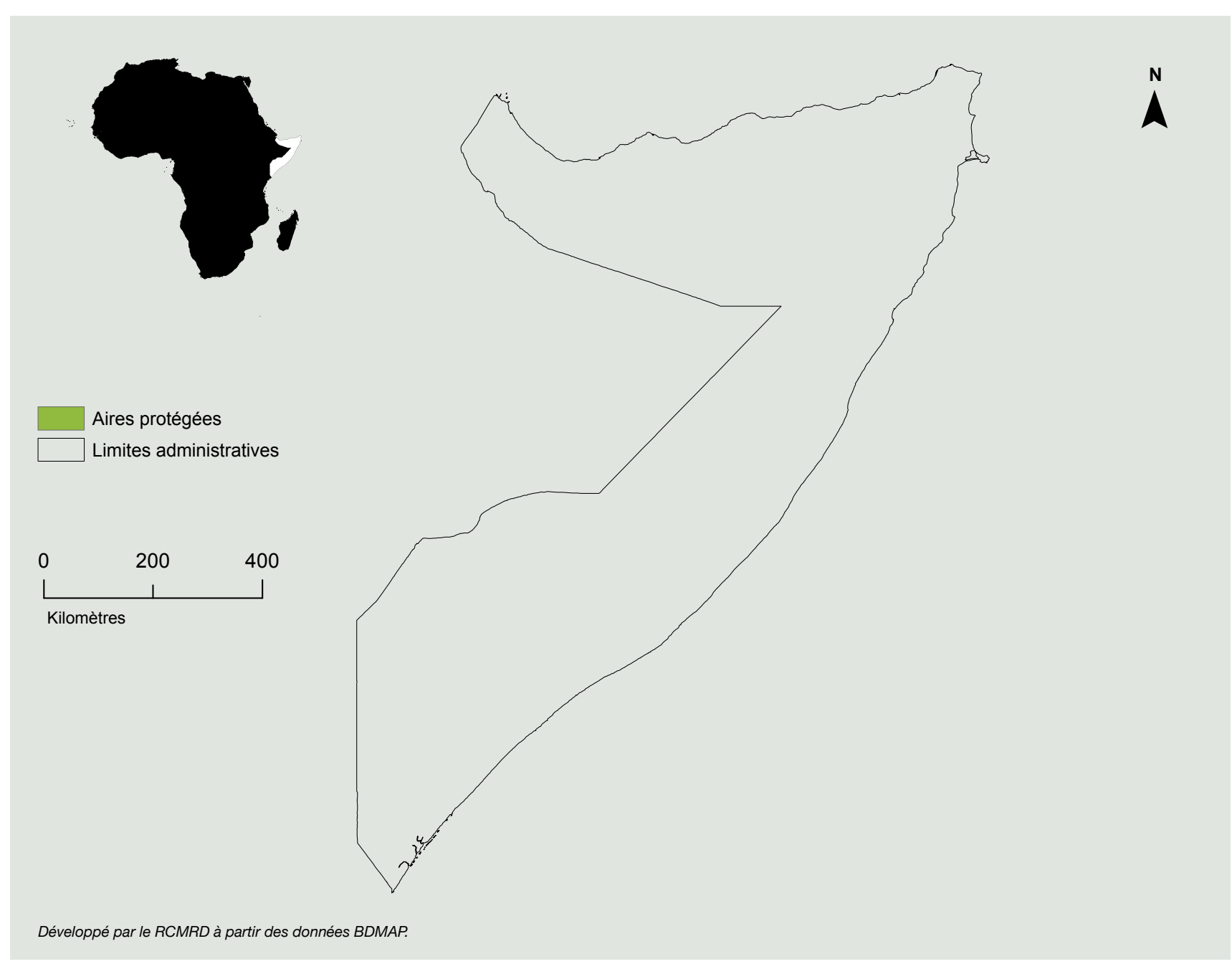

\section{Pressions et menaces ${ }^{84}$}

Les menaces critiques pour la biodiversité de la Somalie incluent la perte et la dégradation des habitats, la déforestation, la pauvreté, la pollution, les pressions politiques, les changements climatiques, la conversion des forêts pour l'agriculture et l'urbanisation, l'exploitation non durable et les espèces exotiques envahissantes. Ces menaces sont renforcées par des facteurs indirects, tels que la pauvreté, l'insécurité et les conflits civils, ainsi que par le manque de capacités institutionnelles pour la conservation. 


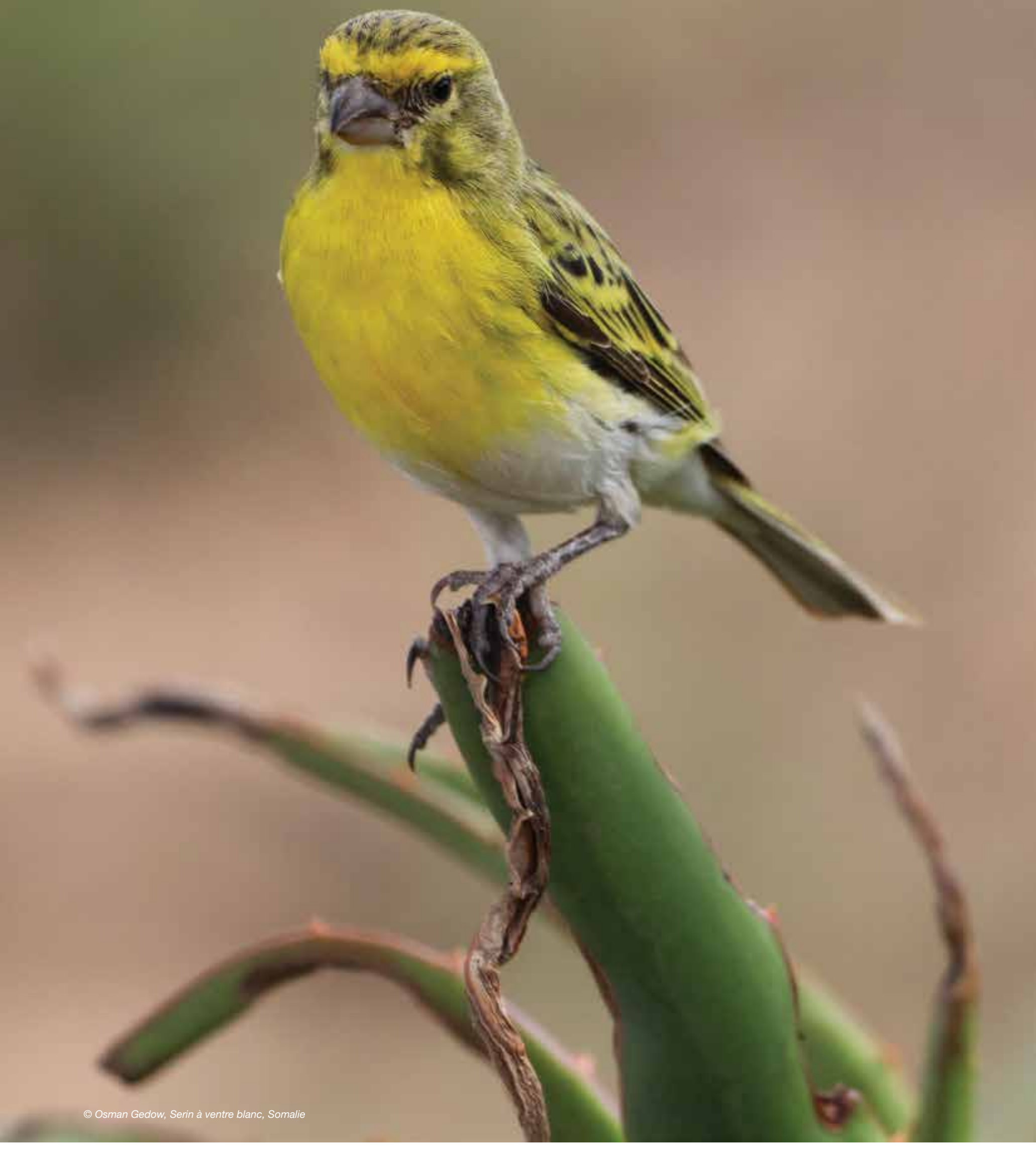




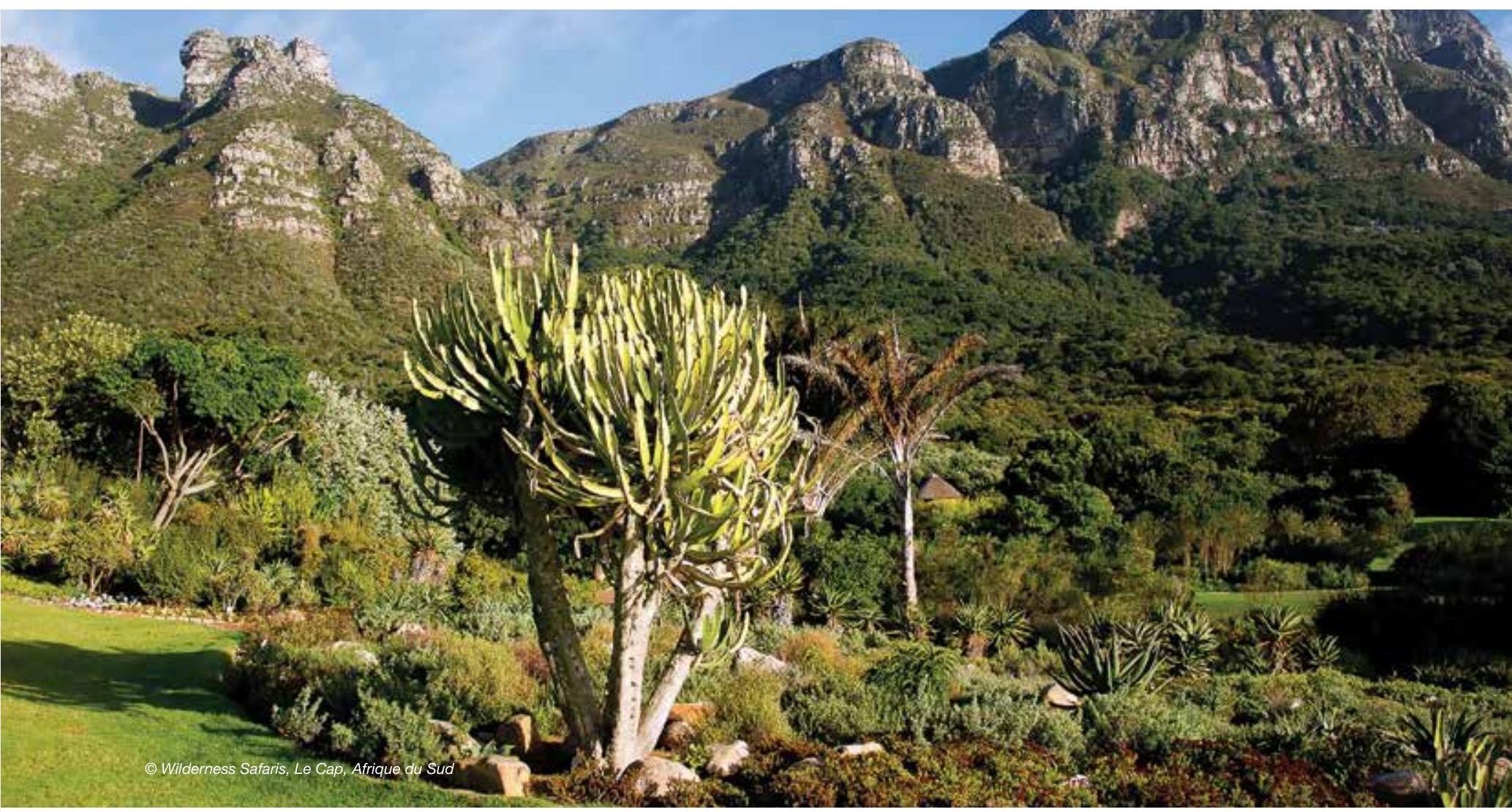

\subsection{Afrique du Sud}

\section{Aires protégées et de conservation d'Afrique du Sud $^{85}$}

L'Afrique du Sud compte 1580 aires protégées couvrant 102060 $\mathrm{km}^{2}$ d'écosystèmes terrestres et $224640 \mathrm{~km}^{2}$ d'écosystèmes marins (UNEP-WCMC et IUCN, 2019s).

En octobre 2018, le gouvernement sud-africain a approuvé la déclaration de 18 nouveaux sites, renforçant ainsi son réseau d'aires protégées. II existe neuf autorités provinciales de conservation en plus de l'Agence des parcs nationaux d'Afrique du Sud, qui gèrent les aires protégées et supervisent la conservation de la diversité végétale en dehors des réserves.

Les niveaux de protection ne sont pas uniformes dans les neuf biomes d'Afrique du Sud, certains (désert, forêt et fynbos) bénéficiant d'une protection sur plus de $17 \%$ de leur superficie, tandis que les six autres se situent à un niveau de protection beaucoup plus faible. Les biomes de prairies et du NamaKaroo, dont moins de $5 \%$ sont protégés, sont particulièrement préoccupants.

En ce qui concerne l'environnement marin, les AMP situées sur le littoral de l'Afrique du Sud couvrent environ $0,4 \%$ de la zone marine du pays. II existe également une grande AMP extracôtière autour de la Zone économique exclusive des îles du Prince-Édouard. Au total, l'espace côtier et marin protégé est supérieur à $10 \%$.

\section{Aires protégées et de conservation transfrontières}

L'Afrique du Sud comprend une partie de six aires de conservation transfrontières, à savoir l'ACT /Ai/Ais-Richtersveld, le Parc transfrontalier et aire de conservation du Grand Limpopo, l'ACT du Grand Mapungubwe, le Parc transfrontalier de Kgalagadi, l'ACT de Lubombo et I'ACT Maloti Drakensberg, ce dernier également un site transfrontalier du Patrimoine mondial.

\section{Contexte politique}

Un rapport complet sur la législation et les politiques relatives à la gestion, à la gouvernance et à l'équité des aires protégées a été réalisé par le programme BIOPAMA. II a identifié 158 lois et politiques pertinentes en Afrique du Sud (Tessema, 2019).

\section{Espèces clées $^{86}$}

L'Afrique du sud est considérée comme l'un des pays les plus biologiquement divers au monde. Elle présente un taux élevé d'endémisme et des écosystèmes divers. Bien qu'elle n'occupe que $2 \%$ de la surface terrestre mondiale, l'Afrique du Sud abrite plus de 95000 espèces, contribuant pour une part importante aux espèces végétales mondiales (6\%), aux espèces de reptiles $(5 \%)$, aux espèces d'oiseaux (8\%) et aux espèces de mammifères $(6 \%)$, de nouvelles espèces étant régulièrement découvertes et décrites. En outre, elle abrite environ $15 \%$ des espèces marines du monde. Les taux d'endémisme atteignent $56 \%$ pour les amphibiens, $65 \%$ pour les plantes, $49 \%$ pour les poissons d'eau douce, $48 \%$ pour les reptiles, $36 \%$ pour les daurades et jusqu'à $70 \%$ pour les invertébrés.

85 Cette section s'appuie sur les informations contenues dans le sixième Rapport national de l'Afrique du Sud à la CDB (Republic of South Africa, 2019).

86 Cette section s'appuie sur les informations contenues dans les cinquième et sixième Rapports nationaux de l'Afrique du Sud à la CDB (Republic of South Africa, 2014; 2019). 
Figure 8.35 : Résumé de l'Afrique du Sud

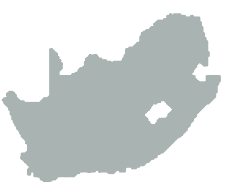

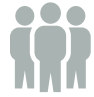

Population totale (en millions)

57,78

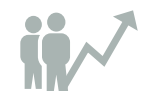

Démographie (\% annuel)

1,40

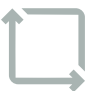

Superficie (en milliers de $\mathrm{km}^{2}$ )

1219,10

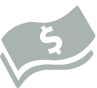

PIB (en milliards de USD actuels)

368,29
Croissance du PIB (\% annuel)

0,80

Source : The World Bank Group, 2018.

Aires protégées :

\section{0 aires protégées}

couverture terrestre couverture marine

$102060 \mathrm{~km}^{2} \quad 224640 \mathrm{~km}^{2}$

Source : UNEP-WCMC et IUCN, 2019

\section{L'un des pays les plus biologiquement divers au monde}

Aires protégées et de conservation d'Afrique du Sud par catégorie de gestion de l'UICN

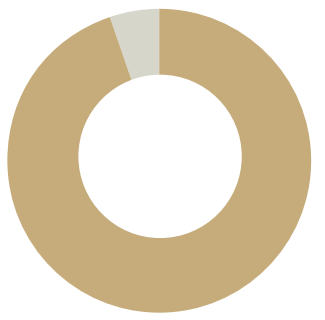

Ne s'applique pas (13)

Non rapportée (1567)

Source : UNEP-WCMC et IUCN (2019s).

Couverture des aires protégées en Afrique du Sud

\begin{tabular}{l|r|r}
\hline Type d'aire protégée & $\begin{array}{r}\text { Aire protégée } \\
\text { ou conservée* }\end{array}$ & $\begin{array}{r}\text { Aire protégée } \\
\text { ou conservée }\end{array}$ \\
\hline $\begin{array}{l}\text { Terrestres et eaux } \\
\text { intérieures }\end{array}$ & $8,34 \%$ & $12,96 \%$ \\
\hline Marines et côtières & $14,56 \%$ & $10,00 \%$ \\
\hline
\end{tabular}

*Ensemble de données de la BDMAP $\quad{ }^{* *}$ Rapport national sur la biodiversité Source : Republic of South Africa (2019); UNEP-WCMC et IUCN (2019s.)

Aires protégées et de conservation désignées comme sites d'importance mondiale en Afrique du Sud

\begin{tabular}{l|r}
\hline Désignation mondiale & $\begin{array}{r}\text { Nombre de } \\
\text { sites }\end{array}$ \\
\hline Réserves de biosphère de l'UNESCO & 10 \\
\hline $\begin{array}{l}\text { Patrimoine Mondial de l'UNESCO } \\
\text { (naturel ou mixte) }\end{array}$ & 5 \\
\hline $\begin{array}{l}\text { Zones humides d'importance internationale } \\
\text { (sites Ramsar) }\end{array}$ & 23 \\
\hline
\end{tabular}

Source : Ramsar (2019) ; UNESCO (2019a, 2019b).

Aires protégées et de conservation d'Afrique du Sud par type de gouvernance de l'UICN

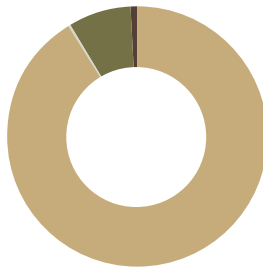

Non rapporté (2)

C. Gouvernance privée (932)

B. Gouvernance partagée (1)

A.Gouvernance par le gouvernement (645)

Désignations nationales des aires protégées et de conservation en Afrique du Sud

\begin{tabular}{l|r|r}
\hline Désignation nationale & $\mathbf{N}^{\circ}$ & $\begin{array}{r}\text { Superficie } \\
\left(\mathbf{k m}^{2}\right)\end{array}$ \\
\hline Parc national & 21 & 39781 \\
\hline $\begin{array}{l}\text { Aire forestière pour la faune } \\
\text { sauvage }\end{array}$ & 12 & 2745 \\
\hline Réserve naturelle forestière & 53 & 1732 \\
\hline Réserve naturelle spéciale & 2 & 336 \\
\hline Réserve naturelle & 1371 & 38719 \\
\hline Environnement protégé & 30 & 7436 \\
\hline Bassin versant de montagne & 16 & 6246 \\
\hline Aire marine protégée & 39 & 224682 \\
\hline Source : UNEP-WCMC et IUCN (2019s). & &
\end{tabular}

Aires prioritaires pour la conservation

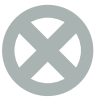

10 sites

Sites de l'Alliance pour une extinction zéro

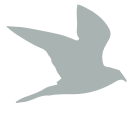

\section{9 sites}

Zones importantes pour les oiseaux et la biodiversité

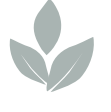

\section{6 sites}

Zones clés pour la biodiversité

Source : AZE Secretariat (2019) ; BirdLife International (2019b, 2019c).

Source : UNEP-WCMC et IUCN (2019s). 
Figure 8.36 : Aires protégées d'Afrique du Sud

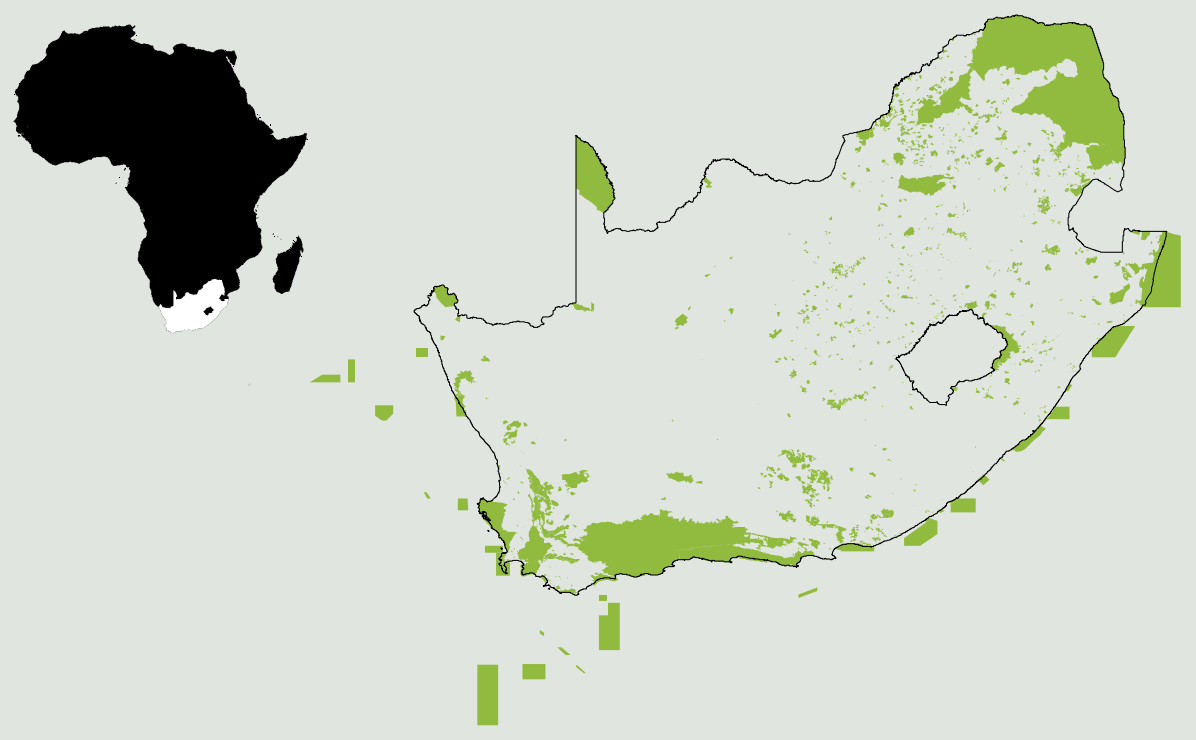

Aires protégées

Limites administratives

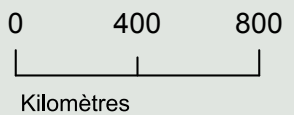

Développé par le RCMRD à partir des données BDMAP.

\section{Pressions et menaces ${ }^{87}$}

Les principales pressions sur la biodiversité de l'Afrique du Sud incluent la perte et la dégradation des habitats naturels dans les écosystèmes terrestres, d'eau douce, estuariens et marins en raison de pratiques d'utilisation non durables des terres, d'utilisations inappropriées ou mal localisées des terres, les espèces exotiques envahissantes (végétales et animales), la destruction et la surexploitation d'espèces, en particulier dans le milieu marin, le trafic illégal d'espèces sauvages et autres utilisations illégales des ressources, la surexploitation de l'eau et la pollution des écosystèmes aquatiques, la perturbation des moteurs naturels du fonctionnement des écosystèmes (tels que les cycles d'incendies) et les impacts induits par les changements climatiques. 


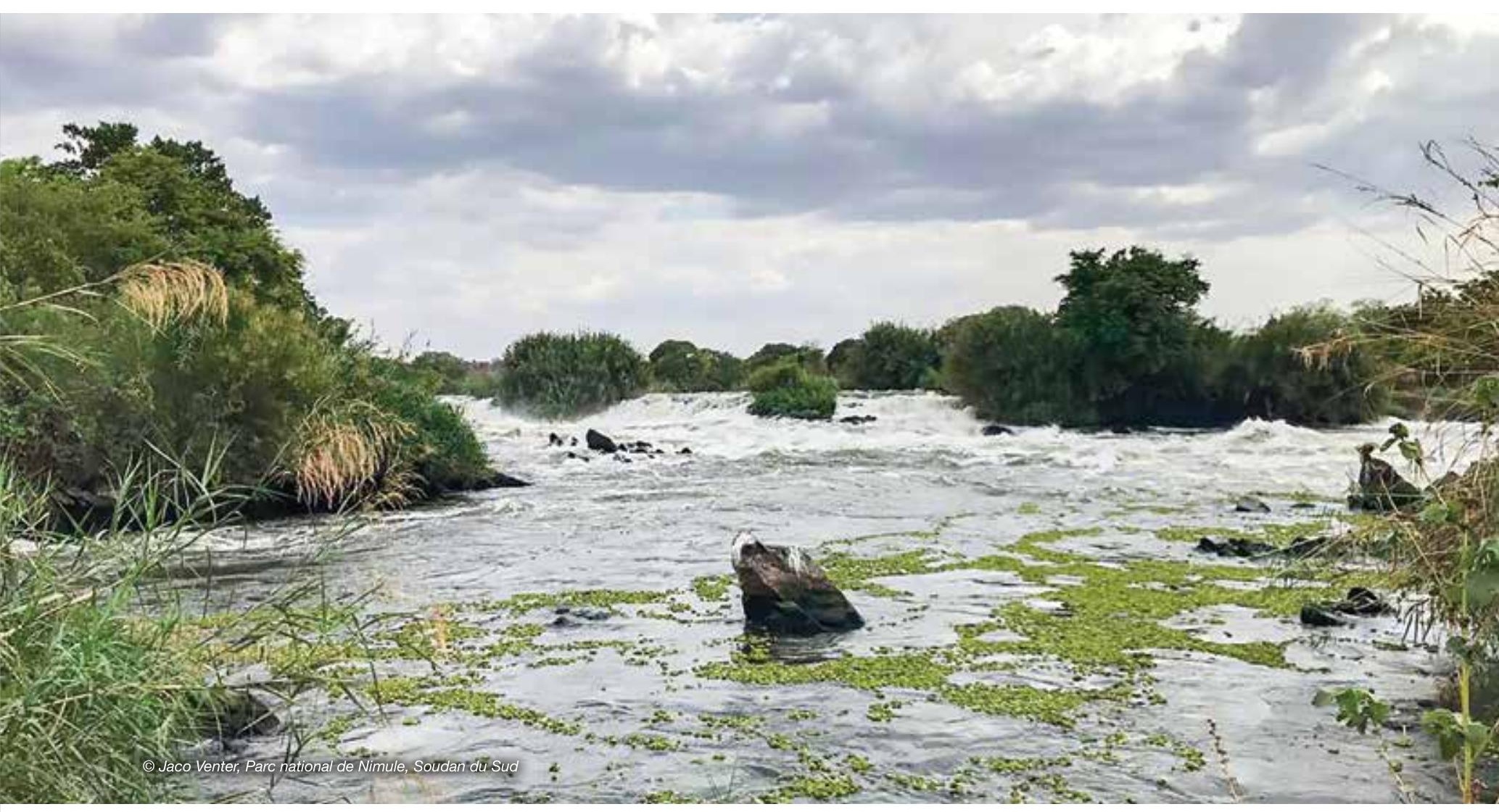

\subsection{Soudan du Sud}

\section{Aires protégées et de conservation du Soudan du Sud ${ }^{88}$}

Le Soudan du Sud compte 27 aires protégées couvrant $98214 \mathrm{~km}^{2}$ d'écosystèmes terrestres (UNEP-WCMC et IUCN, 2019t).

Plusieurs sites ont été proposées pour être désignés comme aires protégées, ce qui contribuerait à dépasser l'Objectif d'Aichi 11 . Malgré une large couverture d'aires protégées, la plupart des sites souffrent d'un manque de gestion active ou adéquate. Les limites non-clairement définies de plusieurs aires protégées constituent un défi majeur, limitant l'efficacité des contrôles. En outre, un manque de clarté semble exister dans le secteur forestier quant à qui, aux différents niveaux de gestion, est propriétaire de quelle ressource forestière.

En raison de nombreuses années de conflit ayant entravé les actions sur le terrain, les aires protégées doivent être réévaluées afin de s'assurer qu'elles soient toujours représentatives et écologiquement pertinentes.

\section{Aires protégées et de consevation transfrontières}

Le Soudan du Sud comprend une partie de quatre aires de conservation transfrontières : le Parc national de Boma-Gambella avec l'Éthiopie, la Réserve de gibier de Kidepo-Valée de Kidepo avec I'Ouganda, Lantoto-Garamba avec le Congo et le Parc national de Nimule-Réserve de faune sauvage d'Otze avec l'Ouganda.

\section{Contexte politique}

Un rapport complet sur la législation et les politiques relatives à la gestion, à la gouvernance et à l'équité des aires protégées a été réalisé par le programme BIOPAMA. II a identifié huit lois et politiques pertinentes au Soudan du Sud (Tessema, 2019).

\section{Espèces clées $^{89}$}

Le Soudan du Sud possède un large éventail d'habitats supportant une riche diversité animale et végétale. II est le théâtre de l'une des plus grandes migrations au monde, impliquant des cobes de Buffon (Kobus kob leucotis), des sassabis (Damaliscus lunatus tiang), des gazelles Mongalla (Eudorcas albonotata) et des cobes des roseaux (Redunca redunca). Le pays constitue un bastion pour le bec-en-sabot du Nil (Balaeniceps rex), en danger, ainsi que pour la grue couronnée (Balearica pavonina).

Le Soudan du sud compte également de nombreuses espèces de reptiles, de poissons d'eau douce et de plantes, y compris de nombreuses espèces endémiques.

\section{Pressions et menaces ${ }^{90}$}

Les menaces directes à la biodiversité du Soudan du Sud incluent le braconnage et le trafic d'espèces sauvages, la déforestation due à la production de charbon de bois et à l'exploitation illégale des feuillus, l'expansion de l'élevage et de l'agriculture, la fragmentation des habitats, notamment à cause des industries extractives, ainsi que les conflits homme-faune. 
Figure 8.37 : Résumé du Soudan du Sud

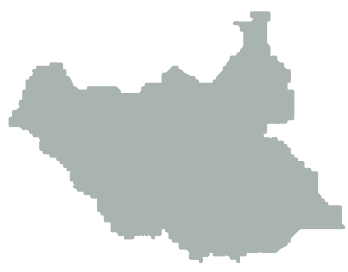

Source : The World Bank Group, 2018

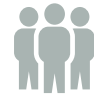

Population totale (en millions)

10,98

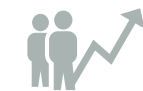

Démographie (\% annuel)

0,60

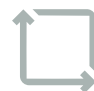

Superficie (en milliers de $\mathrm{km}^{2}$ )

1882,00

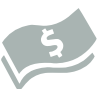

PIB (en milliards de USD actuels)

3,07
Croissance du PIB (\% annuel)

$-11,2$

\section{Aires protégées :}

\section{7 aires protégées}

couverture terrestre 98214 km $^{2}$

Source : UNEP-WCMC et IUCN (2019t)

Aires protégées et de conservation du Soudan du Sud par catégorie de gestion de l'UICN

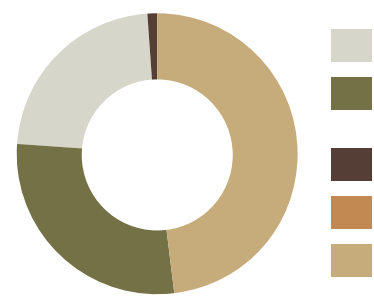

Non rapportée (1)

VI. Aire protégée avec utilisation durable des ressources naturelles (13)

V. Paysage terrestre / marin protégé (1)

IV. Aire de gestion habitats / espèces (3)

II. Parc national (9)
Couverture des aires protégées au Soudan du Sud

\begin{tabular}{l|r|r}
\hline Type d'aire protégée & $\begin{array}{r}\text { Aire protégée } \\
\text { ou conservée* }\end{array}$ & $\begin{array}{r}\text { Aire protégée } \\
\text { ou conservée** }\end{array}$ \\
\hline $\begin{array}{l}\text { Terrestres et eaux } \\
\text { intérieures }\end{array}$ & $15,50 \%$ & $13,00 \%$ \\
\hline
\end{tabular}

* Ensemble de données de la BDMAP $\quad{ }^{* *}$ Rapport national sur la biodiversité

Source : Republic of South Sudan (2015); UNEP-WCMC et IUCN (2019t).

Aires protégées et de conservation désignées comme sites d'importance mondiale au Soudan du Sud

\begin{tabular}{l|r}
\hline Désignation mondiale & $\begin{array}{r}\text { Nombre de } \\
\text { sites }\end{array}$ \\
\hline $\begin{array}{l}\text { Zones humides d'importance internationale } \\
\text { (sites Ramsar) }\end{array}$ & 1 \\
\hline
\end{tabular}

Source : Ramsar (2019) ; UNESCO (2019a, 2019b)

Aires protégées et de conservation du Soudan du Sud par type de gouvernance de l'UICN

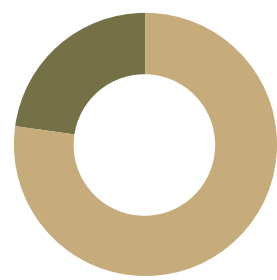

Non rapporté (1)

A.Gouvernance par le gouvernement (26)
Désignations nationales des aires protégées et de conservation au Soudan du Sud

\begin{tabular}{l|r|r}
\hline Désignation nationale & $\mathbf{N}^{\circ}$ & $\begin{array}{r}\text { Superficie } \\
\left(\mathbf{k m}^{2}\right)\end{array}$ \\
\hline Parc national & 10 & 74991 \\
\hline Réserve de gibier & 12 & 29792 \\
\hline $\begin{array}{l}\text { Aire de conservation de la } \\
\text { nature }\end{array}$ & 2 & 2499 \\
\hline Réserve forestière & 1 & 1160 \\
\hline Sanctuaire pour les oiseaux & 1 & 4999 \\
\hline Source: UNEP-WCMC et IUCN (2019t). & & \\
\hline
\end{tabular}

\section{Aires prioritaires pour la conservation}

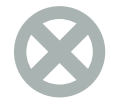

1 site

12 sites

3 sites

Sites de l'Alliance pour une extinction zéro

Zones importantes pour les oiseaux et la biodiversité
Zones clés pour la biodiversité 
Les menaces indirectes incluent les conflits armés passés et actuels, ainsi que les crises humanitaires de populations déplacées à l'intérieur du pays et la prolifération d'armes à feu qui en résultent, des capacités juridiques, institutionnelles et administratives inadéquates et inefficaces, les effets négatifs de la croissance démographique et du développement économique, le manque d'aménagement du territoire, la faible sensibilisation du public, et l'exploration et la production pétrolières émergentes.

\section{Figure 8.38 : Aires protégées du Soudan du Sud}

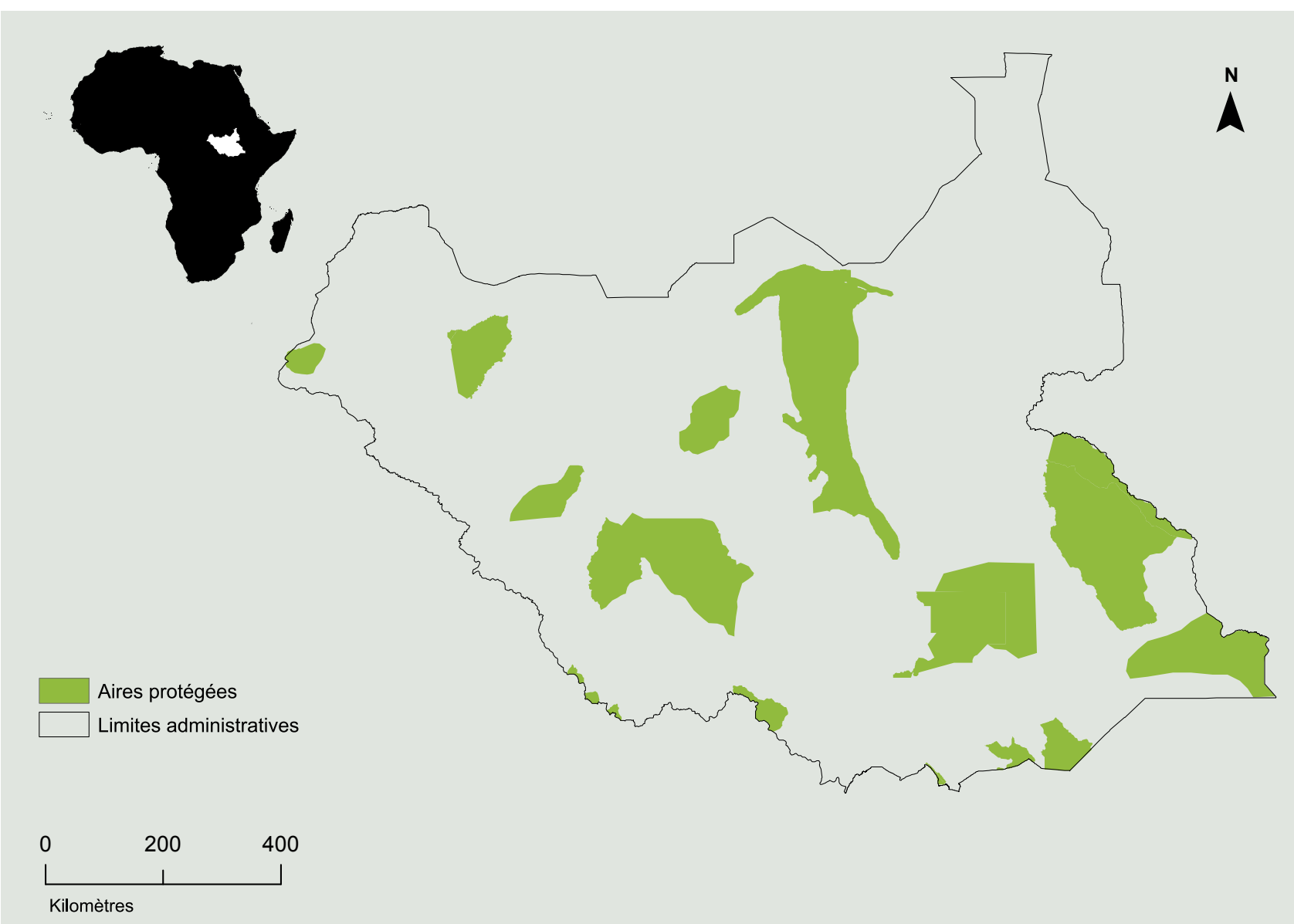

Développé par le RCMRD à partir des données BDMAP.

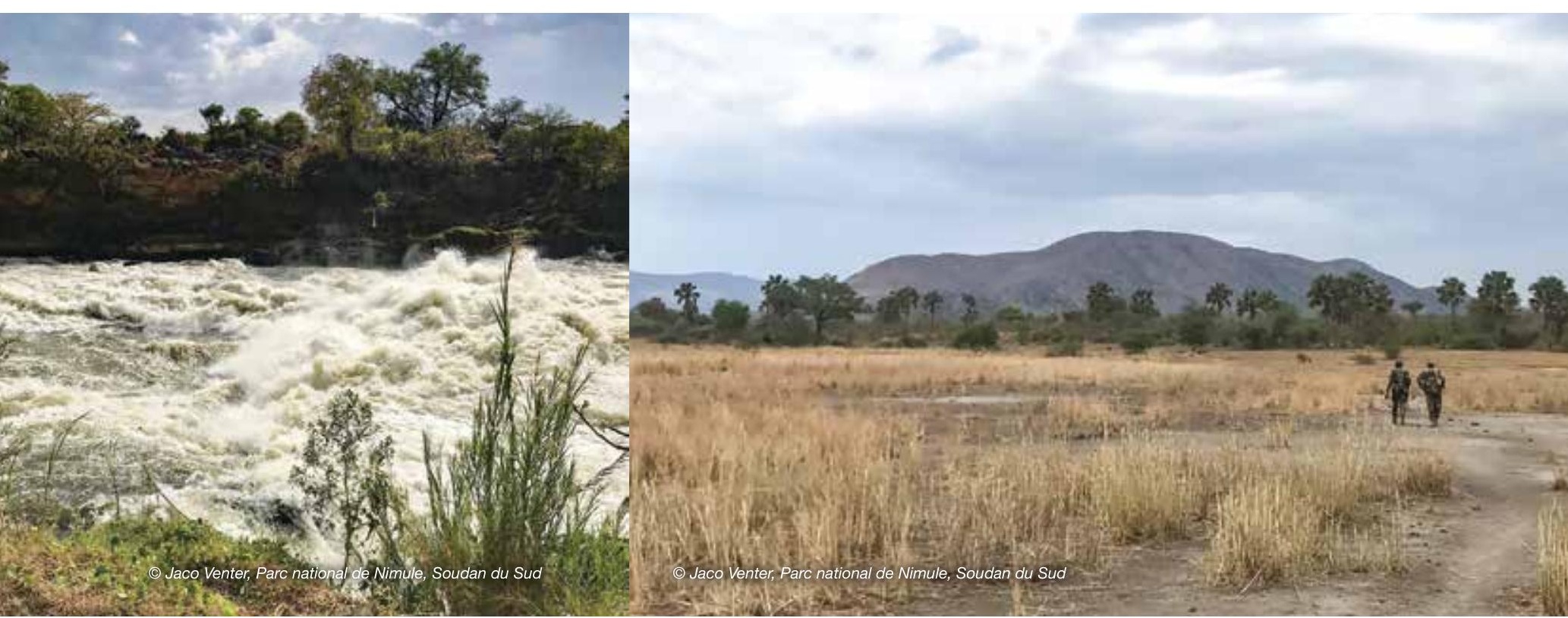




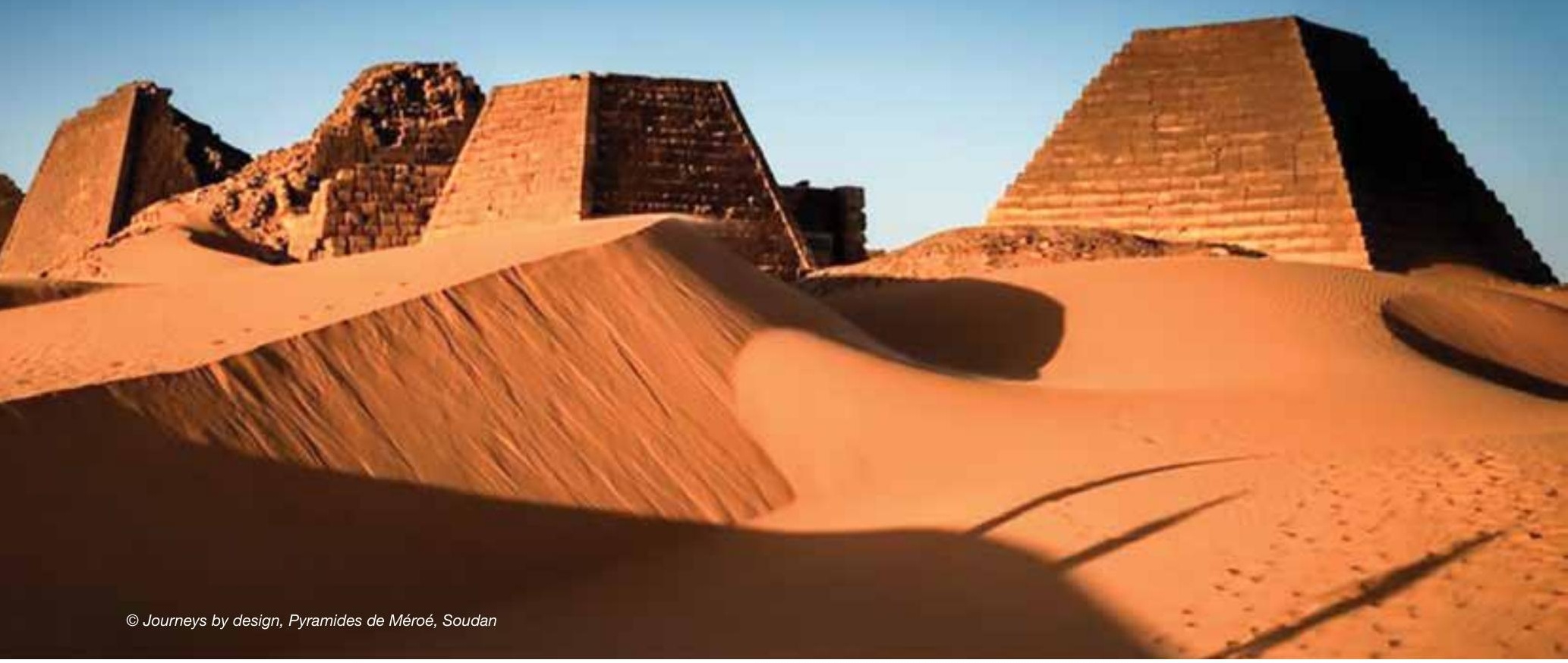

\subsection{Soudan}

\section{Aires protégées et de conservation au Soudan ${ }^{91}$}

Le Soudan compte 23 aires protégées couvrant $42698 \mathrm{~km}^{2}$ d'écosystèmes terrestres et $10662 \mathrm{~km}^{2}$ d'écosystèmes marins (UNEP-WCMC et IUCN, 2019u).

La faune sauvage est présente dans les aires protégées et dans des habitats fragmentés à l'extérieur des aires protégées, comprenant des zones désertiques, semi-désertiques, des savanes boisées à faibles ou à forte pluviométrie et des écosystèmes marins. Bon nombre d'espèces ont diminué ou disparu de beaucoup de leurs anciens habitats.

II n'existe pas d'aire protégée désignée représentant les écosystèmes d'eau douce, à l'exception du projet d'aire protégée de la zone humide d'Umgur.

\section{Aires protégées et de conservation transfrontières}

Le Soudan ne compte aucune aire de conservation transfrontière.

\section{Contexte politique}

Un rapport complet sur la législation et les politiques relatives à la gestion, à la gouvernance et à l'équité des aires protégées a été réalisé par le programme BIOPAMA. II a identifié 18 lois et politiques pertinentes au Soudan (Tessema, 2019).

\section{Espèces clées $^{92}$}

Le large éventail d'écosystèmes du Soudan abrite une grande diversité d'espèces. Les informations sur la répartition et l'abondance actuelles des ressources fauniques au Soudan sont très limitées. Le pays abrite 937 espèces d'oiseaux, dont 17 espèces préoccupantes pour la conservation à l'échelle mondiale. Les mangroves sont une espèce importante des habitats côtiers, mais sont très menacées. Le Soudan possède une biodiversité marine et d'eau douce diversifiée, notamment des récifs coralliens, des herbiers marins et un large éventail d'espèces telles que requins, dugongs, tortues et oiseaux marins. II n'existe que très d'information disponibles concernant la composition des espèces, en particulier depuis la séparation du Soudan du Sud.

\section{Pressions et menaces ${ }^{93}$}

Le Soudan est confronté à un certain nombre de menaces, dont la dégradation de l'environnement, l'expansion des constructions civiles et des activités économiques, les changements climatiques et la sécheresse, l'expansion des cultures, la pollution et les espèces exotiques envahissantes. 
Figure 8.39 : Résumé du Soudan

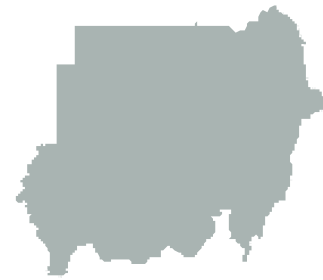

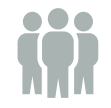

Population totale (en millions)

41,80

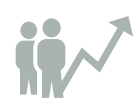

Démographie (\% annuel)

2,40

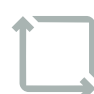

Superficie (en milliers de $\mathrm{km}^{2}$ )

658,84

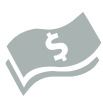

PIB (en milliards de USD actuels)

40,85

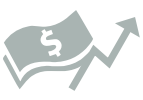

Croissance du PIB (\% annuel)

$-2,30$

Source : The World Bank Group, 2018

Aires protégées :

23 aires protégées terrestre couverture

42698 km$^{2}$

couverture marine

10662 km $^{2}$

Source : UNEP-WCMC et IUCN (2019u)

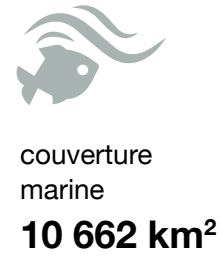

Aires protégées et de conservation du Soudan par catégorie de gestion de l'UICN

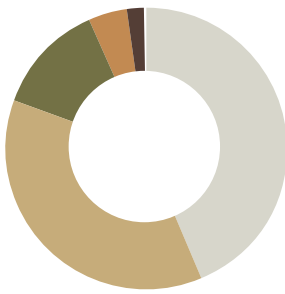

Ne s'applique pas (3)

Non rapportée (13)

VI. Aire protégée avec utilisation durable des ressources naturelles (3)

IV. Aire de gestion habitats / espèces (1)

II. Parc national (3)
Très peu d'informations disponibles sur la composition des espèces
937 espèces d'oiseaux

17 préoccupantes pour la conservation à l'échelle mondiale

\section{Couverture des aires protégées au Soudan}

\begin{tabular}{l|r|r}
\hline Type d'aire protégée & $\begin{array}{r}\text { Aire protégée } \\
\text { ou conservée }\end{array}$ & $\begin{array}{r}\text { Aire protégée } \\
\text { ou conservée }\end{array}$ \\
\hline $\begin{array}{l}\text { Terrestres et eaux } \\
\text { intérieures }\end{array}$ & $2,28 \%$ & $5,80 \%$ \\
\hline Marines et côtières & $15,96 \%$ & $10,00 \%$ \\
\hline
\end{tabular}

* Ensemble de données de la BDMAP ${ }^{* *}$ Rapport national sur la biodiversité Source : Republic of Sudan (2019); UNEP-WCMC et IUCN (2019u).

Aires protégées et de conservation désignées comme sites d'importance mondiale au Soudan

\begin{tabular}{l|r}
\hline Désignation mondiale & $\begin{array}{r}\text { Nombre de } \\
\text { sites }\end{array}$ \\
\hline $\begin{array}{l}\text { Patrimoine Mondial de l'UNESCO } \\
\text { (naturel ou mixte) }\end{array}$ & 1 \\
\hline $\begin{array}{l}\text { Zones humides d'importance internationale } \\
\text { (sites Ramsar) }\end{array}$ & 3 \\
\hline
\end{tabular}

Source : Ramsar (2019) ; UNESCO (2019a, 2019b).

Aires protégées et de conservation du Soudan par type de gouvernance de l'UICN

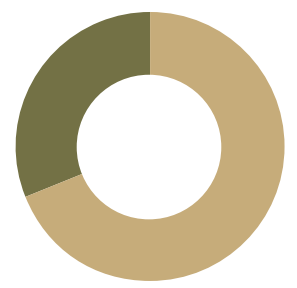

Non rapporté (14)

A.Gouvernance par le gouvernement (9)
Désignations nationales des aires protégées et de conservation au Soudan

\begin{tabular}{l|r|r}
\hline Désignation nationale & $\mathbf{N}^{\circ}$ & $\begin{array}{r}\text { Superficie } \\
\left(\mathbf{k m}^{2} \mathbf{)}\right.\end{array}$ \\
\hline Réserve naturelle gérée & 1 & 300 \\
\hline Parc national & 4 & 22398 \\
\hline Réserve de gibier & 2 & 7459 \\
\hline Aire de conservation de la nature & 2 & 6299 \\
\hline Parc national marin & 2 & 1012 \\
\hline Sanctuaire pour les oiseaux & 4 & 1150 \\
\hline Sanctuaire de faune sauvage & 2 & 940 \\
\hline
\end{tabular}

Source : UNEP-WCMC et IUCN (2019u).

\section{Aires prioritaires pour la conservation}

\section{1 sites}

Zones importantes pour les oiseaux et la biodiversité

Source : BirdLife International (2019c). 
Figure 8.40 : Aires protégées du Soudan
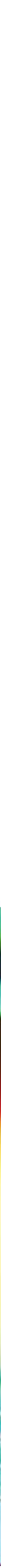


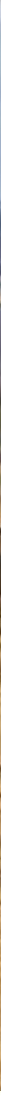

\subsection{Tanzanie}

\section{Aires protégées et de conservation de Tanzanie ${ }^{94}$}

La Tanzanie compte 840 aires protégées couvrant $361594 \mathrm{~km}^{2}$ d'écosystèmes terrestres et $7330 \mathrm{~km}^{2}$ d'écosystèmes marins (UNEP-WCMC et IUCN, 2019v).

Les écosystèmes terrestres sont les mieux protégés, tandis que les milieux côtiers et marins sont moins protégés. Ses vastes parcs nationaux, ses montagnes de " l'Arc Oriental ", ses zones humides, ses forêts côtières et ses systèmes marins et d'eau douce sont autant de réservoirs exceptionnels d'espèces végétales et animales, et font de la Tanzanie l'un des plus grands réservoirs de biodiversité au monde. Le pays abrite également une grande variété d'espèces endémiques d'amphibiens, de lézards, de serpents, d'oiseaux et de variétés de café sauvage, ainsi que la célèbre violette africaine.

L'Aire de conservation du Ngorongoro et le Parc national du Serengeti sont des Réserves de biosphère et des sites du Patrimoine mondial connus pour la migration de grands mammifères la plus spectaculaire au monde, chaque année. Dans le Parc national du Serengeti, ceux-ci traversent les vastes prairies et les forêts d'Acacia-Commiphora, l'un des principaux écosystèmes forestiers du pays, tandis que dans l'Aire de conservation du Ngorongoro, ils parcourent le couloir supérieur Kitete/Selela, le long de la vallée du Grand Rift, qui les relie au Parc national du lac Manyara, utilisé par les éléphants et les buffles. II va sans dire que les corridors fauniques sont gravement menacés en Tanzanie, et font face à d'intenses pressions liées à des changements d'affectation des terres. Récemment, le Président a promulgué la création des Parcs nationaux Julius Nyerere, Kigosi et River Ugalla.

\section{Aires protégées et de conservation transfrontières}

La Tanzanie comprend une partie de huit aires de conservation transfrontières, à savoir I'ACT Amboseli-Kilimandjaro-LongidoKagera, l'ACT baie de Mnazi-Quirimbas, l'ACT de Niassa-Selous, baie de Sango-Minziro, Serengeti-Mara, le Système de réserves marines de Tanga et Parc marin de Tanga Coelacanth, Diani Chale et Kisitee-Mpunguti, ainsi que le Parc marin transfrontalier de l'océan Indien occidental.

\section{Contexte politique}

Un rapport complet sur la législation et les politiques relatives à la gestion, à la gouvernance et à l'équité des aires protégées a été réalisé par le programme BIOPAMA. II a identifié 74 lois et politiques pertinentes en Tanzanie (Tessema, 2019).

\section{Espèces clées $^{95}$}

La Tanzanie possède une grande diversité d'espèces, avec au moins 14500 espèces connues et confirmées, et figure parmi les 15 pays du monde présentant le plus grand nombre d'espèces endémiques et menacées. Elle abrite plus d'un tiers du total des espèces végétales d'Afrique et se classe douzième en termes d'espèces d'oiseaux à l'échelle mondiale. Le pays accueille environ $20 \%$ de la population de grands mammifères d'Afrique.

Sur toutes les espèces présentes dans le pays, plus de la moitié (54\%) sont des espèces végétales. Plus de $25 \%$ de toutes les espèces végétales sont utilisées comme plantes médicinales récoltées à l'état sauvage.

Le nombre exact d'espèces endémiques dans le pays n'est pas connu. Cependant, les informations disponibles indiquent que le pays pourrait compter entre 400 et 3000 espèces endémiques.

94 Cette section s'appuie sur les informations contenues dans les cinquième et sixième Rapports nationaux de la Tanzanie sur la mise en œuvre de la CDB (United Republic of Tanzania, 2014; 2019).

95 Cette section s'appuie sur les informations contenues dans le cinquième Rapport national de la Tanzanie sur la mise en œuvre de la CDB (United Republic of Tanzania, 2014). 
Figure 8.41 : Résumé de la Tanzanie

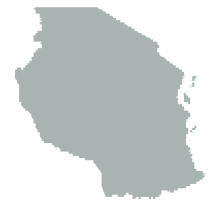

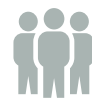

Population totale (en millions)

56,32

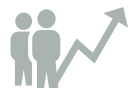

Démographie (\% annuel)

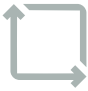

Superficie (en milliers de $\mathrm{km}^{2}$ )

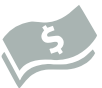

PIB (en milliards de USD actuels)
Croissance du PIB (\% annuel)

5,20

Source : The World Bank Group, 2018.

Aires protégées et de conservation de Tanzanie par catégorie de gestion de l'UICN
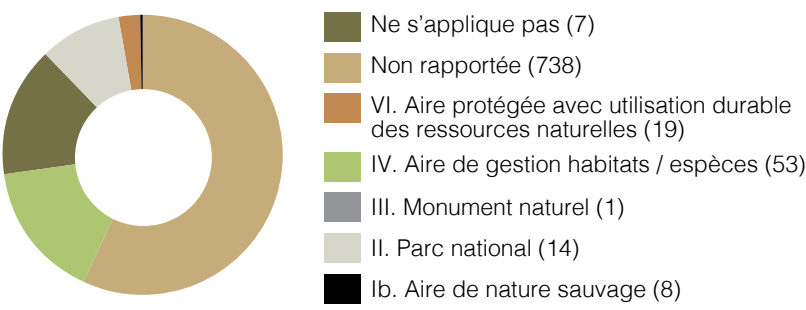

Source : UNEP-WCMC et IUCN (2019v).
Couverture des aires protégées en Tanzanie

\begin{tabular}{l|r|r}
\hline Type d'aire protégée & $\begin{array}{r}\text { Aire protégée } \\
\text { ou conservée }\end{array}$ & $\begin{array}{r}\text { Aire protégée } \\
\text { ou conservée }\end{array}$ \\
\hline $\begin{array}{l}\text { Terrestres et eaux } \\
\text { intérieures }\end{array}$ & $38,17 \%$ & $54,60 \%$ \\
\hline Marines et côtières & $3,02 \%$ & $6,50 \%$ \\
\hline
\end{tabular}

"Ensemble de données de la BDMAP ${ }^{* *}$ Rapport national sur la biodiversité Source: UNEP-WCMC et IUCN (2019v); United Republic of Tanzania (2019).

\section{Aires protégées et de conservation désignées} comme sites d'importance mondiale en Tanzanie

\begin{tabular}{l|r}
\hline Désignation mondiale & $\begin{array}{r}\text { Nombre de } \\
\text { sites }\end{array}$ \\
\hline Réserves de biosphère de l'UNESCO & 5 \\
\hline $\begin{array}{l}\text { Patrimoine Mondial de l'UNESCO } \\
\text { (naturel ou mixte) }\end{array}$ & 4 \\
\hline $\begin{array}{l}\text { Zones humides d'importance internationale } \\
\text { (sites Ramsar) }\end{array}$ & 4 \\
\hline
\end{tabular}

Source : Ramsar (2019) ; UNESCO (2019a, 2019b).

\section{Aires protégées et de conservation de Tanzanie par type de gouvernance de I'UICN}

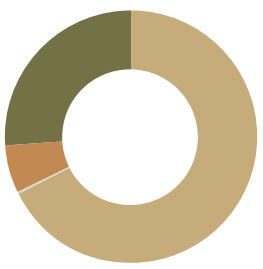

Non rapporté (19)

D. Gouvernance par les peuples autochtones ou communautés locales (39)

C. Gouvernance privée (1)

B. Gouvernance partagée (4)

A. Gouvernance par le gouvernement (777)

Source : UNEP-WCMC et IUCN (2019v).

Désignations nationales des aires protégées et de conservation en Tanzanie

\begin{tabular}{|c|c|c|}
\hline Désignation nationale & $\mathbf{N}^{\circ}$ & $\begin{array}{r}\text { Superficie } \\
\left(\mathbf{k m}^{2}\right)\end{array}$ \\
\hline Réserve naturelle forestière & 1 & 257 \\
\hline Aire de conservation & 4 & 9674 \\
\hline Réserve de gibier & 19 & 94050 \\
\hline Parc national & 17 & 48430 \\
\hline Aire contrôlée pour le gibier & 19 & 70901 \\
\hline $\begin{array}{l}\text { Zone de gestion collaborative de } \\
\text { la pêche }\end{array}$ & 1 & 1913 \\
\hline Réserve marine & 2 & 35 \\
\hline $\begin{array}{l}\text { Aire de gestion de la faune } \\
\text { sauvage }\end{array}$ & 14 & 33162 \\
\hline Plantations forestières & 23 & 730 \\
\hline Aire marine gérée localement & 1 & 3 \\
\hline Parc marin & 2 & 1445 \\
\hline Réserve naturelle & 6 & 1996 \\
\hline Aire ouverte & 24 & 53235 \\
\hline $\begin{array}{l}\text { Aire de gestion de la faune } \\
\text { sauvage }\end{array}$ & 13 & 3999 \\
\hline Réserve forestière & 694 & 92195 \\
\hline $\begin{array}{l}\text { Sanctuaire et réserve forestière } \\
\text { fermée }\end{array}$ & 1 & 1 \\
\hline $\begin{array}{l}\text { Réserve forestière et aire } \\
\text { contrôlée pour le gibier }\end{array}$ & 1 & 1015 \\
\hline
\end{tabular}

\section{Aires prioritaires pour la conservation}

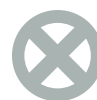

\section{3 sites}

Sites de l'Alliance pour une extinction zéro

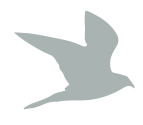

\section{7 sites}

Zones importantes pour les oiseaux et la biodiversité

\section{4 sites}

Zones clés pour la biodiversité

Source : AZE Secretariat (2019) ; BirdLife International (2019b, 2019c). 


\section{Figure 8.42 : Aires protégées de Tanzanie}

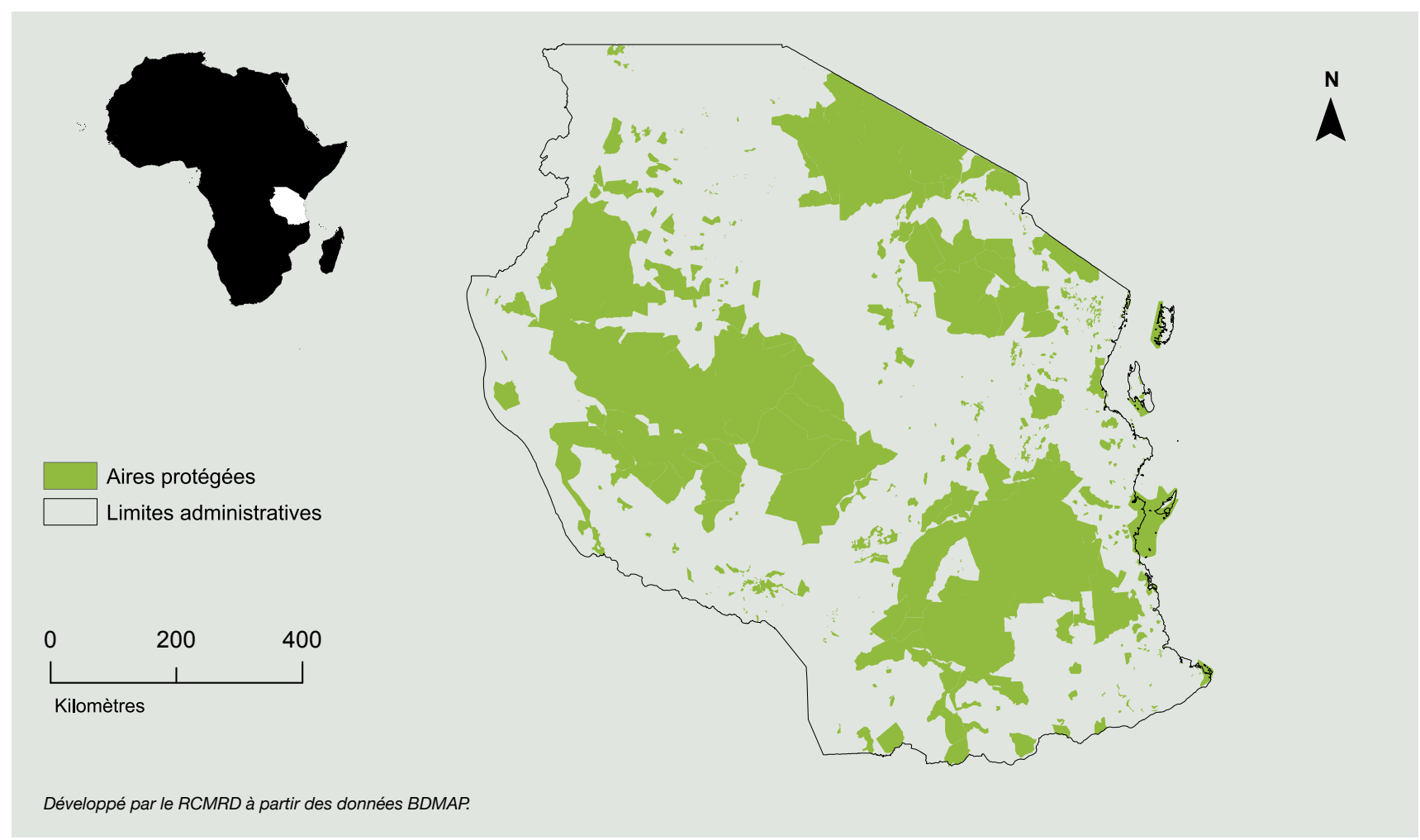

À partir d'une analyse des espèces menacées dans le pays, et tenant compte de leur importance écologique, économique et sociale, les espèces préoccupantes comprennent, sans s'y limiter, le rhinocéros noir (Diceros bicornis) et l'éléphant d'Afrique (Loxodonta africana), en voie de disparition en raison du braconnage. D'autres espèces d'importance critique incluent le chimpanzé (Pan troglodytes), les colobes (dont Procolobus gordonorum et Procolobus kirkii), les mangabey (dont Rungwecebus kipunji et Cercocebus sanjei), le léopard (Panthera pardus), le guépard (Acinonyx jubatus) et le lycaon (Lycaon pictus). La Tanzanie abrite la plus grande population de lions (Panthera leo) au monde. Elle abrite également des essences de bois de grande valeur (dont Afzelia spp, Pterocarpus spp., Diospyros mespiliformis). En outre, on y trouve des espèces marines importantes, y compris des crevettes (Metapenaeus monocerus, Penaeus indicus, P. monodon), des thons, des dugongs et des tortues marines.

\section{Pressions et menaces ${ }^{96}$}

Comme dans d'autres pays, la richesse en biodiversité de la Tanzanie est de plus en plus menacée par un certain nombre de facteurs naturels et humains. Les principales menaces pour la biodiversité en Tanzanie sont la perte et la destruction des habitats par leur conversion à d'autres utilisations des terres, telles que les établissements humains, l'agriculture et le pâturage, la surexploitation des espèces végétales et animales, l'introduction d'espèces exotiques, la pollution et les changements climatiques.

Les activités humaines, telles que le braconnage, la déforestation, le chalutage de fond dans les océans et les pratiques de pêche non durables, l'endiguement et le dragage des cours d'eau, des rivières et des lacs, ainsi que l'assèchement et la dégradation des zones humides, des estuaires et des mangroves sont responsables d'une perte de biodiversité dans les plans d'eau. Ces activités sont une conséquence de la croissance économique et démographique, de la pauvreté, du commerce mondial d'espèces végétales et animales et des changements climatiques.

Parmi les autres menaces importantes pour les habitats figurent la déforestation, la destruction des coraux, la dégradation des habitats due aux incendies, l'utilisation non planifiée des terres, l'extraction non gérée des ressources naturelles, l'augmentation du commerce de viande de brousse et la construction de routes et autres infrastructures. Les corridors fauniques sont l'un des types d'habitats soumis à une forte pression, susceptibles d'être convertis à d'autres formes d'utilisation des terres.

Les habitats marins sont gravement menacés par la destruction des mangroves et des coraux, la pêche à la dynamite et les filets de pêche illégaux, tandis que les habitats d'eau douce font face à une baisse des niveaux d'eau due à la réduction des précipitations et à une évaporation accrue, au déclin de la diversité des espèces de poissons dû à la surexploitation des stocks, à la pêche illégale, à l'introduction de poissons et autres espèces exotiques, en particulier la perche du Nil et la jacinthe d'eau, et à la pollution et l'eutrophisation due à un enrichissement en nutriments, et en particulier en phosphore et en azote.

Les habitats terrestres sont soumis à une pression énorme due à l'exploitation non durable des espèces animales. Les principales espèces victimes de cette pression comprennent les grands carnivores, tels que les lions, les léopards, les guépards et les lycaons, ainsi que le groupe des herbivores, y compris la population d'éléphants, de girafes (Giraffa camelopardalis), de zèbres (Equus burchelli), de buffles (Syncerus caffer), d'antilopes, de gnous (Connochaetus taurinus) et de rhinocéros noir (Diceros bicornis). 


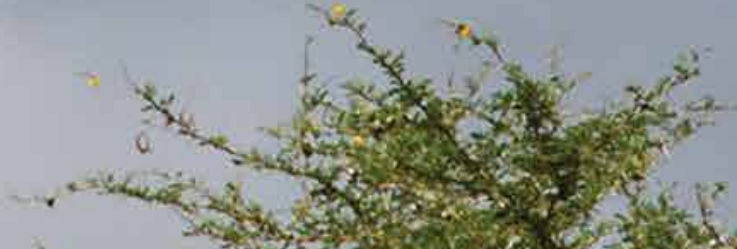

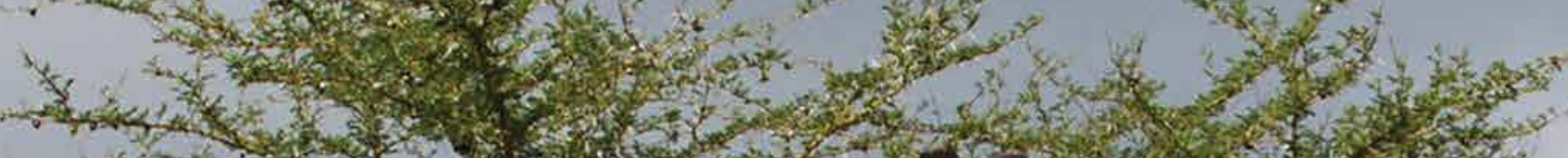
H.

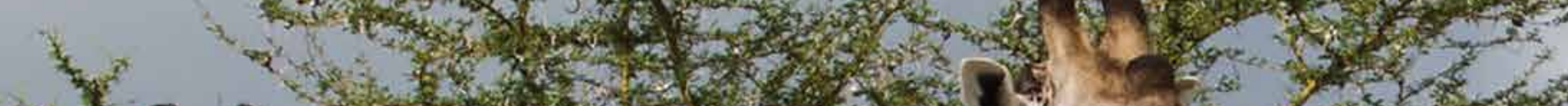
1.

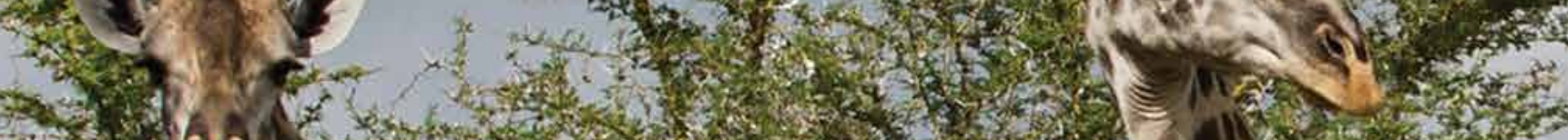

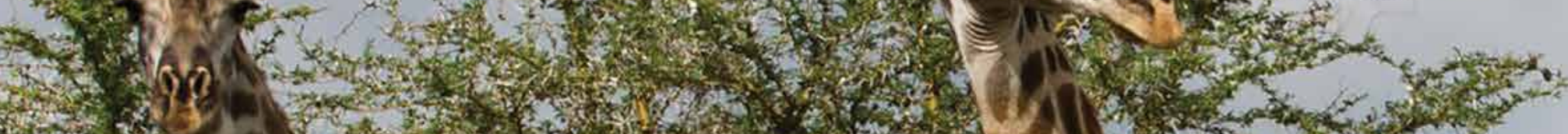

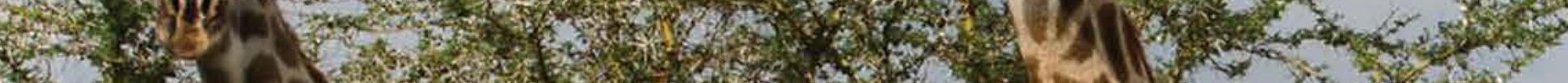

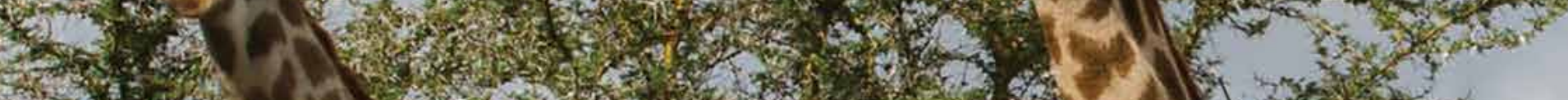

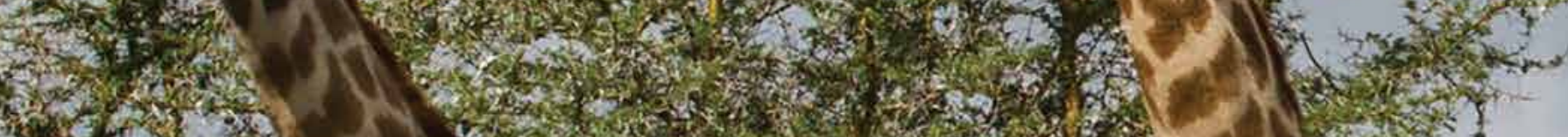
1.

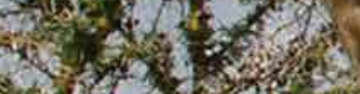

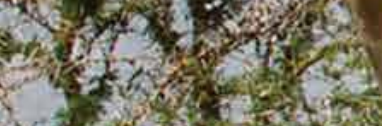

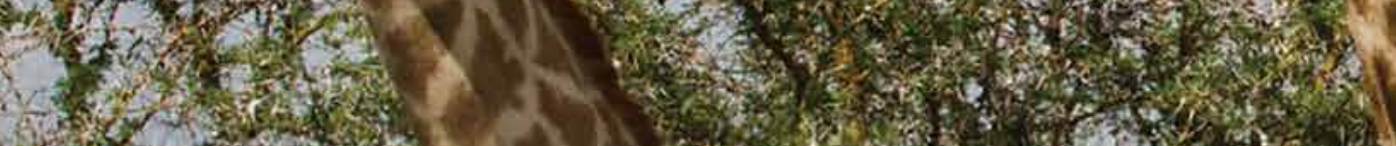

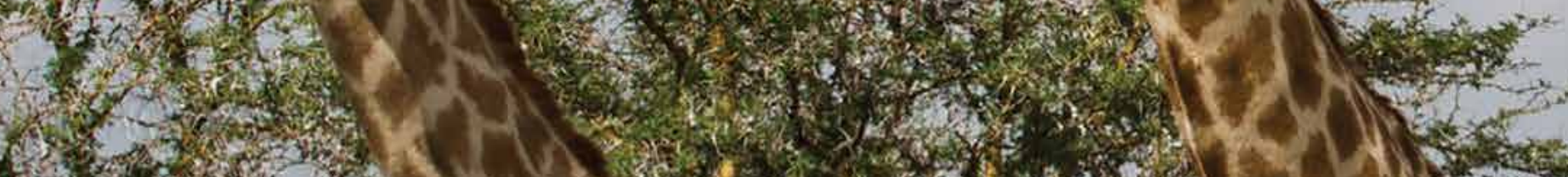

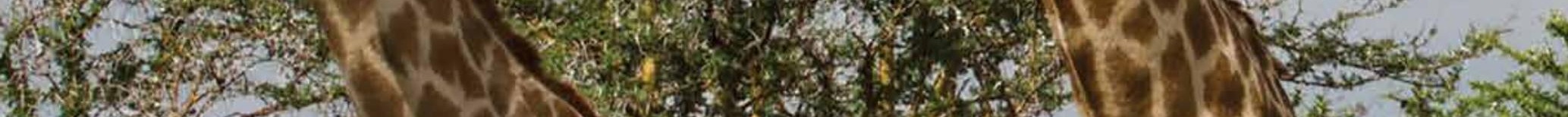

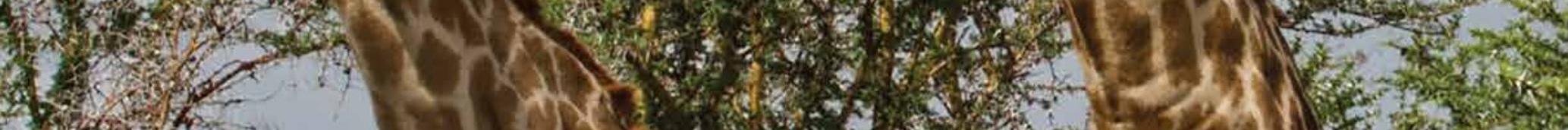

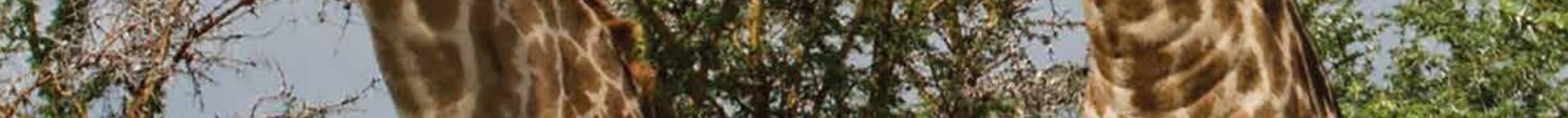

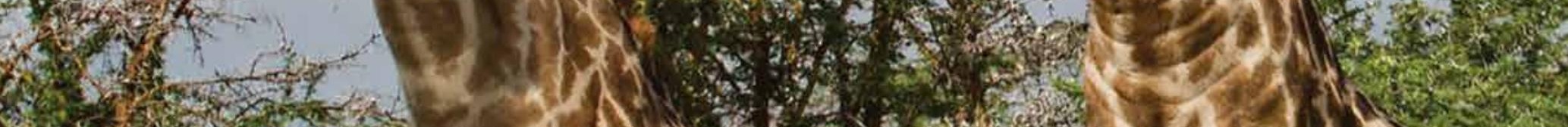

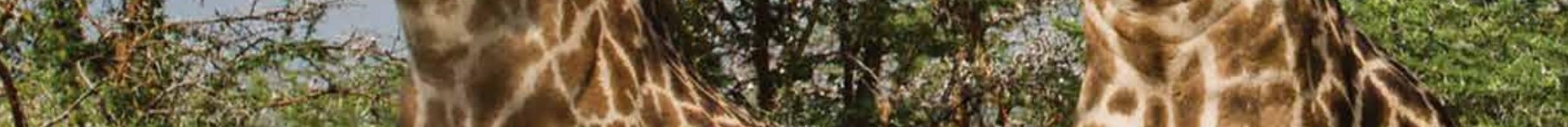

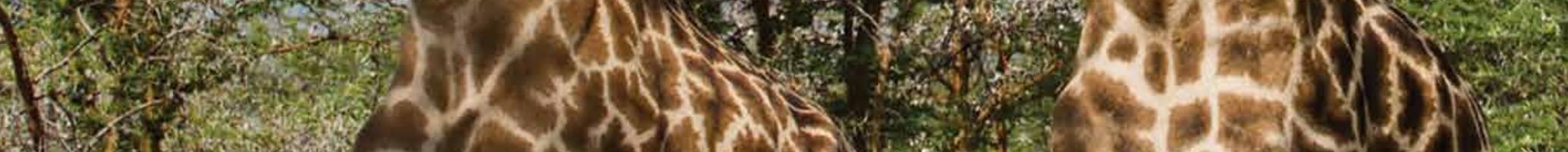

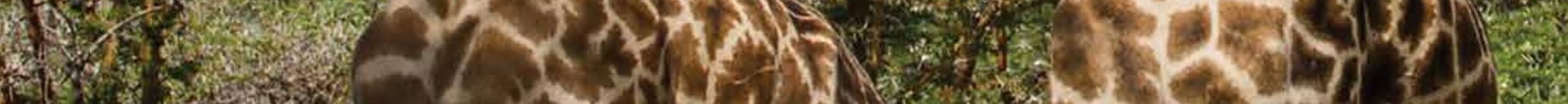

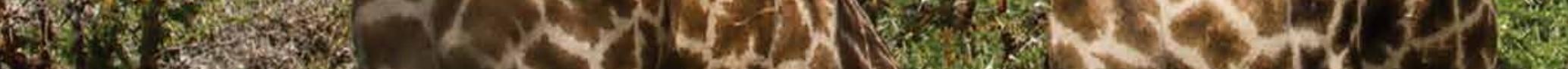
15.

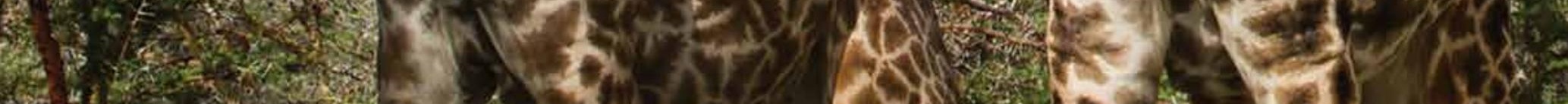

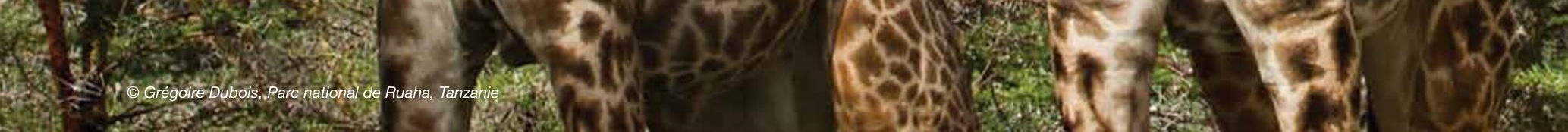




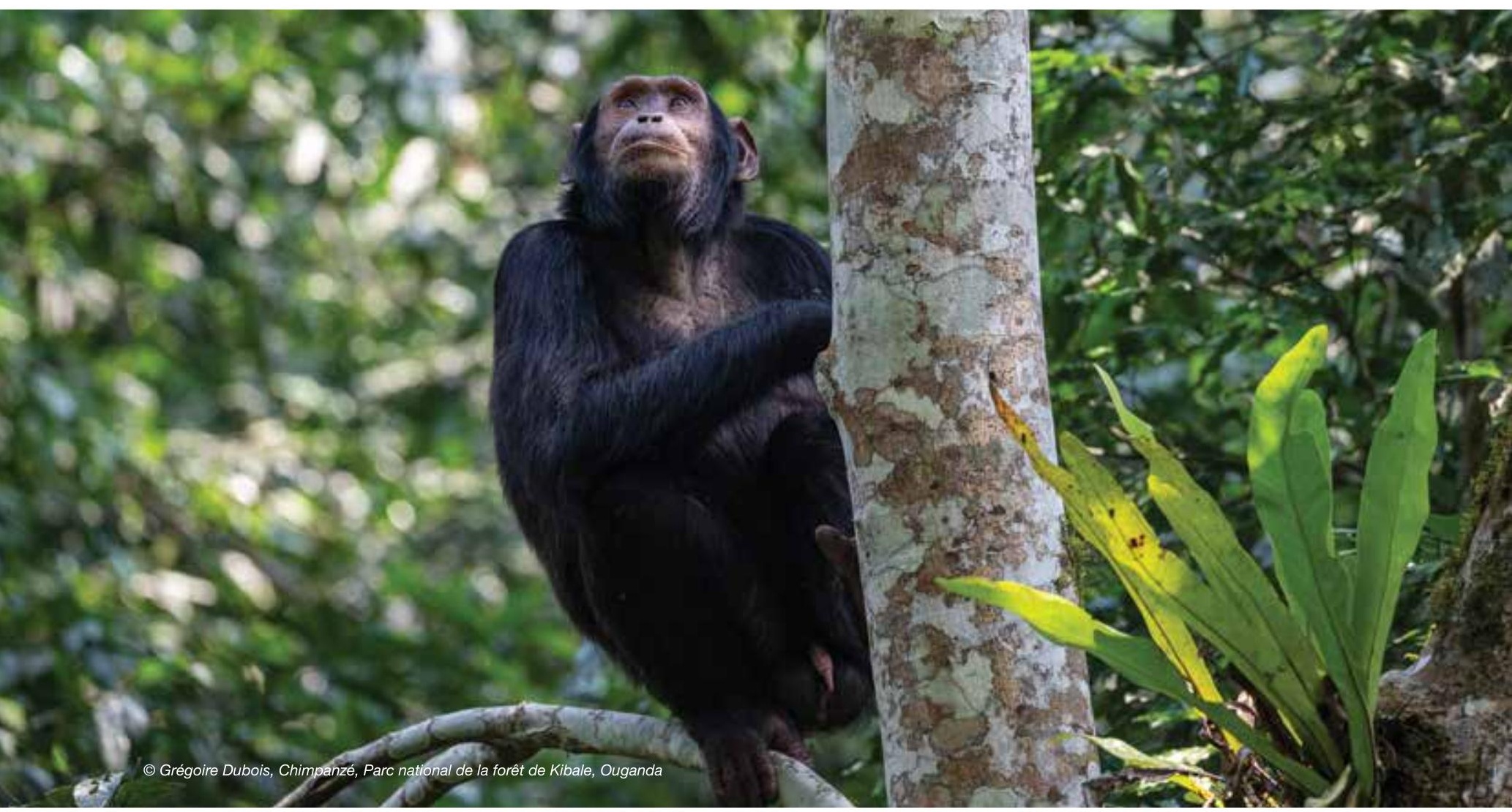

\subsection{Ouganda}

\section{Aires protégées et de conservation d'Ouganda ${ }^{97}$}

L'Ouganda compte 712 aires protégées couvrant $39059 \mathrm{~km}^{2}$ d'écosystèmes terrestres (UNEP-WCMC et IUCN, 2019w).

L'Ouganda représente une zone de convergence de cinq des zones écologiques importantes d'Afrique et abrite environ la moitié des montagnes du monde. Ces dernières années, l'Ouganda a été considéré comme un modèle pour de nombreuses approches visant à relever des défis complexes, en matière de conservation et de développement, tels que la conservation communautaire et le paiement pour services écosystémiques. Le projet financé par le Fonds pour l'environnement mondial (FEM), incitant les propriétaires fonciers à conserver et à restaurer les habitats forestiers importants pour les chimpanzés et autres espèces de flore et de faune, en est un exemple. Celui-ci a permis de fournir des incitations à quelque 400 agriculteurs (propriétaires forestiers privés) de 68 villages pour la conservation de la biodiversité dans les forêts sur des terres privées et publiques non répertoriées comme réserves forestières.

En 2018, le gouvernement a lancé un processus de désignation et déclaration d'une partie des zones humides de l'Ouganda en tant qu'aires protégées. Les zones humides d'Ouganda couvrent une superficie de $11 \%$ du pays. L'Ouganda se caractérise par une tendance à la réduction des zones boisées dans les aires protégées, les parcs nationaux et les réserves de faune, ainsi que dans les réserves forestières centrales. Le couvert forestier est passé de 1,59 million d'ha en 1990 à 1,13 million d'ha en 2015 .

\section{Aires protégées et de conservation transfrontières}

L'Ouganda comprend une partie de cinq aires de conservation transfrontières, à savoir le Grand paysage des Virunga, l'ACT de Kagera, le Paysage de Kidepo, le Mont Elgon et la baie de SangoMinziro.

\section{Contexte politique}

Un rapport complet sur la législation et les politiques relatives à la gestion, à la gouvernance et à l'équité des aires protégées a été réalisé par le programme BIOPAMA. II a identifié 48 lois et politiques pertinentes en Ouganda (Tessema, 2019).

\section{Espèces clées $^{98}$}

L'Ouganda possède une riche biodiversité, avec près de 19000 espèces de flore et de faune. Les connaissances sur ces espèces sont biaisées en faveur des mammifères, des oiseaux, des papillons, de certaines plantes, des reptiles, des amphibiens et des poissons. L'Ouganda abrite environ 380 espèces de mammifères et plus de 1000 espèces d'oiseaux, soit près de la moitié de toutes les espèces recensées en Afrique. La biodiversité des poissons en Ouganda est dominée par la famille des cichlidés, avec un haut niveau d'endémisme. On trouve 98 espèces d'amphibiens et 150 espèces de reptiles en Ouganda. Sur les quelque 5000 espèces de plantes supérieures, 70 sont endémiques. Les champignons, les lichens et les insectes sont moins bien documentés.

7 Cette section s'appuie sur les informations contenues dans le cinquième Rapport national de l'Ouganda à la CDB (Uganda National Environment Management Agency, 2014)

98 Cette section s'appuie sur les informations contenues dans le cinquième Rapport national de l'Ouganda à la CDB, ainsi que dans son deuxième SPANB (Republic of Uganda, 2016; Uganda National Environment Management Agency, 2014). 
Figure 8.43 : Résumé de l'Ouganda

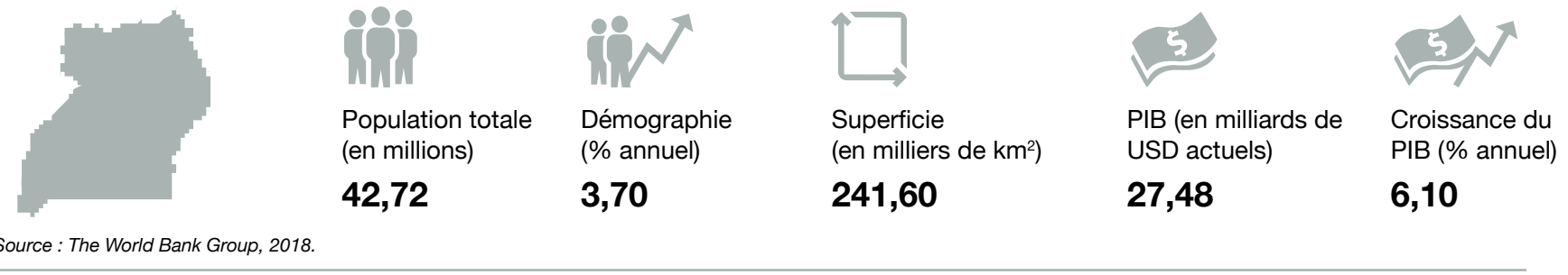

\section{Aires protégées :}

712

aires

protégées

couverture terrestre

39059 km² $^{2}$
19000 espèces de flore et de faune

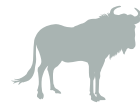

380 espèces de mammifères

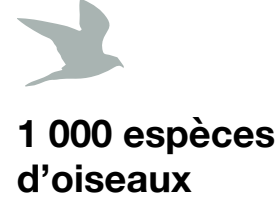

Aires protégées et de conservation d'Ouganda par catégorie de gestion de I'UICN

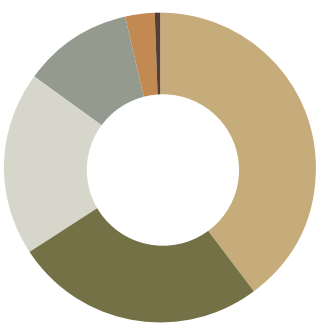

Ne s'applique pas (4)

Non rapportée (673)

VI. Aire protégée avec utilisation durable des ressources naturelles (13)

IV. Aire de gestion habitats / espèces (1)

III. Monument naturel (11)

II. Parc national (10)

Source : UNEP-WCMC et IUCN (2019w)

150 espèces

98 espèces de reptiles
5000 espèces végétales

\section{Couverture des aires protégées en Ouganda}

\begin{tabular}{l|r|r}
\hline Type d'aire protégée & $\begin{array}{r}\text { Aire protégée } \\
\text { ou conservée }\end{array}$ & $\begin{array}{r}\text { Aire protégée } \\
\text { ou conservée }\end{array}$ \\
\hline $\begin{array}{l}\text { Terrestres et eaux } \\
\text { intérieures }\end{array}$ & $16,06 \%$ & $0,80 \%$ \\
\hline${ }^{*}$ Ensemble de données de la BDMAP & ${ }^{* *}$ Rapport national sur la biodiversité \\
Source : Uganda National Environment Management Agency (2014); UNEP-WCMC et \\
IUCN (2019w).
\end{tabular}

Aires protégées et de conservation désignées comme sites d'importance mondiale en Ouganda

\begin{tabular}{l|r}
\hline Désignation mondiale & $\begin{array}{r}\text { Nombre de } \\
\text { sites }\end{array}$ \\
\hline Réserves de biosphère de l'UNESCO & 2 \\
\hline $\begin{array}{l}\text { Patrimoine Mondial de l'UNESCO } \\
\text { (naturel ou mixte) }\end{array}$ & 2 \\
\hline $\begin{array}{l}\text { Zones humides d'importance internationale } \\
\text { (sites Ramsar) }\end{array}$ & 12 \\
\hline
\end{tabular}

Source : Ramsar (2019) ; UNESCO (2019a, 2019b).

Aires protégées et de conservation d'Ouganda par type de gouvernance de l'UICN

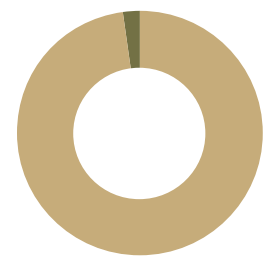

Non rapporté (13)

A.Gouvernance par le gouvernement (699)
Désignations nationales des aires protégées et de conservation en Ouganda

\begin{tabular}{l|r|r}
\hline Désignation nationale & $\mathbf{N}^{\circ}$ & $\begin{array}{r}\text { Superficie } \\
\left(\mathbf{k m}^{2}\right)\end{array}$ \\
\hline Sanctuaire & 1 & 187 \\
\hline Parc national & 10 & 11251 \\
\hline Réserve de faune sauvage & 12 & 8461 \\
\hline $\begin{array}{l}\text { Aire communautaire de } \\
\text { gestion de la faune }\end{array}$ & 5 & 4239 \\
\hline Réserve forestière & 661 & 12342 \\
\hline Sanctuaire de faune sauvage & 7 & 554 \\
\hline Source : UNEP-WCMC et IUCN (2019w). & &
\end{tabular}

\section{Aires prioritaires pour la conservation}

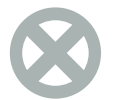

\section{4 sites}

Sites de l'Alliance pour une extinction zéro

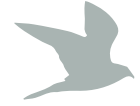

\section{4 sites}

Zones importantes pour les oiseaux et la biodiversité

\section{3 sites}

Zones clés pour la biodiversité 
Figure 8.44 : Aires protégées d'Ouganda

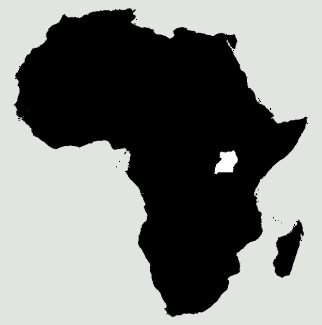

Aires protégées

Limites administratives
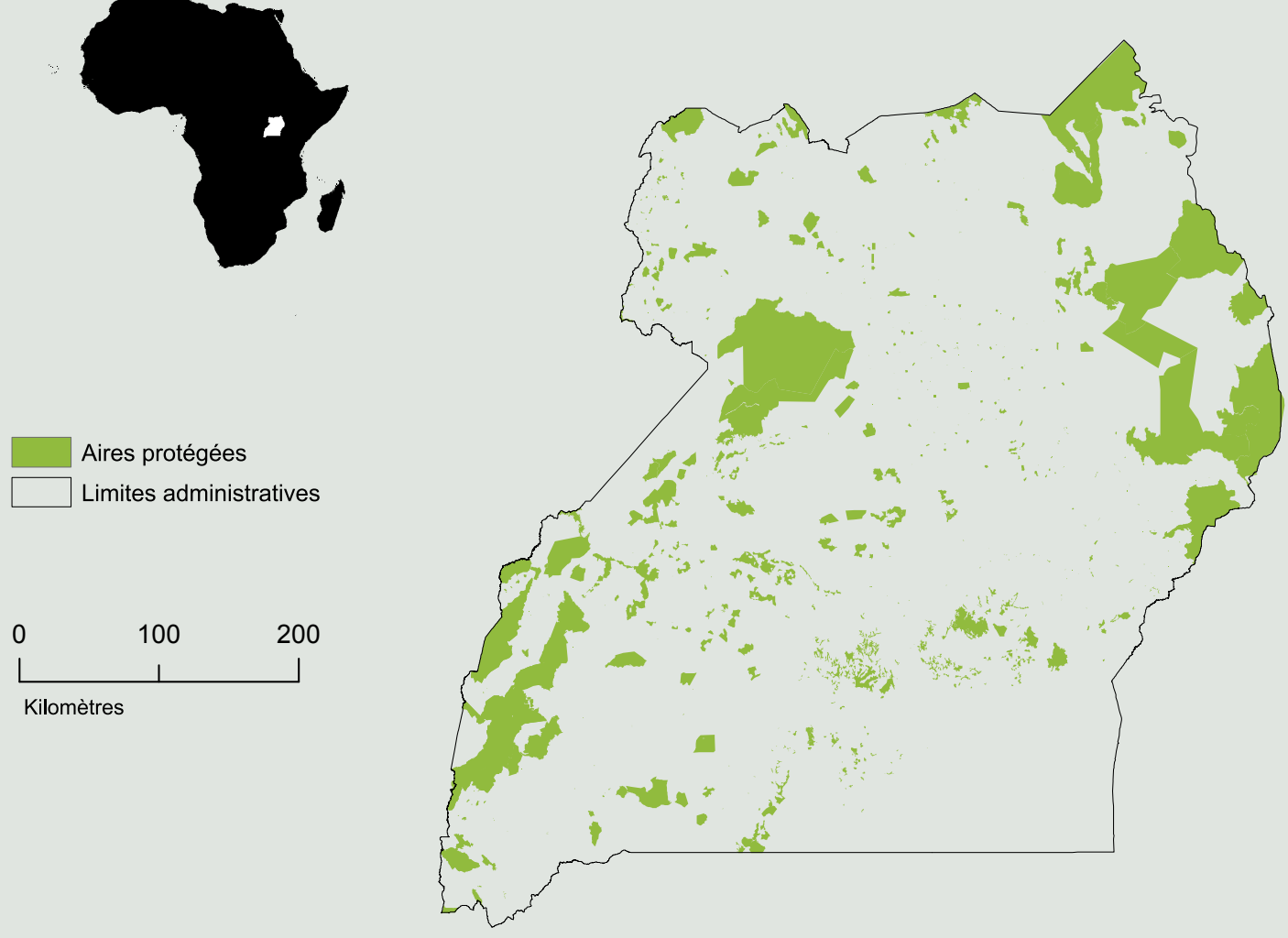

\section{Pressions et menaces ${ }^{99}$}

L'Ouganda fait face à de nombreuses menaces pour sa biodiversité, dont la plus grave est la perte et la dégradation de ses habitats. L'empiétement excessif est répandu et les conflits homme-faune sont un problème permanent et croissant. Le braconnage et le commerce illicite d'espèces sauvages constituent également un grave problème, tout comme les pratiques de pêche destructrices. Les espèces exotiques envahissantes constituent des menaces particulières pour certains écosystèmes.

Le taux élevé de croissance démographique et le développement rapide de l'Ouganda pèsent sur les habitats naturels restants dans le pays. Des niveaux élevés de pauvreté font que les personnes dépendent toujours des ressources naturelles pour leur survie.

99 Cette section s'appuie sur les informations contenues dans le cinquième Rapport national de l'Ouganda à la CDB, ainsi que son deuxième SPANB (Republic of Uganda, 2016 Uganda National Environment Management Agency, 2014). 


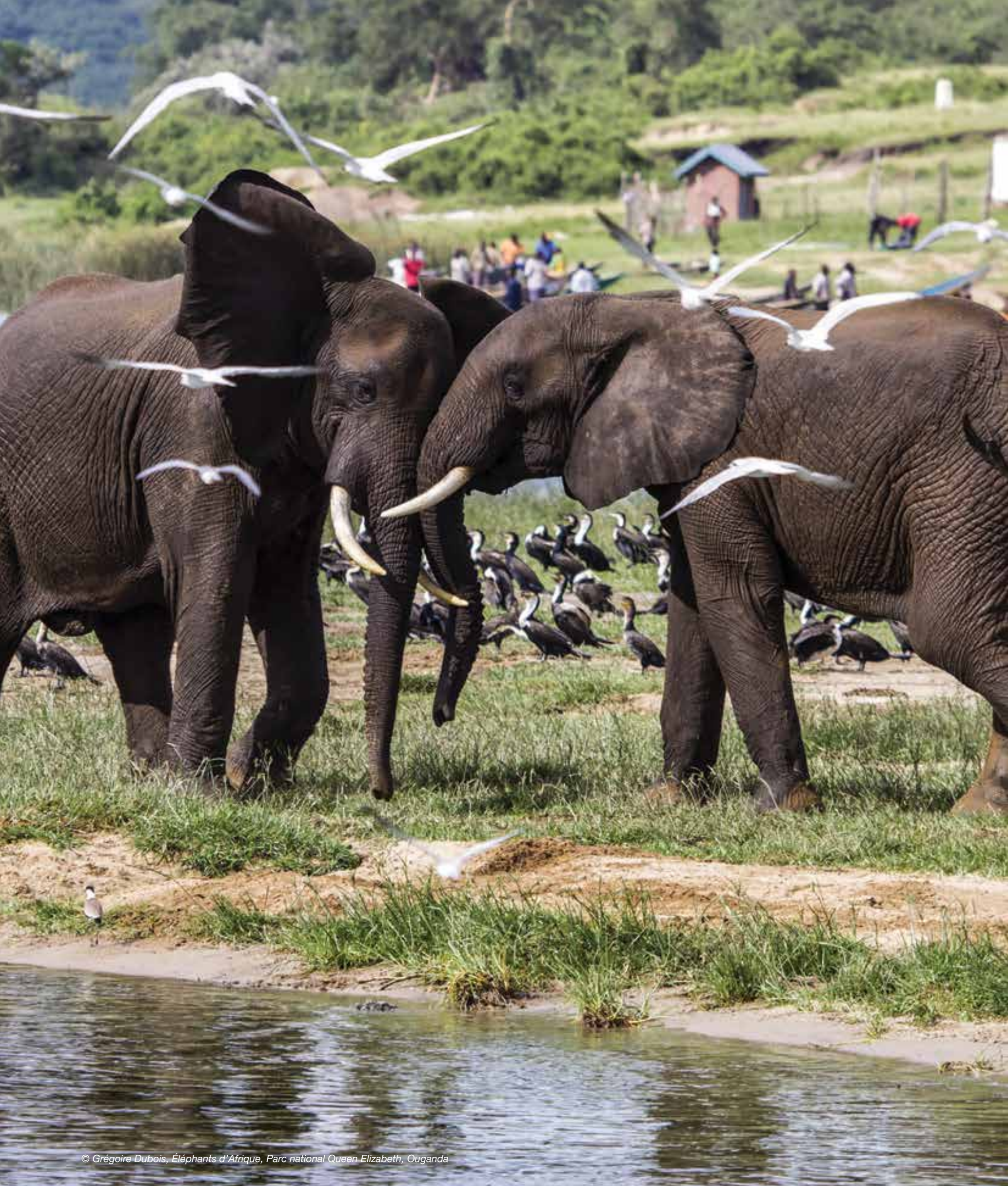




\subsection{Zambie}

\section{Aires protégées et de conservation de Zambie ${ }^{100}$}

La Zambie compte 635 aires protégées couvrant 286161 km² d'écosystèmes terrestres (UNEP-WCMC et IUCN, 2019x).

Pays enclavé et forestier d'Afrique australe, les agroécosystèmes et les zones humides de Zambie sont les écosystèmes les plus importants pour l'économie nationale et les moyens de subsistance ruraux. À ce jour, la conservation de la biodiversité a été entreprise grâce à la gestion du système existant d'aires protégées et à la promotion de l'utilisation durable des ressources naturelles dans les zones ouvertes.

Les principaux changements dans le statut des parcs nationaux, des réserves forestières et du système d'aires protégées de gestion du gibier depuis 2009 ont été la création d'un nouveau parc national à Lusaka, le déclassement de certaines réserves forestières et l'identification des lacunes de représentation des espèces végétales et animales dans les parcs nationaux et les aires de gestion du gibier existants, le plan de conservation par reclassement guidant les actions de conservation, dans la mesure du possible.

\section{Aires protégées et de conservation transfrontières}

La Zambie comprend une partie de six aires de conservation transfrontières, à savoir l'ACT du Kavango-Zambèze, l'ACT des plaines de Liuwa-Mussuma, l'ACT du Bas Zambèze-Mana Pools, I'ACT Malawi-Zambie, le site transfrontalier du Patrimoine mondial de Mosi-oa-Tunya / Chutes Victoria, et I'ACT ZIMOZA.

\section{Contexte politique}

Un rapport complet sur la législation et les politiques relatives à la gestion, à la gouvernance et à l'équité des aires protégées a été réalisé par le programme BIOPAMA. II a recensé 79 lois et politiques pertinentes en Zambie (Tessema, 2019).

\section{Espèces clées ${ }^{101}$}

La Zambie abrite plus de 12500 espèces, dont près de 200 ont été évaluées comme menacées par la Liste rouge de I'UICN. Près de 4000 espèces végétales et 563 microorganismes ont été recensés. 224 espèces de mammifères ont été observées, dont beaucoup sont économiquement importantes pour la chasse et le tourisme, ainsi que 490 espèces de poissons. La Zambie abrite également plus de 750 espèces d'oiseaux, un chiffre relativement élevé pour un pays enclavé dominé par un seul biome.

\section{Pressions et menaces ${ }^{102}$}

Les écosystèmes zambiens sont confrontés à des menaces majeures, dont le déclassement des réserves forestières, principalement à des fins minières, la déforestation et la dégradation des habitats, les empiétement humains excessifs dans les aires protégées, les feux de brousse tardifs incontrôlés, la surexploitation de certaines espèces d'arbres ainsi que de mammifères pour la viande de brousse et le commerce illégal d'espèces sauvages, la surpêche des écosystèmes d'eau douce, la pollution liée à l'agriculture, l'exploitation minière et autres activités industrielles, et les espèces exotiques envahissantes.

100 Cette section s'appuie sur les informations contenues dans les cinquième et sixième Rapports nationaux de la Zambie à la CDB (Republic of Zambia, 2015; 2019).

01 Cette section s'appuie sur les informations contenues dans le cinquième Rapport national de la Zambie à la CDB (Republic of Zambia, 2015).

102 lbid. 
Figure 8.45 : Résumé de la Zambie

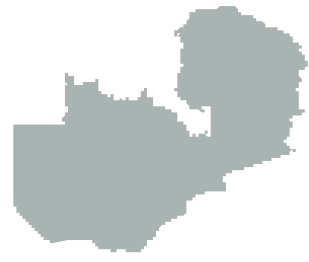

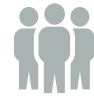

Population totale (en millions)

17,35

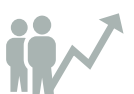

Démographie (\% annuel)

2,90

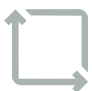

Superficie (en milliers de $\mathrm{km}^{2}$ )

752,60

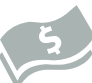

PIB (en milliards de USD actuels)

26,72
Croissance du PIB (\% annuel)

Source : The World Bank Group, 2018.

\section{Aires protégées :}

\section{5}

aires

protégées

couverture terrestre

$286161 \mathrm{~km}^{2}$

Source : UNEP-WCMC et IUCN (2019x)

\section{Plus de 12500 espèces}

\section{catégorie de gestion de l'UICN}

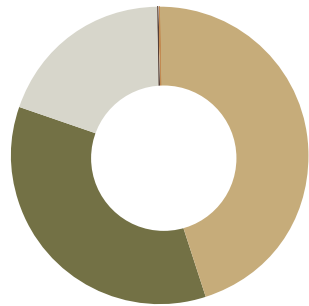

Ne s'applique pas (1)

Non rapportée (562)

VI. Aire protégée avec utilisation durable des ressources naturelles (36)

IV. Aire de gestion habitats / espèces (1)

III. Monument naturel (16)

II. Parc national (19)

Source : UNEP-WCMC et IUCN (2019x).

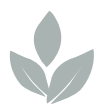

\section{0 espèces végétales}

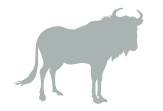

224 espèces de mammifères
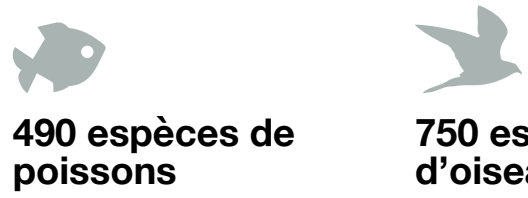
poissons
Couverture des aires protégées en Zambie

\begin{tabular}{l|r|r}
\hline Type d'aire protégée & $\begin{array}{r}\text { Aire protégée } \\
\text { ou conservée* }\end{array}$ & $\begin{array}{r}\text { Aire protégée } \\
\text { ou conservée** }\end{array}$ \\
\hline $\begin{array}{l}\text { Terrestres et eaux } \\
\text { intérieures }\end{array}$ & $37,87 \%$ & $37,80 \%$ \\
\hline
\end{tabular}

* Ensemble de données de la BDMAP $\quad{ }^{* *}$ Rapport national sur la biodiversité

Source : Republic of Zambia (2019); UNEP-WCMC et IUCN (2019x).

Aires protégées et de conservation désignées comme sites d'importance mondiale en Zambie

\begin{tabular}{l|r}
\hline Désignation mondiale & $\begin{array}{r}\text { Nombre de } \\
\text { sites }\end{array}$ \\
\hline $\begin{array}{l}\text { Patrimoine Mondial de l'UNESCO } \\
\text { (naturel ou mixte) }\end{array}$ & 1 \\
\hline $\begin{array}{l}\text { Zones humides d'importance internationale } \\
\text { (sites Ramsar) }\end{array}$ & 8 \\
\hline
\end{tabular}

Source : Ramsar (2019) ; UNESCO (2019a, 2019b).

Aires protégées et de conservation de Zambie par type de gouvernance de I'UICN

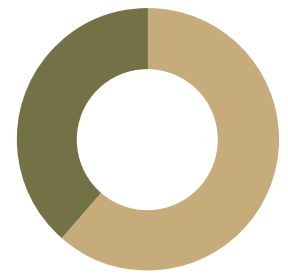

Non rapporté (586)

A.Gouvernance par le gouvernement (49)
Désignations nationales des aires protégées et de conservation en Zambie

\begin{tabular}{l|r|r}
\hline Désignation nationale & $\mathbf{N}^{\circ}$ & $\begin{array}{r}\text { Superficie } \\
\left(\mathbf{k m} \mathbf{2}^{2}\right.\end{array}$ \\
\hline Aires de conservation* & 1 & $\begin{array}{r}\text { Information non } \\
\text { disponible }\end{array}$ \\
\hline Parc national & 19 & 60457 \\
\hline Monument naturel & 16 & 74 \\
\hline Aire de gestion de la chasse & 34 & 140447 \\
\hline Réserve forestière & 555 & 79893 \\
\hline Sanctuaire pour les oiseaux & 1 & 127 \\
\hline $\begin{array}{l}\text { Source : UNEP-WCMC et IUCN (2019x). } \\
\text { *Ce site n'est associé à aucune superficie dans la BDMAP }\end{array}$ \\
\end{tabular}

\section{Aires prioritaires pour la conservation}

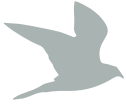

\section{2 sites}

Zones importantes pour les oiseaux et la biodiversité

\section{6 sites}

Zones clés pour la biodiversité 
Figure 8.46 : Aires protégées de Zambie

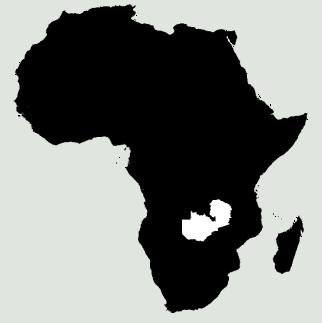

Aires protégées

Limites administratives

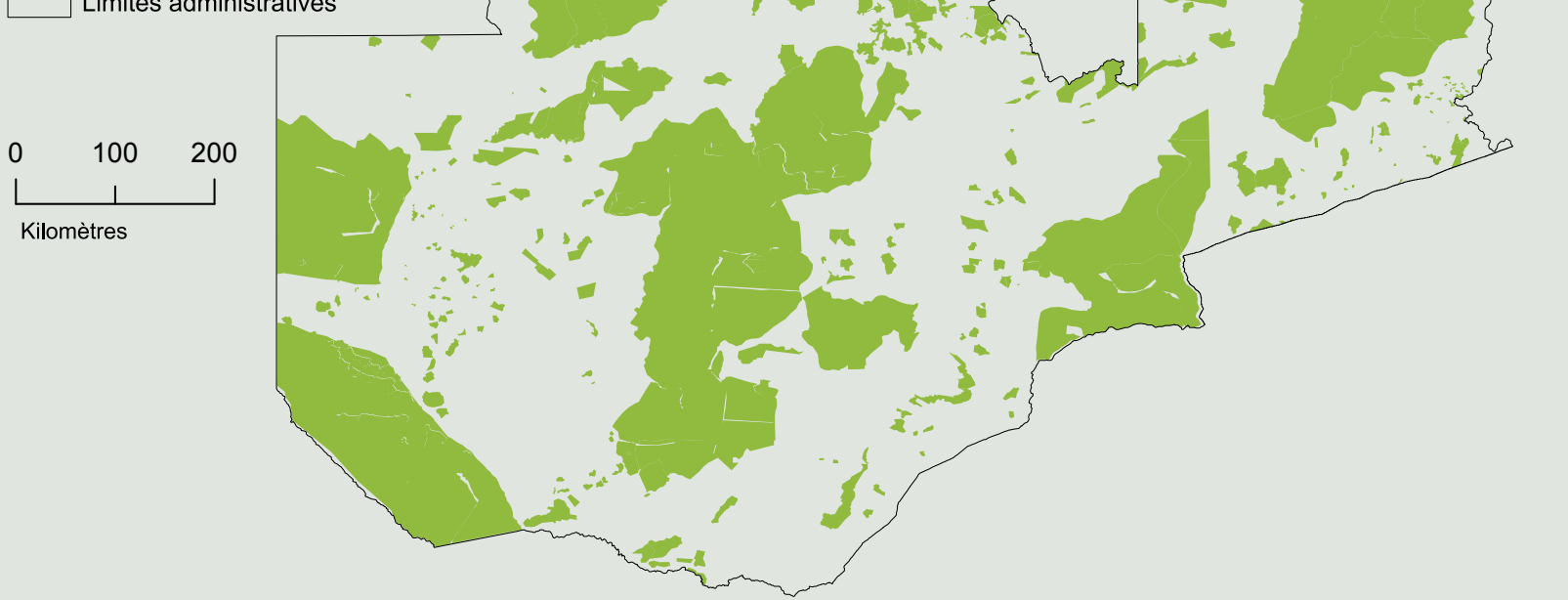

Développé par le RCMRD à partir des données BDMAP.

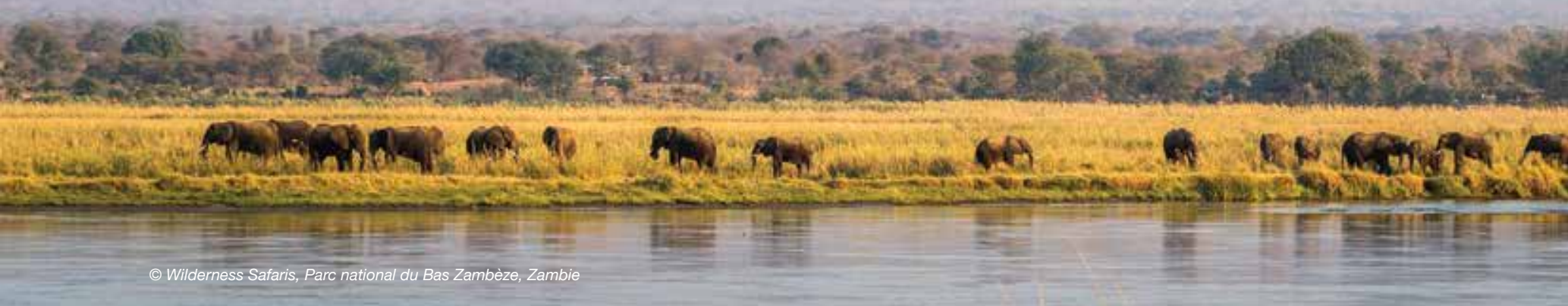




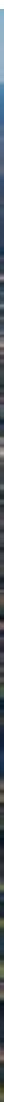

\subsection{Zimbabwe}

\section{Aires protégées et de conservation du Zimbabwe ${ }^{103}$}

Le Zimbabwe compte 232 aires protégées couvrant 106838 km² (UNEP-WCMC et IUCN, 2019y).

Le Zimbabwe possède une riche histoire de conservation de la biodiversité. Le pays a mis en place un vaste réseau d'aires protégées et adopté une législation pour la conservation et la préservation strictes de certains sites, et une utilisation durable dans d'autres. Son réseau d'aires protégées place le Zimbabwe parmi les 50 premiers pays du monde en ce qui concerne la couverture des aires protégées. La biodiversité est une base importante pour l'économie du Zimbabwe, et soutient les moyens de subsistance de la majorité de sa population. Le cadre politique et les stratégies élaborés au cours de la dernière décennie reconnaissent l'importance de la conservation de la biodiversité pour le développement durable, et celle-ci a été intégrée à tous les secteurs.

Le gouvernement a mis en place le programme CAMPFIRE dans le but de maximiser les options de subsistance des agriculteurs déplacés, en particulier ceux vivant dans des zones où la production agricole ne présente qu'un potentiel limité, en assurant une utilisation rentable, équitable et durable de la faune sauvage et autres ressources. Les projets CAMPFIRE impliquent les communautés dans la cogestion de la faune sauvage au sein de zones communautaires.

\section{Aires protégées et de conservation transfrontières}

Le Zimbabwe comprend une partie de sept aires de conservation transfrontières, à savoir l'ACT de Chimanimani, le Parc transfrontalier et aire de conservation du Grand Limpopo, l'ACT du Grand Mapungubwe, I'ACT du Kavango-Zambèze, l'ACT Bas Zambèze-Mana Pools, la site transfrontalier du Patrimoine mondial de Mosi-oa-Tunya / Chutes Victoria, et l'ACT ZIMOZA.

\section{Contexte politique}

Un rapport complet sur la législation et les politiques relatives à la gestion, à la gouvernance et à l'équité des aires protégées a été réalisé par le programme BIOPAMA. II a identifié 25 lois et politiques pertinentes au Zimbabwe (Tessema, 2019).

\section{Espèces clées ${ }^{104}$}

Le Zimbabwe abrite près de 6000 espèces de plantes vasculaires, dont 214 sont endémiques. 211 espèces sont considérées comme menacées, mais il s'agit là d'un chiffre incomplet, car seulement $10 \%$ des espèces ont été évaluées quant à leur statut de menace. Le Zimbabwe abrite également 670 espèces d'oiseaux, 270 mammifères, 156 reptiles, 120 amphibiens et 151 espèces de poissons. Les connaissances sur les microorganismes sont limitées.

103 Cette section s'appuie sur les informations contenues dans le sixième Rapport national du Zimbabwe à la CDB (Republic of Zimbabwe, 2019).

104 Cette section s'appuie sur les informations contenues dans le cinquième Rapport national du Zimbabwe à la CDB, ainsi que dans son deuxième SPANB (Republic of Zimbabwe, 2014, 2015). 
Figure 8.47 : Résumé du Zimbabwe

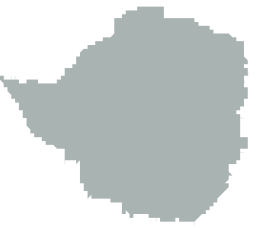

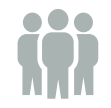

Population totale (en millions)

14,44

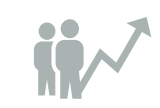

Démographie (\% annuel)

1,40

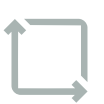

Superficie (en milliers de $\mathrm{km}^{2}$ )

390,80

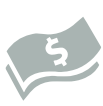

PIB (en milliards de USD actuels)

31,00

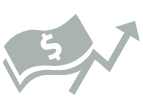

Croissance du PIB (\% annuel)

6,20

\section{Aires protégées :}

\section{2 aires protégées \\ couverture terrestre 106838 km² $^{2}$}

Aires protégées et de conservation du Zimbabwe par catégorie de gestion de I'UICN

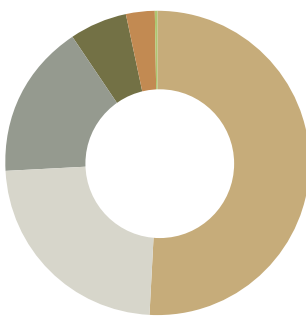

Ne s'applique pas (3)

Non rapportée (166)

VI. Aire protégée avec utilisation durable des ressources naturelles (19)

V. Paysage terrestre / marin protégé (12)

IV. Aire de gestion habitats / espèces (19)

III. Monument naturel (2)

II. Parc national (10)

Source : UNEP-WCMC et IUCN (2019y).

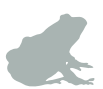

120 amphibiens
151 espèces de poissons
156 espèces de reptiles

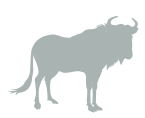

270 mammifères

670 espèces d'oiseaux
Couverture des aires protégées au Zimbabwe

\begin{tabular}{l|r|r}
\hline Type d'aire protégée & $\begin{array}{r}\text { Aire protégée } \\
\text { ou conservée* }\end{array}$ & $\begin{array}{r}\text { Aire protégée } \\
\text { ou conservée** }\end{array}$ \\
\hline $\begin{array}{l}\text { Terrestres et eaux } \\
\text { intérieures }\end{array}$ & $27,21 \%$ & $28,00 \%$ \\
\hline *Ensemble de données de la BDMAP & ** Rapport national sur la biodiversité \\
Source : Republic of Zimbabwe (2015); UNEP-WCMC et IUCN (2019y).
\end{tabular}

Aires protégées et de conservation désignées comme sites d'importance mondiale au Zimbabwe

\begin{tabular}{l|r}
\hline Désignation mondiale & $\begin{array}{r}\text { Nombre de } \\
\text { sites }\end{array}$ \\
\hline Réserves de biosphère de l'UNESCO & 1 \\
\hline $\begin{array}{l}\text { Patrimoine Mondial de I'UNESCO } \\
\text { (naturel ou mixte) }\end{array}$ & 2 \\
\hline $\begin{array}{l}\text { Zones humides d'importance internationale } \\
\text { (sites Ramsar) }\end{array}$ & 7 \\
\hline
\end{tabular}

Source : Ramsar (2019) ; UNESCO (2019a, 2019b).

Aires protégées et de conservation du Zimbabwe par type de gouvernance de l'UICN

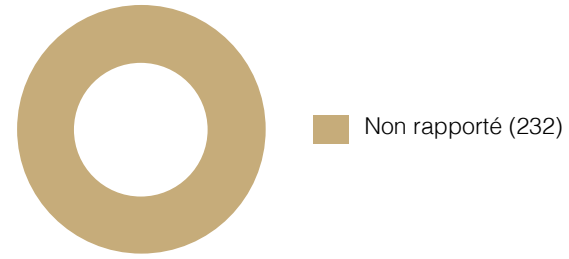

Source : UNEP-WCMC et IUCN (2019y).

Désignations nationales des aires protégées et de conservation au Zimbabwe

\begin{tabular}{l|r|r}
\hline Désignation nationale & $\mathbf{N}^{\circ}$ & $\begin{array}{r}\text { Superficie } \\
\left(\mathbf{k m}^{2}\right)\end{array}$ \\
\hline Sanctuaire & 11 & 6660 \\
\hline Parc national & 11 & 26896 \\
\hline Parc de loisirs & 9 & 3642 \\
\hline Monument national & 1 & 7 \\
\hline $\begin{array}{l}\text { Aire de gestion de la faune } \\
\text { sauvage }\end{array}$ & 104 & 39376 \\
\hline Réserve botanique & 14 & 16 \\
\hline Réserve naturelle & 1 & 17 \\
\hline Parc de loisirs & 3 & 129 \\
\hline Jardin botanique & 3 & 6 \\
\hline Aire de safari & 16 & 18988 \\
\hline Forêt publique & 43 & 9341 \\
\hline Forêt protégée & 6 & 608 \\
\hline
\end{tabular}

Source : UNEP-WCMC et IUCN (2019y).

\section{Aires prioritaires pour la conservation}
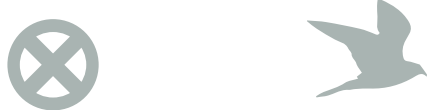

$\begin{array}{ll}1 \text { site } & 18 \text { sites } \\ \text { Sites de l'Alliance } & \text { Zones importantes } \\ \text { pour une extinction } & \begin{array}{l}\text { pour les oiseaux } \\ \text { et la biodiversité }\end{array}\end{array}$

6 sites

Zones clés pour la biodiversité 
Figure 8.48 : Aires protégées du Zimbabwe

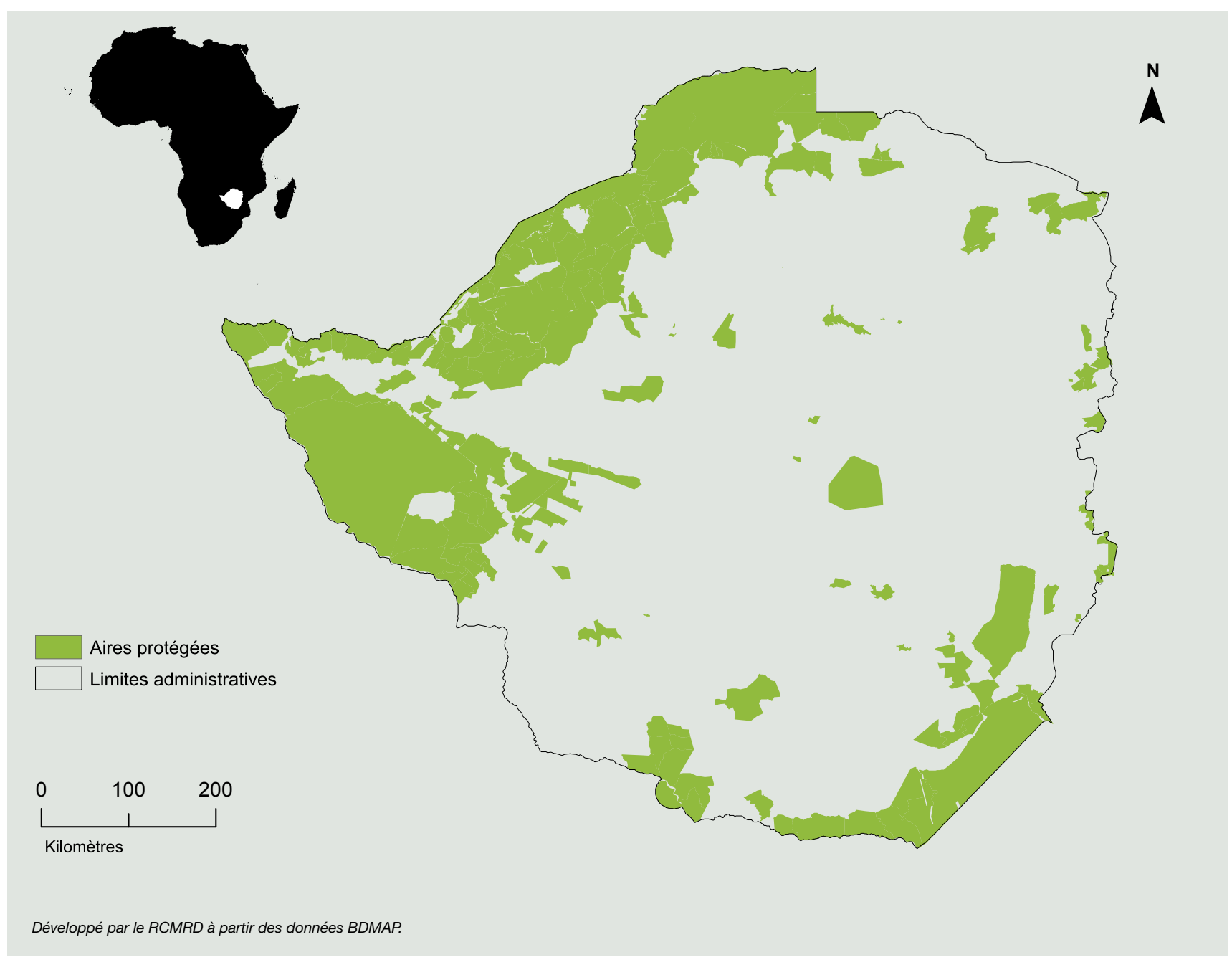

\section{Pressions et menaces ${ }^{105}$}

Les principales causes de perte de biodiversité au Zimbabwe sont la perte et la dégradation des habitats dues à l'expansion agricole non durable, le surpâturage, l'utilisation des arbres comme source d'énergie, les dommages causés par les incendies, l'exploitation minière et le développement d'infrastructures, les espèces exotiques envahissantes et les changements climatiques. De nombreux oiseaux, reptiles, amphibiens et mammifères sont également directement menacés par l'exploitation illégale ou non durable, pour le commerce illégal de viande de brousse. Les niveaux élevés de pollution dans les systèmes aquatiques du Zimbabwe ont également eu un impact important sur la biodiversité du pays.

Ces menaces directes découlent des défis à long terme que constituent la pauvreté, un développement économique incontrôlé et le manque de capacités institutionnelles pour gérer durablement les ressources naturelles. 

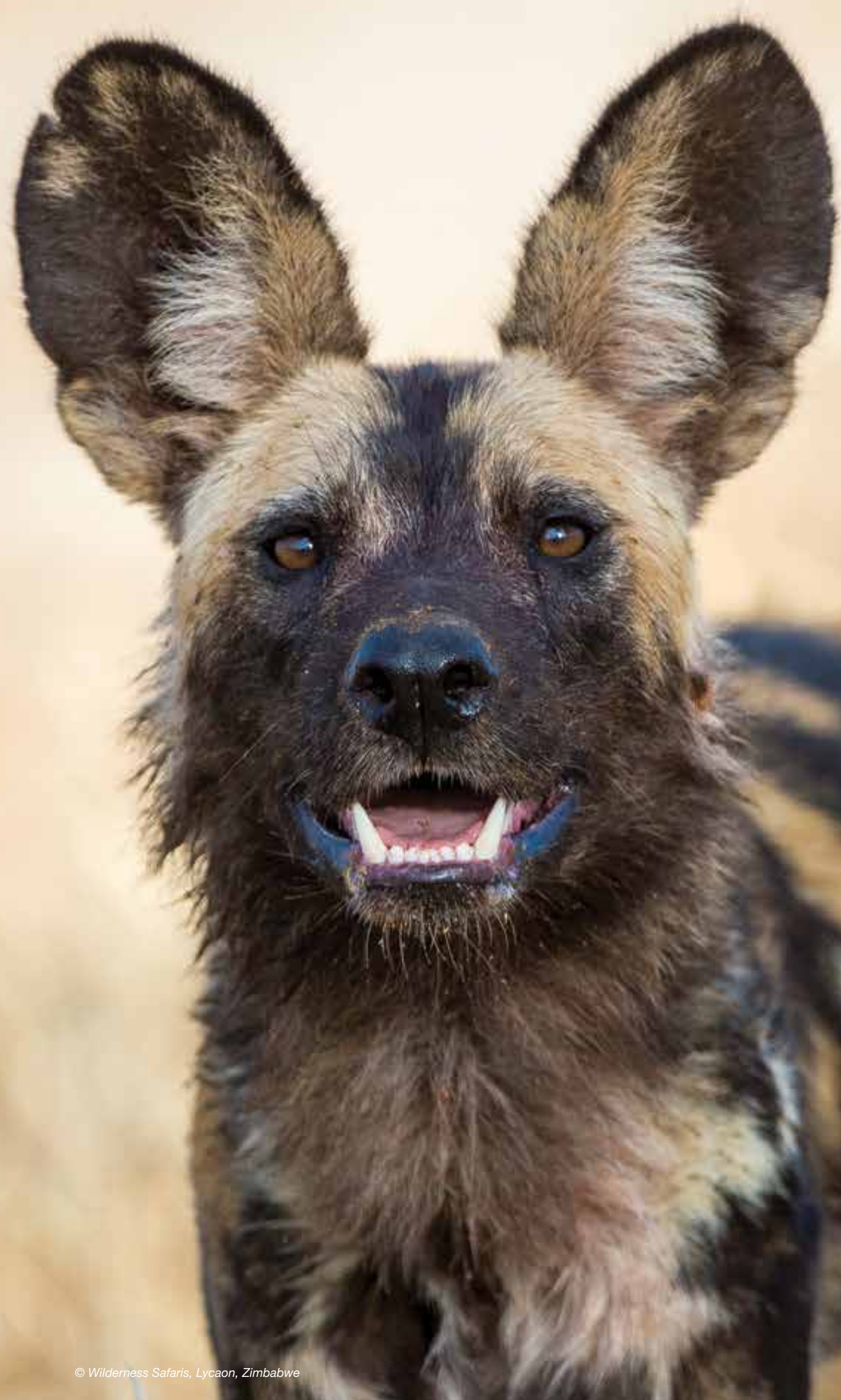

Partie III - Gouvernance et efficacité de la gestion

\section{Gouvernance et équité des aires protégées $^{106}$}


Les aires protégées sont la pierre angulaire des efforts mondiaux de conservation. Elles protègent la biodiversité, restaurent les paysages dégradés, fournissent des services écologiques et des moyens de subsistance et restent un lieu de reconnexion avec la nature. Cependant, les aires protégées ont également été l'objet de préoccupations fréquentes quant à des résultats injustes pour les personnes, y compris sur des questions de justice sociale et de droits de l'Homme. Des rapports récents de Rapporteurs spéciaux des Nations Unies ont mis en évidence l'ampleur de ces problèmes, en particulier en ce qui concerne les peuples autochtones et les communautés locales (ONU, 2016).

Depuis le début des années 1980, ces questions ont été analysées par la communauté de la conservation à l'échelle internationale (McNeely et Miller, 1984), et notamment lors du Ve Congrès mondial des parcs de I'UICN, en 2003 (UICN, 2005a; 2005b). En 2010, l'Objectif d'Aichi 11, adoptée par les 193 États Parties à la CDB, a déclaré que les aires protégées devaient être gérées de façon équitable d'ici 2020 (CDB, 2010b). Le mot "équité » traduit la notion de justice, et la raison d'être de son incorporation à la conservation par zone est articulée dans le texte soutenant le Programme de travail sur les aires protégées (PTAP) : " les aires protégées devront également être créées et gérées en étroite collaboration avec les communautés autochtones et locales, et les populations vulnérables, et par des processus équitables reconnaissant et respectant leurs droits " (SBSTTA, 2010). Peu d'informations sont encore disponibles sur ses éléments de l'Objectif d'Aichi 11 (Gannon et al., 2019) du fait, à la fois, de la complexité du concept d'équité et de l'absence de systèmes d'évaluation adéquats.

Bien que peu de tentatives pour comprendre et évaluer l'équité en matière de conservation aient vu le jour, des travaux substantiels sur ces questions ont été entrepris dans le contexte similaire des paiements pour services écosystémiques (McDermott et al., 2013). Ces travaux concluent que l'équité peut être conceptualisée selon trois dimensions fondamentales: reconnaissance, procédure et répartition.

Dans le contexte de la conservation des aires protégées, les trois dimensions de l'équité peuvent être interprétées comme suit :

- La reconnaissance fait référence à la reconnaissance et au respect des droits et de la diversité des identités, des valeurs, des systèmes de connaissances et des institutions des ayantdroits et des parties prenantes (voir également l'Encadré 9.1).

- La procédure fait référence à la transparence, à la responsabilité et à l'inclusivité de la prise de règles et de décisions.

- La répartition fait référence à l'atténuation des coûts affectant les communautés autochtones et locales, et au partage équitable des avantages découlant de la gestion des aires protégées (Schreckenberg et al., 2016)

Sur la base de ce cadre, les Parties à la CDB ont adopté des Directives volontaires sur l'équité lors de la CDP14, en novembre 2018, censées s'appliquer à n'importe quel contexte de conservation de la nature et de développement durable (CDB, 2018).

L'amélioration de l'équité augmente la contribution des aires protégées au bien-être humain, à la fois en augmentant et en partageant plus équitablement les avantages et en réduisant les coûts (équité dans la répartition), mais également par la contribution directe au bien-être subjectif d'une reconnaissance et d'un respect plus forts des parties prenantes (équité dans la reconnaissance) et de processus plus justes (équité des procédures) (Franks et al., 2018). Des données démontrent que l'amélioration de l'équité peut contribuer à une conservation plus fructueuse et plus efficace de la biodiversité (Oldekop et al., 2016).

Dans ce chapitre, deux points d'entrée distincts mais interdépendants permettant d'aborder l'équité en matière de conservation seront examinés :

(1) en améliorant la gouvernance au moyen d'évaluations de la gouvernance permettent d'identifier les faiblesses à corriger et les points forts à renforcer en matière de gouvernance ; et

(2) en augmentant les avantages et en réduisant les coûts au moyen d'évaluations sociales permettant de mieux comprendre les impacts positifs et négatifs des aires protégées sur le bienêtre des populations.

Le concept émergent des "zones de conservation " est un autre moyen d'accroître l'équité en matière de conservation par zone. La Section 2.3 du présent rapport aborde les zones de conservation plus en détail, ainsi que la reconnaissance du concept par la CDB à travers l'expression « autres mesures de conservation efficaces par zone » (AMCE).

\subsection{Gouvernance des aires protégées}

La gouvernance est un concept puissant pour l'équité, les droits et les moyens de subsistance. En effet, l'équité en matière de conservation est avant tout une question de gouvernance (Franks et al., 2018).

\section{Encadré 9.1 : Ayant-droits et parties prenantes, quelle différence ?}

Dans le contexte des aires protégées et de conservation, le terme " ayant-droit » désigne les acteurs socialement dotés de droits légaux ou coutumiers en relation avec les terres, l'eau et les ressources naturelles.

Les parties prenantes, quant à elles, possèdent des intérêts directs ou indirects en relation avec les ressources naturelles, mais ne disposent pas nécessairement de droits légaux ou sociaux sur celles-ci (Borrini-Feyerabend et al., 2014).

La définition de I'UICN de la gouvernance adopte une perspective dynamique : aborder la gouvernance ne consiste pas seulement à comprendre qui prend les décisions, mais va au-delà de cela pour prendre en compte les interactions entre les structures, les processus et les traditions qui déterminent comment le pouvoir et les responsabilités sont exercés, comment les décisions sont prises et comment les citoyens et autres parties prenantes ont leur mot à dire (Borrini-Feyerabend et al., 2014).

Dans le contexte des aires protégées, la gouvernance se préoccupe de savoir qui prend les décisions, comment ces décisions sont prises et dans quelle mesure elles sont appropriées, adaptatives et équitables pour toutes les parties concernées. Cela est essentiel car la gouvernance doit tenir compte d'une foule de facteurs, de la diversité des acteurs aux différents processus et phénomènes qui 


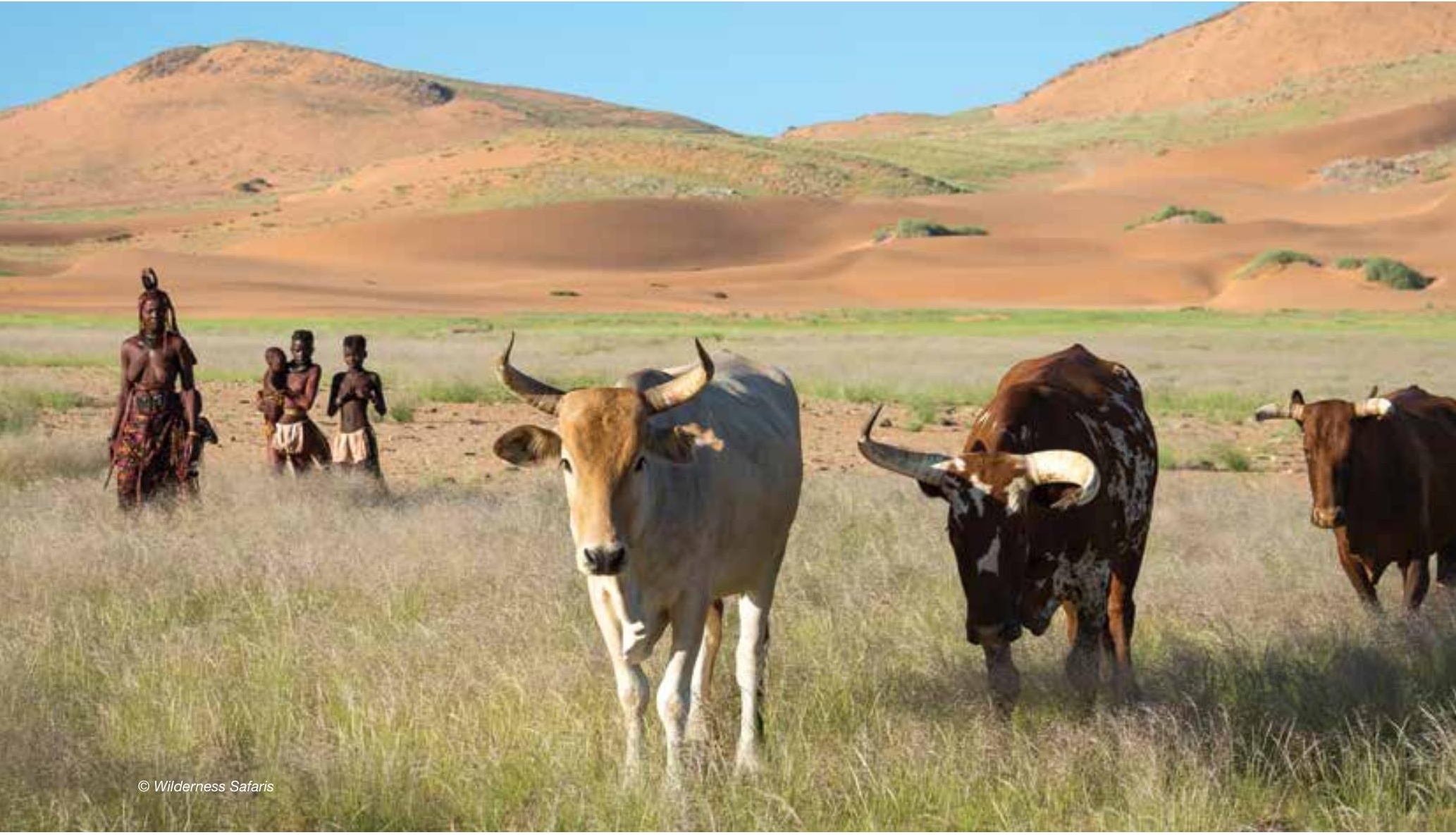

conduisent à la prise de décisions. Il s'agit également de déterminer qui a le mandat et les ressources nécessaires pour prendre des décisions, et qui devrait être tenu responsable de ces décisions. Un mandat de gouvernance peut être légitimé par une reconnaissance de jure (juridique), comme dans le cas d'une agence gouvernementale chargée des aires protégées, ou par une reconnaissance de facto, lorsque certains acteurs sont considérés comme prenant légitimement des décisions (par exemple, une communauté adoptant ses propres règles d'interdiction de pêche pour des motifs de restauration). Voir l'Encadré 9.2.

La gouvernance doit être distinguée de la gestion, bien que les deux termes soient étroitement liés. Là où la gestion concerne les activités entreprises pour atteindre certains objectifs, tels que les activités et les ressources décrites dans un plan de gestion, la gouvernance concerne les acteurs ayant décidé d'élaborer ce plan de gestion et les considérations ayant été prises pour cela. La gouvernance est couramment discutée et de plus en plus évaluée selon deux dimensions : la diversité de la gouvernance (ou type de gouvernance) et la qualité de la gouvernance (ou bonne gouvernance).

\subsubsection{Diversité de la gouvernance}

La diversité de la gouvernance vise à reconnaître le large éventail d'acteurs de la gouvernance, de jure ou de facto, détenant une responsabilité et une autorité en matière d'aires protégées. À ce jour, la plupart des aires protégées de la région ont été établies par les gouvernements des États au moyen de lois et de politiques à l'échelle nationale. Cela se reflète dans les données de la BDMAP
(UNEP-WCMC et IUCN, 2019b). Cependant, de nombreuses aires protégées existantes sont enracinées dans une forme ou une autre de modalités de gouvernance locale, par des communautés dans leurs propres aires de conservation ou par le biais d'initiatives privées. En plus des aires protégées gérées par les gouvernements, il existe des aires protégées établies par des peuples autochtones, des communautés locales, des particuliers, des opérateurs d'écotourisme ou autres. Comme pour les six catégories de gestion des aires protégées, allant de réserves naturelles intégrales (Catégorie la) à des paysages terrestres et marins protégés en vue d'une utilisation durable des ressources naturelles (Catégorie VI), I'UICN et la CDB encouragent également la pleine reconnaissance de la diversité des types de gouvernance dans les systèmes nationaux d'aires protégées. À cet égard, quatre grands types de gouvernance sont reconnus pour les aires protégées (voir le Tableau 9.1), représentant entre eux un éventail complet de la diversité de la gouvernance dans les systèmes d'aires protégées (Belle et al., 2015; Borrini-Feyerabend et al., 2014; CDB, 2004 et 2010a; Dudley, 2008).

Sur tout le continent africain, la plupart des aires protégées sont gérées par les gouvernements (type A), bien que les types $B$ et $C$ soient également représentés, même s'ils ne sont pas toujours rapportés ou bien compris (UNEP-WCMC, 2019a; UNEP-WCMC \& IUCN, 2019a). Les aires protégées vont de parcs nationaux gérés par les gouvernements à des aires protégées partagées, gouvernées conjointement par des organismes publics et des communautés, en passant par des réserves privées et des partenariats public-privé entre gouvernements et entreprises privées ou ONG. La quatrième catégorie, ou Type $D$, peut-être 
Tableau 9.1: Types de gouvernance de I'UICN pour les aires protégées

\begin{tabular}{l|l}
\hline Type de gouvernance & Sous-types \\
\hline Type A : Gouvernance par un gouvernement & $\begin{array}{l}\text { - Ministère ou agence nationale des aires protégées } \\
\text { - Agence infranationale (à tous les niveaux) }\end{array}$ \\
\hline Type B : Gouvernance partagée & $\begin{array}{l}\text { - Modalités de gouvernance transfrontalière } \\
\text { - Gouvernance collaborative (par le biais de diverses façons de travailler ensemble } \\
\text { avec divers acteurs et institutions) }\end{array}$ \\
& $\begin{array}{l}\text { - Gouvernance conjointe (conseil pluraliste ou autre organe directeur multipartite) } \\
\text { Type C : Gouvernance privée }\end{array}$ \\
& $\begin{array}{l}\text { - Propriétaires fonciers individuels } \\
\text { - Organisations à but non lucratif ou à but lucratif }\end{array}$ \\
\hline $\begin{array}{l}\text { Type D : Gouvernance par les peuples } \\
\text { autochtones et / ou les communautés locales } \\
\text { (souvent appelées APAC ou territoires de vie) }\end{array}$ & $\begin{array}{l}\text { - Aires et territoires du patrimoine autochtone et communautaire, établies et gérées } \\
\text { pares communautaires de conservation : établies et gérées par des communautés } \\
\end{array}$ \\
\hline
\end{tabular}

Source : Borrini-Feyerabend et al. (2014).

moins bien comprise mais présentant un grand potentiel, est celle des aires du patrimoine autochtone et communautaire (APAC). Les APAC sont reconnues non seulement par la CDB, mais également par d'autres politiques et accords internationaux, et sont étroitement liées aux instruments des Nations Unies sur les droits de l'Homme et les peuples autochtones. Les APAC peuvent être comptabilisées dans les statistiques nationales concernant l'Objectif d'Aichi 11 en vertu des dispositions relatives aux AMCE. Les Aires marines gérées localement (AMGL) représentent un modèle de gouvernance établi et géré grâce à une forte implication des communautés et des autorités locales (voir l'Encadré 9.3), et peuvent également être reconnues comme aires protégées ou AMCE.

Sur le plan politique, le PTAP (CDB, 2004) a appelé les Parties à la CDB à :

- soutenir des types innovants de gouvernance pour les aires protégées (voir l'Encadré 9.3 pour un exemple au Zimbabwe) ;

- les reconnaître dans la législation nationale ou par d'autres moyens efficaces ;

- rechercher l'équité et l'efficacité en matière de conservation, tout en élargissant la couverture ;

- intensifier les efforts de restauration ; et

- impliquer les connaissances, les compétences et les institutions autochtones et traditionnelles.

II est essentiel de noter qu'il n'existe pas de modalité de gouvernance universelle ou « meilleure » dans un contexte donné. II est plus réaliste d'analyser dans quelle mesure ces modalités seront appropriées, légitimes et utiles dans différentes circonstances. Une modalité de gouvernance pour une aire protégée donnée ne peut être considérée comme appropriée que lorsqu'elle est adaptée à son contexte historique et social, et qu'elle est efficace pour produire des résultats durables de conservation et des avantages en matière de moyens de subsistance. Tous les principes de qualité de la gouvernance énoncés à la Section 9.1.2 devraient s'appliquer à n'importe quel site, quel que soit le type de gouvernance, bien que le niveau de participation des parties prenantes et des ayant-droits puisse varier.

\subsubsection{Qualité de la gouvernance}

Encourager la gamme complète de types de gouvernance dans un contexte national est l'une des principales conditions favorables à l'équité (Schreckenberg et al., 2016), bien que ceci ne garantisse pas que toutes ces aires protégées soient gérées de manière équitable ou efficace.

À l'échelle des sites, d'autres préoccupations apparaissent également, telles que :

- Comment les décisions sont-elles prises au sujet de l'aire protégée?

- Ces décisions sont-elles équitables ?

- Quelles valeurs guident ces décisions ?

- À quel point la prise de décision est-elle transparente ?

- Les ayant-droits (ceux disposant d'un droit légal ou coutumier sur la terre et les ressources) sont-ils impliqués ?

- Les parties prenantes (ceux possédant un intérêt direct ou indirect) ont-elles été impliquées ?

À partir de ces questions, et en s'appuyant sur les principes des Nations Unies pour une bonne gouvernance (Graham et al., 2003), un sentiment de qualité de la gouvernance, parfois appelé bonne gouvernance (Tableau 9.2) commence à se développer.

Les principes de bonne gouvernance offrent des moyens de mettre en œuvre des approches fondées sur les droits et d'aborder les questions d'équité et d'égalité hommes-femmes, ainsi que d'inclusion des groupes marginalisés. À ce titre, la bonne gouvernance habilite les ayant-droits et autres parties prenantes, permettant une meilleure intégration des aires protégées dans le paysage local et les préoccupations plus générales de la société (voir l'Encadré 9.5).

Ensemble, la diversité et la qualité de la gouvernance sont les pierres angulaires de l'équité dans la conservation des aires protégées et de l'efficacité à long terme de la conservation de la biodiversité (de Koning et al., 2016; Eklund et Cabeza, 2017; Gutiérrez et al., 2011; Schultz et al., 2015; Stoll-Kleeman et al., 2006).

Les rapports sur la diversité et la qualité de la gouvernance à l'aide d'évaluations de la gouvernance constituent aujourd'hui un intérêt majeur au sein de la communauté de la conservation (voir la Section 9.4). 


\section{Encadré 9.2: Relancer la conservation marine grâce à la gestion locale de la pêche}

À Andavadoaka, Madagascar, les fermetures volontaires et temporaires des zones de pêche au poulpe sont utilisées comme point d'entrée pour la conservation communautaire. Les fermetures couvrent généralement $25 \%$ de la zone de pêche globale au poulpe d'une communauté et restent en vigueur pendant 2 à 3 mois chaque fois. II existe des preuves convaincantes que ce système améliore les rendements de pêche et les revenus locaux, renforçant ainsi le soutien à la protection des ressources naturelles par le biais d'aires marines gérées localement (AMGL), des sites où la gestion des ressources marines est, au moins en partie, sous contrôle communautaire. Les AMGL utilisent souvent des stratégies de gestion marine, telles que des interdictions des pratiques de pêche destructrices et des zones d'interdiction permanentes imposées par les communautés.

Parmi les défis rencontrés dans la région figurent les changements climatiques, la surpêche, la pauvreté et l'insécurité alimentaire côtières croissantes, ainsi que le manque d'incitations à la conservation. De nombreux efforts de conservation marine échouent. La déclaration descendante de vastes zones d'interdiction définitive de la pêche met trop souvent la conservation en contradiction avec les besoins des communautés côtières, au détriment des personnes tributaires de la pêche pour leur subsistance. Pour de nombreuses communautés côtières tropicales, renoncer à la pêche dans les aires protégées représente un sacrifice économique extrêmement grave et un coût d'opportunité important.
Des études sur l'efficacité des mesures d'interdiction temporaire de pêche au poulpe ont montré que celles-ci peuvent améliorer les captures et les revenus, les débarquements de poissons provenant de sites de pêche soumis à une interdiction temporaire augmentant de plus de $700 \%$ dans le mois suivant la levée de l'interdiction, et augmentant les captures par pêcheur et par jour de près de $90 \%$ sur la même période. À Madagascar, le succès des interdictions précoces a conduit d'autres communautés à suivre l'exemple, et plus de 270 interdiction temporaires ont été mises en place à ce jour. Leur adoption augmente chaque année, non seulement à Madagascar, mais également dans d'autres pays de la région. L'approche a également été reproduite pour la pêche artisanale au crabe de palétuvier et à la langouste. Suite à la mise en place réussie des interdictions temporaires de pêche, les communautés de pêcheurs de Madagascar se sont regroupées pour créer plus de 190 associations de gestion et 70 AMGL interdisant les pratiques de pêche destructrices. MIHARI, le réseau d'AMGL de Madagascar, couvre aujourd'hui plus de $17 \%$ des fonds marins de l'île, et bénéficie de soutiens aux plus hauts niveaux du gouvernement. À la fin de 2017, les travaux de Blue Ventures à Madagascar amélioraient la vie de plus de 200000 personnes. L'impératif est maintenant de répliquer cette approche fructueuse dans d'autres communautés côtières de l'océan Indien.

Contribution de Rupert Quinlan (Blue Ventures, Madagascar).

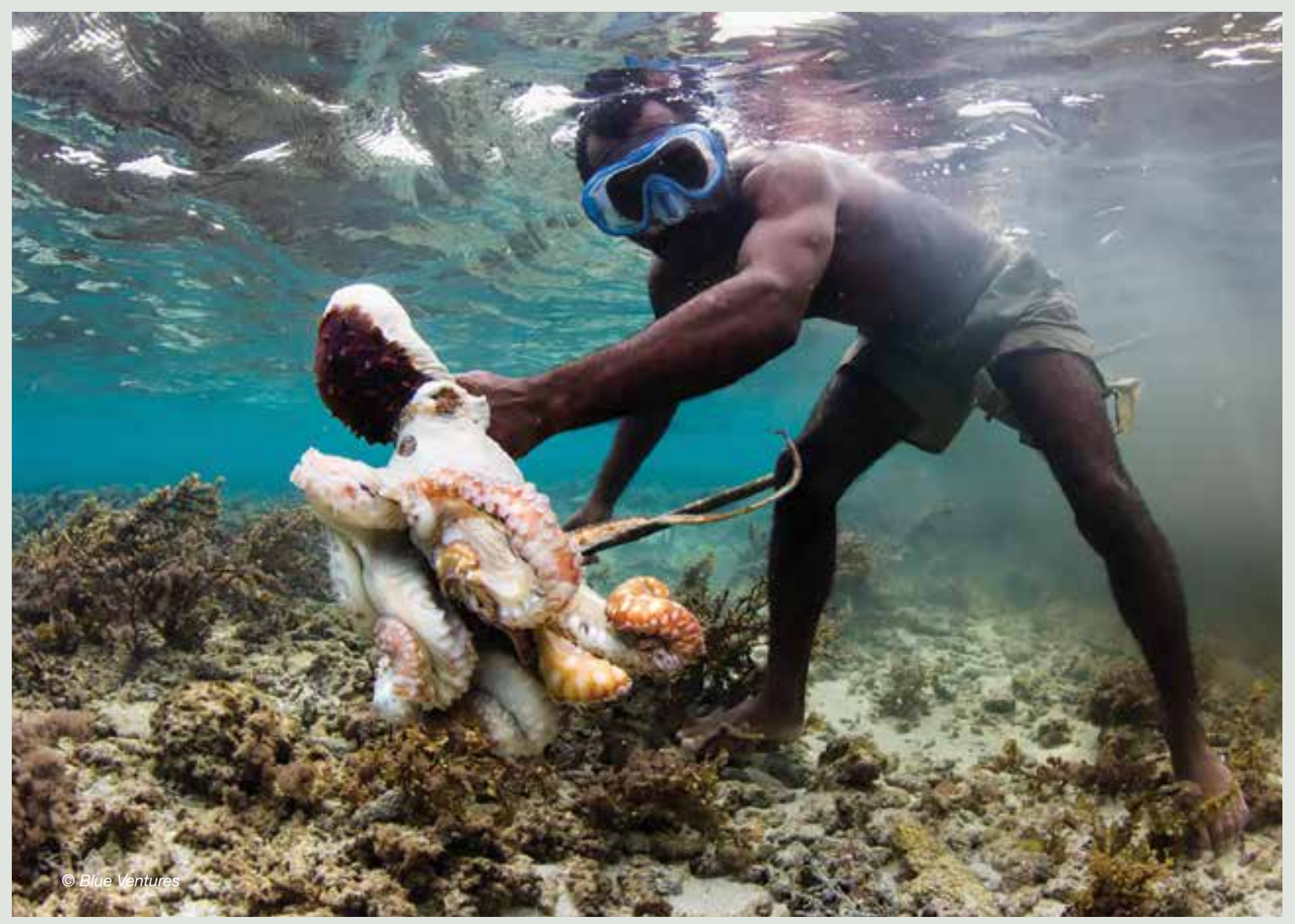




\subsection{Bonne gouvernance et Liste verte de I'UICN des aires protégées et de conservation}

Comme décrit dans la Section 2.4, la norme de la Liste verte de I'UICN des aires protégées et de conservation (norme de la Liste verte de l'UICN) est la nouvelle norme internationale de durabilité permettant de comparer les aires protégées et de conservation en termes d'efficacité et d'équité (Hockings et al., 2019).

La norme de la Liste verte de I'UICN décrit un ensemble cohérent de 17 critères à l'échelle mondiale, classés en quatre composantes, accompagnés de 50 indicateurs concernant les aires protégées et de conservation, pour une conservation réussie à l'échelle des sites. La première composante de la norme est axée sur la bonne gouvernance ou qualité de la gouvernance.

Les sites candidats s'engageant volontairement à rejoindre le programme de la Liste verte de I'UICN analyseront d'abord le critère de la composante de bonne gouvernance de I'UICN, qui concerne la légitimité et la voix. Cela vise à garantir qu'une autorité de gouvernance équitable, fonctionnelle et légitime soit en place, et qu'elle tienne compte des voix et intérêts de tous les ayantdroits locaux et parties prenantes concernés de manière significative. L'évaluation commence par l'autorité de gouvernance elle-même et examine la légitimité de l'autorité et son fonctionnement. Par la suite, la norme vise à garantir le maintien d'un dialogue actif avec tous les ayant-droits et toutes les parties prenantes, et en particulier les femmes. L'accent est mis sur la recherche de solutions répondant, au moins en partie, aux préoccupations et intérêts de chacun, tout en promouvant le respect mutuel entre tous les acteurs.

Le deuxième critère de la composante de bonne gouvernance de I'UICN vise à faire en sorte que l'autorité dirigeante soit tenue responsable devant le public en tant que décideur, et que les personnes sachent qui est responsable de l'accomplissement des différentes responsabilités à différents niveaux. L'objectif est de maintenir l'intégrité et l'engagement de tous les décideurs, tout en veillant à ce que les moyens d'exiger des comptes soient accessibles à tous.

Le troisième et dernier critère concerne la vitalité de la gouvernance. Il analyse dans quelle mesure la planification et la gestion s'appuient sur les meilleures connaissances disponibles dans le contexte social et écologique du site, et utilisent un cadre de gestion adaptative qui anticipe, apprend et réagit. En particulier, le critère vise à déterminer s'il existe des procédures permettant de s'assurer que les résultats du suivi guident les décisions de gestion. Cela peut inclure le fait que la gestion tienne compte de changements historiques qui aideront à guider les projections futures de conditions sociales, écologiques et climatiques. II analyse la réceptivité des décisions aux questions soulevées par les ayantdroits et les parties prenantes. Un exemple de déploiement de la Liste verte de l'UICN est présenté dans l'Encadré 9.6.

\subsection{Mesurer et évaluer la gouvernance}

Les approches d'évaluation de la gouvernance vont de processus d'évaluation et évaluation rapides à des processus d'évaluation

\section{Encadré 9.3 : La diversité de la gouvernance en pratique - établir des zones marines gérées localement pour lutter contre le déclin des poissons à Kuruwitu, sur la côte nord du Kenya}

L'Association pour la conservation et le développement de Kuruwitu (KCWA, selon ses sigles en anglais) a été créée en 2003 par des membres de la communauté préoccupés par la dégradation de leur océan. Sur la côte nord du Kenya, la surpêche et les effets des changements climatiques constituaient des défis urgents à aborder, avant que l'écosystème marin ne soit irrémédiablement endommagé. Les pêcheurs et résidents concernés, qui se souvenaient de la santé et de la productivité marine dans le passé, estimaient qu'il était nécessaire d'agir avant qu'il ne soit trop tard. En 2005, ils prirent l'initiative sans précédent d'établir une AMP de 30 hectares. II s'agissait de la première aire marine corallienne gérée localement (AMGL) au Kenya. Douze ans plus tard, la région a connu une récupération remarquable. La pêche étant interdite à l'intérieur de l'APM, les poissons ont augmenté en abondance, en taille et en diversité. La pêche s'est améliorée et des entreprises génératrices de revenus alternatifs ont été mises en place. Kuruwitu est devenu un modèle de conservation marine durable, la KCWA partageant régulièrement ses connaissances avec d'autres communautés côtières locales et régionales.

Le développement d'initiatives durables non basées sur la pêche, telles que l'artisanat, la fabrication de meubles, l'apiculture et la confection textile, a réduit la dépendance à l'égard de la pêche de subsistance, entraînant une diminution de la pression sur les zones de pêche. Les stocks de poissons se sont considérablement améliorés au sein de l'AMGL, et un rapport indépendant montre une augmentation considérable de la biomasse halieutique et de la biodiversité de la vie marine dans la région. Cela a permis d'augmenter les captures de poissons dans les zones de pêche voisines et d'améliorer les moyens de subsistance. Les tortues et leurs nids dans la région sont protégés par un système d'indemnisation communautaire. Des communautés provenant de la côte ainsi que d'autres pays voisins visitent Kuruwitu pour voir notre salle de classe vivante. Au moins 20 autres projets similaires ont été lancés par d'autres communautés côtières, inspirées par la KCWA.

La KCWA a démontré l'importance de la participation communautaire aux plans de gestion des ressources naturelles, un principe qui a influencé un changement de politique de l'État vers les communautés locales. Kuruwitu a été choisi pour piloter une initiative de cogestion en collaboration avec diverses parties prenantes, couvrant une superficie d'environ $100 \mathrm{~km}^{2}$. II s'agit de l'un des premiers systèmes de gestion collaborative de ce type sur la côte kényane, et constituera un précédent.

Contribution de Des Bowden (Association pour la conservation et le développement de Kuruwitu). 


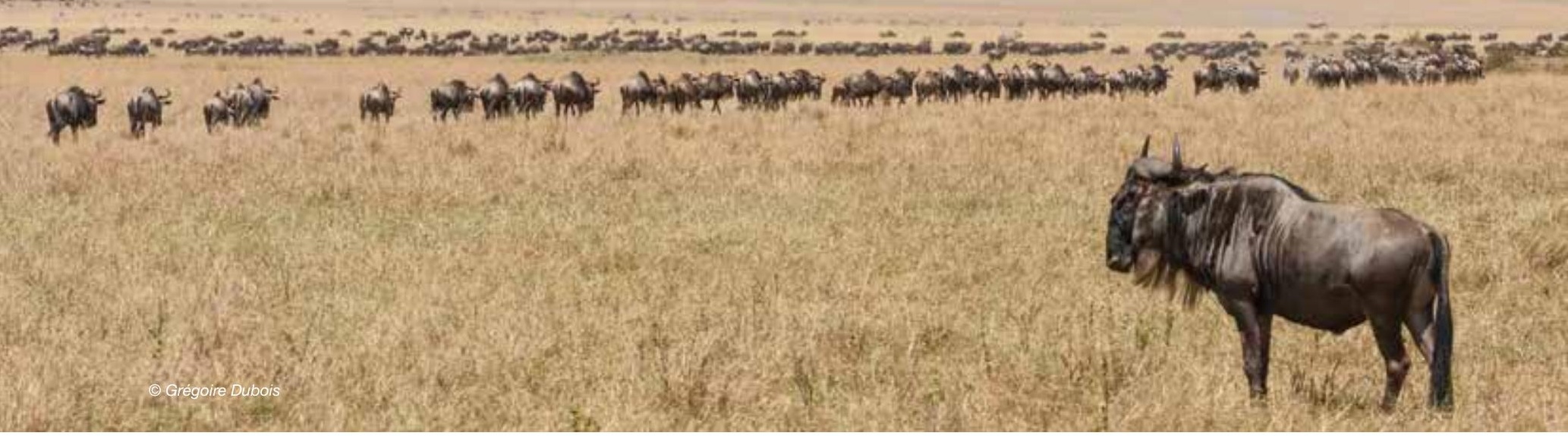

\section{Encadré 9.4 : Cogestion du Parc national de Gonarezhou}

Le Parc national de Gonarezhou est le deuxième plus grand parc national du Zimbabwe, avec une superficie de $5053 \mathrm{~km}^{2}$. II fait partie du parc transfrontalier du Grand Limpopo (GLTP, selon ses sigles en anglais), qui comprend le Parc national Kruger en Afrique du Sud et le Parc national du Limpopo au Mozambique, couvrant une superficie combinée de $36000 \mathrm{~km}^{2}$.

En 2007, l'Autorité de gestion des parcs et de la faune du Zimbabwe (ZPWMA, selon ses sigles en anglais) s'est associée à la Société zoologique de Francfort (FZS, selon ses sigles en anglais) pour créer le Projet de conservation de Gonarezhou, fournissant une assistance financière et technique aux opérations de la ZPWMA sur le terrain. Malgré d'importants succès en matière de protection et de conservation générale du Parc, on estimait toujours que le potentiel de celui-ci n'était pas réalisé et que le modèle de gestion en place à l'époque n'était pas suffisamment axé sur les possibilités et les menaces spécifiques que présente ce paysage complexe. La viabilité financière à long terme n'était pas prise en compte, les effectifs du personnel étaient insuffisants pour mener à bien des projets clés sur la biodiversité, tels que la réintroduction du rhinocéros noir, et les relations avec les communautés voisines étaient limitées et conflictuelles.

La situation a conduit à une analyse du partenariat en 2013, aboutissant à la création du Gonarezhou Conservation Trust (Fiducie de conservation du Ghanorezhou) en 2017, une entité spécifiquement mandatée et un modèle de cogestion entre la ZPWMA et la FZS. Le Gonarezhou Conservation Trust est chargé de la gestion quotidienne et du développement du Parc national de Gonarezhou pour les 20 prochaines années. La création de la fiducie s'appuie sur la réputation de l'Autorité zimbabwéenne de la faune sauvage en tant qu'entité progressiste et à la recherche de solutions innovantes, telles que la création de CAMPFIRE dans les années 1980, qui impliquait directement les communautés dans la gestion de la faune sauvage et introduisait le partage des avantages.
Les principaux aspects de la fiducie incluent :

- gestion par un Conseil d'administration, dans lequel la ZPWMA et la FZS sont représentées à parts égales ;

- gestion décentralisée, dont le siège social est situé dans le parc ;

- responsabilité de tous les frais de gestion;

- directement en charge de tout le personnel ;

- priorité affirmée sur l'emploi local et l'établissement de relations significatives avec les communautés ;

- rétention de tous les revenus touristiques et contrôle de la planification et du développement du tourisme.

L'un des défis fut de surmonter une certaine méfiance à l'échelle locale et nationale, découlant de la perception que la gestion d'un bien national zimbabwéen avait été externalisée. II fallut mettre en place des structures relevant auparavant directement de la ZPWMA au niveau du parc (telles que la gestion des ressources humaines ou du tourisme), et établir une base de financement durable nécessaire pour couvrir tous les coûts de gestion.

\section{La fiducie a :}

- investi massivement dans l'application de la loi, réduisant ainsi considérablement les niveaux de braconnage ;

- lancé un modèle novateur d'engagement communautaire, le «Mphfuka» (pèlerinage), basé sur le fait que les communautés sont un élément clé de l'économie centrée sur la conservation; et

- commencé à redéfinir son offre touristique dans le but de faire en sorte que le tourisme profite à la conservation et aux communautés, et non l'inverse.

Grâce aux avancées réalisées non seulement dans l'application de la loi, mais également dans les relations avec les communautés, ainsi qu'à la présence croissante de touristes dans le parc, les principaux problèmes ayant motivé la création de la fiducie sont progressivement abordés.

Contribution d'Elsabé van der Westhuizen (Société zoologique de Francfort). 


\section{Encadré 9.5 : Travailler avec les communautés en faveur de la conservation}

Le Fonds Peregrine (FP) a commencé ses travaux à Madagascar en 1990. Les objectifs du programme dans le pays sont la conservation des espèces endémiques menacées, en particulier les oiseaux de proie, les oiseaux aquatiques et autres éléments de la biodiversité, afin d'empêcher l'extinction de ces espèces et de préserver leurs habitats. Le FP se concentre sur le renforcement des capacités nationales en matière de conservation de la biodiversité pour les professionnels, les étudiants et les communautés locales.

Depuis 1991, le FP travaille dans la zone humide de Manambolomaty (un site Ramsar), entourée d'une forêt tropicale sèche typique de l'ouest de Madagascar. La région abrite de nombreux oiseaux d'eau, dont plus de $12 \%$ de la population mondiale de pygargue de Madagascar (Haliaeetus vociferoides), une espèce de rapace en danger critique d'extinction, endémique de Madagascar. Dans les années 1990, la surpêche sur ce site menaçait la population de pygargues de Madagascar, entraînant la nécessité d'un processus de gestion de la zone, afin de protéger les espèces d'oiseaux en danger critique d'extinction et autres éléments de biodiversité, ainsi que pour améliorer les moyens de subsistance des communautés locales.

Depuis 2001, le FP travaille en étroite collaboration avec les associations locales pour gérer les lacs et la forêt environnante. Des réunions avec les parties prenantes (chefs de villages, autorités locales et communautés) ont été organisées. À partir de ces réunions, une feuille de route pour la gestion des ressources naturelles a été élaborée. Elle comprenait des périodes d'ouverture et de fermeture de la pêche, une zone centrale de protection à l'intérieur des lacs, une limite au nombre de pêcheurs et un campement temporaire pour ceux-ci.

En outre, un programme de moyens de subsistance alternatifs a été développé pour fournir un soutien scolaire et du matériel aux activités agricoles. En étroite collaboration avec les agences régionales, des activités de renforcement des capacités ont été organisées à l'intention des communautés dans le domaine de la gestion de la pêche et des forêts.

Le FP a travaillé en étroite collaboration avec les membres des associations locales pour faciliter la gestion et la surveillance du programme de reboisement. Chaque année, grâce à ce programme, les membres ont planté des semis. Le programme a fourni des canoës en fibre aux pêcheurs, dans le but de réduire l'abattage de grands arbres pour la fabrication de canoës en bois.

Aujourd'hui, la communauté locale est convaincue de l'importance des ressources naturelles pour les générations futures. Très peu d'arbres ont été extraits de l'aire protégée et la communauté reste active dans la plantation de nouveaux arbres. Les revenus de la gestion de la pêche ont augmenté, les enfants peuvent aller à l'école, et les activités agricoles et d'élevage sont plus lucratives.

Après 18 ans de collaboration avec les communautés locales, cette aire protégée est considérée comme un site important pour la conservation communautaire à Madagascar.

Contribution de Lily-Arison René de Roland (Fonds Peregrine, Madagascar).

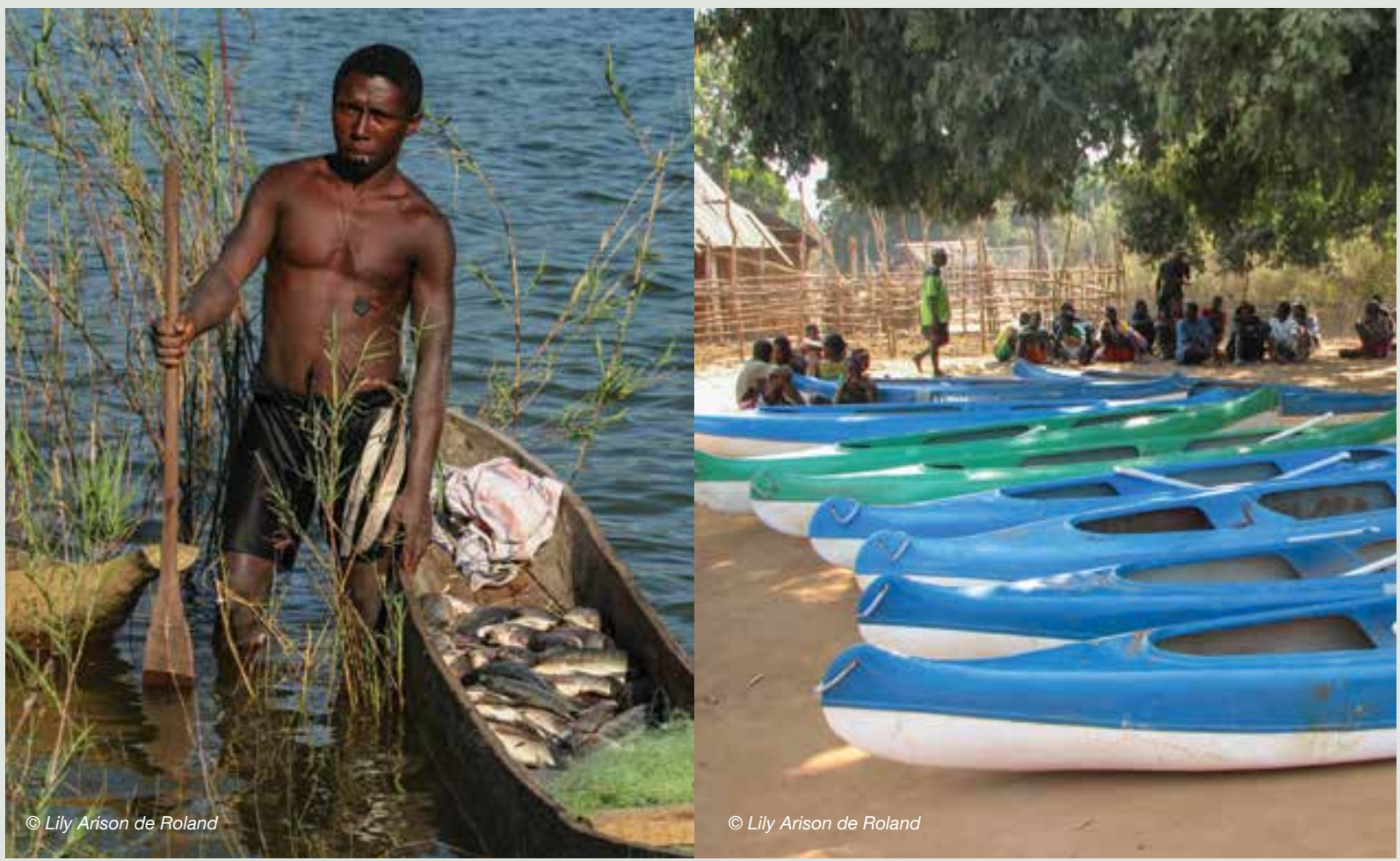




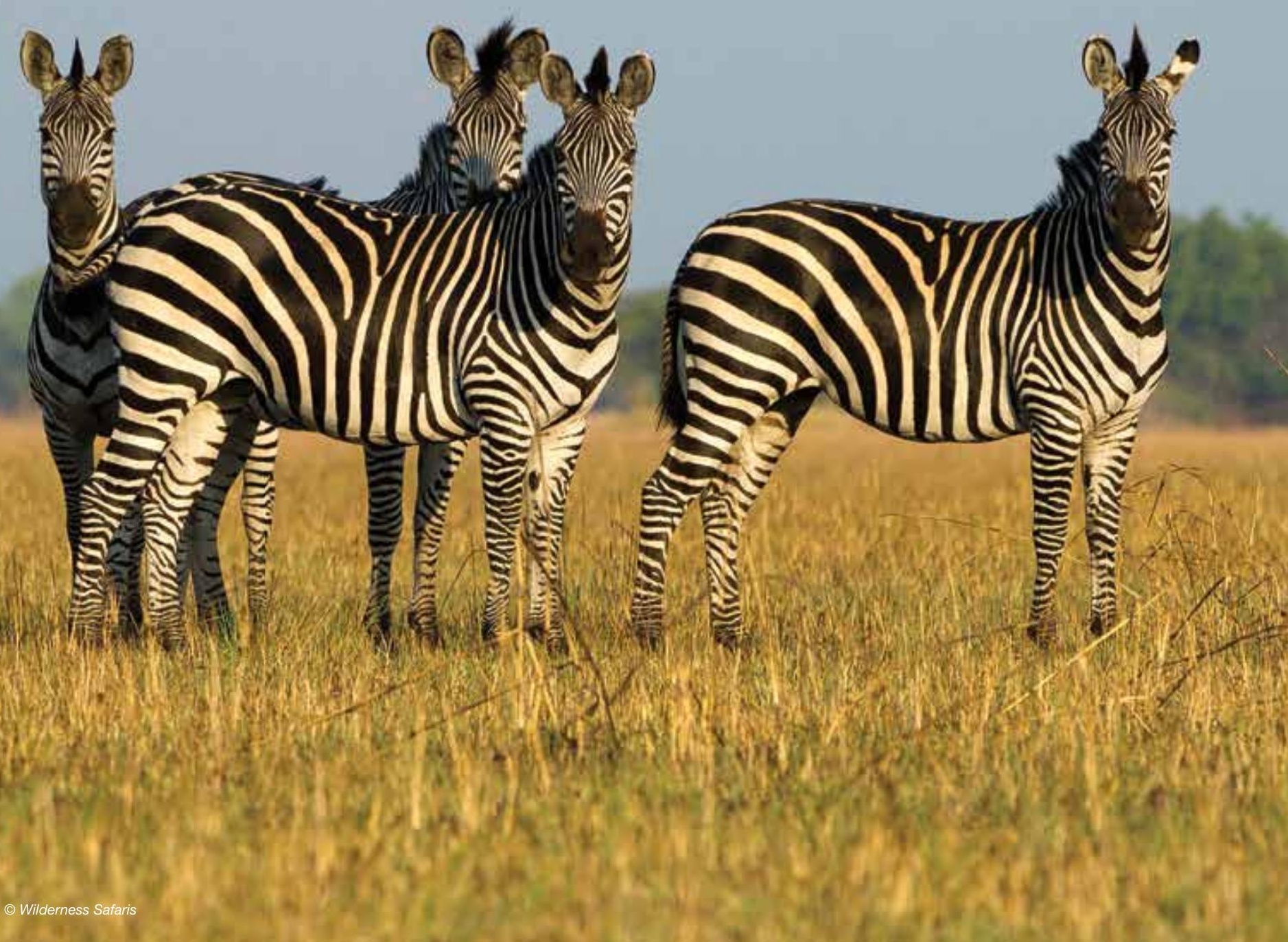




\section{Tableau 9.2 : Principes de bonne gouvernance de I'UICN pour les aires protégées}

\begin{tabular}{|c|c|}
\hline Principes & Considérations relatives aux principes \\
\hline $\begin{array}{l}\text { Légitimité et } \\
\text { voix }\end{array}$ & $\begin{array}{l}\text { - Établir et maintenir des institutions de gouvernance qui bénéficient d'une large acceptation et reconnaissance } \\
\text { - Sar la société. } \\
\text { pertinentes et en quantité suffisantes, qu'ils puissent être représentés, et qu'ils aient leur mot à dire lors des } \\
\text { consultations et/ou des prises des décisions. } \\
\text { - Encourager l'engagement actif des acteurs sociaux pour appuyer les aires protégées, tout en faisant respecter } \\
\text { la diversité et l'équité hommes-femmes. } \\
\text { - Fournir un appui particulier aux groupes les plus vulnérables, tels que les peuples autochtones, les femmes et } \\
\text { les jeunes, et prévenir toute forme de discrimination basée sur l'appartenance ethnique, le genre, la classe } \\
\text { - } \text { sociale, les biens financiers, etc. } \\
\text { - } \text { aux préoccupations et aux intérêts de tous. } \\
\text { - Honomourer les règles convenues, respectées parce qu'elles sont la « propriété » des personnes mêmes, et non } \\
\text { pas uniquement par crainte d'une punition ou d'une répression. } \\
\text { - Attribuer, autant que possible, l'autorité et la responsabilité de la gestion aux institutions compétentes les plus } \\
\text { proches des ressources naturelles (subsidiarité). }\end{array}$ \\
\hline Direction & $\begin{array}{l}\text { - Développer et suivre une vision stratégique attrayante et cohérente (perspective générale à long terme) pour } \\
\text { les aires protégées et leurs objectifs de conservation, fondée sur des valeurs convenues et une appréciation } \\
\text { des complexités écologiques, historiques, sociales et culturelles propres à chaque contexte. } \\
\text { - Veiller à ce que les pratiques de gouvernance et de gestion pour chaque aire protégée soient conformes aux } \\
\text { valeurs convenues. } \\
\text { - Veiller à ce que les pratiques de gouvernance et de gestion soient compatibles et bien coordonnées avec les } \\
\text { plans et politiques d'autres secteurs et échelons au sein du paysage terrestre/marin plus général, et qu'elles } \\
\text { respectent les obligations nationales et internationales (y compris du PTAP de la CDB). } \\
\text { - Fournir des orientations politiques claires quant aux enjeux principaux concernant l'aire protégée et, en } \\
\text { particulier, les questions sensibles (p.ex. priorités de conservation, relations avec les intérêts commerciaux et } \\
\text { les industries extractives), et s'assurer que ces orientations soient cohérentes avec les allocations budgétaires } \\
\text { ainsi qu'avec les pratiques de gestion. } \\
\text { - Évaluer et guider les progrès sur la base des résultats d'un suivi régulier et d'une approche consciencieuse de } \\
\text { gestion adaptative. } \\
\text { Favoriser l'émergence de « champions " pour générer de nouvelles idées et permettre / promouvoir } \\
\text { soigneusement des tentatives d'innovations, y compris des innovations en matière de gouvernance et de } \\
\text { gestion des aires protégées. }\end{array}$ \\
\hline Performance & $\begin{array}{l}\text { - Atteindre les objectifs de conservation et autres objectifs comme prévu et suivi, y compris par une évaluation } \\
\text { continue de l'efficacité de la gestion. } \\
\text { - Promouvoir une culture d'apprentissage des politiques et de la pratique de la gouvernance des aires } \\
\text { protégées sur la base de mécanismes, d'outils et de partenariats favorisant l'apprentissage collaboratif } \\
\text { continu et le partage des expériences. } \\
\text { - S'engager dans le plaidoyer et la sensibilisation en faveur des aires protégées. } \\
\text { - Répondre aux besoins des ayant-droits et autres parties prenantes, notamment en fournissant, en temps et en } \\
\text { heure, des réponses efficaces à leurs questions et demandes raisonnables en matière de changements des } \\
\text { - } \text { pratiques de gouvernance et de gestion. } \\
\text { possèdent les capacités nécessaires pour assumer leurs responsabilités et leurs rôles dans la gestion, et que } \\
\text { - } \text { - Utiliser efficacement les ressources financières et promouvoir la durabilité financière. } \\
\text { Promouvoir la durabilité et la résilience sociales, à savoir la capacité de gérer les risques, de surmonter les } \\
\text { crises inévitables et de sortir renforcés de ces expériences. }\end{array}$ \\
\hline
\end{tabular}




\begin{tabular}{|c|c|}
\hline Principes & Considérations relatives aux principes \\
\hline Responsabilité & $\begin{array}{l}\text { - Affirmer l'intégrité et l'engagement de toutes les personnes chargées de responsabilités spécifiques en } \\
\text { relation avec les aires protégées. } \\
\text { - Assurer la transparence, en fournissant aux ayant-droits et autres parties prenantes un accès opportun aux } \\
\text { informations concernant les enjeux de la prise de décisions, les processus et institutions susceptibles } \\
\text { comercer une influence, qui est responsable de quoi, et comment ces personnes peuvent rendre des } \\
\text { - Assurer un partage clair et approprié des rôles dans les aires protégées, ainsi que des lignes de responsabilité } \\
\text { et de rapport / réponse. } \\
\text { - Veiller à ce que les ressources financières et humaines allouées à la gestion des aires protégées soient } \\
\text { - Eorrectement ciblées, conformément aux objectifs et plans définis. } \\
\text { résultats à des récompenses ou sanctions concrètes et appropriées. } \\
\text { - Mettre en place des canaux de communications (p.ex. sites web) par lesquels les données et les rapports } \\
\text { relatifs aux performances des aires protégées seront mis à disposition. } \\
\text { - Encourager les groupes de la société civile et les médias à commenter ces résultats. } \\
\text { Veiller à ce qu'une ou plusieurs institutions publiques indépendantes (p.ex. un médiateur, une commission des } \\
\text { droits de l'Homme, une agence d'audit) possède l'autorité et la capacité de superviser et de remettre en } \\
\text { question l'action des organes de gouvernance et du personnel des aires protégées. }\end{array}$ \\
\hline Justice et droits & $\begin{array}{l}\text { - S'efforcer de réaliser un partage équitable des coûts et bénéfices issus de la création et de la gestion des } \\
\text { - Vires protégées, et de prendre toutes les décisions pertinentes de façon équitable. } \\
\text { façon négative par les aires protégées, que celles-ci ne créent pas ou n'aggravent pas la pauvreté ou les } \\
\text { phénomènes migratoires socialement déstabilisants, et que les coûts des aires protégées, notamment ceux } \\
\text { engendrés pour les populations les plus vulnérables, soient accompagnés de compensations appropriées. } \\
\text { - Veiller à ce que la conservation soit entreprise avec décence et dignité, sans humilier ni porter atteinte à } \\
\text { - } \quad \text { Travailler équitablement avec le personnel et les employés temporaires des aires protégées. } \\
\text { - Appliquer les lois et règlements de manière impartiale et cohérente dans le temps, sans discrimination et en } \\
\text { - } \text { assurant un droit de recours (État de droit). } \\
\text { individuels) sur la terre, l'eau et les ressources naturelles en relation avec les aires protégées, ainsi que pour } \\
\text { réparer les violations passées de ces droits. } \\
\text { - Prendre des mesures concrètes pour respecter les droits procéduraux relatifs aux aires protégées, y compris : } \\
\text { une information et une consultation appropriées des ayant-droits et autres parties prenantes, des pratiques } \\
\text { équitables de gestion des conflits et un recours non-discriminatoire à la justice. } \\
\text { - Respecter les droits de l'Homme, y compris les droits individuels et collectifs et l'équité hommes-femmes. } \\
\text { - } \text { Respecter les droits des peuples autochtones, comme décrit dans la Déclaration des Nations Unies des droits } \\
\text { des peuples autochtones. } \\
\text { proposition de relocalisation en lien avec les aires protégées. } \\
\text { des aires protégées. }\end{array}$ \\
\hline
\end{tabular}

Source : Borrini-Feyerabend et al. (2014). 
participative pouvant inclure une recherche, une validation et une discussion avec une plus grande variété d'acteurs, tels que des autorités gouvernementales, des ayant-droits et des parties prenantes, ainsi que des spécialistes de la conservation. Le processus particulier d'évaluation de la gouvernance devrait être choisi une fois que l'ampleur et la portée de l'intérêt ont été décidées. L'évaluation de la gouvernance doit être considérée comme un processus social et politique, débutant par une analyse diagnostique des problèmes et se dirigeant vers une composante pratique et de résolution. Les évaluations peuvent être entreprises à plusieurs échelles, et plusieurs outils ont été développés pour différents objectifs (Campese et Sulle, 2019).

\subsubsection{Lignes directrices sur les meilleures pratiques de la CMAP-UICN}

L'UICN a publié un ensemble de lignes directrices sur les meilleures pratiques pour les évaluations de la gouvernance à l'échelle des systèmes et des sites (Borrini-Feyerabend et al., 2014). Ces lignes directrices proposent des concepts et des outils pour comprendre les quatre principaux types de gouvernance des aires protégées et l'ensemble de principes de bonne gouvernance reconnus par I'UICN, sur la base d'exemples dans le monde entier. Elles offrent également des conseils pratiques à ceux qui souhaiteraient s'engager dans un processus d'analyse, d'évaluation et d'amélioration de la gouvernance de leurs systèmes d'aires protégées ou de sites individuels d'aires protégées.

\subsection{2 Évaluation à l'échelle des systèmes}

Une évaluation à l'échelle d'un système est une approche à long terme et à l'échelle macro visant à analyser et à évaluer la gouvernance des aires protégées. Elle se concentre sur le système des aires protégées, c'est-à-dire le système spatial existant des aires protégées, son cadre juridique correspondant et la diversité et la gamme des catégories de gestion des aires protégées et des types de gouvernance de I'UICN. Une évaluation à l'échelle du système suppose qu'aucune aire protégée ne sera efficace ou équitable si elle n'est pas considérée dans le cadre son paysage plus général. La plupart des menaces pesant sur les aires protégées proviennent de l'extérieur des limites des sites eux-mêmes (Davey, 1998), y compris un empiétement excessif, une mauvaise connectivité dans le paysage plus général et un manque de ressources (Schulze et al., 2018). Les aires protégées ne sont pas des îles, mais font partie d'une mosaïque d'utilisations des terres et d'intérêts divers. Une évaluation à l'échelle du système analyse tout d'abord le potentiel de l'ensemble des types de gouvernance dans un pays donné, et formule des recommandations pour une reconnaissance et une soutien des modalités de gouvernance existants de fait. Elle analyse ensuite l'ensemble du paysage et examine en particulier la coordination des secteurs imbriqués et des utilisations des sols.

L'UICN donne des indications sur ce qu'est un système d'aires protégées et note au moins cinq caractéristiques clés d'un tel système (Davey, 1998). Elles comprennent: la représentation, l'exhaustivité et l'équilibre, la pertinence, la cohérence et la complémentarité, l'harmonisation, ainsi que l'efficacité et l'équité. Une évaluation de la gouvernance à l'échelle du système menée par l'UICN est en cours en Tanzanie (voir l'Encadré 9.5).

\subsection{3 Évaluation à l'échelle des sites}

Une évaluation de la gouvernance à l'échelle d'un site se concentre sur la qualité de la gouvernance (voir l'Encadré 9.6 pour un exemple en Zambie). Contrairement à une évaluation à l'échelle du système, elle n'analyse pas le choix du type de gouvernance, mais évalue plutôt la mesure dans laquelle les modalités de gouvernance sont conformes au type de gouvernance, c'est-à-dire quelle partie prenante détient le pouvoir décisionnel principal dans la réalité, ainsi que le niveau d'influence sur la prise de décision des autres parties prenantes.

\section{Encadré 9.6 : Aire de conservation OI Kinyei et la Liste verte de l'UICN}

Le ranch collectif OI Kinyei était l'une des zones de pâturage traditionnelles des Massaï, au nord de la Réserve nationale de Mara (RNMM). Au début des années 1990, les responsables du ranch collectif se sont lancés dans la subdivision de leurs terres, au nord de la RNMM. La plupart des sections ont été subdivisées en parcelles de 60 à 150 hectares. Avec la fragmentation du ranch collectif, les zones de dispersion de la faune entourant la RNMM se sont vues de plus en plus menacées, car les terres de pâturage étaient rapidement converties en petites exploitations agricoles et en établissements communautaires. En 2005, l'Aire de conservation OI Kinyei s'est associée à des propriétaires fonciers et à des exploitants touristiques pour gérer conjointement la conservation et établir une zone d'habitat faunique protégée. II s'agissait de promouvoir la régénération de la végétation et d'accroître la biodiversité et les populations de faune sauvage qui, à leur tour, favoriseraient l'écotourisme. Les baux fonciers (initialement d'environ 5000 acres et actuellement de 18500 acres) génèrent des revenus et des emplois pour les communautés locales. Ol Kinyei s'est engagée et a débuté son processus d'évaluation dans le cadre de la Liste verte de l'UICN.
Afin de se conformer au premier critère de la composante "légitimité et voix » d'une bonne gouvernance, la structure de gouvernance devait démontrer comment les différents groupes communautaires étaient impliqués dans les processus décisionnels, comment les représentants étaient choisis et dans quelle mesure leurs points de vue étaient été pris en compte par l'organe exécutif. Afin de démontrer le deuxième critère (responsabilité et transparence), les décisions prises par le plus haut organe décisionnel devaient être accessibles au public et sur demande. Un mécanisme efficace et opportun de règlement des griefs a également été mis en place pour répondre aux demandes des parties prenantes.

La structure de gouvernance partagée a permis d'établir une plateforme stable pour la conservation et d'assurer une répartition équitable des avantages tirés de la conservation entre les membres de la communauté des propriétaires fonciers, développant ainsi un plus grand sentiment d'appartenance, d'appréciation et de compréhension de l'importance de la conservation du patrimoine faunique du Kenya.

Contribution de Beatrice Chataigner (UICN PAPACO, Kenya). 


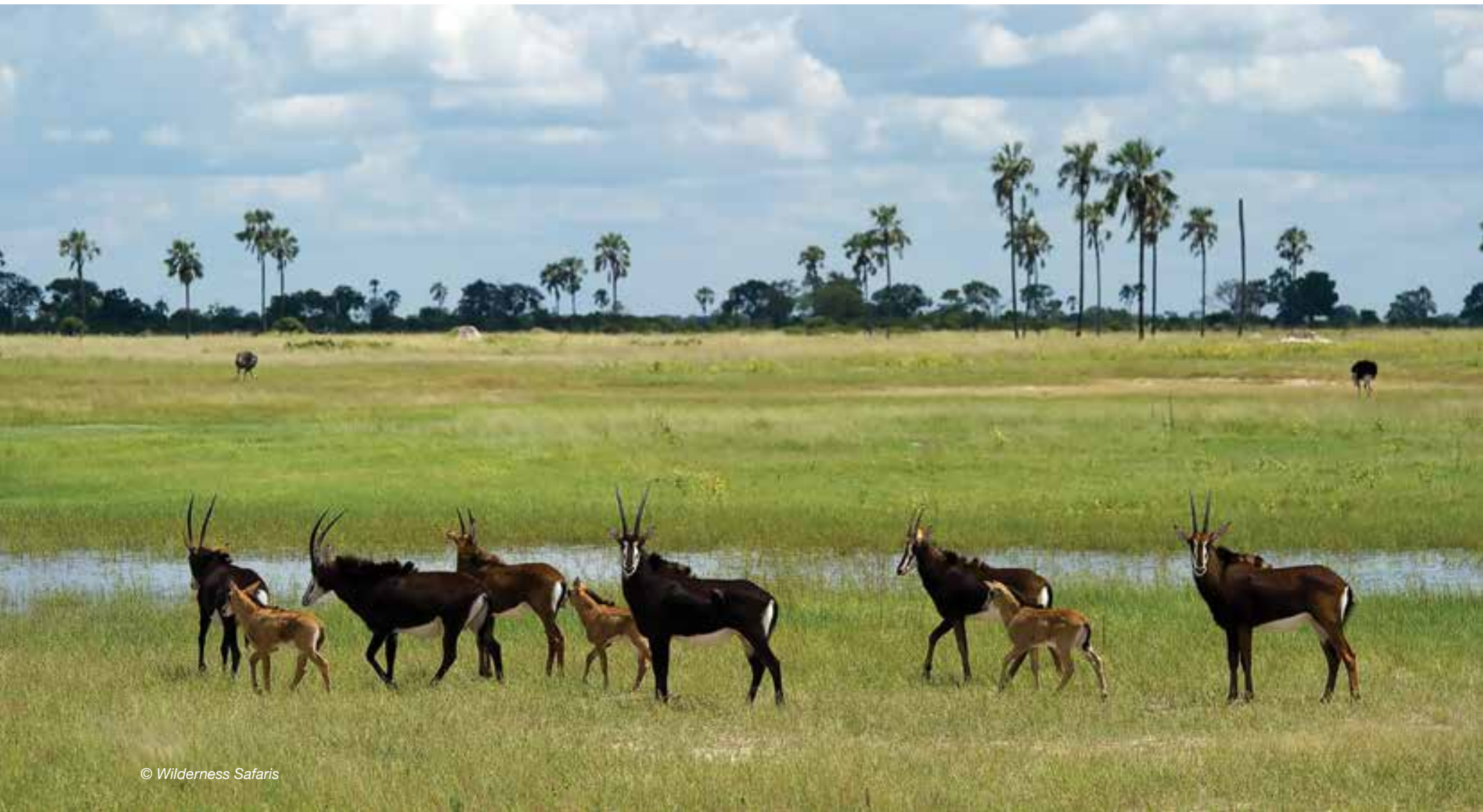

Les évaluations de la gouvernance à l'échelle d'un site peuvent également considérer les composantes de divers modèles de gouvernance et analyser leurs forces, leurs points faibles et leurs facteurs habilitants (voir l'Encadré 9.7).

\subsection{4 Évaluation de la gouvernance et de l'équité à l'échelle des sites (EGES)}

L'EGES est une méthodologie permettant d'évaluer la qualité de la gouvernance d'une aire protégée ou de conservation, y compris l'équité, grâce à un cadre de 10 principes de gouvernance et d'équité basés sur les lignes directives de I'UICN et de la CDB (IIED, 2020). II s'agit d'un processus rapide permettant aux parties prenantes d'un site d'identifier les défis de gouvernance et les actions potentielles permettant de les relever, et fournissant aux gestionnaires de niveaux supérieurs une évaluation de la qualité de la gouvernance susceptible d'être utilisée pour la supervision de la gestion, les rapports et le processus de Liste verte de l'UICN.

Comme pour de nombreuses méthodologies EfGAP, l'EGES génère des données de notation à l'aide d'un questionnaire comportant environ 40 questions ( 3 à 5 questions pour chaque principe). L'EGES utilise un processus multipartite. L'activité principale consiste en un atelier d'un à deux jours débutant par une évaluation par groupes de parties prenantes de façon séparée, révélant ainsi les différents points de vue des parties prenantes. Ces dernières discutent ensuite des raisons de toute différence de notation et identifient les mesures visant à améliorer la gouvernance et l'équité susceptibles d'être prises par une ou plusieurs parties prenantes.

Le résultat d'une EGES comporte trois éléments principaux :

a) Profil du site : de l'aire protégée ou de conservation et questions contextuelles liées à la gouvernance et à l'équité. b) Analyse d'impact: y compris les impacts environnementaux des activités humaines et autres facteurs de risque (c.-à-d. les menaces pour le site) et les impacts sociaux du site et sa conservation sur les personnes.

c) Tableau de bord de la gouvernance et de l'équité : y compris les notes et les données des différents groupes de parties prenantes pour chacune des 40 questions, les notes moyennes et les fourchettes de notation par question et principe, et les suggestions d'action pour renforcer la gouvernance.

Bien que l'EGES identifie les forces et faiblesses de la gouvernance, il ne s'agit pas d'un outil de diagnostic permettant d'explorer les causes profondes sous-jacentes des problèmes de gouvernance. Pour une évaluation approfondie, l'Évaluation de la gouvernance des aires protégées et de conservation (EGAP) serait l'outil le plus approprié (Franks et Booker, 2018; IIED, 2018) (voir la section suivante).

\subsection{5 Évaluation de la gouvernance des aires protégées et de conservation (EGAP)}

L'EGAP est une évaluation multipartite destinée aux gestionnaires de sites, aux communautés vivant à l'intérieur et autour d'une aire protégée ou de conservation, ou autres parties prenantes et ayantdroits à l'échelle locale et nationale (Franks et Booker, 2018; IIED, 2018). L'objectif principal de l'EGAP est d'améliorer la gouvernance du site concerné et de toutes les activités de conservation et de développement connexes.

La méthodologie utilise une combinaison de: (i) entretiens avec des informateurs clés et groupes de discussions afin d'identifier les forces et les défis en matière de gouvernance, ainsi que les possibilités d'action, et ii) ateliers avec les parties prenantes pour 


\section{Encadré 9.7 : Évaluation de la gouvernance à l'échelle d'un système en Tanzanie}

La Tanzanie abrite des dizaines de millions de personnes et est l'un des pays les plus riches en biodiversité au monde, avec des milliers d'espèces et d'écosystèmes. Elle comprend neuf grands bassins hydrographiques, le plus haut sommet d'Afrique, des zones arides, des savanes et des zones côtières et marines. Depuis 2017, I'UICN réalise une évaluation participative de la gouvernance à l'échelle du système en Tanzanie, en collaboration avec des partenaires nationaux et les parties prenantes, afin d'analyser les questions relatives à l'équité dans le système d'aires protégées (AP). Ce travail comprend un mélange d'activités de recherche et d'ateliers, y compris une recherche historique, des analyses juridiques, la documentation des quatre types de gouvernance de I'UICN / CDB et l'analyse de divers paramètres de gouvernance à l'aide de principes de bonne gouvernance. Le processus a montré que la Tanzanie est l'un des pays les plus riches de la planète en ce qui concerne son domaine de conservation, et le pays s'est engagé à atteindre des objectifs nationaux ambitieux en la matière. Son système actuel d'AP dépasse, de loin, les Objectifs mondiaux minimaux de couverture. La diversité des types de gouvernance dans le domaine de la conservation est tout aussi impressionnante.

Le système est vaste. II comprend des aires protégées dirigées par le gouvernement (Type A), telles que les quatre sites naturels du Patrimoine mondial : l'Aire de conservation du Ngorongoro, le Parc national du Kilimandjaro, la Réserve de gibier de Selous (aujourd'hui Parc national Nyerere) et le Parc national du Serengeti. II comprend également des modèles de gouvernance partagée (Type B), tels que l'Aire de gestion de la faune sauvage de Burunge, ainsi que d'autres modèles participatifs dans toute une gamme de Réserves naturelles forestières, de Forêts villageoises et de Réserves de chasse. Le Parc corallien privé de l'île de Chumbe (Type C) est un exemple de conservation volontaire de la nature au sein du système. La quatrième catégorie, APAC / Territoires de vie (Type D), des sites faisant l'objet d'une gouvernance, d'une gestion et d'une intendance traditionnelles, ont démontré une efficacité de conservation à long terme. II s'agit notamment de sites faisant actuellement l'objet d'une documentation via les Certificats de droit coutumier d'occupation (CCRO, selon leurs sigles en anglais). Des travaux sont en cours pour cartographier et documenter ces APAC / Territoires de vie, ainsi que pour les enregistrer à l'échelle nationale et dans le Registre des APAC hébergé par la BDMAP. Par exemple, des institutions traditionnelles pour la conservation du paysage dans les hauts plateaux de Matengo illustrent comment les connaissances traditionnelles, dans le cadre du système coutumier Sengu, peuvent permettre à la fois des moyens de subsistance durables et la conservation des paysages. La structure de gouvernance du système Sengu a été formalisée dans le cadre réglementaire Tanzanien. Cela révèle un enracinement remarquable de la conservation dans les identités culturelles nationales traditionnelles et modernes, un exemple potentiel pour le reste du monde.

Contribution de Jennifer Kelleher (UICN) et Grazia BorriniFeyerabend et Emmanuel Sulle (Consortium APAC). discuter et valider les résultats et analyser les idées d'action pour améliorer la situation. II existe une option supplémentaire : iii) un tableau de bord de la gouvernance à l'échelle du site visant à fournir une évaluation quantitative des problèmes de gouvernance liés au site et de la diversité des points de vue sur ces questions au sein et entre les communautés. L'évaluation elle-même prend généralement de cinq à 10 jours, selon la taille du site et la logistique. Après l'évaluation, une phase d'action comprend un ensemble d'activités visant à soutenir les parties prenantes dans la mise en œuvre des actions clés visant à améliorer la gouvernance suggérées par l'évaluation. Un manuel d'utilisation détaillé est disponible (Booker et Franks, 2019). Pour un exemple de résultats d'une EGAP, voir l'étude de cas de la Zambie (Encadré 9.6).

\subsubsection{Indicateurs}

Bien que l'ampleur d'une enquête soit un élément important, l'élaboration d'indicateurs réels, liés à l'évaluation de la gouvernance, est une caractéristique essentielle pour rendre compte efficacement de la gouvernance et de l'équité. BorriniFeyerabend et al. (2014) fournissent une longue liste d'exemples d'indicateurs de gouvernance dans les annexes de la publication. Plus récemment, une étude mondiale a conduit à l'élaboration de tels indicateurs et montre les résultats d'un grand nombre de pays (ICCA Registry, s.d.; Zafra-Calvo et al., 2017). Le manuel EGAP fournit un cadre pratique de principes et d'indicateurs (appelés thèmes), qui constitue la base des méthodologies EGAP et EGES.
De plus amples détails sur les méthodes et outils d'évaluation de la gouvernance les plus couramment utilisés sont disponibles dans Campese et Sulle (2019).

\section{4 Évaluations sociales}

La contribution des aires protégées à la réduction de la pauvreté, offrant des possibilités d'emploi et des moyens de subsistance aux personnes vivant dans et autour de celles-ci, a été notée par le PTAP de la CDB (CDB, 2004). Au mieux, les aires protégées devraient dans tous les cas s'efforcer de réduire la pauvreté, et les coûts et avantages devraient être équitablement partagés (conformément à l'élément de répartition du cadre d'équité de la CDB). En 2008, une étude a identifié plus de 30 méthodes permettant d'évaluer les impacts sociaux des aires protégées (Schreckenberg et al., 2010). Une méthodologie d'évaluation sociale a été spécifiquement adaptée au contexte des aires protégées à partir de cette étude. La méthodologie d'évaluation sociale des aires protégées (ESAP) est conçue pour aider les gestionnaires d'aires protégées et autres parties prenantes à comprendre et promouvoir les impacts sociaux positifs, tout en réduisant les impacts négatifs (Franks et al., 2018; IIED, s.d.). Comme l'EGAP, elle utilise une approche multipartite pour s'assurer que toutes les parties prenantes et ayant-droits concernés soient pleinement impliqués dans la conception de l'évaluation, la collecte d'informations, l'interprétation des résultats et l'élaboration de recommandations d'action. L'Encadré 9.8 donne un exemple des résultats d'une ESAP au Kenya. 


\section{Encadré 9.8 : Évaluation de la gouvernance à l'échelle d'un site dans l'AGG de Mumbwa, Zambie}

Les Aires de gestion du gibier (AGG) couvrent 22\% de la superficie de la Zambie. Elles jouent un rôle essentiel, à la fois sur le plan écologique en tant que zones de dispersion et de corridors reliant les principaux parcs nationaux, et sur le plan financier en tant que source d'une grande partie des revenus soutenant la conservation dans le pays (par le biais de concessions de chasse). Les AGG sont gérées dans le cadre d'une entente de gouvernance partagée appelée Gestion communautaire des ressources naturelles (GCRN), entre le ministère des Parcs nationaux et de la Faune sauvage (DNPW) et les communautés vivant autour et à l'intérieur de la zone de développement de l'AGG. La plupart de ces ententes de GCRN ont été établies il y a plus de 20 ans et n'ont reçu que peu de soutien ces dernières années. Au cours des dernières années, un certain nombre d'études ont noté que des faiblesses dans la gouvernance posent un problème majeur et croissant, compromettant gravement la conservation et les résultats sociaux.
En 2018, avec le soutien de l'Institut international pour l'environnement et le développement (IIED) et de l'Initiative mondiale de soutien aux APAC du PNUD, le Forum zambien pour la GCRN a aidé les parties prenantes (communautés, gouvernement et opérateurs de la chasse) de l'AGG de Mumbwa, qui borde le Parc national de Kafue, à réaliser une évaluation de la gouvernance à partir de la méthodologie EGAP de l'IIED. À l'aide de cette méthodologie, incluant des entretiens avec des informateurs clés et des discussions de groupe, les parties prenantes ont évalué les forces et les faiblesses de l'AGG en matière de gouvernance, et identifié des mesures visant à l'améliorer, en se concentrant en particulier sur quatre principes de bonne gouvernance. Le tableau ci-dessous résume quelques-unes des principales conclusions et idées d'action suggérées.

Contribution de Jennifer Kelleher (UICN).

\begin{tabular}{l|l|l}
\hline Principe & Défi & Idées d'action \\
\hline $\begin{array}{l}\text { Participation effective des } \\
\text { acteurs concernés à la prise de } \\
\text { décisions }\end{array}$ & $\begin{array}{l}\text { Les ministères dominent le processus } \\
\text { décisionnel lié à l'AGG et les communautés } \\
\text { n'ont donc que peu d'influence sur le } \\
\text { processus décisionnel. }\end{array}$ & $\begin{array}{l}\text { Toutes les parties prenantes doivent s'asseoir } \\
\text { et dialoguer pour reconnaître la voix des } \\
\text { communautés dans la prise de décision. }\end{array}$ \\
\hline $\begin{array}{l}\text { Partage équitable des } \\
\text { avantages selon une stratégie } \\
\text { de ciblage convenue par les } \\
\text { acteurs concernés }\end{array}$ & $\begin{array}{l}\text { Les chefs traditionnels partagent les } \\
\text { ressources naturelles au sein de l'AGG avec } \\
\text { la famille et les amis, oubliant les autres } \\
\text { membres de la communauté. }\end{array}$ & $\begin{array}{l}\text { Le gouvernement aidera à sensibiliser les } \\
\text { chefs traditionnels au partage équitable des } \\
\text { avantages entre chefs traditionnels et } \\
\text { communauté }\end{array}$ \\
\hline $\begin{array}{l}\text { Transparence soutenue par un } \\
\text { accès rapide aux informations } \\
\text { pertinentes }\end{array}$ & $\begin{array}{l}\text { Les informations mettent beaucoup de } \\
\text { temps à parvenir aux membres de la } \\
\text { communauté (par exemple, informations sur } \\
\text { les quotas de chasse) }\end{array}$ & $\begin{array}{l}\text { Utilisez différentes méthodes pour partager les } \\
\text { informations avec les communautés (dépliants, } \\
\text { SMS, églises), ainsi que des canaux plus } \\
\text { modernes de communication }\end{array}$ \\
\hline $\begin{array}{l}\text { Application équitable et } \\
\text { efficace des lois et règlements }\end{array}$ & $\begin{array}{l}\text { Le gouvernement est réticent à expulser } \\
\text { certaines personnes empiétant dans l'AGG } \\
\text { car ils ont peur de perdre des voix }\end{array}$ & $\begin{array}{l}\text { Augmentation des salaires des employés de la } \\
\text { DNPW et des éclaireurs des villages, afin } \\
\text { d'aider à réduire les illégalités, telles que les } \\
\text { pourboires et les pots de vin }\end{array}$ \\
\hline
\end{tabular}

Source : Lubilo (2019).

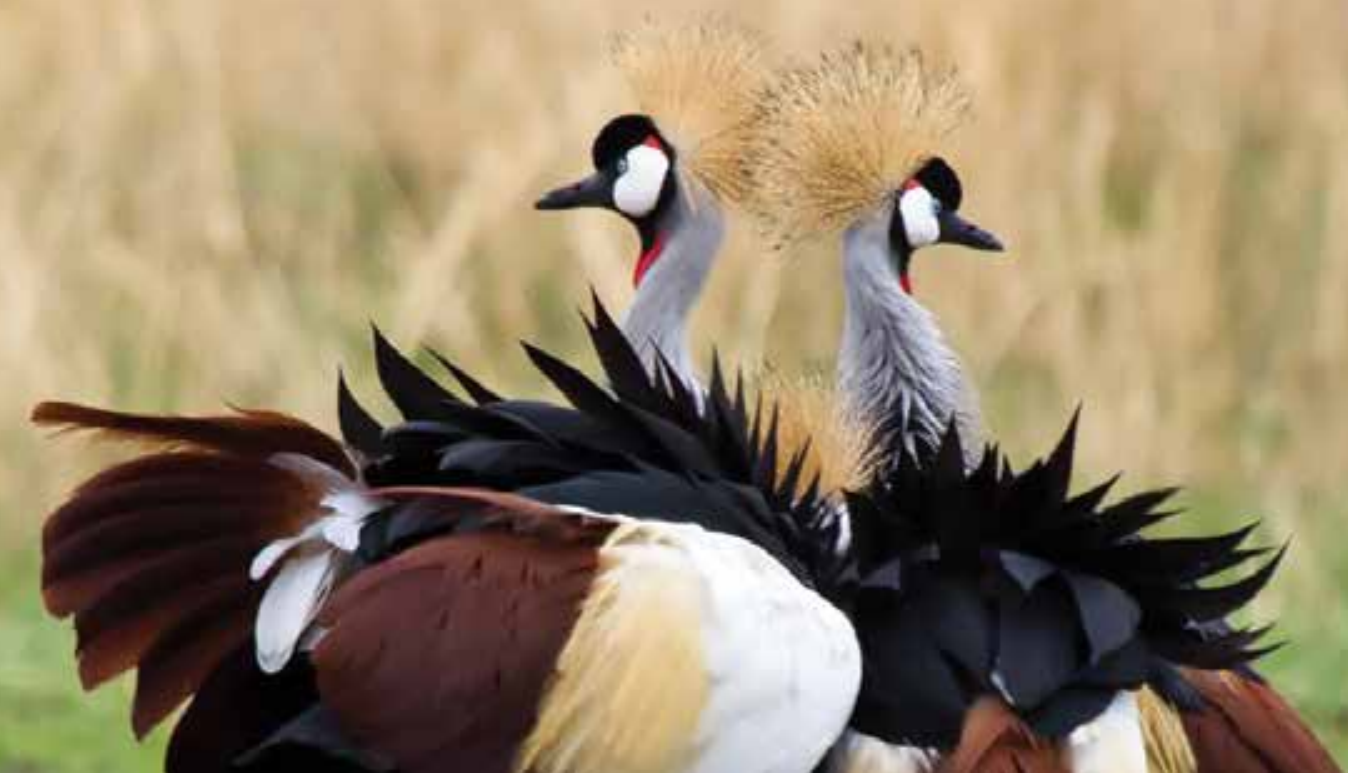




\section{Encadré 9.9 : État des aires de conservation autochtones et communautaires en Tanzanie}

La Tanzanie possède l'un des systèmes de gouvernance rurale locale les mieux établis d'Afrique subsaharienne. Les communautés des zones rurales sont gérées par plus de 12000 conseils de village, à leur tour responsables devant les assemblées de village. La législation habilite les villages à établir leurs propres règlements, y compris sur la gestion des ressources naturelles.

On ne saurait trop insister sur l'importance du cadre institutionnel local pour la gestion et la conservation des ressources naturelles locales en Tanzanie. Les conseils et assemblées de village tiennent des réunions de conseil de village, et constituent le mécanisme statutaire de prise de décision et de négociation collective des communautés locales en matière d'utilisation des terres et des ressources. La Loi sur les terres des villages permet à ceux-ci de délimiter des zones communales et individuelles au moyen de plans d'utilisation des terres, et d'officialiser ces zones par des règlements villageois. Cela permet aux communautés de soutenir les pratiques traditionnelles d'utilisation des terres grâce à des plans et règlements statutairement reconnus. Des centaines, voire des milliers d'Aires communautaires autochtones tanzaniennes de conservation (APAC) pourraient exister en tant qu'entités juridiques à l'échelle des villages dans le cadre de ce système, telles que les réserves pastorales de pâturage en saison sèche. Bon nombre de ces aires conservées localement sont mal documentées, et l'application de la loi à l'échelle locale dépend d'une série de facteurs.

La politique et la législation forestières de la Tanzanie s'appuient également sur le régime foncier et les institutions de gouvernance locale présentes dans le pays pour fournir des conditions favorables solides aux communautés locales pour posséder et gérer les forêts. Là où le cadre historique de gestion forestière en Tanzanie mettait l'accent sur des restrictions légales à l'exploitation et sur la création centralisée de réserves forestières, à partir du milieu des années 1990, la Tanzanie a commencé à expérimenter officiellement la gestion forestière communautaire. En 1998, le pays a adopté une politique forestière nationale visant à renforcer le " cadre juridique pour la promotion de la propriété privée et communautaire des forêts et des arbres " (United Republic of Tanzania, 1998, p. 1). Par la suite, la Loi sur les forêts de 2002 a été adoptée pour que les forêts soient gérées au niveau le plus bas de gouvernement possible, et pour que des modalités institutionnelles souples soient mises en place pour la gestion et la propriété des forêts à l'échelle locale. Celles-ci incluent notamment les réserves forestières des terres villageoises (RFTV), gérées par les villages, ainsi que les réserves forestières communautaires (RFC), qui peuvent être gérées par un sousgroupe de personnes au sein d'un village. Ce cadre juridique et politique est très favorable à une gestion communautaire et à la propriété des forêts, et a conduit à l'expansion rapide de réserves forestières locales reconnues par la loi (principalement des RFTV). Par conséquent, les forêts des terres villageoises sont reconnues par la loi comme une contribution viable et de plus en plus importante au domaine forestier sous protection formelle.

Comme pour les forêts, la Tanzanie a connu un processus de réforme du secteur de la faune sauvage dans les années 1990, et a publié une nouvelle Politique relative à la faune sauvage en 1998 et la Loi sur la conservation de la faune sauvage no. 5 de 2009, appelant à la dévolution des droits et responsabilités en matière de gestion de la faune sauvage aux villages, par le biais de nouvelles APAC statutaires appelées Aires de gestion de la faune (AGF). Les objectifs des AGF, décrites dans la Politique relative à la faune sauvage comme des sites conservés par et pour les communautés locales, avec des droits de gestion et un contrôle sur les avantages décentralisés, sont clairement conformes à une définition de travail des APAC. Cependant, conformément au règlement de 2002, les droits effectivement accordés aux communautés pour gérer la faune dans les AGF sont limités. Par exemple, les communautés ne disposent que de droits très limités pour gérer la chasse commerciale de la faune sauvage dans les AGF, et que d'un contrôle peu clair sur les revenus provenant de la faune sauvage de ces sites. Des préoccupations concernant le maintien d'un régime foncier villageois sûr dans les AGF ont également conduit à une certaine résistance des communautés pastorales à ce concept. Telles qu'actuellement établies, les AGF se limitent à une forme quelque peu nébuleuse de cogestion, le gouvernement conservant un degré d'autorité considérable, et ne devraient probablement pas être considérées comme des APAC tant que leurs modalités institutionnelles n'auront pas été révisées.

Des APAC sont également réparties le long des zones côtières et montagneuses de Tanzanie. De vastes systèmes de connaissances sont présents dans les communautés vivant dans ces régions. Certaines des APAC sont formalisées, alors que d'autres ne le sont pas, mais toutes remplissent le besoin critique de conserver nos paysages. Le groupe Mpingo sur la côte est, le système traditionnel d'organisation de l'écologie politique Kumbi le long des rives du lac Malawi / Niassa / Nyasa ou la propriété foncière Ntambo dans les hauts plateaux de Matengo dans la partie sud-ouest de la Tanzanie illustrent tous l'importance des systèmes de connaissances autochtones dans la conservation communautaire des ressources naturelles.

Contribution de Stephen Nindi (Commission d'aménagement du territoire, Tanzanie).

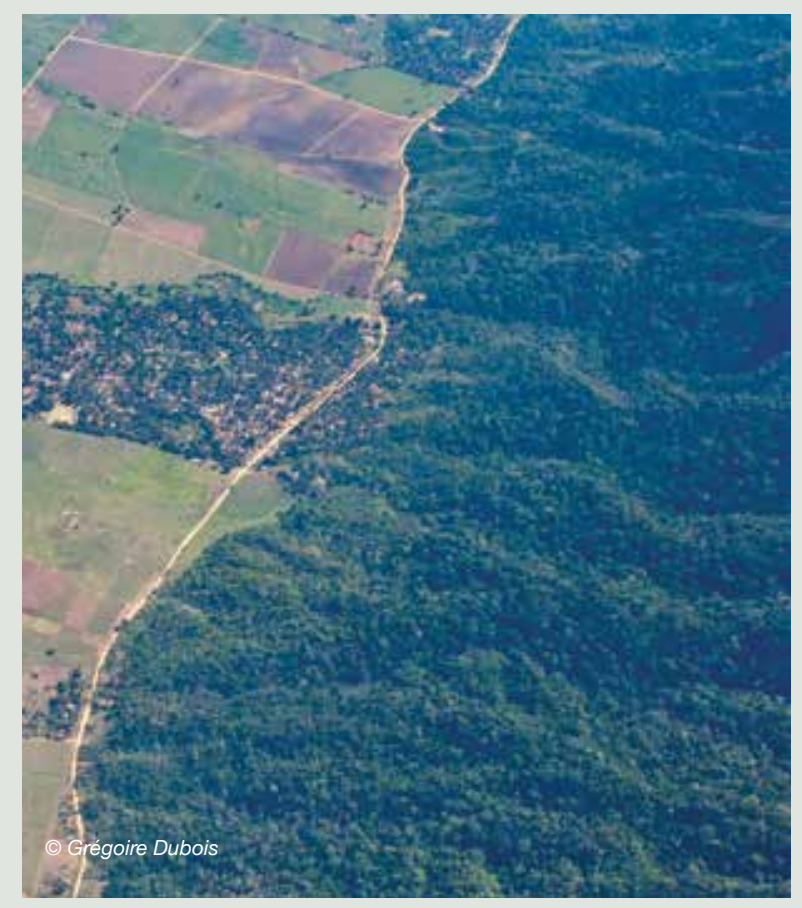




\subsection{L’EGAP en Afrique orientale et australe}

Cette section du rapport s'appuie sur l'analyse réalisée par Jessica Campese et Emmanuel Sulle dans leur rapport intitulé Management Effectiveness, Governance and Social Assessments of Protected and Conserved Areas in Eastern and Southern Africa: a rapid inventory and analysis to support the BIOPAMA programme and partners, préparé pour le programme BIOPAMA (Campese et Sulle, 2019). Le rapport a considéré l'efficacité de la gestion, la gouvernance et les évaluations sociales dans des aires terrestres et / ou marines protégées ou de conservation en Afrique orientale et australe. L'accent a été mis principalement sur les méthodologies élaborées spécifiquement pour évaluer une ou une combinaison de ces questions, et destinées à une utilisation répétée.

L'inventaire n'est pas exhaustif. Toutes les évaluations répertoriées n'ont pas été inclues dans les analyses détaillées, car elles ne constituaient pas des évaluations complètes utilisant des méthodes facilement reproductibles. Elles sont alors classées comme « Autres ». ${ }^{107}$

\subsection{1 Évaluations de la gouvernance en Afrique orientale et australe}

Trois cent quatre-vingts évaluations de la gouvernance ont été répertoriées (voir les Figures 9.1 et 9.2). La plupart étaient des évaluations à l'échelle de sites de forêts communautaires ${ }^{108}$ en Tanzanie, à l'aide du Tableau de bord de la gouvernance forestière communautaire. Sept évaluations EGAP d'aires protégées ont été menées au Kenya, en Ouganda et en Zambie, dont deux analyses utilisant le cadre " choix et reconnaissance " répertoriées au Kenya et en Ouganda. Enfin, quatre évaluations ont été répertoriées à l'aide d'un prototype de questionnaire sur l'équité au Kenya, en Tanzanie, en Ouganda et au Zimbabwe. Des évaluations de la gouvernance ont été répertoriées en Tanzanie, en Namibie, au Kenya, à Madagascar, en Ouganda, en Zambie, au Zimbabwe et à l'échelle de plusieurs pays.

\subsection{2 Évaluations sociales}

Cinquante évaluations sociales ont été répertoriées depuis 1996, dont 19 évaluations ESAP en Éthiopie, au Kenya, au Malawi, au Mozambique, en Ouganda, en Zambie et au Zimbabwe (voir les Figures 9.3 et 9.4). Des détails complets sur les méthodologies utilisées et les pays dans lesquels ces évaluations ont été menées sont disponibles dans le rapport complet (voir les Figures 9.1 et 9.3).

L'importance de mettre l'accent sur la gouvernance et l'équité des aires protégées est plus claire que jamais (Bennett et Dearden, 2014; Oldekop et al., 2015; Bennett et al., 2019). La gouvernance et l'équité sont des facteurs clés pour déterminer l'efficacité et l'efficience de la gestion dans les aires protégées. Elles sont essentielles pour garantir que les aires protégées soient équitables et procurent des avantages écologiques, sociaux, économiques et culturels, sans porter préjudice aux personnes par des coûts injustes. Par conséquent, elles répondent aux objectifs énoncés dans le PTAP, selon lequel les aires protégées sont considérées comme mieux intégrées dans les paysages plus généraux, mais aussi dans la société dans son ensemble.

\subsection{Résultats des évaluations sociales et de gouvernance en Afrique orientale et australe}

Dans la région d'Afrique orientale et australe, seuls 18 sites ont jusqu'à présent évalué leurs composantes sociales et de gouvernance à partir du cadre de gouvernance et d'équité des outils EGAP, ESAP et EGES de l'IIED (voir le Tableau 9.3).

À partir de l'analyse de ces évaluations, un certain nombre de points forts et de défis ont été mis en évidence. Les points forts portaient sur le partage équitable des avantages, comme les revenus tirés de projets de développement communautaire et l'accès aux ressources dans les aires protégées. Il a également été observé que des canaux de communication visant à mobiliser les communautés étaient en place, et que la prise de décisions dans certains domaines se faisait conjointement, $p$. ex. la sélection de projets à financer.

Les questions identifiées portaient sur la participation à la prise de décision, et plus précisément, entre autres, sur le fait que les responsables des aires protégées et les représentants du gouvernement avaient plus d'influence sur la prise de décision que les populations locales. Parmi les autres défis, on peut citer la transparence et l'accès à l'information, en particulier en ce qui concerne le partage des revenus et la sensibilisation aux droits. L'application équitable et efficace de la loi fait défaut dans certains cas, où elle est considérée comme irrégulière.

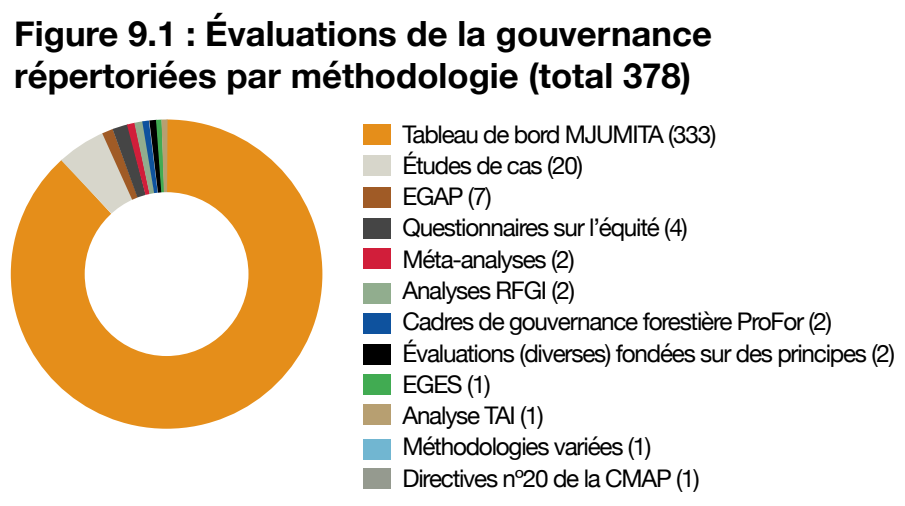

Source : Campese et Sulle (2019, p. 48)

\section{Figure 9.2 : Évaluations de la gouvernance répertoriées par pays (total 378 )}
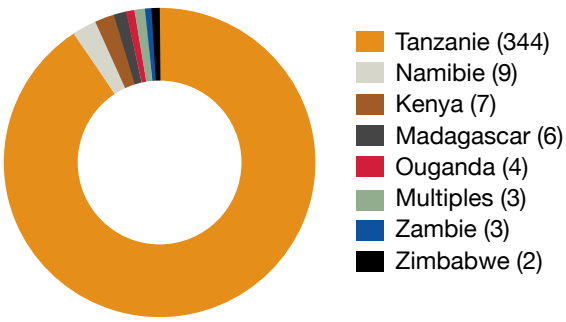

Source : Campese et Sulle (2019, p. 49)

107 Le rapport complet est disponible sur https://biopama.org/node/349

108 Il est important de noter qu'en Tanzanie, ce sont des AMCE, principalement établies par des communautés pour la gestion des forêts et la REDD+ plutôt que pour la conservation de la biodiversité en soi. Elles ne figurent pas dans la BDMAP. 
Figure 9.3 : Évaluations sociales répertoriées par méthodologie (total 50)

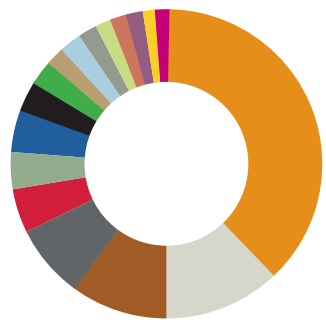

\section{Figure 9.4 : Nombre total d'évaluations sociales} répertoriées par pays

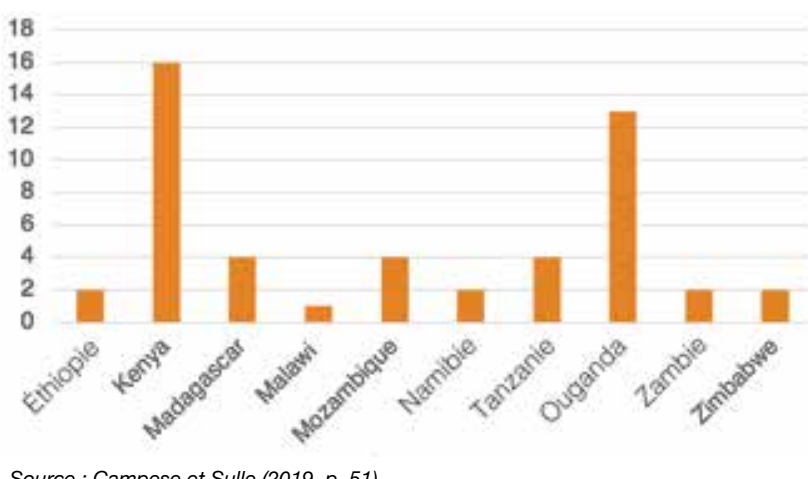

Source : Campese et Sulle (2019, p. 50).

\section{Encadré 9.10 : Évaluation sociale dans l'Aire de conservation OI Pejeta, au Kenya}

L'Aire de conservation OI Pejeta Conservancy (OPC, selon ses sigles en anglais) est une aire protégée privée kényane, détenue et gérée par une fiducie de conservation. Depuis sa conversion d'un élevage de bétail en un site de conservation au début des années 1990, et grâce au soutien important de donateurs, I'OPC est devenu une destination touristique populaire, générant suffisamment de revenus pour compenser les coûts opérationnels et fournissant des sommes substantielles, chaque année, pour son programme communautaire qui investit dans l'éducation, la santé, la vulgarisation agricole et l'approvisionnement en eau.

En 2014, l'OPC a réalisé une évaluation des impacts sociaux positifs et négatifs de la conservation sur les communautés locales à partir de la méthodologie ESAP, et a répété l'exercice en 2019. L'ESAP utilise une méthode d'évaluation rurale participative dans certaines communautés afin d'identifier les impacts les plus importants, une courte enquête auprès des ménages pour étudier ces impacts plus en détail et les questions de gouvernance connexes (mais avec beaucoup moins de détail que la méthodologie EGAP), ainsi qu'un atelier des parties prenantes où les principales parties prenantes analysent les résultats et identifient des pistes d'action.

L'évaluation de 2019 a réitéré les conclusions de 2014, selon lesquelles les avantages les plus importants d'un point de vue communautaire sont la clôture autour du site de conservation, qui a réduit les conflits homme-faune, et l'amélioration de la sécurité assurée par la présence du personnel d'application de la loi de l'OPC dans une zone autrement peu sûre. Cette constatation, selon laquelle certaines activités de gestion du parc semblent avoir une plus grande valeur pour la communauté que les activités de développement du programme communautaire, a été une véritable révélation en 2014. Cela n'a pas conduit à une réduction des activités de développement, mais à une approche plus ciblée accordant une plus grande priorité aux avantages que les gens considèrent comme plus précieux, notamment les bourses scolaires. Une autre conclusion clé est que ces bourses semblent être plus appréciées par les ménages les plus riches, ce qui suggère un certain biais dans leur allocation, qui doit être corrigé. Un message fort a également émergé, selon lequel plus d'avantages étaient accordés aux communautés du côté sud-est, plus près de la route principale. Cette situation a depuis été largement corrigée. Cependant, une préoccupation demeure parmi les femmes et les personnes les plus pauvres quant à cette question. Certaines des pistes pour améliorer cette situation incluent une meilleure communication, car le problème est en partie causé par le fait que les gens ne savent tout simplement pas quels avantages sont attribués aux autres, et soupçonnent un biais qui peut ne pas être réel.

La perception de partialité dans l'attribution des projets de développement et des emplois apparaît également comme un impact négatif important, ainsi que les dommages causés aux cultures par les animaux (malgré les clôtures). Cependant, ces préoccupations semblent relativement mineures, car la perception globale de l'aire protégée par les communautés, en tenant compte de tous les avantages et coûts, s'est améliorée depuis 2014.

Contribution de Jennifer Kelleher (UICN).

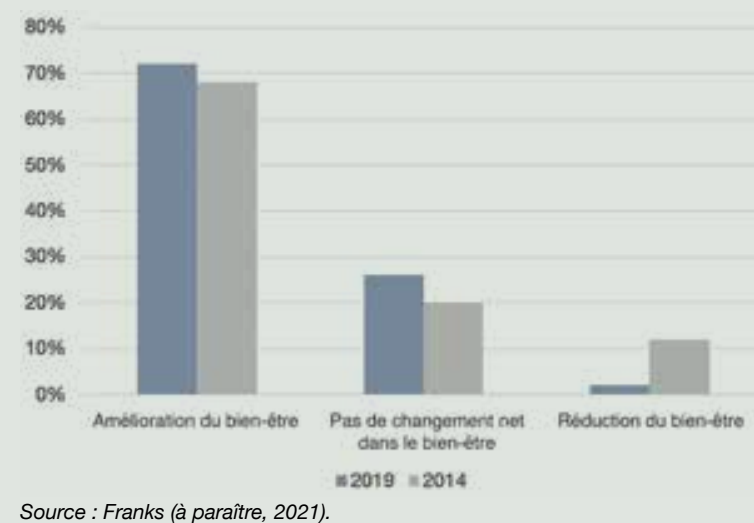


Tableau 9.3 : Évaluations ESAP, EGAP et EGES réalisées à ce jour

\begin{tabular}{|c|c|c|}
\hline \multicolumn{3}{|c|}{ ESAP } \\
\hline Pays & Superficie & Version \\
\hline Éthiopie & Parc national d'Awash & $\mathrm{v} 1$ \\
\hline Kenya & Parc national/Réserve de Marsabit & v2 \\
\hline Kenya & Aire de conservation OI Pejeta & v2 \\
\hline Kenya & Aire de conservation de Borana & v2 \\
\hline Kenya & Aire de conservation de Loisaba & v2 \\
\hline Kenya & Aire marine protégée de Kisite & v2 \\
\hline Kenya & Parc national de Ruma & v2 \\
\hline Mozambique & Parc national de Maputo & v2 \\
\hline Ouganda & Parc national de Ruwenzori & v1 \\
\hline Ouganda & Parc national du lac Mburo & $\mathrm{v} 1$ \\
\hline Ouganda & Parc national de Kibale & v2 \\
\hline Ouganda & Parc national de Mgahinga & v2 \\
\hline Ouganda & Parc national de Murchison & v2 \\
\hline Ouganda & Parc national de Bwindi & v2 \\
\hline Zambie & $\begin{array}{l}\text { Aire de gestion de la chasse de } \\
\text { Mumbwa }\end{array}$ & $\mathrm{v} 1$ \\
\hline Zambie & $\begin{array}{l}\text { Aire de gestion de la chasse de } \\
\text { Lupande }\end{array}$ & $\mathrm{v} 1$ \\
\hline
\end{tabular}

\begin{tabular}{|c|c|}
\hline \multicolumn{2}{|r|}{ EGAP } \\
\hline Pays & Superficie \\
\hline Kenya & Aire de conservation de Mara Nord \\
\hline Kenya & Aire de conservation d'Olderkesi \\
\hline Kenya & Aire de conservation de Kalama \\
\hline Zambie & Aire de gestion de la chasse de Chiawa \\
\hline Zambie & Aire de gestion de la chasse de Mumbwa \\
\hline
\end{tabular}

\begin{tabular}{l|l}
\hline \multicolumn{2}{c}{ EGES } \\
\hline Pays & Superficie \\
\hline Zambie & Aire de gestion de la chasse de Mulobezi \\
\hline Tanzanie & Aire de gestion de la faune de Randilen \\
\hline
\end{tabular}

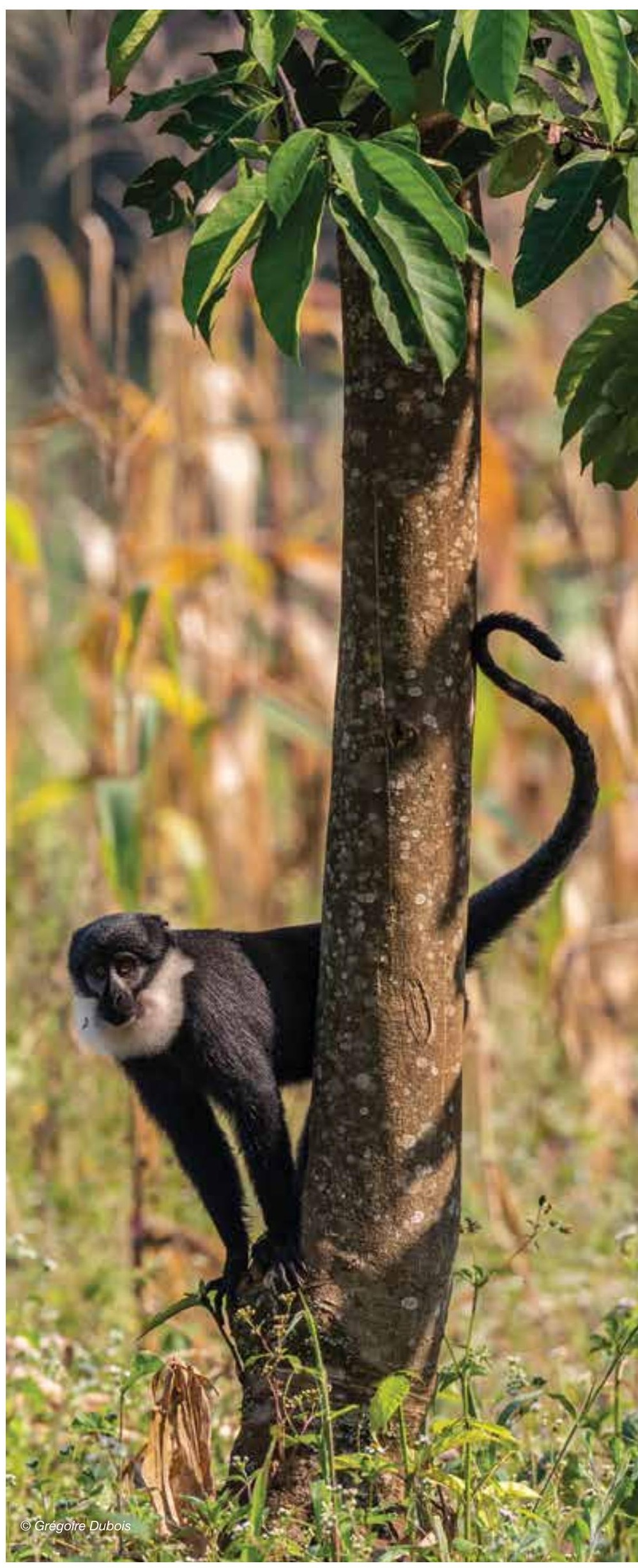




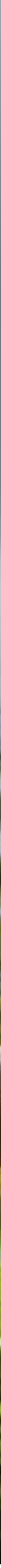




\section{Efficacité de la gestion des aires protégées}




\subsection{Qu'est-ce qu'une gestion efficace?}

L'efficacité de la gestion se rapporte à la façon dont les aires protégées sont gérées, et principalement à la mesure dans laquelle la gestion est efficace pour conserver les valeurs et atteindre les buts et objectifs définis, tels que la protection de la biodiversité (Hockings et al., 2008; Leverington et al., 2010). Les éléments spécifiques d'une bonne gestion varient selon le contexte et les caractéristiques de chaque aire protégée. Par exemple, une aire protégée communautaire isolée, avec peu de visiteurs, aura besoin de moins de personnel et d'installations récréatives qu'une destination touristique emblématique.

Toutes les aires protégées ne sont pas gérées efficacement pour protéger les valeurs pour lesquelles elles ont été conçues, et la qualité de la gestion de la plupart des aires protégées est mal connue (Geldmann et al., 2015). Des données suggèrent qu'il existe des corrélations positives entre certains aspects de la gestion des aires protégées (comme le personnel et les budgets) et les résultats en matière de conservation des espèces (Edgar et al., 2014; Geldmann et al., 2013). Beaucoup de travail a été fait, au cours des 30 dernières années, pour définir les caractéristiques générales d'aires protégées bien gérées, puis pour mesurer dans quelle mesure des sites individuels correspondaient à ces standards. Ces caractéristiques souhaitables ont été incorporées en tant qu'indicateurs dans des méthodologies, telles que l'outil de suivi de l'efficacité de la gestion, et ont constitué la base du «format commun de rapport » pour la compilation mondiale de données sur l'efficacité de la gestion (Leverington et al., 2010). Plus récemment, le processus de la Liste verte a entrepris un exercice détaillé et robuste pour élaborer des normes mondiales pour les aires protégées, pouvant être adaptées et interprétées pour différents pays.

Certaines études ont été entreprises sur des types particuliers d'aires protégées. Par exemple, une étude sur la performance des aires protégées en relation avec les lions a montré que les aires protégées avaient tendance à être plus efficaces pour la conservation des lions et / ou de leurs proies lorsque les budgets de gestion étaient plus élevés, lorsque le tourisme photographique constituait la principale utilisation des terres et, pour les proies, lorsque des clôtures étaient présentes. Les lions et leurs proies s'en tirent moins bien par rapport à leurs capacités de charge potentielles estimées dans les pays pauvres, lorsque des personnes sont installées dans les aires protégées et lorsque les aires protégées n'étaient utilisées ni pour le tourisme photographique ni pour la chasse aux trophées (Lindsey et al., 2017).

\section{2 Évaluer l'efficacité de la gestion}

L'évaluation de l'efficacité de la gestion est un thème de plus en plus important dans la gestion des aires protégées et la conservation de la biodiversité mondiale, depuis de nombreuses années (voir l'Encadré 10.1). Elle fournit une perspective permettant d'analyser des thèmes importants pour la gestion des aires protégées, en particulier :

1) les problèmes de conception de sites individuels ou de systèmes d'aires protégées ;

2) l'adéquation et la pertinence des systèmes et des processus de gestion ; et

3) la réalisation des objectifs des aires protégées, y compris la conservation de leurs valeurs (Hockings et al., 2008).
D'une manière générale, l'évaluation de l'efficacité de la gestion peut :

- permettre et soutenir une approche adaptative de la gestion des aires protégées ;

- contribuer à une allocation plus efficace des ressources entre les sites et à l'intérieur de ceux-ci ;

- promouvoir la responsabilisation et la transparence par des rapports sur l'efficacité de la gestion à l'intention des parties prenantes intéressées et du public ; et

- aider à impliquer la communauté plus vaste des parties prenantes, y compris les agences gouvernementales, les ONG et les communautés locales, à constituer des groupes de soutien et à promouvoir les valeurs des aires protégées (Hockings et al., 2008).

Au fur et à mesure que la communauté mondiale de la conservation accordait une plus grande attention à la question de l'efficacité de la gestion et à la nécessité d'outils pour aider à l'évaluer, il est devenu évident qu'avec une telle variété de systèmes et de contextes, la conception d'un seul outil d'évaluation ne serait pas pratique. L'évaluation de l'efficacité de la gestion devait être adaptée aux exigences particulières de chaque site, étant donné que chaque aire protégée présente une variété de caractéristiques biologiques et sociales, de pressions et d'utilisations.

En 2000, la CMAP de I'UICN a élaboré un cadre visant à guider l'élaboration de systèmes d'évaluation de l'efficacité de la gestion. Ce cadre a été mis à jour en 2006 et continue de constituer le cadre auquel la plupart des approches EfGAP se rapportent conceptuellement (Coad et al., 2015). Le cadre identifie six composantes principales, chacune associée à différents aspects de l'efficacité de la gestion : contexte, planification, intrants, processus, extrants et résultats (voir la Figure 10.1) (Hockings et al., 2008).

\section{Figure 10.1: Cycle de gestion et évaluation de la gestion des aires protégées}

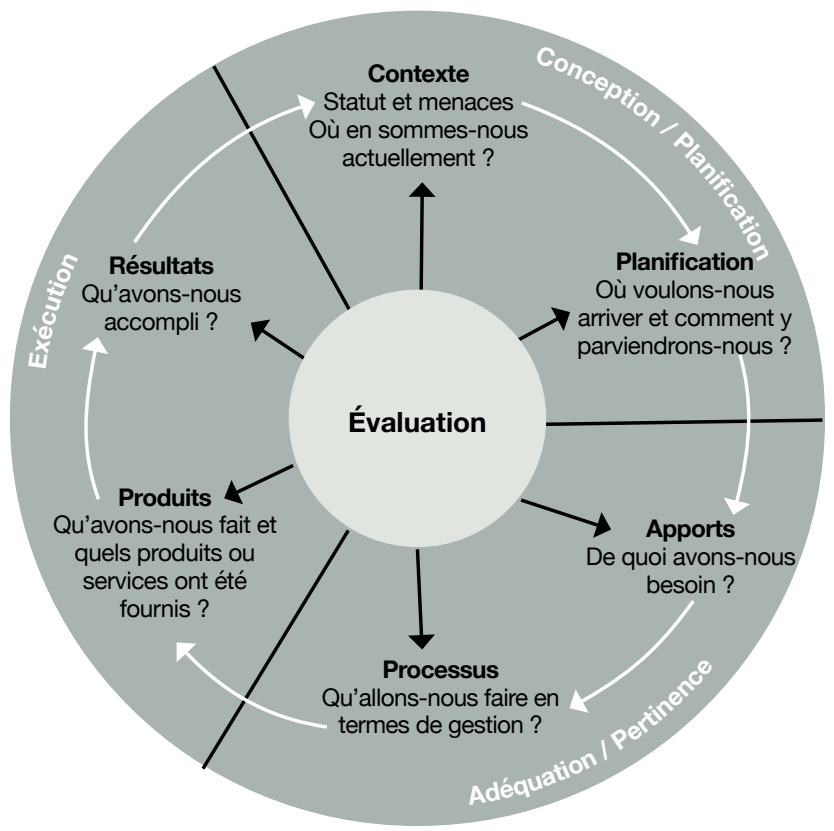

Source : Hockings et al. $(2008$, p. 12) 


\subsection{Engagements internationaux en matière d'évaluation de l'efficacité de la gestion}

L'Objectif d'Aichi 11 reconnaît que l'augmentation de la couverture ne suffira pas, à elle seule, pour enrayer la perte de biodiversité, et souligne la nécessité d'une gestion efficace :

Objectif 11 : D'ici à 2020, au moins $17 \%$ des zones terrestres et d'eaux intérieures et $10 \%$ des zones marines et côtières, $y$ compris les zones particulièrement importantes pour la diversité biologique et les services fournis par les écosystèmes, sont conservées au moyen de réseaux écologiquement représentatifs et bien reliés d'aires protégées gérées efficacement et équitablement et autres mesures de conservation efficaces par zone, et intégrées dans l'ensemble du paysage terrestre et marin (CDB, 2010a, p. 9).

Les EfGAP sont citées à plusieurs endroits du PTAP de la CBD. Par exemple, l'Objectif 4.2 vise à "évaluer et améliorer l'efficacité de gestion des aires protégées " (CDB, 2004, p. 20).

La décision X/31 de la CDP10 de la CDB appelle les Parties à

... étendre et institutionnaliser les évaluations de l'efficacité de la gestion pour atteindre l'évaluation de $60 \%$ de la superficie totale des aires protégées d'ici à 2015, en employant différents outils nationaux et régionaux et en communiquant les résultats dans la base de données mondiale sur l'efficacité de la gestion (CDB, 2010b, p. 5).

La résolution WCC-2012-Res-076 de I'UICN appelle à la mise en œuvre de systèmes d'évaluation de l'efficacité de la gestion des aires marines protégées (UICN, 2012), tandis que la résolution WCC-2016-Res-036 de I'UICN appelle à une plus grande évaluation de l'efficacité des aires protégées privées dans la conservation de la biodiversité, du patrimoine naturel et des services écosystémiques (UICN, 2016b).

\subsection{Base de données mondiale sur l'efficacité de la gestion des aires protégées (BD-EGAP)}

La BD-EGAP a été développée grâce à la collaboration d'universités, de I'UICN et d'organisations non gouvernementales, et est aujourd'hui maintenu par l'UNEP-WCMC en collaboration avec des gouvernements, des organisations non gouvernementales, des universités et l'industrie (UNEP-WCMC et IUCN, 2019aa).

Elle documente plusieurs milliers d'évaluations EfGAP dans le monde, et indique quelles méthodologies ont été utilisées, où et quand. En 2019, plus de 240000 aires protégées figuraient dans la BDMAP, et 21743 (9\%) d'entre elles disposaient d'informations concernant des évaluations de l'efficacité de la gestion. Cela équivaut à $20 \%$ de la superficie de toutes les aires protégées de la BDMAP. L'absence de rapports systématiques, les doubles évaluations d'un même site, l'utilisation de multiples outils d'évaluation et, parfois, le manque de volonté politique rendent cet élément de l'Objectif d'Aichi 11 particulièrement difficile à suivre (UNEP-WCMC et al., 2019). Bien que chaque méthodologie recueille des informations différentes, un "format de rapport commun" a été développé, permettant l'analyse croisée des informations EfGAP obtenues à partir d'une gamme de méthodologies d'évaluation différentes (Leverington et al., 2010).

\section{Encadré 10.1 : Pourquoi informer sur l'efficacité de la gestion des aires protégées ?}

Il existe un certain nombre de raisons pour lesquelles les pays pourraient souhaiter rendre compte de leurs évaluations de l'efficacité de la gestion :

- Respecter les obligations des pays en vertu de la CDB (les EfGAP sont un indicateur officiel au titre de l'Objectif d'Aichi 11).

- L'inventaire des données nationales stockées de manière systématique fournit une image claire de l'efficacité de la gestion des aires protégées à l'échelle nationale et peut contribuer à une gestion adaptative.

- La BD-EGAP permet d'identifier les points forts et les faiblesses de la gestion des aires protégées, fournissant ainsi des informations pour aider les pays à prioriser l'allocation de ressources et à cibler le développement des capacités. Elle fournit également des informations sur les menaces.

- Les informations contenues dans la BD-EGAP peuvent être analysées à l'échelle de la région, du continent et de la planète, afin de mieux comprendre la relation entre efficacité de la gestion et résultats en matière de biodiversité.

Pour consulter les données et télécharger le manuel d'utilisation de la BD-EGAP, voir : https://pame.protectedplanet.net/.

Pour soumettre des données ou pour plus d'informations, veuillez contacter : protectedareas@unep-wcmc.org ou rcmrd@rcmrd.org.

Ceci peut être utilisé en conjonction avec une analyse qualitative des rapports sur l'efficacité de la gestion et autres documents pour générer des analyses et des rapports détaillés sur l'efficacité de la gestion, y compris les principaux problèmes, forces, faiblesses et menaces, dans toutes les régions du monde (Leverington et al., 2010; Nolte et al., 2010) (voir l'Encadré 10.1). Malheureusement, cette analyse n'a pas été réalisée depuis 2010.

\subsection{Outils d'évaluation de l'efficacité de la gestion}

Le cadre de la CMAP-UICN (voir la Figure 10.1) a permis l'élaboration d'une grande variété de méthodologies d'évaluation EfGAP. Celles-ci vont d'études détaillées à l'échelle d'un site à des évaluations générales à l'échelle de systèmes utilisant de nombreux processus différents, y compris, entre autres, des questionnaires et des ateliers (Hockings et al., 2015; Leverington et al., 2010).

Des méthodologies ont été développées pour différents types d'aires protégées, de celles déclarées à l'échelle nationale jusqu'à celles déclarées dans le cadre de conventions et accords régionaux et internationaux, tels que les sites du Patrimoine mondial (voir le Tableau 10.1).

\subsection{Principes applicables aux évaluations EfGAP}

De nombreux avantages justifient une évaluation de l'efficacité de la gestion des aires protégées et de conservation, mais il existe aussi des défis et des limites, et il est impératif que les évaluations 
Tableau 10.1: Méthodologies EfGAP les plus couramment utilisées en Afrique orientale et australe

\begin{tabular}{l|l}
\hline Acronyme & Outil \\
\hline IBA Birdlife & Évaluations des sites d'importance pour les oiseaux et la biodiversité - BirdLife \\
\hline EoH & $\begin{array}{l}\text { Enhancing our Heritage / Valoriser notre patrimoine (principalement pour les sites naturels du } \\
\text { Patrimoine mondial) }\end{array}$ \\
\hline IEG & Évaluations du Groupe d'évaluation indépendant (Banque mondiale) \\
\hline OSEG & Outil de suivi de l'efficacité de la gestion \\
\hline OSEGAP & Adaptation de l'OSEG à Madagascar \\
\hline RAPPAM & Évaluation rapide et priorisation de la gestion des aires protégées \\
\hline SAPM & Évaluation de l'efficacité de la gestion du système d'aires protégées de Madagascar \\
\hline SGBD / SMART & Variation du SMART spécifique à Madagascar \\
\hline SMART & Outil de suivi et de rapport spatiaux \\
\hline $\begin{array}{l}\text { AMP de l'océan Indien } \\
\text { Occidental }\end{array}$ & Évaluation des aires marines protégées de l'océan Indien occidental \\
\hline Rapport Perspectives du \\
Patrimoine mondial
\end{tabular}

soient entreprises de manière appropriée afin d'atténuer ces risques (Hockings et al., 2008). Afin de soutenir la sélection et l'application des méthodologies, huit principes d'évaluation de l'efficacité d'une bonne gestion ont été élaborés (Hockings et al., 2015).

Les évaluations de l'efficacité de la gestion des aires protégées devraient être :

1) inclues dans un cycle de gestion efficace, lié à des valeurs, des objectifs et des politiques définis, ainsi que dans la planification stratégique, la planification du parc et les cycles commerciaux et financiers :

2) pratiques à mettre en œuvre à partir des ressources disponibles, avec un bon équilibre entre la mesure, les rapports et la gestion ;

3) utiles et pertinentes pour améliorer la gestion de l'aire protégée, fournir des explications et montrer les tendances, et améliorer la communication, les relations et la sensibilisation;

4) logiques et systématiques, travaillant dans un cadre logique et convenu, avec une approche équilibrée ;

5) basées sur de bons indicateurs, holistiques, équilibrés et utiles ;

6) précises, fournissant des informations exactes, objectives, cohérentes et à jour ;

7) coopératives et participatives, avec une bonne communication, un bon travail d'équipe et une bonne participation des gestionnaires d'aires protégées et des parties prenantes à toutes les étapes du projet, dans la mesure du possible; et

8) axées sur une communication positive et opportune et la mise en œuvre des résultats.

Les évaluations, bien que très techniques, sont aussi des processus politiques et sociaux. II est essentiel d'analyser qui participe au processus et quels points de vue seront inclus dans les résultats. II existe un risque que des personnes non-inclues puissent contester les résultats, et leurs points de vue pourraient être très différents. Une compréhension des raisons sous-jacentes à la réalisation d'évaluations est également importante pour assurer l'adhésion et le soutien. Elles ne doivent pas être perçues comme un examen du rendement du personnel, car cela aurait une incidence sur l'exactitude des évaluations. Il est également important d'examiner attentivement la communication des résultats des évaluations. Sans une communication efficace, les résultats peuvent être mal interprétés ou utilisés de manière inappropriée, par exemple par des comparaisons injustifiées (Campese et Sulle, 2019). Les résultats de l'évaluation peuvent également être limités par la disponibilité et la qualité des données de référence. Une fois les résultats communiqués, il est également important que les domaines d'amélioration identifiés soient pris en compte, et que suffisamment de fonds et de capacités soient disponibles pour assurer un changement efficace pour répondre aux menaces, aux problèmes et aux défis identifiés dans les évaluations. Si ce n'est pas le cas et que rien ne change, cela peut conduire à la complaisance et au découragement des gestionnaires d'aires protégées, ainsi qu'à une diminution de l'intérêt pour la réalisation d'évaluations futures. Les évaluations et les processus permettant de les réaliser devraient aboutir à une gestion adaptative positive, qui se traduira par une gestion plus efficace des aires protégées.

\subsection{Intégrer l'efficacité de la gestion à la gouvernance et aux évaluations sociales}

La plupart des méthodologies d'évaluation EfGAP n'abordent pas en détail les questions de gouvernance ou d'équité sociale. Il existe cependant une synergie substantielle entre les différentes évaluations et beaucoup à gagner à les réaliser de façon simultanée. Toutes les méthodologies EfGAP analysent l'ampleur de la participation des parties prenantes, les menaces pour les aires protégées, et certaines explorent également les avantages et les aspects connexes des aspects sociaux de la gestion. Une exploration plus approfondie de la gouvernance et de l'équité des aires protégées est disponible au Chapitre 4

Certaines des normes et méthodologies développées intègrent des éléments substantiels d'efficacité de la gestion à l'évaluation sociale et / ou de la gouvernance (Campese et Sulle, 2019), comme c'est le cas de la Liste verte des aires protégées et de conservation (voir la Section 9.2). 


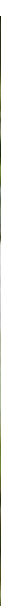

\subsection{Les EfGAP en Afrique orientale et australe}

L'analyse du pourcentage d'aires protégées disposant d'une évaluation EfGAP dans la BD-EGAP (Figure 10.2) montre que I'Afrique a fait un travail important dans ce domaine. Initialement, de nombreuses évaluations étaient liées aux exigences de financement des donateurs, mais au fil des ans, de nombreux pays de la région ont institutionnalisé les évaluations, et certains, dont Madagascar, l'Afrique du Sud et la Zambie, ont adapté l'outil OSEG à leurs objectifs spécifiques. L'Afrique du Sud réalise des évaluations OSEG depuis un certain nombre d'années, utilisant les objectifs de l'OSEG pour améliorer la gestion et comme un véritable moyen de résoudre les problèmes.

Malheureusement, peu d'analyses des résultats de ces évaluations sont disponibles pour comprendre quels étaient les résultats à l'échelle de la région.

Depuis 1990, un changement s'est produit dans le monde en termes de qui dirige les évaluations EfGAP. Initialement, la plupart des évaluations étaient dirigées par des ONG, mais de 2010 à 2014, une augmentation des efforts dirigés par des organismes gouvernementaux s'est produite (Coad et al., 2015).

Dans la BD-EGAP, 681 aires protégées disposent d'au moins une évaluation EfGAP en Afrique orientale et australe (Tableau 10.2). Cela ne représente que $13 \%$ des aires protégées de la région. Bon nombre des aires protégées ont été évaluées plus d'une fois, ce qui porte le nombre total d'évaluations à 1510 . La Figure 10.3 montre le nombre d'aires protégées disposant d'évaluations EfGAP dans la BD-EGAP en Afrique orientale et australe, tandis que la Figure 10.4 montre le pourcentage d'aires protégées disposant d'évaluations EfGAP dans la BD-EGAP.

\subsubsection{Inventaire des évaluations EfGAP en Afrique orientale et australe}

Cette section du rapport s'appuie grandement sur l'analyse réalisée par Jessica Campese et Emmanuel Sulle dans leur rapport intitulé Management Effectiveness, Governance and Social Assessments of Protected and Conserved Areas in Eastern and Southern Africa: a rapid inventory and analysis to support the BIOPAMA programme and partners, préparé pour le programme
BIOPAMA (Campese et Sulle, 2019). Le rapport a analysé l'efficacité de la gestion, la gouvernance et les évaluations sociales dans les aires protégées ou de conservation terrestres et / ou marines en Afrique orientale et australe. L'accent a été mis principalement sur les méthodologies élaborées spécifiquement pour évaluer une ou une combinaison de ces questions, et destinées à une utilisation répétée.

L'inventaire comprenait la BD-EGAP, ainsi que des études universitaires et des évaluations complètes ou partielles contenues dans des rapports plus généraux. II comprenait également des évaluations ayant été rapportées dans les réponses aux enquêtes et aux entretiens, mais n'ayant pas été rapportées à la BD-EGAP. En particulier, l'analyse incluait 294 évaluations OSEG en Afrique du Sud en 2015, 2017 et 2019, sur la base des réponses d'enquêtes (et de documents publiés) associées à des confirmations lors d'entretiens de suivi selon lesquelles l'Afrique du Sud réalise des évaluations OSEG-AS au moins tous les deux ans (et dans certains sites, chaque année) dans toutes les aires protégées terrestres gérées par le gouvernement. Les évaluations d'impact propres à des projet et les rapports d'examen préalable n'ont pas été inclus. Bien que l'inventaire soit vaste, il n'est pas exhaustif. Toutes les évaluations répertoriées n'ont pas été inclues dans les analyses détaillées, car elles ne constituaient pas des évaluations complètes utilisant des méthodes facilement reproductibles. Elles sont alors classées comme «Autres ».

En plus des types d'évaluation décrits ci-dessous, l'inventaire comprenait des évaluations de la gouvernance et des évaluations sociales réalisées dans des paysages abritant des aires protégées et de conservation, ainsi que des processus plus généraux et novateurs impliquant des éléments de gouvernance et d'évaluation sociale ${ }^{109}$. Les Protocoles communautaires bioculturels (PCB), par exemple, "articulent les valeurs, les procédures et les priorités déterminées par les communautés ", y compris (le cas échéant) en ce qui concerne les aires protégées et de conservation. Le processus peut comprendre la description, la réflexion et la reconnaissance de systèmes de gouvernance des territoires des peuples autochtones et des communautés locales, ainsi que des droits et responsabilités connexes. Des PCB ont été mis en place dans plusieurs pays de la région, notamment au Kenya, à Madagascar, en Namibie et en Afrique du Sud (voir le site web de Natural Justice).

109 II existe également de nombreuses expériences et ressources connexes qui n'ont pas été inclues dans l'inventaire car, bien que pertinentes pour le sujet, elles ne comportaient pas d'évaluation en soi. Cela comprend des études de cas en Afrique orientale et australe inclues dans le Registre des APAC.

$110 \mathrm{https}: / /$ biopama.org/node/349 
Tableau 10.2 : Évaluations EfGAP en Afrique orientale et australe

\begin{tabular}{|c|c|c|c|c|c|}
\hline Pays & $\begin{array}{r}\text { Nombre } \\
\text { d'aires } \\
\text { protégées } \\
\text { (BDMAP) }\end{array}$ & $\begin{array}{r}\text { Nombre d'aires } \\
\text { protégées disposant } \\
\text { d'une évaluation } \\
\text { EfGAP (BD-EGAP) }\end{array}$ & $\begin{array}{r}\text { Nombre } \\
\text { d'évaluation EfGAP } \\
\text { (BD-EGAP) }\end{array}$ & $\begin{array}{l}\text { Nombre d'évaluations } \\
\text { EfGAP répertoriées par } \\
\text { Campese et Sulle (2019) }\end{array}$ & $\begin{array}{r}\text { Nombre d'aires } \\
\text { protégées ayant fait } \\
\text { l'objet de plus d'une } \\
\text { évaluation }\end{array}$ \\
\hline Angola & 14 & 4 & 4 & 4 & 0 \\
\hline Botswana & 22 & 6 & 8 & 9 & 2 \\
\hline Comores & 8 & 0 & 0 & 0 & $\begin{array}{r}\text { Aucune évaluation dans } \\
\text { la BD-EGAP }\end{array}$ \\
\hline Djibouti & 7 & 1 & 1 & 1 & 0 \\
\hline Érythrée & 4 & 0 & 0 & 0 & $\begin{array}{r}\text { Aucune évaluation dans } \\
\text { la BD-EGAP }\end{array}$ \\
\hline Eswatini & 14 & 0 & 0 & 6 & $\begin{array}{r}\text { Aucune évaluation dans } \\
\text { la BD-EGAP }\end{array}$ \\
\hline Éthiopie & 104 & 17 & 20 & 27 & 3 \\
\hline Kenya & 411 & 41 & 70 & 112 & 18 \\
\hline Lesotho & 4 & 2 & 1 & 1 & 0 \\
\hline Madagascar & 157 & 78 & 79 & 476 & 1 \\
\hline Malawi & 133 & 19 & 23 & 29 & 4 \\
\hline Maurice & 44 & 13 & 19 & 13 & 4 \\
\hline Mozambique & 44 & 10 & 44 & 45 & 11 \\
\hline Namibie & 148 & 18 & 40 & 44 & 10 \\
\hline Rwanda & 10 & 4 & 6 & 5 & 2 \\
\hline Seychelles & 40 & 6 & 10 & 12 & 2 \\
\hline Somalie & 21 & 0 & 0 & 0 & $\begin{array}{r}\text { Aucune évaluation dans } \\
\text { la BD-EGAP }\end{array}$ \\
\hline Afrique du Sud & 1580 & 205 & 722 & 1606 & 173 \\
\hline $\begin{array}{l}\text { Soudan du } \\
\text { Sud }\end{array}$ & 27 & 4 & 4 & 4 & $\begin{array}{r}\text { Aucune évaluation dans } \\
\text { la BD-EGAP }\end{array}$ \\
\hline Soudan & 23 & 2 & 2 & 2 & 0 \\
\hline Tanzanie & 840 & 183 & 329 & 340 & 80 \\
\hline Ouganda & 712 & 37 & 54 & 53 & 10 \\
\hline Zambie & 635 & 22 & 65 & 70 & 12 \\
\hline Zimbabwe & 232 & 9 & 9 & 14 & 1 \\
\hline
\end{tabular}

Source : Campese et Sulle (2019); UNEP-WCMC et IUCN (2019a)

Figure 10.2 : Pourcentage de couverture des évaluations de l'efficacité de la gestion par région

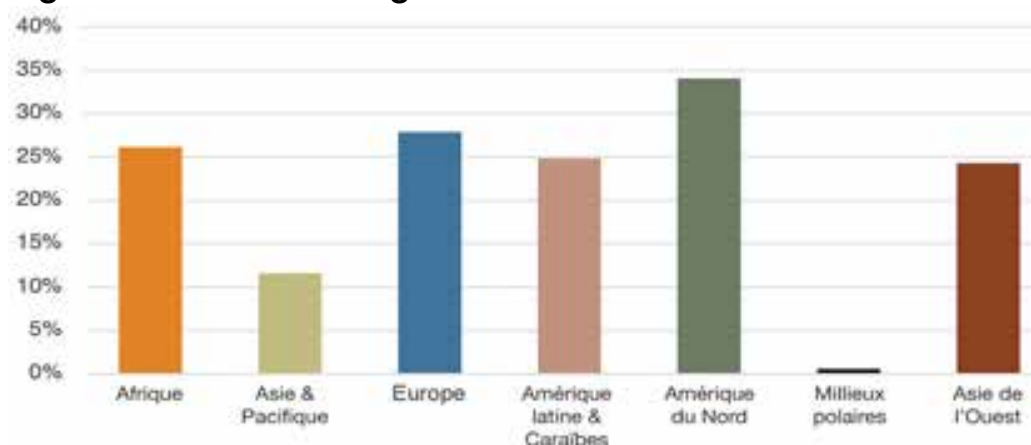

Source : UNEP-WCMC et IUCN (2019a).

Note : Pourcentage de couverture de toutes les aires protégées par région, évaluées quant à leur efficacité de gestion à l'aide de différents outils d'Efficacité de la gestion des aires protégées (EfGAP) 
Figure 10.3 Nombre d'aires protégées présentant une évaluation EfGAP dans la BD-EGAP en Afrique orientale et australe

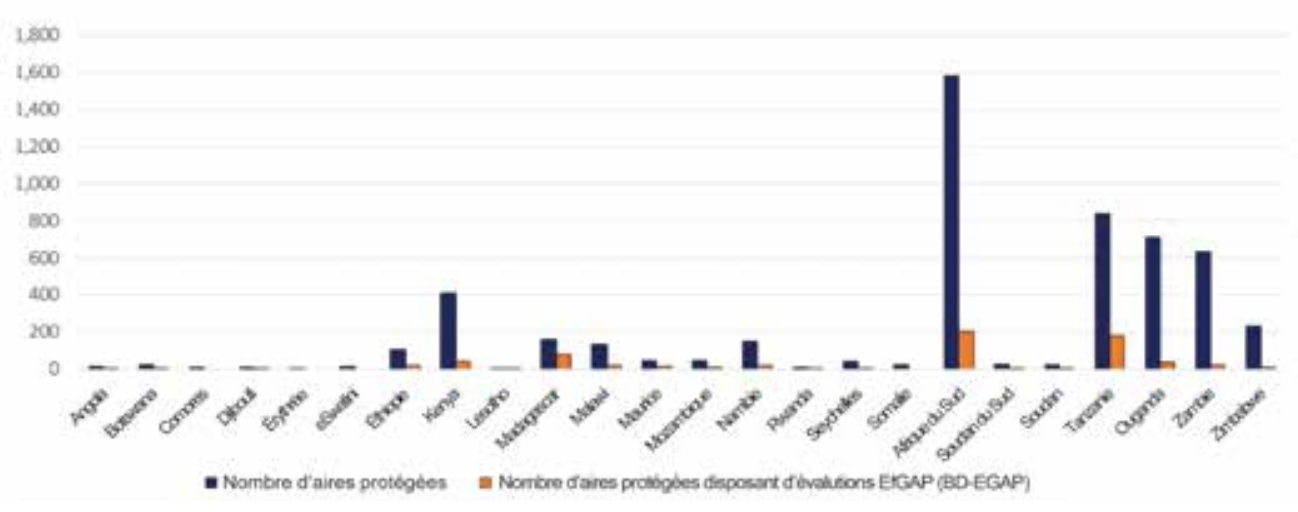

Source : UNEP-WCMC et IUCN (2019a).

Figure 10.4 : Pourcentage d'aires protégées possédant des évaluations EfGAP dans la BD-EGAP

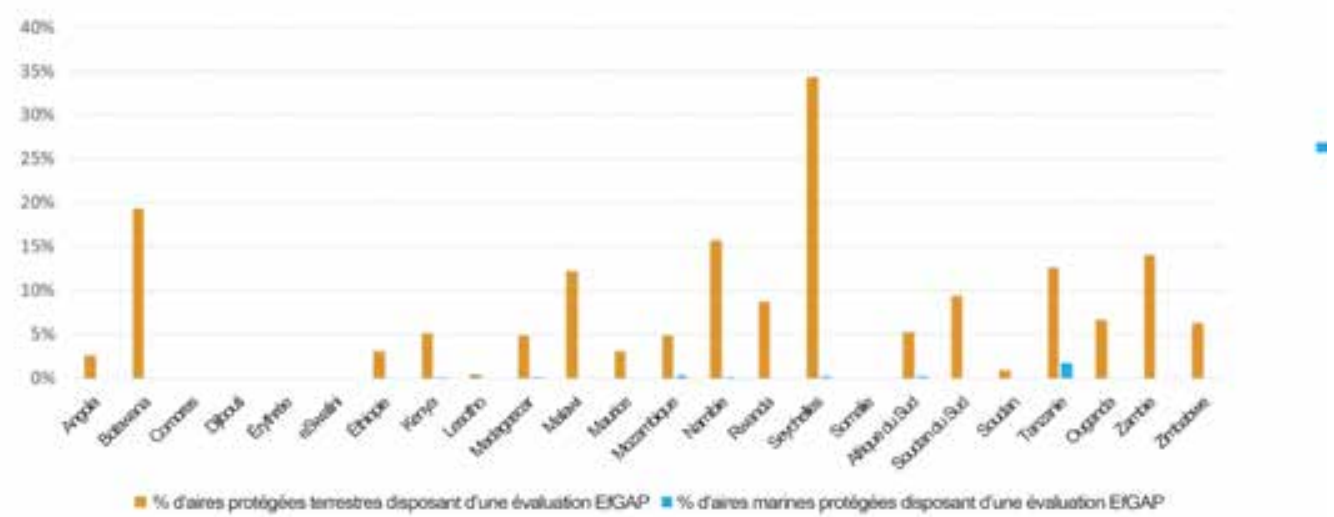

Source : UNEP-WCMC et IUCN (2019a)

Figure 10.5 : Évaluations EfGAP répertoriées en Afrique orientale et australe par méthodologie / outil (total : 2878)
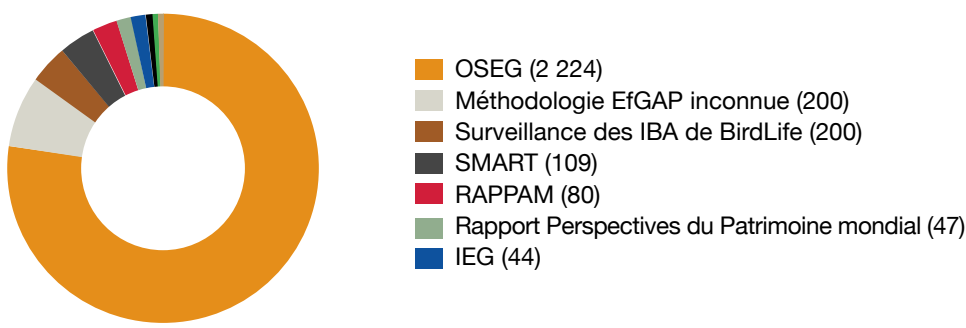

RAPPAM (80)

Rapport Perspectives du Patrimoine mondial (47)

IEG (44)

\section{Source : Campese et Sulle (2019, p. 44).}

Figure 10.6 : Répartition des évaluations EfGAP répertoriées par pays

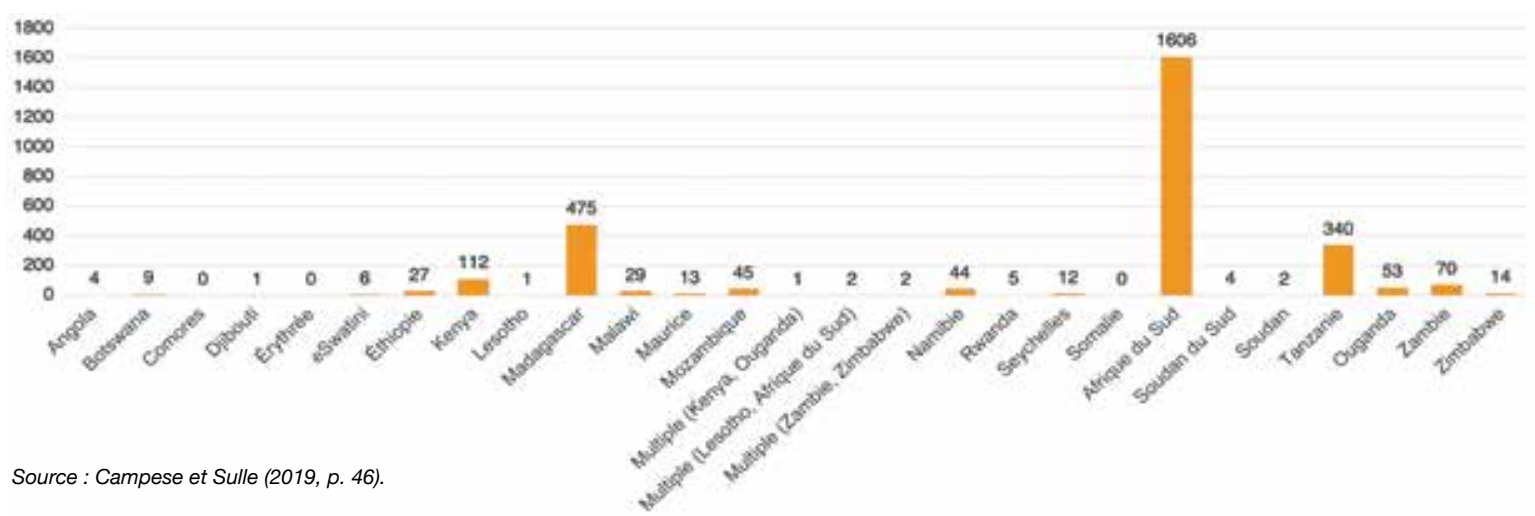


Le rapport complet est disponible en ligne. ${ }^{110}$

Au total, 2686 évaluations de l'efficacité de la gestion ont été répertoriées dans l'analyse EfGAP de Campese et Sulle (2019). Quatre-vingts d'entre elles faisaient partie d'évaluations RAPPAM à l'échelle de systèmes. Les évaluations OSEG, y compris les versions adaptées par les pays, constituent la grande majorité des évaluations EfGAP répertoriées : 2035 (soit plus de 75\%) (Figure 10.5).

Les évaluations EfGAP ont souvent été répétées dans les mêmes sites, en partie parce que de nombreux donateurs, y compris le FEM et la Banque mondiale, exigent des évaluations multiples au fil du temps comme condition à leur financement. Des évaluations OSEG, en particulier, ont été répétées dans de nombreux sites et, ces dernières années, ont été réalisées de façon annuelle ou biannuelle dans des aires protégées gérées par l'État en Afrique du Sud, à Madagascar et en Zambie. Des rapports sur les Perspectives du Patrimoine mondial ont été réalisés pour 24 sites en 2014, et répétés en 2017.

Des informations sur les types de gouvernance était disponibles pour 2046 des évaluations EfGAP. Plus de 95\% ont été menées dans des aires protégées gérées par les gouvernements, suivies de la gouvernance communautaire $(2 \%)$, de la gouvernance privée (2\%) et de la gouvernance partagée (moins de $1 \%$ ).

La majorité des évaluations EfGAP citées dans l'analyse ont été réalisées en Afrique du Sud (53\%), un pays ayant adopté l'OSEG à l'échelle nationale pour suivre l'efficacité de la gestion et ayant répété des évaluations sur plusieurs sites. Madagascar représente $18 \%$ des évaluations et la Tanzanie 13\% (voir la Figure 10.6). Seules les Comores, l'Érythrée et la Somalie n'ont pas signalé d'évaluations.

Le nombre d'évaluations EfGAP effectuées chaque année dans la région a augmenté au fil du temps (voir la Figure 10.7), de plus en plus d'évaluations OSEG, en particulier, étant entreprises de façon annuelle (voir la Figure 10.8).

\subsubsection{Inventaire des évaluations combinées en Afrique orientale et australe}

L'inventaire comprenait une analyse des évaluations sociales et de gouvernance des aires protégées, ainsi que des méthodologies combinant deux éléments ou plus, c'est à dire efficacité de la gestion, impact social et / ou gouvernance, compliquant leur classement dans une seule catégorie. La Figure 10.9 montre les évaluations " combinées » répertoriées par méthodologie / outil.

Sur les 31 évaluations de la catégorie " combinée », 20 ont utilisé l'Approche d'évaluation des risques du Forest Stewardship Council (FSC), cinq sites ayant utilisé la Liste verte de l'UICN (voir la Section 9.2). La Liste verte inclut une prise en compte explicite de l'efficacité de la gestion, de la gouvernance et de l'évaluation sociale. Les évaluations des risques du FSC, bien que rarement citées parmi les évaluations des aires protégées et de conservation, ont été inclues dans l'inventaire du fait que la norme FSC-US Forest Management Standard (Norme de gestion forestière du FSC-États-Unis) comprend des questions sur la gestion forestière et la gouvernance, ainsi que certains aspects de l'impact social, et que ces évaluations ont été relativement largement utilisées dans les forêts conservées de la région. Ceci inclut 17 réserves forestières de terres villageoises en Tanzanie, évaluées en vertu d'un certificat FSC collectif dans le cadre de l'Initiative de conservation et développement de Mpingo (MCDI, 2019).

\subsection{Résultats des évaluations EfGAP en Afrique orientale et australe}

Bien que de nombreuses évaluations EfGAP aient été réalisées dans toute l'Afrique orientale et australe (voir la Section 10.8), il n'existe aucune tentative récente et globale, à l'échelle régionale, pour compiler et analyser les résultats de ces évaluations.

La dernière méta-analyse mondiale comprenant une analyse régionale pour l'Afrique a été réalisée en 2010 (Leverington et al., 2010). Selon cette analyse, un peu plus de 960 évaluations ont été enregistrées en Afrique, et les données ont été analysées pour 644 sites à partir de l'évaluation la plus récente disponible pour chaque aire protégée. Le score d'efficacité moyen global (moyenne pour tous les indicateurs individuels) était de $49 \%$, ce qui était inférieur à la moyenne mondiale $(53 \%)$ ainsi qu'à toute autre région. Quelque $22 \%$ des évaluations se situaient dans le tiers inférieur de l'échelle (clairement inacceptable), tandis que seulement $17 \%$ se trouvaient dans le tiers supérieur (gestion adéquate) (Leverington et al., 2010).

Pour les sites naturels et mixtes (naturels et culturels) du Patrimoine mondial, Perspectives du Patrimoine mondial de I'UICN évalue 14 aspects différents de la protection et de la gestion, y compris le cadre législatif, le système de gestion, les relations avec les populations locales, le suivi, les limites du site, les programmes d'éducation, etc., avant de calculer une évaluation globale de l'efficacité de la protection et de la gestion de chaque site. Selon l'évaluation la plus récente, en 2017 (Osipova et al., 2018), les perspectives de conservation des sites naturels et mixtes du Patrimoine mondial en Afrique orientale et australe sont " bonnes " ou «bonnes malgré quelques inquiétudes " pour $71 \%$ des sites, tandis que $21 \%$ ont été évalués comme " très préoccupants " et $8 \%$ considérés comme " critiques ». Par exemple, par rapport à l'évaluation précédente de 2014, les résultats de la Réserve naturelle intégrale de Tsingy de Bemaraha, à Madagascar, sont passés de « bons " à " bons malgré quelques inquiétudes ", tandis que ceux du Parc national du Serengeti, en Tanzanie, se sont améliorés de «très préoccupants" à «bons malgré quelques inquiétudes ". Les perspectives de conservation de tous les autres sites de la région sont restés inchangés (Osipova et al. 2017). La moitié des sites naturels et mixtes du Patrimoine mondial en Afrique orientale et australe ont été évalués comme bénéficiant d'une protection et d'une gestion «globalement efficaces " ou "très efficaces", tandis que $29 \%$ ont été évalués comme "préoccupants " et $21 \%$ comme « très préoccupants ". Les notes individuelles des perspectives globales de conservation pour chacun des sites naturels / mixtes sont indiquées dans le Tableau 4.2.

Une analyse de l'efficacité de la gestion en Afrique de l'Est, réalisée dans le cadre du programme BIOPAMA en 2017, a utilisé 25 indicateurs principaux, tels que définis dans le rapport de Leverington et al. (2014) et représentant tous les éléments du cycle de gestion des aires protégées (BIOPAMA, non publié). Les résultats ont montré que $8 \%$ des aires protégées évaluées présentaient un bon niveau de gestion, tandis que $34 \%$ ne disposaient que d'une gestion basique (voir la Figure 10.10). Près de la moitié (40\%) des aires protégées citées dans l'analyse disposaient d'une gestion basique, mais présentant des lacunes majeures. La gestion de dix-huit pour cent des aires protégées a été jugée inadéquate. La Figure 10.11 montre l'emplacement de certaines des aires protégées citées dans l'analyse, ainsi que leur niveau d'efficacité de gestion. 
Figure 10.7 : Évaluations de l'efficacité de la gestion répertoriées par année

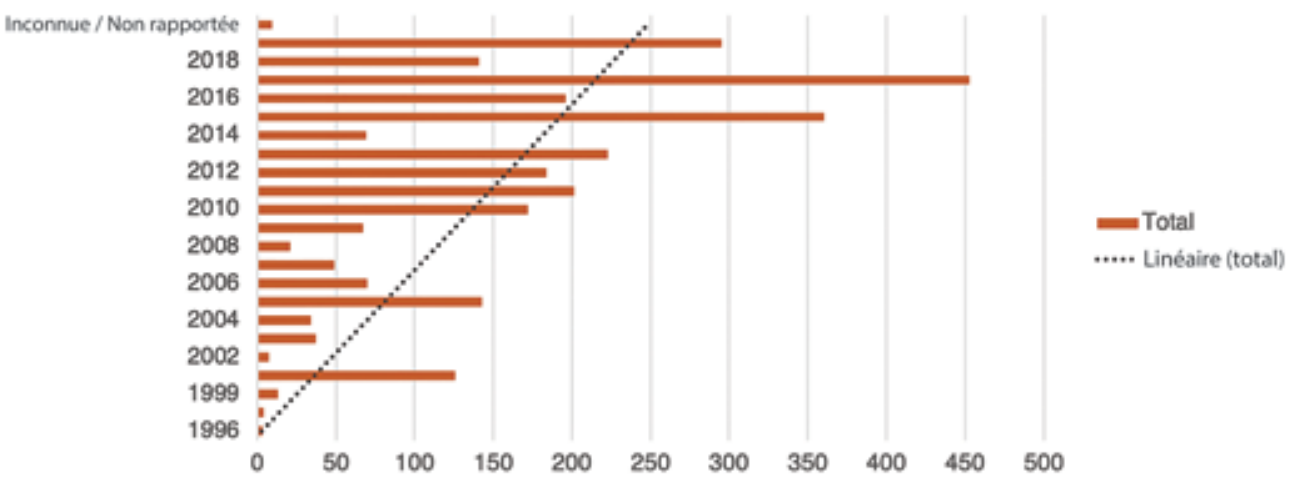

Source : Campese et Sulle (2019, p. 47).

Une petite erreur dans la répartition des évaluations entre 2014 et 2015 a été identifiée depuis la publication de Campese et Sulle (2019). Elle a été corrigée dans cette figure.

Figure 10.8 : Évaluations OSEG répertoriées par année

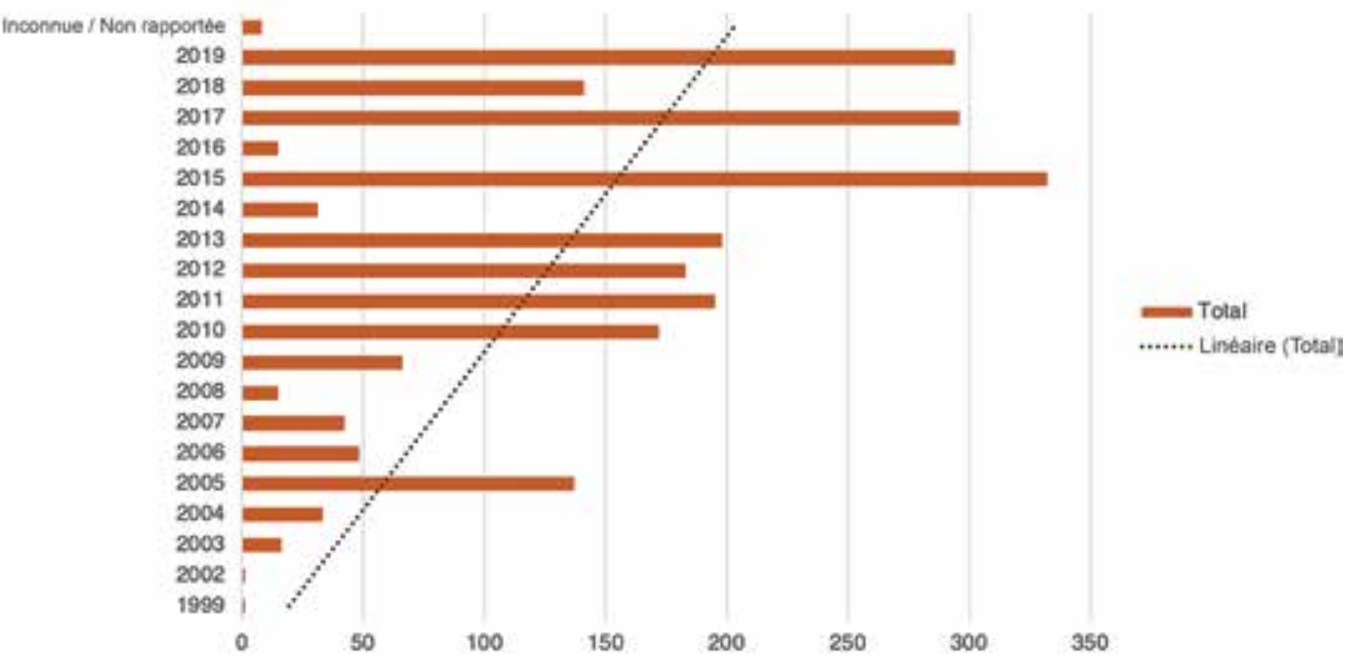

Source : Campese et Sulle (2019, p. 52).

Figure 10.9 : Évaluations « combinées » répertoriées par méthodologie / outil

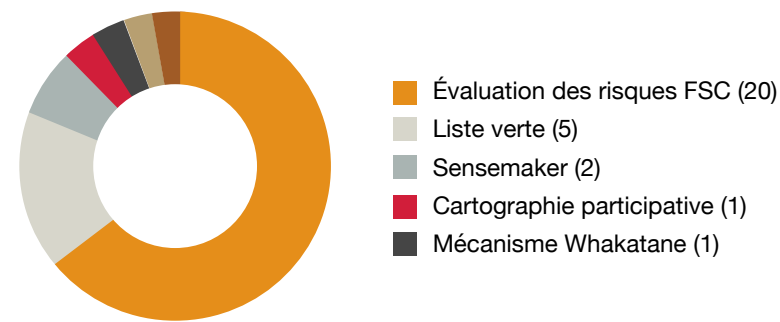

Source: Campese et Sulle (2019, p. 53).

Figure 10.10 : Résultats d'efficacité de la gestion des aires protégées évaluées en Afrique de l'Est

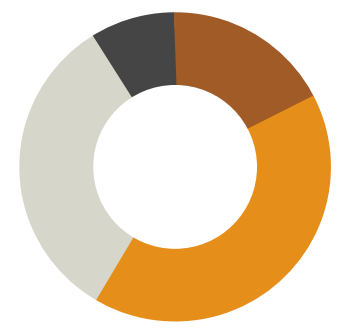

Basique (50-66\%)

Basique - déficiences majeures (33,3-50\%)

Inadéquate $(<33,3 \%)$

Robuste (>66\%)

Note : les aires protégées ont été classées en fonction de leurs scores moyens d'efficacité de la gestion (entre parenthèses) selon l'évaluation la plus récente. Source : BIOPAMA (2017). 
Figure 10.11 : Carte montrant les résultats d'efficacité de la gestion des aires protégées évaluées en Afrique de l'Est

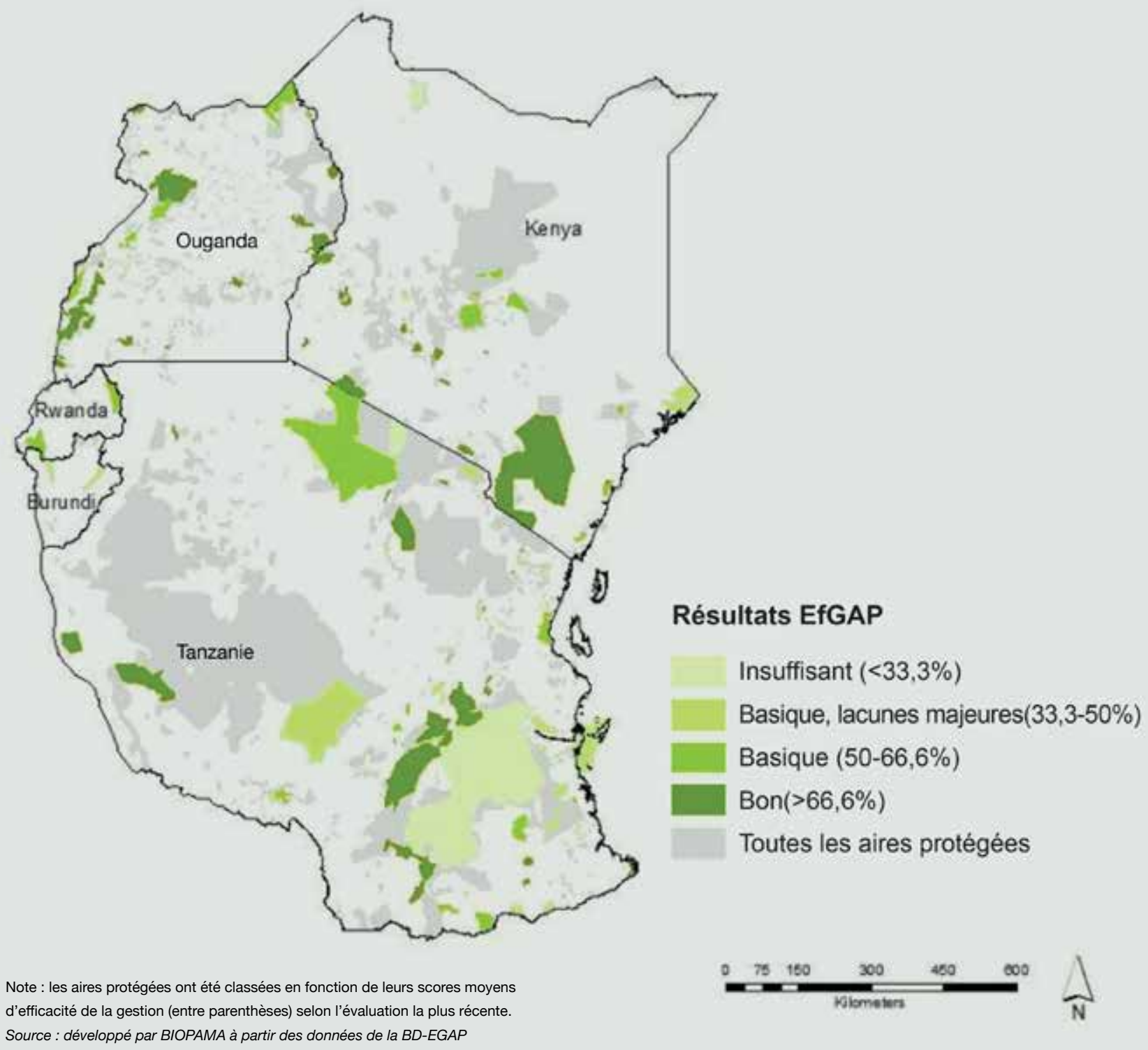

Afin de déterminer quels aspects de la gestion des aires protégées sont les plus efficaces, une analyse plus approfondie des évaluations a été effectuée pour obtenir des scores moyens pour les indicateurs principaux, de façon individuelle (voir Figure 10.12).

L'analyse est basée sur l'évaluation la plus récente disponible pour chaque aire protégée. Les indicateurs présentant moins de 20 échantillons ont été retirés de l'analyse.

Dans l'ensemble, la planification est apparu comme l'élément le plus robuste de la gestion, en particulier pour les aspects de création de sites, tandis que la planification de la gestion est apparue comme un peu plus faible. En matière d'intrants, les indicateurs reflétant la disponibilité de financements et de matériel figuraient parmi les aspects les plus faibles de la gestion. Certains indicateurs ont révélé des résultats mitigés. Par exemple, la gouvernance, le leadership et la participation des communautés et des parties prenantes ont été évalués comme relativement robustes, mais cela ne se reflétait pas dans les effets positifs de l'aire protégée sur les communautés locales.

Des évaluations ont également été entreprises à l'échelle de pays. Par exemple en 2014, l'Afrique du Sud a réalisé une analyse de l'efficacité de la gestion de ses aires marines protégées (Chadwick et al., 2014). Celle-ci a mis en évidence un certain nombre d'améliorations par rapport à l'analyse précédente, en 2009, notamment des programmes de suivi, le renforcement des capacités d'application de la loi et l'amélioration de la participation des parties prenantes. Elle a, en outre, noté que les budgets, les processus administratifs, les réglementations inadéquates, la disponibilité de personnel qualifié dans les AMP et l'élaboration de plans stratégiques étaient toujours déficients. 


\subsection{Financement et ressources des aires protégées $^{111}$}

Les aires protégées et de conservation jouent un rôle clé dans la protection de la diversité biologique et des services écosystémiques dont dépendent l'économie et les populations africaines. Ces sites ont besoin de sources de financement fiables et durables pour maintenir leurs opérations de gestion quotidiennes, atteindre leurs objectifs de conservation, offrir des expériences de qualité aux visiteurs, le cas échéant, et offrir des avantages aux communautés vivant à proximité des aires de conservation.

Les sources de financement actuelles sont cependant insuffisantes. Un certain nombre d'études ont été réalisées pour évaluer le déficit financier pour la gestion des aires protégées (Credit Suisse et al., 2014; Emerton et al., 2006; Parker et al., 2012). Bien que le chiffre exact puisse varier, il existe un consensus général sur le fait que le montant actuel des fonds disponibles pour la protection et la gestion des aires de conservation est totalement insuffisant. Un rapport du Crédit Suisse, du WWF et du groupe McKinsey en 2014 a estimé que USD 300 à 400 milliards sont nécessaires chaque année pour financer la protection de la biodiversité mondiale. Le rapport théorise que, même si les efforts de conservation gouvernementaux et philanthropiques actuels sont doublés pour atteindre environ USD 100 milliards par an, la conservation mondiale de la biodiversité sera toujours confrontée à un déficit de financement mondial de USD 200 à 300 milliards par an (Credit
Suisse et al., 2014). L'Initiative de financement de la biodiversité (BIOFIN) du Programme des Nations Unies pour le développement (PNUD) suggère une estimation similaire du déficit de financement annuel mondial à USD 150-440 milliards (BIOFIN, 2019).

Une estimation exacte des dépenses mondiales consacrées à la biodiversité et aux services écosystémiques est difficile à obtenir, en raison de lacunes et d'incohérences considérables dans les rapports et le suivi sur le financement de la biodiversité (OCDE, 2019). Selon Parker et al. (2012), les dépenses mondiales consacrées à la biodiversité et aux services écosystémiques ont atteint USD 53 milliards par an en 2010. L'OCDE a estimé que les dépenses consacrées aux activités liées à la biodiversité (sur la base des données disponibles sur les budgets publics) étaient de USD 49 milliards en 2015. À titre de comparaison, les secteurs des combustibles fossiles et de l'agriculture ont reçu USD 500 milliards de subventions et de soutien public par an (OCDE, 2019). Sur les USD 53 milliards alloués à la conservation de la biodiversité, $74 \%$ ont été dépensés dans le monde développé, seulement $6 \%$ en Afrique (Parker et al., 2012) et $5 \%$ en Amérique latine.

Une étude récente portant sur 2167 aires protégées, représentant $23 \%$ du parc mondial d'aires protégées terrestres, a révélé que moins de $25 \%$ des aires protégées disposent de ressources, de personnel ou d'un budget adéquats (Coad et al., 2019). Dans les pays en développement, ce déficit de financement des aires protégées a été estimé à environ USD 0,2 à 0,9 milliard par an en 2005 (CDB, 2005), tandis que moins de $6 \%$ des pays ayant soumis

\section{Figure 10.12 : Résultats moyens pour les indicateurs principaux des évaluations les plus récentes}

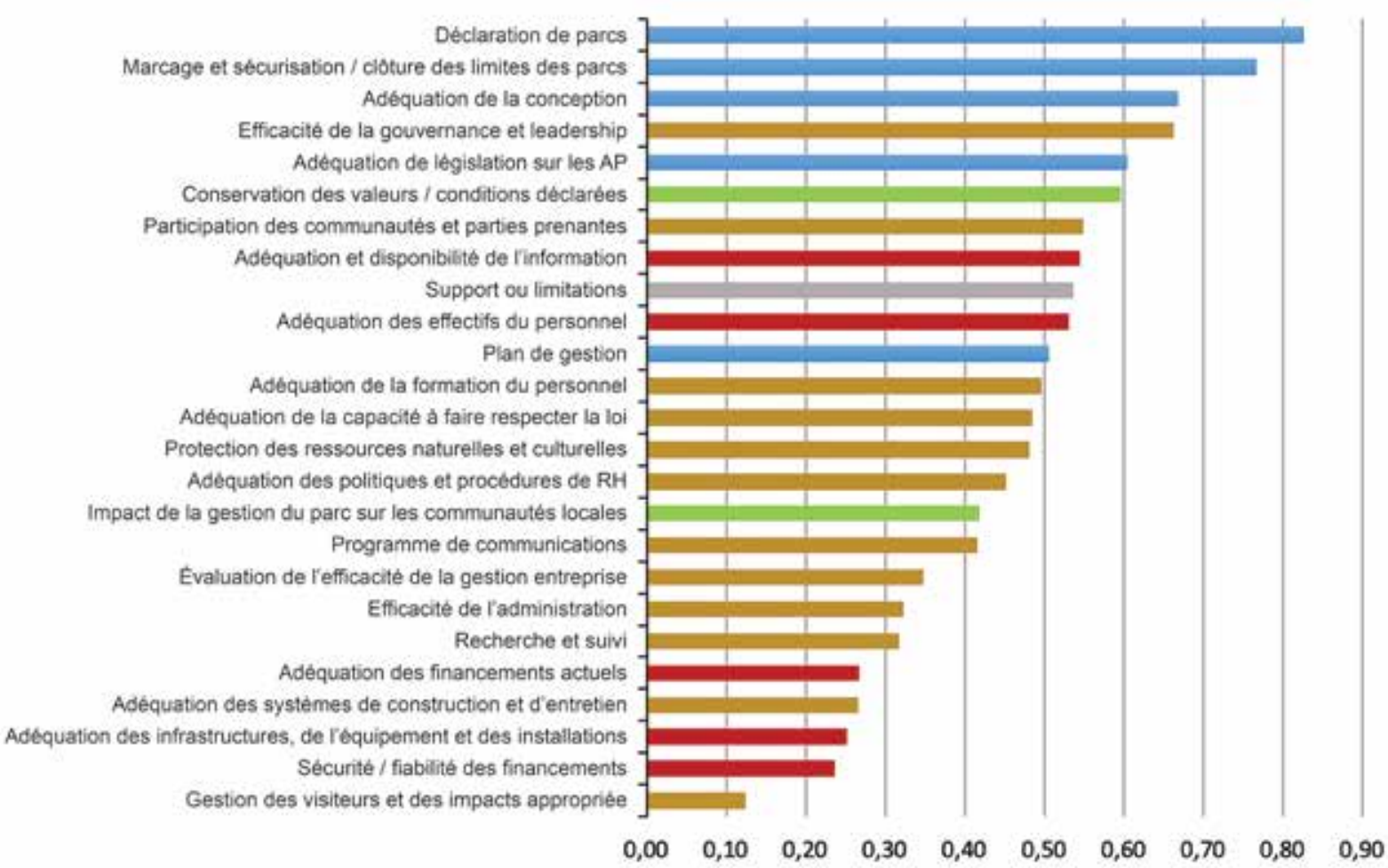

Contexte $\square$ Planification $\square$ intrants $\square$ Processus $\square$ Résutats 
des rapports à la $\mathrm{CDB}$ ont indiqué disposer de ressources suffisantes pour la gestion de leurs aires protégées (Watson et al., 2014).

\subsubsection{Déficit de financement en Afrique orientale et australe}

Les aires protégées d'Afrique orientale et australe sont confrontées à un important défi de financement et de ressources, en particulier celles protégeant des grands mammifères, tels que le rhinocéros, l'éléphant, le lion et le lycaon. Une étude a révélé que le coût annuel de gestion des aires protégées abritant des lions est d'environ $2.000 \mathrm{USD} / \mathrm{km}^{2}$ dans les sites non clôturés, et de $500 \mathrm{USD} / \mathrm{km}^{2}$ dans les sites clôturés (IUCN ESARO, 2020, p. 16). Ces résultats ont par la suite été confirmés par Lindsey et al. (2018), qui ont estimé qu'une gestion efficace des aires protégées abritant des lions nécessite 1000 à 2000 USD/km² (IUCN ESARO, 2020, p. 16). Cependant, la majorité des aires protégées en Afrique sont gérées avec moins de $50 \mathrm{USD} / \mathrm{km}^{2}$ (Fitzgerald, 2017), ce qui suggère que ces sites sont largement sous-financées d'environ 90\% (IUCN ESARO, 2020, p. 16).

Bien que le financement, la gestion et les besoins en personnel associés des aires protégées varient en fonction de facteurs tels que les caractéristiques géographiques locales, la forme, le climat, le contexte culturel, les espèces présentes sur le site, les utilisations des terres adjacentes et les populations, il existe un consensus quant à un déficit de financement important dans toute l'Afrique orientale et australe.

Une étude de 2019 a évalué les coûts de gestion, les recettes et les subventions de 282 aires protégées appartenant à l'État et abritant des lions, et a conclu que les fonds disponibles ne satisfaisaient qu'à $10 \%$ à $20 \%$ des besoins de gestion. Au total, le déficit de financement de ces aires protégées a été estimé à environ USD 1,5 milliard par an (IUCN ESARO, 2020, p. 16).

Une analyse des données financières des aires protégées dans 15 pays de la région a également montré que 12 d'entre eux font face à des déficits de financement importants (voir la Figure 10.13). Même si l'Afrique de l'Est et l'Afrique australe présentent généralement des déficits de financement similaires (56\% et $64 \%)$, certains pays, comme l'Afrique du Sud, le Kenya et le Rwanda (voir l'Encadré 10.2), semblent être mieux financés, ce qui suggère que les pays disposant d'une législation habilitante (comme les politiques de propriété des espèces sauvages de l'Afrique du Sud) et d'un tourisme de nature bien développé sont en mesure de contribuer davantage au financement de leurs aires protégées.

\subsubsection{Sources de financement actuelles}

Les options de financement traditionnelles des aires protégées et de conservation en Afrique orientale et australe se limitent généralement au financement public, au soutien de donateurs et au financement auto-généré, fondé sur le marché, comme par exemple les revenus générés par le tourisme de nature. Bien que les pays, les aires protégées et leurs besoins de financement associés diffèrent, très peu d'aires protégées sont en mesure de générer des revenus suffisants par des moyens internes, rendant la plupart dépendantes d'une forme quelconque de soutien de donateurs ou des gouvernements. Ces sources de financement externes restent cependant insuffisantes.

\section{Financement externe}

- Soutien gouvernemental : à l'échelle mondiale, environ la moitié des dépenses destinées à la biodiversité sont couvertes par un financement gouvernemental national du pays hôte (Parker et al., 2012). En Afrique orientale et australe, toutes les agences chargées des aires protégées reçoivent un certain niveau de financement de leurs gouvernements nationaux. Par exemple, au Kenya, 47\% du budget 2015 du Service de la faune du Kenya a été fourni par le gouvernement Kenyan (Kenya Wildlife Service, 2015). Cependant, les gouvernements sont souvent confrontés à des besoins concurrentiels en matière d'infrastructures, de santé, d'éducation et de sécurité alimentaire, détournant ainsi le financement de la conservation vers ces besoins sociaux. Il est donc essentiel de diversifier les revenus, tout en augmentant les recettes provenant de moyens auto-générateurs, afin d'assurer la viabilité à long terme du financement et de la gestion des aires protégées. De même, des investissements dans la gestion des aires protégées sont également nécessaires pour s'assurer que les infrastructures requises soient en place et que la faune sauvage ou les produits de nature soient financièrement en sécurité.

- Soutien de donateurs et gestion collaborative : selon l'étude d'Emerton et al. (2006), les subventions externes, les dons et le soutien philanthropique, ainsi que le soutien gouvernemental, restent parmi les principales sources de financement pour la conservation et la gestion des aires protégées en Afrique orientale et australe. En 2018, par exemple, plus des trois quarts des dépenses de fonctionnement et d'investissement d'une organisation kenyane, le Fiducie des pâturages du nord qui soutient 30 aires de conservation communautaires, ont été couvertes grâce au soutien de donateurs (The Northern Rangelands Trust, 2018). En revanche, en Afrique du Sud, 80\% des revenus de Parcs Nationaux Sudafricains sont autofinancés et proviennent du tourisme.

Les organisations locales et internationales de conservation jouent également un rôle important dans le soutien, le financement et les ressources disponibles pour les aires protégées africaines. Par exemple, depuis plus de 30 ans, la Société zoologique de Francfort (FZS), en partenariat avec le Département des parcs nationaux et de la faune sauvage de Zambie, soutient la conservation dans le Parc national du Nord de Luangwa ainsi que dans les AGG environnantes (FZS, 2019). II existe différents modèles de soutien non gouvernemental à la gestion des aires protégées (voir la Section 11.1). Les données financières de 15 pays d'Afrique orientale et australe montrent que le soutien des donateurs représente plus de $50 \%$ des financements (Lindsey et al., 2018).

Compte tenu de sa compatibilité avec la conservation en tant qu'utilisation des terres, le tourisme de nature est souvent la principale (et dans de nombreux cas la seule) source de revenus générés par les aires protégées. Le tourisme de nature fait référence à un tourisme dont le but principal est d'observer ou de profiter de l'environnement naturel, ce qui comprend, entre autres activités, la randonnée, l'observation des oiseaux ou les safaris d'observation de la faune. Une analyse des sept autorités chargées des aires protégées en Eswatini, Éthiopie, Kenya, Namibie, Tanzanie, Afrique du Sud et Ouganda (totalisant plus de 240 aires protégées et 40 millions d'hectares gérés) montre que le tourisme génère environ $80 \%$ de tous les revenus générés en interne (voir la Figure 10.14).

Un certain nombre de pays d'Afrique orientale et australe ont la possibilité d'accroître les recettes tirées du tourisme existant et de développer de nouvelles formes de revenus grâce au tourisme basé sur la faune sauvage. D'autres tendances clés en matière de 
Figure 10.13 : Déficit de financement et ressources financières disponibles dans 15 pays d'Afrique orientale et australe
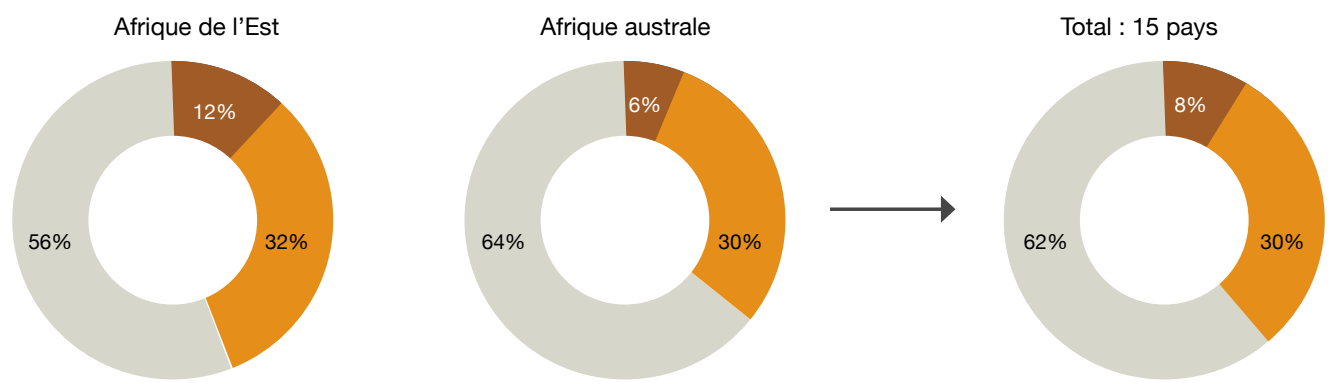

Source : IUCN ESARO (2020, fig. 5, p. 16).

Figure 10.14: Répartition des revenus générés en interne dans sept pays (Afrique du Sud, Eswatini, Éthiopie, Kenya, Namibie, Tanzanie et Ouganda)

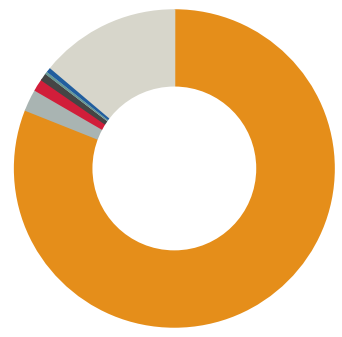
Revenus du tourisme
Revenus de la chasse
- Boutiques / vente de marchandises
Vente de récoltes de produits naturels
Crédits carbone, compensations de biodiversité, autres PSE
Frais de tournage et de photographie, marathons
Autres

Source : Développé par Conservation Capital (2019) ${ }^{112}$

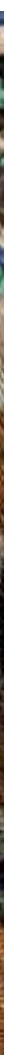

112 Ce graphique a été développé par Conservation Capital à l'aide des sources de données suivantes : rapports financiers et annuels du Service de la faune du Kenya, de Parcs nationaux de Tanzanie, de Parcs nationaux d'Afrique du Sud, de la Commission nationale de fiducie d'Eswatini, de l'Autorité éthiopienne de conservation de la faune, de l'Autorité ougandaise de la faune et de la Association namibienne de gestion communautaire des ressources naturelles. La catégorie " Autres » comprend, lorsqu'elle est spécifiée, la location d'équipement et d'installations, les intérêts et redevances reçus, les contraventions du parc, les frais de garage et de main-d'œuvre, les frais de sauvetage, la recherche et autres revenus. 


\section{Encadré 10.2 : La vigueur de l'économie touristique au Rwanda}

Le Rwanda présente un marché des voyages de loisirs solide et en augmentation, la plupart de ses 1,4 million de visiteurs provenant des pays voisins (43\% proviennent de la Communauté d'Afrique de l'Est (EAC) et 45\% d'autres parties de l'Afrique) (RDB, 2017), et 80000 visiteurs venant de l'étranger (notamment d'Europe et d'Inde).

Le tourisme d'affaires et de conférence prend de plus en plus d'importance et génère la part de revenus la plus élevée (RDB, 2017). Par exemple, plus de 50\% des arrivées par avion (hors transit, retour des résidents et visite d'amis ou de la famille) viennent pour affaires ou une conférence, les vacances représentant 35\% (National Institute of Statistics of Rwanda, 2017).

Le tourisme est la principale source de devises du Rwanda, et provient principalement de l'écotourisme, identifié comme une priorité par le gouvernement rwandais du fait de ses avantages sociaux et économiques. Les revenus totaux générés par les voyages d'agrément sont passés de USD 390 millions en 2016 à USD 438 millions en 2017, soit 14\% du produit intérieur brut (PIB) du pays (KNOEMA, 2018).

Le tourisme au Rwanda soutient 98000 emplois directs (soit $5 \%$ du total des emplois non agricoles), et un total (direct et indirect) de 250000 emplois (soit 14\% des emplois non agricoles). Le nombre de visites dans les parcs nationaux a augmenté de $54 \%$ depuis 2012, passant de 61000 à près de 94000 visites en 2017. Cette augmentation a entraîné une consolidation significative des revenus, avec USD 18,6 millions en 2017 , soit une augmentation de près de $50 \%$ par rapport à 2012 (IUCN ESARO, 2020, p. 28).

La majorité des revenus écotouristiques du Rwanda sont générés par les permis de trekking pour l'observation des gorilles, qui coûtent actuellement USD 1500 par permis. Le Rwanda possède également le modèle de partage des revenus communautaires le plus élevé d'Afrique, fournissant $10 \%$ de tous les revenus du parc aux communautés et $5 \%$ supplémentaires à un fonds de gestion des conflits hommefaune pour les communautés. Compte tenu de la dépendance excessive à l'égard des revenus dérivés des gorilles de montagne, qui ont généré USD 18,3 millions en 2017 (RDB, 2017), le Rwanda a commencé à élargir et à diversifier son offre de tourisme de nature en développant et en attirant des investissements dans ses autres aires protégées, telles que le Parc national de l'Akagera, dans la partie orientale du pays, qui offre un produit touristique différent, dans un paysage de savane. En diversifiant ses produits, le gouvernement vise à garder les personnes dans le pays plus longtemps, augmentant ainsi la génération de revenus (RDB, comm. pers., 2019). Le Parc national d'Akagera est cogéré avec Parcs Africains, une organisation à but non lucratif dont le siège est situé en Afrique du Sud (voir la Section 11.1).

\section{Contribution de Conservation Capital.}


financement des aires protégées en Afrique orientale et australe sont décrites ci-dessous.

- II existe d'importants écarts de revenus entre les aires protégées et les pays. Par exemple, sur 14 parcs en Tanzanie, plus de $75 \%$ des revenus en 2012 / 2013 ont été générés par seulement deux parcs: les Parcs nationaux du mont Kilimandjaro (42\%) et du Serengeti (33\%). Au Rwanda, le Parc national des volcans représente $38 \%$ de toutes les visites et génère plus de $90 \%$ de l'ensemble des revenus (RDB, 2017).

- Les recettes, les dépenses et la rétention sont un aspect clé pour assurer une gestion efficace de la conservation. Les plans d'activités des aires protégées (individuelles et systèmes) aident à faire en sorte que toute augmentation des financements soit gérée correctement, améliorant ainsi les rendements en matière de conservation. La plupart des agences chargées des aires protégées dans la région sont tenues de reverser leurs revenus au budget gouvernemental, puis de demander leur budget annuel, certaines recevant moins que ce qu'elles ont généré. Par conséquent, même si un parc est en mesure de générer des revenus suffisants pour soutenir ses opérations, ces bénéfices sont utilisés pour subventionner des parcs moins rentables. Par exemple, en Tanzanie, TANAPA gère 506 aires protégées, mais deux parcs nationaux, le Kilimandjaro et le Serengeti, généraient à eux seuls $74 \%$ des revenus en 2013 (Tanzania National Parks, 2013). En Afrique du sud, sur 19 parcs nationaux, les parcs de Table Mountain et Kruger ont accueilli $77 \%$ de l'ensemble des visiteurs en 2017-2018, générant des revenus importants grâce aux droits de conservation et de concession (SANParks, 2018). Au Rwanda, le Parc national des volcans représente $38 \%$ de l'ensemble des visites et génère plus de $90 \%$ de tous les revenus du Conseil de développement du Rwanda, le département chargé de la gestion des aires protégées et de la faune sauvage dans le pays (RDB, 2017).

- Dépendance à l'égard du potentiel de génération de revenus d'espèces emblématiques. La plupart des fonds sont destinés à des sites emblématiques, de sorte que de nombreuses aires protégées ne sont pas fonctionnelles. Par exemple, une majorité du budget du Service de la faune du Kenya est consacrée aux parcs nationaux d'Amboseli, de Tsavo et du mont Kenya, laissant d'autres parcs sous-financés et non opérationnels en raison d'une pénurie de financement (BIOPAMA, non publié). En Ouganda, $58 \%$ des revenus de l'Autorité ougandaise de la faune ont été générés par les permis d'observation des gorilles de montagne en 2015 (UWA, non publié), tandis qu'au Rwanda, $76 \%$ des touristes visitant le parc national des Volcans ont participé à l'observation des gorilles, générant USD 15,4 millions ou $86 \%$ de l'ensemble des revenus (IUCN ESARO, 2020, p. 27). Bien que ces espèces et parcs emblématiques soient un excellent produit d'appel pour les pays respectifs, la viabilité à long terme du système d'aires protégées dépend de ces lieux et de ces espèces, ce qui constitue un risque majeur. Par exemple, si le virus ébola a un impact sur une population de grands singes dont dépend le revenu d'un pays, cela aura un impact non seulement sur l'espèce, mais également sur l'économie de l'ensemble du système.

En plus de générer des revenus pour les aires protégées, l'industrie du tourisme, si elle est conçue de manière appropriée et durable, peut dissuader le braconnage et autres activités illicites d'extraction de ressources naturelles. Dans le monde entier, le tourisme de nature augmentait de $10 \%$ à $12 \%$ par an en 2004 (Space For Giants et al., 2019). Une étude antérieure (Balmford et al., 2009) a montré que les visites dans les aires protégées étaient en augmentation dans les trois quarts des pays où des données étaient disponibles.

L'Afrique orientale et australe est particulièrement bien adaptée au développement du tourisme basé sur la faune sauvage, compte tenu de ses atouts naturels et culturels uniques, de sa facilité d'accès et de sa faune spectaculaire. L'utilisation des terres dans la région est également compatible avec un tourisme basé sur la faune sauvage, $16,54 \%$ des terres étant protégées en Afrique orientale et australe (voir la Section 4), ce qui signifie que 2,1 millions de $\mathrm{km}^{2}$ de terres offrent un potentiel pour un tourisme basé sur la faune sauvage. Ce chiffre est supérieur à d'autres destinations touristiques majeures dans le monde présentant des paysages très divers, comme les États-Unis.

En Afrique orientale et australe, les voyages et le tourisme ont représenté 9,5\% du PIB (soit USD 75 milliards) en 2018 (WTTO, 2019). Les dépenses touristiques dans la région ont représenté USD 50 milliards, dont environ USD 35 milliards pour les loisirs et environ USD 25 milliards pour les visiteurs internationaux (WTTO, 2019).

Le tourisme joue déjà un rôle important dans la région, générant des revenus pour les pays, fournissant des emplois, directement et indirectement, et soutenant les services sociaux vitaux.

Quelques faits marquants de son rôle sont mentionnés ci-après :

- En Afrique du Sud, les parcs nationaux ont accueilli plus de 7 millions de touristes et généré USD 109 millions de revenus touristiques pour l'année se terminant au 31 mars 2018 (SANParks, 2017).

- Environ 2,9 millions de personnes ont visité les aires protégées du Kenya en 2018 (KNBS, 2019).

- Environ 46\% (590 000) des visiteurs internationaux en Tanzanie ont visité une aire protégée (Spenceley et al., 2017; The World Bank Group, s.d.).

- Les aires protégées d'Ouganda ont reçu 305000 visiteurs au cours de l'année se terminant en juin 2018, générant des revenus de USD 28 millions pour l'Autorité ougandaise de la faune (UWA, 2018).

- Environ $80 \%$ des touristes partant en vacances en Afrique y vont pour observer la faune sauvage, selon une enquête menée auprès de 48 institutions gouvernementales de 31 pays d'Afrique subsaharienne et 145 voyagistes vendant des voyages en Afrique (WTO, 2014).

- Les aires protégées d'Afrique attirent chaque année environ 69 millions de visiteurs récréatifs, principalement des touristes internationaux (EC JRC, 2018).

En extrapolant les statistiques sud-africaines et ougandaises et en tenant compte d'une marge d'erreur importante, on estime que les autorités chargées des aires protégées dans la région pourraient générer entre USD 300 millions et 1 milliard de revenus annuels, grâce à 30 à 50 millions de visites par an.

Bien que le tourisme basé sur la faune sauvage ne soit pas approprié dans un certain nombre d'endroits, il existe encore d'importantes possibilités en Afrique orientale et australe de développer un tourisme durable qui permette d'augmenter les revenus pour la gestion des aires protégées. Le même environnement favorable nécessaire pour le tourisme basé sur la faune sauvage est également nécessaire pour certains des 


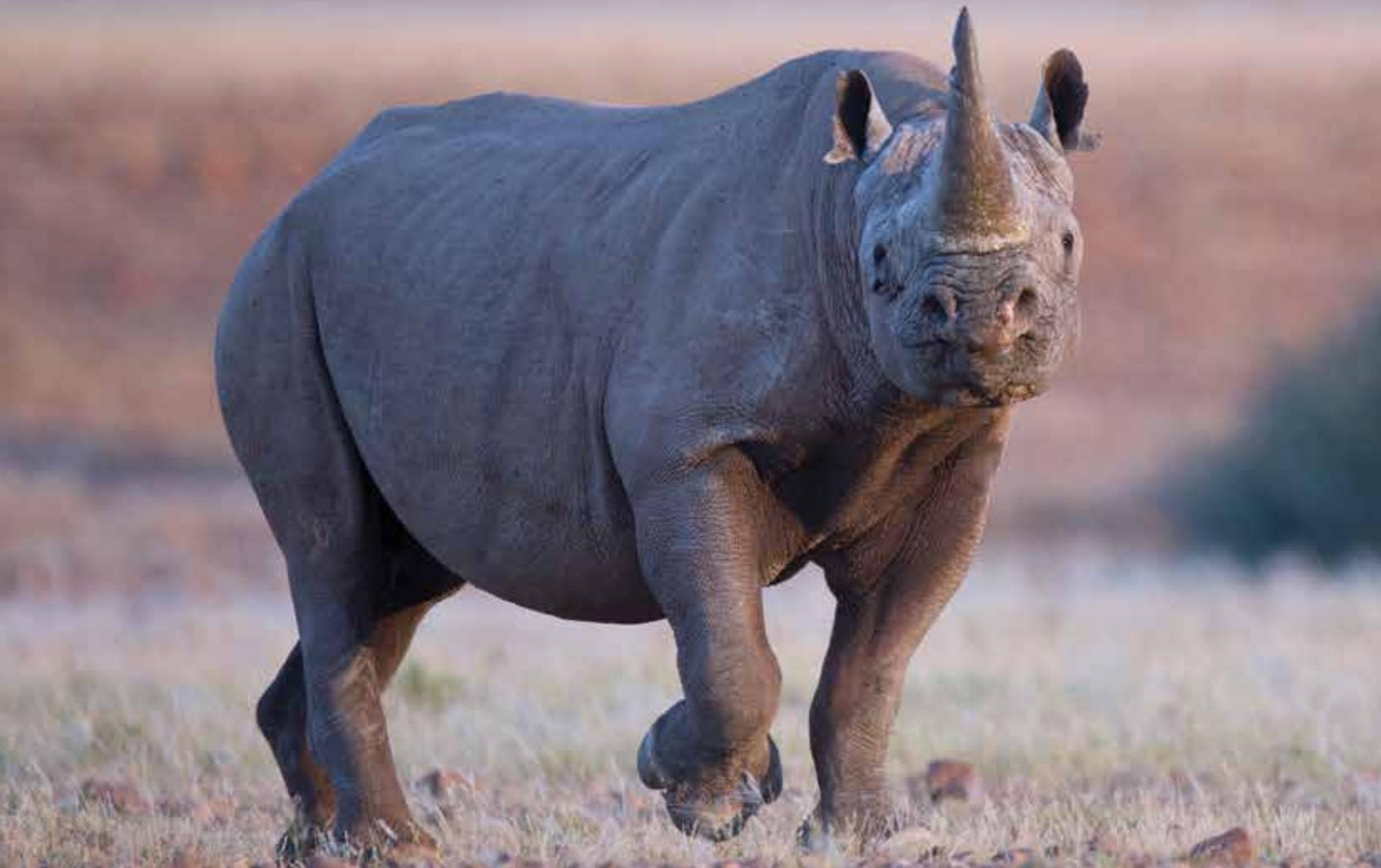

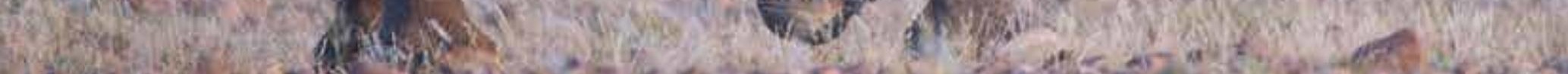

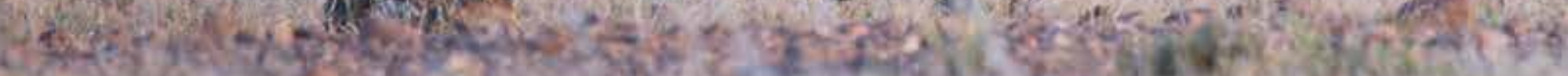
prath

(๑) Wilderness Safaris 
mécanismes de financement créatifs mentionnés dans la section suivante. La meilleure méthodologie pour accroître le financement et la durabilité du financement des aires protégées est une approche diversifiée. Par exemple, l'Aire de conservation OI Pejeta, une réserve de 90000 acres au Kenya et l'un des refuges de rhinocéros noirs les plus importants d'Afrique de l'Est, génère des revenus du tourisme, d'un élevage compatible avec la faune sauvage et d'une agriculture zonée (OI Pejeta Conservancy, s.d.). Cette approche diversifiée lui permet de résister à la sécheresse et au cycle naturel de la fréquentation touristique. Bien que ces utilisations des terres ne soient pas autorisées dans toutes les aires protégées, elles montrent l'importance et le potentiel d'une approche diversifiée.

\subsubsection{Sources de financement nouvelles et émergentes pour les aires protégées}

Il est largement reconnu que le financement des donateurs ne peut pas et ne sera pas en mesure de combler le déficit de financement des aires protégées, en raison de sa nature instable, des défis concurrents des pays hôtes et des priorités des donateurs. Un certain nombre de mécanismes de financement novateurs ont été développés à l'échelle mondiale, tels que :

- Échanges « dette contre nature ». Un échange « dette contre nature » est un accord réduisant l'encours ou la servitude de la dette d'un pays en développement en échange d'un engagement à protéger la nature de la part du gouvernement débiteur. II s'agit d'opérations volontaires par lesquelles le ou les donateurs annulent une partie ou la totalité de la dette détenue par le gouvernement d'un pays en développement. En échange, le gouvernement débiteur s'engage à investir les sommes accumulées dans la conservation de la biodiversité, l'atténuation climatique et la conservation des paysages. Les Obligations bleues des Seychelles en sont un exemple (The World Bank Group, 2018).

- Incitations fiscales, grâce auxquelles les propriétaires fonciers obtiennent une déduction fiscale pour leur engagement en faveur de la conservation lors de la déclaration de réserves naturelles sur des terres privées, comme en Afrique du Sud (Swart, 2019). Voir l'Encadré 10.3.

- Les compensations de biodiversité compensent les impacts nets d'un projet de développement après la mise en œuvre d'autres mesures d'atténuation. Les compensations devraient viser à ne réaliser aucune perte nette et de préférence un gain net de biodiversité. Les compensations peuvent, par exemple, générer des avantages pour la biodiversité (par exemple, un reboisement) par le biais d'une transaction, dans laquelle les vendeurs de compensations (par exemple, une ONG de conservation ou un gouvernement) vendent des compensations à des promoteurs (par exemple, une société minière ou un promoteur immobilier) cherchant à compenser une perte nette de biodiversité résultant de leurs activités (par exemple, une exploitation minière).

- Programmes de compensation carbone, tels que le projet Wildlife Works Kasigau REDD+ au Kenya (Wildlife Works, s.d.). Bien que les compensations carbone puissent générer des financements pour la conservation, elles ne peuvent le faire que si un acheteur est disposé à compenser ses émissions de carbone en achetant des crédits carbone dans une aire protégée ou un projet de conservation. Les lois sur le carbone peuvent surmonter cet obstacle en obligeant les pollueurs à acheter des crédits de carbone.
- Fonds fiduciaires pour la conservation, comme en Ouganda, avec le Fonds fiduciaire pour la conservation de la biodiversité (Uganda Biodiversity Fund, s.d.). Les fonds fiduciaires pour la conservation, parfois appelés fonds environnementaux, sont définis comme des "institutions privées, juridiquement indépendantes, fournissant un financement durable pour la conservation de la biodiversité et finançant souvent une partie des coûts de gestion à long terme du système d'aires protégées $(A P)$ d'un pays » (CFA, 2008, p. 1) ou d'une aire protégée spécifique.

- Obligations à impact sur les espèces, telles que les obligations à impact sur les rhinocéros (UNDP Ecosystems \& Biodiversity, 2018).

- Paiement pour services écosystémiques, tels que le projet de PSE Kilombero Plantation Limited (Athanas, 2018).

- Les Mécanismes de financement axés sur les résultats sont des instruments de financement novateurs attirant des capitaux d'investissement pour résoudre des problèmes traditionnellement financés par le secteur public. Les obligations d'espèces ou d'aires protégées sont un exemple de tels mécanismes. Ce sont des instruments d'investissement à échéance fixe, dont le but est d'accroître un échantillon de la population d'une espèce donnée sur des sites clés. Les investisseurs de l'obligation ne reçoivent un rendement financier qu'à la réalisation de l'objectif, ce rendement étant financé par les payeurs des résultats.

- Les obligations vertes peuvent être utilisées pour financer un large éventail de projets, notamment les énergies renouvelables, l'efficacité énergétique, la gestion durable des déchets, l'utilisation durable des terres, la conservation de la biodiversité, les transports et l'eau propres (DuPont et al., 2016). Cependant, elles n'ont pas encore été utilisées pour financer la conservation à grande échelle. En 2017, il a été estimé que seulement $\%$ du produit des obligations allaient à la conservation des terres et $4 \%$ à la conservation de la biodiversité.

- Obligations bleues. Lorsque le gouvernement d'un pays s'engage à protéger une partie de ses espaces marins côtiers et à mettre en œuvre des mesures de conservation (par exemple, améliorer la gestion de la pêche et réduire la pollution), le coût d'une telle transition est souvent élevé, en particulier pour les petits États insulaires. Les obligations bleues aident à financer cette transition. Un gouvernement émet une obligation, souvent avec l'aide/la garantie d'une ONG et/ou d'une organisation telle que la Banque mondiale, entraînant potentiellement des taux d'intérêt plus bas et des délais de remboursement plus longs. Une partie de ces sommes finance les nouvelles aires marines protégées et les activités de conservation auxquelles le pays s'est engagé.

- Le projet Financement de la persistance utilise une technique de financement de projet pour faciliter le financement complet et initial de projets ou d'aires de conservation à grande échelle en réunissant les bailleurs de fonds lors d'une seule étape. À titre d'exemple, on peut citer un accord de USD 57 millions visant à protéger 2 millions d'hectares au Costa Rica, et un projet de USD 215 millions visant à conserver 60 millions d'hectares de l'Amazonie brésilienne (Seol, 2016). En s'attaquant au problème du financement fragmentaire ou insuffisant dès le départ, ce système garantit que les interventions de conservation soient correctement planifiées, permanentes et entièrement financées. Pour réussir, ces projets 
nécessitent un engagement politique, une stratégie d'investissement solide et des plans financiers rigoureux, ainsi qu'une collaboration entre gouvernements, ONG et bailleurs de fonds publics et privés.

- Les loteries sont populaires dans la plupart des pays et peuvent générer des revenus substantiels, souvent à des fins socialement bénéfiques telles que la conservation de la nature (WWF, 2009). Par exemple, en Afrique du Sud, la Commission nationale des loteries distribue des fonds à une série de causes, y compris des organismes de bienfaisance environnementaux (NLCSA, 2019).

- Image de marque. Le Lion's Share (2020) est une initiative de financement de la conservation lancée en septembre 2018, dans le cadre de laquelle une petite taxe est prélevée sur l'utilisation d'animaux dans les campagnes publicitaires et redistribuée aux ONG de conservation via le Fonds Lion's Share, avec un cofinancement du PNUD. Le Lion's Share vise à lever plus de USD 100 millions par an. Parmi les entreprises privées participantes figurent Mars Inc, Nielsen, International Airline Group, JCDecaux, The Economist et Batten, Barton, Durstine \& Osborn. En Afrique orientale et australe, le Lion's Share finance une étude sur l'économie de l'éléphant d'Afrique, visant à catalyser les investissements gouvernementaux dans la conservation des éléphants et la promotion d'une économie basée sur la nature. Au Mozambique, la mise à niveau du système de radiocommunication numérique de la Réserve nationale de Niassa a également été possible grâce aux fonds provenant du Lion's Share.

- Autres instruments financiers: BIOFIN a travaillé avec neuf pays de la région pour identifier les instruments de financement de la conservation prioritaires pour chacun (IUCN ESARO, 2020, p. 60).

Bien que ces modèles de financement novateurs existent, ils n'ont pas encore été adoptés ou utilisés à grande échelle en Afrique orientale et australe, en raison d'un soutien technique, de ressources et d'un environnement favorable limités. En outre, bien que ces modèles offrent un potentiel d'application et de réplication dans toute la région, des sources de financement plus traditionnelles et éprouvées, telles que le tourisme de nature, bien que largement utilisées en Afrique orientale et australe, n'ont pas encore été développées à leur plein potentiel. Cependant, la situation s'est aggravée avec la pandémie de COVID-19, qui a entraîné la fermeture de l'industrie du tourisme et, par conséquent, une diminution significative du financement lié à la conservation des aires protégées, dont les principales recettes sont basées sur le tourisme (voir l'Encadré 10.4). Dans toute l'Afrique, les accords de collaboration deviennent des outils de plus en plus populaires pour accroître le soutien financier et le développement des capacités dans les aires protégées, beaucoup d'entre elles étant gravement sous-financées. En outre, certains donateurs exigent des accords de collaboration pour obtenir un financement. La gestion collaborative s'obtient par l'association d'une organisation à but non lucratif ou d'une entité du secteur privé et d'une autorité chargée de la faune sauvage dans le pays, dans laquelle cette dernière sous-traite certains aspects de gestion ou activités de conservation spécifiques (par exemple, suivi écologique, éducation, engagement communautaire, restauration d'écosystèmes) à l'organisation partenaire, ou conclut un accord avec le partenaire privé couvrant l'ensemble des aspects de gestion. Ceci prend de plus en plus la forme d'un partenariat public-privé (PPP) (voir la Section 11.1 pour plus d'informations).

\subsection{Conclusions}

La fréquence des évaluations de l'efficacité de la gestion a augmenté dans toute l'Afrique orientale et australe au fil du temps. Cependant, il est encore possible d'étendre l'évaluation de l'efficacité de la gestion à un plus grand nombre de pays de la région et aux zones sous gouvernance partagée ou non étatique (Campese et Sulle, 2019). En particulier, des évaluations EfGAP devraient être inclues dans le cycle de gestion régulier des aires protégées, y compris le suivi nécessaire pour mettre en œuvre les mesures visant à améliorer cette efficacité de la gestion.

La méthode OSEG est la méthode la plus couramment utilisée à l'échelle des sites, et il est important de s'assurer qu'elle soit utilisée conformément aux meilleures pratiques (Stolton et Dudley, 2016). Un certain nombre d'évaluations OSEG sont effectuées dans le cadre des exigences des donateurs et ne contiennent souvent aucun commentaire ou " prochaines étapes ", ce qui limite leur utilité. Néanmoins, un certain nombre de pays ont adapté I'OSEG à une utilisation nationale, en particulier pour les aires protégées gérées par l'État. RAPPAM est la méthodologie la plus couramment utilisée à l'échelle des systèmes et présente également de nombreux avantages. L'utilisation de méthodologies intégrées, tenant compte de l'efficacité de la gestion ainsi que des questions de gouvernance et d'équité sociale, pourrait être utile pour veiller à ce que les aires protégées et de conservation soient évaluées de manière adéquate pour l'ensemble des aspects de l'Objectif d'Aichi 11, de sorte que des améliorations puissent être apportées au bénéfice de la biodiversité et des personnes.

De plus, d'autres méthodes, telles que le nouvel Outil intégré sur l'efficacité de la gestion (OIEG) développé dans le cadre de BIOPAMA, ont été conçues pour aider les organismes et gestionnaires d'aires protégées à planifier, gérer et réaliser un suivi des sites. L'OIEG est un logiciel qui collecte et organise des données et des informations sur la gestion des aires protégées, une analyse statistique interne fournissant des estimations sous forme de score de la qualité de la gestion, tandis que des composants visuels offrent un système d'aide à la décision. L'OIEG est basé sur un cadre de l'UICN visant à mesurer l'efficacité de la gestion des aires protégées, et inspiré par d'autres outils, tels que l'OSEG, la boîte à outils Enhancing our Heritage, et autres.

Les exigences des donateurs ont entraîné une plus grande attention à la question de l'efficacité de la gestion et une augmentation du nombre d'évaluations EfGAP en cours d'achèvement. II convient de s'en féliciter, mais il est également essentiel de veiller à ce que ces évaluations servent une fonction d'apprentissage de fond, ainsi qu'une meilleure gestion, et ne soient pas seulement un exercice consistant à cocher des cases. 


\section{Encadré 10.3 : Première incitation fiscale efficace pour la biodiversité en Afrique du Sud}

La Loi sud-africaine sur l'impôt sur le revenu ( $n^{\circ} 58$ de 1962) fait référence à une incitation fiscale spécifique pour la biodiversité dans son article 37D, qui vise à obtenir une viabilité financière pour les aires protégées situées sur des terres privées ou communales, ainsi qu'à motiver et récompenser l'engagement des propriétaires fonciers. L'article 37D permet de déduire la valeur des terres déclarées comme Réserve naturelle ou Parc national du revenu imposable, réduisant ainsi l'impôt dû par un propriétaire foncier. Cela garantit une plus grande liquidité pour la gestion de la conservation et la durabilité économique du site. Cette incitation fiscale est à la fois unique au monde et une première nationale. Cette réussite en matière de financement de la biodiversité a reçu la première mention spéciale du Prix Pathfinder, attribuées à Mme Candice Stevens et au gouvernement Sud-Africain.

Les deux principaux avantages de cet incitatif fiscal spécifique à la biodiversité sont les suivants :

1) Soutien à la création d'aires protégées privées et communautaires robustes.

Les exigences de la Loi sur l'impôt sur le revenu correspondent spécifiquement aux exigences de la Loi sud-africaine sur les aires protégées (NEMPAA $n^{\circ} 57$ de 2003), garantissant que les sites éligibles à cette déduction fiscale soient déclarés aires protégées d'une façon qui garantissent leur sécurité juridique, leur permanence, leur gestion et leur intention à long terme.

2) Création d'un outil innovant pour la viabilité financière des paysages.

L'article 37D crée un avantage financier substantiel et tangible qui aide les propriétaires fonciers à s'acquitter de leurs responsabilités de gestion, renforce leur motivation à moyen et long terme, et facilite l'efficacité fiscale essentielle au succès durable d'activités économiques compatibles avec les aires protégées.

\section{Contribution de Candice Stevens (Fondation Wilderness} Afrique).

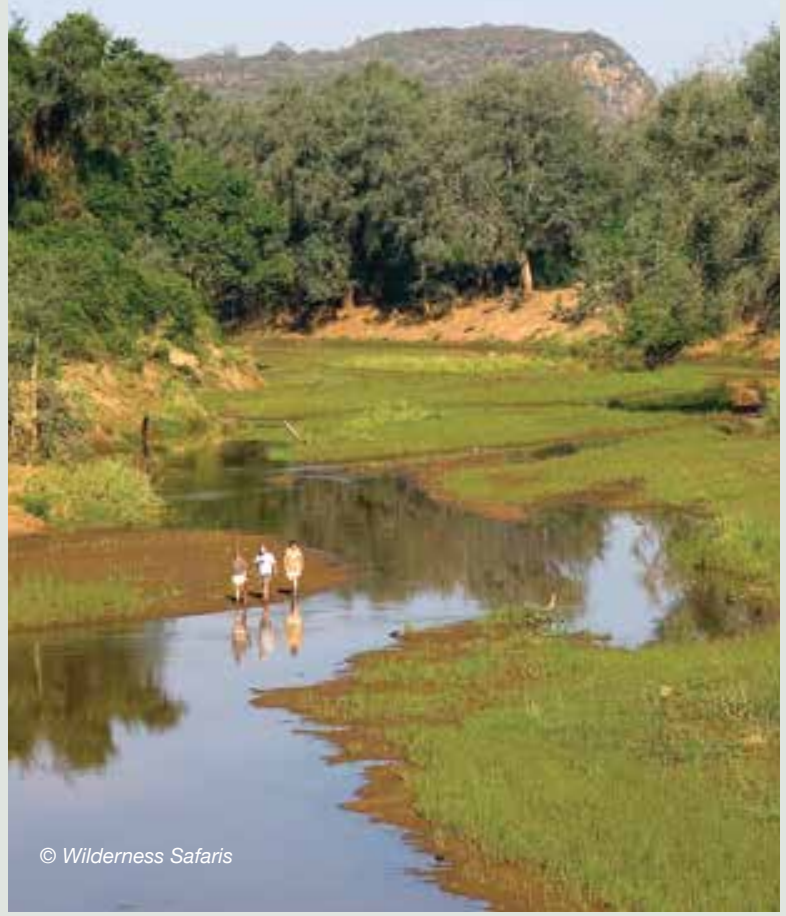

\section{Encadré 10.4 : Impact de la pandémie de COVID-19 sur les aires protégées en Afrique orientale et australe}

La pandémie de COVID-19 a généré une crise urgente pour la gestion des aires protégées en Afrique orientale et australe.

La pandémie a déjà entraîné une cascade d'impacts immédiats sur les aires protégées, tels que :

- la fermeture des aires protégées aux tourisme et aux loisirs ;

- une baisse des effectifs du personnel des parcs, du fait des cas d'isolement ;

- une éducation des patrouilles des gardes forestiers en raison de la réduction des effectifs, susceptible d'entraîner une augmentation des activités préjudiciables à l'environnement ;

- des impacts directs potentiels sur certaines espèces menacées charismatiques, comme les grands singes ;

- la suspension des programmes courants de gestion et de restauration.

La pandémie est associée à une crise économique mondiale. À mesure que cette crise s'installe, les niveaux de pauvreté sont susceptibles d'augmenter, en particulier en Afrique subsaharienne. II existe une menace liée à l'utilisation accrue et non durable des ressources naturelles, ainsi que la possibilité d'une augmentation du braconnage commercial. Ces menaces sont inversement proportionnelles aux apports financiers qui sous-tendent la conservation et la gestion des aires protégées. Le soutien financier de toutes les sources actuelles, y compris les bailleurs de fonds bilatéraux et multilatéraux, les donateurs privés et fortunés, ainsi que l'industrie touristique, sera probablement réduit.

Bien qu'il puisse exister certains avantages associés à l'arrêt du tourisme, tels qu'une réduction de la sur-fréquentation dans les écosystèmes délicats, la crise financière à laquelle sont confrontées les aires protégées, quelle que soit leur forme de gouvernance, ne saurait être sous-estimée. Les recommandations formulées dans ce rapport concernant la diversification des sources de revenus pour la gestion des aires protégées sont de plus en plus urgentes à mettre en œuvre dans le contexte de cette crise mondiale.

Contribution de Leo Niskanen (UICN, ESARO). 


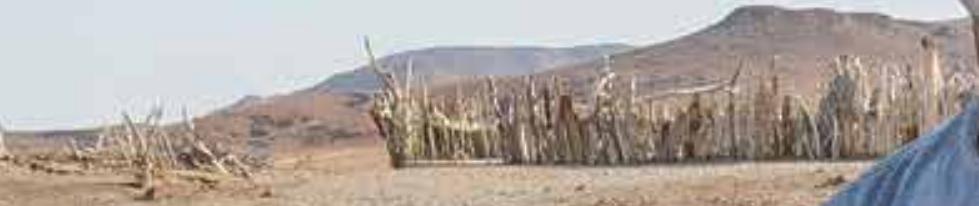

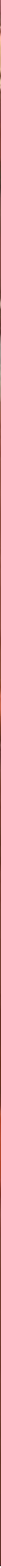




\section{Innovations et expériences régionales}


La région démontre un certain nombre d'innovations en termes d'amélioration de l'efficacité de la gestion, de la gouvernance et de l'équité, d'autant plus que la technologie a été développée à cette fin. Cette section contient des informations sur certaines de ces innovations.

\subsection{Gestion collaborative des aires protégées}

Les aires protégées sont reconnues à l'échelle mondiale comme le moyen le plus efficace de conserver la biodiversité et les biens culturels associés, ainsi qu'un moyen important de promouvoir un développement rural durable. Dans toute l'Afrique orientale et australe, de vastes aires protégées ont été destinées à la conservation. Ces aires protégées soutiennent une biodiversité d'une valeur mondiale substantielle, y compris la plus grande abondance mondiale de mégafaune (Ripple et al., 2016). En moyenne, dans toute l'Afrique subsaharienne, le financement des États est bien inférieur au minimum recommandé de USD 500 à 900 par km² (Lindsey et al., 2017). Des fonds importants de donateurs existent pour certaines aires protégées, mais dans de nombreux cas, la capacité de gérer efficacement ces fonds est insuffisante pour atteindre les objectifs de l'aire protégée ( $\mathrm{O}$ 'Connell et al., 2019).

L'établissement de partenariats de gestion collaborative avec des organisations non gouvernementales peut constituer un mécanisme important pour surmonter ces défis, et son importance a augmenté dans l'ensemble des aires protégées d'Afrique orientale et australe. II existe aujourd'hui de nombreux exemples de partenariats de gestion collaborative pour la gestion des aires protégées, et toute une variété de modèles différents a vu le jour.

Une analyse récente les a classés en différents modèles (Baghai et al., 2018) et en deux catégories : selon leur gouvernance (qui a le pouvoir d'établir des priorités et des stratégies globales, ainsi que la manière dont ces décisions sont prises), et selon leur gestion (les opérations quotidiennes et la mise en œuvre sur le terrain) (BorriniFeyerabend et al., 2014) (voir le Tableau 11.1).

L'analyse entreprise par Baghai et al. consistait en une série d'entretiens semi-structurées et en un atelier visant à développer le cadre et comprendre le contexte dans lequel chaque modèle s'est développé, ainsi que les forces et faiblesses de chacun. ${ }^{113}$

Des modèles de gestion déléguée ont toujours existé dans les aires protégées les plus gravement sous-dotées en ressources, dans des situations difficiles (comme l'extrême éloignement ou l'instabilité politique), lorsque la capacité et les ressources des autorités nationales chargées de la faune sauvage sont extrêmement faibles, et lorsque les revenus du tourisme sont faibles ou inexistants et que les populations sauvages ont été gravement réduites ou sont en danger de l'être. De telles circonstances extrêmes exigent un apport important de ressources et d'expertise technique, et constituent donc des candidats idéals à une gestion déléguée. Plus récemment, cependant, Parcs Africains s'est vu déléguer la gestion d'aires protégées de plus grande envergure, suggérant la possibilité que certains États soient de plus en plus disposés à utiliser ce modèle. Les modèles de cogestion offrent un partage plus équitable des responsabilités de gestion que les accords de gestion déléguée. Ils peuvent permettre aux partenaires de capitaliser sur leurs forces uniques, combinant la légitimité politique et les connaissances locales de l'État avec l'innovation, l'efficacité et l'expertise du secteur non gouvernemental. Un tel partenariat réduit le risque que l'autorité publique chargée de la faune sauvage se sente mise à l'écart ou dominée. Toutefois, le partage du pouvoir de gestion entre deux entités présentant des structures organisationnelles, des cultures, des styles de gestion et de leadership différents peut générer une certaine confusion, des conflits et des coûts de transaction élevés. Dans certains cas, les accords de cogestion ont évolué à partir de partenariats de soutien financier et technique s'étant avérés insuffisants pour atteindre les objectifs des partenaires. Comme dans le modèle délégué, l'investissement supplémentaire lié aux modèles de cogestion amènent souvent le partenaire non gouvernemental à rechercher un plus grand pouvoir décisionnel, et le partage de ce pouvoir rend les deux partenaires responsables l'un envers l'autre.

Des partenariats d'appui financier et technique sont présents dans le plus large nombre de pays et de contextes. Ce modèle a été, de loin, le plus important en Afrique pendant de nombreuses décennies, et plusieurs répondants ont indiqué que le passage à des modèles plus décentralisés comme la cogestion et la gestion déléguée était le résultat d'une longue expérience avec le modèle de soutien financier et technique et son incapacité, dans de nombreuses circonstances, à atteindre les résultats souhaités. Néanmoins, il s'agit toujours du modèle le plus courant et le plus répandu, et lorsqu'il est bien mis en œuvre dans les contextes appropriés, il peut s'avérer très efficace.

Le manque d'autorité des associations à but non lucratif en matière de gouvernance et de prise de décision de gestion qui caractérise ces partenariats est le résultat de divers facteurs. Premièrement, dans certains pays (comme le Botswana, le Kenya, la Namibie, la Tanzanie et l'Afrique du Sud), l'État dispose d'une capacité, d'un financement et d'un engagement importants en matière de gestion des aires protégées, et en particulier des parcs nationaux. Dans ces pays, le soutien financier et technique est logique lorsqu'il existe un engagement solide du gouvernement pour une gestion de base de l'aire protégée, mais qu'il existe des menaces spécifiques, des défis, voire des opportunités, que le gouvernement n'est pas en mesure de relever seul et que les organisations à but non lucratif peuvent soutenir. Deuxièmement, comme l'ont révélé les entretiens, certains pays peuvent être réticents à s'engager dans des modèles impliquant un partage ou une délégation de pouvoir en raison de sensibilités politiques et postcoloniales.

Troisièmement, certaines organisations à but non lucratif ne disposent pas des ressources ou de l'expertise nécessaires pour assumer d'importantes responsabilités de gestion. Enfin, certaines organisations à but non lucratif estiment que leur rôle est de soutenir (et non de supplanter) l'État, considéré comme l'autorité de gestion appropriée pour les aires protégées, même lorsque la capacité est faible.

Certains des modèles de cogestion dans la région incluent :

- En Éthiopie, le projet de conservation Bale Mountains - Société zoologique de Francfort (FZS-BMCP) a été créé en 2005 pour fournir tous les aspects du soutien à la gestion du Parc national des monts Bale (développement de l'écotourisme, sensibilisation communautaire, utilisation durable des ressources naturelles, opérations et gestion écologique). En 2007, le Président de la région Oromia a ratifié le Plan de gestion général décennal du parc. FZS-BMCP travaille actuellement en partenariat avec les autorités à la mise en

113 Information en grande partie tirée de Baghai et al. (2018). 
Tableau 11.1 : Cadre modèle pour les partenariats de gestion collaborative

\begin{tabular}{|c|c|c|}
\hline Modèle & Gouvernance & Gestion \\
\hline Gestion déléguée & $\begin{array}{l}\text { Stratégie et supervision généralement } \\
\text { gérées par une entité spéciale créée par } \\
\text { les deux partenaires. Une organisation } \\
\text { non gouvernementale nomme } \\
\text { généralement le gestionnaire du parc }\end{array}$ & Géré par une organisation non gouvernementale \\
\hline Cogestion & $\begin{array}{l}\text { Partagée, à des degrés divers, entre l'État } \\
\text { et une organisation non gouvernementale } \\
\text { (peut inclure ou non la création d'une } \\
\text { entité à vocation spéciale) }\end{array}$ & $\begin{array}{l}\text { Partagée, à des degrés divers, entre l'État et une } \\
\text { organisation à but non lucratif, sauf dans certains } \\
\text { cas pour la gestion de l'application de la loi } \\
\text { (gérée par l'État) et l'emploi du personnel (en } \\
\text { particulier du personnel chargé de l'application } \\
\text { de la loi), qui peut être géré par l'État ou } \\
\text { indépendamment par les partenaires }\end{array}$ \\
\hline Cogestion de projets & $\begin{array}{l}\text { L'État dirige la stratégie et le contrôle, } \\
\text { avec la participation et le consensus } \\
\text { d'une organisations non gouvernementale } \\
\text { sur les domaines liés au projet. Le Comité } \\
\text { directeur conjoint nomme la direction du } \\
\text { projet }\end{array}$ & $\begin{array}{l}\text { L'État supervise la gestion de l'application de la } \\
\text { loi et la gestion de tout le personnel, et partage } \\
\text { l'autorité avec l'organisation non } \\
\text { gouvernementale pour toutes les décisions liées } \\
\text { au projet et financées par le projet }\end{array}$ \\
\hline $\begin{array}{l}\text { Appui financier et technique (mise } \\
\text { en œuvre) }\end{array}$ & L'État est l'autorité principale & $\begin{array}{l}\text { L'État est l'autorité principale. L'organisation non } \\
\text { gouvernementale joue différents rôles pour } \\
\text { soutenir des objectifs communs, employer du } \\
\text { personnel et aider à mettre en œuvre les } \\
\text { décisions de gestion }\end{array}$ \\
\hline $\begin{array}{l}\text { Appui financier et technique } \\
\text { (conseil) }\end{array}$ & L'État est l'autorité principale & L'État est l'autorité principale \\
\hline
\end{tabular}

Source : Baghai et al. (2018).

œuvre de ce plan. Grâce à un nouveau soutien financier de KfW, FZS a mis à jour son accord de cogestion avec le gouvernement afin d'améliorer la gestion et la gouvernance du parc. La Fondation African Wildlife a conclu un accord similaire pour un soutien au Parc national des monts Simien.

- Au Rwanda, le RDB a conclu un accord de gestion déléguée avec Parcs Africains pour la gestion du Parc national d'Akagera. Depuis, Parcs Africains et le RDB ont réintroduit des espèces sauvages et développé des installations touristiques commercialement viables. Le Rwanda espère que le développement du Parc national d'Akagera aidera le pays à diversifier ses produits touristiques du seul tourisme des gorilles et à garder les touristes au Rwanda plus longtemps.

- Au Mozambique, un accord de cogestion intégrée a été établi après la guerre civile pour la gestion de la Réserve nationale de Niassa, entre le gouvernement et une société privée mozambicaine représentant principalement une personne fortunée. Ce partenariat, Sociedade para a Gestão e Desenvolvimento da Reserva do Niassa, a été principalement soutenu par Fauna \& Flora International et a pris fin en 2012. À la fin de 2019, Wildlife Conservation Society (WCS) tentait de conclure un accord bilatéral de cogestion pour la réserve. En outre, différents partenaires du secteur privé et des ONG ont conclu des accords de gestion pour des concessions dans l'ensemble de la réserve. Dans un autre exemple, la Fondation Carr a signé un accord de gestion avec le gouvernement mozambicain en 2008 pour restaurer et protéger le Parc national de Gorongosa en tant que source de revenus touristiques pour la population locale. Deux accords ont été signés en 2019 avec la Fondation Peace Parks pour fournir une assistance technique et financière à la Réserve spéciale de Maputo pour le développement du tourisme, et pour soutenir le Parc national de Banhine, dans la Province de Gaza, pour lutter contre le braconnage (Wright, 2018). En outre, APN possède un accord délégué sur le Parc national de Bazaruto.

- Au Zimbabwe, le Parc national de Gonarezhou est régi par le Gonarezhou Conservation Trust, dont les administrateurs sont nommés par l'Autorité de gestion des parcs et de la faune du Zimbabwe et FZS, représentés à parts égales. Développé grâce à une solide relation de soutien de neuf ans de la FZS à Gonarezhou, le Trust est directement responsable de la gestion du parc sur une période de 20 ans, et est devenu pleinement responsable en 2017.

- À travers l'Afrique. Parcs Africains est une organisation de conservation à but non lucratif créée en 2000 , qui assume l'entière responsabilité de la réhabilitation et de la gestion à long terme des parcs nationaux, en partenariat avec les gouvernements et les communautés locales. Elle gère actuellement 17 parcs nationaux et aires protégées (dont 10 en Afrique orientale et australe) dans 11 pays, couvrant environ 14 millions d'hectares.

Les gouvernements ayant conclu ces accords de gestion optimisent stratégiquement les relations avec les partenaires. En sélectionnant des partenaires appropriés et compétents, les autorités chargées des aires protégées peuvent augmenter les revenus pour les aires protégées et le système dans son ensemble, en tirant parti des compétences, de l'expérience et du capital des partenaires, et en combinant les différentes compétences apportées par chaque partenaire. En outre, cela contribue à réduire les risques en impliquant d'autres partenaires, ce qui attire un certain nombre de grands bailleurs de fonds bilatéraux et multilatéraux. 


\section{Encadré 11.1 : Renforcement des capacités de lutte contre le braconnage - le cas du Collège de la faune d'Afrique australe}

À titre d'exemple, le Collège de la faune d'Afrique australe ${ }^{114} a$ identifié un besoin prioritaire de capacités pour faire face à la crise du braconnage, et a innové avec un déploiement et une gestion canine à des fins de lutte contre le braconnage. Cette expansion était fortement axée sur le déploiement non traditionnel de chiens dans un mode de poursuite ou tactique, afin d'effectuer l'arrestation des braconniers. Un centre de formation $\mathrm{K} 9$ a été créé pour héberger, sélectionner et former les chiens d'assistance et les maîtres-chiens.

Sur une période de trois à quatre ans, diverses techniques ont été testées, avec une utilisation croissante du modèle de meute en liberté, soutenu par un maître-chien et une équipe de rangers anti-braconnage. Les chiens et les maîtres-chiens ont été formés conjointement avec Airwing et les rangers antibraconnage, afin d'être déployés par hélicoptère et autres véhicules lors des opérations anti-braconnage. L'utilisation de télémétrie avancée, d'un suivi par collier et de la collecte de données s'est avérée très efficace.

Les leçons apprises, les défis et les avantages comprennent :

1. le coût de mise en place du centre de formation a nécessité un appui intensif en matière de collecte de fonds ;
2. la formation conjointe avec SAWC et SANParks a permis un déploiement et une interopérabilité efficaces ;

3. les chiens et les maîtres-chiens sont interchangeables ;

4. le bien-être et la santé des animaux étaient d'une importance cruciale pour le succès individuel et de la meute ;

5. il existait une pénurie de compétences de formation K9 en Afrique du Sud, la plupart des compétences étant axées sur la formation de chiens pour le travail de détection; et

6. les données collectées par les différents capteurs de suivi $\mathrm{K} 9$ représentaient également un domaine d'innovation et de recherche.

Le modèle développé à SAWC a été adopté pour le développement des capacités K9 lors des opérations antibraconnage dans une zone de gibier dangereuse. Le projet SAWC K9 a reçu plusieurs prix pour sa grande efficacité dans les opérations anti-braconnage.

Une contribution de Ashwell Glasson (Collège de la faune d'Afrique australe).

\subsection{Renforcement des capacités pour les aires protégées et de conservation}

Le renforcement des capacités et des institutions est essentiel pour permettre aux autorités chargées des aires protégées d'atteindre leurs objectifs (EU, 2015). Diverses institutions dans la région disposent d'un mandat et se concentrent spécifiquement sur le renforcement des capacités, notamment: le Collège de gestion de la faune africaine (Mweka) en Tanzanie, le Collège de la faune d'Afrique australe en Afrique du Sud (voir l'Encadré 11.1), la Faculté de conservation de la faune de l'Université pour le leadership africain au Rwanda, I'Université namibienne des sciences et de la technologie, anciennement connue sous le nom d'Université polytechnique de Namibie, le RCMRD Nairobi et le Centre pour l'excellence en matière de biodiversité et de gestion des ressources naturelles au Rwanda, entre autres. Ces institutions innovent et élargissent leur gamme de formations en réponse aux besoins exprimés par les gouvernements et les organisations de conservation.

\subsection{Rôle de la technologie dans la gestion des aires protégées ${ }^{115}$}

$\mathrm{Au}$ cours des 10 dernières années, les défenseurs de l'environnement se sont de plus en plus concentrés sur l'utilisation de la technologie pour résoudre les problèmes de conservation de la faune sauvage. La promesse de la technologie est une gestion axée sur des données à grande échelle en temps (quasi) réel, offrant un niveau de détail élevé. L'adoption de nouvelles technologies peut améliorer la connaissance de la situation en temps réel pour faciliter les capacités de commandement et de contrôle. L'impulsion initiale pour cela est venue d'une exigence de protection et d'application de la loi, mais l'accent est mis aujourd'hui sur des besoins plus généraux de gestion des aires protégées.

Les gestionnaires d'aires protégées ont toujours été lents à adopter la technologie, en grande partie du fait d'un historique de résultats décevants. La technologie adaptée aux environnements commerciaux ou de consommation de masse n'est souvent pas assez robuste pour les conditions environnementales difficiles des aires protégées. En outre, une technologie robuste est souvent hors de portée des budgets disponibles pour les gestionnaires d'aires protégées. Des technologues bien intentionnés ont fait don de technologie appropriée, mais sans fournir de plans d'entretien ou de durabilité à long terme, entraînant une utilité de courte durée.

La situation a commencé à changer en Afrique au cours des cinq dernières années, à mesure que les gestionnaires d'aires protégées s'affirment en tant que consommateurs de technologie et qu'un groupe de technologues dédiés à la mission de conservation de la faune émerge. Aujourd'hui, les gestionnaires se posent les bonnes questions sur les exigences en matière de capacité en personnel, coûts de maintenance, plans d'affaires à long terme, exigences en matière de connectivité, et besoins de formation et de soutien. Ils sont mieux préparés à refuser des solutions qui ne soient pas en phase avec les réalités des problèmes de gestion des aires 
protégées.

L'écosystème émergent des données et des technologies de gestion des aires protégées comprend des ONG de conservation, de grandes sociétés technologiques, des philanthropes privés et de bons entrepreneurs sociaux. Ceux-ci créent des solutions fondées sur une compréhension des défis auxquels sont confrontés les gestionnaires d'aires protégées, résolvant des problèmes tels que la génération de données adéquates grâce aux progrès des technologies de télédétection, l'obtention de données en temps opportun grâce aux progrès des technologies de réseau et l'analyse sur des plateformes appliquant les dernières technologies en matière d'intelligence artificielle et de reconnaissance d'images. Le domaine des "technologies de la conservation " devient une réalité (voir l'Encadré 11.2).

II est utile de considérer l'application de la technologie dans les aires protégées selon un « quadrant » dans lequel la maturité de la gestion se situe le long de l'axe $Y$ et l'adoption de la technologie le long de l'axe $X$ (voir la Figure 11.1). La plupart des aires protégées se trouvent dans la partie inférieure gauche du quadrant, avec une faible maturité de gestion et peu d'infrastructures technologiques. En d'autres termes, la plupart des sites doivent renforcer leurs capacités de gestion avant de penser à appliquer des solutions technologiques sophistiquées. Des équipes de rangers bien formées et bien équipées sont nécessaires, ainsi que des plans de gestion efficaces et un financement suffisant pour répondre à ces besoins opérationnels de base. Le partenariat SMART a été pionnier d'une gestion des aires protégées axée sur les données tirant parti de la technologie, grâce au logiciel SMART (Outil de suivi et de rapport spatial) ${ }^{116}$. L'objectif était de pousser les sites à faible capacité et infrastructure minimale vers une gestion axée sur les données. Le partenariat SMART et autres partenariats ont permis de déplacer de nombreux parcs vers la partie supérieure gauche du quadrant.

Des organisations de gestion de pointe ont commencé à pousser les aires protégées dont elles ont la gestion de la partie supérieure gauche vers la partie supérieure droite du quadrant. De nouvelles technologies de communication sont appliquées et des tests de pièges photographiques capables de reconnaître des images de haute précision sont en cours. Des logiciels sophistiqués, capables d'intégrer des données provenant de sources hétérogènes en une seule image opérationnelle, sont également utilisés. Enfin, les données sont mises à disposition de technologues développant des algorithmes d'intelligence artificielle avancés, qui font la promesse (encore à réaliser) d'une gestion prédictive et proactive. D'ici cinq à 10 ans, la technologie promet de faire passer la gestion des aires protégées de réactive à proactive, tout en s'appuyant sur les bases d'une bonne gestion et sur des rangers bien formés et bien équipés (voir les Encadrés 11.3 et 11.4)

\subsection{S'adapter aux changements climatiques}

La planète subit actuellement l'une des transformations climatiques les plus rapides de l'histoire de la Terre. Les changements climatiques anthropiques ont déjà un impact sur la plupart des

\section{Figure 11.1 : Quadrant de l'application de la technologie dans les aires protégées d'Afrique}

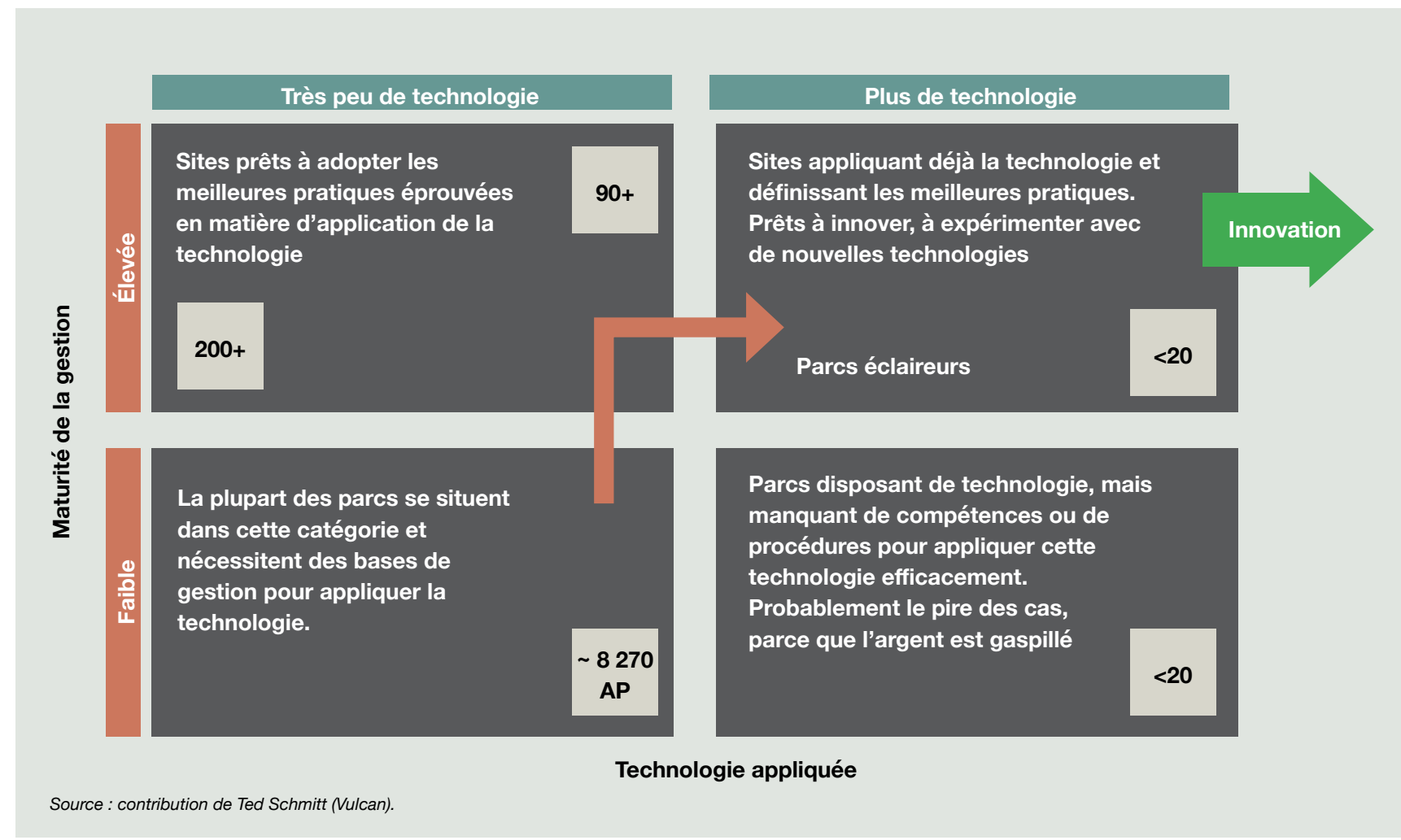

116 Pour plus d'informations, veuillez consulter: https://smartconservationtools.org/ 


\section{Encadré 11.2 : EarthRanger - connaître la situation pour sécuriser les aires protégées et réduire les conflits homme-faune}

Au cours des dernières années, les gestionnaires de parcs ont introduit de plus en plus de solutions technologiques pour améliorer la gestion des aires protégées grâce à une prise de décision en temps réel, basée sur des données. Ils utilisent la technologie pour recueillir des données d'observation des patrouilles, fournir des communications, suivre les animaux et les biens tels que les avions et les véhicules, détecter les intrusions et avoir une idée de ce qui se passe dans l'aire protégée qu'ils gèrent. Ces données, certaines historiques et d'autres (quasi) en temps réel, étaient préalablement séparées, chacune avec sa propre interface utilisateur.

Bien que ces données puissent être utiles de façon séparée, les gestionnaires étaient rapidement dépassés lorsqu'ils tentaient de synthétiser les données dans leur tête, voire sur une carte physique, afin d'avoir une image complète de la situation de l'aire protégée. II était nécessaire d'obtenir une visualisation unique, fournissant une connaissance de la situation nécessaire pour prendre des décisions efficaces et effectives, en temps réel.

EarthRanger est un logiciel en ligne qui collecte, intègre et visualise les données historiques et en temps réel disponibles dans une aire protégée : faune, rangers, informations spatiales et détection des menaces.* EarthRanger permet aux gestionnaires d'aires protégées et aux rangers de prendre des mesures immédiates et proactives pour prévenir et atténuer les incidents liés aux menaces. L'utilisation d'une salle d'opérations centrale avec visualisation en temps réel est apparue avec EarthRanger, en tant que système nerveux central des opérations dans les aires protégées.

Les données issues de la technologie sur ce qui se passe dans une aire protégée associées à EarthRanger agissent comme un multiplicateur pour les opérations de sécurité, avec une capacité de visualisation permettant aux gestionnaires d'acquérir une compréhension approfondie en temps réel des activités liées au braconnage et autres menaces pour les habitats. En Tanzanie, par exemple, la réserve de Grumeti utilise EarthRanger pour suivre les mouvements des rangers lors des patrouilles et réagir aux incidents d'incursion. Le suivi est couplé avec des pièges photographiques qui détectent les incursions et autres technologies fournissant une image complète de la situation en matière de sécurité à tout moment, et permettant au personnel de réagir en toute sécurité et efficacement aux incursions.

En partenariat avec Parcs Africains, l'équipe de gestion du Parc national de Liwonde, au Malawi, utilise EarthRanger pour surveiller les éléphants lorsque ceux-ci dépassent les limites géographiques du parc, afin d'intervenir avant qu'ils n'atteignent les cultures des agriculteurs voisins. Grâce à des géo-barrières (limites virtuelles établies autour d'un emplacement géographique), les rangers de Liwonde peuvent surveiller en permanence les limites du parc, détecter tout conflit potentiel entre les hommes et la faune à partir de leur salle d'opérations, et réagir rapidement aux alertes de géobarrières et intervenir avant qu'une situation conflictuelle ne survienne. L'atténuation proactive des conflits homme-faune grâce à des alertes rapides et transparentes permet aux gestionnaires de réduire les incidents de conflit et d'aider les communautés à coexister avec la faune.

Le suivi des habitats, y compris l'utilisation du paysage par la faune sauvage, au moyen de données de suivi et de déplacements, de capteurs et de rapports permet une planification et une gestion de l'utilisation des terres basée sur les données. Big Life, un groupe de conservation de la faune basé dans l'écosystème Amboseli au Kenya, a créé des couloirs permettant à la faune de se déplacer entre les aires protégées. Afin de s'assurer que les autorités puissent maintenir les corridors et suivre la fréquence à laquelle la faune les utilise, le personnel d'Amboseli utilise EarthRanger pour consolider les données produites par diverses technologies et les visualiser sur une carte intuitive.

Les organisations de gestion des aires protégées de plus de 30 aires protégées dans 13 pays d'Afrique utilisent désormais EarthRanger pour sécuriser leurs sites, atténuer les conflits homme-faune et gérer leurs écosystèmes.

* Pour plus d'informations, veuillez consulter : https://earthranger.com.

Contribution de Ted Schmitt (Vulcan).

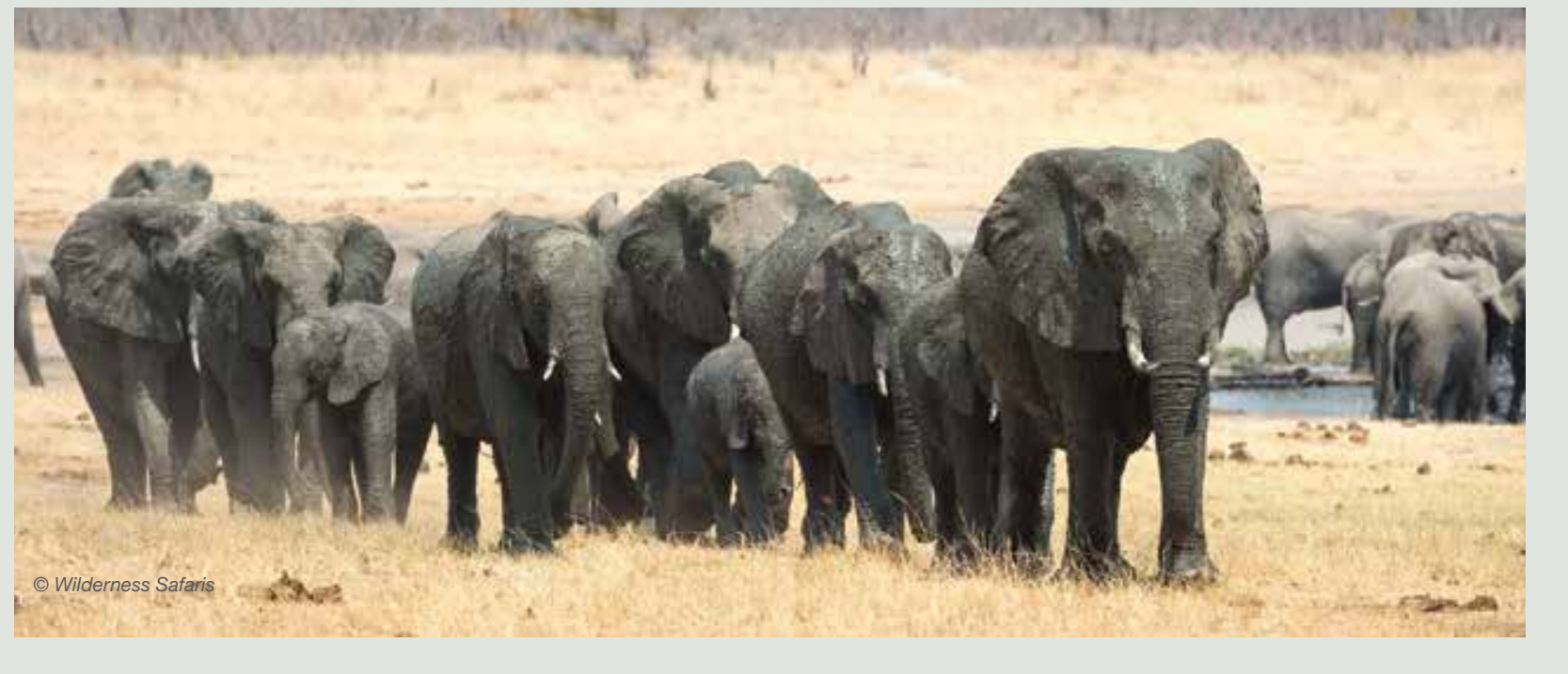




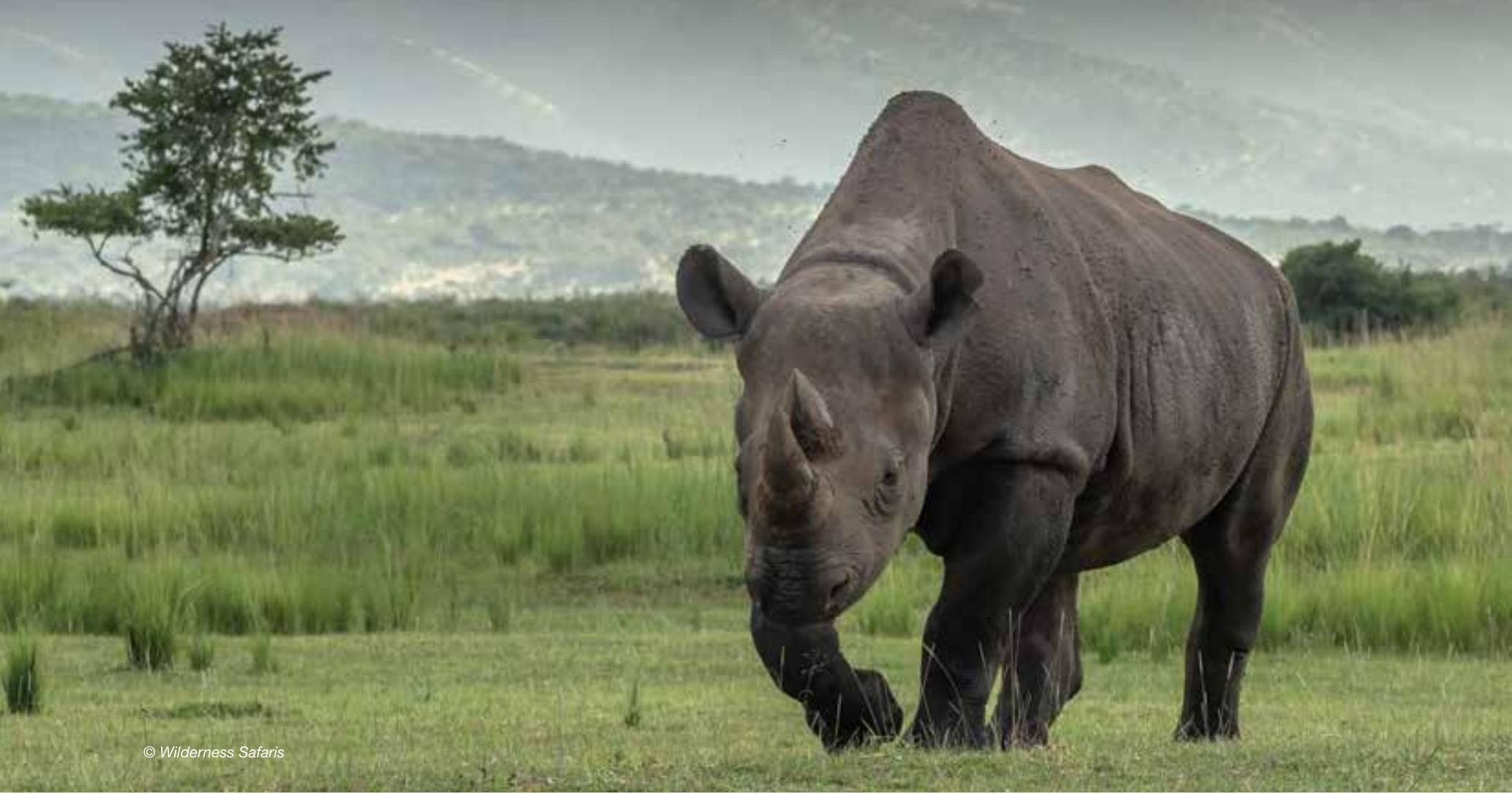

\section{Encadré 11.3 : Programme de suivi des rhinocéros après réintroduction}

Les programmes emblématiques de "retour à la vie sauvage » nécessitent un suivi et une maintenance continus pour assurer leur succès. Depuis la réintroduction de 17 rhinocéros noirs de l'est (Diceros bicornis michaeli) dans le Parc national d'Akagera, au Rwanda en mai 2017, un programme de suivi à plusieurs volets a été utilisé pour assurer la sécurité de la nouvelle population et suivre son état et son comportement. Au cœur du programme se trouve une équipe de traqueurs de rhinocéros. Ces individus suivent quotidiennement les rhinocéros afin de consigner leur état, noter les blessures physiques, consigner les comportements et observer les interactions sociales entre les animaux. Les priorités de suivi sont déterminées par une combinaison des tendances récentes de l'état, du nombre de jours depuis la dernière observation et des facteurs d'application de la loi dans la zone utilisée par un rhinocéros spécifique. La télémétrie à très haute fréquence (VHF) est utilisée pour certains animaux, tandis que les méthodes de suivi traditionnelles (repérage) sont utilisées pour d'autres individus, sans émetteurs dans les cornes. L'objectif du programme de suivi est d'observer chaque animal au moins une fois tous les 14 jours.

Actuellement, les traqueurs de rhinocéros observent chaque animal tous les huit jours, et voient près de trois animaux par jour, dépassant largement les objectifs d'observation. Ces taux d'observation élevés sont facilités par un suivi aérien et des pièges photographiques. Des vols en hélicoptère, effectués toutes les deux semaines, utilisent la télémétrie VHF pour se concentrer sur les individus dotés d'émetteurs. La vitesse de détection par hélicoptère permet de voir beaucoup plus d'animaux en peu de temps (jusqu'à 10 en deux heures). Les survols sont utilisés pour une notation rapide de l'état et pour des contrôles de sécurité, mais n'offrent pas la capacité de suivre le comportement. Le piégeage photographique permet souvent de combler les lacunes dans les données comportementales. Des caméras placées le long des mares de boue et des trous d'eau, ou des sentiers couramment utilisés par les animaux, permettent de détecter les interactions sociales et les comportements plus naturels sans déranger les animaux. Les pièges photographiques collectent également des images la nuit, fournissant des informations sur l'activité et les interactions nocturnes entre les rhinocéros.

À ce jour, aucun animal n'a été perdu à cause du braconnage, et des données utiles ont été recueillies sur les domaines vitaux, les interactions sociales et la composition alimentaire. Les programmes de suivi étroit permettent une compréhension détaillée de la population et renforcent la capacité d'intervention rapide en cas de situation de danger. Le suivi continuera de progresser et les améliorations technologiques seront constamment testées. Cependant, rien ne remplacera jamais les bottes et les jumelles en matière de suivi. Des pisteurs, des rangers et du personnel dévoués, motivés et dotés de ressources suffisantes font toute la différence pour assurer le succès de tels projets de réintroduction.

Contribution de Drew Bantlin (Parcs Africains). 


\section{Encadré 11.4 : Piégeage photographique pour le suivi écologique et la sécurité}

Les pièges photographiques déclenchés à distance par le mouvement ou la chaleur permettent un suivi autrement impossible. Dans les aires protégées ne disposant que de peu de routes et présentant une topographie difficile, comme le Parc national d'Akagera au Rwanda, les pièges photographiques peuvent combler les lacunes dans la compréhension des espèces et l'écologie du parc. Plusieurs formes de déploiement de pièges photographiques sont utilisées. Des pièges photographiques infrarouges, moins dérangeants pour les animaux, sont placés systématiquement sur un quadrillage de $1 \mathrm{~km}$ dans l'ensemble du parc. Cela permet de mieux comprendre la composition des espèces dans le parc et leur répartition dans le paysage. Les mouvements saisonniers et l'utilisation des habitats peuvent être analysés. Des données comportementales et sur les interactions inter- et intra-espèces peuvent être obtenues à partir des photos.

Plusieurs caméras sont également réservées à un usage spécial en dehors du quadrillage. Les caméras dédiées au suivi des rhinocéros sont souvent déplacées dans les zones les plus utilisées pour suivre le comportement, la condition et les interactions sociales. D'autres caméras sont utilisées pour suivre des sujets spéciaux, tels que les tanières de hyènes, le nettoyage et la décomposition de carcasses ou les conflits homme-faune le long des limites du parc. Les pièges photographiques à flash blanc offrent des images nettes d'espèces au pelage à motifs, comme les léopards, pour une identification individuelle.

Les caméras permettent d'observer des comportements qui ne seraient souvent pas visibles lors d'observations en personne, plus perturbatrices. De même, les espèces rares, difficiles à observer ou nocturnes sont souvent capturées par les caméras.

Les caméras jouent également un rôle important dans l'application de la loi. À partir des informations des équipes de rangers sur le terrain, des caméras sont déployées le long des sentiers couramment utilisés par les braconniers et le long de la ligne de clôture, aux endroits où les braconniers entrent dans le parc. La surveillance silencieuse et invisible des activités des braconniers informe les patrouilles, les patrouilles réactives et les activités de maintien de l'ordre dans les communautés environnantes. La plupart du temps inaperçues, les caméras fournissent souvent des images pouvant être utilisées pour identifier les braconniers. Cela a conduit à de nombreuses arrestations et a servi de preuve critique devant les tribunaux, lors de procès. Plus important encore, les caméras soutiennent les équipes de rangers sur le terrain, fournissant des informations de renseignement et améliorant les opérations d'application de la loi dans le parc.

Contribution de Drew Bantlin (Parcs Africains). processus écologiques, des gènes aux communautés, dans l'ensemble des systèmes terrestres, d'eau douce et marins. Ces changements provoquent des altérations écologiques à grande échelle, car les espèces sont obligées de se déplacer pour trouver un nouvel habitat convenable. Les aires protégées et de conservation sont l'un des outils les plus efficaces pour la protection de la biodiversité. Cependant, la plupart de ces sites ont été choisis sans tenir compte des impacts climatiques futurs. Une bonne planification des redistributions futures des espèces et des habitats peut aider à maintenir et à améliorer les garanties de biodiversité, afin de préserver les services écosystémiques et de réduire la menace d'extinction. Le projet SPARC (Aménagement du territoire pour la conservation par zone en réponse aux changements climatiques), par exemple, a identifié des sites terrestres prioritaires afin de réduire les risques climatiques en Afrique subsaharienne (voir l'Encadré 11.5). 


\section{Encadré 11.5 : SPARC - Réduire les risques climatiques pour les réseaux de conservation}

La planète subit actuellement l'une des transformations climatiques les plus rapides de l'histoire de la Terre (Diffenbaugh et Field, 2013). Les changements climatiques anthropiques ont déjà un impact sur la plupart des processus écologiques, des gènes aux communautés, dans l'ensemble des systèmes terrestres, d'eau douce et marins (Scheffers et al., 2016). Ces changements provoquent des altérations écologiques à grande échelle, car les espèces sont obligées de se déplacer pour trouver un nouvel habitat convenable (Parmesan et Yohe, 2003). Les aires de conservation sont l'un des outils les plus efficaces pour protéger la biodiversité, mais la plupart de ces sites ont été choisis sans tenir compte des impacts climatiques futurs. Une bonne planification des redistributions futures des espèces et des habitats peut aider à maintenir et à améliorer les garanties de biodiversité, afin de préserver les services écosystémiques et réduire la menace d'extinction.

Le projet SPARC (Planification spatiale pour la conservation par zone en réponse aux changements climatiques) a utilisé la vitesse des changements climatiques (Loarie et al., 2009), des cartes de stratification environnementale (Metzger et al., 2013), 10 modèles climatiques mondiaux et les distributions futures de plus de 28000 espèces pour déterminer les zones terrestres les plus prioritaires afin de réduire les risques climatiques en Afrique subsaharienne (Figure a). [Pour plus d'informations, voir : sparc-website.org]

L'Angola, par exemple, possède une biodiversité exceptionnelle. Le pays présente la plus grande diversité de biomes en Afrique, formant une zone de transition cruciale de la mosaïque forestière congolaise vers les forêts, les savanes et les prairies de l'escarpement Angolais, les prairies inondées Zambéziennes et le désert de Kaokoveld (Huntley, 2019). Si les émissions mondiales continuent d'augmenter, l'Angola pourrait connaître une transition presque complète de ses zones climatiques à l'échelle nationale dans les 50 prochaines années (SPARC).

La plupart des parcs nationaux Angolais sont situés dans des zones à haute vitesse climatique, où les espèces devront parcourir de longues distances pour suivre leur climat préféré. L'ouest, cependant, avec sa grande diversité altitudinale et sa faible vitesse climatique, offre des opportunités importantes pour maximiser la protection des espèces et des habitats dans une zone la plus petite possible. L'augmentation des efforts de conservation ou la protection formelle des zones les plus prioritaires pour la résilience climatique (Figure b) aidera les espèces angolaises à éviter les pires impacts des changements climatiques. En fait, le maintien d'un corridor d'habitats occidental bien connecté est l'une des priorités de conservation les plus élevées du continent (Figure a), formant l'épine dorsale d'un corridor de déplacement des espèces topographiquement divers, s'étendant de la République du Congo à l'Afrique du Sud. Cette voie protégera les espèces le long des routes migratoires actuelles, qui devraient devenir de plus en plus importantes à mesure qu'un nombre croissant d'espèces se disperseront vers le sud, suivant les températures plus fraîches.
Figure a : Prioriser les efforts de conservation ou protéger officiellement ces zones résilientes au climat aidera à réduire la menace d'extinction dans toute l'Afrique (sur la base des projections à 2070 dans le cadre du PCR 8.5).

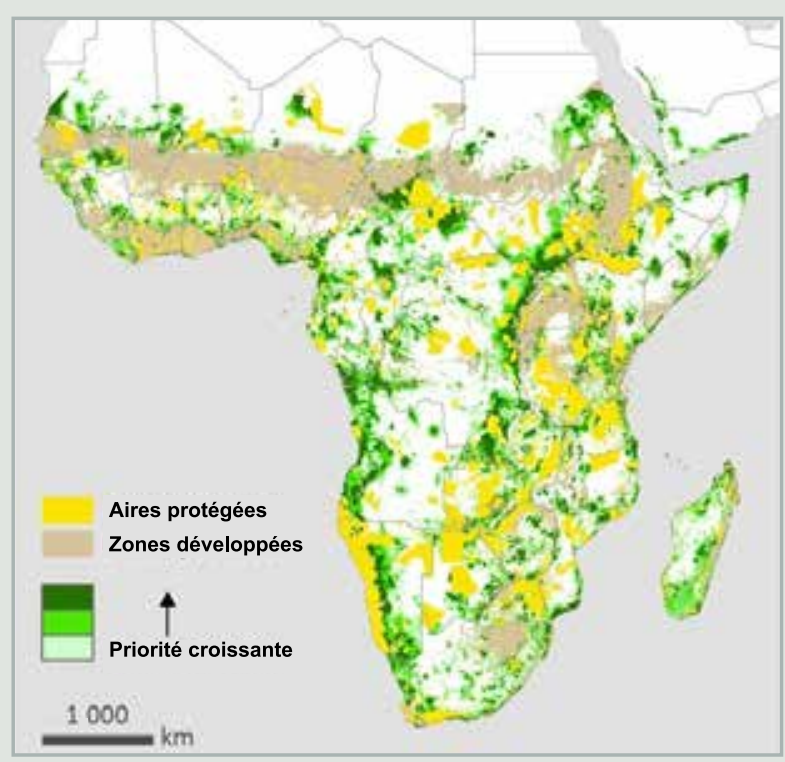

Figure b: Un examen plus approfondi des priorités en matière de résilience climatique pour l'Angola révèle l'importance de protéger un corridor d'habitats occidental interconnecté (sur la base des projections à 2070 dans le cadre du PCR 8.5).

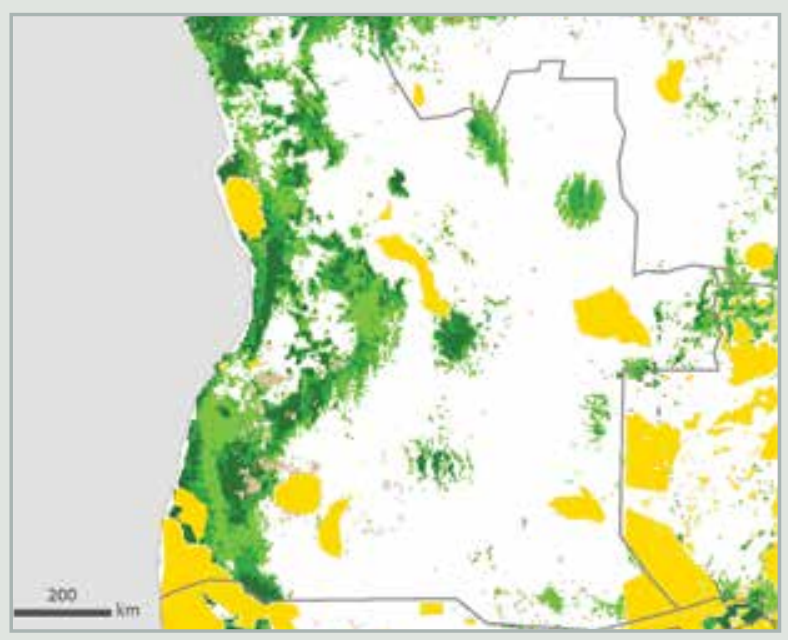

Source des Figures a et b : Hannah et al. (2020).

Le texte et la carte sont une contribution de Caitlin Kelly (Planification spatiale pour la conservation par zone en réponse aux changements climatiques). 

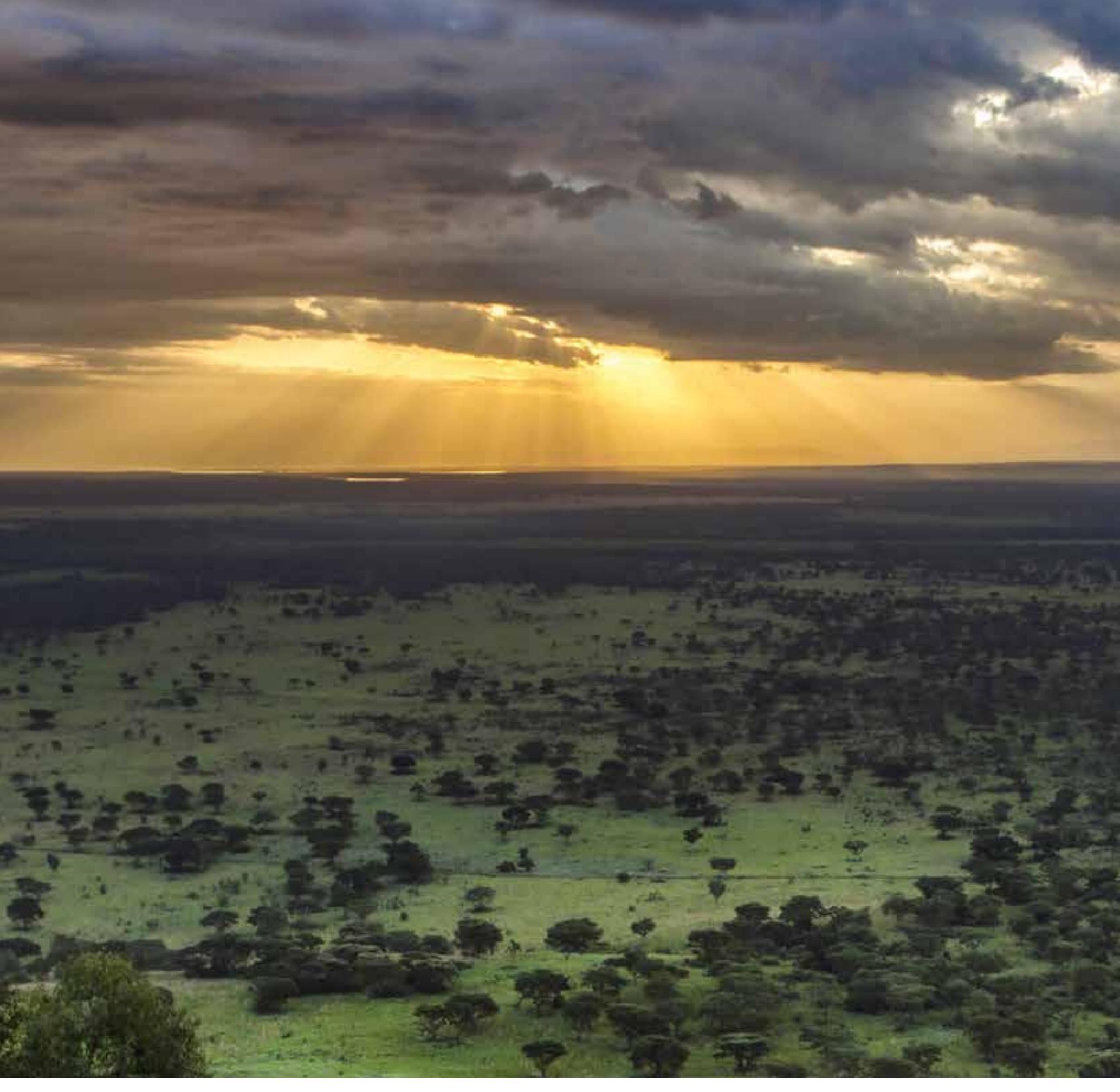


\section{Partie IV}

\section{Recommandations}


Les aires protégées continueront d'être un élément essentiel des efforts mondiaux de conservation de la biodiversité dans l'ère post-2020, protégeant la précieuse biodiversité, maintenant les processus naturels au sein des paysages et fournissant des habitats et des refuges clés pour les espèces dans une ère de changements rapides et sans précédent (Ceballos et al., 2015). Les aires protégées offrent également des avantages de subsistance aux populations, de l'eau potable à la sécurité alimentaire, en plus d'une myriade d'autres avantages culturels, spirituels et socioéconomiques, mais les mesures de conservation peuvent également avoir des impacts sociaux négatifs.

Des défis menacent l'existence et l'efficacité des aires protégées, alors que la biodiversité mondiale continue de se détériorer (Secrétariat de la CDB, 2014; Thomas et Gillingham, 2015). Compte tenu des principaux problèmes liés aux changements climatiques et à la perte de biodiversité, un système élargi et efficacement géré d'aires protégées et autres aires de conservation est non seulement de plus en plus vital, mais nécessite également un niveau plus élevé d'investissements bien ciblés et coordonnés.

La liste suivante de recommandations constitue une priorité pour les autorités chargées des aires protégées, les donateurs, les ONG et les partenaires de toute l'Afrique orientale et australe, afin d'atteindre les Objectifs mondiaux et de veiller à ce que les aires protégées puissent à la fois conserver la biodiversité et contribuer à l'amélioration des moyens de subsistance dans toute la région.

Le plan de travail de BIOPAMA, élaboré à l'issue de consultations nationales et régionales et d'une évaluation des besoins nationaux et régionaux, s'aligne sur les recommandations énoncées ci-après. Il comprend le renforcement des capacités et autres activités liées à chacune des recommandations, afin d'appuyer une amélioration de l'efficacité de la gestion, de la gouvernance et de l'équité.

\subsection{Accroître le financement durable et le soutien politique aux aires protégées et de conservation}

Un financement adéquat et durable est essentiel pour la gestion des aires protégées et de conservation. Alors que la région est actuellement loin d'atteindre cet objectif, il existe de nouveaux mécanismes passionnants pour le financement innovant des aires protégées, et de plus amples travaux sont nécessaires pour tester et intensifier ces approches dans divers contextes, dans toute l'Afrique orientale et australe. En outre, des travaux supplémentaires sont nécessaires pour démontrer l'importance des aires protégées et de conservation dans la fourniture de services écosystémiques et le soutien aux moyens de subsistance ruraux. Cela peut contribuer à accroître la volonté politique et les engagements des gouvernements et, espérons-le, conduire à une augmentation des allocations budgétaires au secteur de la conservation, nécessaires pour assurer un soutien durable et à long terme à ces réseaux. L'importance de l'économie de la faune sauvage et le rôle important de la conservation de la biodiversité sont de plus en plus reconnus par les parties prenantes comme l'une des clés du développement durable dans la région.

\subsection{Renforcer les capacités de gestion des aires protégées et de conservation}

Le renforcement des capacités dans l'ensemble du secteur de la gestion des aires protégées et de la conservation de la biodiversité est un besoin urgent dans toute la région. Cela inclut le soutien au personnel de première ligne, tel que les rangers, mais s'étend également au personnel de "bureau " ainsi qu'aux organisations de soutien communautaires, aux ONG et aux donateurs. Le renforcement des capacités des cadres intermédiaires du secteur est également essentiel, car bon nombre d'entre eux quittent leurs postes sur le terrain et n'ont pas les compétences administratives, financières et de négociation nécessaires pour réussir dans leur nouveau poste de cadres intermédiaires des aires protégées et de conservation. Le renforcement des capacités est nécessaire, non seulement dans la gestion traditionnelle des aires protégées et la lutte contre le braconnage, mais également dans les technologies de la conservation, l'engagement communautaire, les marchés et les entreprises, les financements innovants (par exemple les marchés du carbone) et les partenariats, y compris les partenariats public-privé.

\subsection{Diversifier la gouvernance des aires protégées et reconnaître les initiatives efficaces de gouvernance à l'échelle locale et communautaire et de cogestion}

L'Afrique orientale et australe présente une grande diversité de modèles de gouvernance pour la protection et la conservation de la biodiversité. Un soutien continu et des environnements politiques plus favorables renforceront ce secteur en pleine croissance. L'identification d'AMCE est essentielle pour comprendre et maximiser l'éventail complet des opportunités d'innovation en matière de conservation de la biodiversité dans la région. L'établissement de partenariats de gestion collaborative avec des organisations non gouvernementales peut constituer un mécanisme important pour surmonter ces défis, et son importance a augmenté dans l'ensemble des aires protégées d'Afrique orientale et australe. Les partenariats public-privé représentent une occasion importante d'accroître le financement et d'améliorer la gestion des aires protégées dans la région. Des politiques, des structures et du personnel doivent être en place pour faciliter et superviser ces arrangements novateurs.

\subsection{Combler les lacunes dans la couverture des écosystèmes marins et terrestres dans les aires protégées et de conservation}

Les outils technologiques disponibles pour analyser la connectivité et la représentativité des aires protégées et de conservation augmentent et continueront d'augmenter. Il est nécessaire d'utiliser ces outils pour identifier les lacunes critiques dans la couverture, 
ce qui permettra, dans un premier temps, au processus d'assurer leur protection, et permettra aux parties prenantes de se concentrer davantage sur une approche paysagère, plutôt que sur la conservation de sites isolées. Les avantages d'une conservation à l'échelle des paysages sont de plus en plus évidents, et les analyses des chevauchements entre espèces importantes (de la faune et de la flore) et sites de conservation doivent constituer un domaine d'intervention clé pour les décideurs et les planificateurs de l'utilisation des terres.

\subsection{Renforcer la collaboration transfrontalière et sectorielle pour faire face aux menaces existantes et émergentes}

En ces temps de changements climatiques drastiques, d'accélération de la perte de biodiversité, d'augmentation du commerce illégal d'espèces sauvages et de changements démographiques rapides, l'Afrique orientale et australe est confrontée à un défi monumental dans sa quête de maintenir un réseau d'aires protégées robuste et connecté. Le «statu quo » ne s'est pas révélé efficace, et il est nécessaire de renforcer la collaboration transfrontalière et sectorielle pour faire face aux menaces émergentes, grâce à un recours accru aux mécanismes de partage de l'information. Le Centre régional de ressources de BIOPAMA constitue une plateforme importante pour le partage d'informations et l'échange de connaissances.

\subsection{Améliorer la conservation transfrontière}

L'Afrique orientale et australe abrite 30 aires de conservation transfrontières établies et potentielles. Ces sites ont le potentiel de soutenir une action à des échelles écologiquement et économiquement significatives, et présentent un intérêt pour les bailleurs de fonds bilatéraux et multilatéraux. La SADC a mis en place un programme d'ACT robuste, susceptible de servir de modèle utile pour l'Afrique de l'Est dans ses efforts pour améliorer la conservation transfrontière dans la sous-région. Un certain nombre d'aires de conservation importantes en Afrique de l'Est sont transfrontalières, et une collaboration accrue dans la conservation de ces sites est nécessaire. En outre, les aires marines et côtières de conservation sont généralement sousreprésentées en matière d'ACT.

\subsection{Améliorer la couverture des évaluations de l'efficacité de la gestion, de la gouvernance et de l'équité}

À l'heure actuelle, seulement $13 \%$ des aires protégées de la région ont fait l'objet d'au moins une évaluation de l'efficacité de la gestion, et une proportion beaucoup plus faible a évalué la gouvernance et l'équité. En outre, aucune analyse régionale récente des résultats de ces évaluations n'a été effectuée. L'Objectif d'Aichi 11 indique clairement que le but est d'arriver à des aires protégées gérées de manière efficace et équitable. En l'absence de données, il est impossible de savoir dans quelle mesure la région progresse vers cet objectif important. L'amélioration de la capacité d'entreprendre des évaluations de l'efficacité de la gestion, de la gouvernance et de l'équité à l'échelle locale et nationale est donc une priorité. Dans le même temps, il est également important de sensibiliser et de multiplier les conseils sur la façon de partager les rapports disponibles avec les plateformes mondiales permettant de suivre la réalisation des objectifs. Cellesci sont importantes pour assurer la durabilité et renforcer l'institutionnalisation des évaluations. Une analyse approfondie des résultats des évaluations récentes effectuées dans la région d'Afrique orientale et australe est nécessaire pour aider à dresser un tableau régional de l'état de l'efficacité de la gestion et de la gouvernance équitable, ainsi que pour guider les interventions futures.

\subsection{Améliorer la fréquence et l'exhaustivité des rapports à la Base de données mondiale des aires protégées}

La région d'Afrique orientale et australe a presque atteint l'Objectif d'Aichi 11 pour les aires protégées terrestres, avec près de $17 \%$ de sa superficie terrestre couverte par des aires protégées. En ce qui concerne la protection marine et côtière, la région a atteint un peu plus de la moitié de l'objectif de $10 \%$, avec $5,6 \%$ de sa zone côtière et marine sous protection. Avec l'élargissement de l'objectif permettant d'inclure les AMCE, les pays sont encouragés à signaler toutes leurs aires protégées et de conservation à la BDMAP. Étant donné la forte proportion de catégories de gestion et types de gouvernance de l'UICN « non déclarés », les pays sont encouragés à clarifier les catégories des aires protégées et de conservation existantes. Les données de la BDMAP sont utilisées pour établir et mesurer de nombreux objectifs mondiaux et régionaux. II est donc crucial que les pays veillent à ce que les données les concernant soient à jour et exactes. 


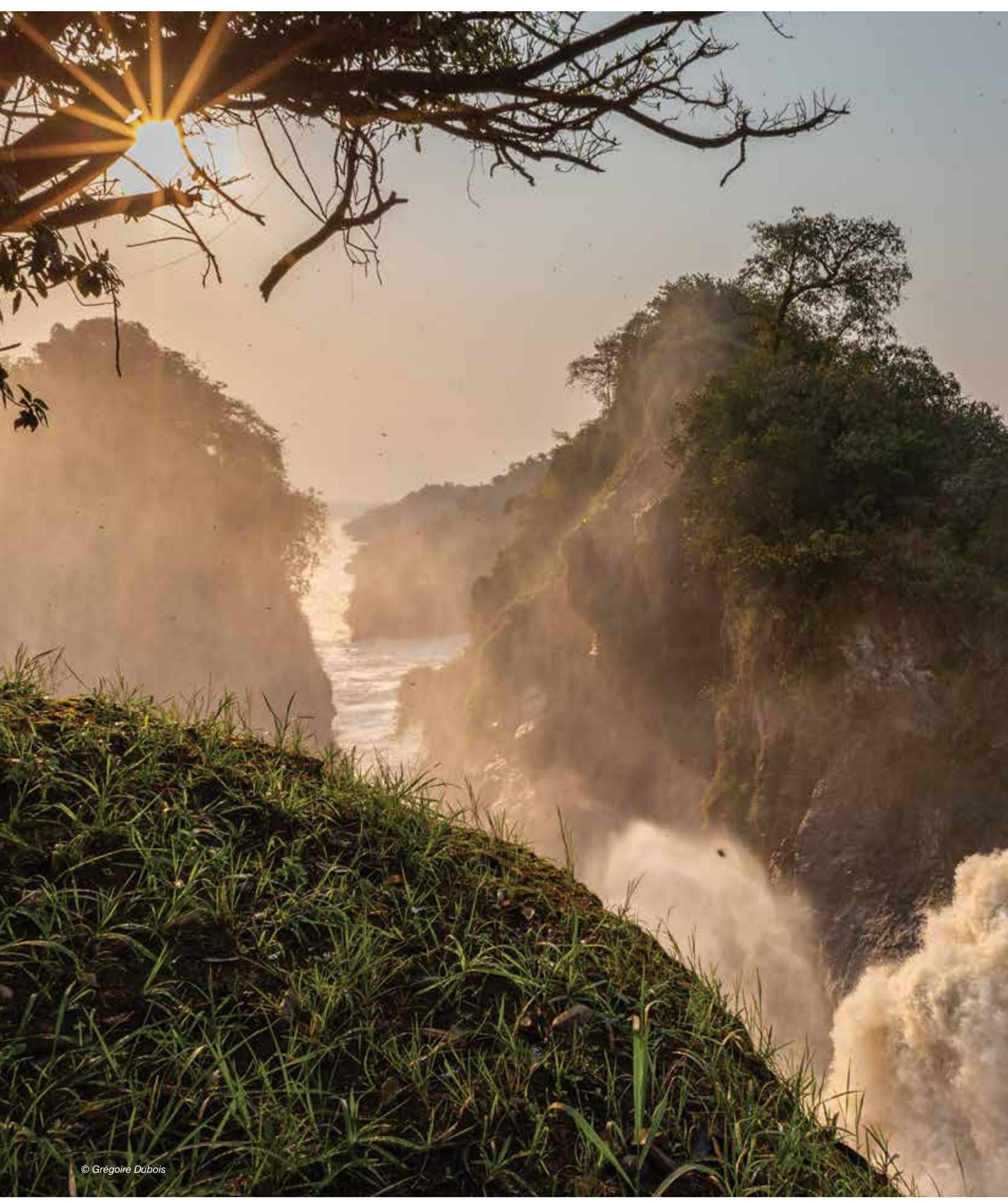


Athanas, A. (2018). 'Engaging business to boost sustainability in African agriculture'. Panorama [site web],(22 novembre 2018). https:// panorama.solutions/en/solution/engaging-business-boost-sustainability-african-agriculture.

Alliance for Zero Extinction (AZE) Secretariat (s.d.). AZE [site web] . http://zeroextinction.org/.

Baghai, M., Miller, J.R.B., Blanken, L.J., Dublin, H.T., Fitzgerald, K.H., Gandiwa, P., Laurenson, K., Milanzi, J. Nelson, A., Lindsey, P. (2018). 'Models for the collaborative management of Africa's protected areas'. Biological Conservation 218: 73-82. https://doi. org/10.1016/j.biocon.2017.11.025

Balmford, A., Beresford, J., Green, J., Naidoo, R., Walpole, M. et Manica, A. (2009). 'A Global Perspective on Trends in Nature-Based Tourism'. PLoS Biology 7(6): e100014. https://doi.org/10.1371/journal.pbio.1000144

Bastin, L., Mandrici, A., Battistella, L. et Dubois, G. (2017). 'Processing Conservation Indicators with Open Source Tools: Lessons Learned from the Digital Observatory for Protected Areas'. Free and Open Source Software for Geospatial (FOSS4G) Conference Proceedings 17(6): 101-111. https://doi.org/10.7275/R5XK8CQS

Belle, E., Wicander, S., Bingham, H. et Shi, Y. (2015). Governance of protected areas in Africa: A global review. Cambridge, RoyaumeUni : UNEP-WCMC. https://papaco.org/wp-content/uploads/2015/04/PAPACO-study-17_GOVERNANCE-STUDY-0-FINAL_REPORTCONTEXT.pdf

Bennett, N.J. et Dearden, P. (2014). 'Why local people do not support conservation: Community perceptions of marine protected area livelihood impacts, governance and management in Thailand'. Marine Policy 44: 107-116. https://doi.org/10.1016/j.marpol.2013.08.017

Bennett, N.J., Franco, A.D., Calò, A., Nethery, E., Niccolini, F., Milazzo, M. et Guidetti, P. (2019). 'Local support for conservation is associated with perceptions of good governance, social impacts, and ecological effectiveness'. Conservation Letters 12(4). https://doi. org/10.1111/conl.12640

Biodiversity Finance Initiative (BIOFIN) (2017). Biodiversity Finance Initiative [site web]. https://www.biodiversityfinance.net/

(2019). 'Finance for nature, a commitment of the whole society to the sustainability of the planet'. BIOFIN [site web], (1 juillet 2019$)$ https://www.biodiversityfinance.net/news-and-media/finance-nature-commitment-whole-society-sustainability-planet.

Biodiversity and Protected Areas Programme (BIOPAMA) (non publié). State of Protected Areas Report for East Africap. Nairobi, Kenya : CAE, UICN ESARO, CCR.

BIOPAMA et International Union for Conservation of Nature (IUCN) (2016). IMET (Integrated Management Effectiveness Tool) training summary report. Mbale, Ouganda: IMET Training Workshop. Non publié.

BirdLife International (2019a). 'Sites and Habitats (IBAs and KBAs)'. BirdLife International [site web]. http://www.birdlife.org/worldwide/ programmes/sites-habitats-ibas-and-kbas

(2019b). World Database of Key Biodiversity Areas. Développée par le partenariat KBA : BirdLife International, Union internationale pour la conservation de la nature, Amphibian Survival Alliance, Conservation International, Critical Ecosystem Partnership Fund, Fonds pour l'environnement mondial, Global Wildlife Conservation, NatureServe, Rainforest Trust, Royal Society for the Protection of Birds, Wildlife Conservation Society et World Wildlife Fund. Disponible à : www.keybiodiversityareas.org. [consulté le 20/10/2019].

(2019c). 'Important Bird and Biodiversity Areas'. World Database of Key Biodiversity Areas. Développée par le partenariat KBA : BirdLife International, Union internationale pour la conservation de la nature, Amphibian Survival Alliance, Conservation International, Critical Ecosystem Partnership Fund, Fonds pour l'environnement mondial, Global Wildlife Conservation, NatureServe, Rainforest Trust, Royal Society for the Protection of Birds, Wildlife Conservation Society et World Wildlife Fund. Disponible à : www.keybiodiversityareas. org. [consulté le 20/10/2019].

Booker, F. et Franks, P. (2019). Governance Assessment for Protected and Conserved Areas (GAPA): Methodology manual for GAPA facilitators. Londres : IIED. https://www.sprep.org/attachments/Publications/articles/governance-assessment-protected-conservedareas.pdf

Borrini-Feyerabend, G., Dudley, N., Jaeger, T., Lassen, B., Pathak Broome, N., Phillips, A. et Sandwith, T. (2014). Gouvernance des aires protégées : de la compréhension à l'action. Lignes directrices des meilleures pratiques pour les aires protégées $N^{\circ} 20$. Gland, Suisse : UICN. https://portals.iucn.org/library/node/44864 (Également disponible en anglais, portugais et espagnol)

Burgess, N.D., Malugu, I., Sumbi, P., Kashindye, A., Kijazi, A., Tabor, K., Mblinyi, B., Kashaigili, J., Wright, T.M., Gereau, R.E. et al. (2017) 'Two decades of change in state, pressure and conservation responses in the coastal forest biodiversity hotspot of Tanzania'. Oryx 51(1): 77-86. https://doi.org/10.1017/S003060531500099X

Campese, J. et Sulle, E. (2019). Management Effectiveness, Governance, and Social Assessments of Protected and Conserved Areas in Eastern and Southern Africa: A rapid inventory and analysis to support the BIOPAMA programme and partners. A report prepared for BIOPAMA Eastern and Southern Africa. BIOPAMA, UICN ESARO. https://biopama.org/sites/default/files/Report_BIOPAMA\%20ESA Sept_2019_web.pdf

Ceballos, G., Ehrlich, P.R., Barnosky, A.D., García, A., Pringle, R.M. et Palmer, T.M. (2015). Accelerated modern human-induced species losses: 'Entering the sixth mass extinction'. Science Advances 1(5). https://doi.org/10.1126/sciadv.1400253 
Chadwick, P., Duncan, J. et Tunley, K. (2014). State of Management of South Africa's Marine Protected Areas. WWF South Africa No. 2014/Marine/001. Afrique du Sud : WWF. http://awsassets.wwf.org.za/downloads/final_wwf_marine_report_02_dec_2014_web_1.pdf

Coad, L., et al. (2015). 'Measuring impact of protected area management interventions: current and future use of the Global Database of Protected Area Management Effectiveness'. Philosophical Transactions of the Royal Society B: Biological Sciences 370(1681). https:// doi.org/10.1098/rstb.2014.0281

Coad, L., Watson, J.E., Geldmann, J., Burgess, N.D., Leverington, F., Hockings, M., Knights, K., Marco, M.D. (2019). 'Widespread shortfalls in protected area resourcing undermine efforts to conserve biodiversity'. Frontiers in Ecology and the Environment 17(5): 259-264. https://doi.org/10.1002/fee.2042

Conservation Finance Alliance (CFA) 2008. Rapid Review of Conservation Trust Funds.Second Edition. Prepared for the CFA Working Group on Environmental Funds by Barry Spergel and Philippe Taïeb. https://www.cbd.int/financial/trustfunds/g-rapidassess.pdf

Conservation International (Cl) et World Wildlife Fund (WWF) (s.d.). PADDDtracker.org Data Release Version 2.0 (Mai 2019$)$. Arlington, VA et Washington, DC : Cl et WWF. DOI: 10.5281/zenodo.3371733 (Consulté le 13 août 2019).

Convention sur la diversité biologique (CDB) (2004). Décision adoptée par la Conférence des Parties à la Convention sur la diversité biologique à sa septième réunion VII/28. Aires protégées [Article 8, points (a) à (e)]. N UNEP/CBD/COP/DEC/VII/28. Kuala Lumpur, Malaisie : Convention sur la diversité biologique. https://www.cbd.int/decision/cop/?id=7765 (en ligne)

(2005). Options pour mobiliser des ressources financières suffisantes en vue de garantir la mise en œuvre du programme de travail sur les aires protégées dans les pays en développement, en particulier les pays les moins avancés d'entre eux et les petits Etats insulaires, et les pays à économie en transition. N UNEP/CBD/WG-PA/1/6. https://www.cbd.int/meetings/PAWG-01 (liens vers six langues des Nations Unies aux formats Word et PDF).

(2010a). Décision adoptée par la Conférence des Parties à la Convention sur la diversité biologique à sa dixième réunion X/2. Plan stratégique 2011-2020 et objectifs d'Aichi relatifs à la diversité biologique. N UNEP/CBD/COP/DEC/X/2. Nagoya, Japon : Convention sur la diversité biologique. https://www.cbd.int/doc/decisions/cop-10/cop-10-dec-02-fr.pdf

(2010b). Décision adoptée par la Conférence des Parties à la Convention sur la diversité biologique à sa dixième réunion: X/31. Aires protégées. № UNEP/CBD/COP/DEC/X/31. Nagoya, Japon : Convention sur la diversité biologique. https://www.cbd.int/doc/ decisions/cop-10/cop-10-dec-31-fr.pdf

(2018). Décision adoptée par la Conférence des Parties à la Convention sur la Diversité Biologique 14/8. Aires protégées et autres mesures de conservation efficaces par zone. № CBD/COP/DEC/14/8. Charm El-Cheikh, Égypte : Convention sur la diversité biologique. https://www.cbd.int/doc/decisions/cop-14/cop-14-dec-08-fr.pdf

Credit Suisse, WWF et McKinsey (2014). Conservation Finance: Moving beyond donor funding toward an investor-driven approach. https://www.cbd.int/financial/privatesector/g-private-wwf.pdf

Davey, A.G. (1998). National system planning for protected areas. Best Practice Protected Area Guidelines Series No. 1. Gland, Suisse et Cambridge, Royaume-Uni : Commission mondiale des aires protégées de l'UICN. https://portals.iucn.org/library/node/7394 (également disponible en arabe, chinois et russe)

Deguignet, M., Arnell, A., Juffe-Bignoli, D., Shi, Y., Bingham, H., MacSharry, B. et Kingston, N. (2017). 'Measuring the extent of overlaps in protected area designations'. PLOS ONE 12(11): e0188681. https://doi.org/10.1371/journal.pone.0188681

de Koning, M., Parr, J.W.K., Sengchanthavong, S. et Phommasane, S. (2016). 'Collaborative governance improves management effectiveness of Hin Nam No National Protected Area in Central Lao PDR'. Parks 22(2): 27-40. https://doi.org/10.2305/IUCN.CH.2016. PARKS-22-2MdK.en

Diffenbaugh, N.S. et Field, C.B. (2013). 'Changes in ecologically critical terrestrial climate conditions'. Science 341: 6145. https://doi. org/10.1126/science.1237123

Donald, P.F. et al. (2019). 'The prevalence, characteristics and effectiveness of Aichi Target 11's "other effective area-based conservation measures" (OECMs) in Key Biodiversity Areas'. Conservation Letters 12(5): e12659. https://doi.org/10.1111/conl.12659

Dubois, G. et al. (2016). 'Integrating Multiple Spatial Datasets to Assess Protected Areas: Lessons Learnt from the Digital Observatory for Protected Areas (DOPA)'. ISPRS International Journal of Geo-Information 5(12). https://doi.org/10.3390/ijgi5120242

Dudley, N. (éd.) (2008). Lignes directrices pour l’application des catégories de gestion aux aires protégées. Gland, Suisse : UICN. https:// portals.iucn.org/library/node/9244

DuPont, C.M., Levitt, J. et Bilmes, L. (2016). Green bonds and land conservation: The evolution of a new financing tool. Harvard Environmental Economics Program (Discussion Paper 16-67). https://doi.org/10.2139/ssrn.2700311

East African Community (EAC) (2010). East African Community Transboundary Ecosystems Management Bill, 2010. http://www.eala.org/ uploads/Transboundary_Bill.pdf

(2018). Strategy to Combat Poaching, Illegal Trade and Trafficking of Wildlife and Wildlife Products 2017/18-2021/22. https://www. eac.int/documents/category/tourism-wildlife-management 
Edgar, G.J., et al. (2014). 'Global conservation outcomes depend on marine protected areas with five key features'. Nature 506(7487): 216-220. https://doi.org/10.1038/nature13022

Eklund, J. et Cabeza, M. (2017). 'Quality of governance and effectiveness of protected areas: crucial concepts for conservation planning'. Annals of the New York Academy of Sciences 1399(1): 27-41. https://doi.org/10.1111/nyas.13284

Emerton, L., Bishop, J. et Thomas, L. (2006). Sustainable Financing of Protected Areas. A global review of challenges and options. Best Practice Protected Area Guidelines series No. 13. Gland, Suisse : UICN. https://doi.org/10.2305/IUCN.CH.2005.PAG.13.en

Eswatini (2014). Swaziland's Fifth National Report to the Convention of Biological Diversity. Eswatini Environment Authority. https://www. cbd.int/doc/world/sz/sz-nr-05-en.pdf

Eswatini Environment Authority (2016). Eswatini's Second National Biodiversity and Action Plan. National Biodiversity Strategy and Action Plan (NBSAP) No. 2. Ministry of Tourism and Environmental Affairs. https://www.cbd.int/doc/world/sz/sz-nbsap-v2-en.pdf

European Commission (EC) (2015). Larger than elephants: Inputs for the design of an EU strategic approach to Wildlife Conservation in Africa. Bruxelles, Belgique : CE. doi:10.2841/123569 Centre commun de recherche de la CE (2018). Science for the AU-EU Partnership - Building knowledge for sustainable development. https://ec.europa.eu/jrc/en/publication/eur-scientific-and-technical-researchreports/science-au-eu-partnership (inclut un lien vers le rapport principal et le résumé en six langues)

EC Joint Research Centre (JRC)/Digital Observatory for Protected Areas (DOPA) (2019a). An introduction to DOPA Explorer 4.0. DOPA Factsheet No. A.1. CE et DOPA. https://dopa.jrc.ec.europa.eu/sites/default/files/DOPA\%20Factsheet\%20A1\%20EN\%20An\%20 introduction\%20to\%20DOPA\%20Explorer_0.pdf. Consulté le : 8/7/2019

(2019b). Regional factsheet 201910 Africa (Eastern) and (Southern). CCR CE /DOPA [site web]. https://dopa.jrc.ec.europa.eu/en/ regional-factsheet. Consulté le : 15/11/2019

(2019c). Connectivity of terrestrial protected areas. DOPA Factsheet C.1. https://dopa.jrc.ec.europa.eu/sites/default/files/ DOPA \%20Factsheet\%20C1\%20EN\%20Connectivity.pdf. Consulté le : 8/7/2019

Federal Republic of Somalia (2014). Fifth national report on the implementation of the Convention on Biological Diversity of Somalia. National Report on Biodiversity No. 5. Mogadiscio, Somalie : Ministry of Fisheries and Marine Resource. https://www.cbd.int/doc/world/ so/so-nr-05-en.pdf

(2019). Sixth National Report to the Convention of Biological Diversity. The Clearing-House Mechanism of the Convention on Biological Diversity. https://chm.cbd.int/pdf/documents/nationalReport6/248495/1 (PDF) ou https://chm.cbd.int/database/ record?documentID=248495 (en ligne)

Fitzgerald, K.H. (2017). 'The challenge of funding Africa's protected area system'. Swara (Juillet-Septembre): 59-61. https://swara.co.ke/ making-africa-s-protected-area-system-financially-viable/

Frankfurt Zoological Society (FZS) (2019). 'North Luangwa conservation programme'. FZS [site web].https://fzs.org/en/projects/ north-luangwa/

Franks, P. et Booker, F. (2018). Governance Assessment for Protected and Conserved Areas (GAPA): Early experience of a multistakeholder methodology for enhancing equity and effectiveness. IIED Working Paper. Londres : IIED. https://pubs.iied.org/ pdfs/17632lIED.pdf

Franks, P., Small, R. et Booker, F. (2018). Social Assessment for Protected and Conserved Areas (SAPA). Methodology manual for SAPA facilitators. Second edition. IIED, Londres. https://pubs.iied.org/pdfs/14659IIED.pdf

Franks, P., Booker, F. et Small, R. (eds.). (à paraître en 2021). Social Assessment for Protected Areas and Conserved Areas. IIED Results Report. Londres, Royaume-Uni : International Institute for Environment and Development.

Gannon, P., Dubois, G., Dudley, N., Ervin, J., Ferrier, S., Gidda, S., MacKinnon, K., Richardson, K., Schmidt, M., Seyoum-Edjigu, E. et al. (2019). 'An update on progress towards Aichi Biodiversity Target 11'. Parks 25.2 Novembre 2019.http://dx.doi.org/10.2305/IUCN.

CH.2019.PARKS-25-2PG.en

Geldmann, J., Barnes, M., Coad, L., Craigie, I.D., Hockings, M. et Burgess, N.D. (2013). 'Effectiveness of terrestrial protected areas in reducing habitat loss and population declines'. Biological Conservation 161: 230-238. https://doi.org/10.1016/j.biocon.2013.02.018

Geldmann, J., Coad, L., Barnes, M., Craigie, I.D., Hockings, M., Knights, K., Leverington, F., Cuadros, I.C., Zamora, C., Woodley, S. et al. (2015). 'Changes in protected area management effectiveness over time: A global analysis'. Biological Conservation 191: 692-699. https://doi.org/10.1016/j.biocon.2015.08.029

Golden Kroner, R.E., Qin, S., Cook, C.N., Krithivasan, R., Pack, S.M., Bonilla, O.D., Cort-Kansinally, K.A., Coutinho, B., Feng, M., Martínez Garcia, M.I. et al. (2019). 'The uncertain future of protected lands and waters'. Science 364(6443): 881-886. https://doi.org/10.1126/ science.aau5525

Godoy, F., Tabor, K., Burgess, N., Mbilinyi, B., Kashaigili, J. et Steininger, M. (2012). 'Deforestation and CO2 emissions in coastal Tanzania from 1990 to 2007'. Environmental Conservation 39(1): 62-71. https://doi.org/10.1017/S037689291100035X 
Gorenflo, L.J., Corson, C., Chomitz, K.M., Harper, G., Honzák, M. et Özler, B. (2011). 'Exploring the Association Between People and Deforestation in Madagascar'. Dans : Cincotta, R.P. et L.J. Gorenflo (eds.). Human Population: Its Influences on Biological Diversity, pp. 197-221. Berlin, Heidelberg: Springer. https://doi.org/10.1007/978-3-642-16707-2_11

Government of Malawi (2014). Fifth National Report To The Convention on Biological Diversity. Lilongwe, Malawi: Environmental Affairs Department. https://www.cbd.int/doc/world/mw/mw-nr-05-en.pdf

(2015). National Biodiversity Strategy and Action Plan II (2015-2025). Lilongwe, Malawi: Environmental Affairs Department. https://www.cbd.int/doc/world/mw/mw-nbsap-v2-en.pdf

(2019). Sixth National Report to the Convention on Biological Diversity.Ministry of Natural Resources, Energy and Mining. https://www.cbd.int/doc/nr/nr-06/mw-nr-06-en.pdf

Government of Seychelles (2014a). Fifth National Report to the Convention on Biological Diversity. Victoria. https://www.cbd.int/ doc/world/sc/sc-nr-05-en.pdf

(2014b). Seychelles National Biodiversity Strategy and Action Plan 2015-2020. National Biodiversity Strategy and Action Plan No. 2. https://www.cbd.int/doc/world/sc/sc-nbsap-v2-en.pdf

Graham, J., Bruce, A. et Plumptre, T. (2003). Governance principles for protected areas in the 21st century. The Fifth World Parks Congress in September 2003. Durban, Afrique du Sud : Institute On Governance. https://www.files.ethz.ch/isn/122197/pa governance2.pdf

Gutiérrez, N.L., Hilborn, R. et Defeo, O. (2011). 'Leadership, social capital and incentives promote successful fisheries'. Nature 470(7334): 386-389. https://doi.org/10.1038/nature09689

Hannah, L., Roehrdanz, P.R., Marquet, P.A., Enquist, B.J., Midgley, G., Foden, W., Lovett, J.C., Corlett, R.T., Corcoran, D., Butchart, S.H.M. et al. (2020). '30\% land conservation and climate action reduces tropical extinction risk by more than $50 \%$ '. Ecography 43: 943-953. https://doi.org/10.1111/ecog.05166

Hockings, M. et al. (2019). 'The IUCN green list of protected and conserved areas: Setting the standard for effective conservation'. PARKS 25(2): 57-66. https://doi.org/10.2305/IUCN.CH.2019.PARKS-25-2MH.en

Hockings, M., Leverington, F. et Cook, C. (2015). 'Protected Area Management Effectiveness'. Dans : Worboys, G.L., M. Lockwood, A. Kothari, S. Feary, et Pulsford, I. (eds.). Protected Area Governance and Management, pp. 889-928. ANU Press, Canberra. http://press-files.anu.edu.au/downloads/press/p312491/pdf/CHAPTER28.pdf

Hockings, M., Stolton, S., Leverington, F., Dudley, N. et Courrau, J. (2008). Evaluation de l'efficacité : un cadre pour l'évaluation de l'efficacité de la gestion des aires protégées. Lignes directrices sur les meilleures pratiques pour les aires protégées No. 14. Gland, Suisse et Cambridge, Royaume-Uni : UICN. https://portals.iucn.org/library/node/9255

Howard, P. et Bertzky, B. (2020). Le patrimoine mondial naturel en Afrique : Avancées et perspectives. BIOPAMA Programme. Nairobi, Kenya et Ouagadougou, Burkina Faso : UICN ESARO et UICN PACO. https://portals.iucn.org/library/node/49059

Hummel, C., Poursanidis, D., Orenstein, D., Elliott, M., Adamescu, M. C., Cazacu, C., Chrysoulakis, N., van der Meer, J., Hummel, H. (2019). "Gestion des aires protégées: Fusion et confusion avec l'approche des services écosystémiques". Science of The Total Environment 651: 2432-2443. https://doi.org/10.1016/j.scitotenv.2018.10.033

Huntley, B.J. (2019). 'Angola in outline: Physiography, climate and patterns of biodiversity'. Dans : B. Huntley, V. Russo, F. Lages, N. Ferrand (eds.), Biodiversity of Angola. Cham, Suisse: Springer. https://doi.org/10.1007/978-3-030-03083-4_2

Huntley, B.J., Russo, V., Lages, F. et Ferrand, N. (eds.) (2019). Biodiversity of Angola: Science and conservation: A modern synthesis. Springer. https://doi.org/10.1007/978-3-030-03083-4

Indigenous and Community Conserved Areas (ICCA) Registry (s.d.). ICCA Registry [site web]. http://www.iccaregistry.org/

Intergovernmental Science-Policy Platform on Biodiversity and Ecosystem Services (IPBES) (2018). IPBES regional assessment report on biodiversity and ecosystem services for Africa. Bonn, Allemagne: Secrétariat de la Plateforme intergouvernementale scientifique et politique sur la biodiversité et les services écosystémiques. https://ipbes.net/sites/default/files/africa assessment_report_20181219_0.pdf et https://ipbes.net/assessment-reports/africa (inclut des liens directs vers des résumés et autres documents et commentaires).

International Institute for Environment and Development (IIED) (2018). 'Assessing governance at protected and conserved areas (GAPA)'. International Institute for Environment and Development. https://www.iied.org/assessing-governance-protectedconserved-areas-gapa

(2020). Assessing governance and equity at protected and conserved areas (SAGE). International Institute for Environment and Development. https://www.iied.org/assessing-governance-equity-protected-conserved-areas-sage accessed 23 January 2020.

(s.d.). 'Assessing social impacts of protected and conserved areas (SAPA)'. IIED [site web]. https://www.iied.org/ assessing-social-impacts-protected-conserved-areas-sapa 
IUCN Eastern and Southern Africa Region (ESARO) (2020). Closing the gap. The financing and resourcing of protected and conserved areas in Eastern and Southern Africa. Nairobi, Kenya: UICN ESARO; BIOPAMA. https://portals.iucn.org/library/ node/49045

IUCN et World Commission on Protected Areas (WCPA) (2017). IUCN Green List of Protected and Conserved Areas: Standard, Version 1.1. Gland, Suisse: UICN. https://www.iucn.org/theme/protected-areas/our-work/iucn-green-list-protected-andconserved-areas/global-standard

Groupe de travail sur les autres mesures de conservation efficaces par zone (AMCE) de la CMAP-UICN (2020). Reconnaissance et signalement des autres mesures de conservation efficaces par zone. Gland, Suisse: UICN. https://doi.org/10.2305/IUCN.CH.2019. PATRS.3.fr

Jonas, H. et Sandwith, T. (eds.) (2019). Towards Recognising, Reporting and Supporting OECMs: Report of the Fourth Expert Meeting of the IUCN-WCPA Task Force on Other Effective Area-based Conservation Mesaures. Gland, Suisse: UICN. https:// www.bfn.de/fileadmin/BfN/ina/Dokumente/Tagungsdoku/2019/towards_recognising_reporting_and_supporting_OECMs_report_of_4th_meeting_of_the_task_force_on_OECMs_-_june_2019bf.pdf

Key Biodiversity Area (KBA) Secretariat (2019). Key biodiversity areas proposal process: Guidance on proposing, reviewing, nominating and confirming sites. Version 1.0. Cambridge, Royaume-Uni: KBA Secretariat et KBA Committee of the KBA Partnership. http://www.keybiodiversityareas.org/userfiles/files/KBA\%20Proposal\%20Process-v1.0.pdf

KBA Standards and Appeals Committee (2019). Guidelines for using A global standard for the identification of Key Biodiversity Areas: Version 1.0. Prepared by the KBA Standards and Appeals Committee of the IUCN Species Survival Commission and IUCN World Commission on Protected Areas. Gland, Suisse: UICN. https://portals.iucn.org/library/node/47982

Kenya National Bureau of Statistics (KNBS) (2019). Economic survey 2019. Nairobi, Kenya: Kenya National Bureau of Statistics. https://www.knbs.or.ke/?wpdmpro=economic-survey-2019

Kenya Wildlife Service (KWS) (2015). Annual Report. Nairobi, Kenya: KWS. http://www.kws.go.ke/file/2559/ download?token=skN48S4I

Kingdom of Eswatini (2019). Sixth National Report to the United Nations Convention on Biological Diversity Project. Ministry of Tourism and Environmental Affairs. https://www.cbd.int/doc/nr/nr-06/sz-nr-06-en.pdf

Kingdom of Lesotho (2019). Sixth national report: Lesotho vision 2020. National Report on Biodiversity (draft) No. 6. https://www. cbd.int/doc/nr/nr-06/ls-nr-06-en.pdf

Knoema (s.d.). 'Rwanda - Contribution of travel and tourism to GDP as a share of GDP'. Knoema [site web] https://knoema.com// atlas/Rwanda/topics/Tourism/Travel-and-Tourism-Total-Contribution-to-GDP/Contribution-of-travel-and-tourism-to-GDPpercent-of-GDP?origin=knoema.fr. Consulté le: 27 mars 2020.

Leverington, F., Lemos Costa, K., Courrau, J., Pavese, H., Nolte, C., Marr, M., Coad, L., Burgess, L.N., Bomhard, B. et Hockings, M. (2010). Management effectiveness evaluation in protected areas - A global study. Second edition - 2010. Brisbane, Australie: Université du Queensland. https://www.eci.ox.ac.uk/publications/downloads/coad11-protected-areas.pdf

Lewis, E., MacSharry, B., Juffe-Bignoli, D., Harris, N., Burrows, G., Kingston, N. et Burgess, N.D. (2017). 'Dynamics in the global protected-area estate since 2004'. Conservation Biology 33(3): 570-579. https://doi.org/10.1111/cobi.13056

Lindsey, P.A. et al. (2017). 'The performance of African protected areas for lions and their prey'. Biological Conservation 209: 137-149. https://doi.org/10.1016/j.biocon.2017.01.011

Lindsey, P.A. et al. (2018). 'More than $\$ 1$ billion needed annually to secure Africa's protected areas with lions'. Proceedings of the National Academy of Sciences 115(45): E10788-E10796. https://doi.org/10.1073/pnas.1805048115

Loarie, S.R., Duffy, P.B., Hamilton, B., Asner, G.P., Field, C.B., et Ackerly, D.D. (2009). 'The velocity of climate change'. Nature 462: 1052-1055. https://doi.org/10.1038/nature08649

Long, S.A. (2002). Disentangling benefits: Livelihoods, natural resource management and managing revenue from tourism: The experience of the Torra Conservancy, Namibia. Directorate of Environmental Affairs, Ministry of Environment and Tourism. http:// www.met.gov.na/services/research-discussion-papers-rdp/158/

Lubilo R, Sitai N, Daka D, Kalaluka N, Booker F et Franks P (2019). 'Governance Assessment for Protected Areas and Conserved Areas (GAPA) '. Case study report. International Institute for Environment and Development. https://www.iied.org/assessing-governanceprotected-conserved-areas-gapa

Mascia, M.B. et Pailler, S. (2011). 'Protected area downgrading, downsizing, and degazettement (PADDD) and its conservation implications'. Conservation Letters 4(1): 9-20. https://doi.org/10.1111/j.1755-263X.2010.00147.x

Mascia, M.B., Pailler, S., Krithivasan, R., Roshchanka, V., Burns, D., Mlotha, M.J., Murray, D.R., Peng, N. (2014). 'Protected area downgrading, downsizing, and degazettement (PADDD) in Africa, Asia, and Latin America and the Caribbean, 1900-2010'. Biological Conservation 169: 355-361. https://doi.org/10.1016/j.biocon.2013.11.021 
Mayaux, P., Pekel, J.-F., Desclée, B., Donnay, F., Lupi, A., Achard, F., Clerici, M., Bodart, C., Brink, A., Nasi, R. et Belward, A. (2013). 'State and evolution of the African rainforests between 1990 and 2010'. Philosophical Transactions of the Royal Society B: Biological Sciences 368: 20120300. https://doi.org/10.1098/rstb.2012.0300

McDermott, M., Mahanty, S. et Schreckenberg, K. (2013). 'Examining equity: A multidimensional framework for assessing equity in payments for ecosystem services'. Environmental Science and Policy 33: 416-427. https://doi.org/10.1016/j.envsci.2012.10.006

McNeely, J.A. et Miller, K. (1984). 'The role of protected areas in sustaining society'. Dans: National Parks, Conservation and Development. The role of protected areas in sustaining society. Proceedings of the World Congress on National Parks, Bali, Indonesia, 11-22 October 1982. Washington, DC, États-Unis: Smithsonian Institute Press. https://portals.iucn.org/library/node/5846

Metzger, M.J., Bunce, R.G.H., Jongman, R.H.G., Sayre, R., Trabucco, A. et Zomer, R. (2013). 'A high-resolution bioclimate map of the world: a unifying framework for global biodiversity research and monitoring'. Global Ecology and Biogeography 22: 630-638. https://doi. org/10.1111/geb.12022

Millennium Ecosystem Assessment (MEA) (2005). Ecosystems and Human Well-Being: Synthesis. Washington, DC, États-Unis: Island Press. https://www.millenniumassessment.org/documents/document.356.aspx.pdf

Mpingo Conservation and Development Initiative (MCDI) (2019). 'Group Certificate Members'. Mpingo Conservation and Development Initiative [site web] http://www.mpingoconservation.org/what-we-do/forest-certification/certificate-members/?L=378

Namibian Association of CBNRM Support Organisations (NACSO) (s.d.). 'Regional Communal Conservancies'. NACSO [site web]. http:// www.nacso.org.na/conservancies. Consulté le: 9/9/2019.

National Institute of Statistics of Rwanda (2017). Statistical year book 2017. Kigali, Rwanda. https://www.statistics.gov.rw/file/6157/ download?token=UErS25hP

Nations Unies (ONU) (2016). Rapport de la Rapporteuse spéciale sur les droits des peuples autochtones : Conservation et droits des peuples autochtones. United Nations General Assembly, Seventy-first Session, A/71/229. New York: Organisation des Nations Unies. https://www.un.org/en/ga/search/view_doc.asp?symbol=A/71/229\&Lang=F

Nolte, C., Leverington, F., Kettner, A., Marr, M., Nielsen, G., Bomhard, B., Stolton, S., Stoll-Kleemann, S. et Hockings, M. (2010). Protected area management effectiveness assessments in Europe: A review of applications, methods and results. BfN- Scripten No. 271a. Vilm, Allemagne: BfN. https://www.bfn.de/fileadmin/BfN/service/Dokumente/skripten/Skript_271a.pdf

O’Connell, M.J., Nasirwa, O., Carter, M., Farmer, K.H., Appleton, M., Arinaitwe, J., Bhanderi, P., Chimwaza, G., Copsey, J., Dodoo, J. et al. (2019). 'Capacity building for conservation: problems and potential solutions for sub-Saharan Africa'. Oryx 53(2): 273-283. https:// doi.org/10.1017/S0030605317000291

Oldekop, J.A., Holmes, G., Harris, W.E. et Evans, K.L. (2015). 'A global assessment of the social and conservation outcomes of protected areas'. Conservation Biology 30(1): 133-141. https://doi.org/10.1111/cobi.12568

OI Pejeta Conservancy (s.d.). Ol Pejeta Conservancy [site web]. https://www.olpejetaconservancy.org/about-us/our-story/. Consulté le 5 janvier 2020.

Olson, D.M., Dinerstein, E., Wikramanayake, E.D., Burgess, N.D., Powell, G.V.N., Underwood, E.C., D’amico, J.A., Itoua, I. Strand, H.E., Morrison, J.C. et al. (2001). 'Terrestrial ecoregions of the world: A new map of life on earth: A new global map of terrestrial ecoregions provides an innovative tool for conserving biodiversity'. BioScience 51(11): 933-938. https://doi.org/10.1641/00063568(2001)051[0933:TEOTWA]2.0.CO;2

Organe subsidiaire chargé de fournir des avis scientifiques, techniques et technologiques (SBSTTA) (2010). Examen approfondi de la mise en oeuvre du programme de travail sur les aires protégées. No UNEP/CBD/SBSTTA/14/5. Nairobi: Convention sur la diversité biologique. https://www.cbd.int/doc/meetings/sbstta/sbstta-14/official/sbstta-14-05-fr.pdf (français) et https://www.cbd.int/kb/record/ meetingDocument/67344?RecordType=meetingDocument (pour des liens vers des formats Word et d'autres langues)

Orgnanisation des Nations Unies pour l'éducation, la science et la culture (UNESCO) (1971). Convention relative aux zones humides d'importance inter nationale particulièrement comme habitats de la sauvagine. Paris. https://treaties.un.org/doc/Publication/UNTS/ Volume\%20996/volume-996-I-14583-French.pdf

(1972). Convention pour la protection du patrimoine mondial, culturel et naturel. Adoptée par la Conférence générale à sa dixseptième session, 16 novembre 1972. Paris: UNESCO. https://whc.unesco.org/archive/convention-fr.pdf

(s.d.a). 'Réserves de biosphère'. UNESCO [site web] https://fr.unesco.org/biosphere/wnbr

(s.d.b). 'Liste du patrimoine mondial'. UNESCO World Heritage Centre [site web]. https://whc.unesco.org/fr/list/

Organisation for Economic Cooperation and Development (OECD) (2019). Biodiversity: Finance and the economic and business case for action, report prepared for the G7 environment ministers' meeting. https://www.oecd.org/env/resources/biodiversity/biodiversityfinance-and-the-economic-and-business-case-for-action.htm (liens vers le rapport, le résumé et les annexes, et version française)

Osipova, E. et al. (2018). Horizon du patrimoine mondial de l'UICN 2 : Une évaluation globale de la conservation des sites du patrimoine mondial naturel. Gland, Suisse: UICN. https://doi.org/10.2305/IUCN.CH.2017.17.fr 
Packer, C., Loveridge, A., Canney, S., Caro, T., Garnett, S.T., Pfeifer, M., Zander, K.K., Swanson, A., MacNulty, D., Balme, G. et al. (2013). 'Conserving large carnivores: dollars and fence'. Ecology Letters 16(5): 635-641. https://doi.org/10.1111/ele.12091

Parker, C., Cranford, M., Oakes, N. et Leggett, M. (eds.) (2012). The little biodiversity finance book: A guide to proactive investment in natural capital - 3rd ed. Oxford: Global Canopy Programme. https://www.globalcanopy.org/sites/default/files/documents/resources/ LittleBiodiversityFinanceBook_3rd\%20edition.pdf

Parmesan, C. et Yohe, G. (2003). 'A globally coherent footprint of climate change impacts across natural systems'. Nature 421: 37-42. https://doi.org/10.1038/nature01286

Qin, S., Golden Kroner, R.E., Cook, C., Tesfaw, A.T., Braybrook, R., Rodriguez, C.M., Poelking, C., Mascia, M.B. (2019). 'Protected area downgrading, downsizing, and degazettement as a threat to iconic protected areas'. Conservation Biology 33(6): 1275-285. https://doi. org/10.1111/cobi.13365

Ramsar Convention on Wetlands (s.d.). 'Sites \& Countries'. Ramsar [site web]. https://www.ramsar.org/sites-countries/the-ramsar-sites Consulté le 12 september 2019. https://www.ramsar.org/sites-countries

Republic of Angola (2014). 5th National Report on Biodiversity in Angola 2007-2012. Luanda, Angola. https://www.cbd.int/doc/world/ao/ ao-nr-05-en.pdf (en anglais); https://www.cbd.int/doc/world/ao/ao-nr-05-fr.pdf (en français);

Republic of Botswana (2015). Fifth National Report to the Convention of Biological Diversity 2015. Gabarone, Botswana: Department of Environmental Affairs. https://www.cbd.int/doc/world/bw/bw-nr-05-en.pdf

(2016). National Biodiversity Strategy and Action Plan. Gaborone, Botswana: Department of Environmental Affairs. https://www. cbd.int/doc/world/bw/bw-nbsap-v3-en.pdf

(2019). The Sixth National Report for the Convention of Biological Diversity. https://chm.cbd.int/pdf/documents/ nationalReport6/246394/1 (pdf) ou https://chm.cbd.int/database/record?documentID=246394 (en ligne)

République de Djibouti (2014). 5ème Rapport Convention sur la Diversité Biologique. National Report on Biodiversity No. 5. Ministère de l'Habitat, de l'Urbanisme et de l'Environnement. https://www.cbd.int/doc/world/dj/dj-nr-05-fr.pdf

(2017). Stratégie et Programme d'Action Nationaux pour la Biodiversite. (National Biodiversity Strategy and Action Plan). Ministère de l'Habitat, Urbanisme et l'Environnement, Direction de l'Aménagement du territoire et de l'environnement. https://www.cbd.int/doc/ world/dj/dj-nbsap-v2-fr.pdf

(2019). 6ème Rapport. Convention sur la Diversité Biologique 2011-2020. National Report on Biodiversity No. 6. Ministère de I'Urbanisme, de l'Environnement et du Tourisme (MUET), Direction de l'Environnement et du Développement Durable. https://www.cbd. int/doc/nr/nr-06/dj-nr-06-fr.pdf

Republic of Ethiopia and Ethiopian Biodiversity Institute (2014). Ethiopia's Fifth National Report to the Convention on Biological Diversity. Addis-Abeba. https://www.cbd.int/doc/world/et/et-nr-05-en.pdf

(2015). Ethiopia's National Biodiversity Strategy and Action Plan 2015-2020. Addis-Abeba. https://www.cbd.int/doc/world/et/ et-nbsap-v2-en.pdf

(2019). Sixth National Report (2014-2018) to the Convention on Biological Diversity. https://chm.cbd.int/pdf/documents/ nationalReport6/245702/3 (PDF) ou https://chm.cbd.int/database/record?documentID=245702 (en ligne)

Republic of Kenya (2015). Fifth National Report to the Conference of Parties to the Convention on Biological Diversity 2015. Nairobi, Kenya: Ministry of Environment, Natural Resources and Regional Development Authorities. https://www.cbd.int/doc/world/ke/ke-nr-05en.pdf

Republic of Madagascar (2014). Cinquième rapport national de la Convention sur la Diversité Biologique de Madagascar Antananarivo, Madagascar: Ministère de l'Environnement et des Forêts. https://www.cbd.int/doc/world/mg/mg-nr-05-fr.pdf

(2016). National Biodiversity and Action Plan 2015-2025. National Biodiversity Strategy and Action Plan. Antananarivo,

Madagascar: Ministère de l'environnement, de l'écologie, de la mer et des forêts. https://www.cbd.int/doc/world/mg/mg-nbsap-v2-en. pdf (anglais) and https://www.cbd.int/doc/world/mg/mg-nbsap-v2-fr.pdf (français)

(2019). Gème Rapport national sur la diversité biologique de Madagascar. Ministère de l'Environnement et du Développement Durable. https://www.cbd.int/doc/nr/nr-06/mg-nr-06-fr.pdf

Republic of Mauritius (2015). Fifth National Report on the Convention on Biological Diversity. Ministry of Agro-Industry and Food Security. https://www.cbd.int/doc/world/mu/mu-nr-05-en.pdf

(2017). National Biodiversity Strategy and Action Plan 2017 - 2025. Ministry of Agro-Industry and Food Security. https://www.cbd. int/doc/world/mu/mu-nbsap-v2-en.pdf

Republic of Mozambique (2014). Fifth National report on the implementation of Convention on Biological Diversity in Mozambique. Maputo: Ministry for the Coordination of Environmental Affairs. https://www.cbd.int/doc/world/mz/mz-nr-05-en.pdf 
(2015). National Strategy and Action Plan of Biological Diversity of Mozambique (2015-2035). Maputo: Ministério da Terra, Ambiente e Desenvolvimento Rural. https://www.cbd.int/doc/world/mz/mz-nbsap-v3-en.pdf

Republic of Namibia (2014). Fifth National report to the Convention on Biological Diversity (2010-2014). National Report on Biodiversity No. 5. Windhoek, Namibie: Ministry of Environment and Tourism. https://www.cbd.int/doc/world/na/na-nr-05-en.pdf

(2018). Sixth National Report to the Convention on Biological Diversity (2014-2018). Ministry of Environment and Tourism. https:// www.cbd.int/doc/nr/nr-06/na-nr-06-en.pdf

Republic of Rwanda (2009). Fourth national report to the Convention on Biological Diversity. National Report on Biodiversity No. 4. Kigali: Rwanda Environment Management Authority, Ministry of Natural Resources. https://www.cbd.int/doc/world/rw/rw-nr-04-en.pdf

(2014). Fifth National Report to the Convention on Biological Diversity. https://www.cbd.int/doc/world/rw/rw-nr-05-en.pdf

Republic of South Africa (2014). South Africa's Fifth National Report to the Convention on Biological Diversity. Pretoria: Department of Environmental Affairs. https://www.cbd.int/doc/world/za/za-nr-05-en.pdf

(2019). The Sixth National Report for the Convention of Biological Diversity. National Report on Biodiversity No. 6. https://chm.cbd. int/pdf/documents/nationalReport6/241240/2 (PDF) ou https://chm.cbd.int/database/record?documentID=241240 (en ligne)

Republic of South Sudan (2015). Fifth national report to the Convention of Biological Diversity. Ministry of Environment. https://www.cbd. int/doc/world/ss/ss-nr-05-en.pdf

(2019). National Biodiversity Strategy and Action Plan (2018-2027). Ministry of Environment and Forestry. https://www.cbd.int/doc/ world/ug/ug-nr-05-en.pdf

(2019). Sixth National Report to the Convention on Biological Diversity (6th NR) (Draft). Ministry of Environment and Forestry. https://www.cbd.int/doc/nr/nr-06/ss-nr-06-en.pdf

Republic of Sudan (2014). Sudan Fifth National Report to the Convention on Biological Diversity (CBD). Khartoum, Soudan: Ministry of Environment, Forestry and Physical Development, Higher Council for Environment and Natural Resources. https://www.cbd.int/doc/ world/sd/sd-nr-05-en.pdf

(2019). Sixth National Report for the Convention of Biological Diversity. https://chm.cbd.int/pdf/documents/ nationalReport6/241358/2 (PDF) et https://chm.cbd.int/database/record?documentID=241358 (en ligne)

Republic of Uganda (2016). National Biodiversity Strategy and Action Plan II (2015-2025). Theme: Supporting Transition to a Middle Income Status and Delivery of Sustainable Development Goals. Kampala, Ouganda: National Environment Management Authority (NEMA). https://chm.cbd.int/api/v2013/documents/13784B07-8850-A5BE-8960-90D65EAC1211/attachments/Uganda\%20-NBSAPResigned.pdf

Republic of Zambia (2015). Fifth National Report on Biodiversity. Lusaka: Ministry of Lands Natural Resources and Environmental Protection. https://www.cbd.int/doc/world/zm/zm-nr-05-en.pdf

(2019). Sixth National Report for the Convention of Biological Diversity. https://chm.cbd.int/pdf/documents/ nationalReport6/241363/3 (PDF) ou https://chm.cbd.int/database/record?documentID=241363 (en ligne)

Republic of Zimbabwe (2014). National Biodiversity Strategy and Action Plan 2014. National Biodiversity Strategy and Action Plan No. 2. Harare: Ministry of Environment, Water and Climate. https://www.cbd.int/doc/world/zw/zw-nbsap-v2-en.pdf

(2015). Fifth National Report to the Convention on Biological Diversity. Harare: Ministry of Environment, Water and Climate. https:// www.cbd.int/doc/world/zw/zw-nr-05-en.pdf

(2019). Zimbabwe's Sixth National Report to the Convention on Biodiversity. Ministry of Environment, Tourism and Hospitality Industry. https://www.cbd.int/doc/nr/nr-06/zw-nr-06-en.pdf

Ripple, W.J., Chapron, G., López-Bao, J.V., Durant, S.M., Macdonald, D.W., Lindsey, P.A., Bennett, E.L., Beschta, R.L., Bruskotter, J.T., Campos-Arceiz, A. et al. (2016). 'Saving the World's Terrestrial Megafauna'. BioScience 66(10): 807-812. https://doi.org/10.1093/biosci/ biw092

Rwanda Development Board (RDB) (2017). 2017Annual Report. Kigali, Rwanda: Rwanda Development Board. https://rdb.rw/wpcontent/uploads/2018/08/RDB-Annual-Report-2017-Final.pdf

Saura, S., Bastin, L., Battistella, L., Mandrici, A. et Dubois, G. (2017). 'Protected areas in the world's ecoregions: How well connected are they'? Ecological Indicators 76: 144-158. https://doi.org/10.1016/j.ecolind.2016.12.047

Saura, S., Bertzky, B., Bastin, L., Battistella, L., Mandrici, A. et Dubois, G. (2018). 'Protected area connectivity: Shortfalls in global targets and country-level priorities'. Biological Conservation 219: 53-67. https://doi.org/10.1016/j.biocon.2017.12.020

(2019). 'Global trends in protected area connectivity from 2010 to 2018'. Biological Conservation 238(108183). https://doi.

org/10.1016/j.biocon.2019.07.028 
Scheffers, B.R., De Meester, L., Bridge, T.C.L., Hoffmann, A.A., Pandolfi, J.M., Corlett, R.T., Butchart, S.H.M., Pearce-Kelly, P., Kovacs, K.M., Dudgeon, D., et al. (2016). 'The broad footprint of climate change from genes to biomes to people'. Science 354: 6313 . https://doi. org/10.1126/science.aaf7671

South African National Parks (SANParks) (2017). South African National Parks Annual Performance Plan Financial Year 2018/19. Pretoria, Afrique du Sud: SANParks. https://www.sanparks.org/assets/docs/about/annual_performance_plan_2018-2019.pdf

(2018). Annual Report 2017/2018. Pretoria, Afrique Du Sud. https://www.sanparks.org/assets/docs/general/annual-report-2018. pdf

Southern African Development Community (SADC) Secretariat (2013). SADC Programme for Transfrontier Conservation Areas. Gaborone, Botswana: SADC. https://www.sadc.int/files/4614/2122/3338/SADC_TFCA_Programme_FINAL_doc_Oct_2013.pdf

(2018). Guidelines for Community Engagement in Southern African Development Community Transfrontier Conservation Areas - Final Draft. Gaborone, Botswana: SADC. https://tfcaportal.org/sites/default/files/public-docs/SADC\%20TFCA\%20Guideline\%20for\%20 Community\%20Engagement\%20\%20in\%20TFCAs\%20-\%20\%20Nov\%202018-\%20English\%20-\%20not\%20yet\%20endorsed.pdf

SADC Transfrontier Conservation Areas (TFCA) (2019). SADC TFCA Portal [site web] https://tfcaportal.org/sadc-tfcas. Consulté le 13 août 2019.

Schreckenberg, K., Camargo, I., Withnall, K., Corrigan, C., Franks, P., Roe, D., Scherl, L. M. et Richardson, V. (2010). Social assessment of conservation initiatives: A review of rapid methodologies. Natural Resources Issues No. 22. Londres: IIED. https://pubs.iied.org/ pdfs/14589IIED.pdf?

Schreckenberg, K., Franks, P., Martin, A. et Lang, B. (2016). 'Unpacking equity for protected area conservation'. Parks 22(2): 11-26. https://doi.org/10.2305/IUCN.CH.2016.PARKS-22-2KS.en

Schultz, L., Folke, C., Österblom, H. et Olsson, P. (2015). 'Adaptive governance, ecosystem management, and natural capital'. Proceedings of the National Academy of Sciences 112(24): 7369-7374. https://doi.org/10.1073/pnas.1406493112

Schulze, K., Knights, K., Coad, L., Geldmann, J., Leverington, F., Eassom, A., Marr, M., Butchart, S.H.M., Hockings, M., Burgess, N.D. (2018). 'An assessment of threats to terrestrial protected areas'. Conservation Letters 11(3): e12435. https://doi.org/10.1111/conl.12435

Secrétariat de la Convention sur la diversité biologique (2014). Perspectives mondiales de la diversité biologique 4 - Résumé et conclusions. Montréal, Canada: Secrétariat de la CDB. https://www.cbd.int/gbo/gbo4/publication/gbo4-fr-Ir.pdf

Seol, M. (2016). 'New finance model brings extraordinary conservation measures to life'. Harvard Government Innovators Network [article de blog], 13 septembre 2016. https://www.innovations.harvard.edu/blog/new-finance-model-brings-extraordinary-conservationmeasures-life

Snyman, S. (2012). 'Ecotourism joint ventures between the private sector and communities: An updated analysis of the Torra Conservancy and Damaraland Camp partnership, Namibia'. Tourism Management Perspectives 4: 127-135. https://doi.org/10.1016/j. tmp.2012.07.004

South African National Lotteries Commission (NLCSA) (2019). National Lotteries Commission [site web]. http://www.nlcsa.org.za/ wp-content/uploads/2019/02/National-Lotteries-Commision-54X10-Light-Blue-Final.pdf

Space For Giants, UN Environment and Conservation Capital (2019). Building a wildlife economy. Working Paper 1: Developing NatureBased Tourism in African State Protected Areas.https://spaceforgiants.org/wp-content/uploads/2019/06/Building-Africas-WildlifeEconomy-Space-for-Giants-Working-Paper-1.pdf

Spalding, M.D., Agostini, V.N., Rice, J. et Grant, S.M. (2012). 'Pelagic provinces of the world: A biogeographic classification of the world's surface pelagic waters'. Ocean and Coastal Management 60: 19-30. https://doi.org/10.1016/j.ocecoaman.2011.12.016

Spalding, M.D. et al. (2007). 'Marine Ecoregions of the World: A Bioregionalization of Coastal and Shelf Areas'. BioScience 57(7): 573-583. https://doi.org/10.1641/B570707

Spenceley, A. (2018). Development of a SADC Guideline on cross border tourism products in TFCAs. SADC Guideline for cross-border tourism products. https://www.tfcaportal.org/sites/default/files/public-docs/SADC\%20Guideline\%20on\%20Cross-border\%20 tourism\%20products\%20in\%20TFCAs_2\%20August\%202018\%20Final\%20Draft_\%20not\%20yet\%20endorsed.pdf

Spenceley, A., Rylance, A. et Laiser, S.L. (2017). 'Protected area entrance fees in Tanzania: The search for competitiveness and value for money'. Koedoe - African Protected Area Conservation and Science 59(1): a1442. https://doi.org/10.4102/koedoe.v59i1.1442

State of Eritrea (2014). The 5th National Report on the Implementation of the UNCBD. Asmara, Érythrée. https://www.cbd.int/doc/world/ er/er-nr-05-en.pdf

(2015). Revised National Biodiversity Strategy and Action Plan for Eritrea (2014-2020). National Biodiversity Strategy and Action Plan (NBSAP) No. 2. Asmara, Érythrée: Ministry of Land, Water and Environment, Department of Environment. https://www.cbd.int/doc/ world/er/er-nbsap-v2-en.pdf

Stattersfield, A.J., Crosby, M.J., Long, A.J. et Wege, D.C. (1998). Endemic Bird Areas of the World. Priorities for biodiversity conservation. BirdLife Conservation Series No. 7. Cambridge: BirdLife International. http://datazone.birdlife.org/info/pubEBAs 
Stoll-Kleeman, S., Bender, S., Berghöfer, A., Bertzky, M., Fritz-Vietta, N., Schliep, R. et Thierfelder, B. (2006). Linking governance and management perspectives with conservation success in protected areas and Biosphere Reserves. Perspectives on Biodiversity Governance and Management No. Discussion Paper 01. Berlin: GoBi Research Group. https://citeseerx.ist.psu.edu/viewdoc/ download?doi=10.1.1.474.1324\&rep=rep1\&type=pdf

Stolton, S. et Dudley, N. (2016). METT Handbook: A guide to using the Management Effectiveness Tracking Tool (METT). WWF-UK, Woking. https://www.protectedplanet.net/system/comfy/cms/files/files/000/000/208/original/WWF_METT_Handbook_2016_FINAL_0. pdf

Swart, I. (2019). 'Carbon tax effective from 1 June 2019 following Presidential assent'. Deloitte South Africa [article en ligne].https:// www2.deloitte.com/za/en/pages/tax/articles/carbon_tax_2019.html. Consulté le 21 janvier 2020.

Symes, W.S., Rao, M., Mascia, M.B. et Carrasco, L.R. (2016). 'Why do we lose protected areas? Factors influencing protected area downgrading, downsizing and degazettement in the tropics and subtropics'. Global Change Biology 22(2): 656-665. https://doi. org/10.1111/gcb.13089

Tanzania National Parks (non publié). Annual report 2013.

Tessema, Y. (non publié). A review of policy and legislation related to protected area management, governance and equity in the Eastern and Southern Africa region. A report prepared for BIOPAMA Eastern and Southern Africa. BIOPAMA, UICN ESARO.

The Lion's Share (2020). The Lion's Share [site web]. https://thelionssharefund.com/

The Nature Conservancy (s.d.). 'IUCN-CMP Unified Classifications of Direct Threats and Conservation Actions'. Conservation Gateway [site web].https://www.conservationgateway.org/ExternalLinks/Pages/iucn-cmp-unified-classifi.aspx (Consulté le 20 novembre 2019).

The Northern Rangelands Trust (2018). State of Conservancies Report 2018. Kenya: The Northern Rangelands Trust. https://static1. squarespace.com/static/5af1629f12b13f5ce97ca0b5/t/5c9df55b71c10b45cbb2c862/1553856154045/SOCR2018

The World Bank Group (2018). 'Sovereign blue bond issuance: Frequently Asked Questions'. Banque mondiale [reportage en ligne], 29 octobre 2018.https://www.worldbank.org/en/news/feature/2018/10/29/sovereign-blue-bond-issuance-frequently-asked-questions.

Thomas, C.D. et Gillingham, P.K. (2015). 'The performance of protected areas for biodiversity under climate change'. Biological Journal of the Linnean Society 115(3): 718-730. https://doi.org/10.1111/bij.12510

Uganda Biodiversity Fund (s.d.). Uganda Biodiversity Fund. https://ugandabiodiversityfund.org/. Consulté le 21 janvier 2020.

Uganda National Environment Management Agency (2014). Fifth National Report to the Convention on Biological Diversity. Kampala, Ouganda: National Environment Management Authority, Ministry of Water and Development. https://www.cbd.int/doc/world/ug/ ug-nr-05-en.pdf

Uganda Wildlife Authority (UWA) (non publié). Annual Report 2015.

(2018). Uganda Wildlife Authority Corporate Report 2018. https://www.ugandawildlife.org/download/category/12-annualreports?download=39:corporate-annual-report-2018

Union internationale pour la conservation de la nature (UICN) (2005a). 'Gouvernance : de nouveaux moyens de travailler ensemble'. Dans: Bénéfices par delà les frontières : procès-verbaux du Ve Congrès mondial sur les parcs de l'UICN, pp. 67-79. Gland, Suisse et Cambridge, Royaume-Uni: UICN. https://portals.iucn.org/library/node/8755. Également disponible en anglais: https://portals.iucn.org/library/node/8662 et en espagnol: https://portails.l'uicn.org/library/node/8756

(2005b). 'L'Accord de Durban'. Dans: Bénéfices par delà les frontières : procès-verbaux du Ve Congrès mondial sur les parcs de I'UICN, pp. 233-238. UICN, Gland, Suisse et Cambridge, Royaume-Uni. https://portals.iucn.org/library/node/8662. Également disponible en anglais: https://portals.iucn.org/library/node/8662 et en espagnol: https://portails.l'uicn.org/library/node/8756

(2012). Accélérer le rythme de création d'aires marines protégées à l'échelle mondiale et la certification de l'efficacité de leur gestion. WCC-2012-Res-076-FR. UICN. https://portals.iucn.org/library/node/44043 (liens vers les versions anglaise, française et espagnole)

(2016a). Standard mondial pour l'identification des Zones Clés pour la Biodiversité, Version 1.0. Gland, Suisse: UICN. https://portals.iucn.org/library/node/46320

(2016b). Appuyer les aires protégées à gouvernance privée. WCC-2016-Res-036-FR. UICN. https://portals.iucn.org/library/ node/46453 (liens vers les versions anglaise, française et espagnole)

UNDP Ecosystems and Biodiversity (2018). 'Results for rhinos. Using innovative financing to achieve conservation outcomes'. Exposure [article en ligne], 2 mars 2018. https://undp-biodiversity.exposure.co/results-for-rhinos

United Nations Environment Programme Wildlife Conservation Management Centre (UNEP-WCMC) et IUCN (2016). Protected Planet Report 2016: How protected areas contribute to achieving global targets for biodiversity. Cambridge, Royaume-Uni et Gland, Suisse: PNUE-WCMC et UICN. https://www.iucn.org/theme/protected-areas/publications/protected-planet-report 
UNEP-WCMC et UICN. https://www.protectedplanet.net/

(2019b). Protected Planet: User Manual for the World Database on Protected Areas and world database on other effective areabased conservation measures: 1.6. Cambridge, Royaume-Uni: UNEP-WCMC. https://www.protectedplanet.net/c/BDMAP-manual/ BDMAP-manual-v16.

(2019c). 'Protected Planet: Protected area dataset for Angola'; The World Database on Protected Areas (WDPA)/The Global Database on Protected Areas Management Effectiveness (GD-PAME)] [En ligne], Septembre 2019. Cambridge, Royaume-Uni: UNEPWCMC et UICN. https://www.protectedplanet.net/country/AO.

(2019d). 'Protected Planet: Protected area dataset for Botswana'; The World Database on Protected Areas (WDPA)/The Global Database on Protected Areas Management Effectiveness (GD-PAME)] [En ligne], Septembre 2019. https://www.protectedplanet.net/ country/BW

(2019e). 'Protected Planet: Protected area dataset for Comoros'; The World Database on Protected Areas (WDPA)/The Global Database on Protected Areas Management Effectiveness (GD-PAME)] [En ligne], Septembre 2019. https://www.protectedplanet.net/ country/KM.

(2019f). 'Protected Planet: Protected area dataset for Djibouti'; The World Database on Protected Areas (WDPA)/The Global Database on Protected Areas Management Effectiveness (GD-PAME)] [En ligne], Septembre 2019. https://www.protectedplanet.net/ country/DJ.

(2019g). 'Protected Planet: Protected area dataset for Eritrea'; The World Database on Protected Areas (WDPA)/The Global Database on Protected Areas Management Effectiveness (GD-PAME)] [En ligne], Septembre 2019. https://www.protectedplanet.net/ country/ER

(2019h). 'Protected Planet: Protected area dataset for eSwatini'; The World Database on Protected Areas (WDPA)/The Global Database on Protected Areas Management Effectiveness (GD-PAME)] [En ligne], Septembre 2019. https://www.protectedplanet.net/ country/SZ

(2019i). 'Protected Planet: Protected area dataset for Ethiopia'; The World Database on Protected Areas (WDPA)/The Global Database on Protected Areas Management Effectiveness (GD-PAME)][En ligne], Septembre 2019. https://www.protectedplanet.net/ country/ET.

(2019j). 'Protected Planet: Protected area dataset for Kenya'; The World Database on Protected Areas (WDPA)/The Global Database on Protected Areas Management Effectiveness (GD-PAME)] [En ligne], Septembre 2019. https://www.protectedplanet.net/country/KE.

(2019k). 'Protected Planet: Protected area dataset for Lesotho'; The World Database on Protected Areas (WDPA)/The Global Database on Protected Areas Management Effectiveness (GD-PAME)] [En ligne], Septembre 2019. https://www.protectedplanet.net/ country/LS.

(2019l). 'Protected Planet: Protected area dataset for Madagascar'; The World Database on Protected Areas (WDPA)/The Global Database on Protected Areas Management Effectiveness (GD-PAME)] [En ligne], Septembre 2019. https://www.protectedplanet.net/ country/MG

(2019m). 'Protected Planet: Protected area dataset for Malawi'; The World Database on Protected Areas (WDPA)/The Global Database on Protected Areas Management Effectiveness (GD-PAME)] [En ligne], Septembre 2019. https://www.protectedplanet.net/ country/MW

(2019n). 'Protected Planet: Protected area dataset for Mauritius'; The World Database on Protected Areas (WDPA)/The Global Database on Protected Areas Management Effectiveness (GD-PAME)] [En ligne], Septembre 2019. https://www.protectedplanet.net/ country/MU.

(2019o). 'Protected Planet: Protected area dataset for Mozambique; The World Database on Protected Areas (WDPA)/The Global Database on Protected Areas Management Effectiveness (GD-PAME)] [En ligne], Septembre 2019. https://www.protectedplanet.net/ country/MZ.

(2019p). 'Protected Planet: Protected area dataset for Namibia'; The World Database on Protected Areas (WDPA)/The Global Database on Protected Areas Management Effectiveness (GD-PAME)] [En ligne], Septembre 2019. https://www.protectedplanet.net/ country/NA.

(2019q). 'Protected Planet: Protected area dataset for Rwanda'; The World Database on Protected Areas (WDPA)/The Global Database on Protected Areas Management Effectiveness (GD-PAME)] [En ligne], Septembre 2019. https://www.protectedplanet.net/ country/RW.

(2019r). 'Protected Planet: Protected area dataset for Seychelles'; The World Database on Protected Areas (WDPA)/The Global Database on Protected Areas Management Effectiveness (GD-PAME)] [En ligne], Septembre 2019. https://www.protectedplanet.net/ country/SC.

(2019s). 'Protected Planet: Protected area dataset for Somalia'; The World Database on Protected Areas (WDPA)/The Global 
Database on Protected Areas Management Effectiveness (GD-PAME)][En ligne], Septembre 2019. https://www.protectedplanet.net/ country/SO.

(2019t). 'Protected Planet: Protected area dataset for South Africa'; The World Database on Protected Areas (WDPA)/The Global Database on Protected Areas Management Effectiveness (GD-PAME)] [En ligne], Septembre 2019. https://www.protectedplanet.net/ country/ZA.

(2019u). 'Protected Planet: Protected area dataset for South Sudan'; The World Database on Protected Areas (WDPA)/The Global Database on Protected Areas Management Effectiveness (GD-PAME)] [En ligne], Septembre 2019. https://www.protectedplanet.net/ country/SS.

(2019v). 'Protected Planet: Protected area dataset for Sudan'; The World Database on Protected Areas (WDPA)/The Global Database on Protected Areas Management Effectiveness (GD-PAME)] [En ligne], Septembre 2019. https://www.protectedplanet.net/ country/SD.

(2019w). 'Protected Planet: Protected area dataset for Tanzania'; The World Database on Protected Areas (WDPA)/The Global Database on Protected Areas Management Effectiveness (GD-PAME)] [En ligne], Septembre 2019. https://www.protectedplanet.net/ country/TZ.

(2019x).'Protected Planet: Protected area dataset for Uganda'; The World Database on Protected Areas (WDPA)/The Global Database on Protected Areas Management Effectiveness (GD-PAME)] [En ligne], Septembre 2019. https://www.protectedplanet.net/ country/UG.

(2019y). 'Protected Planet: Protected area dataset for Zambia'; The World Database on Protected Areas (WDPA)/The Global Database on Protected Areas Management Effectiveness (GD-PAME)] [En ligne], Septembre 2019. https://www.protectedplanet.net/ country/ZM.

(2019z). 'Protected Planet: Protected area dataset for Zimbabwe'; The World Database on Protected Areas (WDPA)/The Global Database on Protected Areas Management Effectiveness (GD-PAME)] [En ligne], Septembre 2019. https://www.protectedplanet.net/ search?q=zimbabwe.

(2019aa). 'Protected Planet: Protected Area Management Effectiveness (PAME)'. The World Database on Protected Areas (WDPA)/ The Global Database on Protected Areas Management Effectiveness (GD-PAME)] [En ligne], 10 août 2019. Cambridge, Royaume-Uni: UNEP-WCMC et UICN. https://www.protectedplanet.net/c/protected-areas-management-effectiveness-pame. Consulté le 10 août 2019.

UNEP-WCMC, IUCN and National Geographic Society (NGS) (2018). Protected Planet Report 2018: Tracking progress towards global targets for protected areas. Cambridge Royaume-Uni; Gland, Suisse; and Washington, DC, États-Unis: UNEP-WCMC, UICN et NGS. https://livereport.protectedplanet.net/pdf/Protected_Planet_Report_2018.pdf

(2019). Protected Planet Live Report 2019. Cambridge Royaume-Uni; Gland, Suisse; et Washington, DC, États-Unis: UNEPWCMC, UICN et NGS. Consulté en septembre 2019.

United Nations Global Compact (UNGC) et IUCN (2012). A framework for corporate action on biodiversity and ecosystem services. https://portals.iucn.org/library/node/10174

Union des Comores (2014). 5ème Rapport national sur la diversité biologique (Fifth National Report on Biodiversity of Comoros). https:// www.cbd.int/doc/world/km/km-nr-05-fr.pdf

(2016). Stratégie nationale et Plan d'Action Actualisés pour la Diversité Biologique V2.2 (Updated National Strategy and Action Plan for Biological Diversity V2.2). https://www.cbd.int/doc/world/km/km-nbsap-v2-fr.pdf

(2017). Stratégie d'expansion du système national des aires protégées aux Comores, 2017-2021 (Strategy to expand the system of national protected areas of Comoros, 2017-2021). Directorate General for Environment and Forestry (DGEF). PNUD/GEF Comores: DGEF, VP-MAPEATU.

(2019). Gème Rapport national sur la biodiversité de l'Union des Comores (Sixth National Report on Biodiversity of Comoros). Ministère de l'Agriculture, de la Pêche et de l'Environnement. https://www.cbd.int/doc/nr/nr-06/km-nr-06-fr.pdf

United Republic of Tanzania (1998). National Forestry Policy. Dar es Salaam, Tanzanie: Ministry of Natural Resources and Tourism. http:// www.fao.org/forestry/15159-06c36bd31a5b3877ae3168cc5bedadd18.pdf

(2014). Fifth National Report on the Implementation of the Convention on Biological Diversity. Dar es Salaam, Tanzanie: Division of Environment, Vice President's Office. http://www.cbd.int/doc/world/tz/tz-nr-05-en.pdf

(2019). The Sixth National Report for the Convention of Biological Diversity. https://chm.cbd.int/pdf/documents/ nationalReport6/245938/1 (PDF) ou https://chm.cbd.int/database/record?documentID=245938 (en ligne)

Visconti, P., Marco, M.D., Álvarez-Romero, J.G., Januchowski-Hartley, S.R., Pressey, R.L., Weeks, R. et Rondinini, C. (2013). 'Effects of Errors and Gaps in Spatial Data Sets on Assessment of Conservation Progress'. Conservation Biology 27(5): 1000-1010. https://doi. org/10.1111/cobi.12095

Watson, J.E.M., Dudley, N., Segan, D.B. et Hockings, M. (2014). 'The performance and potential of protected areas'. Nature 515(7525): 
Wildlife Works (s.d.). Wildlife works. REDD+ conservation programme [site web]. https://www.wildlifeworks.com Consulté le 21 janvier 2020.

World Bank Group (s.d.). 'International tourism, number of arrivals'. World Bank DataBank [site web], https://data.worldbank.org/ indicator/st.int.arvl. Consulté le 15 octobre 2019

Worldometer (s.d.). 'Africa Population'. Worldometer [site web]. https://www.worldometers.info/world-population/africa-population/. Consulté le 17 décembre 2019.

World Tourism Organization (WTO) (2014). Towards measuring the economic value of wildlife watching tourism in Africa. Briefing Paper. Madrid: UNWTO. https://doi.org/10.18111/9789284416752

World Travel and Tourism Council (WTTO) (2019). 'Country reports'. WTTO [site web]. https://www.wttc.org/economic-impact/countryanalysis/country-reports/

Wright, E. (2018). 'Leveraging PPPs in Mozambique to scale conservation and promote economic development'. World Bank [article de blog], 18 juillet 2018. https://blogs.worldbank.org/ppps/leveraging-ppps-mozambique-scale-conservation-and-promote-economicdevelopment. Consulté le 27 mars 2020.

World Wildlife Fund (WWF) (2009). Guide to Conservation Finance: Sustainable Financing for the Planet. Washington DC, États-Unis: Fonds mondial pour la nature (WWF). http://awsassets.panda.org/downloads/wwf_guide_to_conservation_finance.pdf

(2017). 'Southern Africa: Northwestern Madagascar'. The Global Ecoregions [site web]. https://www.worldwildlife.org/ecoregions/ at0202 Zafra-Calvo, N., Pascual, U., Brockington, D., Coolsaet, B., Cortes-Vazquez, J.A., Gross-Camp, N., Palomo, I., Burgess, N.D. (2017). 'Towards an indicator system to assess equitable management in protected areas'. Biological Conservation 211(Part A): $134-141$. https://doi.org/10.1016/j.biocon.2017.05.014

Zunckel, K. (2014). Southern African Development Community Transfrontier Conservation Guidelines: The establishment and development of TFCA initiatives between SADC member states. Gaborone, Botswana: SADC. https://www.academia.edu/12527362/SOUTHERN_

AFRICAN_DEVELOPMENT_COMMUNITY_TRANSFRONTIER_CONSERVATION_GUIDELINES_The_establishment_and_development_ of_TFCA_initiatives_between_SADC_Member_States 



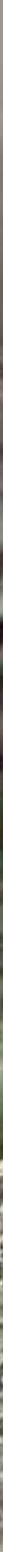




\section{Annexes}




\section{Table des matières}

Annexe 1. Points focaux BIOPAMA.

Annexe 2. Statistiques régionales sur les aires protégées et de conservation en Afrique orientale et australe 220

A2-Tableau 1. État des aires protégées et de conservation d'Afrique orientale et australe...................................................220

A2-Tableau 2. Aires côtières et marines protégées et de conservation d'Afrique orientale et australe ....................................221

A2-Tableau 3. Catégories de gestion de I'UICN des aires protégées et de conservation d'Afrique orientale et australe ............221

A2-Tableau 4. Type de gouvernance de I'UICN des aires protégées et de conservation d'Afrique orientale et australe.............222

Annexe 3. Sites d'importance mondiale en Afrique orientale et australe .....................................................................223

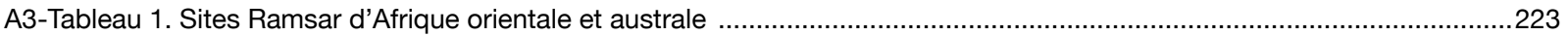

A3-Tableau 2. Réserves de biosphère d'Afrique orientale et australe........................................................................226

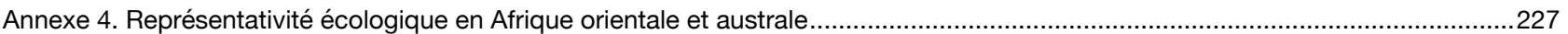

A4-Tableau 1. Représentativité écologique des aires protégées d'Afrique orientale et australe ..........................................227

Annexe 5. Instruments juridiques soutenant l'équité et la gouvernance non-étatique des aires protégées ......................................228

Annexe 6. Aires protégées et de conservation selon les catégories de gestion de l'UICN par pays .............................................230

Annexe 7. Aires protégées et de conservation selon les types de gouvernance de l'UICN par pays .............................................236 


\section{Annexe 1. Points focaux BIOPAMA}

\begin{tabular}{|c|c|c|}
\hline Pays & Nom du point focal & Institution \\
\hline Angola & Marta Zumbo & Ministère de l'Environnement, Responsable des Aires Protégées \\
\hline Botswana & Bakang Mokime & $\begin{array}{l}\text { Département de la faune et des parcs nationaux, ministère de l'Environnement, } \\
\text { de la Faune et du Tourisme }\end{array}$ \\
\hline Comores & Moina Hali & Direction générale de l'environnement et des forêts \\
\hline Djibouti & Mohamed Elmni Obsieh & Ministère de l'Environnement \\
\hline Érythrée & Estefanios Bein & Ministère des Terres, de l'Eau et de l'Environnement \\
\hline Érythrée & Fatsum Hagos & Autorité des forêts et de la faune \\
\hline Eswatini & Thulani Methula & Commission nationale de fiducie d'Eswatini \\
\hline Éthiopie & Gebremeskel Gizaw Kassa & Autorité éthiopienne de conservation de la faune \\
\hline Kenya & Arthur Tuda pour les AMP & Service de la faune du Kenya (KWS, selon ses sigles en anglais) \\
\hline Lesotho & Mamasheane Motabotabo & $\begin{array}{l}\text { Département de l'Environnement, ministère du Tourisme, de l'Environnement et } \\
\text { de la Culture }\end{array}$ \\
\hline Malawi & Davis Kalima & Département des parcs nationaux et de la faune \\
\hline Madagascar & Ramanantsoa Seheno & Ministère de l'Environnement, de l'Écologie et des Forêts \\
\hline Madagascar & Rakotobe Domoina & Société de conservation de la faune \\
\hline Maurice & Kevin Ruhomaun & Service des parcs nationaux et de la conservation \\
\hline Mozambique & Raimundo Vasco Matusse & Administration nationale des aires de conservation \\
\hline Namibie & Shayne Kotting & Ministère de l'Environnement et du Tourisme \\
\hline Rwanda & Eugene Mutangana & Conseil de développement du Rwanda \\
\hline Seychelles & Selby Remy & Autorité des parcs nationaux des Seychelles \\
\hline Somalie & Mohamed Moallim Osman & $\begin{array}{l}\text { Directeur de la sensibilisation à l'environnement, Bureau des affaires } \\
\text { environnementales du Cabinet du Premier ministre }\end{array}$ \\
\hline Afrique du Sud & Karl Naude & Département des affaires environnementales \\
\hline Afrique du Sud & Thivhulawi Nethononda & Département des affaires environnementales \\
\hline Soudan du Sud & Malik Doka Morgan & Ministère de la Conservation de la faune et du Tourisme \\
\hline Soudan du Sud & Lona Nalurit Darius & Ministère de la Conservation de la faune et du Tourisme \\
\hline Soudan & Noureldin Ahmed Abdalla & Conseil supérieur de l'environnement et des ressources naturelles \\
\hline Soudan & Khidir Elsadig Jabir Arin & Administration générale de la conservation de la faune \\
\hline Tanzanie & Paul Banga & Autorité des parcs nationaux de Tanzanie \\
\hline Tanzanie & Dr James Wakibara & Autorité de gestion de la faune de Tanzanie \\
\hline Tanzanie & Asanterabi Lowassa & Institut de recherche sur la faune de Tanzanie \\
\hline Tanzanie & Prof Dos Santos (CEO) & Service des forêts de Tanzanie \\
\hline Ouganda & John Makombo & Autorité ougandaise de la faune \\
\hline Zambie & Chisha Moseni & Département des parcs nationaux et de la faune \\
\hline Zambie & Sydney Tembo & Département des parcs nationaux et de la faune \\
\hline Zimbabwe & Geoffreys Matipano & Autorité de gestion des parcs et de la faune du Zimbabwe \\
\hline
\end{tabular}




\section{Annexe 2. Statistiques régionales sur les aires protégées et de conservation en Afrique orientale et australe}

\section{A2-Tableau 1. État des aires protégées et de conservation d'Afrique orientale et australe}

\begin{tabular}{|c|c|c|c|c|c|}
\hline Pays & $\begin{array}{r}\text { Nombre d'aires } \\
\text { protégées* }\end{array}$ & $\begin{array}{r}\text { Superficie } \\
\text { terrestre couverte } \\
\text { par les aires } \\
\text { protégées }\left(\mathbf{k m}^{2 *}\right)\end{array}$ & $\begin{array}{r}\% \text { de la superficie } \\
\text { terrestre couverte } \\
\text { par les aires } \\
\text { protégées* }\end{array}$ & $\begin{array}{r}\% \text { de la superficie } \\
\text { terrestre couverte } \\
\text { par les aires } \\
\text { protégées et de } \\
\text { conservation }^{\star *}\end{array}$ & $\begin{array}{r}\text { \% de la superficie } \\
\text { terrestre protégée } \\
\text { et connectée }\end{array}$ \\
\hline Angola & 13 & 87507 & $6,97 \%$ & $12,50 \%$ & $2,56 \%$ \\
\hline Botswana & 22 & 169370 & $29,14 \%$ & $29,10 \%$ & $18,37 \%$ \\
\hline Comores & 5 & 173 & $10,15 \%$ & $22,00 \%$ & $10,21 \%$ \\
\hline Djibouti & 3 & 344 & $1,57 \%$ & $1,34 \%$ & $1,34 \%$ \\
\hline Érythrée & 4 & 5936 & $4,87 \%$ & $\begin{array}{r}\text { Aucune } \\
\text { correspondance }\end{array}$ & $3,21 \%$ \\
\hline Eswatini & 14 & 738 & 4,26 & $3,90 \%$ & $2,7 \%$ \\
\hline Éthiopie & 104 & 200074 & $17,62 \%$ & $14,00 \%$ & $8,28 \%$ \\
\hline Kenya & 391 & 72545 & $12,36 \%$ & $8 \%$ & $5,55 \%$ \\
\hline Lesotho & 4 & 80 & $0,26 \%$ & $0,50 \%$ & $0,24 \%$ \\
\hline Madagascar & 109 & 33242 & $5,59 \%$ & $\begin{array}{r}\text { Aucune } \\
\text { correspondance }\end{array}$ & $1,7 \%$ \\
\hline Malawi & 133 & 27190 & $22,88 \%$ & $15,12 \%$ & $11,39 \%$ \\
\hline Maurice & 15 & 97 & $4,73 \%$ & $4,00 \%$ & $3,41 \%$ \\
\hline Mozambique & 42 & 170662 & $21,57 \%$ & $26,00 \%$ & $8,87 \%$ \\
\hline Namibie & 146 & 313534 & $37,89 \%$ & $17,00 \%$ & $28,08 \%$ \\
\hline Rwanda & 10 & 2320 & $9,11 \%$ & $10,10 \%$ & $5,75 \%$ \\
\hline Seychelles & 10 & 242 & $49,64 \%$ & $46,60 \%$ & $36,96 \%$ \\
\hline Somalie & 20 & $0^{117}$ & $0,00 \%$ & $0,80 \%$ & $\mathrm{n} / \mathrm{a}$ \\
\hline Afrique du Sud & 1444 & 102060 & $8,34 \%$ & $12,96 \%$ & $2,47 \%$ \\
\hline Soudan du Sud & 27 & 98214 & $15,50 \%$ & $13,00 \%$ & $6,65 \%$ \\
\hline Soudan & 19 & 42698 & $2,28 \%$ & $5,80 \%$ & $1,17 \%$ \\
\hline Tanzanie & 709 & 361594 & $38,17 \%$ & $54,60 \%$ & $21,55 \%$ \\
\hline Ouganda & 712 & 39059 & $16,06 \%$ & $18,00 \%$ & $6,66 \%$ \\
\hline Zambie & 635 & 286161 & $37,87 \%$ & $37,80 \%$ & $16,28 \%$ \\
\hline Zimbabwe & 232 & 106837 & $27,21 \%$ & $28,00 \%$ & $19,76 \%$ \\
\hline TOTAL & $4821^{118}$ & $2120112^{119}$ & $16,54 \%$ & $\mathrm{n} / \mathrm{a}$ & $\mathrm{n} / \mathrm{a}$ \\
\hline
\end{tabular}

Sources : *Base de données mondiale des aires protégées (UNEP-WCMC et IUCN, 2019a); ** Rapports nationaux à la Convention sur la diversité biologique. ${ }^{* *}$ CE CCR/DOPA (2019). 
A2-Tableau 2. Aires côtières et marines protégées et de conservation d'Afrique orientale et australe

\begin{tabular}{|c|c|c|c|c|}
\hline Nom & $\begin{array}{r}\text { Nombre } \\
\text { (BDMAP) }\end{array}$ & $\begin{array}{r}\text { Superficie côtière et marine } \\
\text { couverte par les aires } \\
\text { protégées }\left(\mathrm{km}^{2}\right)^{\star}\end{array}$ & $\begin{array}{r}\% \text { de superficie côtière et } \\
\text { marine couverte par } \\
\text { les aires protégées. }\end{array}$ & $\begin{array}{r}\% \text { de superficie côtière et } \\
\text { marine couverte par les } \\
\text { aires protégées }\end{array}$ \\
\hline Angola & 1 & 24 & 0 & $0,0 \%$ \\
\hline Comores & 3 & 37 & 0 & $0,02 \%$ \\
\hline Djibouti & 4 & 12 & $0,46 \%$ & $0,17 \%$ \\
\hline Érythrée & 0 & 0 & 0 & $0,0 \%$ \\
\hline Kenya & 20 & 904 & 0 & $0,8 \%$ \\
\hline Madagascar & 48 & 8998 & 0 & $0,75 \%$ \\
\hline Maurice & 29 & 50 & 0 & $0,0 \%$ \\
\hline Mozambique & 2 & 12821 & 0 & $2,23 \%$ \\
\hline Namibie & 2 & 9646 & $0,01 \%$ & $1,71 \%$ \\
\hline Seychelles & 30 & 209930 & $0,03 \%$ & $15,66 \%$ \\
\hline Somalie & 1 & 0 & 0 & 0 \\
\hline Afrique du Sud & 136 & 224640 & $10 \%$ & $14,56 \%$ \\
\hline Soudan & 4 & 10662 & $0,03 \%$ & $15,96 \%$ \\
\hline Tanzanie & 131 & 7330 & $6,50 \%$ & $3,02 \%$ \\
\hline TOTAL & 411 & 473815 & $\mathrm{~N} / \mathrm{A}$ & $5,60 \%$ \\
\hline
\end{tabular}

Sources : *Base de données mondiale des aires protégées (UNEP-WCMC et IUCN, 2019a); ** Rapports nationaux à la Convention sur la diversité biologique.

Note : voir le Chapitre 8 pour plus d'informations sur les rapports nationaux à la CDB, de 2014 à 2019.

A2-Tableau 3. Catégories de gestion de l'UICN des aires protégées et de conservation d'Afrique orientale et australe

\begin{tabular}{|c|c|c|}
\hline Catégorie de gestion de I'UICN & Nombre & Superficie $\left(\mathrm{km}^{2}\right)^{120}$ \\
\hline la. Réserve naturelle intégrale & 9 & 3788 \\
\hline Ib : Zone de nature sauvage & 17 & 103882 \\
\hline II. Parc national & 209 & 522053 \\
\hline III. Monument naturel & 32 & 8388 \\
\hline IV. Aire de gestion des habitats / espèces & 164 & 147821 \\
\hline V. Paysage terrestre ou marin protégé & 49 & 19918 \\
\hline VI. Aire protégée avec utilisation durable des ressources naturelles & 155 & 384507 \\
\hline Non rapportée & 4538 & 1498805 \\
\hline Non applicable & 56 & 158898 \\
\hline Non définie & 3 & 4019 \\
\hline
\end{tabular}

Source : UNEP-WCMC et IUCN, 2019a.

120 II ne s'agit pas d'une nouvelle couverture par catégorie de gestion. Certaines des aires protégées se chevauchent et pourraient avoir des catégories de gestion de l'UICN différentes. Si deux aires protégées couvrent un même emplacement mais ont des catégories de gestion différentes, les deux catégories sont comptées. 
A2-Tableau 4. Type de gouvernance de l'UICN des aires protégées et de conservation d'Afrique orientale et australe

\begin{tabular}{l|r|r}
\hline Types de gouvernance de l'UICN & Nombre & Superficie $\left.\mathbf{( k m}^{\mathbf{2}}\right)^{\mathbf{1 2 1}}$ \\
\hline A. Gouvernance par un gouvernement & 2468 & 1424849 \\
\hline B. Gouvernance partagée & 18 & 5214 \\
\hline C. Gouvernance privée & 959 & 33271 \\
\hline $\begin{array}{l}\text { D. Gouvernance par les peuples autochtones et } \\
\text { communautés locales }\end{array}$ & 238 & 199957 \\
\hline Non rapporté & 1549 & 1131803 \\
\hline
\end{tabular}

Source : UNEP-WCMC et IUCN, 2019a.

\section{Annexe 3. Sites d'importance mondiale en Afrique orientale et australe ${ }^{122}$}

A3-Tableau 1. Sites Ramsar d'Afrique orientale et australe

\begin{tabular}{|c|c|c|c|c|}
\hline Pays & $\begin{array}{l}\text { Date d'entrée en vigueur } \\
\text { de la convention }\end{array}$ & $\begin{array}{r}\text { Nombre de } \\
\text { sites }\end{array}$ & Sites & $\begin{array}{r}\text { Superficie } \\
\text { couverte (ha) }\end{array}$ \\
\hline Botswana & 9 avril 1997 & 1 & Système du delta de l'Okavango & 5537400 \\
\hline \multirow[t]{3}{*}{ Comores } & \multirow[t]{3}{*}{9 juin 1995} & \multirow[t]{3}{*}{3} & Lac Dziani Boundouni & \multirow[t]{3}{*}{16030} \\
\hline & & & Karthala & \\
\hline & & & Mont Ntringui & \\
\hline Djibouti & 22 mars 2003 & 1 & Haramous-Loyada & 3000 \\
\hline \multirow[t]{3}{*}{ Eswatini } & \multirow[t]{3}{*}{15 juin 2013} & \multirow[t]{3}{*}{3} & Barrage et réserve naturelle de Hawane & \multirow[t]{3}{*}{1183} \\
\hline & & & Barrage de la rivière Sand & \\
\hline & & & Barrage de Van Eck & \\
\hline \multirow[t]{6}{*}{ Kenya } & \multirow[t]{6}{*}{5 octobre 1990} & \multirow[t]{6}{*}{6} & Lac Baringo & \multirow[t]{6}{*}{265449} \\
\hline & & & Lac Bogoria & \\
\hline & & & Lac Elmenteita & \\
\hline & & & Lac Naivasha & \\
\hline & & & Lac Nakuru & \\
\hline & & & Site Ramsar du delta du fleuve Tana & \\
\hline Lesotho & 1er novembre 2004 & 1 & Lets'eng-la-Letsie & 434 \\
\hline
\end{tabular}




\begin{tabular}{|c|c|c|c|c|}
\hline Pays & $\begin{array}{l}\text { Date d'entrée en vigueur } \\
\text { de la convention }\end{array}$ & $\begin{array}{r}\text { Nombre de } \\
\text { sites }\end{array}$ & Sites & $\begin{array}{r}\text { Superficie } \\
\text { couverte (ha) }\end{array}$ \\
\hline \multirow[t]{20}{*}{ Madagascar } & \multirow[t]{20}{*}{25 janvier 1999} & \multirow[t]{20}{*}{20} & Barrière de corail de Nosy Ve Androka & \multirow[t]{20}{*}{2094911} \\
\hline & & & Complexe des lacs Ambondro et Sirave (CLAS) & \\
\hline & & & Complexe des lacs de Manambolomaty & \\
\hline & & & Complexe des zones humides de Bemanevika & \\
\hline & & & Îles Barren & \\
\hline & & & Lac Kinkony & \\
\hline & & & Lac Sofia & \\
\hline & & & Lac Alaotra : zones humides et bassins versants & \\
\hline & & & Mangroves de Tsiribihina & \\
\hline & & & Marais de Torotorofotsy et leurs bassins versants & \\
\hline & & & Parc de Tsarasaotra & \\
\hline & & & Parc national de Tsimanampesotse & \\
\hline & & & Rivière Nosivolo et affluents & \\
\hline & & & Site bioculturel d'Antrema & \\
\hline & & & Zone humide de Mandrozo & \\
\hline & & & Zones humides Ankarafantsika (CLSA) & \\
\hline & & & Zones humides d'Ambondrobe & \\
\hline & & & Zones humides de Bedo & \\
\hline & & & Zones humides de l'Onilahy & \\
\hline & & & Zones humides de Sahamalaza & \\
\hline \multirow[t]{2}{*}{ Malawi } & \multirow[t]{2}{*}{14 mars 1997} & \multirow[t]{2}{*}{2} & Elephant Marsh & \multirow[t]{2}{*}{286356} \\
\hline & & & Lac Chilwa & \\
\hline \multirow[t]{3}{*}{ Maurice } & \multirow[t]{3}{*}{30 septembre 2001} & \multirow[t]{3}{*}{3} & Parc marin de Blue Bay & \multirow[t]{3}{*}{401} \\
\hline & & & Zone humide de Pointe d'Esny & \\
\hline & & & $\begin{array}{l}\text { Refuge d'oiseaux de l'estuaire du fleuve Terre } \\
\text { Rouge }\end{array}$ & \\
\hline \multirow[t]{2}{*}{ Mozambique } & \multirow[t]{2}{*}{3 décembre 2004} & \multirow[t]{2}{*}{2} & Lac Niassa et sa zone côtière & \multirow[t]{2}{*}{4534872} \\
\hline & & & Delta du Zambèze & \\
\hline \multirow[t]{5}{*}{ Namibie } & \multirow[t]{5}{*}{23 décembre 1995} & \multirow[t]{5}{*}{5} & Site Ramsar de Bwabwata-Okavango & \multirow[t]{5}{*}{67656} \\
\hline & & & Plaine d'Etosha & \\
\hline & & & Embouchure de la rivière Orange & \\
\hline & & & Sandwich Harbour & \\
\hline & & & Walvis Bay & \\
\hline Rwanda & 1er avril 2006 & 1 & Rugezi-Burera-Ruhondo & 6736 \\
\hline \multirow[t]{3}{*}{ Seychelles } & \multirow[t]{3}{*}{22 mars 2005} & \multirow[t]{3}{*}{3} & Atoll d'Aldabra & \multirow[t]{3}{*}{44025} \\
\hline & & & $\begin{array}{l}\text { Zones humides d'eau douce d'altitude de la Mare } \\
\text { aux cochons }\end{array}$ & \\
\hline & & & Zones humides côtières de Port Launay & \\
\hline
\end{tabular}




\begin{tabular}{|c|c|c|c|c|}
\hline Pays & $\begin{array}{l}\text { Date d'entrée en vigueur } \\
\text { de la convention }\end{array}$ & $\begin{array}{r}\text { Nombre de } \\
\text { sites }\end{array}$ & Sites & $\begin{array}{r}\text { Superficie couverte } \\
\text { (ha) }\end{array}$ \\
\hline \multirow[t]{27}{*}{ Afrique du Sud } & \multirow[t]{27}{*}{21 décembre 1975} & \multirow[t]{27}{*}{27} & Barberspan & \multirow[t]{27}{*}{557028} \\
\hline & & & Blesbokspruit & \\
\hline & & & Système estuarien de Bot-Kleinmond & \\
\hline & & & Réserve naturelle de l'île Dassen & \\
\hline & & & De Hoop Vlei & \\
\hline & & & De Mond & \\
\hline & & & $\begin{array}{l}\text { Réserve naturelle provinciale de l'île Dyer et } \\
\text { Réserve naturelle provinciale de l'île Geyser }\end{array}$ & \\
\hline & & & Geyser & \\
\hline & & & Réserve naturelle de False Bay & \\
\hline & & & Réserve de montagne de Kgaswane & \\
\hline & & & Baie de Kosi & \\
\hline & & & Lac Sibaya & \\
\hline & & & Langebaan & \\
\hline & & & Zones humides de Makuleke & \\
\hline & & & Parc du Natal Drakensberg & \\
\hline & & & Réserve de gibier de Ndumo & \\
\hline & & & Réserve naturelle de Ntsikeni & \\
\hline & & & Réserve naturelle de Nylsvley & \\
\hline & & & Embouchure de la rivière Orange & \\
\hline & & & Îles du Prince-Edward & \\
\hline & & & Réserve naturelle de Seekoeivlei & \\
\hline & & & Système de Sainte-Lucie & \\
\hline & & & $\begin{array}{l}\text { Plages de tortues / récifs coralliens du Tonga- } \\
\text { land }\end{array}$ & \\
\hline & & & Réserve naturelle d'uMgeni Vlei & \\
\hline & & & Réserve naturelle de Verloren Valei & \\
\hline & & & Verlorenvlei & \\
\hline & & & Lacs naturels & \\
\hline Soudan du Sud & 10 octobre 2013 & 1 & Sudd & 5700000 \\
\hline \multirow[t]{3}{*}{ Soudan } & \multirow[t]{3}{*}{7 mai 2005} & \multirow[t]{3}{*}{3} & Parc national de Dinder & \multirow[t]{3}{*}{248960} \\
\hline & & & Baie de Dongonab - Marsa Waiai & \\
\hline & & & Suakin-Golfe d'Agig & \\
\hline \multirow[t]{4}{*}{ Tanzanie } & \multirow[t]{4}{*}{13 août 2000} & \multirow[t]{4}{*}{4} & Plaine inondable de la vallée de Kilombero & \multirow[t]{4}{*}{4868424} \\
\hline & & & Bassin du lac Natron & \\
\hline & & & Zones humides de Malagarasi-Muyovozi & \\
\hline & & & Rufiji-Mafia-Site Ramsar marin de Kilwa & \\
\hline
\end{tabular}




\begin{tabular}{|c|c|c|c|c|}
\hline Pays & $\begin{array}{l}\text { Date d'entrée en vigueur } \\
\text { de la convention }\end{array}$ & $\begin{array}{r}\text { Nombre de } \\
\text { sites }\end{array}$ & Sites & $\begin{array}{r}\text { Superficie couverte } \\
\text { (ha) }\end{array}$ \\
\hline \multirow[t]{12}{*}{ Ouganda } & \multirow[t]{12}{*}{4 juillet 1988} & \multirow[t]{12}{*}{12} & Système de zones humides du lac Bisina & \multirow[t]{12}{*}{454303} \\
\hline & & & Lac George & \\
\hline & & & $\begin{array}{l}\text { Système de zones humides du lac Mburo-Na- } \\
\text { kivali }\end{array}$ & \\
\hline & & & Système de zones humides du lac Nabugabo & \\
\hline & & & Système de zones humides du lac Nakuwa & \\
\hline & & & Système de zones humides du lac Opeta & \\
\hline & & & $\begin{array}{l}\text { Système de zones humides de la baie de Lu- } \\
\text { tembe }\end{array}$ & \\
\hline & & & $\begin{array}{l}\text { Système de zones humides de la baie de } \\
\text { Mabamba }\end{array}$ & \\
\hline & & & $\begin{array}{l}\text { Chutes Murchison - Système de zones humides } \\
\text { du delta Albert }\end{array}$ & \\
\hline & & & Système de zones humides de Nabajjuzi & \\
\hline & & & Site Ramsar des monts Rwenzori & \\
\hline & & & $\begin{array}{l}\text { Baie de Sango - Île Musambwa - système des } \\
\text { zones humides de Kagera (SAMUKA) }\end{array}$ & \\
\hline \multirow[t]{6}{*}{ Zambie } & \multirow[t]{6}{*}{28 décembre 1991} & \multirow[t]{6}{*}{6} & Marais de Bangweulu & \multirow[t]{6}{*}{4030500} \\
\hline & & & Marais de Busanga & \\
\hline & & & Kafue Flats & \\
\hline & & & Plaines inondables de Luangwa & \\
\hline & & & Marais de Lukanga & \\
\hline & & & Mweru wa Ntipa & \\
\hline \multirow[t]{7}{*}{ Zimbabwe } & \multirow[t]{7}{*}{3 mai 2013} & \multirow[t]{7}{*}{6} & Parc de loisirs des grottes de Chinhoyi & \multirow[t]{7}{*}{453828} \\
\hline & & & Barrage de Cleveland & \\
\hline & & & Prairies de Driefontein & \\
\hline & & & Lac Chivero et Manyame & \\
\hline & & & Parc national Mana Pools & \\
\hline & & & Zone humide de Monavale & \\
\hline & & & Parc national des chutes Victoria & \\
\hline \multicolumn{4}{|c|}{ SUPERFICIE TOTALE } & 32021044 \\
\hline
\end{tabular}

Source : Ramsar Convention on Wetlands, 2019. 


\section{A3-Tableau 2. Réserves de biosphère d'Afrique orientale et australe}

\begin{tabular}{|c|c|c|c|}
\hline Pays & Nombre de sites & Réserve de biosphère & Date de la désignation \\
\hline \multirow[t]{5}{*}{ Éthiopie } & \multirow[t]{5}{*}{5} & Kafa & 2010 \\
\hline & & Yayu & 2010 \\
\hline & & Sheka & 2012 \\
\hline & & Lac Tana & 2015 \\
\hline & & Forêt de Majang & 2017 \\
\hline \multirow[t]{6}{*}{ Kenya } & \multirow[t]{6}{*}{6} & Mont Kenya & 1978 \\
\hline & & Mont Kulal & 1978 \\
\hline & & Malindi-Watamu & 1979 \\
\hline & & Kiunga & 1980 \\
\hline & & Amboseli & 1991 \\
\hline & & Mont Elgon & 2003 \\
\hline \multirow[t]{5}{*}{ Madagascar } & \multirow[t]{5}{*}{5} & Mananara Nord & 1990 \\
\hline & & Sahamalaza-îles Radama & 2001 \\
\hline & & Littoral de Toliara & 2003 \\
\hline & & Belo-sur-Mer - Kirindy-Mite & 2016 \\
\hline & & Tsimanampesotse-Nosy Ve Androka & 2018 \\
\hline Maurice & 1 & Macchabee/Bel Ombre & 1977 \\
\hline \multirow[t]{2}{*}{ Malawi } & \multirow[t]{2}{*}{2} & Mont Mulanje & 2000 \\
\hline & & Zone humide du lac Chilwa & 2006 \\
\hline Mozambique & 1 & Quirimbas & 2018 \\
\hline Rwanda & 1 & Volcans & 1983 \\
\hline \multirow{10}{*}{$\begin{array}{l}\text { Afrique du } \\
\text { Sud }\end{array}$} & \multirow[t]{10}{*}{10} & Kogelberg & 1998 \\
\hline & & Côte ouest du Cap & 2000 \\
\hline & & Waterberg & 2001 \\
\hline & & Kruger aux Canyons & 2001 \\
\hline & & Vignes du Cap & 2007 \\
\hline & & Vhembe & 2009 \\
\hline & & Cluster de Gouritz & 2015 \\
\hline & & Magaliesberg & 2015 \\
\hline & & Garden Route & 2017 \\
\hline & & Marico & 2018 \\
\hline \multirow[t]{5}{*}{ Tanzanie } & \multirow[t]{5}{*}{5} & Lac Manyara & 1981 \\
\hline & & Serengeti-Ngorongoro & 1981 \\
\hline & & Usambara Est & 2000 \\
\hline & & Baie de Jozani-Chwaka & 2016 \\
\hline & & Gombe Masito Ugalla & 2018 \\
\hline \multirow[t]{2}{*}{ Ouganda } & \multirow[t]{2}{*}{2} & Queen Elizabeth & 1979 \\
\hline & & Mont Elgon & 2005 \\
\hline Zimbabwe & 1 & Zambèze Moyen & 2010 \\
\hline
\end{tabular}

Source : UNESCO (2019). 


\section{Annexe 4. Représentativité écologique en Afrique orientale et australe}

A4-Tableau 1. Degré de protection des écorégions terrestres représentées dans la région

\begin{tabular}{r|r|r|r|r}
\hline & $\begin{array}{r}\text { Nombre } \\
\text { d'écorégions }\end{array}$ & $\begin{array}{r}\text { Écorégions } \\
\text { avec <75\% de } \\
\text { superficie dans la } \\
\text { région }\end{array}$ & $\begin{array}{r}\text { Écorégions } \\
\text { avec 75-99\% de super- } \\
\text { ficie dans la région }\end{array}$ & $\begin{array}{r}\text { Écorégions } \\
\text { exclusives à la } \\
\text { région }\end{array}$ \\
\hline 0 & 5 & 5 & 0 & 0 \\
\hline 0,01 à $4 \%$ & 7 & 3 & 2 & 4 \\
\hline 4 à $8 \%$ & 14 & 2 & 1 & 4 \\
\hline 8 à $12 \%$ & 8 & 0 & 1 & 7 \\
\hline 12 à $17 \%$ & 11 & 4 & 6 & 6 \\
\hline$>17 \%$ & 37 & 4 & 27 \\
\hline
\end{tabular}

Source : EC JRC/DOPA (2019).

A4-Tableau 2. Degré de protection des écorégions marines et des provinces pélagiques représentées dans la région

\begin{tabular}{|c|c|c|c|c|}
\hline Protection & $\begin{array}{r}\text { Nombre } \\
\text { d'écorégions }\end{array}$ & $\begin{array}{r}\text { Écorégions } \\
\text { avec }<75 \% \text { de } \\
\text { superficie dans la } \\
\text { région }\end{array}$ & $\begin{array}{r}\text { Écorégions } \\
\text { avec } 75-99 \% \text { de } \\
\text { superficie dans la } \\
\text { région }\end{array}$ & $\begin{array}{r}\text { Écorégions } \\
\text { exclusives à la } \\
\text { région }\end{array}$ \\
\hline 0 & 9 & 0 & 7 & 2 \\
\hline 0,01 à $5 \%$ & 10 & 2 & 3 & 5 \\
\hline 5 à $10 \%$ & 5 & 1 & 1 & 3 \\
\hline$>10 \%$ & 6 & 0 & 3 & 3 \\
\hline
\end{tabular}

Source : EC JRC/DOPA (2019). 


\section{Annexe 5. Instruments juridiques soutenant l'équité et la gouvernance non- étatique des aires protégées}

\begin{tabular}{|c|c|}
\hline Pays & Loi, section et article pertinents \\
\hline Kenya & $\begin{array}{l}\text { Loi de } 2013 \text { sur la Conservation et la gestion de la faune sauvage } \\
\text { Art. 4. La mise en œuvre de la présente loi est guidée par les principes suivants } \\
\text { (a) la conservation et la gestion des espèces sauvages sont dévolues, chaque fois que cela est possible et } \\
\text { approprié, aux propriétaires et gestionnaires des terres où se trouvent ces espèces sauvages ; } \\
\text { (b) la conservation et la gestion des espèces sauvages doivent impliquer une participation effective du public ; } \\
\text { (c) dans la mesure du possible, la conservation et la gestion des espèces sauvages doivent être encouragées } \\
\text { selon une approche écosystémique ; } \\
\text { (d) la conservation et la gestion des espèces sauvages doivent être encouragées et reconnues comme une } \\
\text { forme d'utilisation des terres publiques, communautaires et privées ; } \\
\text { (e) des avantages de la conservation des espèces sauvages doivent être tirés par l'utilisateur des terres afin de } \\
\text { compenser les coûts et de s'assurer que la valeur et la gestion des espèces sauvages ne diminuent pas ; } \\
\text { (p. 1250-1251) } \\
\text { La Loi de gestion et coordination environnementale (1999, révisée en 2012) et la Loi sur la conservation et gestion } \\
\text { des espèces sauvages (WCMA) } 2013 \text { permettent des servitudes de conservation des terres. }\end{array}$ \\
\hline Mozambique & $\begin{array}{l}\text { Droit foncier (Loi 19/97) } \\
\text { L'article } 24 \text { (p. 1301) reconnaît le rôle des communautés locales dans la gestion des ressources naturelles et la } \\
\text { résolution des conflits, entre autres. La loi autorise également la chasse avec un simple permis } \\
\text { La Loi sur les forêts et la faune sauvage couvre la protection des normes et pratiques coutumières : valeur historico- } \\
\text { culturelle et utilisation des terres; exploitation sous licence } \\
\text { Loi sur la conservation de la biodiversité, Loi No 16/2014, } 20 \text { Juin. } \\
\text { L'article } 4 \text { (p. 1297) aborde sept principes : patrimoine écologique, souveraineté, égalité, participation des citoyens à } \\
\text { la gestion et aux avantages, responsabilité environnementale, développement, partenariats public-privé, de principe } \\
\text { de précaution et décision éclairée, et coopération internationale } \\
\text { L’article } 7 \text {, alinéa } 1 \text { (p. 1298) fait référence à la création du Conseil de gestion des aires de conservation, composé } \\
\text { de représentants des communautés locales, du secteur privé, d'associations et d'organismes publics locaux } \\
\text { L'article } 9 \text {, alinéas } 1 \text { et } 2 \text { (p. 1298) stipule que l'État peut établir des partenariats en vue de créer des synergies en } \\
\text { faveur de la conservation de la diversité biologique. }\end{array}$ \\
\hline Namibie & $\begin{array}{l}\text { Politique nationale de gestion communautaire des ressources naturelles, mars } 2013 \text {, Section } 4.4 \text { (p. 9) } \\
\text { Le gouvernement s'est engagé, conformément à ses propres lois sur l'accès et le partage des avantages et aux } \\
\text { politiques et conventions mondiales, à protéger les droits de propriété intellectuelle des communautés en ce qui } \\
\text { concerne les ressources naturelles et leur gestion, et à assurer une répartition juste et équitable des avantages } \\
\text { découlant de l'utilisation des ressources naturelles. }\end{array}$ \\
\hline Afrique du Sud & $\begin{array}{l}\text { Politique nationale et plan d'action pour la biodiversité } \\
\text { L'article } 2 \text { (f) (p. 12) stipule que la NEMPAA « vise à promouvoir la participation des communautés locales à la } \\
\text { gestion des aires protégées, le cas échéant }(\text { ». } \\
\text { L'article } 42 \text { (p. 34) prévoit qu'« un accord de cogestion peut concerner » toute une gamme de questions, y compris } \\
\text { (entre autres) : } \\
\text { • la délégation des pouvoirs de l'autorité de gestion à l'autre partie à l'accord ; } \\
\text { • la répartition de tout revenu de gestion de l'aire protégée ou toute autre forme de partage des bénéfices entre les parties; } \\
\text { •l'utilisation des ressources biologiques du site ; } \\
\text { •l'accès au site ; } \\
\text { - l'occupation de l'aire protégée ou de parties de celle-ci ; et } \\
\text { •le développement de débouchés économiques au sein ou à proximité de l'aire protégée ; }\end{array}$ \\
\hline
\end{tabular}




\begin{tabular}{|c|c|}
\hline Pays & Loi, section et article pertinents \\
\hline Ouganda & $\begin{array}{l}\text { Politique nationale de l'Ouganda sur la faune sauvage, Section } 26 \text { (p. 22) } \\
\text { Droits historiques des individus dans les aires de conservation } \\
\text { (1) Les dispositions de la présente Section ne portent pas atteinte aux personnes dont les droits ont été préservés, } \\
\text { jusqu'à l'entrée en vigueur de la présente loi, par:- } \\
\text { (a) la Loi sur le gibier (préservation et contrôle), à savoir:- } \\
\text { (i) les personnes, leurs femmes et leurs enfants résidant effectivement dans des réserves de gibier au } 1 \mathrm{er} \\
\text { juillet } 1959 \text {; } \\
\text { (ii) les personnes résidant effectivement dans les réserves de gibier à la date de leur déclaration, pour les } \\
\text { réserves } \\
\text { de gibier déclarées après le 1er septembre } 1959 \text {; } \\
\text { (b) la Loi sur les parcs nationaux, à savoir, les personnes qui ont légalement acquis des droits dans les parcs } \\
\text { nationaux avant } \\
\text { le } 3 \text { avril } 1952 \text {; } \\
\text { (c) la Loi sur les forêts, à savoir, les personnes résidant dans les forêts que le ministre peut avoir exemptées } \\
\text { des dispositions de cette Loi et dont les forêts ont depuis été déclarées parcs nationaux en vertu de la } \\
\text { Loi sur les parcs nationaux. } \\
\text { (2) L'Autorité peut établir des lignes directrices pour l'accès des communautés voisines des aires de conservation } \\
\text { aux ressources essentielles à la survie de ces communautés. }\end{array}$ \\
\hline Zimbabwe & $\begin{array}{l}\text { Loi sur les parcs et la faune sauvage (Chapitre 20:14) } 1996 \\
\text { L'article } 2 \text { confère des privilèges aux propriétaires ou aux occupants de terres aliénées en tant que gardiens de la } \\
\text { faune et offre aux Conseils de district ruraux le statut d'“ autorité appropriée " sur les questions de faune sauvage } \\
\text { dans leurs terres communales respectives au nom de leurs communautés locales rurales, appelées "communautés } \\
\text { de producteurs". } \\
\text { Politique pour la faune sauvage du Zimbabwe } 1999 \\
\text { La politique vise à donner aux propriétaires fonciers les moyens de conserver les ressources fauniques existantes } \\
\text { sur leurs terres, y compris les terres communales et privées, et d'en tirer des avantages. } \\
\text { Politique de réforme agraire fondée sur la faune sauvage } 2004 \text {. } \\
\text { Section } 3 \text { : «faciliter l'indigénisation du secteur de la faune sauvage et assurer un accès plus équitable de la majorité } \\
\text { des Zimbabwéens aux ressources terrestres et fauniques et aux opportunités commerciales qui découlent de ces } \\
\text { ressources ". }\end{array}$ \\
\hline
\end{tabular}

Source : Tessema (s.d.)"issued":\{“date-parts":[““2019"]\}\}\}],"schema”:"https://github.com/citation-style-language/schema/raw/master/csl-citation.json"\} . 


\section{Appendice 6. Aires protégées et de conservation selon les catégories de gestion de I'UICN par pays}

Aires protégées et de conservation de l'Angola par catégorie de gestion de l'UICN

\begin{tabular}{l|r|r}
\hline Catégorie de gestion de I'UICN & $N^{\circ}$ & $\%$ de couverture \\
\hline II. Parc national & 8 & 77,49 \\
\hline IV. Aire de gestion des habitats/espèces & 4 & 16,42 \\
\hline V. Paysage terrestre ou marin protégé & 1 & 0,24 \\
\hline Non rapporté & 1 & 5,26 \\
\hline
\end{tabular}

Source : UNEP-WCMC et IUCN (2019c).

Aires protégées et de conservation du Botswana selon les catégories de gestion de l'UICN

\begin{tabular}{l|r|r}
\hline Catégorie de gestion de I'UICN & $N^{\circ}$ & $\%$ de couverture \\
\hline Ib : Zone de nature sauvage & 7 & 61,12 \\
\hline II. Parc national & 6 & 2,40 \\
\hline IV. Aire de gestion des habitats/espèces & 7 & 1,08 \\
\hline Non rapporté & 1 & 37,78 \\
\hline Non applicable & 1 & 12,07 \\
\hline
\end{tabular}

Source : UNEP-WCMC et IUCN (2019C).

Aires protégées et de conservation des Comores par catégorie de gestion de l'UICN

\begin{tabular}{l|r|r}
\hline Catégorie de gestion de l'UICN & No $^{\circ} \%$ de couverture \\
\hline II. Parc national & 1 & 17,74 \\
\hline Non rapporté & 7 & 81,75 \\
\hline
\end{tabular}

Source : UNEP-WCMC et IUCN (2019d).

Aires protégées et de conservation de Djibouti par catégorie de gestion de l'UICN

\begin{tabular}{l|r|r}
\hline Catégorie de gestion de l'UICN & No $^{\circ}$ & 1 \\
\hline IV. Aire de gestion des habitats/espèces & 2 & $0,00 \%$ \\
\hline V. Paysage terrestre ou marin protégé & 1 & $0,00 \%$ \\
\hline VI. Aire protégée avec utilisation durable des ressources naturelles & 3 & $0,00 \%$ \\
\hline Non rapporté & $100 \%$ \\
\hline
\end{tabular}

Source : UNEP-WCMC et IUCN (2019e). 
Aires protégées et de conservation de l'Érythrée par catégorie de gestion de l'UICN

\begin{tabular}{l|r|r}
\hline Catégorie de gestion de I'UICN & No & $\%$ de couverture \\
\hline IV. Aire de gestion des habitats/espèces & 3 & 100,00 \\
\hline Non rapporté & 1 & \\
\hline
\end{tabular}

Source : UNEP-WCMC et IUCN (2019f).

Aires protégées et de conservation de l'Eswatini par catégorie de gestion de l'UICN

\begin{tabular}{l|r|r}
\hline Catégorie de gestion de I'UICN & N $^{\circ}$ & \% de couverture \\
\hline II. Parc national & 6 & 94,20 \\
\hline IV. Aire de gestion des habitats/espèces & 2 & 0,19 \\
\hline V. Paysage terrestre ou marin protégé & 1 & 2,14 \\
\hline Non rapporté & 5 & 3,09 \\
\hline
\end{tabular}

Source : UNEP-WCMC et IUCN (2019g).

Aires protégées et de conservation de l'Éthiopie par catégorie de gestion de l'UICN

\begin{tabular}{l|r|r}
\hline Catégorie de gestion de I'UICN & No $^{\circ}$ \% de couverture \\
\hline II. Parc national & 17 & 17,35 \\
\hline IV. Aire de gestion des habitats/espèces & 8 & 11,69 \\
\hline VI. Aire protégée avec utilisation durable des ressources naturelles & 18 & 75,76 \\
\hline Non rapporté & 58 & 0,02 \\
\hline Non applicable & 3 & 0,07 \\
\hline
\end{tabular}

Source : UNEP-WCMC et IUCN (2019h).

Aires protégées et de conservation du Kenya par catégorie de gestion de l'UICN

\begin{tabular}{l|r|r}
\hline Catégorie de gestion de l'UICN & N $^{\circ}$ & \% de couverture \\
\hline II. Parc national & 36 & 46,15 \\
\hline IV. Aire de gestion des habitats/espèces & 5 & 0,65 \\
\hline VI. Aire protégée avec utilisation durable des ressources naturelles & 16 & 10,91 \\
\hline Non rapporté & 345 & 46,19 \\
\hline Non applicable & 9 & 5,23 \\
\hline
\end{tabular}

Source : UNEP-WCMC et IUCN (2019i).

Aires protégées et de conservation du Lesotho par catégorie de gestion de l'UICN

\begin{tabular}{l|r|r}
\hline Catégorie de gestion de I'UICN & $\mathrm{N}^{\circ}$ & $\%$ de couverture \\
\hline IV. Aire de gestion des habitats/espèces & 1 & 86,89 \\
\hline Non rapporté & 2 & 5,43 \\
\hline Non applicable & 1 & 7,00 \\
\hline
\end{tabular}

Source : UNEP-WCMC et IUCN (2019j). 
Aires protégées et de conservation de Madagascar par catégorie de gestion de I'UICN

\begin{tabular}{l|r|r}
\hline Catégorie de gestion de l'UICN & N $^{\circ}$ & \% de couverture \\
\hline Ia. Réserve naturelle intégrale & 3 & 2,00 \\
\hline II. Parc national & 30 & 19,00 \\
\hline IV. Aire de gestion des habitats/espèces & 22 & 14,00 \\
\hline VI. Aire protégée avec utilisation durable des ressources naturelles & 7 & 4,00 \\
\hline V. Paysage terrestre ou marin protégé & 29 & 18,00 \\
\hline Non rapporté & 61 & 39,00 \\
\hline Non applicable & 5 & 3,00 \\
\hline
\end{tabular}

Source : UNEP-WCMC et IUCN (2019k).

Aires protégées et de conservation du Malawi par catégorie de gestion de l'UICN

\begin{tabular}{l|r|r}
\hline Catégorie de gestion de I'UICN & N & \% de couverture \\
\hline II. Parc national & 5 & 25,60 \\
\hline IV. Aire de gestion des habitats/espèces & 4 & 14,03 \\
\hline Non rapporté & 121 & 64,73 \\
\hline Non applicable & 3 & 0,27 \\
\hline
\end{tabular}

Source : UNEP-WCMC et IUCN (2019).

Aires protégées et de conservation de Maurice par catégorie de gestion de l'UICN

\begin{tabular}{l|r|r}
\hline Catégorie de gestion de l'UICN & No $^{\circ}$ \% de couverture \\
\hline la. Réserve naturelle intégrale & 1 & 0,21 \\
\hline II. Parc national & 10 & 42,74 \\
\hline IV. Aire de gestion des habitats/espèces & 21 & 42,47 \\
\hline Non rapporté & 10 & 0,32 \\
\hline Non affecté & 1 & 0,01 \\
\hline
\end{tabular}

Source : UNEP-WCMC et IUCN (2019m).

Aires protégées et de conservation du Mozambique par catégorie de gestion de l'UICN

\begin{tabular}{l|r|r}
\hline Catégorie de gestion de I'UICN & N $^{\circ}$ & \% de couverture \\
\hline II. Parc national & 6 & 24,62 \\
\hline IV. Aire de gestion des habitats/espèces & 4 & 9,82 \\
\hline VI. Aire protégée avec utilisation durable des ressources naturelles & 3 & 0,71 \\
\hline Non rapporté & 29 & 63,70 \\
\hline Non affecté & 2 & 2,19 \\
\hline
\end{tabular}

Source: UNEP-WCMC et IUCN (2019n). 
Aires protégées et de conservation de Namibie par catégorie de gestion de l'UICN

\begin{tabular}{l|r|r}
\hline Catégorie de gestion de I'UICN & No $^{\circ}$ \% de couverture \\
\hline II. Parc national & 9 & 31,01 \\
\hline III. Monument naturel & 2 & 0,00 \\
\hline IV. Aire de gestion des habitats/espèces & 1 & 0,00 \\
\hline V. Paysage terrestre ou marin protégé & 3 & 0,16 \\
\hline VI. Aire protégée avec utilisation durable des ressources naturelles & 1 & 2,94 \\
\hline Non rapporté & 131 & 72,49 \\
\hline Non applicable & 1 & 9,52 \\
\hline
\end{tabular}

Source : UNEP-WCMC et IUCN (20190).

Aires protégées et de conservation du Rwanda par catégorie de gestion de I'UICN

\begin{tabular}{l|r|r}
\hline Catégorie de gestion de I'UICN & $\mathrm{N}^{\circ}$ & $\%$ de couverture \\
\hline II. Parc national & 2 & 50,98 \\
\hline IV. Aire de gestion des habitats/espèces & 3 & 45,38 \\
\hline Non rapporté & 4 & 2,96 \\
\hline
\end{tabular}

Source : UNEP-WCMC et IUCN (2019p).

Aires protégées et de conservation des Seychelles par catégorie de gestion de l'UICN

\begin{tabular}{l|r|r}
\hline Catégorie de gestion de l'UICN & $N^{\circ}$ & $\%$ de couverture \\
\hline la. Réserve naturelle intégrale & 5 & 1,16 \\
\hline Ib : Zone de nature sauvage & 1 & 0,00 \\
\hline II. Parc national & 8 & 0,04 \\
\hline VI. Aire protégée avec utilisation durable des ressources naturelles & 6 & 0,00 \\
\hline Non rapporté & 18 & 98,36 \\
\hline Non applicable & 2 & 0,21 \\
\hline
\end{tabular}

Source : UNEP-WCMC et IUCN (2019q).

Aires protégées et de conservation de Somalie par catégorie de gestion de l'UICN

\begin{tabular}{l|r|r}
\hline Catégorie de gestion de I'UICN & $\mathrm{N}^{\circ}$ & $\%$ de couverture \\
\hline Non rapporté & 21 & 0,00 \\
\hline
\end{tabular}

Source : UNEP-WCMC et IUCN (2019r).

Aires protégées et de conservation d'Afrique du Sud par catégorie de gestion de l'UICN

\begin{tabular}{l|r|r}
\hline Catégorie de gestion de l'UICN & $N^{\circ}$ & $\%$ de couverture \\
\hline Non rapporté & 1567 & 97,75 \\
\hline Non applicable & 13 & 5,15 \\
\hline
\end{tabular}

Source : UNEP-WCMC et IUCN (2019s). 
Aires protégées et de conservation du Soudan du Sud par catégorie de gestion de l'UICN

\begin{tabular}{l|r|r}
\hline Catégorie de gestion de I'UICN & $N^{\circ}$ & $\%$ de couverture \\
\hline II. Parc national & 9 & 52,35 \\
\hline IV. Aire de gestion des habitats/espèces & 3 & - \\
\hline V. Paysage terrestre ou marin protégé & 1 & 1,18 \\
\hline VI. Aire protégée avec utilisation durable des ressources naturelles & 13 & 30,33 \\
\hline Non rapporté & 1 & 24,66 \\
\hline
\end{tabular}

Source : UNEP-WCMC et IUCN (2019t).

Aires protégées et de conservation du Soudan par catégorie de gestion de l'UICN

\begin{tabular}{l|r|r}
\hline Catégorie de gestion de I'UICN & N $^{\circ} \%$ de couverture \\
\hline II. Parc national & 3 & 39,19 \\
\hline IV. Aire de gestion des habitats/espèces & 1 & 2,17 \\
\hline VI. Aire protégée avec utilisation durable des ressources naturelles & 3 & 13,57 \\
\hline Non rapporté & 13 & 46,66 \\
\hline Non applicable & 3 & 4,84 \\
\hline
\end{tabular}

Source : UNEP-WCMC et IUCN (2019u).

Aires protégées et de conservation de Tanzanie par catégorie de gestion de l'UICN

\begin{tabular}{l|r|r}
\hline Catégorie de gestion de I'UICN & $\mathrm{N}^{\circ}$ & $\%$ de couverture \\
\hline Ib : Zone de nature sauvage & 8 & 0,10 \\
\hline II. Parc national & 14 & 11,77 \\
\hline III. Monument naturel & 1 & 0,00 \\
\hline IV. Aire de gestion des habitats/espèces & 53 & 19,95 \\
\hline VI. Aire protégée avec utilisation durable des ressources naturelles & 19 & 3,02 \\
\hline Non rapporté & 738 & 70,98 \\
\hline Non applicable & 7 & 18,76 \\
\hline
\end{tabular}

Source : UNEP-WCMC et IUCN (2019v).

\section{Aires protégées et de conservation d'Ouganda par catégorie de gestion de l'UICN}

\begin{tabular}{l|r|r}
\hline Catégorie de gestion de I'UICN & N $^{\circ}$ & \% de couverture \\
\hline II. Parc national & 10 & 28,80 \\
\hline III. Monument naturel & 11 & 21,19 \\
\hline IV. Aire de gestion des habitats/espèces & 1 & 0,48 \\
\hline VI. Aire protégée avec utilisation durable des ressources naturelles & 13 & 12,74 \\
\hline Non rapporté & 673 & 44,24 \\
\hline Non applicable & 4 & 3,38 \\
\hline
\end{tabular}

Source : UNEP-WCMC et IUCN (2019w). 
Aires protégées et de conservation de Zambie par catégorie de gestion de l'UICN

\begin{tabular}{l|r|r}
\hline Catégorie de gestion de I'UICN & No & \% de couverture \\
\hline II. Parc national & 19 & 21,13 \\
\hline III. Monument naturel & 16 & 0,03 \\
\hline IV. Aire de gestion des habitats/espèces & 1 & 0,04 \\
\hline VI. Aire protégée avec utilisation durable des ressources naturelles & 36 & 49,11 \\
\hline Non rapporté & 562 & 38,15 \\
\hline Non applicable & 1 & 0,01 \\
\hline
\end{tabular}

Source : UNEP-WCMC et IUCN (2019x).

Aires protégées et de conservation du Zimbabwe par catégorie de gestion de l'UICN

\begin{tabular}{l|r|r}
\hline Catégorie de gestion de I'UICN & $\mathrm{N}^{\circ}$ & $\%$ de couverture \\
\hline Ib : Zone de nature sauvage & 1 & 0,01 \\
\hline II. Parc national & 10 & 25,15 \\
\hline III. Monument naturel & 2 & 0,02 \\
\hline IV. Aire de gestion des habitats/espèces & 19 & 0,12 \\
\hline V. Paysage terrestre ou marin protégé & 12 & 3,41 \\
\hline VI. Aire protégée avec utilisation durable des ressources naturelles & 19 & 17,79 \\
\hline Non rapporté & 166 & 54,84 \\
\hline Non applicable & 3 & 6,33 \\
\hline
\end{tabular}

Source : UNEP-WCMC et IUCN (2019y). 


\section{Annexe 7. Aires protégées et de conservation par type de gouvernance de I'UICN par pays}

Aires protégées et de conservation de l'Angola par types de gouvernance de I'UICN

\begin{tabular}{l|r|r}
\hline Catégorie de gouvernance de l'UICN & $N^{\circ}$ & $\%$ de couverture \\
\hline Non rapporté & 14 & 100,00 \\
\hline
\end{tabular}

Source : UNEP-WCMC et IUCN (2019c).

Aires protégées et de conservation du Botswana par type de gouvernance de l'UICN

\begin{tabular}{l|r|r}
\hline Catégorie de gouvernance de l'UICN & $N^{\circ}$ & $\%$ de couverture \\
\hline A. Gouvernance par un gouvernement & 18 & 63,58 \\
\hline C. Gouvernance privée & 1 & 0,44 \\
\hline $\begin{array}{l}\text { D. Gouvernance par les peuples autochtones et les communautés } \\
\text { locales }\end{array}$ & 1 & 0,57 \\
\hline Non rapporté & 2 & 37,80 \\
\hline
\end{tabular}

Source : UNEP-WCMC et IUCN (2019d).

Aires protégées et de conservation des Comores par type de gouvernance de l'UICN

\begin{tabular}{l|r|r}
\hline Catégorie de gouvernance de l'UICN & $N^{\circ}$ & \% de couverture \\
\hline B. Gouvernance partagée & 6 & 23,29 \\
\hline Non rapporté & 2 & 76,19 \\
\hline
\end{tabular}

Source : UNEP-WCMC et IUCN (2019d).

Aires protégées et de conservation de Djibouti par type de gouvernance de l'UICN

\begin{tabular}{l|r|r}
\hline Catégorie de gouvernance de l'UICN & $N^{\circ}$ & $\%$ de couverture \\
\hline Gouvernance par un gouvernement & 3 & 90,84 \\
\hline Non rapporté & 1 & 8,43 \\
\hline
\end{tabular}

Source : UNEP-WCMC et IUCN (2019e).

Aires protégées et de conservation de l'Érythrée par type de gouvernance de l'UICN

\begin{tabular}{l|r|r}
\hline Catégorie de gouvernance de l'UICN & $N^{\circ}$ & $\%$ de couverture \\
\hline Non rapporté & 4 & 100,00 \\
\hline
\end{tabular}

Source : UNEP-WCMC et IUCN (2019f).

Aires protégées et de conservation de l'Eswatini par type de gouvernance de l'UICN

\begin{tabular}{l|r|r}
\hline Catégorie de gouvernance de l'UICN & $N^{\circ}$ & $\%$ de couverture \\
\hline B. Privée & 3 & 2,33 \\
\hline Non rapporté & 11 & 97,29 \\
\hline
\end{tabular}

Source : UNEP-WCMC et IUCN (2019g).

* L'Eswatini rapporte des informations supplémentaires qui ne figurent pas encore dans la BDMAP. Tous les pays n'ont pas été mis à jour dans la BDMAP avant la publication du présent rapport. Les pays sont encouragés à mettre à jour leurs données SIG et tabulaires dans la BDMAP dans tous les cas où leurs données ne correspondraient pas à celles du présent rapport. 
Aires protégées et de conservation de l'Éthiopie par type de gouvernance de l'UICN

\begin{tabular}{l|r|r}
\hline Catégorie de gouvernance de l'UICN & $N^{\circ}$ & $\%$ de couverture \\
\hline Non rapporté & 104 & 100,00 \\
\hline
\end{tabular}

Source : UNEP-WCMC et IUCN (2019h).

Aires protégées et de conservation du Kenya par type de gouvernance de l'UICN

\begin{tabular}{l|r|r}
\hline Catégorie de gouvernance de l'UICN & $N^{\circ}$ & $\%$ de couverture \\
\hline Gouvernance par un gouvernement & 76 & 67,68 \\
\hline B. Gouvernance partagée & 1 & 0,45 \\
\hline C. Gouvernance privée & 16 & 2,59 \\
\hline $\begin{array}{l}\text { D. Gouvernance par les peuples autochtones et les communautés } \\
\text { locales }\end{array}$ & 51 & 1,97 \\
\hline Non rapporté & & \\
\hline
\end{tabular}

Source : UNEP-WCMC et IUCN (2019i).

Aires protégées et de conservation du Lesotho par type de gouvernance de l'UICN

\begin{tabular}{l|r|r}
\hline Catégorie de gouvernance de l'UICN & $N^{\circ}$ & $\%$ de couverture \\
\hline Gouvernance par un gouvernement & 3 & 92,32 \\
\hline Non rapporté & 1 & 7,00 \\
\hline
\end{tabular}

Source : UNEP-WCMC et IUCN (2019j)

Aires protégées et de conservation de Madagascar par type de gouvernance de l'UICN

\begin{tabular}{l|r|r}
\hline Catégorie de gouvernance de l'UICN & $N^{\circ}$ & $\%$ de couverture \\
\hline Gouvernance par un gouvernement & 8 & 3,50 \\
\hline B. Gouvernance partagée & 2 & 0,05 \\
\hline C. Gouvernance privée & 2 & 4,97 \\
\hline $\begin{array}{l}\text { D. Gouvernance par les peuples autochtones et les communautés } \\
\text { locales }\end{array}$ & 34 & 11,12 \\
\hline Non rapporté & & \\
\hline
\end{tabular}

Source : UNEP-WCMC et IUCN (2019k).

Aires protégées et de conservation du Malawi par type de gouvernance de l'UICN

\begin{tabular}{l|r|r}
\hline Catégorie de gouvernance de I'UICN & $N^{\circ}$ & $\%$ de couverture \\
\hline Gouvernance par un gouvernement & 10 & 41,87 \\
\hline Non rapporté & 123 & 62,76 \\
\hline
\end{tabular}

Source : UNEP-WCMC et IUCN (2019). 
Aires protégées et de conservation de Maurice par type de gouvernance de l'UICN

\begin{tabular}{l|r|r}
\hline Catégorie de gouvernance de l'UICN & $N^{\circ}$ & $\%$ de couverture \\
\hline A. Gouvernance par un gouvernement & 42 & $82,74 \%$ \\
\hline C. Gouvernance privée & 2 & $1,67 \%$ \\
\hline
\end{tabular}

Source : UNEP-WCMC et IUCN (2019m).

\section{Aires protégées et de conservation du Mozambique par type de gouvernance de l'UICN}

\begin{tabular}{l|r|r}
\hline Catégorie de gouvernance de l'UICN & $N^{\circ}$ & $\%$ de couverture \\
\hline A. Gouvernance par un gouvernement & 28 & 69,94 \\
\hline B. Gouvernance partagée & 1 & 2,00 \\
\hline $\begin{array}{l}\text { D. Gouvernance par les peuples autochtones et les communautés } \\
\text { locales }\end{array}$ & 1 & 0,00 \\
\hline Non rapporté & 14 & 33,31 \\
\hline
\end{tabular}

Source: UNEP-WCMC et IUCN (2019n).

* D'autres sites signalés par le Mozambique ne figurent pas encore dans la BDMAP. Tous les pays n'ont pas été mis à jour dans la BDMAP avant la publication du présent rapport. Les pays sont encouragés à mettre à jour leurs données SIG et tabulaires dans la BDMAP dans tous les cas où leurs données ne correspondraient pas à celles du présent rapport.

\section{Aires protégées et de conservation de Namibie par type de gouvernance de l'UICN}

\begin{tabular}{l|r|r}
\hline Catégorie de gouvernance de l'UICN & $N^{\circ}$ & $\%$ de couverture \\
\hline A. Gouvernance par un gouvernement & 31 & 47,58 \\
\hline C. Gouvernance privée & 2 & 0,89 \\
\hline $\begin{array}{l}\text { D. Gouvernance par les peuples autochtones et les communautés } \\
\text { locales }\end{array}$ & 112 & 50,60 \\
\hline Non rapporté & 3 & 10,12 \\
\hline
\end{tabular}

Source : UNEP-WCMC et IUCN (2019o).

Aires protégées et de conservation du Rwanda par type de gouvernance de l'UICN

\begin{tabular}{l|r|r}
\hline Catégorie de gouvernance de l'UICN & $N^{\circ}$ & $\%$ de couverture \\
\hline Gouvernance par un gouvernement & 3 & 94,88 \\
\hline Non rapporté & 7 & 4,44 \\
\hline
\end{tabular}

Source : UNEP-WCMC et IUCN (2019p).

Aires protégées et de conservation des Seychelles par type de gouvernance de l'UICN

\begin{tabular}{l|r|r}
\hline Catégorie de gouvernance de l'UICN & $N^{\circ}$ & $\%$ de couverture \\
\hline Gouvernance par un gouvernement & 20 & 1,20 \\
\hline Non rapporté & 20 & 100,00 \\
\hline
\end{tabular}

Source : UNEP-WCMC et IUCN (2019q).

\section{Aires protégées et de conservation de Somalie par type de gouvernance de l'UICN}

\begin{tabular}{l|r|r}
\hline Catégorie de gouvernance de l'UICN & N$^{\circ}$ & $\%$ de couverture \\
\hline Gouvernance par un gouvernement & 21 & 0,00 \\
\hline
\end{tabular}

Source : UNEP-WCMC et IUCN (2019r). 
Aires protégées et de conservation d'Afrique du Sud par type de gouvernance de I'UICN

\begin{tabular}{l|r|r}
\hline Catégorie de gouvernance de l'UICN & No & \% de couverture \\
\hline Gouvernance par un gouvernement & 645 & 92,29 \\
\hline B. Gouvernance partagée & 1 & 0,18 \\
\hline C. Gouvernance privée & 932 & 7,84 \\
\hline Non rapporté & 2 & 0,81 \\
\hline
\end{tabular}

Source : UNEP-WCMC et IUCN (2019s).

Aires protégées et de conservation du Soudan du Sud par type de gouvernance de I'UICN

\begin{tabular}{l|r|r}
\hline Catégorie de gouvernance de l'UICN & $N^{\circ}$ & $\%$ de couverture \\
\hline Gouvernance par un gouvernement & 26 & 83,87 \\
\hline Non rapporté & 1 & 24,66 \\
\hline
\end{tabular}

Source : UNEP-WCMC et IUCN (2019t).

Aires protégées et de conservation du Soudan par type de gouvernance de l'UICN

\begin{tabular}{l|r|r}
\hline Catégorie de gouvernance de l'UICN & $N^{\circ}$ & $\%$ de couverture \\
\hline Gouvernance par un gouvernement & 9 & 73,50 \\
\hline Non rapporté & 14 & 32,93 \\
\hline
\end{tabular}

Source : UNEP-WCMC et IUCN (2019u).

Aires protégées et de conservation de Tanzanie par type de gouvernance de l'UICN

\begin{tabular}{l|r|r}
\hline Catégorie de gouvernance de I'UICN & N $^{\circ}$ & \% de couverture \\
\hline Gouvernance par un gouvernement & 777 & 87,24 \\
\hline B. Gouvernance partagée & 4 & 0,15 \\
\hline C. Gouvernance privée & 1 & 0,00 \\
\hline $\begin{array}{l}\text { D. Gouvernance par les peuples autochtones et les communautés } \\
\text { locales }\end{array}$ & 39 & 7,98 \\
\hline Non rapporté & 19 & 33,54 \\
\hline
\end{tabular}

Source : UNEP-WCMC et IUCN (2019v).

Aires protégées et de conservation d'Ouganda par type de gouvernance de l'UICN

\begin{tabular}{l|r|r}
\hline Catégorie de gouvernance de l'UICN & $N^{\circ}$ & $\%$ de couverture \\
\hline Gouvernance par un gouvernement & 699 & 98,00 \\
\hline Non rapporté & 13 & 2,00 \\
\hline
\end{tabular}

Source : UNEP-WCMC et IUCN ((2019w).

Aires protégées et de conservation de Zambie par type de gouvernance de l'UICN

\begin{tabular}{l|r|r}
\hline Catégorie de gouvernance de l'UICN & $N^{\circ}$ & $\%$ de couverture \\
\hline Gouvernance par un gouvernement & 49 & 66,35 \\
\hline Non rapporté & 586 & 41,50 \\
\hline
\end{tabular}

Source : UNEP-WCMC et IUCN (2019x).

Aires protégées et de conservation du Zimbabwe par type de gouvernance de l'UICN

\begin{tabular}{l|r|r}
\hline Catégorie de gouvernance de I'UICN & N$^{\circ}$ & $\%$ de couverture \\
\hline Non rapporté & 232 & 100,00 \\
\hline
\end{tabular}

Source : UNEP-WCMC et IUCN (2019y). 


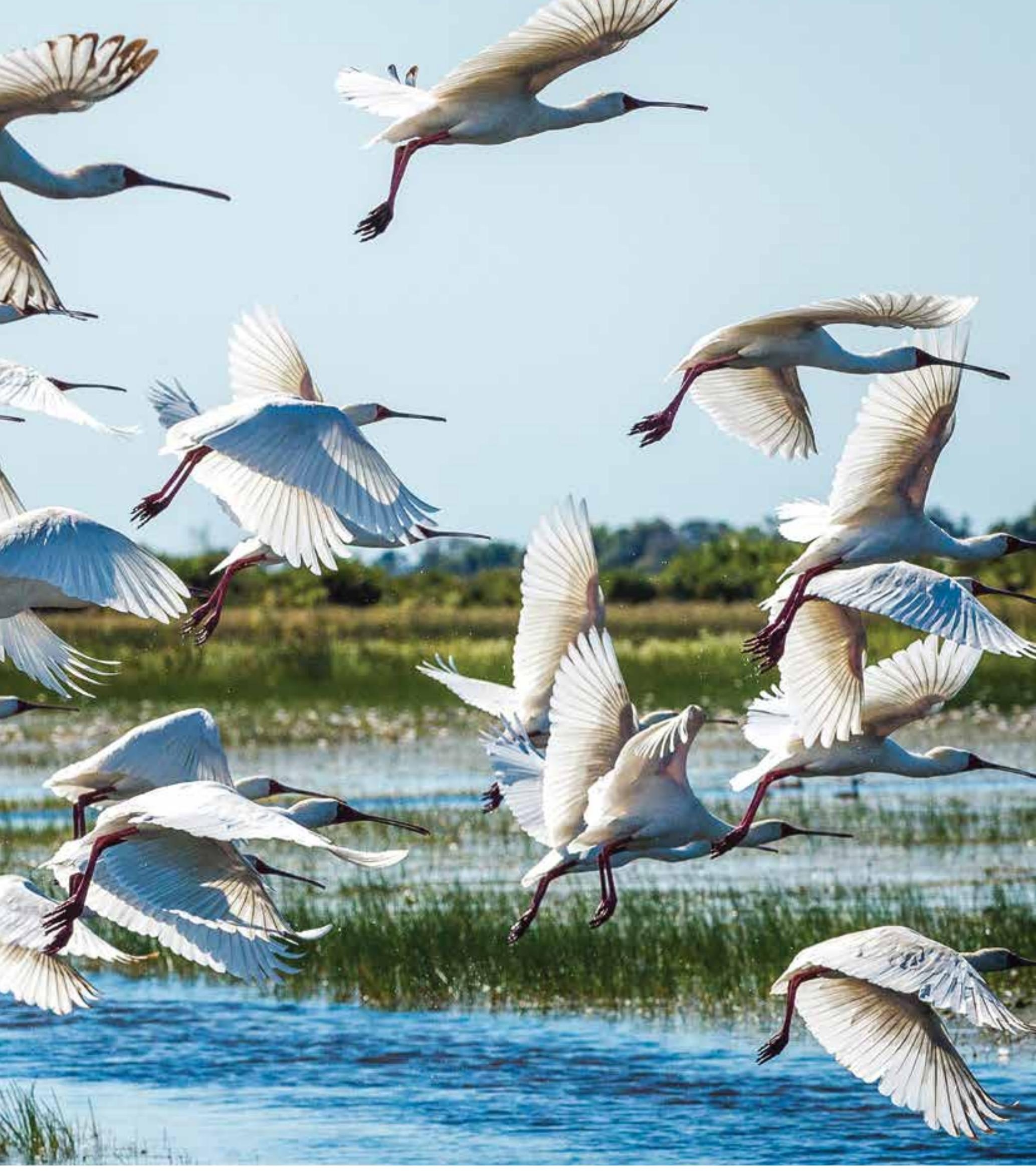




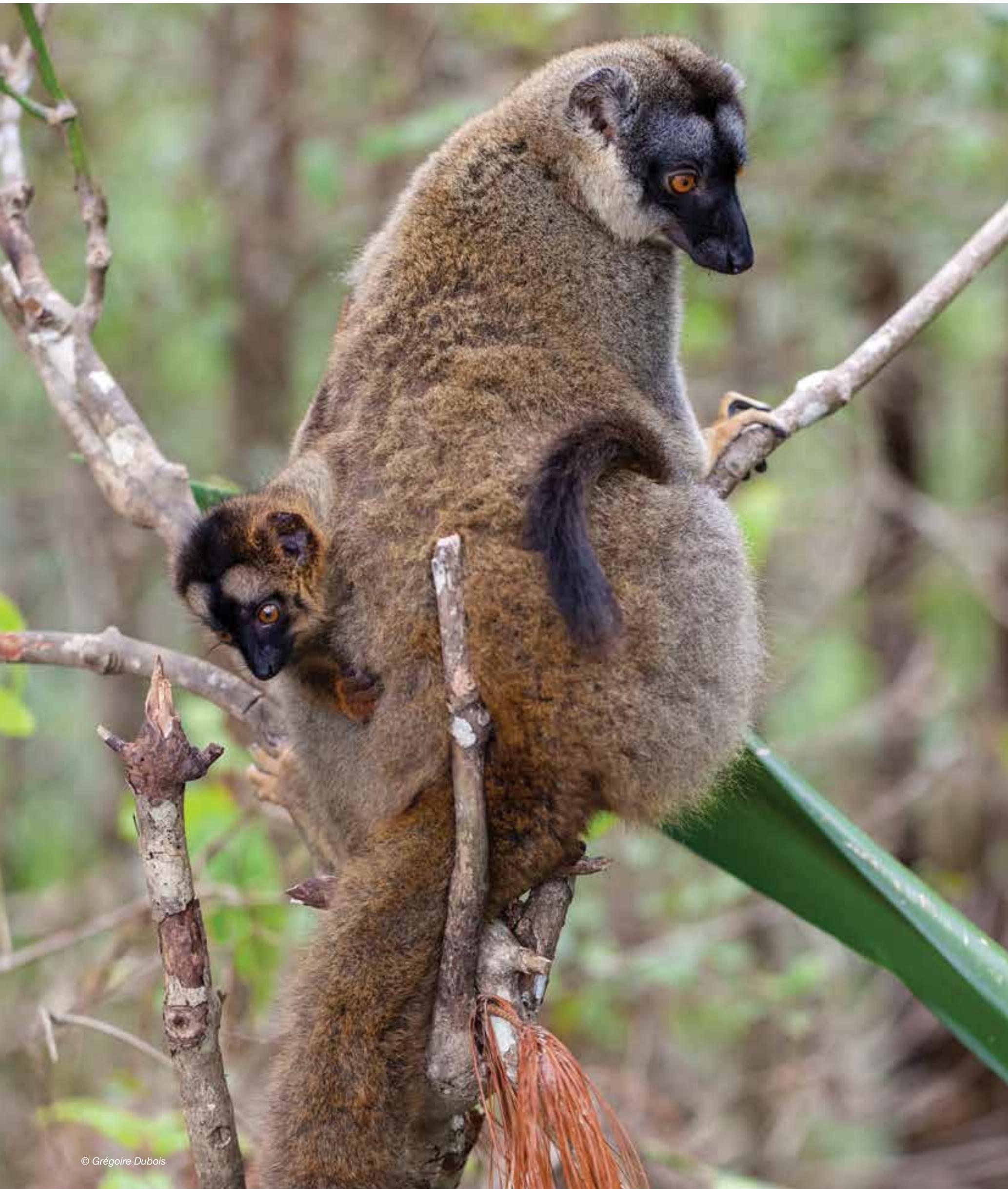





\section{UICN}

UNION INTERNATIONALE

POUR LA CONSERVATION DE LA NATURE

Bureau régional pour l'Afrique orientale et australe

Centre Wasaa pour la Conservation,

Mukoma Road (près de Magadi Road, City Square)

P. O Box 68200,200

Nairobi, Kenya.

Téléphone fixe : +254 20 2493561/65/70

Courrier électronique : info.esaro@iucn.org

Site web : https://www.iucn.org/esaro 